\title{
Rainer Schmalz-Bruns
}

\section{Reflexive Demokratie}

Die demokratische Transformation moderner Politik 



\section{Rainer Schmalz-Bruns}

\section{Reflexive Demokratie}

Die demokratische Transformation moderner Politik 
Die Deutsche Bibliothek - CIP-Einheitsaufnahme

\section{Schmalz-Bruns, Rainer:}

Reflexive Demokratie : Die demokratische Transformation moderner Politik / Rainer Schmalz-Bruns. - 1. Aufl. - Baden-Baden : Nomos Verl.-Ges., 1995

ISBN 3-7890-3559-9

1. Auflage 1995

(C) Nomos Verlagsgesellschaft, Baden-Baden 1995. Printed in Germany. Alle Rechte, auch die des Nachdrucks von Auszügen, der photomechanischen Wiedergabe und der Übersetzung, vorbehalten. 
Für Heidrun und Oliver 


\section{Inhaltsverzeichnis}

Vorwort

Einleitung

I

Zur Idee deliberativer Politik

1. Demokratietheorie im Spiegel der Krise staatlicher Politik 25

1.1 Die Not des Staates - eine demokratische Tugend? 26

1.2 Exkurs: Zur Theorie politischer Institutionen 36

1.3 Demokratietheoretische Antworten im Überblick 43

2. Staatsbürgermoral und politische Institutionen:

Die Konturen eines neuen Republikanismus

2.1 Moralität, Sittlichkeit und Reflexivität:

Zur Institutionentheorie Durkheims

2.2 Die moralische Erneuerung liberaler Politik:

Zu einigen Aspekten des kommunitaristischen Institutionenverständnisses $\quad 64$

2.3 Das Modell eines pluralistischen Republikanismus bei Walzer

3. Selbstgesetzgebung oder Selbstregierung?

3.1. Zum Begriff politischer Öffentlichkeit

3.2. Das Modell deliberativer Politik bei Habermas

II

Das Modell der »reflexiven Demokratie«

4. Zum Konzept der »Civil Society»

5. Ansätze zu einer Radikalisierung des Modells zivilgesellschaftlicher Politik

6. Die Idee der reflexiven Demokratie 
7. Institutionelle Implikationen

7.1 Die Balancierung von demokratischer Legitimität und politischer Effektivität

7.2 Institutionelle Reformperspektiven

7.3 Institutionen als Mittel staatsbürgerlicher Selbstqualifikation?

III

Jenseits von Staat und Gesellschaft:

Zur assoziationspolitischen Modernisierung der Demokratie

8. Perspektiven einer »dritten demokratischen Tranformation«

8.1 Politische Öffentlichkeit(en) in der »kreativen Demokratie«

8.2 Policy-Analyse als Demokratiewissenschaft

9. Zur Erweiterung des demokratischen Handlungsrahmens:

Netzwerke, Verhandlungssysteme und »deliberative Arenen«

9.1 Zur materialen Politisierung der gesellschaftlichen Entwicklung

9.2 Politik in Verhandlungssystemen

9.3 Politische Problemlösung in deliberativen Arenen

Literaturverzeichnis 


\section{Vorwort}

Die Ausbildung transnationaler Handlungssphären im Bereich von Ökonomie, Technik, Ökologie, Wissenschaft und Friedenserhaltung; die Integration der Europäischen Gemeinschaft zur Europäischen Union; die gleichzeitige soziale, politische und ökonomische Transformation osteuropäischer Gesellschaften und bei alledem die abnehmende Handlungsfähigkeit des Nationalstaates nach innen und außen sowie die Strapazierung der Kräfte der sozialen Kohäsion durch Prozesse der zunehmenden Individualisierung und Pluralisierung von Lebensformen - dieser vielfach unbewältigte Problemstau scheint ein Indikator dafür zu sein, daß die institutionellen Mittel des Staates, in dem sich die moderne Gesellschaft als Einheit beschreiben, ihre Entwicklung beobachten und im Bedarfsfalle korrigierend auf diese einwirken konnte, in der expansiven und korrosiven Dynamik der politischen Gesellschaft verbraucht oder entwertet worden sind.

Die Herausforderung, die in solchen oder ähnlichen Krisendiagnosen liegt, hat in den letzten Jahren auf seiten der Politikwissenschaft und Sozialphilosophie in Verbindung mit der Einschätzung, daß die Engpässe und Sackgassen moderner Politik zu einem gewichtigen Teil nicht auf ein $» Z u v i e l \ll$, sondern eher auf ein »Zuwenig« an gesellschaftlicher Demokratie und staatsbürgerlicher Teilhabe zurückzuführen seien, zu energischen und zum Teil bemerkenswerten Anstrengungen geführt, die Reartikulation demokratischer Prinzipien mit der Adjustierung ihrer Formen an die Prozesse einer komplexen und arbeitsteiligen politischen Willensbildung zu verbinden. Das setzte jenseits rein pragmatischer Erwägungen auch eine Neubesinnung auf Fragen durchaus fundamentaler Art voraus. Und zwar derart, daß Fragen nach der Rechtfertigung demokratischer Prinzipien neben Fragen nach Problemen der Anwendung dieser Prinzipien treten und sich mit Fragen nach der Genese demokratischer Formen verbinden; daß Prinzipien der individuellen (Präferenz-)Autonomie mit der Idee kollektiver Selbstbestimmung neu zu balancieren waren; oder $\mathrm{da} \beta$ Formeln der normativen Integration demokratischer Gesellschaften gefunden werden mußten, die für Prozesse systemischer Differenzierung und Phänomene ethisch-kultureller Pluralisierung aufnahmefähig bleiben sollten. Nicht zuletzt aber, und auch darïber herrschte und herrscht weitgehend Konsens, mußte es um den Preis der Irrelevanz demokratischer Prinzipien darauf ankommen, Möglichkeiten zu erkunden, wie es gelingen könnte, den politischen Entscheidungen dorthin zu folgen, wo sie tatsächlich fallen und die Installation demokratischer Strukturen ober- und unterhalb der Schwelle des Nationalstaates ins Auge zu fassen.

Nun ist es angesichts dieser zum Teil hochgesteckten Ziele und der positiven Erwartungen an das Prinzip demokratischer Partizipation nicht verwunderlich, daß mit Blick auf die damit verbundenen strukturellen, institutionellen und subjektiven Anforderun- 
gen an die »weitergehende Demokratisierung real existierender Demokratien « auch die Schatten notorischer Zweifel an einer bürgerschaftlichen, zivilgesellschaftlichen Radikalisierung der Idee der Demokratie schnell wieder länger wurden. Im Kern beziehen sich diese Zweifel auf die praktische Grundfrage, ob man es den Menschen zutrauen kann, sich als Gleiche selbst zu organisieren und das für sie kollektiv Beste und Vernünftige selbst zu ermitteln - kurz: ob man, in realistischer Einstellung, nicht besser davon ausgehen sollte, daß die partizipatorische Demokratie als Regierungsform zu einfach für komplexe Probleme und dennoch zu komplex und anforderungsreich für ihre Bürger ist. Derartige Zweifel haben, auch wenn sie zunächst erneut, wie nicht anders zu erwarten, vor allem von Vertretern eines realistischen, elitenorientierten Ansatzes artikuliert wurden, inzwischen auch jene eingeholt, die im Prinzip eine energische Reform und Ergänzung repräsentativer Strukturen befürworten - und auch dafür gibt es durchaus Gründe: der Einfluß der Bürgerbewegungen in Osteuropa ist ihrer Institutionalisierungsschwäche zum Opfer gefallen, während die neuen sozialen Bewegungen im Westen im Zuge ihrer politischen Professionalisierung und institutionellen Anpassung einiges von ihrem basisdemokratischen Charme verloren haben; die Politik einer Selbstmoralisierung der bürgerlichen Gesellschaft, die schon immer das notwendige Komplementärstück eines autonomen zivilgesellschaftlichen Handlungszusammenhangs darstellte, scheint an strukturellen Grenzen der Moralisierbarkeit individuellen und kollektiven Handelns aufzulaufen; und die Probleme der Globalisierung von Handlungszusammenhängen scheinen den Bedingungen und Voraussetzungen partizipatorischer Demokratie eher entgegenzustehen.

Diese Erfahrungen der letzten Jahre sind gewiß geeignet, allzu euphorischen Erwartungen entgegenzuwirken. Sie nötigen aber nicht zur Preisgabe der Reformideen, sondern legen es im Gegenteil eher nahe, bei der Bestimmung angemessener Reformperspektiven ein größeres $\mathrm{Maß}$ an institutioneller Phantasie, die den gegebenen Verfassungsrahmen auch übersteigen darf, zu investieren. Und das deshalb, weil die Skepsis gegenüber allzu radikalen Alternativen zur Logik und zum Modell des repräsentativen Rechtsstaates nicht die aus einer allenthalben sichtbaren Konditions- und Leistungsschwäche des modernen Staates resultierenden pragmatischen Gründe verdecken sollte, die neben normativen Fragen für eine Neukonzeptualisierung des Projekts der Demokratie maßgeblich sind. Zwar gerät die Idee der Demokratie im Zuge ihrer erweiterten Inanspruchnahme unter einen gewissen Streß; aber diesen Streßfaktoren kann und muß, wie ich hoffe zeigen zu können, ein anderer institutioneller Zuschnitt demokratischer Prozesse wenigstens ein Stück weit Rechnung tragen.

Bei dem vorliegenden Text handelt es sich um die leicht veränderte und in Teilen ergänzte Fassung der Arbeit, die vom Fachbereich 05 der Universität Hamburg im Sommersemester 1994 als Habilitationsschrift angenommen worden ist. Sie fußt auf Gedanken, die sich im Laufe der letzten Jahre langsam entwickelt haben. Dieser Prozeß ist denn auch dadurch dokumentiert, daß ich an verstreuten Stellen auf bereits publizierte Arbeiten zurückgegriffen und die darin enthaltenen Überlegungen in den hier vorgelegten übergreifenden Argumentationszusammenhang eingefügt habe. Darüber hinaus stellt die Arbeit selbstverständlich keine isolierte Einzelleistung dar, sondern ist in gewisser Weise auch ein Gemeinschaftsprodukt - wenn auch als solches von den 
daran im engeren Sinne über Gespräche, Diskussionen und eingehende Kritik Beteiligten nicht kollektiv intendiert oder gar zu verantworten. Aus dem Kreis dieser Personen kann ich an dieser Stelle nur jene besonders hervorheben, die die Arbeit in den Jahren ihrer Entstehung mit ständiger Diskussionsbereitschaft, wertvollen Hinweisen oder deutlicher, aber immer konstruktiver Kritik freundschaftlich begleitet haben. Dafür möchte ich mich vor allem bei Udo Bermbach, Hubertus Buchstein, Gerhard Göhler, Michael Th. Greven, Hans Grünberger, Ansgar Klein, Herfried Münkler, Frank Nullmeier, Thomas Saretzki und Rudolf Speth bedanken. Für die Publikation schließlich war das geduldige Interesse von Herrn Kühler vom Nomos-Verlag und die vertrauensvolle Zusammenarbeit mit ihm für mich von großem Wert.

Freilich hätte die Arbeit trotz dieser Bemühungen ohne die andauernde Ermunterung und Unterstützung durch Heidrun und Oliver so nicht entstehen können. Und zwar nicht nur, weil sie mir den notwendigen privaten Rückhalt gerade angesichts der notorischen Unsicherheiten und immer wieder aufkommenden Zweifel nie versagt haben; sondern vor allem auch deshalb, weil es ihnen gelungen ist, dafür zu sorgen, daß sich mein Leben während dieser Zeit nie gänzlich auf eine Logik des »Danach « eingestellt hat - Ihnen ist dieses Buch gewidmet. 


\section{Einleitung}

Das Thema der Demokratie hat, weltweit gesehen, in den letzten Jahren einen hervorragenden Platz auf der politischen Agenda eingenommen. Beispiele dafür bieten sowohl die Ablösung von Militärdiktaturen durch liberaldemokratische Regime als auch der, wenn auch mühsame, Versuch der Überwindung der Apartheit in Südafrika wie die demokratische Transformation osteuropäischer Gesellschaften. Gewiß gibt es keinen Anlaß anzunehmen, daß diese Prozesse im Sinne einer geschichtlichen Notwendigkeit unumkehrbar seien oder daß sich hier der von der Modernisierungstheorie behauptete Gleichschritt von ökonomischer Modernisierung und politischer Demokratisierung bestätige. Vielmehr gibt es einigen Anlaß, diese zentrale modernisierungstheoretische Annahme selbst einer Revision zu unterziehen und sich für die Spannungen zu sensibilisieren, die in Prozessen einer gleichzeitigen ökonomischen, sozialen und politischen Transformation aufbrechen; Spannungen, die durch das Prinzip der Demokratie häufig genug nicht nur nicht aufgelöst, sondern zum Teil akzentuiert und zugespitzt werden und in populistischen, nationalistischen und autoritären Reaktionen auf ökonomische Modernisierung und soziale Umbrüche auslaufen.

Die gute Nachricht angesichts des Geburtstags der Erfindung (und des dann folgenden sukzessiven Ausbaus) des unwahrscheinlichen und voraussetzungsvollen Ordnungstyps der Demokratic im fünften vorchristlichen Jahrhundert im Zuge der Kleisthenischen Reformen ist zunächst, daß mittlerweile der Triumph der Demokratie zumindest als einer abstrakten Idee fast vollständig und allgemein zu sein scheint. Weltweit steht die Errichtung von Demokratien oder die weitergehende Demokratisierung schon bestehender demokratischer Ordnungen auf der Agenda; und kaum jemand, seien es politische Führer, Wissenschaftler, Dissidenten oder Aktivisten, kommt darum hin, in dem Bemühen um dic Rechtfertigung politischer Ordnung auf die Sprache der Demokratie zurückzugreifen oder ihr zumindest eine formelhafte Referenz zu erweisen. Kurz, die Dinge scheinen für die Demokratie, faßt man die Entwicklung nach dem zweiten Weltkrieg (vgl. etwa Eisenstadt, 1992) und insbesondere nach der Involution auch der sozialistischen Gesellschaften Osteuropas nach 1989 zusammen, nicht schlecht zu stehen. Doch man kann gewiß auch berechtigte Zweifel haben, ob die Demokratie wirklich das lang ersehnte Licht am Ende eines langen evolutionären Tunnels politischer Ordnungsformen spendet; mischen sich doch in dieses Bild evolutionären Fortschritts immer wieder und auch in jüngster Zeit Erfahrungen abgebrochener, steckengebliebener oder gewaltsam aufgehaltener Refornprozesse (etwa in Lateinamerika, in den sich modernisierenden Volkswirtschaften im ostasiatischen Raum und in China, die eher für einen Typus autoritärer Modernisierung stehen). Auch die Entwicklungen in Osteuropa geben durchaus Anlaß zu der Befürchtung, daß Widersprüche oder konfliktreiche Spannungen zwischen Prozessen der ökonomischen Moderni- 
sierung, der sozialen Reform und der politischen Demokratisierung auftreten und den Rückgriff auf autoritäre Muster begünstigen, die, um ein Bild Claus Offes zu gebrauchen, die Entwicklung durch das Licht der Demokratie in einen neuen Tunnel führen könnten (Offe, 1994).

In solchen Entwicklungen könnte sich die Einsicht zum Ausdruck bringen, daß demokratische Ordnungen nicht allein auf die Hervorbringung einer handlungsfähigen Regierung hin ausgelegt sein können, sondern einen Handlungszusammenhang etablieren müssen, der in der Lage ist, ein gewisses Maß an Gemeinschaftlichkeit zu reproduzieren. Diese Annahme kann sich auf mehrere Sorten von Gründen stützen, von denen ich an dieser Stelle nur zwei hervorheben möchte. Zum einen kann man davon ausgehen, daß die Viabilität und Stabilität theoretisch elaborierter Ordnungsmodelle davon abhängen wird, inwieweit sie die aus einer bestimmten Tradition hervorgehenden gemeinsam geteilten Überzeugungen der Bürger aufgreifen und reflektieren: »A theory of democracy is viable to the extent that there is a discourse or combination of discourses to which it can relate« (Dryzek/Berejikian, 1993: 48) - insofern hat die Demokratietheorie immer auch einen rekonstruktiven Gehalt, indem sie die Demokratiemodelle aus dem politischen Sprachgebrauch herauspräpariert, von denen sich die Bürger in ihrem Selbstverständnis, in ihren Einstellungen zur Politik wie in der Beschreibung ihrer Rechte und Verpflichtungen tatsächlich bestimmen lassen. Zum anderen ergibt sich der Umfang, der Charakter und die jeweils besondere Struktur gemeinschaftlicher Beziehungen, die in den politischen Prozeß eingehen, auch aus der Beschreibung der spezifischen Probleme, denen sich die moderne Politik konfrontiert sieht. Selbstverständlich ist einzuräumen, daß die Abkehr vom antiken Polis-Modell und der Triumph der konstitutionellen und repräsentativen Demokratie mit der historischen Zäsur der Entwicklung der kapitalistischen Ökonomie und des modernen Staates aufs engste verknüpft ist, weil diese beiden fundamentalen Formelemente moderner Gesellschaften eine gleichsam selbstselektive Wirkung auf die institutionellen Strukturen ausüben, die den demokratischen Prozeß bestimmen (vgl. Dunn, 1993: $240 \mathrm{ff}$.). Aber auch diese Einsicht läßt sich nicht umstandslos in die These vom Ende der Geschichte umsetzen, nach der die liberale, repräsentative Demokratie wenigstens im Prinzip die endgültige Auflösung des Rätsels der Balancierung von Gleichheit, individueller Freiheit und Autonomie wie kollektiver Vernunft bereithält. Und das hat nicht nur damit zu tun, daß (normativ) die griechische Erfahrung der direkten Demokratie nach wie vor einen Stachel im Fleisch der mit institutionellen Mitteln einer zunehmenden politischen Entfremdung des Bürgers arbeitenden repräsentativen Demokratie bildet. Eine diesbezügliche Skepsis gründet sich vielmehr auf drei fundamentale Probleme, denen sich das repräsentative Modell gerade auf der Höhe seines Triumphs konfrontiert sieht und die ohne eine verstärkte Inanspruchnahme der Kompetenzen der einzelnen Bürger wie ohne die Erschließung zusätzlicher Quellen gesellschaftlicher Solidarität kaum zu lösen sein dürften. Erstens wird die schon immer überzogene Auffassung, der moderne Staat könne, wie in Durkheims Vorstellung, als eine Art Gehirn oder kognitives Steuerungszentrum der Gesellschaft fungieren, zunehmend unplausibel: im Gegenzug kommt es damit zu einer Dezentralisierung oder auch Resubjektivierung einer kognitiv und moralisch anspruchsvollen Willensbildung, und die dringliche und schwierige 
Frage ist, "how exactly we should see the relation between science or knowledge and the claims of different human beings to be equipped to rule, or even to decide between the merits of different possible rulers « (Dunn, 1993: 260) - eine Antwort könnte darin liegen, die sozialen und politischen Institutionen stärker auf die Praxis öffentlicher Diskussion und allgemeiner politischer Deliberation hin auszulegen. Zweitens nimmt durch die generelle Kontraktion der Wirtschaft einerseits der Streß nationaler und internationaler Verteilungskämpfe wieder zu, während andererseits die Ressource der Solidarität knapper wird. Drittens schließlich wird im Zuge der ethnischen Differenzierung und kulturellen Pluralisierung moderner Gesellschaften das Ideal staatsbürgerlicher Gleichheit neuen Belastungen ausgesetzt. Zwar können wir nicht hoffen, uns auf nationaler oder gar internationaler Ebene zu einem kollektiv handlungsfähigen Subjekt zu bilden, als das Kleisthenes den Athenischen Demos konstituierte - doch auch wenn wir diesbezüglich über keine klaren Vorstellungen verfügen, bleibt es eine ständige Aufgabe »to reinvent political and social agency throughout the world in which we now live (Dunn, 1993: 265), und dies ist ohne die Rekonstitution auch von Gemeinschaftlichkeit, von geteilten Hoffnungen, Sinn und Zwecken nicht zu haben.

Faßt man diese Beobachtungen und Überlegungen zusamınen, dann scheint weitgehendes Einvernehmen darüber zu herrschen, daß die Viabilität und Stabilität moderner Demokratien nicht allein und vielleicht nicht einmal in erster Linie von der Gerechtigkeit ihrer institutionellen Grundstrukturen (Rawls), sondern von den Qualitäten und Einstellungen ihrer Bürger abhängt. Die »Rückkehr des Bürgers « (vgl. Kymlicka/ Norman, 1994) auf die Bühne der Demokratietheorie führt schließlich auch zu einer Neuthematisierung ziviler Tugenden, weil zum einen klar geworden ist, daß rein prozedurale Mechanismen kaum ausreichen, um eine lediglich auf Selbstinteresse basierende kompetitive Interessenpolitik effektiv zu balancieren, die häufig genug der Lösung anspruchsvoller kollektiver Handlungsprobleme entgegensteht. Zum anderen verdankt sich die Aktualisierung des Staatsbürger- und Tugenddiskurses der wachsenden Einsicht in das Ausmaß, in dem der Erfolg moderner Politik und der politischen Steuerung der Entwicklung moderner Gesellschaften auch von entgegenkommenden, verantwortlichen individuellen Lebensstilentscheidungen abhängig ist. Dieser Bedarfsdiagnose, die Offe treffend unter den Begriff einer »Resubjektivierung von Steuerungsleistungen « bringt, steht die vor allem im Zusammenhang der Kommunitarismus-Debatte artikulierte Sorge gegenüber, daß, entgegen dem steigenden Bedarf, die Bereitschaft und Fähigkeit zur Übernahme verantwortungsethischer Einstellungen eher abnimmt. Aus dieser Spannung resultiert denn auch die Suche nach jenen Quellen, aus denen sich zugleich staatsbürgerliche Einstellungen regenerieren und entsprechende Qualifikationen verbessern ließen.

Angesichts dieser Lage ist es umso bemerkenswerter, daß sich die liberaldemokratischen Systeme des Westens darauf zu beschränken scheinen, ihr Verfassungs- und Politikmodell zur einfachen Nachahmung zu empfehlen, ohne selbstkritisch auf die Tatsache zu reagieren, daß auch im Westen das Vertrauen, daß diese Institutionen in der Lage seien, die dringendsten Probleme zu lösen und das soziale und ökonomische Leben effektiv zu gestalten, zu erodieren beginnt: daß sie sich, m.a.W., als unfähig oder unwillig erweisen, dem Verdacht nachzugehen, die wesentlich im 19. Jahrhundert 
entwickelten Formen der konstitutionellen, liberalen Demokratie könnten zu wenig aufnahmefähig sein für die Anforderungen einer modernen, nicht mehr im Staat zu zentrierenden Politik. Unter dieser Voraussetzung gibt es denn auch für die westlichen Demokratien einigen Anlaß, der Frage der institutionellen Übersetzung und Effektuierung demokratischer Ideale mit Blick auf das sich wandelnde Anspruchsprofil moderner Politik mehr Aufmerksamkeit zu schenken. Wie aber ist auf diese strukturelle Herausforderung zu reagieren? Man kann grob vier Strategien unterscheiden, die sich aus den politiktheoretischen und politisch-philosophischen Debatten des letzten Jahrzehnts herausschälen lassen (vgl. Cohen/Rogers, 1992: $396 \mathrm{ff}$.). Da ist zum einen die Strategie einer reaktiven Form der Staatsentlastung, die unter dem Etikett eines »neoliberalen Konstitutionalismus « die Quelle der meisten Übel des politischen Lebens in einer politisch induzierten Fehlallokation von Ressourcen identifiziert und entsprechend auf eine Stärkung des Marktes, auf Entpolitisierung und eine scharfe Begrenzung der Staatsfunktionen setzt - dieser Ansatz überschätzt nicht nur systematisch die Leistungsfähigkeit eines gegenüber Gründen und Argumenten unempfindlichen Marktprinzips, das demzufolge selbst unter idealen Bedingungen zu ergebnisoffen bleibt, um den Anforderungen rationaler Problemlösung gerecht zu werden, sondern er bleibt auch unempfindlich gegenüber den Rationalitäts- und Effizienzverlusten, die aus der weitgehenden Freisetzung und Entfaltung sozialer Macht resultieren. An diesen Punkten setzt denn auch eine zweite Strategie der Staatsverbesserung an, die bestreitet, daß sich die Substanz staatlicher Politik in Bargaining-Prozessen zwischen Interessengruppen fixieren läßt und demgegenüber die Bedeutung deliberativer Momente in der politischen Willensbildung und Entscheidungsfindung hervorhebt - diese »zivilrepublikanische « Sicht auf den politischen Prozeß läuft indessen aus Sorge um die vernünftige, gemeinwohlverbürgende Qualität von Politik umgekehrt Gefahr, die Faktizität des gesellschaftlichen Pluralismus normativ zu unterlaufen, Gruppenpolitik generell unter Verdacht zu stellen und in der Folge eine staatlich konzentrierte Willensbildung gegen die Interessenartikulation gesellschaftlicher Gruppen zu insulieren. Auf diese Schwäche kann man dann mit einer Strategie der progressiven Staatsentlastung reagieren, die ihrerseits zwei Formen annehmen kann. Zunächst bietet sich - drittens - ein Konzept an, das man als »egalitären Pluralismus « kennzeichnen könnte und das eine rein prozedurale Fassung politischer Legitimation mit Strategien zur Überwindung struktureller Ungleichheiten auf der Ebene der Interessenrepräsentation zu kombinieren sucht. Dem liegt allerdings wiederum ein lediglich aggregatives Modell von Politik zugrunde, in dem das irreduzible deliberative Moment demokratischer Politik nicht recht zur Geltung gebracht werden kann. Deshalb bietet es sich an, eine Organisationsform demokratischer Politik ins Auge zu fassen, die in der Lage ist, die Perspektive eines normativen Pluralismus mit der Aufgabe einer deliberativen Qualifikation des politischen Prozesses zu verschränken. Eine solche Strategie versuchen Cohen und Rogers unter dem Titel einer »associative democracy « zu plausibilisieren, die im Kern auf eine Politik der Ermutigung solcher Formen der Gruppenbildung und -repräsentation zielt, die den demokratischen Idealen der Selbstregierung, der kompetenten Willensbildung und der sozialen Chancengleichheit (Cohen/Rogers, 1992: $416 \mathrm{ff}$.) von sich aus entgegenkommen: »Emphasizing both qualitative variations among groups and the >artifactual< 
aspect of associations, we suggest that the range of cures for the mischiefs of faction is commonly understood too narrowly. The potential cures are not limited to the options of imposing stringent constitutional limits on the affirmative state, accomodating groups while seeking to ensure equality in the >pluralist bazaar $<$, or constructing cloistered deliberative arenas alongside that bazaar. In addition to these strategies, and in many respects preferable to them, is the cure of using public powers to encourage less factionalizing forms of secondary associations - of engaging in an artful democratic politics of secondary association« (Cohen/Rogers, 1992: 395).

Das ist denn auch die Perspektive, in der ich in der vorliegenden Arbeit den Versuch unternehmen möchte, den Bedarf, die Bedingungen und Chancen einer assoziationspolitisch und zivilgesellschaftlich - kurz: radikaldemokratisch - gerichteten Reform der politischen Institutionen der repräsentativen Demokratie zu sondieren und ein Stück weit zu konkretisieren, ohne damit lediglich der unbedingten Forderung nach einer Generalisierung partizipatorischer Formen erneut das Wort reden zu wollen. Zwar gibt es gute Gründe für die Vermutung, daß ein Mehr an staatsbürgerlicher Beteiligung nicht nur normativ geboten oder zumindest wünschenswert ist, sondern daß sie in vielen Fällen auch die Legitimität, Responsivität, sachliche Qualität und Effizienz der Politik erhöhen und verbessern könnte - aber eben auch nicht in jedem Fall. Deshalb geht es auch nicht um eine Maximierung von Partizipation, sondern um eine Optimierung der demokratischen Willensbildung und Entscheidungsfindung im Lichte dieser Kriterien - diese Idee einer demokratischen Politik der Rationalisierung von Politik ist mithin auch nicht gegen den liberalen Rechtsstaat, sondern gegen die staatliche Konzentration von Politik im Rechtsstaat in Gestalt der rein repräsentativen (Wahl)Demokratie gerichtet.

Die Arbeit ist in drei größere Abschnitte gegliedert. Der erste Abschnitt (Kapitel 1-3) hat grob die Aufgabe, im Durchgang durch einige Stationen der jüngeren Debatte über Staats-, Institutionen- und Demokratietheorie die pragmatischen, praktischen und moralischen Motive einzuführen, die die Suche nach Formen einer zivilrepublikanischen Alternative zur repräsentativen Demokratie bestimmen. Zu diesem Zweck werde ich zunächst einige der Gründe kurz in Erinnerung rufen, die für die vielfach verzeichnete Leistungs- und Konditionsschwäche des Staates angesichts der größer werdenden Kluft zwischen (immer noch wachsenden) Staatsaufgaben einerseits und strukturellen Grenzen der Staatstätigkeit andererseits verantwortlich sind. Aus verständlichen Gründen hat sich nicht zuletzt an solchen Diagnosen auch die demokratietheoretische Debatte in den letzten Jahren erneut entzündet, wobei die Vorschläge zur Überwindung der diagnostizierten Defizite moderner Politik zunächst auf bekannten und eingefahrenen Bahnen entwickelt werden. In diesem Zusammenhang gehe ich in einer gerafften Skizze auf das realistische Modell, die Theorie des politischen Liberalismus und das Modell deliberativer Politik ein, von denen am Ende nur die Idee deliberativer Politik eine ausreichende Grundlage für die Neukonzeptualisierung des Projekts der Demokratie zu bieten scheint. Diese Option bestätigt sich, und damit schließe ich die vorbereitenden Überlegungen $a b$, auch in der Perspektive einer normativen Theorie politischer Institutionen. Sie hat der Einsicht Rechnung zu tragen, daß Moral der Preis der Moderne ist (Höffe), und ihr kommt somit die Aufgabe zu, moralische 
Ansprüche an Politik in arbeitsteilige, reflexiv aufeinander bezogene institutionelle Strukturen zu übersetzen, die auch die moralischen Handlungsdispositionen der an inklusiven Willensbildungsprozessen Beteiligten stützen, ermutigen und fördern können (1).

Die Konzeption, die im folgenden entwickelt werden soll, stützt sich mithin grundlegend auf die Idee deliberativer Politik. Indessen ist es für diesen Zweck notwendig, dieses Thema zunächst noch einmal in einer genaueren Feineinstellung zu behandeln und unterschiedliche Modellvorstellungen, die innerhalb dieses grundbegrifflichen Rahmens entfaltet worden sind, gegeneinander zu konturieren und auf ihre spezifische Leistungsfähigkeit hin zu befragen. Denn was sich hier konstruktiv andeutet, ist eine Art republikanischer Familienstreit um die Frage, an welchem Ort und unter welchen institutionellen Voraussetzungen sich die im Zentrum der republikanischen Vision stehende Idee einer deliberativen Politik am besten entfalten und implementieren läßt (vgl. Cohen/Rogers, 1992: 406, Fn. 27 und Gutmann, 1993: 42 ff.): Das Spektrum der jeweils favorisierten Optionen reicht dann von dem Versuch, die deliberative Rolle des Parlaments hervorzuheben und durch entsprechende Reformen der parlamentarischen Arbeit besser zur Geltung zu bringen - diesen Weg schlagen vor allem Habermas und Sunstein ein; daneben hält etwa Michelman dafür, daß die Rechtsprechung, spezieller die Verfassungsrechtsprechung, der privilegierte Ort deliberativer Verfahren sei - der Gefahr eines verfassungsgerichtlichen Paternalismus einer rein judiziellen Demokratie (vgl. Gerstenberg, 1994) kann man in dieser Perspektive dadurch entgegenwirken, daß man das Parlament wie die Verfassungsgerichtsbarkeit als die Orte faßt, auf die gesellschaftliche Prozesse der deliberativen Rechtserzeugung und -fortbildung zulaufen (vgl. etwa Habermas, 1992 und Maus, 1992); dem entspricht in gewisser Weise die Auffassung Ackerman's, der Bezugs- und Ansatzpunkte einer deliberativen »Massen«-Politik nurmehr in den außeralltäglichen Situationen großer konstitutioneller Transformationsprozesse zu entdecken vermag (Ackerman, 1991) und es der Justiz überläßt, die Ergebnisse dieser Perioden eines breiten öffentlichen Engagements zu bewahren und zu verwalten; schließlich kann man argumentieren, und dem werde ich mich anschließen, daß die republikanische Idee einer deliberativen Form der Selbstregierung vom Kernbestand repräsentativer Institutionen abzulösen und gesellschaftlichen Assoziationsverhältnissen einzuschreiben wäre. Wie immer man an dieser Stelle optiert, handelt es sich um Antworten auf die entscheidende Frage, wie man die im Begriff deliberativer Politik angelegten Spannungen zwischen demokratischen Beteiligungsnormen und Kompetenzerwartungen, zwischen Legitimität und Effizienz und zwischen einer unvermeidlichen Anspannung der moralischen Kräfte des einzelnen Bürgers und unrealistischen Tugendzumutungen aufzulösen gedenkt. Daran wird sich am Ende entscheiden, ob es gelingen kann, das Projekt der Demokratie in eine Richtung zu lenken, in der man über eine kritische Affirmation der Verhältnisse einer liberalen, repräsentativen Demokratie hinauskommen kann. Vor diesem Hintergrund möchte ich zunächst einen Blick auf die kommunitaristische Kritik am Liberalismus werfen, allerdings ohne mich dabei genauer auf die moralphilosophischen und metatheoretischen Aspekte dieser Debatte einzulassen; diese werde ich nur insoweit berücksichtigen, wie sie für die politiktheoretische Kernfrage nach einer angemessenen institutionellen Übersetzung der Idee deliberativer Demokratie relevant sind. Dabei 
schält sich das Modell eines »pluralistischen Republikanismus« (Walzer) heraus, das allerdings hinsichtlich einer genaueren Orts- und Funktionsbestimmung demokratischer Öffentlichkeiten noch stark ergänzungsbedürftig bleibt (2). Eine solche Perspektive bietet erst das Modell deliberativer Politik, wie es Habermas in »Faktizität und Geltung « entwickelt hat (3) - dieses stellt den (unhintergehbaren) Ausgangspunkt für jeden Versuch dar, der Idee der Demokratie eine radikalere und zugleich funktionstüchtigere Gestalt zu geben, als sie die liberale, repräsentative Demokratie bereithält.

Im zweiten Abschnitt (Kapitel 4-7) wende ich mich dann darauf aufbauend der Aufgabe zu, ein Modell demokratischer Politik in den Grundzügen zu skizzieren, das es erlaubt, die demokratischen Ideale der Selbstgesetzgebung und Selbstregierung zu verbinden und das den Forderungen nach einer Verbesserung der Legitimität, Qualität und Effizienz demokratischer Politik auch unter Bedingungen hoher gesellschaftlicher Komplexität entgegenkommt, ohne dafür den Preis einer weitgehenden Mediatisierung von Teilhabeansprüchen entrichten zu müssen. Zu diesem Zweck ist zunächst ein Übersetzungsvorschlag zu prüfen, der unter dem Sammelbegriff der »Zivilgesellschaft « in den letzten Jahren einige Aufmerksamkeit auf sich gezogen hat. Dabei wird sich herausstellen, daß dieser Ansatz, bei allen Unterschieden im einzelnen, am Ende in die demokratietheoretisch mißliche Disjunktion von (öffentlichem) Diskurs und (politischer) Entscheidung führt (4). Das hat vor allem damit zu tun, daß vor dem Hintergrund des aufrechterhaltenen Dualismus von Staat und ziviler Gesellschaft der Gehalt der Vorstellung gesellschaftlicher Selbstbestimmung und Selbstorganisation demokratietheoretisch nicht ausgeschöpft werden kann; daß die zivilrepublikanische Herausforderung der Ausarbeitung eines normativen Staatsbürgerbegriffs nicht oder nicht zureichend aufgenommen wird und daß der Politikbegriff einseitig auf die selbstbezügliche Reproduktion gesellschaftlicher Praxis hin ausgelegt wird, ohne diese mit staatlicher Politik in einem Begriff guter Politik auch institutionell zu vermitteln (5). Diese Spezifizierungen des konzeptionellen Rahmens führen mich dann zu dem Vorschlag einer reflexiven Zuspitzung der Idee der Demokratie, in die drei Annahmen eingehen: die Selbstblockade demokratischer Prozesse, die wenigstens z.T. auch auf das Gegeneinander unterschiedlicher Formen der Beteiligung zurückzuführen ist, wäre durch eine bewußte und demokratisch gesteuerte Verschränkung von (politischen) Themen, Strukturen (partizipatorisch, direktdemokratisch-majoritär, repräsentativ) und Modi (diskursiv, konfliktorisch oder adverserial) der Meinungs- und Willensbildung zu überwinden; damit werden auch institutionelle Aspekte einer angemessenen Genese des Volkswillens thematisch, was zu einem grundsätzlichen Vorrang für solche Arrangements führt, die an einer Verbesserung der bürgerschaftlichen Meinungserwerbs-, Artikulations- und Wirkungschancen ansetzen; was impliziert, daß auch der Selbstüberforderung partizipatorischer Potentiale und Energien entgegengewirkt werden muß - etwa durch eine institutionelle Integration selektiver, aber gleichwohl offener und effektiver Mobilisierungsmechanismen, wie sie in den letzten Jahren vor allem in Bereichen der Umwelt-, Technik- und Technologiepolitik entwickelt wurden (6). Dies hat, gerade wenn partizipatorische Optionen nicht in eine bloße Konkurrenz zu repräsentativen Formelementen treten sollen, auch Implikation für die Struktur und Aufgaben der im engeren Sinne staatlich-institutionellen Willensbildung und eröffnet 
eine Reihe von Reformperspektiven auf dieser Ebene, denen ich in einem weiteren Schritt nachgehe (7).

Im dritten Abschnitt (Kapitel 8 und 9) konzentriere ich mich dann auf die faktischen Prozesse einer stärkeren Vergesellschaftung von Politik und solche Entwicklungen, die den abstrakt entwickelten Modellvorstellungen schon entgegenkommen und insofern geeignet sein sollten, einem vorschnellen Utopismus-Verdacht entgegenzuwirken. Gerade im Hinblick auf das Problem einer Effektuierung und Optimierung inklusiver Teilhabeansprüche ist schließlich zu zeigen, daß sich die Reflexivität staatlich-institutioneller Strukturen auch auf die Ebene einzelner Handlungsprogramme und Problemlösungen im Zusammenhang einzelner Policies so absenken läßt, daß die sich zunehmend ausprägende Vielzahl diskursiver und verhandlungsorientierter politischer Netzwerke für die politische Willensbildung und Entscheidungsfindung erschlossen werden kann, ohne die allgeıneine demokratische Legitimationskette zu zerreißen.

Verstreut über ein breites Feld von Forschungen u.a. zur Analyse risikogesellschaftlicher Strukturen, zu Fragen der Regierbarkeit moderner Gesellschaften im Kontext der Korporatismusforschung oder des Neo-Institutionalismus in der Policy-Forschung und damit zusammenhängend der neueren Staatstheorie sind in den letzten Jahren insgesamt beeindruckende Evidenzen dafür zusammengetragen worden, daß sich die moderne Gesellschaft nur durch einen fundamentalen Wandel ihrer Architektur und eine tiefgreifende Reform ihres Systems der politischen Willensbildung und Entscheidungsfindung auf die zunehmend wissensbasierte Lösung der Probleme ihrer sozialen, technischen und ökologischen Reproduktion wird einstellen können. Selbst vor diesem Hintergrund aber muß die Empfehlung einer stärkeren gesellschaftlichen Allokation von politischen Entscheidungsrechten und Verantwortlichkeiten nicht nur mit Hinweisen auf die mögliche Fragmentierung, Segmentierung und Selbstblockade der politischen Willensbildung im Zuge einer Dezentralisierung und partizipatorischen Öffnung politischer Entscheidungsstrukturen rechnen; vielmehr ist auch nicht auszuschließen, daß eine asymmetrisch verteilte soziale Macht, die durch die Trennung von Staat und Gesellschaft und die gewaltenteilige Balance des staatlichen Institutionensystems auch eingehegt und diszipliniert werden kann, sich nur ungehinderter entfaltet und unmittelbarer in politische Entscheidungen umsetzt. Hinter diesem Hinweis steht die gewiß nicht unberechtigte Sorge, daß das parlamentarische Prinzip, in dem sich die Idee der Publizität historisch materialisiert hat und das zusammen mit der Gewährleistung autonomer Öffentlichkeiten und dem Organisationsmittel der Parteienkonkurrenz die Idee der Volkssouveränität zum Ausdruck bringen soll, unterlaufen wird, ohne daß ein adäquater Ersatz zur Verfügung stünde. Dennoch läßt sich die hier eingenommene Perspektive einer reflexiven Demokratisierung auch gegen realistische Einwände und eine nicht unbegründete normative Skepsis durchaus verteidigen: Verbesserungen materialer Politik lassen sich ohne Verletzung der normativen Präsuppositionen des liberalen Rechtsstaates dann erreichen, wenn man gleichgerichtete, integrierte Strukturreformen auf den unterschiedlichen Ebenen und Aggregationsstufen des politischen Prozesses vornimmt. Die allgemeine Logik, die hinter der Idee einer Radikalisierung der im Prinzip der institutionellen Gewaltenteilung und -verschränkung bereits angelegten Refle- 
xivität politischer Prozesse steht, ist im Rahmen eines Stufenmodells institutioneller Reform bereits angedeutet. Das Problem, das sich auch angesichts der soeben noch einmal aufgenommenen Einwände jetzt stellt, ist die Frage, wie sich diese Reflexivität auf die Ebene konkreter Entscheidungen in Policy-Arenen oder in dezentralen, lokalen Zusammenhängen der politischen Problemlösung absenken läßt, um so der Idee einer deliberativen Politik einen über die Form repräsentativen Parlamentarismus hinausweisenden demokratischen Handlungsrahmen zu erschließen.

Entsprechend gehe ich in zwei Schritten vor. Es ist offensichtlich, daß man ohne eine weitergehende Institutionalisierung politischer Öffentlichkeiten nicht auskommen wird, weil nur so die notwendige Fokussierung von Aufmerksamkeitsenergien und die punktgenauere Kanalisierung von öffentlichen Meinungsbildungsprozessen in ein entscheidungsbezogenes Problemlösungshandeln auf der Ebene materialer Politiken zu erreichen ist. Hier kann man an Überlegungen anschließen, mit denen Dewey auf die demokratischen Herausforderungen einer Steigerung der Komplexität gesellschaftlicher Verhältnisse reagiert hat, ohne den auch damals dominanten Suggestionen einer elitären Auslegung des Demokratieprinzips zu erliegen. Diese Überlegungen hat Dahl in den letzten Jahren verstärkt aufgegriffen und zu der Forderung einer »dritten demokratischen Transformation « verdichtet. In dieser Perspektive verschärfen sich jedoch zunächst die nicht unterdrückbaren Zweifel an Modellen der partizipatorischen Demokratie vor allem mit Blick auf steigende Anforderungen an die Kompetenz, das Engagement und die moralischen Einstellungen des Bürgers. Es macht wenig Sinn, diese Fragen der Belastbarkeit zu unterschätzen oder gar zu unterdrücken: gesucht ist deshalb ein Modell, daß flexibel auf flottierende Teilhabeanspriiche reagieren kann, zugleich aber einen stabilen Kristallisationskern für erweiterte Teilhabeforderungen ausbildet und diese effektiv und effizient zu kanalisieren vermag (8). Im Anschluß daran zeige ich beispielhaft, daß die Forderung einer allgemeinen Verbesserung der Rationalität politischer Entscheidungen, ihrer Legitimität, sachlichen Angemessenheit und Implementierbarkeit Formen der Selbstorganisation nahelegt, die dem selbstsektorierenden und selbstformatierenden Charakter ergebnisorientierter Politiken entgegenkommen: darauf reagieren Überlegungen zur demokratischen Selbstadaptation etwa von Verhandlungssystemen, in denen die Rationalitätsvorteile von Verhandlungen mit dem demokratischen Legitimationsprinzip reflexiv zusammengeführt werden, einerseits und Vorschläge zur Einführung stärker diskursiver Verfahren der Konfliktregulierung und Problemlösung andererseits. Derartige Formen horizontaler Selbstorganisation und kooperativer Problemlösung erzeugen aber schließlich Reflexionsprobleme eigener Art, auf die auch institutionelle Antworten gefunden werden müssen (9).

Freilich behalten diese Überlegungen zu einer reflexiven Modernisierung der Demokratie insgesamt, trotz des Bemühens, den Anschluß an die Wirklichkeit nicht zu verlieren und normative wie eher empirisch-analytische Ansätze zusammenzuführen, noch einen programmatischen und tentativen Charakter. Dennoch hoffe ich, wenigstens einige Argumente für die Notwendigkeit und Möglichkeit einer weitergehenden Demokratisierung »real existierender Demokratien« anbieten zu können. Dabei räume ich gerne ein, daß die Argumentation über weite Strecken eher von der Negation einer in unzureichenden institutionellen Formen zunehmend erstarrenden Politik als von der 
Überzeugungskraft der angedeuteten Alternativen profitiert, die gewiß einer weiteren und gründlichen Ausarbeitung bedürfen. Daß allerdings die verstärkte Suche nach solchen Alternativen unabweisbar ist, ergibt sich daraus, daß eine zunehmend wissensbasierte Politik von institutionellen Strukturen abhängig ist, die auf Anforderungen einer demokratischen Erzeugung und Distribution relevanten Wissens eingestellt sind, d.h. dem Prinzip der Publizität und dem Modus deliberativer Politik eine breitere faktische Basis verschaffen. Die Schwierigkeiten einer weitergehenden institutionellen Präzisierung des Modells resultieren zum einen sicher daraus, daß dabei stets die Balance zwischen dem Anspruch der partizipatorischen Öffnung und Erweiterung des demokratischen Handlungsrahmens einerseits und den unter normativen Gesichtspunkten irreduziblen Strukturen des liberalen Rechtsstaates zu halten ist. Zum anderen ist es aber mit der Idee der reflexiven Demokratie auch nicht verträglich, nun etwa eine detailgenaue Blaupause für institutionelle Reformen zu liefern - dies ist dem demokratischen Prozeß und den Akteuren vorbehalten, die sich die zur Lösung kollektiver Handlungsprobleme erforderlichen Mittel und Strukturen selber schaffen müssen. Schließlich sollten uns diese Schwierigkeiten aber nicht dazu veranlassen, vor der Herausforderung auszuweichen, den schon beobachtbaren Strukturveränderungen moderner Politik eine zusammenhängende Deutung zu geben und sie in einen übergreifenden konzeptionellen Rahmen einzupassen. Diesem Anspruch kommt nicht zuletzt entgegen, daß sich das Bewußtsein dafür, daß die Lösung anspruchsvoller Gestaltungsaufgaben auf reflexivere Strukturen der Willensbildung angewiesen ist, unter ständigem Problemdruck und Entscheidungsstreß auch auf der Seite staatlicher Politik auszubilden beginnt. Und auch auf seiten zivilgesellschaftlicher Akteure könnte ein entsubstantialisiertes, reflexives Institutionenverständnis, das das Unterfutter einer auf Dauer gestellten Politik der Verbesserung der Legitimität und Qualität von Politik bildet, dazu beitragen, die Bedingungen für institutionelles Lernen wie Prozesse der institutionellen Selbstadaptation in den assoziativen Grundstrukturen der Gesellschaft zu verbessern. 
I

Zur Idee deliberativer Politik 


\section{Demokratietheorie im Spiegel der Krise staatlicher Politik}

Spätestens seit Mitte des 17. Jahrhunderts hat der neuzeitliche, nach innen und außen als souverän vorgestellte Staat mit seinen in der Folge sukzessiv ausgebauten praktischen Funktionen der Friedensstiftung, der (positiven) Rechtsetzung und -wahrung und der Freiheits- und Wohlfahrtssicherung einen wesentlichen Teil der Bedingungen neu definiert, denen die Einrichtung einer legitimen und effizienten politischen Ordnung Rechnung tragen können mußte. Davon konnte auch das Demokratieverständnis und die Vorstellung der Formen, in denen es sich zur Geltung bringen sollte, nicht unberührt bleiben. Insoweit ist John Dunn zuzustimmen, wenn er diese Entwicklung auf die Formel bringt, daß die konstitutionelle, repräsentative Demokratie, die sich als allgemeines Modell in der Folge der amerikanischen und französischen Revolution durchsetze, eine Form der Demokratie ist, »madc safe for the modern state (Dunn, 1993: 248). Damit diese Gleichung aufgehen konnte, mußte, unter Wahrung der normativen Präsuppositionen der Idee der Demokratie, der Demos politisch weitgehend mediatisiert und auf die Funktion der Legitimationszufuhr an das staatliche Handlungs- und Reflexionszentrum der Gesellschaft beschränkt werden. Was aber, wenn auch unter funktionalen Gesichtspunkten die normativen Kosten dieses Modells durch Gewinne an kollektiver Handlungsfähigkeit nicht mehr kompensiert werden können?

Heute mehren sich jedenfalls die Anzeichen dafür, daß der Machtkreislauf der repräsentativen Demokratic an dieser legitimationsempfindlichen Stelle unterbrochen ist, weil die gesellschaftlich erzeugte und staatlich verdichtete und konzentriette Macht nicht mehr als aggregiertes Mittel der Selbsteinwirkung in diese zurückgespeist, sondern staatlich nurmehr akkumuliert und stillgestellt wird. Man braucht gar nicht die Position eines generalisierten steuerungstheoretischen Agnostizismus einzunehmen, wie er etwa durch die Systemtheorie Luhmanns nahegelcgt wird, ${ }^{1}$ um unterhalb dieser Schwelle einer prinzipiellen Unsteuerbarkeit moderner Gesellschaften drei Komplexe von Ursachen auszumachen, die für die abnehmende Leistungsfähigkeit staaticher Politik verantwortlich zeichnen. Zum einen zeigt sich, daß die inneren Strukturen der Regierungsorganisation kaum noch auf die Prozesse der internen wie externen Diffusion staatlicher Souveränität abgestimmt sind, so daß sich die "Sub«-Politisierung der Gesellschaft einerseits und die Globalisierung der Politik andererseits wie Schranken vor

1 Diese extreme Form eines systemtheoretisch induzierten Steuerungspessimismus hat u.a. Scharpf (1992) mit guten Gründen auch empirisch zurückgewiesen. Zudem gibt es Anzeichen dafür, daß Luhmann vielfach ciner Reifizierung analytischer Systeme zu realen Systemen aufsitzt und daß sich die Plausibilität der Theorie der Autopoiesis mit Blick auf das politische System häufig nur daraus ergibt, »daß er das Ablaufen politischer Entscheidungsprozesse nach institutionalisierten Regeln schon als autopoietisches Operieren eines Systems« deutet (Münch, 1994: 399). 
die Rationalität des Staates legen müssen, zumal dann, wenn diese Handlungsebenen institutionell gar nicht oder nur unzureichend vermittelt sind (1). Zum zweiten kommt es im Zuge der funktionalen Differenzierung und Spezifizierung gesellschaftlicher Handlungssysteme zu einer Art Dispersion von Steuerungsressourcen wie Macht, Geld, Einfluß, Wertbindungen oder Wahrheit (Wissen), die zum Zweck der politischen Steuerung mobilisiert und mit Blick auf die Lösung kollektiver Handlungsprobleme zusammengeführt werden müssen (vgl. Münch, 1994: passim) - das verweist vor allem auf das Problem des angemessenen institutionellen Zuschnitts realer Handlungs- oder Funktionssysteme - dies ist ein wichtiger Gegenstand der Theorie politischer Institutionen oder des "New Constitutionalism " (2). Schließlich können wir beobachten, daß staatliche Steuerungsansprüche in ihrer Wirkung immer adressatenabhängiger werden und in nicht oder nur schwach organisierte Bereiche der alltäglichen Lebenspraxis hinein vermittelt werden müssen, wo sie nicht mehr auf die Hilfe gesellschaftlicher Gruppen und Verbände rechnen können. Beispielhaft dafür sind die Bereiche der Umwelt-, Gesundheits-, Verkehrs- oder Sozialpolitik, in denen sich erwünschte Wirkungen und Entwicklungen nur unter der Voraussetzung einer rational motivierten Folgebereitschaft wie entgegenkommenden Lebensstilentscheidungen einzelner noch einstellen diese Subjektivierung von Steuerungsleistungen bildet das Gegenstück zur Aufgabe der Demokratietheorie, die Bedingungen auszuzeichnen, unter denen sich solche Verpflichtungseffekte einstellen und »moralische Kapazitäten und Kooperationsbereitschaften« (Offe, 1990a: 187) aktiviert werden können (3).

\subsection{Die Not des Staates - eine demokratische Tugend?}

Der Wohlfahrtsstaat ist in den letzten Jahren über das gesamte politische Spektrum hinweg in immer neuen Schüben der Thematisierung ins Gerede gekommen: war es in den 70er Jahren vor allem der mittlerweile unabweisbare Verdacht, daß diese spezifische Form der monetären Neutralisierung des Klassenkonflikts den spätkapitalistischen Staat unvermeidlich in eine Finanzkrise führen müsse (vgl. O'Connor, 1974), so ist diese Perspektive in der Folge von Zweifeln an seiner Effizienz und demokratischen Legitimität überlagert worden (vgl. auch Henningsen, 1986). Zwischen diesen Punkten besteht durchaus ein auch empirisch belegbarer Zusammenhang, insofern dramatisch steigende Kosten und die Ineffizienz von Programmen zu immer weiterreichenden Reglementierungen durch Politik und Verwaltung führen, bis zu dem Punkt, an dem sie in eine Gefährdung der individuellen Freiheit umzuschlagen drohen. Auch wenn diese Phänomene keinesfalls auf den schwedischen Fall begrenzt sind, so hat doch das schwedische Modell des Wohlfahrtsstaates immer wieder eine besondere Aufmerksamkeit auf sich gezogen, gerade weil es den einen als evolutionäre Endstufe des von Marshall skizzierten universalen Prozesses der stufenweise Entfaltung von bürgerlichen, politischen und sozialen Bürgerrechten im Rechtsstaat, demokratischen Rechts- und Verfassungsstaat und schließlich im demokratisch-egalitären Wohlfahrtsstaat galt, während andere darin den paradigmatischen Fall sahen, an dem sich der Verlust der Balance wie die trade-offs zwischen den normativen Grundprinzipien von Freiheit, Gleichheit, Solidarität und Ge- 
rechtigkeit eindringlich nachweisen ließen: was auch die Linke zunehmend irritierte, waren jene hierarchisch-klientelistischen Strukturen im Verhältnis von Staat und Gesellschaft, die die Fragmentierung der Gesellschaft vorantrieben und deren kollektiv-demokratische Handlungsfähigkeit zu unterminieren drohten.

Entscheidend ist nun nicht, ob man in diesen Entwicklungen das Aufkommen eines »neuen Totalitarismus (so Huntford, 1973) identifizieren kann; theoretisch informativer ist der Blick auf die Widersprüche und Grenzen, auf die das dem zugrunde liegende Gesellschaftsmodell des »politischen Funktionalismus« (Henningsen, 1986: 45 ff.) stößt. Geschärft worden ist dieser Blick nicht zuletzt u.a. durch die norwegische Machtstudie, die den strukturellen Wirkungen und institutionellen Implikationen dieses Modells bis ins Detail nachgegangen ist und deren Ergebnisse, weit davon entfernt, lediglich einen skandinavischen Sonderfall zu illustrieren, jene Strukturmuster instrumenteller Politik ins Licht rücken, die in der Folge den wichtigsten Bezugspunkt der sozialwissenschaftlichen Theorieentwicklung bilden - und zwar, und das ist entscheidend, sowohl für die empirisch-analytische wie die im engeren Sinne normative Theoriebildung. ${ }^{2}$ Die norwegische Machtstudie war ein sich über acht Jahre (1972-1980) sich erstreckendes Forschungsprojekt (vgl. dazu Henningsen, 1988: $73 \mathrm{ff}$.), in dessen Rahmen im Auftrag der Regierung zwei Aufgabenbereiche bearbeitet werden sollten: theoretisch ging es um eine Klärung des Konzepts der Macht, während sich das empirische Interesse auf die Erforschung wirtschaftlicher Machtgruppierungen, von Organisationen aus Arbeits- und Wirtschaftsleben, des öffentlichen Verwaltungsapparats, von multinationalen Vereinigungen und schließlich der Massenmedien gerichtet war (Hernes, 1988: 57 ff.). Ohne auf Einzelheiten einzugehen, besteht das Ergebnis im Nachweis von Strukturveränderungen politischer Entscheidungsprozesse, die aus Machtverschiebungen im Inneren wie in den Außenverhältnissen der Steuerungssysteme von Markt, Staat (Legislative und Verwaltung) und Interessenorganisationen resultieren: faktisch konzentriert sich die politische Entscheidungsmacht, gegenläufig zur offiziellen Legitimationskette des demokratischen Staates, im korporatistischen »eisernen Dreieck « von Ministerien, Parlamentsausschüssen und Interessenorganisationen, mit der Folge einer Schwächung des Parlaments, das mehr und mehr in eine bloße Zuschauerrolle gedrängt wird, und der Parteien, die ihre Programm- und Agendahoheit an gesellschaftliche Organisationen und die Massenmedien abtreten müssen. Die auf diese Weise sich etablierende neue Machtgeometrie ist uns über die Korporatismusdiskussion der achtziger Jahre natürlich bestens vertraut; es lohnt sich aber dennoch, sich dieses Bild noch einmal in Erinnerung zu rufen, weil in ihm zugleich die Strukturprobleme sichtbar werden, auf deren Bearbeitung und Lösung in der Folge ein Großteil der theoretischen Energie verwandt worden ist. Ganz grob handelt es sich zum einen um Kapazitätsprobleme, die aus einer sich weiter öffnenden Schere zwischen einem

2 Ein instruktives Beispiel für die nunmehr einsetzende Verschränkung dieser beiden Dimensionen politikwissenschaftlicher Theoriebildung bietet der vor allem von March und Olsen in den achtziger Jahren konzipierte und konturierte neo-institutionalistische Ansatz - ich komme darauf weiter unten noch zurück. Vgl. James G. March/Johan P. Olsen; Rediscovering Institutions. New York (Free Press) 1989. 
Zuwachs an Staatsaufgaben einerseits und einer durch interne Faktionierung abnehmenden Steuerungsfähigkeit des politischen Systems und Steuerbarkeit (vgl. Scharpf, 1989) gesellschaftlicher Subsysteme andererseits resultieren. Wenn auf diese Weise der Erfolg staatlicher Steuerung und Problemlösung immer adressatenabhängiger wird und sich eine gewisse Nötigung zur Herausbildung einer mehr kooperativen Form des Staatshandelns einstellt, so ergeben sich daraus, unter der Bedingung der Machtsteigerung großer, organisationsfähiger gesellschaftlicher Interessen(gruppen) und einer weitgehenden Entformalisierung oder Deinstitutionalisierung der faktischen Entscheidungsabläufe, vier weitere, unmittelbare Folgeprobleme: zunächst ein Autoritätsverlust legitimer Macht, der sich zweitens auch darin äußert, daß die Repräsentation gemeinsamer Interessen keinen institutionell wirksam definierten Ort mehr hat, was dann drittens die kurzfristige und querschnittige Aulage von Politiken befördert und die Fähigkeit zu sachlicher Priorisierung reduziert und schließlich Legitimationsprobleme dergestalt hervorbringt, daß sich die Politik im kleinen Machtkreislauf zwischen Administration und etablierten Interessen so einschließt, daß sie die offizielle Legitimationskette demokratischer Politik durchbricht und die breitere politische Öffentlichkeit marginalisiert.

Deshalb müssen institutionelle Neuarrangements, die den verzeichneten Strukturschwächen entgegenwirken sollen, zunächst grundsätzlich der Einsicht Rechnung tragen, daß der Staat sich pluralisiert und nach innen wie nach außen weder als organisierte Wirkungseinheit noch gar als Reflexionszentrum der sich zugleich differenzierenden und globalisierenden Gesellschaft fungieren kann. Zwar sind die empirischen Belege nicht immer eindeutig, bleibt die Dynamik der Vergesellschaftung des Staates immer auch von kontingenten historischen Konstellationen abhängig, und selbstverständlich variieren die Deutungen dieser Prozesse auch ansatzspezifisch (vgl. Voigt, 1993). Dennoch ist im Kern unbestritten, daß sich die Wirklichkeit moderner Politik nicht mehr dem hierarchischen Organisationsmodell fügt, wie es der (staatsrechtliche) Begriff des Staates suggeriert (vgl. Lietzmann, 1994): diese Wirklichkeit wird in vielen Politikbereichen unvermeidlich geprägt durch insulare oder molekulare Formen der Planung und Durchführung materialer Politiken, und dieser Tendenz zur Selbstsektorierung einzelner Policies entsprechen neue Formen der Selbstformatierung der darum herum sich ausbildenden Akteurkonfigurationen und Handlungszusammenhänge, die besser in Begriffen von policy-communities, Verhandlungssystemen, Netzwerken o.ä. zu erfassen sind. Diese Einsichten in den defizienten Modus einer staatlich zentrierten funktionalistischen Politik haben denn auch eine faktische wie theoretisch reflektierte Gegenbewegung ausgelöst, in der, nach dem Abflauen der Begeisterung über neokorporative Steuerung, eine Vielfalt von staatlichen Steuerungshilfen zur gesellschaftlichen Selbststeuerung und -organisation wieder entdeckt wurden: die Schaffung parastaatlicher Einrichtungen, die Delegation von Staatsaufgaben an gesellschaftliche Gruppen, eine Neubewertung des Subsidiaritätsprinzips, lose Konzertierung u.a. (von Beyme, 1991: 352; vgl. auch Münkler, 1994: 63 ff.).

Wenn man also von der Rationalität von Politik - oder genauer: von den Rationalitätsanforderungen an staatliche Politik - spricht, dann sind Anforderungen gemeint, die mit der Fähigkeit der Gesellschaft zur Einwirkung auf sich selbst, mit der Fähigkeit 
zur Bestimmung vernünftiger Entwicklungen und deren Beförderung wie mit der Fähigkeit zur Verhinderung anderer Entwicklungen zu tun haben. Dem daraus resultierenden Wachstum der Staatsaufgaben in sozial- und wohlfahrtsstaatlicher wie in interventionistischer Hinsicht stehen aber strukturelle Grenzen der Staatstätigkeit gegenüber, die als interne und externe Rationalitätsschranken staatlichen Handelns charakterisiert werden können (a) - in diesen Prozeß einer kumulativen Entwertung der traditionellen »Sachwalter kollektiver Rationalität « (Offe, 1989: 743) wird aber nicht nur der Staat, sondern auch Recht und Gesetz (b) sowie die Verfassung (c) hineingezogen. Damit ist schließlich der Punkt markicrt, an dem Strategien einer demokratischen Modernisierung der Politik ansetzen können, auch wenn durch die demokratische Antwort auf die Probleme des Staates die Idee der Demokratie selber wieder unter einen vermehrten Streß gerät (d).

a) Die Staatstätigkeit hat seit dem ausgehenden 19. Jahrhundert parallel zur sukzessiven Politisierung sozialer Fragen und der einsetzenden Parlamentarisierung des Klassenkonflikts zusammen mit der Einführung des allgemeinen und gleichen Wahlrechts sowohl in quantitativer wie in qualitativer Hinsicht ständig zugenommen. Dabei kann man grob drei Phasen unterscheiden (vgl. Griınm, 1993: 45): In einer ersten Phase kommt es zu Ansätzen einer gesetzlichen Regulierung der Arbeitsbeziehungen und des ökonomischen Wettbewerbs, um Mißbräuche ökonomischer Freiheit einzudämmen; diese gesetzgeberischen Instrumente der Ordnungspolitik wurden, induziert durch die wirtschaftlichen Krisenerfahrungen nach dem Ersten Weltkrieg, durch Instrumente zur Behebung sozialer Notlagen und ökonomischer Engpässe ergänzt, die sich nicht mehr nur auf die Gesetzgebung beschränkten, sondern tatsächliche finanzielle und sächliche Hilfsmaßnahmen umfaßten - es entwickelte sich nach und nach ein System der Vorsorge für die Risiken von Armut, Arbeitslosigkeit, Obdachlosigkeit, Gesundheit u.a.; diese kurativen und kompensatorischen Strategien, in denen sich auch eine gewisse Vorliebe »für teure Symptombekämpfung in Form bürokratischer Routinearbeit« (Jänicke, 1993a: 65) zur Geltung brachte, konnten jedoch den Steuerungsbedarf komplexer Industriegesellschaften nicht decken, so daß3 der Staat in einer dritten Phase nach dem Zweiten Weltkrieg genötigt war, auch Erwartungen bezüglich einer aktiven Steuerung der gesellschaftlichen Entwicklung, der Krisenantizipation, der Initiierung technischen Wandels u.a. zu bedienen. ${ }^{3}$

Die Logik dieser extensiven 'Tendenzen läßt sich allgemeiner unter den Stichworten der Inklusion, der Reintegration einer funktional sich zunehmend ausdifferenzierenden Gesellschaft wie der prospektiven, risikoinduzierten Folgenwahrnehmung, -bewertung, -vermeidung und -bearbeitung fassen - gerade diese Logik aber läßt im Gegenzug die internen und externen Rationalitätsschranken staatlichen Handelns nur umso deutlicher hervortreten. Mit »Inklusion« ist dabei die sozial- und wohlfahrtsstaatliche Tendenz der Einbeziehung immer weiterer Bevölkerungsteile in die Leistungen aller

3 Dieser Prozeß läßt sich auch an der Verfassungs(text)entwicklung belegen, wobei die Verfassung auf den normtechnischen Ebenen der Staatszielbestimmungen, Kompetenzregeln, Grundrechte und Gesetzgebungsaufträge den faktischen Prozeß nicht nur spiegelt, sondern eigendynamisch anregt - vgl. dazu Schulze-Fielitz (1990: 18 ff.). 
gesellschaftlichen Teilsysteme gemeint, die sich längst aus dem Kontext der sozialen Frage des 19. Jahrhunderts gelöst hat und mittlerweile auch Fragen der kulturellen (Erziehung, Bildung, Wissenschaft, kulturelle Teilhabe o.ä.) wie der politischen Reproduktion z.B. im Sinne einer »Staatsbürgerqualifikationspolitik « (Preuß, 1990a: 123 ff.) umfaßt; darüber hinaus hat vor allem die Systemtheorie den Blick dafür geschärft, daß funktionale Differenzierung dazu neigt, immer mehr hoch spezialisierte Teilsysteme hervorzubringen, die »eine hohe Sensibilität für eigene Angelegenheiten mit weitgehender Indifferenz für alle fremden« (Grimm, 1990: 14) kombinieren und so den Staat mit der Maßgabe auf den Plan rufen, Externalitäten zu kompensieren und allgemeine Gesichtspunkte und Interessen in den Handlungsplänen dieser Teilsysteme unterzubringen; mit der risikogesellschaftlich erzwungenen Erweiterung der Politikperspektive von Bestandswahrung auf Zukunftsplanung entsteht schließlich ein Problemtypus, der Politik nicht nur wissens- und expertiseabhängiger macht und insofern einen prozeduralen, aber »resultatoffenen « (Wiesenthal, 1989: 137) Politiktypus überfordert, sondern der sich aus dem kontingenten Zusammenspiel von Einzelhandlungen generiert und insoweit dazu tendiert, die Rationalität einzelner am Prozeß beteiligter Akteure zu überfordern - notwendig wird damit ein Konsens über Zwecke und Inhalt von Politik, der sich von bloß partikularen Orientierungen und subjektiven Interessen von Individuen und Gruppen ablöst.

Interne Rationalitätsschranken ergeben sich dann aus der Tendenz des administrativen Apparats, die Komplexität der gesellschaftlichen Umwelt, auf die er mit seinen Entscheidungen einzuwirken hat, intern selbst noch einmal abzubilden und sich damit den koordinativen Folgeproblemen der internen Differenzierung auszusetzen. Diese Art des Problemdrucks generiert sich also sowohl aus der wachsenden Zahl der Entscheidungsträger wie aus der parallel dazu, aber unabhängig davon verlaufenden Zunahme »intrastaatlicher Politikprozesse (Fürst, 1987: 262 f.), die mit der Pluralisierung (Offe, 1987: 311) und Fragmentierung der Ressortperspektiven zu tun haben. Das Problem besteht nun zunächst auf der Seite des Staates genau darin, daß die Strukturen der institutionellen Willensbildung auf diese Anforderungen kaum oder nur schlecht abgestimmt sind und sich unter Gesichtspunkten der internen wie externen Diffusion der Entscheidungsfindung in eine eher gegenteilige Richtung entwickelt haben. Mit »externer Diffusion « ist hier das Phänomen der Auslagerung von Entscheidungsprozessen in die »dichten Kommunikationsprozesse « (Sarcinelli, 1990: 43) korporativer Verhandlungssysteme gemeint. Dadurch werden zwar auch - wie häufig notiert - Legitimationslücken aufgerissen; entscheidender aber in diesem Zusammenhang ist der Gesichtspunkt, daß damit gerade die gesellschaftlichen Akteure prämiiert werden könnten, die sich durch die vergleichsweise geringste Lernbereitschaft und Innovationsfähigkeit auszeichnen. Komplementär dazu haben wir es mit einer »internen Diffusion « insoweit zu tun, daß sich aufgrund der Art und Weise der Regierungs- und Parlamentsorganisation die von der konservativen Staatsrechtslehre systematisch erzeugte Vorstellung einer einheitlichen "Staatswillensbildung « als Fiktion erweist, die an der Wirklichkeit der bürokratischen Fraktionierung, der kompetitiven Struktur wie der Klientel- und Adressatenbindung der administrativen Entscheidungsprozesse aufbricht. 
Das ist nun insofern interessant, als diese Phänomene zunehmend auf demokratische Defizite der Verfahren der repräsentativen Demokratie und der institutionellen Strukturen der Staatswillensbildung selber zurückgeführt werden. Ein solches Krisenszenario eines gestörten Zusammenspiels von institutionellen Mechanismen, gesellschaftlichen Gestaltungsaufgaben und politischen Problemlösungen läßt sich als ein vierstufiger, kumulativer Prozeß der Selbstinvalidierung staatlicher Politik charakterisieren: auf einer ersten Stufe der Problenwahrnehmung bereits wirkt der konkurrenzdemokratische Machtzyklus wie ein Filter, der nur solche Probleme hindurchläßt, die in ihrer zeitlichen Dimensionierung auf die Kurzfristigkeit und Querschnittigkeit der Handlungsorientierungen von Parteipolitikern abgestimmt sind; auf der Ebene der Problemaufbereitung und -bearbeitung ist es zum einen der Mechanismus der Ressortierung, der der Analyse komplexer Problemstrukturen entgegenwirkt und integrierte Lösungsansätze häufig an Ressortkonkurrenzen scheitern läßt; in die gleiche Richtung wirkt der Mechanismus der Abbildung von Sachstandskonflikten auf die binäre Logik von Regierung und Opposition, der in der Tendenz für eine zusätzliche kognitive Auszehrung des Problemlösungshandelns sorgt; schließlich scheitert die Implementation politischer Entscheidungen und Programme u.a. auch daran, daß die Anwendung der Mehrheitsregel, wie Dewey (1984: 365) klarstellt, den vorherigen Rekurs auf Methoden der Diskussion, Konsultation und Persuasion förmlich erzwingt - m.a.W., der staatliche Interventionismus ist seinerseits auf Assoziationsstrukturen und auf Institutionen angewiesen, »die der Aufgabe gewachsen wären, durch die von ihnen ausgehenden Verpflichtungseffekte ein modernes Äquivalent für republikanische Tugenden zu stützen und unausgeschöpfte moralische Kapazitäten und Kooperationsbereitschaften zu aktivieren« (Offe, 1990a: 187), und so zu der vorgängigen, autonomen Vermittlung von Interesse und Vernunftinteresse beitragen könnten.

Externe Rationalitätsschranken resultieren demgegenüber wesentlich aus Prozessen der Globalisierung, also der räumlichen, sachlichen und sozialen Dispersion von Problemursachen und -folgen einerseits wie der sich weiter öffnenden Schere zwischen realer Problementwicklung und den strukturellen Begrenzungen der politischen Wahrnehmung und Bearbeitung dieser Probleme andererseits (vgl. Böhret, 1993: 39 ff.). Der vielzitierte Verlust der Souveränität und Gestaltungskraft des Staates ist im Kern dann darauf zurückzuführen, daß wir es in vielen Bereichen (Umwelt, Recht, Wirtschaft, Rüstung u.a.) mit einer Art Selbstsektorierung und Selbstformatierung von Politiknetzwerken zu tun haben, die sich in der supra- wie subnationalen Grauzone legitimationsarmer Strukturen einnisten und sich den Mechanismen einer nationalstaatlich organisierten demokratischen Willensbildung weitgehend entziehen. Auf diese Weise zieht sich im Zuge der internen Differenzierung moderner Gesellschaften und der gleichzeitigen Internationalisierung von Wirtschaft, Verkehr, Kommunikation und Umweltgefahren der Gestaltungs- und Problemlösungsanspruch von Politik (so weit er überhaupt noch besteht) in pluralistische, korporatistische und intergouvernementale Verhandlungssysteme zurück (Scharpf, 1993a: 165 ff.). Diese können nun zwar eine gewisse Rationalität effektiver Problemlösung für sich reklamieren; es fehlt ihnen in der Regel jedoch nicht nur der legitimationswirksame Rückbezug auf eine nach wie vor nationalstaatlich begrenzte öffentliche Meinungsbildung, sondern gerade dort, wo dieser Rückbezug im 
Rahmen eines Zwei-Ebenen-Spiels (Scharpf, 1993a: 167 f.) hergestellt wird, untergräbt er durch eine enge optionale Bindung die Autonomie und Effektivität der Verhandlungen: Die Prozesse auf beiden Ebenen sind deshalb schlecht kombinierbar, weil in jedem Teilprozeß die Optionalität verbraucht und vernichtet wird, die die Voraussetzung einer autonomen Entscheidungsfindung auf der jeweils anderen Ebene bildet.

Unter diesen Voraussetzungen scheint es für die Chancen der Demokratie nicht besonders gut zu stehen, und dies nicht zuletzt, weil gerade eine nationalstaatlich starke Demokratie sich in einer starken Beschränkung der politischen Problemverarbeitungsfähigkeit auf internationaler Ebene bemerkbar machen kann, die in die Katastrophe führen könnte (Scharpf, 1993a: 174). Diese im Zuge der inter- wie supranationalen Verflechtung sich zunehınend dringlicher stellende Frage nach der Effizicnz demokratischer Entscheidungsprozesse bildet jedoch nur die eine Seite der Globalisierungsproblematik. Vielleicht nicht so dringlich, aber doch unausweislich geraten wir im Zuge der faktischen Globalisierung aller politischen, ökonomischen und technologischen Prozesse in die normative Spannung zwischen universalen Menschenrechten und partikularen Bürgerrechten: diese Spannung bringt sich als eine Herausforderung an die internen Strukturen der Willensbildung in den demokratischen Gesellschaften des Westens derart zum Ausdruck, daß diese, »bei Strafe des Verrats an ihren eigenen konstitutiven Prinzipien, in ihrem demokratischen Diskurs die Stimmen aller (Herv. i.O.) derer müßten zur Geltung kommen lassen, die von ihren demokratischen Entscheidungen betroffen sind « (Wellmer, 1993: 192). Ungeachtet der schon gewiß nicht unbeachtlichen Probleme der organisatorischen und institutionellen Umsetzung würde die Einlösung eines solchen Anspruchs nur unter starker Anspannung und Strapazierung der moralischen Kräfte derjenigen, die die entsprechenden Transformationsprozesse in Gang zu setzen und zu sanktionieren liätten, überhaupt möglich.

Diese Diagnose eines Auseinanderdriftens von Rationalitätsanforderungen und institutionell verbürgten Rationalitätschancen staatlicher Politik läßt sich zusammenfassend gut vor dem Hintergrund des »handlungstheoretischen Dreiklangs von Wollen, Wissen und Können « (Böhret, 1990: 192) erläutern. Das »Wollen« betrifft die Frage der Verantwortbarkeit von Entscheidungen und durch sie ausgelösten Entwicklungen in bezug auf die Um - und Nachwelt - dem steht nicht nur das Bedenken des konfliktgenerierenden Charakters von Moraldiskursen resp. deren Intrumentalisierung zu Entsorgungsdiskursen selber entgegen, sondern die im wohlfahrtsstaatlichen Paternalismus wie in den repräsentativen Institutionen angelegte Mediatisierung der moralischen Kompetenz des Staatsbürgers und der auf »Querschnittigkeit « und kurzfristige Zeithorizonte festgelegte kompetitive Politiktypus (Böhret, 1990: 197 ff., Sarcinelli, 1990). In der Dimension des »Wissens « geht um die Spannung zwischen der zunehmenden Bedeutung von Wissen als einer Steuerungsressource moderner Gesellschaften (Preuß, 1990: 80 ff.) und der steigenden Konflikthaftigkeit der Wissensproduktion im Sinne von Wahrnehmungs-, Sachstands- und Problemlösungskonflikten (Böhret, 1990: 211 f.), auf deren Auflösung prozeßbezogene, aber resultatoffene institutionelle Strukturen kaum zu beziehen sind (vgl. demgegenüber Nullmeier, 1990). In der Dimension des "Könnens « schließlich geht es um die inverse Entwicklung von Steuerungsbedarf einerseits und staatlicher Steuerungsfähigkeit wie gesellschaftlicher Steuerbarl:iit ande- 
rerseits (Scharpf, 1989 und 1991). Kurz: was wir hier vor uns haben, läßt sich immer noch am ehesten mit dem der Organisationstheorie entlehnten »garbage-can «-Modell der Entscheidungsfindung beschreiben. Danach ergeben sich Entscheidungen nach dem zeitlich strukturierten, gegenüber der Entscheidungsmaterie und prozessualen Rationalitätsanforderungen relativ unempfindlichen (und daher kontingenten) Zusammentreffen von Problemen, Akteuren, Strategien, Programmen und Problemlösungsressourcen (Olsen, 1988 und 1991; Scharpf, 1987 und 1991).

b) Nun ist freilich der Staat nicht der einzige der oben erwähnten Sachwalter kollektiver Rationalität, der unter den Druck einer gesteigerten Reflexivität politischer Prozesse gerät - ähnliches gilt auch für das Recht und die Verfassung. Das ist nun deshalb umso bemerkenswerter, als es die traditionelle Funktion des Rechts ist (und seine spezifische normative Rationalität ausmacht), die in partikularen Handlungskontexten erzeugten Externalitäten zu balancieren und zu regulieren, indem es eine normativ auf die Reproduktion der Einheit der Gesellschaft bezogene Rationalität in den Funktionsimperativen einzelner Subsysteme und deren Interaktionen unterbringt (PreuB 1989b: 551 ff.). Dem steht allerdings die Beobachtung gegenüber, daß das Recht gerade durch seine steigende Inanspruchnahme als Steuerungsmedium in ein »regulatorisches Trilemma« (Teubner, 1984) verwickelt wird, das aus der Inkompatibilität des Rechts mit der Struktur der zu regulierenden Sozialbereiche entsteht und das sich entweder in der Irrelevanz des Steuerungsversuchs oder in der desintegrativen Wirkung auf das Steuerungsmedium selber oder den zu regulierenden Handlungszusammenhang hat. Es ist hier nun nicht der Ort, die vielfältigen Antwortversuche auf dieses Trilemma im einzelnen durchzumustern. Festgehalten werden soll lediglich, daß der Ausweg im Kern darin gesehen wird (unabhängig davon, ob man Recht als reflexives, prozedurales, ökologisches oder kommunikatives Recht konzeptualisiert), Recht als Medium gesellschaftlicher Selbstorganisation aufzufassen (Ladeur, 1990), und zwar so, daß über die Entbindung der in kommunikativen Strukturen angelegten Rationalitätspotentiale zugleich auch eine Nötigung zur gesellschaftlichen Selbstrationalisierung und -verbesserung (Preuß, 1990: 73) ausgeübt wird. Das ist aber ersichtlich nicht zu haben, ohne daß die Strukturen der Rechtserzeugung, -begründung und -anwendung sich selber für die Thematisierung ihrer Angemessenheit öffnen. Auf diese Weise wird Recht in seinen sozialen Reproduktionszusammenhang zurückgestellt und öffentliche Deliberation als eine im Medium von Recht vermittelte reflexive Praxis sichtbar und thematisch.

c) Eine vergleichbare Diagnose ergibt sich denı auch für die »Zukunft der Verfassung« (Grimm, 1990 und 1991), und zwar nun nicht etwa deshalb, weil der Zweck einer einklagbaren Fixierung des normativen Grundkonsenses über die Gestalt der politischen Ordnung entfallen ist. Das Problem scheint in diesem Zusammenhang eher, daß die Verfassung in ihrer Funktion der Verbürgung von Menschen- und Freiheitsrechten durch den o.g. Prozeß der Diffusion der Staatlichkeit marginalisiert wird, weil sie zum einen die nunmehr eigentlichen Adressaten verfassungsrechtlicher Normierungen (korporative Akteure, Verbände, Parteien) nicht mehr erreicht (Grimm, 1990: 24 ff.). Zum anderen gerät offensichtlich der demokratisch-prozedural verbürgte Freiheitsschutz dadurch in Gefahr, unterlaufen zu werden, daß Verfahren allein die Ratio- 
nalität von Entscheidungen unter Risikobedingungen nicht mehr garantieren können (Grimm, 1990: 28). Auf diese Konstellation ist ganz offensichtlich denn auch die Forderung der Steigerung der sachlichen, zeitlichen und sozialen Reflexivität kollektiver Willensbildung (Offe, 1989) bezogen: der Ausweg, der dann vorgeschlagen wird, besteht darin, Freiheitsrechte nicht mehr nur als subjektive Abwehrrechte aufzufassen, sondern sie in den praktischen Reproduktionszusammenhang einer demokratischen Ordnung zu rücken (insofern wird der Konstitutionalismus reflexiv) und die Institutionen zugleich so auszulegen, daß sie einen Zwang in Richtung auf die Rationalisierung der Willensbildung selbst ausüben - insofern wird der Konstitutionalismus moralischreflexiv (Preuß, 1990: 78).

d) Das ist demokratietheoretisch gesehen nun insofern eine gute Nachricht, als sich an dieser und ähnlichen Beschreibungen des Zustands des politischen Systems die gewollte und in der Regel als Stärke empfundene Anspruchslosigkeit realistischer Modelle der Demokratie desavouiert und so der Aufschwung neo-utilitaristischer Ordnungstheorien gebremst wird (Offe, 1990a: $177 \mathrm{ff}$.). Und es verleiht den Versuchen einer Revitalisierung republikanischer Traditionen und partizipatorisch-diskursiv orientierter Modelle von Demokratie zweifellos einen zusätzlichen Auftrieb: Insofern die Analyse der Funktionslücken staatlicher Politik zu der Empfehlung führt, aus der Not des Staates eine demokratische Tugend zu machen, hat die Verklammerung von Staatsund Demokratietheorie durchaus einen nicht nur deskriptiv-analytischen, sondern auch einen normativen Sinn, weil sie auf ein Modell von Demokratie zuläuft, das Strukturen einer inklusiven, partizipatorischen Willensbildung vorsehen muß, die einen deutlichen Entscheidungsbezug aufweisen und insgesamt aufnahmefähig sind für die Rationalitätserwartungen, die sich in der Perspektive der Verbesserung der Qualität politischer Entscheidungen einstellen.

Reflexe dieses neuen Aufgabenverständnisses (vgl. Schulze-Fielitz, 1993: 96 ff.) lassen sich denn auch in Wandlungen der staatlichen Handlungsformen (etwa durch eine Aufwertung des öffentlich-rechtlichen Vertrages und des informativen Staatshandelns, in Gestalt der Privatisierung des Staatshandelns und des informalen Verwaltungshandelns) und spezifischer in Wandlungen der Verwaltungspraxis (Stichworte dazu sind: Aufwertung des Verwaltungsverfahrensrechts, Kooperation als Prinzip des Staatshandelns und Entformalisierung des Gesetzesrechts) nachweisen. Dennoch haftet diesen Entwicklungen häufig ein zu insularer Charakter an, um zu dem aufgegebenen »Paradigmenwechsel der Steuerungsmechanismen« (vgl. Jänicke, 1993a: 70 f.) aufschließen zu können. In dieser Perspektive müßte es zu einer stärker integrierten Institutionalisierung unterschiedlicher Mechanismen und Strukturen kommen, wie sie etwa der folgende Katalog beschreibt: Steuerung von Rahmenbedingungen und Handlungskontexten statt bürokratischer Detailregulierung; Vergesellschaftung der Problembearbeitung unter Einschluß des Staates und der Bürokratie; eine stärkere Dezentralisierung der Problemlösung, die sich mit einer inklusiven und partizipativen Entscheidungsstruktur verbinden kann; Übergang von einem reaktiven zu einem antizipativen Politikmuster u.ä. Entscheidend aber, auch für den Zusammenhang und institutionelle Integration dieser Komponenten einer politischen Modernisierungsstrate- 
gie, ist, daß sich die Idee der Demokratie nicht mehr nur in einzelne Teile des entstehenden Netzwerks einer räumlich, sachlich und sozial differenzierten Willensbildung und Entscheidungsfindung zurückziehen kann. Darüber hinaus muß die demokratische Willensbildung selber reflexiv werden in dem Sinn, daß Verfahren mitinstitutionalisiert werden, die auf die Spezifizierung der institutionellen Arrangements der Entscheidungsfindung eingerichtet sind. In diesem Punkt laufen m.E. die unterschiedlichen Vorschläge eines »Societal constitutionalism« (Sciulli, 1986), einer »reflexiven Staatstätigkeit« (Olsen, 1991; Kleger, 1993; Offe, 1987) oder einer »neuen Staatlichkeit« (Nullmeier/Rüb, 1993) so zusammen, daß nicht nur einc rationalitätssteigernde Herstellung der Offenheit und Öffentlichkeit von Entscheidungsprozessen ins Auge gefaßt wird, sondern daß im Sinne der demokratischen Intuition, »that citizens are competent to make adequately enlightened judgments either about public issues themselves, or about the terms on which they may safely delegate to others the authority to make decisions« (Dahl, 1987: 203), Öffentlichkeit zum privilegierten Ort der Vermittlung institutioneller Reflexivität wird.

Die schlechte Nachricht ist indes, daß die Idee der Demokratie im Zuge einer dermaßen erweiterten Inanspruchnahme für die bewußte Gestaltung der gesellschaftlichen Lebensverhältnisse selber unter einen gewissen Streß gerät, der insgesamt daraus resultiert, daß die institutionelle Umsetzung der Idee der Demokratie unterschiedlichen und nicht unbedingt kompatiblen Optimierungsgesichtspunkten folgt: die Sicherung von Freiheit auch gegen eine mögliche Tyrannei der Mehrheit muß mit allgemeinen Teilhabeansprüchen und diese wiederum mit kompetenz- und rationalitätsverbürgenden Entscheidungsstrukturen balanciert werden (vgl. Fishkin, 1991). Dabei ist es vor allem die Verschränkung der Idee demokratischer Selbstbestimmung mit der auf dic Verbesserung der (sachlichen) Angemessenheit und Qualität von Politik bezogenen Idee vernünftiger Selbstregierung, die zu Spannungen im Verhältnis der Prinzipien von Freiheit, Gleic' heit und Rationalität führen, und die deshalb z.T. energische Abwehrreaktionen auf sich gezogen hat. ${ }^{4}$

Einzuräumen ist, daß, obwohl oder gerade weil die Idee der Demokratie konstitutiv mit der Idee der Vernunft in Gestalt einer deliberativen Praxis der Selbstbestimmung verknüpft ist (vgl. Spragens, 1990), die Demokratietheorie auf die in den letzten Jahren vielfältig artikulierten Vernunftzweifel schon deshalb reagieren können sollte, weil eine Über- oder Fehlakzentuierung der Idee der Rationalität im Kontext demokratischer Politik sich leicht der Gefahr einer elitistischen Involution der Idee der Demokratie selber aussetzt (vgl. auch Greven, 1993). Solche Zweifel können entweder in Form einer Krise des Vernunftsubjekts (so die republikanische Sichtweise) oder in postmoderner Sicht in Form der Diagnose einer Krise des Vernunftbegriffs selber artikuliert werden. Der postmodern inspirierten Kritik des demokratischen Rationalismus läßt sich nun entgegenhalten, daß sie sich selber eines objektivistischen Mißverständnisses

4 Vgl. Greven (1995). In dieser Kritik spielen vernunftkritische Motive, ein machttheoretischer Realismus, ein expressivistisches Ideal individueller Selbstvervollkommnung und differenztheoretische Annahmen auf vielfältige Weise zusammen. Ich kann darauf an dieser Stelle nicht eingehen - vgl. dazu aber genauer Schmalz-Bruns (1994: 375 ff.). 
des demokratischen Prozesses schuldig macht, insofern sie politische Praxis allein aus der systemischen Perspektive eines Beobachters, nicht aber in der Einstellung von $\mathrm{Be}$ teiligten rekonstruiert. Eine derartige Perspektive müßte sich sensibilisieren für die »irreducible activity of agents in sustaining the mutual intelligibility of their interactions « (McCarthy, 1991: 29), und sie würde, entgegen einer einseitigen Abrechnung mit dem illusorischen Charakter von Vernunftideen, den Zugang zu dem pragmatischen Gebrauch eröffnen, den Akteure von Ideen normativer Richtigkeit und theoretischer Wahrheit machen, um sich wechselseitig als für ihre Handlungen verantwortliche Subjekte zu erkennen und anzuerkennen und um Kritierien der Lösung von Interaktionskonflikten zur Verfügung zu halten.

Schwerer wiegt hingegen der republikanische Verdacht einer zunehmenden Entmoralisierung von Handlungsdispositionen im Zeichen eines liberalen Individualismus bei gleichzeitig steigendem Bedarf an »verantwortungsethischen Massenorientierungen « (Offe) in der modernen Politik. Im Zuge der von Offe diagnostizierten »(Re)Subjektivierung von Steuerungsleistungen« (Offe, 1989: 743) bilden moralische Einstellungen des einzelnen, staatsbürgerliche Qualifikationen und sachliche Kompetenzen ein kaum reduzierbares und institutionell nicht substituierbares Ferment des demokratischen Prozesses - sie werden zu knappen Ressourcen, die durch entsprechende institutionelle Strukturen gefördert (vgl. auch Warren, 1993 und Sarcinelli, 1993) und gegen die Ausbeutung durch strategisch-instrumentelle Handlungsdispositionen geschützt werden müssen.

\subsection{Exkurs: Zur Theorie politischer Institutionen}

Damit sind die wesentlichen Gründe benannt, weshalb politische Institutionen in den Sozialwissenschaften über disziplinäre Üblichkeiten und Routinen hinaus wieder zu einem Thema geworden sind. ${ }^{5}$ Und dies nicht einfach im Sinne einer gerade auf konservativer Seite begrüßten Wiederkehr des lange Verdrängten (Lipp, 1990), sondern weil sie in das Zentrum des Nachdenkens über die Gestaltung einer angesichts wachsender Herausforderungen ziemlich orientierungslos gewordenen Politik rücken (vgl. Unseld, 1993). So gilt es mittlerweile als ausgemacht, daß das institutionell geprägte Modell hierarchischer Politik in den westlichen Demokratien aus Effektivitäts- wie aus Effizienzgründen einer ebenso gründlichen »Abwicklung « (Willke, 1993) bedarf wie die sozialen und politischen Institutionen in den sich transformierenden osteuropäischen Gesellschaften. Dabei ist das neue, im Horizont aufscheinende Perfektionsmodell von Politik dann nicht etwa anti-institutionell. Auch am Gegenmodell horizontaler

5 Für einen Überblick vgl. etwa Schmalz-Bruns (1989). Im einzelnen sind hervorzuheben: Benz (1990), Bermbach (1991), Burns/Dictz (1992), Furubotn/Richter (1993), Gebhardt (1992), Göhler (1987 und 1994), Göhler/Lenk/Münkler/Walther (1990), Göhler/Lenk/ Schmalz-Bruns (1990), Gretschmann (1990), Gukenbiehl (1992), Levi (1990), March/OIsen (1989), Melville (1992), North (1990), Pankoke (1990), Scott (1993), Sened (1991), Türk (1989) und Zucker (1988). 
Koordination wird eine scheinbar wesentlich institutionell zu erbringende Leistung für die gesellschaftliche Integration sichtbar: Institutionen besorgen das Geschäft der komplexitätsreduzierenden und -ermöglichenden gesellschaftlichen Optionensteuerung, sollen also gemeinwohlorientierte Handlungsrationalitäten befördern und dem entgegenstehende Handlungsmuster zurückdrängen resp. »impossibilisieren « (Willke, 1993: 60 ff.). In ganz ähnlicher Weise wird auch für Beck (1993) die institutionelle Struktur moderner Politik zu der Schlüsselvariable, an der sich die Möglichkeit einer ökologischen Erneuerung der Moderne entscheiden soll - zu diesem Zweck wird den aus dem institutionellen Gehäuse staatlicher Politik längst ausgewanderten gesellschaftlichen Subpolitiken eine institutionelle Struktur angeraten, die es ihnen erlaubt, sich hinsichtlich ihrer Themen, Entscheidungsprozesse, -verfahren und Regeln permanent selber zum Thema zu machen (Beck, 1993: $204 \mathrm{ff}$.).

Werden hier Institutionen zum Mittel und Gegenstand einer »reflexiven Politik «, die sich vor allem dadurch auszeichnet, daß sie ihre eigenen Strukturen und Regeln laufend auf die Anforderungen eines kollektiven Problemlösungshandelns abstimmt, so versucht Offe darüber hinaus, den Institutionenbegriff seit einiger Zeit dadurch neu zu akzentuieren, daß er Institutionen in ihren Wirkungen auf die moralische und kognitive Qualität politischer Willensbildungsprozesse und Entscheidungen thematisiert: Sie sollen nicht nur »moralische Sensibilität, Realitätssinn und zugleich das Denken in anspruchsvollen Zeiträumen verbürgen « (Offe, 1989: 747). Sie erfüllen auch die Funktion eines Filters, »dessen Selektivität darüber entscheidet, ob und in welchem Umfang die rechtlich geschützten, in Sozialisationsprozessen und durch kulturelle Überlieferung aufgebauten kognitiven und moralischen Kapazitäten der Individuen zur Betätigung und Entfaltung zugelassen und gefördert oder im Gegenteil, sei es durch >Unterforderung ‘, sei es durch übergroße `Zumutungen`, brachgelegt und außer Übung gesetzt werden « (Offe, 1989: 760 f.). Daneben fungieren sie als eine Art demokratischer Selbstschutz gegen die Suggestion einer kollektiven Handlungsfähigkeit des demokratischen Souveräns, gegen die Fiktivität, Fehlbarkeit und Verführbarkeit eines Volkswillens, der sich durch die Einrichtung entsprechender Institutionen unter den Vorbehalt stellt, nicht an jedem Ort, zu jeder Zeit und zu jeder Frage entscheidend Stellung nehmen zu müssen (Offe, 1992).

Schließlich bietet sich, um dieses (vorläufige) Bild zu vervollständigen, eine Bestimmung an, die Jürgen Habermas (1992: 397) den organisatorischen Komplexen staatlicher Politik und vor allem den verfassungsrechtlichen Institutionen zuweist: in seiner Sicht haben sie den »reflexiven Sinn von gegensteuernden Vorkehrungen gegen eine gesellschaftliche Komplexität, die die normativ gehaltvollen Präsuppositionen einer rechtsstaatlichen Praxis unterwandert « (Herv. i.O.) - d.h., sie sorgen in einer Art »komplexitätserhaltender Gegensteuerung « dafür, daß die systemische Integration moderner Gesellschaften nicht vollständig aus dem Horizont einer demokratischen Praxis der Selbstbestimmung und der sie leitenden normativen Ideale heraustreten kann.

Diese knappe Skizze der Motive, die in die Renaissance des Institutionellen eingehen, ist gewiß einseitig und unvollständig, indem sie nur die demokratischen, zivilgesellschaftlichen und reformorientierten Impulse verzeichnet. Daneben gibt es sicher- 
lich auch das Phänomen einer »Restabilisierung der institutionellen Selbstbehauptung « (Rehberg, 1993: 1) als dem entscheidenden Merkmal der konservativen Wende seit den späten 70er Jahren, die in der kaum verhohlenen Freude über die Wiederentdeckung des zu Unrecht Vergessenen oder Verdrängten ihren Ausdruck findet (so etwa Guggenberger, 1979 und Lipp, 1990). Letzteres ist aber vielleicht weniger erstaunlich und auch konzeptuell kaum informativ oder innovativ, insofern in die Erneuerung der institutionellen Selbst- und Geltungsbehauptung vor allem Gehlensche Theorie- und zeitdiagnostische Motive eingehen. Bemerkenswerter ist schon, daß sich auch die "Linke« weder von der Gehlenschen Institutionenontologie noch von der marxistisch inspirierten Ideologiekritik mehr in eine bloß spiegelbildliche Negation und Abwehr des Institutionellen zurückdrängen läßßt (vgl. u.a. Rödel/Frankenberg/Dubiel, 1989: 11 ff.). So liefert etwa Offe an der oben schon zitierten Stelle gleich Hinweise für die Prominenz und den Stellenwert des Institutionenkcnzepts auf seiten der "Linken " mit, was durchaus einiges mit einer tiefgreifenden, demokratischen Reinterpretation des sozialistischen Projekts zu tun hat. Dieses sei, so Offe, nicht nur "für eine Gesellschaftsordnung verwirklichter Emanzipation heute (und nicht erst heute) operativ leer«, sondern dessen Neuinterpretation habe der doppelten Einsicht Rechnung zu tragen, daß es im Zuge einer reflexiven Modernisierung nunmehr gelte, »durch geeignete Verfahren und Institutionen die zerstörerischen Auswirkungen der technologischen, militärischen, wirtschaftlichen, bürokratischen und ökologischen Modernisierungsdynamik dadurch zu bremsen, daß Prinzipien der verantwortlichen Selbstbeschränkung zur Geltung gebracht werden « und daß sich solche Vermeidungskriterien nicht mehr ein für alle Male festlegen lassen, sondern nur im argumentativen Zusammenspiel kognitiv und moralisch aufgeklärter Meinungen jeweils fallweise herausbilden lassen« (Offe, 1989: 746 f.).

Kurz: Es gibt einigen Anlaß, in konstruktiver Absicht die Frage nach dem Design solcher institutionellen Arrangements aufzugreifen, die in der Lage wären, den Staatsbürger aus seiner Klientenrolle heraus- und als verantwortliches Subjekt einer gemeinwohlorientierten Politik hervortreten zu lassen. Das impliziert auch eine Umakzentuierung des grundlegenden Verständnisses von Politik, die nicht mehr (oder jedenfalls nicht primär) nach dem Modell der Aggregation individueller Präferenzen ausgelegt werden könnte, sondern nach dem (deliberativen) Modell der argumentativen Suche nach gemeinwohlverträglichen Lösungen für kollektive Handlungsprobleme: »Much of politics, of course, is that way (d.i.: a matter of bargaining, d. Verf.); but not all of it is. Another kind of politics, or another aspect of politics, centers on deliberation rather than bargaining and involves something more akin to the search for the right answer to a question or the best solution to a problem « (Soltan, 1993: 16). Dieser "Neue Konstitutionalismus« (vgl. Elkin/Soltan, 1993) führt mithin bereits drei grundlegende Intuitionen programmatisch zusammen, deren Ausarbeitung uns im folgenden beschäftigen wird. Erstens beruht danach die Rationalität institutionell regulierten politischen Handelns nicht auf konsequentialistischen Erwägungen, sondern sie folgt primär einer »logic of appropriateness « (March/Osen, 1994: 9), nach der sie ihren Verpflichtungsgehalt primär der Einpassung des Handelns in geteilte Auffassungen des Richtigen, Natürlichen oder Guten verdankt und nach der sich Verpflichtungseffekte dadurch ein- 
stellen sollen, daß sie das Handeln gegen das Eindringen interessenpolitischer Motive und die strategische Ausbeutung gemeinwohlorientierter Handlungsdispositionen abschirmen (vgl. auch Offe, 1990a: 187). Nur unter dieser Voraussetzung können sie zweitens als rationale »devices for social problem-solving «(Elkin, 1993a: 117) fungieren, die der gemeinschaftlichen Suche nach den besten Lösungen und damit der Kraft des besseren Arguments auch die nötige Schubkraft verleihen. Dieser spezifische Effekt wird sich aber drittens nur einstellen, wenn man nicht in den Fehler verfällt, die vorhandenen moralischen und kognitiven Ressourcen auf seiten der Beteiligten zu überschätzen - deswegen enthält diese Programmatik auch ein Element der reflexiven Selbstbegrenzung (Elkin, 1993a: 134 f.), das der Einsicht Rechnung trägt, »that politics depends on the distribution of capabilities for appropriate political action among citizens, groups, and institutions« (March/Olsen, 1994: 21).

Solche Formulierungen lassen nun gevviß die für Gehlens Institutionentheorie konstitutive, subjektivitätskritische Konfrontation von Sittlichkeit und Moralität hinter sich und sensibilisieren geradezu für die Notwendigkeit einer moralisch und pragmatisch orientierten Institutionenkritik. ${ }^{6}$ Gerade wenn man aber wieder zunehmend bereit ist, dem institutionellen Denken in der Politik schon deshalb einen breiteren Raum zu geben, weil der politische Prozeß durch Regeln und Organisationsformen bestimmt ist, die einen überindividuellen Status haben und weil der endogene Charakter von politischer Wirklichkeit, von Interessen, Präferenzen und Akteurkonzepten unübersehbar ist (March/Olsen, 1989: 160), dann muß es umso mehr erstaunen, daß so anspruchsvollen Konzeptualisierungsvorgaben andererseits (immer noch) keine entsprechende begriffliche Klärung und Präzisierung gegenübersteht. Trotz umfangreicher Bemühungen etwa im Zusammenhang einer Theorie politischer Institutionen, im Bereich des politikwissenschaftlichen Neo-Institutionalismus, der Geschichtswissenschaft, des neuen ökonomischen Institutionalismus oder der Organisationstheorie ist der Institutionenbegriff selber nach wie vor in sich vieldeutig, wird weitgehend eher intuitiv verwendet und steht in einem ungeklärten und nur schw̧er systematisierbaren Verhältnis zu einem Begriffsfeld für Sozialregulierungen unterschiedlicher Reichweite, Abstraktion und Bezugsebenen, in dem Korrespondenzbegriffe wie »Gesellschaft «, »Gesellschaftsformation «, »Soziales System «, »Subsystem«, »Organisation «, »Verband «, »Normensystem«, »Wertordnung « oder schließlich »Kultur« (Rehberg, 1990: 116) stehen.

6 Diese Verschränkung des Standpunktes der Sittlichkeit (der etwa für das Gehlensche Konzept der inneren und äußeren Formierung des Menschen maßgeblich ist - vgl. Rehberg, 1990: $117 \mathrm{f}$.) und der Moralität in einer kritischen Institutionentheorie hebt z.B. Offe dadurch deutlich hervor, daß er den rigiden Institutionalismus und Staatsfetischismus der deutschen Verfassungstheorie und -praxis geradezu als einen Mechanismus der Blockade institutionellen Lernens und institutioneller Sclbstadaptation seitens der neuen sozialen Bewegungen identifiziert (Offe, 1990: 248 ff.); in einem ganz anderen Zusammenhang, der Kommunitarismuskontroverse in den USA, mahnt Benhabib eine institutionentheoretische Vermittlung der Prinzipien von Gemeinschaft (Sittlichkeit) und Subjektivität an, um der Versuchung einer komplementären Vereinseitigung eines legalistischen Anti-Individualismus und eines individualistischen Anti-Institutionalismus zu entkommen (Benhabib, 1992: $45 \mathrm{ff}$. und $192 \mathrm{ff}$.). 
Wie läßt sich nun dennoch wenigstens eine gewisse Ordnung in diese zunächst verwirrenden, kaleidoskopartigen begrifflichen und funktionalen Verweisungszusammenhänge bringen? Ein solcher Versuch sollte m.E. mindestens drei Anforderungen genügen: Er sollte geeignet sein, eine spezifische, durch Prozesse der Sozial- wie Systemintegration hindurchgreifende Wirkungsweise des »Institutionellen « in Form eines »institutionellen Mechanismus« oder »institutioneller Mechanismen« (Rehberg, 1993) nachzuweisen oder wenigstens zu thematisieren; er sollte zweitens so angelegt sein, daß er zugleich einen die unterschiedlichen disziplinären Bedürfnisse und Gegenstandsbezüge übergreifenden begrifflichen Einheitsfokus zur Verfügung stellt und offen genug für die jeweiligen Besonderheiten der Verwendungsweise bleibt; und er sollte sich schließlich perspektivisch darauf einstellen, daß Institutionen selber wohl kein eigenschaftsloses Medium sozialer und politischer Prozesse sind und sich deshalb auch für Institutionenkritik offenhalten, also für die Thematisierung der durch Institutionen erzeugten Gefährdungen sozialer und politischer Prozesse, für ihre Leistungen wie Leistungsgrenzen. Auf diese Weise sollte sich der »Mehrwert« des Institutionenbegriffs gegenüber den alternativen Begriffsstrategien sichtbar machen lassen, ein Mehrwert, der nur darin bestehen kann, Ideen oder Intuitionen aufzunehmen, die in den alternierenden Begrifflichkeiten so nicht zum Ausdruck zu bringen sind.

Diese Anforderungen lassen sich nun am ehesten dadurch im Zusammenhang aufnehmen, daß man den Weg einer abgestuften, schrittweisen funktionalen Zuspitzung und semantischen Einengung des Institutionenbegriffs wählt. Sortiert man mithin das o.g. Begriffsfeld nach funktionalen Gesichtspunkten der sozialen Differenzierung und Integration und an Hand der allgemeinen Frage, wie es sozialen Gruppen durch Prozesse der funktionalen Differenzierung und Spezifikation von Handlungszusammenhängen und der Individualisierung hindurch gelingt, sich als Einheit zu erhalten, dann tritt die implizite Relationierung der Konzepte von Einheit, normativer Ordnung und Kultur im Begriff der sozialen Institution deutlicher hervor: Gesellschaften beschreiben sich als Einheit im Horizont kulturell erzeugter, normativ bestimmter kollektiver Identitäten, und die Funktion von Institutionen ist es dann, diese normativen Bezugspunkte in den andererseits eigensinnigen Handlungslogiken gesellschaftlicher Subsysteme präsent zu halten oder mit individuellen Handlungsplänen und -vollzügen zu vermitteln. In dieser, in der soziologischen Tradition vor allem von Durkheim und Parsons her gut vertrauten Perspektive erscheinen Institutionen also zunächst als »Vermittlungsinstanzen kultureller Sinnproduktion«, die ihr soziales Gewicht und ihre Wirklichkeit dadurch erhalten, daß sie gleichzeitig selber (idealtypisch) Sozialformen bilden, »in denen eine Synthese (Herv. i.O.) zwischen Sozialstruktur, Organisation, Normen- und Faktenwissen und den aus alledem sich ergebenden Verhaltenserwartungen und -beurteilungen hergestellt wird « (Rehberg, 1993: 7 f.). Dabei muß man sich die normativ bestimmte Einheit der Gesellschaft nicht notwendigerweise auch als eine im Ganzen sittlich integrierte Lebensform vorstellen, deren Werte und Normen analog dem psychischen Mechanismus der Internalisierung über Institutionen im Bewußtsein des einzelnen zu verankern wäre. Vielmehr kann man die entsprechende institutionelle Leistung auch (wie u.a. Habermas) so verstehen, daß Institutionen die Funktion übernehmen, die kommunikativen Strukturen der kulturellen Reproduktion enttraditionali- 
sierter Lebenswelten mehr formal über entsprechende Verfahren in systemisch geprägte Willensbildungsprozesse und Entscheidungsverfahren zu implementieren.

Recht - oder genauer: verfassungsrechtliche Prinzipien - bilden in dieser Sicht den paradigmatischen Bezugspunkt, an dem sich die Wirkungsweise von Institutionen als Vermittlungsinstanzen kultureller Sinnproduktion generell explizieren läßt. In gewisser Weise kann man die Habermassche Rechtstheorie, in der er systematische Anregungen vor allem von Durkheim und Parsons verarbeitet (vgl. Habermas, 1981: II, 118 ff.), ${ }^{7}$ als ernsthaftesten Kandidaten für die systematische Reformulierung der klassischen soziologischen Institutionentheorie lesen, die zugleich den Vorteil hat, einen fließenden Übergang von einem allgemein soziologischen zu einem spezieller politischen und politikwissenschaftlichen Gebrauch des Institutionenbegriffs zu konzeptualisieren (vgl. dazu insbesondere Habermas, 1992). Die Bestimmung des Verhältnisses von sozialen zu politischen Institutionen oder von soziologischer Institutionentheorie $\mathrm{zu}$ einer »Theorie politischer Institutionen « ist jedenfalls ein Problem, das entsprechende Arbeiten schon seit längerem beschäftigt. Göhler hat in diesem Zusammenhang jüngst den Vorschlag gemacht, einen politikwissenschaftlich relevanten Institutionenbegriff zunächst pragmatisch über Kernprobleme der politischen Theorie und eine dadurch angeleitete Explikation des institutionellen Faktors in der Politik zu gewinnen, um dann nach strukturellen und begrifflichen Entsprechungen in der allgemeinen Institutionentheorie zu suchen und als Theoriebausteine zu nutzen. Ich finde diesen Vorschlag grundsätzlich überzeugend, würde aber, abweichend von Göhler, nicht bei Macht, Rationalität und Repräsentation als den Themen, in denen sich soziologische und politikwissenschaftliche Institutionentheorie verklammern sollen (Göhler, 1994a: $13 \mathrm{f}$.), ansetzen, sondern vielmehr eine paradoxe Leistung von Institutionen in den Mittelpunkt rücken, die sozialen und politischen Institutionalisierungsformen gemeinsam ist, im Bereich der Politik aber besonders gut sichtbar wird. Gemeint ist die Auflösung jener Spannung zwischen der historischen Kontingenz sozial und politisch erzeugter institutioneller Ordnungen oder Ordnungselemente einerseits und der Stilisierung einer gewissen Unverfügbarkeit und Verbürgtheit, die Voraussetzung der Entfaltung der Wirksamkeit institutioneller Momente in sozialen und politischen Prozessen ist, andererseits. ${ }^{8}$ Diese Spannung wird besonders gut sichtbar, wenn man sich klarmacht, daß Institutionen im Kontext von Politik gleichzeitig als Bedingung, als Mittel und als Ergebnis von Politik erscheinen. D.h., der Politik wird eine reflexive Leistung abgefor-

7 In gleicher Weise hatte schon Parsons in den drei Jahre vor der »Structure of Social Action« entstandenen »Prolegomena to a Theory of Social Institutions«, die erstmals 1990 veröffentlicht wurden, auf den juristischen Ursprung des soziologischen Gebrauchs des Institutionenbegriffs hingewiesen und vorgeschlagen, die Institutionentheorie insgesamt als Rechtssoziologie aufzufassen (vgl. Parsons, 1990: 328).

8 Das ist die grundlegende Annahme, vor deren Hintergrund Rehberg neuerdings versuchen möchte, die historische Dynamik und Logik der Entwicklung und Abfolge unterschiedlicher Institutionentypen zu rekonstruieren - vgl. dazu das Arbeitspapier zur Vorstellung ihres Projekts im Rahmen des Schwerpunktprogramms "Theorie politischer Institutionen « unter dem Titel: »Unverfügbarkeit und Reflexivität - Eine Analyse hochkultureller Formveränderungen von Institutionen« (Rehberg u.a., 1993). 
dert, zu deren Bewältigung sie sich des Rechts und eben institutioneller Mechanismen bedient: ähnlich wie das vollpositivierte Recht, das solange gilt, bis es geändert ist, aber gerade in diesem temporalen Geltungsmodus von der Anerkennung der Legitimität einer rechtlichen Ordnung überhaupt abhängig bleibt, funktionieren Institutionen in der Politik nur deshalb, weil sie eine Quelle der normativen Geltung oder eben Eigengeltung erschließen, die sie bloß funktionalen und Zweckmäßigkeitserwägungen auch entziehen und dem politischen Prozeß wo nicht entheben, so doch aus diesem herausheben. Dies vor allem deshalb, weil sich das grundlegende Reflexionsproblem, das aufgrund des zirkulären Zusammenspiels von Politik, Recht und Institution entsteht, rein prozedural wegen der irreduziblen Selbstbezüglichkeit von Verfahren nicht lösen läßt. An dieser Stelle fungieren institutionelle Geltungsbehauptungen gleichsam als Dependenzunterbrecher, an denen die Kontingenz eines grundsätzlich selbstbezüglichen politischen Prozesses zum Stillstand kommen soll - damit aber hängt einiges, wenn nicht alles davon ab, welche Quellen der Eigengeltung sie erschließen, wie sie diese zum Ausdruck bringen und mit welchen Mitteln sie durchgesetzt wird. Dies wird insbesondere dann zu einem Problem, wenn wir in einem dritten Schritt nicht mehr nur von politischen Institutionen sprechen, sondern diese in den normativen Kontext der Idee demokratischer Selbstbestimmung stellen. Ich habe oben bereits angedeutet, welche Erwartungen seitens der modernen Demokratietheorie in die rationalisierende, moralisierende und disziplinierende Wirkung von Institutionen und entsprechend in institutionelle Reformen gesetzt werden. Danach sind es vor allem Institutionen, die die Aufgabe der Ermöglichung, des Schutzes und der Effektuierung moralischer Handlungsdispositionen im politischen Willensbildungs- und Entscheidungsprozeß übernehmen und die Autonomie der demokratischen Praxis gerade dadurch sichern sollen, daß sie diese mit Nötigungen zu reflexiver Bedürfnisinterpretation und -transformation verbinden.

Nun ist der Zusammenhang von Institution und Demokratie aber nicht unbedingt so einsinnig, wie in dem moralischen Perfektionsmodell der Demokratie vorgestellt. Im Gegenteil sollte man wenigstens damit rechnen, daß Institutionen kein eigenschaftsloses Medium bilden, das sich ohne Rückwirkungen und Kosten für demokratische Zwecke einsetzen läßt. Vor einer solchen perspektivischen Verzerrung könnte ein Rückblick auf die Gehlensche Institutionentheorie immerhin bewahren, und auch Rehberg hat in einer Analyse institutioneller Mechanismen indirekt auf Gefährdungen aufmerksam gemacht, die sich für demokratische Prozesse aus einer nicht zu übersehenden und zu unterschätzenden Eigenlogik des Institutionellen ergeben könnten. Zu diesen institutionellen Eigentümlichkeiten zählt Rehberg etwa Prozesse der Abstraktion und der generalisierten Motivbeschaffung, der Autonomisierung als Entstehung von Eigen- oder Sachgesetzlichkeiten, der Enthistorisierung, in der durch die Behauptung reiner Geltung die eigene Genese »vernichtet« oder zumindest unsichtbar gemacht wird (nicht zuletzt, um die Institution gegen extern induzierten Wandel abzuschirmen) und der Akkumulation von Normierungserfolgen und den dabei eingesetzten Mitteln (Rehberg, 1990: 137 ff.). Implizit geht es auf allen diesen analytisch unterscheidbaren Ebenen institutioneller Selbststabilisierung um die "Paradoxie von institutioneller Machtformierung und institutioneller Machtverdrängung« 
(Rehberg, 1993: 27 f.), um das Phänomen also, daß die »Machtsteigerung und Macht¿Speicherung in Institutionen gleichermaßen machtgestützt und durch eine Tabuisierung der Macht garantiert (ist) (Rehberg, 1993: 30) - wobei zwar diese Machttabuisierung durchaus wiederum den paradoxen Effekt einer »zivilisierenden Kraft der Heuchelei (Elster) bewirken kann, aber doch auch auf die andere, »dunkle Seite « von Institutionen als Mittel und Zweck in strategischen Machtauseinandersetzungen verweist (vgl. dazu Moe, 1990 und Sened, 1991).

\subsection{Demokratietheoretische Antworten im Überblick}

Institutionen stellen also gewiß kein eigenschaftsloses Medium dar, dessen man sich ohne Risiken zu Zwecken einer weitergehenden Demokratisierung der repräsentativen Demokratie bedienen könnte. Dennoch kann es sich die Demokratietheorie aus den oben genannten Gründen kaum leisten, sich im Gegenzug gänzlich dem Charme nichtinstitutioneller Politik in den Netzen pluraler, zivilgesellschaftlicher Öffentlichkeiten zu ergeben. Weder kann die Staats- und Institutionenferne einer gesellschaftlichen politischen Praxis für sich genommen schon deren Autonomie verbürgen, noch wird Politik dadurch automatisch demokratisch, daß sie in einer pluralen und konfliktfreudigen, aber fragmentierten Form der öffentlichen Meinungsbildung verharrt. Vielmehr ist nach einem inklusiven Modell politischer Partizipation zu suchen, daß den Anforderungen einer Verbesserung der Legitimtät, Qualität und Effizienz demokratischer Politik auch unter Bedingungen hoher Problem- und Strukturkomplexität entgegenzukommen vermag, ohne die normativen Präsuppositionen des liberalen Rechtsstaats in Gestalt der Prinzipien von individueller Freiheit und allgemeiner Gleichheit zu verletzen. Die Balancierung dieser Momente ist gevviß nicht cinfach zu handhaben, und deshalb konzentriert sich auch die in den letzten Jahren wieder intensiver gewordene demokratietheoretische Debatte auf Vorrangentscheidungen, die regelmäßig zu problematischen trade-offs zwischen den Eckwerten von Freiheit, Gleichheit, Solidarität und Effizienz führt. Vor diesem Hintergrund möchte ich die Vorüberlegungen nunmehr mit einem vergleichenden Blick auf eine aktualisierte Version des realistischen Modells der Demokratie (a), auf Rawls' Theorie des politischen Liberalismus (b) und auf das Modell deliberativer Politik (c) abschließen.

a) »Wenn die Demokratie (von ihren Definierern) falsch definiert wird, so laufen wir alle auf Dauer Gefahr, etwas abzulehnen, was wir gar nicht richtig identifiziert haben, und dafür etwas bekommen, was wir bestimmt nicht haben wollten«. Mit dieser Grundthese schlägt Sartori (1992: 22) ${ }^{9}$ sofort einen engagierten Ton in seinem Bemühen ein, entgegen allen »populistischen « und radikaldemokratischen Zweifeln erneut eine entscheidungstheoretische Sicht der Demokratie zu rechtfertigen und das Modell einer pluralistischen, auf Parteienkonkurrenz gegründeten Elitendemokratie zu restau-

9 Ich beziehe mich im folgenden auf dieses Werk und weise Textbezüge lediglich durch Seitenangaben (in Klammern) aus. 
rieren (24). Ganz im Sinne einer demokratischen Besitzstandswahrung und auf Leistungsfähigkeit, Effizienz und Realismus bedacht, versucht er, potentiell destruktive utopische Energien einzudämmen und normative Theorien auf eine günstigstenfalls regulative Funktion zurückzustutzen.

Mehr als alle anderen Kosten eines demokratischen Idealismus (242 ff.), zu denen u.a. die antiliberale Vernachlässigung der »äußeren Risiken« politischer Entscheidungen (das sind Risiken, die sich bei politischen Entscheidungen dadurch einstellen, daß regelmäßig die Zahl der Entscheidenden kleiner als die der Betroffenen ist, die, weil ohne Mitwirkungschance, die Tatsache einer politischen Entscheidung überhaupt als Risiko empfinden müssen) und die Dialektik der Politisierung zählen, die aus der Wechselwirkung zwischen einer Ausdehnung von Politik und einer Invisibilisierung von institutionell nicht mehr kanalisierbaren Entscheidungsprozessen resultiert (246 f.), beunruhigt Sartori dabei die Aussicht, daß die Mitwirkungsdemokratie eine permanente Nötigung enthält, gleichsam »über unsere Intelligenz « (249) zu leben. Dieser generelle Verdacht bildet so etwas wie das heimliche Organisationszentrum, den Drehund Angelpunkt seiner Auseinandersetzung mit der direkten (Mitwirkungs-) Demokratie: »In dieser Stunde der Wahrheit kann man nicht mehr die Augen vor der Tatsache verschließen, daß Information nicht Sachkenntnis ist und daß wiederum Sachkenntnis - die kognitive Fähigkeit und Beherrschung - immer mehr das Problem wird, wenn die Politik immer komplizierter wird...Je mehr die sichtbare Hand und das politische Konstruieren die unsichtbare Hand der automatischen Anpassungen (oder Fehlanpassungen) ersetzt, und je mehr die Politik überall eindringt, desto weniger haben wir unser Handeln im Griff. Das Problem der Sachkenntnis macht sich auch darin bemerkbar, daß wir auf eine >Wissenskrise « zusteuern « (132 f.). Und es ist keine Frage, daß sich, obwohl »die Demokratietheorie es sich nicht leisten kann, das Problem der Sachkenntnis - der kognitiven Fähigkeit und der Mittel-Zweck-Rationalität - von Anfang bis Ende zu ignorieren « (133), weder ökonomische Theorien der rationalen Wahl noch Mitwirkungstheorien des Problems der kognitiven Unfähigkeit in der Massendemokratic im Ernst stellen.

Vor diesem Hintergrund kann man nunmehr den Weg, den Sartori zu seinem Entscheidungsmodell der Demokratie zurücklegt, in drei (zugegeben: groben) Schritten rekonstruieren. Zunächst akzentuiert er die technische Entwicklung als den Prozeß, der auch der Demokratie ihre allgemeine Entwicklungsrichtung vorgibt. Weil mit dem technischen Fortschritt auch die Wissensanforderungen an eine rationale politische Steuerung steigen, nimmt danach unvermeidlich die Kluft zwischen Nichtfachleuten und Fachleuten zu, und es entsteht ein zunehmendes Ungleichgewicht zwischen dem machtlosen Wissen der Experten und dem »allmächtigen Unwissen« der Mehrheit der Nichtfachleute: daraus zieht er die Konsequenz, daß wir uns der Notwendigkeit einer Demokratie beugen müssen, »die zwar nicht von Experten regiert wird, sich aber wesentlich auf sie stützt. Faktisch, und ohne viel gegenteilige Rhetorik, steuern wir auf weniger Volksmacht zu « (423 f.). Nachdem so klargelegt ist, daß schon die Imperative der technischen Welt dem »Primitivismus« einer Input-Demokratie zuwiderlaufen, hebt er zweitens hervor, daß das Interesse an der Funktionsfähigkeit des demokratischen Systems ein zunehmendes Interesse nicht nur an der demokratischen Legitimität von Ent- 
scheidungen, sondern an deren sachlicher Qualität nach sich ziehen muß (182): in diesem Zusammenhang deutet er zumindest an, daß auch der Liberalismus aufgrund seiner Präokkupation mit konstitutionellen und institutionellen Mechanismen der Machtbegrenzung hier eine offene Flanke hat, weil die »Verfahrensdemokratie« allein die erforderliche Qualität der politischen Entscheidungen nicht verbürgen kann (376). Dies verbindet er drittens mit der Diagnose, daß die unmittelbaren Gefahren für die Demokratie als politischer Form wesentlich in einer »blockierten« Regierungsfähigkeit liegen, die aus einem $» z u$ geringen Widerstand gegenüber Forderungen und geringer Fähigkeit zum Fällen und Durchsetzen von Entscheidungen « (181) resultiert: dieser Art systeminduzierter Unentschlossenheit, Kurzsichtigkeit und Ineffizienz hofft er schließlich durch ein selektives System konkurrierender gewählter Minderheiten, einer selektiven und auf Verdienst beruhenden Polyarchie, entgegenwirken zu können (177 ff.).

Damit sind nun auch die Kriterien benannt, denen sein eigenes Modell einer entscheidungsorientierten Demokratie genügen können muß. Ganz grob muß eine Lösung gefunden werden, die zum einen zu einer neuen Balance zwischen der Minimierung der äußeren Risiken politischer Entscheidungen durch Beteiligung und einer Minimierung der inneren Entscheidungskosten führt - das ist das Problem der optimalen Größe von Entscheidungsgruppen; zum anderen sollte sie, anders als die einfache Mehrheitsregel, eine bessere Kanalisierung der unterschiedlichen Intensitäten politischer Präferenzen erlauben und Mechanismen eines adaptiven »preference-learning « vorsehen. Beides scheint Sartori am ehesten noch in einem System von Ausschüssen gewährleistet (227 ff.), das folgende konstitutive Merkmale aufweist: ein Ausschuß bildet eine kleine interagierende Gruppe mit persönlichem Kontakt; es handelt sich um eine dauerhafte und institutionalisierte Gruppe, die immer eine Abfolge von Entscheidungen zu bewältigen hat; dieser interaktive Kontext erlaubt es, dichotome Entscheidungsstrukturen zu überwinden und komplexe Präferenzordnungen auf seiten der Beteiligten zu aktualisieren; und sie bilden so Foren und Kristallisationspunkte realer Mitwirkung, die sich durch die einfache Vermehrung von Ausschüssen maximieren läßt.

Nun ist freilich in Rechnung zu stellen, daß das Ausschuß-Modell der Willensbildung auf die Rationalisierung der Entscheidungsfindung auf der Ebene politischer Eliten und gewählter Repräsentanten beschränkt bleibt und keine Revision des Urteils über die Chancen direkter Demokratie beinhaltet. Die Mitwirkungsrechte und Einflußchancen breiterer Bevölkerungskreise bleiben auch im Rahmen dieses Modells nicht nur aus technischen, sondern auch aus Kompetenzgründen (s.o.) auf allgemeine Wahlen i.S. einer kontrollierten Machtübertragung beschränkt. Schon deshalb muß m.E. bezweifelt werden, stellt man Erfahrungen z.B. mit dem parlamentarischen Ausschußwesen oder mit Enquetekommissionen in Rechnung, ob die erwarteten Rationalisierungswirkungen wirklich eintreten können, wenn man die Willensbildung in solchen Gremien nicht zur Gesellschaft hin öffnet und intern mit der Meinungs- und Willensbildung in den pluralen demokratischen Öffentlichkeiten verklammert. M.a.W. gibt es eine Reihe von Gründen, die eher dagegen sprechen, daß die von Sartori betriebene Restaurierung des realistischen Modells der elektoralen Demokratie in der Lage ist, die Entwicklungen, die die moderne Demokratie in die Wissens- und Regierbarkeitskrise geführt haben, wirklich aufzunehmen. Zunächst können rationalisierte Verfahren der 
Entscheidungsvorbereitung nur eine begrenzte Wirkung entfalten, so lange sie in die grundlegenden Strukturen einer kompetitiven Ordnung eingebunden bleiben - die Imperative einer »positionalen Politik « (Ueberhorst) wirken vielmehr regelmäßig wie Filter, an denen Versuche der Verbesserung der sachlichen Güte politischer Entscheidungen hängenbleiben, so daß sich schon aufgrund dieses Mechanismus an der häufig (und auch von Sartori) kritisierten Kurzfristigkeit und Querschnittigkeit (Böhret) der Politik wenig ändern dürfte. Darüber hinaus läßt sich so dem Phänomen von aus dem offiziellen Legitimationskreislauf heraustretenden Formen der Willensbildung (u.a. Korporatismus, oder in Sartoris Begriffen: von sozial selektiven Polyarchien), kaum Rechnung tragen. Gleichzeitig kann gesellschaftsseitig kaum erwartet werden, daß auf diese Weise der bestandsgefährdenden Entmoralisierung von Politik im Zuge sich ausbreitender privatistischer und konsumistischer Masseneinstellungen (243 f.) entgegengewirkt werden kann. In diesem Zusammenhang greift Sartori schließlich auch deshalb zu kurz, weil ihm der Engpaß aus dem Blick gerät, der sich auf der Seite der Implementation materialer Politiken und staatlicher Regulierungsansprüche daraus ergibt, daß diese in ihrer Wirkung zunehmend von entgegenkommenden Einstellungen und rational motivierten Folgebereitschaften der einzelnen Bürger und gesellschaftlichen Gruppen abhängig werden.

Das nötigt nun, wie ich meine, dazu, sich in stärkerem Maße auf die institutionellen und assoziativen Bedingungen zu konzentrieren, unter denen es zu einer rational motivierten Präferenzbildung auch seitens der Bürger kommen kann: "In the modern world, individuals are far more likely to affirm rational preferences if they freely engage in informed deliberation than if they persist in uncritical acceptance of their preferences or are denied the opportunity for informed deliberation « (Arneson, 1993: 208). Es spricht einiges dafür, daß es auch neuer Formen der Vergemeinschaftung bedarf, um die Lücken zu schließen, die Sartori in das angemessene Verständnis moderner Demokratie, ihrer Legitimität wie Effizienz, gerissen hat. Sein Versuch der Restauration der realistischen Version jedenfalls ist kaum geeignet, die demokratietheoretische Diskussion von der Aufgabe zu dispensieren, eine neue und den aktiven Bürger einbegreifende Balance zwischen öffentlichem Vernunftgebrauch, politischer Rationalität und allgemeinen Mitwirkungsansprüchen zu finden.

Die genaue Austarierung dicser Momente ist indessen auch davon abhängig, wie man das demokratische Legitimitätskriterium verstehen will und wie die Grenzziehung des Politischen (der Politik) in der modernen Gesellschaft vorgenommen wird. Was die erstgenannte Dimension betrifft, kann man vier Positionen grob danach unterscheiden, welches der drei Prinzipien der (individuellen) Freiheit, der Gleichheit und der (vernünftigen) Autonomie jeweils in Führung geht: so ergibt sich einmal eine libertäre Position, die in einem individualistischen Verständnis der (Wahl-) Freiheit gründet, gegenüber Fragen der Gleichheit eher unempfindlich bleibt und sich zu jenen in das demokratische Legitimitätskriterium eingeschlossenen Vernunftansprüchen insgesamt agnostisch verhält; davon abzusetzen sind jene Auffassungen, für die eine teleologische Auslegung des Legitimitätskriteriums in Abhängigkeit von ontologischen Auffassungen des guten Lebens entscheidend ist - erst von daher kann sich dieser Position zufolge ein angemessenes Verständnis von Freiheit und Gleichheit entwickeln lassen; 
eine dritte Variante ergibt sich im Kontrast dazu dann, wenn man die Legitimität politischer Prozesse von einem öffentlichen Vernunftgebrauch abhängig machen will, der indes nicht in substantiellen Vorstellungen eines guten Lebens, sondern in der moralischen, ethischen und sachlichen Kompetenz und damit der rationalen Autonomie von Bürgern vermittelt ist; schließlich haben wir es auch mit Auffassungen zu tun, die epistemische Deutungen von Politik grundsätzlich unter den Verdacht der Inkompatibilität mit dem demokratischen Legitimitätskriterium stellen, das sich vielmehr in einer gleichberechtigten, in verständnisorienter Dialogizität vermittelten Teilhabe gründet. Nicht deckungsgleich mit, aber auch nicht vollständig unabhängig von diesen normativen Modellen (also: eines liberalen Individualismus, des Kommunitarismus, eines (links-) liberalen Republikanismus und eines radikalen Pluralismus) verlaufen zum anderen die Grenzziehungen hinsichtlich des Gegenstandsbereichs politischen Handelns entlang der Differenz von >privat < und >öffentlich < - sie lassen sich auf einem Kontinuum zwischen einer extrem restriktiven und einer inklusiven Sichtweise abtragen und changieren zwischen ontologischen und historischen Markierungen.

Kombiniert man nun die Unterscheidungen in beiden Dimensionen, lassen sich u.a. die zwei Ansatztypen herauspräparieren, die ich nunmehr kurz skizzieren möchte: Während John Rawls sich im Lichte des Prinzips des öffentlichen Vernunftgebrauchs zu einer thematischen Kontraktion des Politischen genötigt sieht, versucht das Modell deliberativr Politik die Fesseln eines allzu restriktiven Prozeduralismus zu lösen und diskursive Rationalität als Ferment einer partizipatorischen, inklusiven Form politischer Willensbildung und Entscheidungsfindung zu restaurieren.

b) Rawls' (1993) ${ }^{10}$ konzentrierter Versuch, der Idee des politischen Liberalismus eine Gestalt zu geben, in der sie auch den Einwänden ihrer republikanisch gesonnenen Kritiker gewachsen ist, ruht auf der konzeptionellen Verschränkung von drei Elementen: er fokussiert in der Idee des öffentlichen Vernunftgebrauchs, enthält ein darauf abgestimmtes normatives Staatsbürgerideal und politisches Rollenverständnis und bemüht sich um eine kontextsensiblere Darlegung der Bedingungen, unter denen sich ein liberaler Konstitutionalismus stabilisieren kann. Dic Einwände, auf die er mit dieser Strategie reagiert, lassen sich in drei Punkten zusammenfassen. In erster Linie geht es dabei um seinen Personbegriff, der nicht nur als soziologisch uninformiert, sondern auch als normativ kurzschlüssig kritisiert wurde, weil er in der individualistischen Tradition eine Begründungsbasis reklamiere, die schon deshalb keine hinreichende Allgemeinheit verbürgen könne, weil sie in ihrem Geltungsanspruch zu sehr einer spezifischen sittlichen und nicht unkontroversen Auffassung des guten Lebens verhaftet bleibe und nicht als integrativer Bezugspunkt eines Pluralismus vernünftiger Lebensformen fungieren könne; daneben treten Kritiken, die sich daran entzünden, daß Rawls die Fixierung eines konstitutionellen Konsensus durch eine sachliche, zeitliche und soziale Verengung des politischen Handlungsfeldes erkaufe - sachlich durch eine thematische Engführung des Politischen an Fragen rein prozeduraler Gerechtigkeit, zeitlich

10 Soweit ich mich im folgenden auf dieses Werk beziehe, weise ich Zitate und Textbezüge lediglich durch Seitenangaben (in Klammern) aus. 
durch die Beschränkung der öffentlichen Rolle des Bürgers auf (historisch-) konstitutionelle Momente und sozial durch die selbstselektive Wirkung der Anforderungen des öffentlichen Vernunftgebrauchs; beide Stränge laufen schließlich in dem Verdacht zusammen, daß Rawls seine Konzeption in ihrem Formalismus so von lebensweltlichen Einstellungen, Überzeugungen und Werten, aber auch vom materialen Gehalt politischer Probleme abschneide, daß die »fokale Konzeption des Politischen« (XIX) zu einer kaum arbeitsfähigen Unterscheidung zwischen >privat< und >öffentlich < führe.

Rawls' Antwort auf diese Einwände läßt sich nun wiederum in drei Schritten nachzeichnen. Danach beruht die erste Sorte von Kritiken auf einem Mißverständnis hinsichtlich des Status des von ihm im Zusammenhang der »original position « eingeführten Personkonzeptes: dieses beinhalte keineswegs ein gültiges moralisches Ideal des Selbst, sondern stilisiere lediglich jene argumentativen Kompetenzen, die jene wechselseitig in Anspruch nehmen können müssen, die sich an der diskursiven Bearbeitung von Fragen politischer Gerechtigkeit beteiligen. Insofern erscheinen der Urzustand und der "Schleier des Nichtwissens « als Darstellungsmittel, das die Anforderungen an die Herausbildung eines vernünftigen Konsensus bezüglich der politischen Grundnormen einer wohlgeordneten Gesellschaft modelliert: »The idea is to use the original position to model both freedom and equality and restrictions on reasons in such a way that it becomes perfectly evident which agreement would be made by the parties as citizens' representatives « (26); d.h. es ist erforderlich, daß »the parties as representatives ... assess conceptions of justice bearing in mind that the principles they agree to must serve as a public political conception of justice ... (and) that they must reason only from general beliefs shared by citizens generally, as part of their public knowledge « (69 und 70).

Sobald dies klar und die erste Sorte von Einwänden abgewiesen oder zumindest entkräftet ist, wird der sehr eingeschränkte Fokus eines nicht nur für sich stehenden (»freestanding «, wie Rawls reklamiert), sondern in gewisser Weise auch freischwebenden Begründungsprogramms politischer Gerechtigkeit selber zum Problem. Zwar verlangt Rawls, um die Möglichkeit fairer Kooperation unter Bedingungen eines vernünftigen Pluralismus umfassender religiöser, philosophischer und moralischer Doktrinen zu erweisen, zunächst nur, daß die Begründung der Kooperationsnormen von kontroversen Geltungsansprüchen freigehalten werden muß. Das läßt, unter motivationstheoretischen Gesichtspunkten, jedoch offen, wie es auf Dauer möglich sein soll, eine Gesellschaft freier und gleicher Bürger in einem formalen Verfassungskonsens zu integrieren und zu stabilisieren, der sie zu einer Suspendierung (resp.: Privatisierung) ihrer umfassenderen sittlichen und moralischen Einstellungen und substantiellen Ansprüche nötigt (XVIII) - Ansprüche, die sich etwa als Bedürfnis nach »status, power and glory, and for property and wealth«, aber auch nach »attachments and affections, loyalties and devotions of many kinds« (82) zur Geltung bringen? Die Antwort auf dieses Problem sucht Rawls auf zwei Wegen. Den ersten schlägt er mit der Wendung zu einem nunmehr zweistufigen Aufbau der Theorie ein, wobei er auf der zweiten Stufe, die der unabhängigen Begründung der Gerechtigkeitsprinzipien nachgeschaltet ist, unter dem Begriff des »überlappenden Konsensus« die dem konstitutionellen Konsens (158 ff.) entgegenkommenden Momente partikularer Lebensformen stilisiert. Hierbei stützt er sich auf die Annahme einer in Schritten sich vollziehenden wechselseitigen 
Durchdringung von konstitutionellem Konsens und partikularen Lebensformen. Das soll sich einerseits so auswirken, $\gg$ (that) the liberal principles of justice ... tend to shift citizens' comprehensive doctrines so that they at least accept the principles of a liberal constitution « (163); andererseits setzt er darauf, daß sich der zunächst sehr enge, rein prozedurale konstitutionelle Konsens im Laufe der Zeit durch die Wahrnehmung der darin eingeschlossenen Rechte auch material in Richtung auf soziale und Wohlfahrtsrechte erweitert (166).

Freilich wird der Status dieser egalitären Intuitionen im Rahmen des zweistufigen Neuaufbaus der Theorie prekär. Und das aus zwei Gründen. Erstens bleibt, wie Cohen beobachtet, unklar, für welche von drei Möglichkeiten der Beschreibung des Verhältnisses der beiden Stufen sich Rawls entscheidet: »(1) Is it necessary that the correct account of justice satisfy the pluralistic consensus test; (2) satisfying the test is not necessary though it does provide some support for a conception of justice; or (3) satisfying the test is a desideratum that has no bearing on the correctness of an account of justice (Herv. i.O.) (Cohen, 1993: 273). Selbst wenn man nun annimmt, daß Rawls selber die zweite Variante favorisiert, weil er von einer Art sozialer Selbstimplikation der Idee des öffentlichen Vernunftgebrauchs ausgeht, muß das - systematisch gesehen - als persönliche Vorliebe angesehen werden, weil diese spezifisch egalitäre Sichtweise im Zusammenhang der von ihm akzeptierten Tatsache des Pluralismus kaum von allen als integraler Bestandteil ihrer umfassenderen moralischen oder philosophischen Doktrinen betrachtet werden dürfte. Deshalb sieht sich Rawls dann zweitens mit Blick auf die Bedingungen der Stabilität des liberalen Verfassungskonsens genötigt, den übergreifenden Konsens auf prozedurale Verfassungsinhalte zu beschränken, die das Differenzprinzip des zweiten Grundsatzes der » Theorie der Gerechtigkeit« nun nicht mehr einschließen; d.h. er sucht die Schwierigkeiten der Konsensbildung unter dem Faktum des »vernünftigen Pluralismus« und der »burdens of reason « durch einen an grundlegenden Verfassungsfragen enggeführten Politikbegriff und eine nur darauf bezogene, sparsame Mobilisierung des Bürgers in seiner öffentlichen Rolle zu begrenzen. ${ }^{11}$ Nur unter dieser Voraussetzung, so muß man Rawls verstehen, können die anspruchsvollen Erwartungen an deı öffentlichen Vernunftgebrauch, die dem Bürger die moralische Pflicht auferlegen, »anderen zu erklären, inwiefern die von uns in grundlegenden Fragen vertretenen politischen Prinzipien und Programme durch politische Werte der öffentlichen Vernunft gestützt werden « (Rawls, 1994: 8) - mithin also eine moralischdiskursive Haltung an den Tag zu legen -, auch eingelöst werden: »Public reason, then, is public in three ways: as the reason of citizens as such, it is the reason of the public; its subject is the good of the public and matters; and its nature and content is public,

11 Rawls (1994). Rawls selber räumt durchaus ein, daß eine solche Konzeption uns in vielen ökonomischen und sozialen Angelegenheiten kaum weiterhilft (1994: 13), macht aber die Grenzen des öffentlichen Vernunftgebrauchs dann von historischen und sozialen Bedingungen abhängig. Selbst für den Fall einer gegenständlich-inklusiven Bestimmung dieser Grenzen bleibt der Vernunftgebrauch jedoch auf die strikt verallgemeinerungsfähigen Aspekte solcher Fragen beschränkt (1994: 17 f.). Vgl. auch Hinsch (1992) und Goerner (1993). 
being given by the ideals and principles expressed by society's conception of political justice...« (213).

Die Sorge um die Bewahrung einer anspruchsvollen Form des öffentlichen Vernunftgebrauchs, die Rawls als Pflicht zur Bürgerlichkeit (»duty of civility«) anspricht, führt also schließlich nicht nur zu einer restriktiven Bestimmung der Gegenstände und Inhalte eines öffentlichen, moralisch-praktischen Räsonnements (227 ff.). Vielmehr verleitet sie ihn am Ende zu einer Art justiziellen Republikanismus, der die Idee der Volkssouveränität unterläuft, die Suprematie des Parlaments in Verfassungsfragen zurückweist (233) und die allgemeine Öffentlichkeit von der Führung des Verfassungsdiskurses suspendiert, der jedenfalls im Routinemodus normaler Politik Sache juristischer Experten sein soll: »... the courts role is not merely defensive but to give due and continuing effect to public reason by serving as its institutional exemplar (Herv. der Verf.)« (235).

Zusammengefaßt mag man in dieser Entwicklung der Idee des politischen Liberalismus jedenfalls demokratietheoretisch gesehen kaum einen Fortschritt erkennen. Der Grund dafür liegt nicht in den nach wie vor kontroversen Grundentscheidungen im einzelnen, sondern vielmehr darin, daß sich die problematische Wirkung dieser Einzelentscheidungen durch ihre enge Verzahnung noch verstärkt und im Ergebnis zu einer sehr restriktiven Auslegung der staatsbürgerlichen politischen Praxis führt. Das hängt zum einen damit zusammen, daß die an idealen, kontrafaktischen Bedingungen entwickelten Anforderungen an den öffentlichen Gebrauch von Vernunft politisch nur dann greifen und Wirkung zeigen, wenn es gelingt, diese Bedingungen wenigstens z.T. institutionell auch in der politischen Alltagspraxis zu verankern - Ansatzpunkte dafür will Rawls aber lediglich in der justiziellen Praxis vor allem verfassungsgerichtlicher Rechtsprechung entdecken; daraus resultiert eine gewisse Motivationsschwäche dieser Konstruktion, weil sie nur für jene akzeptabel ist, die den öffentlichen Vernunftgebrauch im von Rawls definierten Sinn ohnehin als höchsten Wert betrachten - in diesem Zusammenhang erweist sich gerade die rein prozedurale Fassung öffentlicher Vernunft als defizitär, weil sie die substantiellen Anliegen, die Menschen mit dem Gebrauch argumentativer Vernunft verbinden - nämlich von ihrer Sache zu überzeugen - unterbelichtet läßt (vgl. Brower, 1994). Durch diese Grundentscheidung wird Rawls zum anderen dazu verleitet, spezifische Verkürzungen am modernen Verständnis von Staatsbürgerschaft vorzunehmen: Wenn eine Theorie des Staatsbürgers heute mindestens eine Bestimmung sozialer Rechte und Pflichten, Aussagen zu deren Typus und Form wie Hinweise auf die sozialen Trägerkräfte und jene Arrangements umfassen sollte, die die gesellschaftliche Allokation staatsbürgerlicher Rechte, Pflichten und Teilhabechancen regulieren (könnten), dann bleibt Rawls in allen diesen Punkten hinter berechtigten Erwartungen zurück - insbesondere aber läßt er sich kaum auf die moralischen und institutionellen Anforderungen ein, die mit der partizipatorischen Komponente des modernen Staatsbürgerverständnisses verbunden sind (vgl. Turner, 1993 und Kalberg, 1993). Schließlich besteht die Gefahr, daß Rawls nunmehr, nach der Lüftung des »dichten« Schleiers der Unwissenheit und dessen Ersetzung durch einen »dünneren « Schleier, der die Vertragsparteien nurmehr von Informationen über ihre soziale Position, nicht aber von Informationen über die prozentuale Verteilung der Be- 
völkerung über die relevanten Klassenlagen abschneidet, das Differenz-Prinzip der »Theorie der Gerechtigkeit« unter Bezug auf die Idee des öffentlichen Vernunftgebrauchs kaum noch halten kann (vgl. Ackerman, 1994: 368 ff.).

Auf diese Weise wird die Idee demokratischer Selbstbestimmung von drei Seiten in die Zange genommen: durch eine extreme Kontraktion des Bereichs des Politischen, durch die weitgehende Privatisierung des Bürgers und durch die Unterminierung der wohlfahrtsstaatlichen Grundlagen des Verfassungskonsenses - wie aber sollen sich dann die bürgerlichen Kompetenzen und Einstellungen, kurz: eine politische Kultur, entwickeln und reproduzieren, die ein irreduzibles Ferment auch einer stabilen, liberalen öffentlichen Ordnung bilden?

(c) Insofern bildet die Motivations- und Integrationsfrage nach wie vor die offene Flanke des kontraktualistischen Liberalismus und der prozeduralen Republik Rawlsscher Prägung: »Der Liberalismus muß sich ... darüber belehren lassen, daß das seine normativen Orientierungen und Freiheitskonzepte explizierende Sozialmodell der Vertrags- und Tauschbeziehungen selbst nicht die Wirklichkeit einer von diesen liberalen Wertvorstellungen geprägten Gesellschaft garantieren kann« (Kersting, 1994: 89). Weil, wie Kersting an dieser Stelle hinzufügt, die liberalen Reflexionsformen aber die innere Struktur von Sozialbeziehungen nur unzulänglich beschreiben und erfassen, muß auf das Problem der Verwandlung von normativen Prinzipien in motivationale Ressourcen auch eine andere Antwort gefunden werden, die ohne einen engeren Bezug auf demokratisch-partizipatorische Konzepte nicht zu haben sein dürfte - denn damit sind gesellschaftliche Strukturen anvisiert, die in der Lage sind, »in allen Bürgern die für die Bewahrung der Freiheit nötige politische Motivierung und Kompetenz zu bewahren « (Michelman, 1994: 63) und die somit den Boden bilden, in dem sich das Prinzip der Deliberation unter Freien und Gleichen entwickeln und politisch entfalten kann. Eine solche demokratisch-partizipatorische Antwort auf die Schwächen des politischen Liberalismus nun wird in ihren ersten Umrissen etwas deutlicher, wenn man zunächst einmal an drei grundlegenden Intuitionen festhält und diese zusammenführt (vgl. dazu auch Weale, 1994): Erstens findet gegenüber der von Rawls favorisierten Form eines justiziellen Paternalismus die Praxis der Demokratie ihre basale Rechtfertigung darin, daß sie die Bestimmung und Beförderung gemeinsamer Interessen und Anliegen in die Hände der Mitglieder einer politischen Gemeinschaft legt, die sich wechselseitig als Freie und Gleiche anerkennen - das nötigt zu einer Überwindung (und nicht: justiziellen oder staatlichen Befestigung) der politischen Entfremdung des Bürgers und zur Stärkung jener assoziativen Mechanismen, von denen der Ausbau der kollektiven Handlungsfähigkeit der Staatsbürger abhängig ist (vgl. Offe/Preuß, 1991: 164 ff. und Cohen/Rogers 1992 und 1994); zweitens bleibt die Schaffung eines Systems kollektiver Entscheidungen, das eine breite Partizipation möglich macht, durchaus intim mit der Idee rationaler Autonomie verknüpft - das Verbindungsstück zwischen der Idee der Demokratie als einer Form kollektiver Entscheidungsfindung und den Prinzipien der Freiheit und Gleichheit bildet dann aber die breite Verankerung argumentativer Praktiken in »deliberativen Arenen « (Cohen/Rogers, 1994: 137, Anm. 6 ), in denen die entsprechenden sozialen, kognitiven und moralischen Kompetenzen kultiviert und entwickelt werden können; drittens bedürfen diese Praktiken zweifellos 
des Unterfutters einer solidarischen Reziprozität, die sich wiederum nur entwickeln kann, wenn man dem Begriff politischer Gleichheit eine starke Fassung gibt, nach der sich der individuelle Anspruch auf wohlfahrtsstaatliche Sicherung auch als Ausdruck des Willens zur Bildung einer politischen Gemeinschaft verstehen läßt.

Wenn man dies akzeptiert, wird man allerdings einen entscheidenden Schritt über die konstitutionelle Einhegung eines Pluralismus unterschiedlicher Lebensformen hinausgehen und das demokratische Projekt um die Perspektive einer aktiven staatsbürgerlichen Politik erweitern müssen. In dieser Perspektive stellt sich freilich das Problem der Balancierung von Freiheit, Gleichheit, Partizipation und Rationalität in etwas anderer (und anspruchsvollerer) Weise. Der aussichtsreichste Kandidat für die Lösung dieser anspruchsvollen Aufgabe ist das Modell »deliberativer Demokratie «. Den Angelpunkt der grundlegenden Modellvorstellungen bildet auch hier (wie schon bei Rawls) das Ideal vernünftiger Autonomie, dessen Auslegung allerdings sowohl gegen das Modell der populistischen wie der in negativer Freiheit gründenden liberalen Demokratie konturiert werden kann. Mit Gutman kann man sich dabei im Kern auf folgende Einwände stützen: ${ }^{12}$ Gegen das populistische Modell bringt sie in Anschlag, daß es zum einen zu ergebnisoffen und für Ansprüche unempfindlich ist, die auf die Qualität demokratischer Entscheidungen und Entscheidungsprozesse zielen (127); zum anderen macht sie an ihm eine paradoxe Grundstruktur aus, die in der unaufhebbaren Spannung zwischen dem (empirischen) Volkswillen und den Bedingungen, unter denen sich die Idee der Volkssouveränität stabilisieren kann, gründet (131). Dieser Einwand läßt sich zwar gegen die liberale Demokratie nicht erheben, weil der Liberalismus den Vorrang des Rechts gerade deshalb behauptet, um ein Kriterium bereitzuhalten, an dem sich die Ergebnisse der demokratischen Willensbildung messen lassen müssen; dagegen macht sie geltend, daß die liberale Demokratie einen entschiedenen Mangel an Demokratie aufweise, der sich aus dem subjektiv-rechtlichen Primat negativer Freiheit und einem individualistischen Mißverständnis kollektiver Entscheidungsprozesse ergibt (»Liberals wonder why democrats place so much value on popular rule when in practice each of us has so little chance of affecting the outcome of any decision «: 137).

Gutman's These ist nun, daß beide Positionen normativ unterbelichtet bleiben müssen, weil sie die Ideale der Volkssouveränität und der individuellen Freiheit nicht aufeinander beziehen und deshalb die entscheidenden Fragen gar nicht stellen können: »Why should we value popular will« und »Why should we value personal freedom « (140)? Die Antwort auf diese Fragen enthält erst die Idee deliberativer Demokratie, die sie dann folgendermaßen bestimmt: »Deliberative democracy offers the answer that we value popular will and personal freedom to the extent that the exercise of popular will and personal freedom reflect or express the autonomy of the people, where autonomy

12 Ich kann mich an dieser Stelle mit einer knappen Skizze der in dieses Modell eingehenden Grundvorstellungen begnügen - die notwendige Diskussion und Ausführung dieser Linien ist Gegenstand dieser Arbeit insgesamt (vgl. aber besonders unten Kap. 3.2). Zu diesem Zweck greife ich auf entsprechende Überlegungen Amy Gutman's (1993a) zurïck - die folgenden Seitenangaben (in Klammern) beziehen sich auf diesen Text. 
is understood as self-government, the willingness and ability to shape one's private or public life through deliberation, informed reflection, evaluation, and persuasion that allies rhetoric to reason « (ebda.). Erst in dieser die Prinzipien der (rechtlichen) Freiheit und Volkssouveränität synthetisierenden Rekonstruktion des demokratischen Ideals der Selbstbestimmung als Selbstregierung werden auch die Schwächen des westlichen Modells und die Gründe für die Unzufriedenheit mit dem inneren Zustand dieser Gesellschaften sichtbar. Und es ist provokativ genug, der Demokratietheorie Aufgaben vorzugeben, denen sie sich mit einigem Aufwand an institutioneller Phantasie stellen sollte: Auch wenn es zuallererst eine Frage des autonomen Charakters der Staatsbürger ist, ein politisches Leben in diesem Sinne führen zu wollen, so können politische Praktiken und Institutionen eine Autonomie sowohl ermutigende wie auch entmutigende Wirkung haben - deshalb legt die deliberative Demokratie ein institutionelles Design nahe, daß Autonomie ermutigt und für jeden prinzipiell erreichbar werden läßt; zugleich sollten sie nicht Partizipation schlechthin, sondern solche Formen der Teilhabe prämiieren, die gleichzeitig zu einer diskursiven Rationalisierung der Willensbildung beitragen (142 f.). Kurz: »Deliberative democracy must rely partly on public commitment, bolstered by institutions that require, reward, or at least make room for open and informed political discussion « (144). 


\section{Staatsbürgermoral und politische Institutionen: Die Konturen eines neuen Republikanismus}

Die breit angelegte Debatte zwischen Liberalen und Kommunitaristen in den USA ${ }^{13}$ darf schon deshalb ein besonderes Interesse beanspruchen, weil sie viele der genannten Motive der Kritik an den politischen Institutionen der liberalen Demokratie aufgenommen und im weiteren Kontext einer (sozial)philosophischen Auseinandersetzung über die moralischen Grundlagen moderner Politik und der historisch-ideengeschichtlichen Wiederaneignung der republikanischen Gehalte des amerikanischen politischen Denkens verankert hat. Diese Debatte hat, seit sie 1982 durch Michael Sandel's Kritik an der Gerechtigkeitstheorie von John Rawls ausgelöst wurde, durchaus unterschiedliche theoretische Ausdrucksformen gefunden:

- So wurde sie etwa unter dem Titel eines »unencumbered self« als Auseinandersetzung darüber geführt, ob der in methodischer, normativer und sozialer Weise in die kontraktualistische Rechtfertigungsbasis des Liberalismus eingelassene Individualismus als Bezugspunkt der Rechtfertigung einer gerechten und wohlgeordneten Gesellschaft auch dann fungieren kann, wenn er in seinem universalistischen Anspruch faktisch umstritten bleibt und zugleich in normativer und sozialer Hinsicht zu schwach ist, um die geforderten Begründungsleistungen wirklich tragen zu können;

- oder sie wurde mit Blick auf die liberale Behauptung eines Vorrangs von Fragen der Gerechtigkeit vor solchen des guten Lebens als Streit darüber arrangiert, ob Moraltheorie grundsätzlich eher einen universalistischen oder einen kulturell und historisch partikularen Charakter annehmen sollte, um so mit faktisch vorfindbaren moralischen Intuitionen und ethischen Überzeugungen, die den Boden einer auch politisch zu effektuierenden Moraltheorie bilden sollten, enger verbunden zu bleiben;

- darin war schließlich auch ein Dissens über das Prinzip der Neutralität als dem leitenden Gesichtspunkt der Einrichtung einer gerechten politisch-institutionellen Ordnung der Gesellschaft insofern eingelassen, als unklar blieb, worauf es sich ei-

13 Eine Übersicht über die Programmatik des Kommunitarismus als einer sozialen Bewegung enthält Etzioni (1993), während Phillips (1993) cine Einschätzung des Kommunitarismus vor dem Hintergrund einer Herausarbeitung jener Idealisierungen liefert, die schon der klassische Republikanismus an der Beschreibung der historischen Verhältnisse während der Gründung der USA vorgenommen hatte. Gute Überblicksdarstellungen bieten u.a. Honneth (1993a), Avineri/de-Shalit (1992), Mulhall/Swift (1992) und Zahlmann (1992: mit weiterführenden Literaturhinweisen vor allem auf die US-amerikanische Diskussion). Vgl. neben diesbezüglichen Beiträgen von Habermas (1992) auch Schmalz-Bruns (1992a), Kersting (1993 und 1992) und Brunkhorst (1994) sowie den Diskussionsband von Brumlik/ Brunkhorst (1993). 
gentlich beziehen sollte (Forst, 1993: 192 f.): ist damit die Forderung nach einer »Neutralität der Konsequenzen« gemeint, »nach der die Umsetzung liberaler Prinzipien auf alle in einem politischen System lebenden ethischen Gemeinschaften die gleichen Auswirkungen hat «; oder geht es um die Neutralität der Ziele staatlicher Politik, die keine Privilegierung einer Auffassung des Guten gegenüber anderen ethischen Auffassungen zum Ausdruck bringen darf; oder wird damit die »Neutralität der Rechtfertigung « einer politischen Ordnung reklamiert, die sich nicht auf substantielle ethische Werte, sondern nur auf allgemein anerkannte moralische Normen stützen soll? Nun ist aber schwer zu sehen, wie ein liberaler Staat, dessen Prinzipien im Gegenlicht der Auffassungen nicht-liberaler Gemeinschaften als spezifische Werte erscheinen, den beiden ersten Auslegungsvarianten ohne Selbstwidersprüche soll entsprechen können. So bleibt eigentlich nur die Möglichkeit, Neutralität im Sinne der dritten Auslegung nicht als ergebnisbezogenes, sondern als prozedurales Ideal zu vertreten - es bezieht sich dann auf die Frage, »what sorts of considerations can be invoked in justifying political decision making « (Sinopoli, 1993: 646). Dann bildet das Prinzip der Neutralität ein normatives Kriterium für die Gestaltung politischer Institutionen, und in dieser Gestalt muß es auch von Kommunitaristen nicht bestritten werden, wenn andererseits Liberale bereit sind zuzugeben, $\mathrm{da} ß$ erstens auch ein derartiges institutionelles Ideal der Verankerung in einer entsprechenden politischen Kultur bedarf und daß zweitens dann eine darauf sich stützende institutionelle Ordnung auch einen Wert darstellt, den Liberale gegenüber konkurrierenden Ordnungsentwürfen zu verteidigen bereit sein sollten.

Angesichts dieser Unschärfen ist Honneth (1993b: 7) zuzustimmen, wenn er darauf hinweist, daß die Auseinandersetzung zwischen Kommunitaristen und Liberalen von den Beteiligten selbst zunächst keinesfalls als Streit zwischen »festumrissenen Theoriepositionen wahrgenommen worden « ist. Ähnliches gilt im übrigen auch für den von Sandel ausgelösten Streit um den liberalen Personbegriff, der keineswegs anthropologisch artikuliert werden muß, sondern der den sozialen Prozeß der Konstitution des Selbst zum Inhalt hat. Auch Kommunitaristen bestreiten nicht (oder müssen nicht bestreiten), daß die Autonomie des Individuums, verstanden als die Fähigkeit zum reflexiven Aufbau einer personalen Identität, uns wertvoll ist (Kersting, 1993: 12) - worum es geht, ist im Kern die Frage, ob sich Identitätsbildung im Ernst als monologischer Akt im Modus einer Wahlhandlung (»choice«) verstehen läßt. Wenn man auf diese Weise zugibt, daß das kommunitaristische Projekt nicht den Charakter einer rückwärtsgewandten, dumpfen Gemeinschaftsbildung annehmen muß (und ich sehe nicht, wer unter den dem kommunitaristischen Lager zugerechneten Autoren eine solche Position verteidigt), sondern wesentlich auf eine dialogische, partizipatorische Form der Vergemeinschaftung zielt (Kersting, 1993: 18), dann wird schließlich auch die scheinbar so klar geschnittene Alternative zwischen dem Vorrang der Gerechtigkeit oder des Guten unscharf und bedarf einer Reformulierung: kaum einer der an der Auseinandersetzung Beteiligten wird im Ernst den Wert individueller Freiheitsrechte bestreiten - in Frage steht vielmehr der liberale Versuch, die Idee gleicher Rechte in Spannung zur Idee der Volkssouveränität zu bringen und eine vorpolitische Geltungsbasis von Freiheitsrechten zu reklamieren (vgl. Larmore, 1993: 326 f.). 
Deshalb ergibt sich eine konstruktive Perspektive auf diese Debatte erst, wenn man die historisch-politische Ausgangslage mit der Diagnose eines zunehmenden Verlustes der Leistungsfähigkeit und Integrationskraft liberaler politischer Institutionen in Rechnung stellt und damit die Frage nach den moralisch-institutionellen Grundlagen moderner Politik in den Vordergrund rückt. In diesem Horizont einer historischen Auseinandersetzung zwischen politischem Liberalismus und Republikanismus verschieben sich nicht nur die einzelnen Fragestellungen (so geht es nicht mehr um die Frage der Konstitution des modernen Selbst schlechthin, sondern um den Begriff des Staatsbürgers und ein angemessenes Verständnis der modernen Staatsbürgerrolle). Auch der Zusammenhang zwischen den einzelnen Aspekten der Debatte tritt deutlicher hervor, und damit wird die kommunitaristische Gegenvision zum Liberalismus konturenschärfer und plausibler als in einer rein moralphilosophischen, metatheoretischen Einstellung (vgl. Taylor, 1993). Aus dieser rekonstruktiven Sicht läßt sich der politiktheoretische Gehalt der Debatte auf eine pointierte Formel bringen: Es geht um ein Interesse an guter Politik im Sinne eines Interesses an der Legitimität und Qualität der Ergebnisse von Politik - daraus resultiert ein Interesse an der »Qualität« des Staatsbürgers wie ein Interesse an der moralischen und moralfördernden Qualität politischer Gemeinschaften und Institutionen. ${ }^{14}$ Vor diesem Hintergrund möchte ich nunmehr in drei Schritten ein republikanisches Modell moderner Politik etwas genauer charakterisieren. Zunächst soll im Rückgriff auf die Institutionentheorie Durkheims dieser republikanische Dreischritt erläutert werden (1), bevor ich die Grundzüge eines kommunitaristischen Institutionenverständnisses herausarbeite (2) und mit Blick auf Michael Walzer das Modell eines "pluralistischen Republikanismus« vorstelle (3).

14 Diese Zuspitzung scheint nicht nur weit über das hinauszugehen, was man von einer Wiederbelebung des Erbes des klassischen Republikanismus erwarten sollte. Sie läuft, folgt man Pangle (1992), auch Gefahr, den politischen Prozeß und das öffentliche Gespräch mit »apolitischen « Rationalitätsanforderungen zu überziehen, die die öffentliche Sphäre zu überlasten drohen und den wesentlich begrenzten Charakter »of truly healthy civic deliberation« (128) verdrängen. Demgegenüber möchte Pangle an der aristotelischen Einsicht festhalten, daß die »Veredlung der Demokratie« (so der Titel des Buches) i.S. des klassischen Republikanismus nicht über Wissen (»knowledge «) sondern über Meinung (»opinion«) definiert bleibt. Die (praktischen) Gründe dafür macht er in »severe limitations on strict rationality: by enormous and nigh-unbridgeable diversities of experience, education, talent, and need; by intense pressures of unpredictable occasion and time; by constraints in the sheer number of participants; by the need to maintain consensus regarding essentially disputable and disputed basic opinions as to the goals of civic life« (129) aus. Das sind gewiß einschlägige Bedenken, doch muß man nicht so weit gehen, dafür den Status fundamentaler Einwände zu reklamieren: inwieweit sie sich als »constraints « zur Geltung bringen, hängt vielmehr von situativen, organisatorischen und institutionellen Kontextvariablen ab, die grundsätzlich zu verändern und adaptierbar sind - deshalb ist der ausgeprägte Institutionalismus des Neo-Republikanismus in Rechnung zu stellen, der auch die Funktion hat, die rationale und diskursive Orientierung einer bürgerschaftlichen Politik nicht allein auf die moralischen Kräfte (i.e. Tugenden) der Bürger zurückzuführen, sondern sie in ihrer institutionellen Vermittlung zu thematisieren und daraus einen normativen Begriff politischer Institutionen zu gewinnen. 


\subsection{Moralität, Sittlichkeit und Reflexivität: Zur Institutionentheorie Durkheims}

Die vielstimmige neuerliche Verbindung von Institutionentheorie und einem wachsenden Interesse an der sittlichen, moralischen und reflexiven Qualität moderner Politik mag weniger befremdlich erscheinen, wenn man sich klarmacht, daß dieses Interesse maßgeblich schon in die konzeptuelle Aufarbeitung und begriffliche Fixierung des Institutionenverständnisses etwa bei Durkheim oder Parsons, aber auch bei John Dewey oder George Herbert Mead eingegangen ist. ${ }^{15}$ In Durkheims »Physik der Sitten und des Rechts«, in der er sich der Entwicklung und Entfaltung einer neuen Staatsbürgermoral widmet, stand so die Diagnose Pate, daß das herrschende gesellschaftliche Moralbewußtsein mit der Arbeitsteilung und Differenzierung moderner Gesellschaften, mit der Dynamik von Industrie, Wissenschaft und Technik nicht mitgehalten hat und daß somit das notwendige gesellschaftliche Interesse an Moral auf eine andere Grundlage gestellt werden müsse (Müller, 1991: 309). Notwendig ist dieses Interesse für Durkheim, weil anders, im Horizont eines kollektiven Partikularismus sich nur über strategische Nutzenkalküle vermittelnder, isolierter einzelner, Solidarität und politische Gerechtigkeit als Quellen gesellschaftlicher Integration nicht zu erschließen sind. Auf eine andere (als eine moralphilosophische) Grundlage war das gesellschaftliche Interesse an der Moral zu stellen, weil das Interesse an Moral in Durkheims Sicht moralisch allein weder ausreichend zu begründen noch zu motivieren ist. Die soziologische Einsicht, die Luhmann mit dem Diktum, daß »die Ethik zwar fordern (mag), das Sittengesetz um seiner selbst willen zu beachten «, für Soziologen »solche Extravaganz aber eher ein Krisensymptom sein (wird) als eine wissenschaftliche Erleuchtung « (Luhmann, 1984: 319), zum Ausdruck gebracht hat, entspricht ziemlich genau der Vorstellung, die Durkheim von den Aufgaben der Moralsoziologie hatte, die sich den Zugang zum Inhalt und zur Wirkungsweise moralischer Normen in objektivierender Einstellung, über eine Analyse der Strukturen der Gesellschaft, verschaffen sollte. Vor diesem Hintergrund ist es denn auch kaum ein Zufall, daß Durkheim die Frage der Herausarbeitung einer neuen Staatsbürgermoral primär als Frage nach der angemessenen institutionellen Struktur einer politischen Gesellschaft behandelt. Aus diesen Gründen werde ich im folgenden zunächst den Überlegungen Durkheims in den wichtigsten Aspekten so weit nachgehen, bis seine institutionellen Reformvorstellungen sichtbar und verständlich werden, denen neben ihrer grundlagentheoretischen Bedeutung heute auch eine überraschende Aktualität zukommt.

15 Bei Dewey etwa in seinen Überlegungen zum Reflexionszusammenhang von Staat und Öffentlickeit in der modernen Industriegesellschaft in "The Public and Its Problems " (Dewey, 1984); bei Mead scheint dieser Zusammenhang u.a. in seiner Schrift zu »Naturrecht und die Theorie politischer Institutionen« auf (Mead, 1983). Zweiffellos sind bei allen Gemeinsamkeiten der Fragestellung gravierende Unterschiede, die aus der divergierenden konzeptuellen Grundanlage der resp. Soziologien resultieren, nicht zu übersehen; sie wirken sich andererseits auf die institutionen- und demokratietheoretischen Überlegungen und Einsichten m.E. aber auch nicht so entscheidend aus, wie man vielleicht erwarten sollte. Vgl. dazu u.a. Prager (1981) und mit z.T. anderen Bewertungen Kloppenberg (1986) und Joas (1992). 
Was Durkheim in seinen Vorlesungen zur »Physik der Sitten und des Rechts ${ }^{16}$ vorlegt, ist nicht eigentlich eine politische Soziologie des Staates, sondern vielmehr eine sPolitik in moralsoziologischer Perspektive; und d.h., sie haben ein normatives Modell demokratischer Politik zum Gegenstand (vgl. Prager, 1981). Aus diesem Motiv heraus, einen Beitrag zur Moralökologie moderner Gesellschaften zu leisten, konzentriert sich Durkheim, wie Müller zu Recht hervorhebt, auf die institutionelle Infrastruktur der politischen Gesellschaft, »um den Nomos einer funktional differenzierten Gesellschaft zu entwerfen « (Müller, 1991: 333). Daß er dabei von Anfang an moralische als institutionelle Fragen behandelt und dabei über das Moment des äußeren Zwangs die Wirkungsweise moralischer Normen an jene des Rechts adaptiert, hat zum einen damit zu tun, daß er eine reine Pflichtenethik nach dem Vorbild Kants für etwas psychologisch Unmögliches und lediglich für einen empirischen Grenzfall hält (Müller, 1983: 80); zum anderen bringt sich darin seine Auffassung zur Geltung, daß Moral ein Produkt der Gesellschaft ist, »daß sie von außen in das Individuum eindringt, daß sie seiner physischen Natur und seiner natürlichen Konstitution in gewisser Weise Gewalt antut« und daß deshalb ihre Stärke und Kraft nicht in erster Linie von der moralischen Disposition der Individuen, sondern von der Organisation der Gesellschaft abhängt (108). An dieser Konstellation, an der Habermas etwa grundsätzlich dic Abkehr Durkheims vom bewußtseinstheoretischen Paradigma stilisiert hat (kritisch zu dieser Deutung Joas, 1992: 88), mag man nun die Konfundierung der sozialen Genese von Moralnormen mit Fragen ihrer Geltung monieren und die Dissoziation von institutionell verbürgter, gesellschaftlicher Moral und individueller Moralität als unplausibel zurückweisen; man kann ihr aber auch, und das bietet sich im Lichte der Staats- und Demokratiekonzeption durchaus an, die schwächere Deutung unterlegen, daß Durkheim sich weigert, die moralische Güte einer sozialen und politischen Ordnung allein von der moralischen Disposition der Individuen abhängig zu machen: in dieser Lesart käme den Institutionen eine moralverbürgende, -stützende und -ermöglichende Funktion zu (vgl. dazu weiter unten).

Für die stärkere Deutung spricht hingegen zunächst die Weise, in der er den Institutionenbegriff selber konzeptualisiert ${ }^{17}$ und in die unterschiedliche Grundentscheidungen seiner Soziologie eingehen: zum einen verpflichtet er den Institutionenbegriff definitorisch auf die Klasse verbindlicher, normativer Verhaltensmuster, die sich dem Individuum grundsätzlich über das Moment des sozialen Zwangs mitteilen, wobei sozialer Zwang sich nicht nur über sanktionsbewehrte, staatliche Gewalt sondern auch über moralischen Druck vermitteln kann; zum zweiten ist er von der methodischen Entscheidung informiert, moralische Phänomene als soziale Tatsachen zu behandeln, die aus den gesellschaftlichen Strukturen analytisch herausgearbeitet und umgekehrt - in reformerischer Perspektive und der Absicht der Moralisierung der Gesellschaft - in diese Strukturen konstruktiv hineingearbeitet oder -gewirkt werden müssen; drittens schließlich

16 Die folgenden Seitenangaben in Klammern beziehen sich, sofern nicht anders ausgewiesen, auf die 1991 von Hans-Peter Müller vorgelegte deutsche Übersetzung der Durkheimschen $\gg$ Vorlesungen zur Soziologie der Moral .

17 In der folgenden Darstellung stütze ich mich auf die Analyse von Müller (1983: 74 ff.). 
akzentuiert er damit die in seiner Sicht intime Verschränkung der mentalen und der moralischen Qualität sozialer Phänomene - hier nimmt Durkheim eine Assimilation von evaluativen und expressiven an kognitive Aspekte vor, wonach die moralische Qualität sozialer Normen und Regulierungen und ihr Verpflichtungsgehalt diesen aus ihren kognitiven Status, ihrem Objektivitätsgehalt also, zuwachsen. Diese Verklammerung von normativen, wissenschaftlich-methodischen und praktischen Aspekten enthält nun allerdings durchaus möglicherweise bedenkliche Implikationen: durch die Assimilation sozialer an moralische Phänomene und deren Rückführung auf mentale Prozesse läuft er Gefahr, die Wirkung des Institutionellen allein auf moralische Autorität und nicht auch auf physischen Zwang zurückzuführen oder dieses Moment institutioneller Ordnung zumindest unsichtbar zu machen (vgl. Müller, 1983: 80 ff.); zweitens verführt ihn die konsequent moralsoziologische Perspektive auf moralische Phänomene zu einer positivistischen Verschränkung von Faktizität und Geltung und schließlich gerät er von daher auch in eine gewisse Spannung zu seiner normativen Auffassung von Demokratie als Herrschaftsform der Kommunikation und der Reflexion (131), insoweit er es gleichzeitig ablehnt, die Wahrheitsgeltung analytischer Aussagen auf einen Prozeß argumentativer Einigung zurückzuführen (vgl. Joas, 1992: 86 ff.).

Diese im Rahmen seines soziologischen Grundanliegens gelegten Spuren finden sich unvermeidlich auch in seiner politischen Theorie und insbesondere in seiner Funktionsanalyse des modernen Staates wieder. So setzt er sich von Anfang an gegen liberale Minimalstaatsversionen ab ( $77 \mathrm{ff}$.), gerade weil er aus soziologischen Gründen der naturrechtlichen Tradition der extrasozialen Begründung und Verankerung subjektiver Rechte mißtraut und den Staat auf die Förderung und Sicherung des sozial erzeugten, moralischen Kollektivideals des Individualismus verpflichten möchte. In dieser Sicht wird Staatlichkeit zu einem Perfektionsmodell einer moralischen Ordnung, in der das staatliche Handeln primär auf die Befreiung des Individuums ausgerichtet ist (85). Dementsprechend ist es dann auch die fundamentale Pflicht des Staates, den Prozeß der Individuation so weit zu gewährleisten, wie es der gesellschaftliche Zustand zuläßt (101), zu einer Moralisierung der Gesellschaft im Sinne der Herstellung politischer und sozialer Gerechtigkeit beizutragen (105) und konsequent eben auch dafür Sorge zu tragen, daß die Individuen selber immer mehr ins "moralische Dasein « gerufen werden (102; vgl. auch Tole, 1993). Diese herausgehobene moralische Funktion des Staates ist gewiß ein Reflex seines Mitrauens gegenüber der moralischen Kompetenz, mindestens aber der moralischen Verläßlichkeit der Individuen, die ihn annehmen läßt, daß Moral immer von außen in die Individuen eindringen muß, so daß die Stärke der Moral in erster Linie von der Stärke der gesellschaftlichen Organisation abhängig bleibt (108). Dieser Überzeugung entspricht zunächst nun ziemlich genau der bisweilen irritierende Paternalismus, der sich in den begrifflichen Bestimmungen des Staates als des reflexiven Zentrums der Gesellschaft zum Ausdruck bringt: der Staat ist unvermeidlich autonom gegenüber der Gesellschaft, weil er der Sitz eines klaren, reflexiven Bewußtseins ist, aus dem heraus der Staat für die Gesellschaft denkt und entscheidet und Vorstellungen entwickelt, die für die Gesellschaft bindend sind (74 f.).

Diese Gründe, aus denen Durkheim an der Fiktion des starken Staates festhält und die sich explizit gegen die etwa bei Mead leitende Vorstellung einer Rücknahme des 
Staates in die Gesellschaft sperren (vgl. Mead, 1983: $420 \mathrm{ff}$.), bieten so weit einen berechtigten Angriffpunkt für Bedenken an der Demokratieverträglichkeit des Durkheimschen Ansatzes insgesamt. ${ }^{18}$ Andererseits aber muß man in Rechnung stellen, daß sich Durkheim in einer Wendung gegen Hegel durchaus ebenso ausdrücklich wie eindringlich auch gegen den »mystischen Kult« eines zur gesellschaftlichen Totalität aufgepreizten Staates wendet ( $80 \mathrm{f}$.) und sich von diesen Vorgaben schließlich in seinen Vorstellungen zur institutionellen Ausgestaltung einer modernen Demokratie auch ablöst, die nun selber als Produkt und Form des moralischen Fortschritts erscheint (130). Dieser Widerspruch löst sich auf, wenn man sieht, daß Durkheim die Aufgabe der Moralisierung von Gesellschaft und Politik nicht einfach dem Staat als einem zumindest nach innen souveränen Akteur, sondern einem Arrangement institutionell verschränkter und reflexiv aufeinander bezogener, differenzierter und spezialisierter Meinungs- und Willensbildungsprozesse zuschreibt. Und dahinter steckt mehr als die bloße Anerkennung der Tatsache eines irreduziblen gesellschaftlichen Pluralismus und seine Präferenz für die Montesquieusche Gewaltenteilungsequilibristik gegenüber auf Rousseau zurückgeführten Vorstellungen direkter und identitärer Demokratie. Dies gewiß auch, wie man leicht an der Hervorhebung der Bedeutung intermediärer Instanzen und gesellschaftlicher Assoziationsverhältnisse sehen kann. Die Institutionen der politischen Gesellschaft, zu denen Durkheim neben dem Zentralstaat vor allem dezentrale, föderative Gliederungsstrukturen und die Berufsgruppen zählt (138 ff.), haben aber nicht nur die Funktion der Freiheitssicherung, indem sie die Individuen gegen eine unmittelbare, direkte Entfaltung staatlicher Macht abschirmen. Vielmehr sollen sie, und darin liegt m.E. die eigentliche Pointe eines von Rousseau zurückbehaltenen Ideals deliberativer Politik, als Filter fungieren, an denen sich individuelle wie kollektive Partikularismen absetzen und durch die hindurch nur argumentativ aufgeklärte Meinungen und Einstellungen Eingang in den Prozeß einer gemeinwohlbezogenen politischen Willensbildung finden. In dieser Betonung der »zivilisierenden « Wirkung (91) einer institutionellen Verschränkung und reflexiven Durchdringung von Staat und bürgerlicher Gesellschaft läßt sich Durkheim nicht lediglich von einem allgemeinen Interesse am moralischen Fortschritt der Gesellschaft, sondern darüberhinaus von einem Interesse an der Verbesserung der sachlichen Qualität der Politik leiten. Dieser Intuition verdankt sich schließlich die auch politisch herausgehobene Stellung der Berufsgruppen (139): sie bilden den organisatorischen Rahmen für ein modernisiertes Ideal der Versammlungsdemokratie, in dem Diskussionen die kollektive Form dessen bilden, »was Überlegen und Abwägen für den einzelnen sind - (sie) dienen gerade dem Ziel, alles ins Bewußtsein zu heben, die Menschen zu zwingen, sich über die Motive klar zu werden, die sie in diese oder jene Richtung drängen, und sich des eigenen Tuns bewußt zu werden...Sie sind die einzigen Instrumente, die der Gemeinschaft zur Verfügung stehen, wenn es darum geht, unbedachtes, automatisches und blindes Handeln zu vermeiden« (116).

18 Ganz besonders deutlich wird das bei Joas am Ende seines systematischen Theorienvergleichs zwischen Durkheim und dem Pragmatismus artikuliert: vgl. Joas (1992: 89 f.). 
Diese Motive bündeln sich am Ende der Vorlesungen zur staatsbürgerlichen Moral und Demokratie noch einmal in einer Kritik der allgemeinen und geheimen Wahl. Durkheim ist hier bemüht, die Vorzüge der öffentlichen vor der geheimen Wahl herauszustreichen und bringt darin die Anforderungen an die institutionelle Struktur demokratischer Willensbildung in einer komplexen, arbeitsteilig organisierten Gesellschaft in konzentrierter Form zur Geltung. Diese hat, wie wir gesehen haben, die Aufgabe, in moralischer Absicht die Formprinzipien der Reflexivität, der Diskussion und der Öffentlichkeit mit organisatorischen Mitteln in die soziale Wirklichkeit zu übersetzen. Und so ist es denn auch konsequent, wenn Durkheim an der allgemeinen und geheimen Wahl die spiegelbildlichen Effekte einer »lediglich quantitativen Gewichtung der individuellen Meinungen «, aus der eben kein Anreiz zu einer themenbezogenen, sachlichen Selbstrationalisierung der individuellen Meinungsbildung erwächst einerseits und der »radikalen Inkompetenz « auf Seiten der Abgeordneten andererseits moniert (148). Diesen Defekten möchte er durch eine Kombination des Formprinzips der öffentlichen Diskussion mit den Vorteilen assoziativer Strukturen entgegenwirken, die eben die Möglichkeit bieten, die Menschen "auf dauerhafte Weise in Beziehung zueinander zu setzen und zu gruppieren " und Gefühle zu evozieren, »die über den individuellen Gefühlen stehen«, weil sie aus der Wechselwirkung zwischen assoziierten Individuen resultieren (149). Darin verschränken sich einige Denkmotive, die auch in aktuellen Diskussionen über die Civil Society oder eine kommunitaristische Erneuerung der liberalen Demokratie wieder in den Vordergrund der theoretischen Aufmerksamkeit gerïckt werden (vgl. Offe/Preuß, 1991; Fishkin, 1991 und Buchstein, 1993), so daß es sich durchaus lohnt, sich die Überlegung Durkheims zu einer Überwindung des individualistischen Partikularismus ausnahmsweise im Zusammenhang eines längeren Zitats zu vergegenwärtigen:

\begin{abstract}
»Aber nehmen wir einmal an, die Wahl fände nach einer kollektiven Aufarbeitung statt; dann stünden die Dinge ganz anders. Denn wenn die Menschen gemeinsam denken, ist ihr Denken zum Teil das Werk der Gemeinschaft. Die Gemeinschaft wirkt auf sie ein, lastet mit ihrer ganzen Autorität auf ihnen, hält ihre egoistischen Anwandlungen im Zaum und verleiht dem Denken eine gemeinsame Richtung. Wenn also die Wahlen etwas anderes als die Individuen zum Ausdruck bringen, wenn sie ganz und gar von einem gemeinschaftlichen Geist durchdrungen sein sollen, dann darf das elementare Wahlkollegium nicht aus Personen bestehen, die nur zu diesem außergewöhnlichen Anlaß zusammenkommen, die sich nicht kennen, die nicht zu einer gemeinschaftlichen Meinungsbildung beigetragen haben und nun einer nach dem anderen an die Wahlurne treten. Vielmehr muß es sich um eine kohärente und dauerhaft konstituierte Gruppe handeln, die nicht erst am Tage der Wahl zusammenkommt...Es liegt auf der Hand, daß die Berufsorganisation dieser Anforderung entspricht. Da ihre Mitglieder ständig in engem Kontakt miteinander stehen, bilden ihre Gefühle sich in der Gemeinschaft und sind Ausdruck dieser Gemeinschaft.« (150)
\end{abstract}

Nun kann dieser Vorschlag sicher nicht als die Lösung der darin angesprochenen Probleme gelten, und das nicht nur wegen der zum Teil befremdlichen und bedenklichen kollektivistischen und technokratischen Grundtöne. Auch wenn etwa Beck (1993: 241) jüngst im Rahmen eines Modells reflexiver Politik in enger Anlehnung an Durkheim eine »Politik der Berufe« als wesentlichen Beitrag zur subpolitischen Modernisierung der Politik hervorhebt, ist doch zu bezweifeln, ob korporative Strukturen tatsäch- 
lich zum Kristallisationskern erweiterter und qualitativ verbesserter Teilhabeansprüche werden könnten oder sollten. Darüber hinaus ist unklar, wie sich dieses Modell mit den heutigen Mustern sozialstruktureller und politischer Differenzierung etwa verbinden ließe, und es bleibt völlig offen, wie das Zusammenspiel unterschiedlicher institutioneller, organisierter und nicht-organisierter oder nicht-institutionalisierter Formen der Willensbildung zu konzipieren wäre; und schließlich gerät diese Vorstellung kompetenzorientierter Politik unvermeidlich in eine nicht einmal thematisierte Spannung zum Prinzip politischer Gleichheit. Diese und andere Fragen sind unvermeidlich, und sie sind gewiß geeignet, die Plausibilität des berufsgruppenzentrierten Modells demokratischer Politik zu unterminieren. Aber das ist nur ein Aspekt der Überlegungen Durkheims, und im Zusammenhang von Institutionen- und Demokratietheorie nicht einmal der wichtigste. Entscheidend, und auch heute noch informativ, ist die moralische Imprägnierung des Institutionenverständnisses wie die daraus resultierende institutionelle Perspektive auf Fragen der Moralisierung und Qualitätsverbesserung demokratischer Politik. Und die wichtigste Anregung, die aus dieser Konstellation erwächst, besteht in der Einsicht, daß das Modell demokratischer Politik reflexiv weiterzuentwickeln ist und daß politisches Handeln sich mithin verstärkt auf die Entwicklung angemessener institutioneller Strukturen selber zu richten hat; und dies gerade in der Perspektive einer zunehmenden Vergesellschaftung von Politik und unabhängig von der Hauptaufgabe, die Durkheim den sekundären Organen zuweist, nämlich »sowohl das Individuum vom Staat als auch den Staat vom Individuum « zu befreien (154 f.).

Diese systematisch gesehen nicht notwendigen Relikte eines »Staatskultes« sind zweifellos der Grundentscheidung Durkheims geschuldet, soziale Prozesse auf mentale Strukturen abzubilden. Institutionen in einem weiteren Sinn bilden dann den Zusammenhang von Handlungsregeln, organisierten Vereinigungen und als gültig angesehenen kulturellen Objektiviationen (Acham, 1992: 33 f.) - m.a.W. sie leisten die Übersetzung von Denkformen in Sozialformen oder von Mechanismen kultureller Reproduktion in die Strukturen der Reproduktion von Einzelhandlungen und Handlungssystemen (vgl. auch Parsons, 1990). Auf diese Weise nimmt der Staats- und Institutionenbegriff auch Spuren seines objektivistischen Erkenntnisideals an und gerät in eine irreduzible Spannung zu dem von ihm herausgehobenen moralischen Kollektivideal des Individualismus.

Den Schritt, diese Spannung abzubauen, unternimmt erst Castoriadis, der, in ansonsten enger Anlehnung an Durkheim, den Staat aus der Funktion der zentralen Reflexionsinstanz der Gesellschaft herausrückt und diese Funktion vergesellschaftet. Ähnlich wie Durkheim faßt Castoriadis Demokratie als Herrschaftsform kollektiver Reflexivität und Institutionen oder institutionelle Regulierungen als Bedingung der Möglichkeit einer autonomen Praxis. Die Radikalisierung der Durkheimschen Sicht resultiert daraus, daß auch die vergesellschafteten Subjekte die Aufgabe der permanenten Neu-Instituierung nicht aussetzen oder an den Staat abgeben können, weil der Staat nur eine (historische) Form der Institutionalisierung gesellschaftlicher Autonomie darstellt: mithin ist die Gesellschaft autonom, die ihre Fähigkeit zur Reflexion und Veränderung institutionalisiert und heteronom die, die vergißt oder in ihrer staatlichen Existenzweise unsichtbar macht, daß sie sich selber instituiert hat (Castoriadis, 1989: 68 ff.). Politik ist in dieser Perspektive als autonome und vernünftige gesellschaftliche Praxis verstan- 
den, die die Institutionalisierung der Gesellschaft zum Gegenstand und ein anderes Verhältnis von instituierter und instituierender Gesellschaft zum Ziel hat: es geht um die Freisetzung kollektiver Schöpferkraft, und institutionell zu schützen und auszuzeichnen sind nurmehr soziale Prozesse der Selbsterzeugung der Gesellschaft.

Konzeptuelle Probleme stellen sich dann aber ersichtlich dadurch ein, daß Institutionen analytisch als transzendentaler Reflexionszusammenhang der Selbstkonstitution von Gesellschaft, als Kontext und Ergebnis sozialer Praxis in einem erscheinen (vgl. auch Poltier, 1989). Aus dieser basalen Zirkularität resultiert nicht nur eine gewisse Schwierigkeit, eine bewußte von einer blinden Praxis überhaupt unterscheiden zu können - auch und gerade eine autonome Praxis ist nicht autark gegenüber reflexiven Vernunfteinsichten, denen sich u.a. der normative Status von individueller Autonomie oder der Menschenrechte verdankt. Vielmehr irritiert an dieser Vorstellung, daß auch sie ohne die Projektion eines höherstufigen Subjekts der gesamtgesellschaftlichen Reflexion und der kollektiven Handlungsfähigkeit nicht auskommen kann. Diese Stelle hielt bei Durkheim in Teilen der Staat besetzt - die Abkehr von dieser Vorstellung ist sicherlich ein Fortschritt; andererseits rechnete Durkheim eben nicht mehr mit einer kollektiv-homogenen Form gesellschaftlicher Selbstbestimmung, sondern rekurrierte auf organisatorisch und institutionell differenzierte und vermittelte Prozesse - und insofern bedeutet Castoriadis Aktualisierung des Polis-Gedankens auch einen Rückschritt. Kurz: in einer adäquaten Auslegung der Idee demokratischer Selbstbestimmung sind beide Momente zusammenzuführen, das normative Postulat der Autonomie und die Einsicht in die differenzierte Struktur moderner, arbeitsteiliger Gesellschaften; dann kann man auch, wie Durkheim zumindest angedeutet hat, dem Gesichtspunkt der Effektivität Rechnung tragen, ohne in einen Gegensatz zur Idee der partizipatorischen Demokratie geraten zu müssen.

\subsection{Die moralische Erneuerung liberaler Politik: Zu einigen Aspekten des kommunitaristischen Institutionenverständnisses}

Auf die Ähnlichkeit der Durkheimschen Denkmotive mit den Anliegen einer kommunitaristisch inspirierten Kritik am Liberalismus hat schon Müller an verschiedenen Stellen, u.a. in seinem Nachwort zur deutschen Übersetzung der »Physik der Sitten« (Müller, 1991: 333; vgl. auch Cladis, 1992: 256 ff.) hingewiesen. Und in der Tat kann man beobachten, daß dem kommunitaristischen Lager zuzurechnende Autoren wie Etzioni (1993), Walzer (1992) oder Bellah et al. (1991) zur Klärung und Absicherung ihres Anliegens systematischen Gebrauch von Argumenten machen, wie wir sie etwa bei Dewey oder eben auch bei Durkheim schon vorgebildet finden; und dabei rekurrieren sie nicht zufällig sowohl auf den soeben an Durkheim erläuterten Verwendungszusammenhang wie zum Teil auch auf die Verwendungsweise des Institutionenbegriffs. Das ist nun nicht so erstaunlich, wenn man in Rechnung stellt, daß sie in ihren zeitdiagnostischen Überlegungen und Krisenwahrnehmungen von sehr ähnlichen Befunden ausgehen: auch sie lassen sich in ihrer moralischen und institutionellen Kritik am politischen Liberalismus von dem kulturkritischen Verdacht einer selbstdestruktiven Beschleunigung von Individualisierungsprozessen leiten; auch sie diagnostizieren ei- 
nen wachsenden, funktionalen Bedarf an "verantwortungsethischen Massenorientierungen " (Offe, 1989: 758) und nehmen Fragen der Adaption politisch-demokratischer Vergemeinschaftung an die Strukturen komplexer Gesellschaften in der Perspektive moralermöglichender und -verbürgender institutioneller Veränderung und Reform auf.

Vor diesem Hintergrund läßt sich die kommunitaristische Kritik am Liberalismus nun zunächst in Form einer dreistufig angelegten Krisendiagnose erfassen und genauer beschreiben. Danach haben wir es erstens mit einer Art Dialektik der liberalen Emanzipationsprogrammatik insoweit zu tun, als in den daraus hervortretenden Gestalten eines possessiven und eines expressivistischen Individualismus der in die gemeinschaftliche Konstitution des Selbst eingelagerte moralische Gehalt aufgesogen und soziale Bindungen unterminiert werden; dies führt dann zweitens dazu, daß die gesellschaftliche Integration von Formen der sozialen Anerkennung und moralischen Bindung abgehängt werden $\mathrm{mu} ß$ und ersatzweise in die unpersönlichen Strukturen einer systemischen Vernetzung einerseits und die staatlich-bürokratische Überformung eines zunehmend fragmentierten gesellschaftlichen Lebenszusammenhangs andererseits abgedrängt wird; das legt dann drittens zwar den Gedanken nahe, dem durch die Stärkung gesellschaftlicher Assoziationsverhältnisse und den Ausbau dezentraler, partizipativer Strukturen entgegenzuwirken - doch eine solche Strategie läuft schließlich an Motivationsproblemen auf, die daraus resultieren, daß die unter dem Liberalismus bescheidene Auslegung der Aufgaben einer öffentlichen Moral kaum noch Ansatzpunkte bietet, an denen die Idee des Gemeinwohls angreifen und ihre reflexive Kraft entfalten könnte. Genau an dieser Stelle setzt denn auch die kommunitaristische Neuthematisierung politischer Gemeinschaften (a) und die Entwicklung eines darauf bezogenen Institutionenverständnisses (b) an.

a) Wenn es hierzulande ein herausragendes Rezeptionshindernis für kommunitaristische Vorstellungen gibt, so liegt dies zweifelsohne in einem Gemeinschaftsbegriff, dem der Ruch normativer Unzuverlässigkeit, das Mal einer konzeptionellen Fehlsteuerung der politischen Theorie und von daher ein struktureller Mangel an einschlägiger Empirie anzuhaften scheint. Zwischen diesen Sorten von Gründen, die zusammengenommen in aller Regel eine kritische Distanznahme begründen, besteht fraglos auch ein methodologischer Zusammenhang derart, daß unsicher bleiben muß, welche Art von Empirie überhaupt einschlägig ist, solange die Frage nach der Art von Gemeinschaften, die es empirisch nachzuweisen gilt, ungeklärt ist. ${ }^{19}$ Indessen hängen diese

19 In gewisser Weise gilt auch hier, was Beck/Beck-Gernsheim mit Blick auf die Empirie der Gesellschaft der Individuen angemerkt haben, daß die soziologische Forschung die Frage sträflich vernachlässigt habe, welche Art soziologischer Empirie für eine »Gesellschaft im Flugsand der Individualisierung « überhaupt angemessen sei (vgl. Beck/Beck-Gernsheim, 1994: 32, Anm. 38). Eine ähnliche Beobachtung macht (kritisch gegen Beck) auch Honneth, allerdings mit einem wichtigen Unterschied: eine Verbesserung der Individualisierungsempirie hängt nicht nur, wie bei Beck/ Beck-Gernsheim von methodischen Orientierungen ab, sondern von einer begrifflichen Differenzierung der gesellschaftlichen Prozesse, die unter dem Begriff der Individualisierung in unzulässiger und am Ende uninformativer Weise amalgamiert werden: auf diese Weise kommt Honneth zu der Unterscheidung von Individualisierung, Privatisierung und Autonomisierung - eine Unterscheidung, die auch für die Klärung des kommunitaristischen Gemeinschaftsverständnisses folgenreich und instruktiv ist, wie ich im folgenden noch zeigen möchte (vgl. Honneth, 1994: 24 f.). 
Vorbehalte auch mit charakteristischen Schwierigkeiten zusammen, die dem Bemühen um eine angemessene Würdigung des Kommunitarismus immer noch entgegenstehen (vgl. Joas, 1993): der traditionalistischen Imprägnierung des kontinentalen Gemeinschaftsverständnisses, das zu einer Fehlsteuerung der Erwartungen bezüglich des amerikanischen (und darunter auch des kommunitaristischen) Gemeinschaftsdiskuruses führt; ${ }^{20}$ der eigenen Unübersichtlichkeit auch des amerikanischen Gemeinschaftsdenkens (vgl. auch Fowler, 1991); schließlich der unklaren und überhaupt nur sporadisch hergestellten Verbindung von sozialphilosophischer, politiktheoretischer Reflexion einerseits und einer darauf abgestimmten Gemeinschaftsempirie andererseits. ${ }^{21}$ Aus dieser Lage ziehe ich den Schluß, daß es zunächst einmal darauf ankommen muß, den spezifisch demokratietheoretischen Gebrauch des Gemeinschaftskonzepts in der Kommunitarismus-Debatte so weit freizulegen, bis ein normativ gehaltvoller Begriff von Gemeinschaft erkennbar wird, der dann in Strukturprinzipien und institutionelle oder organisatorische Strukturmechanismen übersetzt werden kann, die ihrerseits erst den Hintergrund für eine relevante Empirie abgeben - diese Regieanweisung mag methodisch gesehen trivial sein, sie führt aber, wie ich hoffe, zeigen zu können, zu nicht ganz so trivialen Ergebnissen.

Wenn man danach fragt, was in der Sicht der Kommunitaristen »integriert« und was »spaltet«, so ist die Antwort prima facie eindeutig: integrierend wirken Gemeinschaften, desintegrierend ein institutionell verstärkter Individualismus, der nicht nur den moralischen Reifungsprozeß des Individuums, sondern auch die kollektive Handlungsfähigkeit eines demokratischen Gemeinwesens bedroht und unterminiert. Doch schon auf den zweiten Blick stellen sich bezüglich dieser binären Kontrastierung von Individualismus und Gemeinschaft Zweifel und Fragen ein, die zu ersten Präzisierungen Anlaß geben. Hinsichtlich der Individualismus-Kritik und-Empirie wäre zu fragen, welche Prozesse man denn genau im Auge hat (Individualisierung, Privatisierung, Autonomisierung? ${ }^{22}$ ); und hinsichtlich der Vorstellungen dessen, was mit >Gemeinschaft< gemeint sein soll, herrscht eine ziemliche Konfusion, die positiv mit der Prominenz des Themas zu korrelieren scheint, weil in der in den USA breit geführten Debatte die aus sehr unterschiedlichen zeitdiagnostischen Ansätzen, Sicht- und Thematisierungsweisen der vorrangigen öffentlichen Probleme sich ergebenden Lösungsvorschläge in eben diesen Begriff projiziert werden, der so zu einer Art Auffangbecken für Reformhoffnungen der unterschiedlichsten Art wird und begrifflich zu einer Residualkategorie zu verkom-

20 Davon sind auch die zurechtweisenden Bemerkungen an die Adresse ratlos gewordener Linksintellektueller, mit denen Rehberg seine Überlegungen zum Verhältnis von »Gemeinschaft und Gesellschaft - Tönnies und Wir« abschließt, nicht ganz frei (vgl. Rehberg, 1993a: 39 f.).

21 Eine Ausnahme bilden hier immer noch die Arbeiten der Autorengruppe um Robert Bellah (vgl. Bellah et al., 1987 und 1991 sowie die Hinweise auf die »vier Mobilitäten«, auf die sich Walzer bezieht - vgl. Walzer, 1993. Einen guten Überblick bietet auch Wolfe (1991).

22 Diese Differenzierung hat Honneth gegenüber Ulrich Beck angemahnt (vgl. Honneth, 1994: 24 f.). 
men droht. ${ }^{23}$ In diesem vielstimmigen Gemeinschaftschor haben auch die Kommunitaristen insofern einen distinkten Part, der politisch in der Intonierung einer linksrepublikanischen Melodie besteht; aber auch sie singen längst nicht mit einer Stimme.

Genauere Aufschlüsse als über einen solchen Versuch Schnittmengenbildung ergeben sich denn auch erst, wenn man den Einführungskontext beachtet, in dem der Gemeinschaftsbegriff seine Prominenz erlangt hat: es geht um das Verhältnis von Moral und Politik, oder, um es mit Offe auf eine zeitdiagnostische Formel zu bringen, um die sich auftuende Schere zwischen der knappen Ressource staatsbürgerlicher Moral einerseits und einem wachsenden funktionalen Bedarf an ethisch-moralischen Masseneinstellungen einerseits; wobei hinzuzufügen wäre, daß in der kommunitaristischen Sicht diese Verknappung moralischer Ressourcen nicht etwa auf einen fehlenden oder abnehmenden moralischen Sinn der Bürger (vgl. Wilson, 1993: 244 ff.), sondern auf die Funktionslogik der sozialen und politischen Institutionen der liberalen Gesellschaft zurückzuführen ist. Erst vor diesem Hintergrund ${ }^{24}$ zeigt sich die Differenz etwa zum Programm des »Politischen Liberalismus« (Rawls), und es ergeben sich erste Hinweise auf den spezifisch normativen Gebrauch, der im Kommunitarismus von der Kategorie der Gemeinschaft gemacht wird: Dort, wo der Liberale im Kern das Problem des Verhältnisses von Moral und Politik als »systemische « Frage nach den »moralanalogen Funktionsprinzipien « eines arbeitsteiligen, rechtsstaatlichen Institutionensystems behandelt, neigt der republikanisch gesonnene Kommunitarist dazu, das institutionell nicht substituierbare individuelle Ferment sozio-moralischer Kompetenzen zu betonen und gemeinschaftliche Beziehungsmuster und Interaktionsformen (auf unterschiedlichen Ebenen) als Reproduktionszusammenhang dieser Kompetenzen ins Auge zu fassen. ${ }^{25}$ In diesem Sinne faßt Etzioni denn auch das kommunitaristische Anliegen dahingehend zusammen, daß der Gebrauch des Begriffs Gemeinschaft nicht oder nicht in erster Linie auf eine Priorisierung sozialer Nä-

23 Vgl. die sehr detaillierte Übersicht, die Fowler auf der Basis einer umfassenden Literaturstudie bietet. Er unterscheidet sieben Fornnen des Gemeinschaftsdiskurses, die nur in einem sehr schwachen und wenig präzisen Sinn darin interferieren, daß $»$ the concept of community invariably invokes the notion of commonality, of sharing in common ... (where) sharing implies an affective or emotional dimension « (Fowler, 1991: 3).

24 Insofern ist Axel Honneth in seiner Einschätzung zuzustimmen. Was ich allerdings für unplausibel halte, ist die von ihm vorgenomme Unterscheidung zwischen Liberalen und Kommunitaristen nach der primären Orientierung entweder an den kulturellen Bestandsvoraussetzungen demokratischer Gesellschaften (die liberale Position) resp. den kulturellen Bedingungen individueller Selbstverwirklichung (der kommunitaristische Ansatz). Richtig ist, daß Liberale auch im zweitgenannten Sinne keine Gemeinschaftsfeinde sein müssen, insofern sie den - prima facie - moralischen Wert von sittlich integrierten Gemeinschaften durchaus anerkennen (Rawls), während umgekehrt auch die Kommunitaristen gemeinschaftsbezogene Sozialisationsprozesse gerade in ihrer Ressourcenfunktion für demokratische Politik thematisieren - durch die systematische Verbindung beider Gesichtspunkte zeichnet sich etwa die Argumentationsstrategie aus, die Taylor einschlägt (vgl. Taylor, 1992).

$25 \mathrm{Zu}$ einem ähnlichen Schluß kommt auch Nunner-Winkler. Allerdings halte ich es für unplausibel, den System- resp. Persönlichkeitsaspekt von Moral auf die Dimension von Kognition resp. Motivation aufzuteilen, weil damit der Blick auf institutionelle Arrangements und Organisationsformen demokratischer Poitik verstellt wird, die beides zusammenführen. Vgl. Nunner-Winkler, 1994: 137 ff.). 
heverhältnisse (»a warm, fuzzy sense of community «) gerichtet ist, sondern seine distinkte Qualität dadurch erhält, daß »communities speak to us in a moral voice. They lay claims on their members « (Etzioni, $1993: 31$ ).

Nunmehr läßt sich auch die kommunitaristische Integrations- resp. Desintegrationshypothese schon ein Stück weit spezifizeiren: Integrierend wirkt die Gemeinschaft moralisch authentischer Bürger, die ihre gemeinsamen Belange öffentlich mit den kommunikativen und diskursiven Mitteln deliberativer Politik mit Blick nicht nur auf egoistische Ziele, sondern auf das Gemeinwohl, gestalten; und desintegrierend wirkt die Gesellschaft des institutionellen Individualismus, in der die (liberalen) strukturbildenden Mechanismen von Markt, bürokratisch-staatlich konzentrierter Politik und der Vorrang subjektiver (Anspruchs-) Rechte den »moralischen Sinn « der Subjekte austrocknen und einen moralischen Privatismus befördern, der Ansätze zu einer gemeinschaftsbezogenen, zivilgesellschaftlichen Praxis verständigungsorientierter Politik untergräbt und einem fragmentierten Typus einer staatsadressierten »claimant politics « ${ }^{26}$ Raum gibt, der demokratische Politik in ihrer Substanz gefährdet, weil sie die Organisationsbasis demokratischer politischer Öffentlichkeiten klientelistisch fragmentiert. ${ }^{27}$

Bezüglich des Gemeinschaftsbegriffs sollte vor diesem Hintergrund so viel klar sein, daß es den Kommunitaristen mit Blick auf die Bestandsvoraussetzungen demokratischer Politik um die Idee einer posttraditionalen Vergmeinschaftung geht, die nicht viel mit dem häufig gepflegten Bild eines regressiven ethischen Traditionalismus (i.S. der »Silent Majority«) oder mit einem freiheitsbedrohenden, bornierten Lokalismus und Parochialismus zu tun hat. Konstitutiv ist ein normatives Konzept, ${ }^{28}$ an das sich dann sekundär auch primordiale Faktoren anheften können, so weit sie eine Ressourcenfunktion für normativ herausgehobene Verhaltensmuster annehmen und nicht in Widerspruch zu den normativen Standards geraten - kurz, es geht um ein Konzept, mit dessen Hilfe die Kontinuität zwischen der moralischen Sozialisation des einzelnen

26 Das ist der Schluß, zu dem Madsen auf der Grundlage einer eindrücklichen Fallstudie zur öffentlich heftig umstrittenen Siedlungspolitik in einer Gemeinde im Süden Kaliforniens gelangt (vgl. Madsen, 1991: 455 ff.).

27 Diese Einschätzung der fragmentierenden Wirkung des Zusammenspiels von Markt, Staat, dem System der Rechte und dem als Privatismus ausgelegten Individualismus finden sich so oder ähnlich bei allen Autoren, die dem kommunitaristischen Lager zugerechnet werden. Vgl. die entsprechenden Kapitel in Etzioni (1993) und Taylor (1992: 109 ff.).

28 Es handelt sich mithin um ein Konzept, daß auch liberalen Reserven gegenüber allen Arten eines ontologisch starken Kollektivverständnisses entgegenkommt. An dessen Stelle tritt vielmehr eine in einem deliberativen Politikverständnis fundierte Gemeinschaftsauffassung, nach der wir versuchen können, »das Feld der politischen Debatte und des Austauschs als eine bereits hinreichend gemeinsame Grundlage dafür zu betrachten, daß ihre politischen Ergebnisse den Geist der Zustimmung und > Gültigkeit< in sich tragen - ohne daß darin ein Widerspruch zu Pluralität und Toleranz liegt« (Michelman, 1994: 65 f.). Damit rükken, wie Michelman zeigt, zwei Prämissen des kommunitaristischen Gemeinschaftsverständnisses in den Vordergrund, die kaum geeignet sein sollten, liberale Feindseligkeiten zu provozieren: die Prämisse, daß Begegnung und Beziehung als "Selbst bildender Umstand « aufzufassen sind und daß Kommunikation und Teilhabe infolgedessen als menschliche (Grund)Güter gelten können (Michelman, 1994: 69 ff.). 
und der Reproduktion einer demokratischen Praxis von Staatsbürgern, zwischen persönlicher und sozialer Verantwortung, persönlicher und sozialer Integrität wie zwischen individueller und kollektiver Urteilsbildung wiederhergestellt werden soll. ${ }^{29}$

Ein Konzept politischer Gemeinschaften, das auf diese Krisendiagnose zugeschnitten ist und gleichzeitig den Bedingungen moderner Politik Rechnung trägt, ist zweifellos nur unter drei, aufeinander aufbauenden Voraussetzungen zu haben: Methodisch wäre von einer nominellen auf eine attributive (oder von einer topographischen auf eine relationale) Verwendungsweise umzustellen, in der dann Strukturprinzipien wie Kommunikation, Interaktion und Merkmale wie geteilte Werte und Interessen, Verantwortung als Kriterien fungieren, an Hand derer sich der spezifische Grad der Vergemeinschaftung anzeigt und was es erlaubt, Gemeinschaftsvorstellungen von konventionellen Kriterien wie Größe und Territorialität und damit bestimmten Gestalten ihrer insularen Realisierung wie in dörflichen oder städtischen Gemeinden oder Nachbarschaften abzulösen. Inhaltlich muß der Gemeinschaftsbegriff dann nicht mehr auf die Vorstellung eines fusionierten Lebens festgelegt werden, sondern ist in Formen sozialer Anerkennung zentriert, in denen die Regulierung, Disziplinierung und Kanalisierung selbstbezüglichen Verhaltens so vermittelt ist, daß es an übergreifende Interessen und Ideale gebunden werden kann. ${ }^{30}$ Das ermöglicht schließlich eine größere Varianz der organisatorischen Formen, in denen sich Gemeinschaftlichkeit zur Geltung bringen kann - diese institutionelle Ablösung von primordialen Faktoren soll sicherstellen, daß das Organisationsprinzip von >Gemeinschaft< eine politisch entscheidende Rolle spielen kann, ohne selbst trennend oder spaltend zu wirken. Nur unter diesen Voraussetzungen wird sich, wenn überhaupt, die Erwartung erfüllen, robustere Gemeinschaftsideen in die Struktur demokratischer Prozesse einfügen und in institutionelle Reformen übersetzen zu können: "Liberalism's thin theory of community weakens its capacity to speak with a clear voice where the public interest demands discipline and duty as well as ... freedom and self-realization ... At bottom, the communitarian challenge is a demand for more extensive responsibilty in every aspect of personal experience and social life« (Selznick, 1992: 385).

Auf diese Anforderungen reagieren die Kommunitaristen nun mit einem relationalen Gemeinschaftsbegriff, der sich grob aus vier Komponenten zusammensetzt (vgl. auch Phillips, 1993: $10 \mathrm{ff}$.): Primär und konstitutiv sind das Prinzip breiter politischer Partizipation, das in moralischen Gefühlen wechselseitiger Anerkennung und solidari-

29 »This establishes a (prima facie, $d$. Verf.) presumption of moral worth. The presumption is rebuttable on a showing that a given community is too narrow or attenuated to provide an effective framework for common life, or that it is too rigid and stultifying to serve the needs of personal and institutional development... (Selznick, 1992: 359). Gemeinschaften sind also spezifisch strukturierte Handlungszusammenhänge, die die Übersetzung moralischer Gefühle in politisches Handeln erleichtern sollen - vgl. Goodin (1992: 151 ff.). Dieser Gedanke findet denn auch in der allgemeinen Definition, die Selznick vorschlägt, Berücksichtigung: »A group is a community to the extent that it encompasses a broad range of activities and interests, and to the extent that participation implicates whole persons rather than segmental interests or activities « ((Selznick, 1992: 358).

30 »The distinctive function of community then is the reconciliation of partial with general perspectives « (Selznick, 1992: 369). 
schen Einstellungen vermittelt bleiben muß; daneben treten im Sinne einer eher funktionalen Zuordnung jene Faktoren oder Kontexte, die in besonderer Weise geeignet sind, diesen Anforderungen entgegenzukommen - wobei Gemeinschaftssinn nicht traditionalistisch vermittelt sein muß und Lokalität keine geographische, sondern eine relationale Kategorie ist. Das wird insbesondere sinnfällig, wenn eine demokratietheoretische Lesart des kommunitaristischen Gemeinschaftsverständnisses zugrunde legt. In dieser Perspektive einer »communal democracy «, die Selznick im Ausgang von der handlungstheoretischen Bestimmung Dewey's, "(that) wherever there is a conjoint activity whose consequences are appreciated as good by all singular persons who take part in it, and where the realization of the good is such as to effect an energetic desire and effort to sustain it in being just because it is a good shared by all, there is in so far community. The clear consciousness of a communal life, in all its implications, constitutes the idea of democracy (Dewey, 1984: 328) entwickelt, ergeben sich folgende Übersetzungen für die genannten Bestinmungsmerkmale von Gemeinschaft: ${ }^{31}$

- das Prinzip der Partizipation wird auf ein dezentrales Modell zivilgesellschaftlicher Politik projiziert, in denen freiwillige Assoziationen aller Art, die als vermittelnde Instanzen zwischen das Individuum und die Regierung treten, die organisatorische Infrastruktur einer Gruppendemokratie bilden (Selznick, 1992: 505 und 517 ff.);

- der relationale Aspekt wird primär in der Gestalt einer diskursiv vermittelten Intersubjektivität und in der Anforderung einer »reflexiven Moralität« aufgenommen, die zusammengenommen gewährleisten sollen, daß sich die kollektive Entscheidungsfindung für argumentative Praktiken öffnet - insofern stellt sich ein Zusammenhang her zwischen der Qualität politischer Entscheidungen und dem Grad der erreichten Gemeinschaftlichkeit (Selznick, 1992: $502 \mathrm{f}$. und $524 \mathrm{f}$.);

- beides schlägt sich drittens in der Unterscheidung von kommunaler und Massendemokratie in einer relationalen Deutung auch von Lokalität nieder - während die (elektorale) Massendemokratie als unvermittelt, nicht-deliberativ und unstabil erscheint, sind es im Gegenzug stabile Netzwerke (von Problemlösungsgemeinschaften), die die Voraussetzungen dafür schaffen sollen, daß die Beteiligten ein angemessenes Verständnis ihrer Interessen erreichen (Selznick, 1992: 522 f.);

- schließlich hat die Stabilität auch einen zeitlichen Aspekt, so daß die geschichtlich oder geographisch vermittelte Dauer von Gemeinschaften einen inhärenten Zug zu langfristigen Orientierungen aufweist, dic für sich genommen der moralischen Verbesserung der Individuen entgegenkommt (Selznick, 1992: 533).

Die distinkte Funktion von Gemeinschaften im Handlungszusammenhang einer demokratischen Gesellschaft besteht also darin, die Voraussetzungen für eine Form der Willensbildung zu schaffen, in der partikulare mit allgemeinen Interessen und Perspektiven versöhnt werden können. Dazu bedarf es nicht der Vorstellung eines eines in Tradition und sozialer Struktur vollständig fusionierten Lebens gemeinschaftlicher Gruppen. Freilich sollte das andererseits nicht zu dem Schluß verleiten, dieses Ziel könnte sich allein auf

31 Das spiegelt sich auch im argumentativen Aufbau der kommunitaristischen Programmschrift, die Etzioni unter dem Titel »The Spirit of Community« veröffentlicht hat. Vgl. Etzioni (1993). 
der Basis freiwilliger Assoziation, im Medium von Kommunikation und persönlicher Interaktion erreichen lassen. Vielmehr bleiben diese Prozesse verwiesen auf die politisch gerichteten, aber vorpolitischen Integrationsleistungen sozialer Institutionen (Familie, Schule, Nachbarschaften o.ä.) und die Kraft politisch-institutioneller Regulierungen - kurz: es bedarf institutioneller Arrangements, die die Über- und Umsetzung dieser Vorgaben gewährleisten. Die kommunitaristische Integrationstheorie ist aus diesem Grunde, nicht nur bei Selznick, in einem großen Maße institutionenzentriert. Diese Institutionen erweisen ihre Qualität aber zugleich darin, daß sie die unterschiedlichen Momente des Gemeinschaftsbegriffs (also Geschichtlichkeit, Identität, Gegenseitigkeit, Pluralität, Autonomie und Partizipation) ${ }^{32}$ in eine Balance bringen und so die Idee der Gemeinschaft effektiv im politischen Strukturaufbau der modernen Gesellschaft zur Geltung bringen sollen.

b) Durch diese Konfiguration ist also der normative Verwendungszusammenhang des Institutionenbegriffs in der kommunitaristisch-republikanischen Diskussion wesentlich bestimmt, und sie geht schließlich in die begriffliche Explikation ebenso ein wie in den praktischen Verwendungssinn des Institutionenkonzepts. ${ }^{33}$ Ich möchte das nunmehr kurz mit Blick auf Vorstellungen Selznick's (1992), Bellah's (1991) und Taylor's (1992) erläutern. Selznick baut seine »Theorie der Institutionen « ${ }^{34}$ auf drei miteinander verschränkten Gnundannahmen auf. Erstens legt er das soziologische Konzept der »Institution« von vornherein auf einen moralischen Gehalt fest - seine differentia specifica gegenüber dem Organisationsbegriff besteht danach genau darin, daß Institutionen intim mit dem Aspekt der sozialen Wertrealisienung verbunden sind, indem sie, vergleichbar der Funktion von Sozialisationsprozessen, in denen das Individuum geformt wird, auf die moralische und ethische Durchdringung und Gestaltung von Gruppen und gesellschaftlichen Praktiken hin ausgelegt sind (232). Damit hängt auch ihre zweite Besonderheit als distinkter Form der Vergesellschaftung resp. Vergemeinschaftung zusammen - sie brin-

32 Dies sind zusammengefaßt die Variablen, die bei Selznick in den Aufbau von Gemeinschaften eingehen und Berücksichtigung finden müssen. Vgl. Selznick (1992: $360 \mathrm{ff}$.).

$33 \mathrm{Daß}$ der Einbau kommunitaristischer Orientierungen in institutionelle Theorien der Politik einen nahezu universellen Zug der neueren demokratietheoretischen Diskussion darstellt, räumen auch March/Olsen (1994: 12 f.) durchaus ein. Allerdings sehen sie sich veranlaßt, an dieser Stelle eine wichtige Unterscheidung bezüglich der konzeptionellen Strategien, mit denen das erreicht werden soll, einzuführen: eine - die sie mit dem kommunitaristischen Gemeinschaftsbegriff in Zusammenhang bringen -, die eine direkte Verbindung zwischen demokratischer Politik und der Verankerung individueller Identitäten und Orientienungen in gemeinschaftlich geprägten Wertvorstellungen herzustellen versuche; und eine, die die Herstellung des notwendigen Bandes an Gemeinsamkeit eher institutionellen Regeln - einer »logic of appropriateness « - ansinnen will. Dabei favorisieren sie cindeutig den zweiten Ansatz, und zwar nicht zuletzt deshalb, weil der direkte Zugriff auf gemeinschaftlich verbürgte Werte immerhin riskiert, daß die so mobilsierten Werte nicht in jedem Fall auch mit demokratischen Institutionen kompatibel sind. Diese Befürchtung eines (kommunitaristischen) Rückfalls in einen ethischen Partikularismus und Parochialismus greift allerdings, wie ich glaube, im Kern ins Leere: auch die Kommunitaristen favorisieren mit Blick auf die Bestandsvoraussetzungen demokratischer Politik Vorstellungen, in denen sich $» v i s i o n s$ of civic identity and a framework of rule-based action (Herv. d. Verf.) « (12) institutionentheoretisch verbinden.

34 Die folgenden Zitatnachweise (in Klammern) beziehen sich alle auf Selznick (1992) 
gen eine Einheit personbezogener, die lebensweltliche Einbettung von Individuen umgreifender Interaktionen zum Ausdruck, die mehr ist als die arbeitsteilige Koordination und Kooperation von Funktionsträgern in einer Organisation (235). Sie sind also gleichsam instrumentell auf die Förderung und Sicherung des Personideals der Autonomie und der Authentitzität bezogen, die ihrerseits eng mit der Integration des Individuums in den größeren Zusammenhang einer sittlichen Lebensform und Gemeinschaft verknüpft sind - das führt ihn drittens zu der Annahme, daß der Bezug auf ein Gemeinschaftsideal konstitutiv in den Prozeß des »institution-buildung « wie der Entwicklung, Reform und Adaptation institutioneller Strukturen eingeht (237), indem spezielle Verhaltensmuster oder einzelne Praktiken von dort ihren spezifischen Sinn und ihre Bedeutung erhalten. In diesem Sinn ist denn auch seine Qualifizierung zu verstehen, daß es sich bei Institutionalisierungsprozessen primär darum handelt, »to infuse with value « (233), also das Verhalten und Handeln von Individuen wie die das Leben sozialer Gruppen intern strukturierenden Verhaltensnormen auf den Reproduktionszusammenhang einer sittlichen Gemeinschaft im Ganzen abzustimmen und in diesen zu integrieren: dieses Gemeinschaftsideal wird gruppen- oder organisationsintern mobilisiert, wenn sich die primäre Quelle der Integration von Zielen auf Werte, »from specific objects to ways of thinking and deciding " verschiebt und extern durch Legitimationsanforderungen, die bedient werden müssen, um der spezifischen Funktion einer Organisation, ihren Eigenwertbehauptungen und ihren Eigenlogiken soziale Anerkennung und Geltung zu sichern (237).

Dieser so entfaltete Institutionenbegriff aber ist, wie Selznick selber durchaus bemerkt (234), normativ wo nicht leer, so doch noch zu unspezifisch. Deshalb versucht er anschließend, und darin liegt die eigentliche Pointe dieses institutionentheoretischen Ansatzes, die einzelnen Aspekte seines Institutionenverständnisses noch einmal mit Bezug auf die normative Idee demokratischer Teilhabe zusammenzuführen und zu erläutern: Religiöse, politische wie Erziehungs- und Rechtsinstitutionen sind »vehicles for meaningful, self-affirming participation in the life of the community « (243), und eine solche Teilhabe ist bedeutungsvoll, »if it makes a difference for personal autonomy and empowerment « (314). Selznick stellt also einen Zusammenhang zwischen den Idealen der Gemeinschaft einerseits und jenen der persönlichen Autonomie und Authentitzität andererseits so her, daß beide in einer intersubjektiven, dialogischen Grundstruktur des Sozialen verankert werden. Die Realisierung dieser Ideale verweist dann auf die Institutionalisierung diskursiver und argumentativer Praktiken in partizipationsoffenen Strukturen (314), so daß schließlich so etwas wie eine sozialtheoretisch begründete Vorrangvermutung für Demokratie und Partizipation entsteht: die partizipatorische Demokratie wird selber zu einem moralischen Ideal und zu einem privilegierten Weg zur Gemeinschaftsbildung in einem (316) - sie erscheint, wenn man so will, als der paradigmatische Fall einer Institutionalisierung.

An die hier ausgearbeiteten grundbegrifflichen Bestimmungen ${ }^{35}$ können nun Bellah et al. und auch Taylor in ihrem Versuch anknüpfen, in praktischer Absicht die Angriffpunkte

35 Die auch bei Selznick vorgenommene Verschränkung von Autonomie, Authentizität, Gemeinschaft als Horizont des bedeutungsvoll Allgemeinen und Dialogizität findet sich auch bei Taylor (1992) und wird dort in historisch-systematischer Perspektive ausgearbeitet. 
und Perspektiven einer auf die weitergehende Realisierung des moralischen Ideals der partizipatorischen Demokratie gerichteten Reform vor allem politischer Institutionen genauer ins Auge zu fassen. Auch Bellah et al. ${ }^{36}$ konzipieren Institutionen im Anschluß an Durkheim, Dewey und Parsons als Formen der Integration von Verhalten und Handeln in einen sittlichen Gesamtzusammenhang und von daher als Muster normativer, d.i. moralischer Erwartungen, ohne sie dadurch andererseits etwa kritischer Reflexion zu entziehen. Gerade ihr moralischer Anspruch soll verbürgen, daß bestehende Institutionen einer ständigen moralischen Debatte über ihre normative Angemessenheit ausgesetzt bleiben: sie sind auf dem Wege immanenter Kritik ebenso daran zu messen, ob sie ihren eigenen Standards genügen, wie andererseits auch die Wertannahmen, auf denen sie aufruhen, moralischer Kritik standhalten können müssen (288). Beide Prämissen bilden nun den Rahmen, innerhalb dessen die Autoren ihre breit angelegte Kritik des amerikanischen Institutionensystems im Zusammenhang entfalten und dabei religiöse Institutionen ebenso in den Blick nehmen wie den Markt, politische, rechtliche Institutionen und Sozialisationsagenturen wie die Schule oder die Familie. Die Klammer, die diese Analysen zusammenhält und miteinander verbindet, ist die Kritik der Ausbreitung und institutionellen Verkörperung instrumenteller Vernunft, die in einem engen technischen Verständnis von Problemlösung nur unsichtbar mache, daß die wesentlichen Probleme, mit denen wir es zu tun haben, eher moralischer und politischer als technischer Natur sind. Deshalb konzentrieren sie sich auf Strukturverbesserungen, die geeignet sind, der wachsenden Entfremdung zwischen (autokratischer) Expertise und staatsbürgerlichem Publikum entgegenzuwirken: »A third democratic transformation «, so schließen sie in Anlehnung an Dahl, »needs to renew a serious public conversation (between government and an enlightened public, der Verf.) and to strengthen the institutions that nurture and extend it $\ll(297) .{ }^{37}$

Von dieser Vorgabe informiert reichen die Vorschläge im Bereich der politischen Institutionen von Veränderungen des Wahlverfahrens über eine Struktur- und Organisationsreform der politischen Parteien und der Entrechtlichung von Politik durch eine Zurückdrängung regulatorischer Rechtsnormen bis hin zu Möglichkeiten der Verbesserung der Bürgerbeteiligung in der Planung, Durchführung und Implementation materialer Politiken (public policies). Ich kann dem hier nicht im einzelnen nachgehen; interessant und informativ aber ist, daß sie auf diesem Wege unter dem Titel einer "politics of generativity« auch normative Kriterien zur Evaluation speziell institutioneller Strukturen einführen: diese sind danach zu beurteilen, ob sie (i) zu einer hinreichenden Aufmerksamkeitskonzentration derart führen, daß »(we) concern ourselves with the larger meaning of things in the longer run, rather than with short-term payoffs. The pursuit of immediate pleasure, or the promise of immediate pleasure, is the essence of

36 Die folgenden Zitatnachweise (in Klammern) beziehen sich alle auf Bellah et al. (1991).

37 Diese dritte demokratische Transformation soll sich auf die Herstellung von Strukturen beziehen, in denen das Zusammenwirken von Expertise oder Professionseliten und staatsbürgerlichem Publikum verbessert werden kann: dies impliziert sowohl die Demokratisierung von Expertise wie umgekehrt die bessere Qualifikation des Staatsbürgers (diese Probleme standen im übrigen auch bereits für Parsons im Zentrum seiner Analysen und Überlegungen zum Universitätssystem - vgl. Turner, 1993). 
distraction. A good society is one in which attention takes precedence over distraction « (273); ob sie (ii) aktive Bürgerbeteiligung und Diskussion ermöglichen (279) und ob sie (iii) Anreize zur Ausbildung von staatsbürgerlicher Kompetenz oder zur Selbstverbesserung der politischen Meinungs- und Willensbildung enthalten (133 ff.).

Eine der wesentlichen Folgerungen, die daraus resultiert, ist, daß die Konzentration entscheidungsorientierter Politik im Staat und die dieser institutionellen Konfiguration unterliegende Logik einer Separierung von Regierung (government) und politischer Öffentlichkeit, von Staat und ziviler Gesellschaft durchbrochen wird. Dazu reicht es nicht, von einem hierarchischen Politikmodell auf ein horizontales Modell von Zentrum und Peripherie der Entscheidungsfindung und Meinungs- resp. Willensbildung (vgl. Peters, 1993: 344 ff.) umzustellen; sondern man muß gleichsam »fokale Strukturen « der problembezogenen Willensbildung und Entscheidung ins Auge fassen, in denen direkt betroffene Bürger, Regierungsvertreter, Dritte-Sektor-Organisationen und Verbände unmittelbar zusammenwirken können (270). Das wäre auch eine Möglichkeit, der von Taylor herausgestellten Gefahr einer zunehmenden Fragmentierung der Gesellschaft insgesamt entgegenzuwirken (Taylor, 1992: $112 \mathrm{ff}$.). Diese Fragmentierung ist, so Taylor, wesentlich auf institutionell beförderte Absorption und Fehlallokation von Aufmerksamkeitsenergien durch bloße Interessenpolitik zurückzuführen. Gerade dies aber trägt umgekehrt dazu bei, daß es immer weniger möglich ist, demokratische Mehrheiten in bezug auf Fragen von allgemeinem Belang zu organisieren: "One might worry abouts its (the political system of procedural liberalism, der Verf.) long-term stability, worry, that is, whether the citizen alienation caused by its less and less functional representative system can be compensated for by the greater energy of its special interest politics. The point has also been made that this style of politics makes issues harder to resolve... Now what emerged above from the example of the recent fate of the ecological movement is that the only way to countervail the drift built into the market and bureaucracy is through the formation of a common purpose. But this is exactly what is difficult in a democratic system that is fragmented « (Taylor, 1992: 116/117). Wie ist diesem Zirkel zu entkommen? Zunächst über institutionelle Reformen; aber institutionelle Reformen stellen sich in der Regel nicht von selber ein - sie sind Ergebnis politischer Auseinandersetzungen und Kämpfe, in denen es, nimmt man die kommunitaristische Botschaft ernst, zugleich um demokratische Ermächtigung und gegen die kulturelle Hegemonie von Individualismus und instrumenteller Vernunft geht (Taylor, 1992: 2 ff.).

Mit dieser Wendung des Arguments wird, wie schon bei Dewey, eine andere als bloß lokalistische Lesart der Kontinuitätsthese, also des Verhältnisses von lebensweltlichen und politischen Gemeinschaftsinstitutionen, greifbar: Im Zentrum des Vergemeinschaftungsmodells stehen Organisationsformen politischer Öffentlichkeit, »which are premised on active citizen involvement and discussion ...-public participation in administrative decisions, constituency involvement in corporate decisions, and a closer public monitoring of legislative action through review commissions and public debates« (Bellah et al., 1991: 279). Diese neuen Orte und Institutionalisierungsformen öffentlicher Politik lösen sich einerseits funktional von geographischen Organisationsstrukturen $a b$, bleiben aber andererseits insofern mit lebensweltlichen Institutionen 
verknüpft, als in diesen jene vor allem moralischen Kompetenzen ausgebildet werden, in denen das erweiterte bürgerschaftliche Engagement vermittelt bleiben muß. Dieses zivilrepublikanische Grundmuster des kommunitaristischen Gemeinschaftsdenkens wird von Madsen im Anschluß an seine Analyse der konventionellen Struktur- und Prozeßformen lokaler Politik in den USA denn auch noch einmal herausgehoben: »The american citizen less seriously seeks to govern himself or herself through the art of association, that is, through debate, negotiation, and compromise with fellow citizens. American citizens of all types now increasingly seek to satisfy themselves through the art of acquiring favorable attention from the state. They do not develop a political discourse that makes sense to one another, just one that elicits a response from the government« (Madsen, 1991: 459).

Wenn man so will, ist dies die kommunitaristische Desintegrationshypothese, daß durch das Zusammenwirken eines rechtlich beförderten Privatismus mit einer im bürokratischen Staatsaufbau sedimentierten instrumentellen Vernunft ein Politiktypus der »claimant politics« entsteht, der die Selbstorganisationsfähigkeit politischer Öffentlichkeiten, und damit die Bedingung wirklicher Demokratie, untergräbt (Madsen, 1991: 459; vgl. auch Taylor, 1992: 112 ff.). Und Abhilfe kann dann nur durch institionelle Reformen des politischen Prozesses geschaffen werden, die von der »art of association « informiert sind.

\subsection{Das Modell eines pluralistischen Republikanismus bei Walzer}

Am entschiedensten wird ein solcher Ansatz nun in der politischen Theorie Walzers durchgeführt. Nicht ohne Grund wählt er zum Zweck einer plakativen Konturierung seiner Überlegungen die Formel vom "pluralistischen Republikanismus «. ${ }^{38}$ Und zweifellos hat gerade sein Versuch, kommunitaristisch-republikanische und Momente eines sozialen Liberalismus zu verbinden, die, wo nicht vehementesten, so doch informativsten Kritiken in der amerikanischen Debatte um den Kommunitarismus auf sich gezogen.

Diese Kritiken an Walzer laufen im Ergebnis auf die Behauptung eines Widerspruchs zwischen der kommunitaristischen Grundorientierung seines Denkens einerseits und seinen sozialen und demokratischen Aspirationen andererseits zu. Sie übersehen freilich die intime Verbindung, die Walzers normativer Begriff von Demokratie und seine Auslegung von »Gemeinschaft « eingehen. Ihren prägnantesten Ausdruck hat die genannte Kritik in Joshua Cohens These vom >simple communitarian dilemma< gefunden. Ich werde deshalb die Grundzüge der Gerechtigkeitstheorie Walzers unter Bezug auf diesen Einwand freilegen (a). Davon ausgehend sollen dann in zwei weiteren

38 So Walzer (1990a: Anm. 21). Man kann bei Walzer zweifelsfrei eine Kontinuität seines Denkens nachweisen, das sich durch die häufiger wechselnden Etikettierungen hindurch durchhält: in jüngeren Publikationen beschreibt er seine eigene Position vorzugsweise als "sozialdemokratisch «(Walzer 1990a: 6f.), die Jahre zuvor als sozial-liberal (1984) oder als »demokratischen Sozialismus« (1980: 70). 
Schritten die konzeptionellen Implikationen des Walzerschen Theoriearrangements soweit nachgezeichnet werden, bis die grundlegenden Konturen seiner politischen Theorie sichtbar werden. Dabei geht es zunächst um den Nachweis, daß seinem Begriff von »shared understandings « kein dumpfer Traditionalismus oder blinder Partikularismus zugrunde liegt, sondern daß dieser der die dialogische Auslegung einer reflexiven Kultur zum Inhalt hat (b). Damit rückt Walzer seine Gerechtigkeitstheorie schlechthin in den Horizont der Praxis demokratischer Selbstbestimmung, auf die die Rechtfertigung kontextspezifischer Regeln distributiver Gerechtigkeit dann bezogen werden kann. So gewinnt die institutionelle Gestalt einer gerechten Gesellschaft erste Konturen. Andererseits geht seine Politische Theorie in dieser republikanischen Perspektive allein nicht auf. Vielmehr versucht Walzer, die republikanische Idee einer in dialogischer Praxis vermittelten Selbstbestimmung mit der liberalen Idee institutioneller Garantien und reflexiv aufeinander anzuwendender Prozesse miteinander zu verschränken. Dieser spluralistische Republikanismus ‘ findet seinen Ausdruck in einem in den assoziativen Strukturen einer Zivilgesellschaft verankerten Modell von Öffentlichkeit, der er zunächst auch die Funktion einer Verbesserung staatlicher Willensbildung und Entscheidungsfindung zuweist (c). Allerdings ist sein Konzept des öffentlichen Dialogs auf diese inklusive Funktionsbestimmung von Öffentlichkeit nicht hinreichend abgestimmt, weil es für die Rationalitätszumutungen, die sich aus dem Anspruch der materialen Verbesserung politischer Entscheidungen ergeben, nicht ausreichend aufnahmefähig ist (d).

a) Das Werk, in dem Walzer seinen Grundintuitionen einen kohärenten theoretischen und zugleich paradigmatischen Ausdruck zu geben versucht hat, sind zweifelsohne die »Sphären der Gerechtigkeit « (1992). Nicht unbescheiden faßt er selbst sein Buch wegen seiner internen Verknüpfung der Anerkennung kultureller Pluralität und gesellschaftlicher Differenzierung mit den Werten demokratischer Selbstbestimmung und sozialer Gleichheit durchaus als Gegenentwurf zu John Rawls' »Theorie der Gerechtigkeit« auf. Ihren normativen Halt finden Walzers Grundintuitionen an der Idee einer demokratischen Lebensform, einer Idee, der er von vornherein sowohl eine substantielle wie auch eine die Grundzüge seines Theorieentwurfs bestimmende methodische Auslegung gibt. In den ersten und letzten Seiten seines Buches legt er den Rahmen fest, in dem er seine Interpretation dessen organisiert, was Gerechtigkeit in einer pluralen, komplex ausdifferenzierten und demokratisch organisierten Gesellschaft bedeutet. In substantieller Hinsicht verbindet Walzer sie mit der Perspektive einer demokratisch-sozialistischen Transformation liberaler Gesellschaften: »This is the working principle of democratic socialism: that politics can be opened up, rates of participation significantly increased, decision making really shared, without a full-scale attack on private life and liberal values, without a religious revival or a cultural revolution. What is necessary, is the expansion of the public sphere (Walzer, 1980: 70). Diesem Prinzip unterlegt Walzer in den »Spären « eine Ausführungsbestimmung, die als prägnante Zusammenfassung seiner materialen Analysen der unterschiedlichen Gerechtigkeitssphären gelesen werden kann: »Die mir unter diesem Blickwinkel für meine eigene, die amerikanische, Gesellschaft als angemessen erscheinenden Strukturen sind die eines dezentralen demokratischen Sozialismus in Gestalt eines starken Wohlfahrtsstaates, 
dessen Vertreter zumindest zum Teil aus lokalen, ehrenamtlich tätigen Gemeindebeamten bestehen, eines regulierten Marktes, eines offenen und entmystifizierten Staatsdienstes, unabhängiger staatlicher Schulen, einer Partizipation aller an harter Arbeit ebenso wie an freier Zeit, des Schutzes religiöser und familialer Aktivitäten, eines von Rücksichten auf Rang und Klassenzugehörigkeit freien Systems der öffentlichen Ehrung und Mißbilligung, einer von Arbeitern ausgeübten Kontrolle über Großbetriebe und Fabriken und einer auf Parteien, Bewegungen, Versammlungen und öffentliche Diskussionen gestützten Politik« (Walzer, 1992: 447 f.).

Dieser Beschreibung der institutionellen Charakteristika einer demokratisch-sozialistischen Gesellschaft fügt er mit der Bemerkung, daß »Strukturen und Institutionen dieser Art ihren Nutzen allerdings nur dann (entfalten), wenn die in ihnen tätigen Männer und Frauen sich in ihnen heimisch fühlen und bereit sind, sie gegen Angreifer zu verteidigen«, einen Nachsatz an, der das zweite, das kommunitaristische Thema seiner Theorie reflektiert. Er legt damit jenes Motiv frei, das ihn veranlaßt, sich in der methodischen Anlage seiner Gerechtigkeitstheorie von den Konstruktionsmerkmalen einer universalistisch gerichteten Theorie des Rawlsschen Typs abzusetzen. Moraltheoretische Reflexionen können danach eine kritische Wirkung nur entfalten, soweit sie in moralischen Überzeugungen der Bürger und der Infrastruktur einer gemeinsamen Lebenswelt verankert sind; deshalb bilden diese für Walzer sowohl den Ausgangs- wie den Bezugspunkt seiner Gerechtigkeitstheorie: » Gerechtigkeit ist kein absoluter, sondern ein relativer Begriff, dessen je konkreter Inhalt in Relation steht zu je bestimmten sozialen Zielen und Sinngehalten ... Und das beschreibende Adjektiv gerecht (Herv. i.O.) bestimmt nicht das reale Leben von Gesellschaften, sondern kennzeichnet es nur $^{39}$...Eine bestehende Gesellschaft ist dann eine gerechte Gesellschaft, wenn sie ihr konkretes Leben in einer bestimmten Weise lebt - in einer Weise, die den gemeinsamen Vorstellungen ihrer Mitglieder entspricht « (Walzer, 1992: 441). Und an anderer Stelle fährt er fort: » Meine Argumentation ist eine streng subjektive [im englischen Original heißt es: »radically particularist« Walzer, 1983: XIV)]. Ich kann nicht behaupten, daß ich jemals eine nennenswerte Distanz zu der Sozialwelt gewonnen hätte, in der ich lebe. Nun besteht ein Weg - möglicherweise ist es der originäre Weg -, den ein Philosoph im Bestreben, sein Geschäft zu betreiben, beschreiten kann, ganz sicher darin, daß er aus den eigenen vier Wänden heraustritt [im englischen Original heißt es unter Anspielung auf das Höhlengleichnis Platons: »walk out of the cave... « (Walzer, 1983: XIV)], die Niederungen des Ortes, an dem er lebt, hinter sich läßt und eine Bergeshöhe erklimmt, die es ihm ermöglicht, das zu tun, was der Normalmensch nicht tun kann, nämlich einen objektiven und universellen Standpunkt einnehmen... Was indes mich selbst angeht, so werde ich diesen Weg nicht einschlagen, sondern mit beiden Beinen fest auf dem Boden der unmittelbaren Tatsachen verharren ... Gerechtigkeit und Gleichheit können möglicherweise als philosophische Artefakte entwickelt werden, für eine gerechte oder eine egalitäre Gesellschaft gilt das nicht. Wenn eine solche

39 Diese Übersetzung ist etwas unglücklich, weil sie Walzer's Intentionen an dieser Stelle verharmlost - im englischen Original (Walzer, 1983: 313) heißt es genauer: »it doesn't determine, it only modifies, the substantive life of the society it describes«. 
Gesellschaft - wenn auch verborgen und versteckt in unseren Konzepten und Kategorien - nicht bereits existierte, dann könnten wir sie auch in Zukunft niemals konkret ausformen und verwirklichen« (Walzer, 1992: 20).

Diese Festlegungen nehmen dann die Gestalt von vier allgemeinen Konstruktionsprinzipien an einer Theorie »komplexer Gleichheit« an. Den entscheidenden konzeptionellen Schritt unternimmt er, wenn er mit Blick auf Fragen distributiver Gerechtigkeit eine Adaption der Gerechtigkeitstheorie an das Faktum einer in eigenlogische Handlungssphären ausdifferenzierten Gesellschaft vornimmt. Diese Handlungsbereiche konstituieren in seiner Optik erst dadurch auch unterschiedliche Sphären der Gerechtigkeit (Mitgliedschaft, Sicherheit und Wohlfahrt, Geld und Waren, öffentliche Ämter, harte Arbeit, Freizeit, Erziehung und Bildung, Verwandtschaft und Liebe, göttliche Gnade, Anerkennung und politische Macht sind die Bereiche, die er unterscheidet), daß in ihnen jeweils spezifische und nur intern gültige Verteilungsregeln wirksam sind. Diese generelle Zuordnung von Verteilungsregeln zu einzelnen Handlungsbereichen rechnet zwar durchaus mit einem begrenzten Reservoir an fundamentalen und aufgrund ihrer kulturellen Verankerung legitimen materialen Gerechtigkeitsprinzipien wie »freier Austausch «, »Bedürfnis« und »Verdienst«. Sie folgt aber - und darin besteht die eigentliche Pointe - der Annahme, daß es die Handlungsbereiche mit ihrer je eigentümlichen Handlungslogik und die Bedeutung der zu verteilenden Güter für die individuelle Reproduktion des allgemeinen Handlungszusammenhangs sind, die ihre eigene Selektivität gegenüber den zur Anwendung zu bringenden materialen Gerechtigkeitsprinzipien entwickeln. Dadurch verschiebt Walzer nicht nur den Fokus der Gerechtigkeitstheorie von der Ebene der Begründung universeller Gerechtigkeitsprinzipien auf die materiale Ebene kontextgebundener Anwendungsfragen, sondern er löst Fragen der distributiven Gerechtigkeit aus dem normativen Bezug auf das Individuum und rückt sie in den Horizont der Selbstreproduktion einer politischen Gemeinschaft von Staatsbürgern.

So nimmt Walzer dann zweitens Fragen der politischen Gerechtigkeit, also Fragen nach der Legitimität einer politischen - und d.h. herrschaftlichen - Ordnung, konsequent in der Perspektive der Sicherung und Stabilisierung des Arrangements plural ausdifferenzierter Gerechtigkeitssphären auf: wenn, wie er im Anschluß an Arendt notiert, erst "gute Zäune gerechte Gesellschaften (garantieren) (Walzer, 1992: 449), dann wird politische Macht zu einer grundsätzlich reflexiv auf die Erhaltung und Überwachung der Grenzen zwischen den einzelnen Sphären bezogenen, zentralen regulativen Instanz (Walzer, 1992: 43, Fn.). Legitime Macht, die dem Staat also nur aus der Erfüllung dieser reflexiven Funktion zuwachsen kann, erscheint dann also selber als ein - und darüber hinaus als das wahrscheinlich wichtigste - Gut, dessen Verteilung nicht nur im Sinne einer »Kunst der Differenzierungen« (Walzer, 1992: 22) bereichsinternen Gesichtspunkten folgen und vor der Kolonisierung durch bereichsfremde Kriterien wie Reichtum oder Sozialstatus geschützt werden soll; darüber hinaus ist es ein Erfordernis politischer Gerechtigkeit, daß politische Macht in ihren eigenen kolonisatorischen Tendenzen beschränkt wird - kurz: Politische Macht ist immer dominant, »jedoch nur an den Grenzen und nicht innerhalb derselben« (Walzer, 1992: 43, Fn.). 
Diese beiden Elemente werden drittens zu einer Theorie »komplexer Gleichheit« verbunden, nach der Gerechtigkeit keine strikt egalitäre Verteilung aller Güter erfordert, sondern sich vielmehr in der Anwendung sphärenspezifischer Verteilungkriterien und der Vermeidung von trade-offs zwischen unterschiedlichen Verteilungspositionen und damit der monopolistischen Ausbeutung nur eines, über alle Sphären generalisierten, dominanten Gutes realisiert. Diese Auffassung komplexer Gleichheit möchte Walzer nun freilich nicht unter dem Gesichtspunkt der Universalisierung begründen oder in einer Theorie der Gesellschaft verankern, sondern sie rekonstruktiv-hermeneutisch auf ein rationales Verständnis der spezifisch amerikanischen politischen Tradition beziehen. Es geht ihm eben nicht darum, "... to sketch an utopia located nowhere or a philosophical idea applicable everywhere«; vielmehr muß es ihm darauf ankommen zu zeigen, daß ein derart mit individueller Freiheit verträgliches Konzept komplexer Gleichheit »...durchaus im Bereich unserer Möglichkeiten (liegt). Sie ist eine praktische Möglichkeit hier und jetzt, die, wie ich nachweisen möchte, in unserem gemeinsamen Verständnis von sozialen Gütern latent bereits existiert «(Walzer, 1992: 19).

Diese Argumentationsstrategie provoziert geradezu den fälligen Einwand, den Cohen auf die griffige Formel des »simple communitarian dilemma« gebracht hat. Danach ergeben sich für das von Walzer vorgeschlagene Modell interpretativer Kritik nur zwei Spielarten, die beide zu gleichermaßen unbefriedigenden Ergebnissen führen: Wenn man einerseits die grundlegenden Werte einer Gemeinschaft ihren Sozialpraktiken ablesen will, wird man die aus diesen Werten abzuleitenden Normen kaum zugleich als kritische Folie eben dieser Praktiken verwenden können; in dem Fall, daß man die Bestimmung der Werte unter Berufung auf eine bestimmte Interpretation der Traditionen einer politischen Gemeinschaft von deren aktuellen Praktiken ablösen möchte, droht diese Interpretation nach ihren eigenen Maßstäben ihre Evidenzbasis zu verlieren, zumal sie ihren Anspruch auf Geltung eben nicht durch Rekurs auf universalistische Kriterien einlösen kann (Cohen 1986: 463 f.). Die kommunitaristische Maxime Walzer's nehme, so Cohen, notwendig einen konservativen Charakter an oder aber sie bleibe normativ leer (Cohen 1986: 466) - mithin bleibt an dieser Stelle zunächst unklar, wie Walzer den Schein einer normativ selbstgenügsamen Praxis zu durchbrechen und diese gegen mögliche moralische Regressionen abzuschirmen gedenkt.

Dies ist schließlich der Punkt, an dem der vierte Argumentationsschritt ansetzt. Denn ersichtlich kann Walzer dem schon skizzierten Einwand des >simple communitarian dilemma< nur dann entgegentreten, wenn es ihm gelingt, ein Verbindungsstück zwischen der kritischen Funktion seiner Gerechtigkeitstheorie einerseits und ihrer normativen Verankerung im Boden gesellschaftlicher Praktiken andererseits zu modellieren, das nicht aus dem Material kontingent geteilter Werte und Überzeugungen erstellt ist. Diese Funktion übernimmt dann - und das ist das vierte wesentliche Konstruktionselement der »Sphären «, in dem die eigentliche Pointe seines kommunitaristischen Ansatzes freigelegt werden kann - die Theorie der Güter, die er mit der entscheidenden Feststellung einleitet, daß alle Güter, die in den Horizont einer Gerechtigkeitstheorie treten, ihrer Natur nach soziale Güter sind, deren Güte nicht in einer ideosynkratischen Perspektive erschlossen werden kann (Walzer, 1992: 30 ff.). Diese Ausgangsbestimmung enthält nun u.a. zwei sich wechselseitig verstärkende Implikationen, die beson- 
ders hervorgehoben werden müssen. Zum einen steckt darin die Behauptung, daß distributive Praktiken nicht beliebig gegenüber der sozialen Bedeutung der zu verteilenden Güter variieren können, die sich aus der Funktion einzelner Güter in der Reproduktion des gesellschaftlichen Handlungszusammenhangs ergibt; zum anderen rückt er durch den Bezug auf die gemeinsam geteilten Überzeugungen, an denen vor allem die liberale Kritik ihren Anstoß genommen hatte und die er selbst als Ergebnis wie als Ferment eines kooperativen Prozesses begreift (Walzer, 1992: 34, Fn.), nicht so sehr einzelne Praktiken wie einen Begriff gesellschaftlicher Praxis als eines dialogischen Erzeugungszusammenhangs kollektiver Identitäten in den Blick, der dann selber einen normativen Gehalt annimmt.

b) Anders also als die liberale Kritik an dem vermeintlich entweder konservativen oder aber normativ gehaltlosen kommunitaristischen Ansatz Walzer's insinuiert, ist der Begriff der »shared understandings « nicht in erster Linie deskriptiv gemeint, sondern enthält einen rationalen Kern, der sich allerdings nicht - und das ist die wichtige verbleibende Differenz - in transzendental-spekulativer Einstellung erschließen läßt (Walzer, 1992: 62 f.). ${ }^{40}$ Vielmehr zielt er auf jene »tieferen Auffassungen, die die Widerspiegelungen jener sozialen Bedeutungen in den Köpfen von Einzelnen sind, die unser gemeinsames Leben konstitutieren (Herv. d.V.)«(Walzer, 1992: 451). Und diese Unterscheidung von »shared understandings « und »common life« (vgl. Thigpen, 1984; Downing/Thigpen, 1986 und Gill, 1987) gründet nicht in einer substantialistischen Projektion eines (des) guten Lebens, sondern in einem normativen Begriff von Demokratie. Dessen Konturen gilt es nunmehr so weit nachzuzeichnen, bis die konzeptuellen Grundentscheidungen sichtbar werden, auf denen dann Walzers im engeren Sinne politische Theorie aufbaut.

Freiheit, so Walzer (Walzer, 1984: 326), ist unter dem Regime komplexer Gleichheit ein additives Prinzip, dessen Realisierung sich nicht allein binden läßt etwa an Demokratic als Form einer breiten und möglichst gleichen Verteilung von Partizipationsrechten in der Sphäre der Politik, der Sicherung von Marktzugangschancen oder der distributiven Sicherung von Wohlfahrtsansprüchen. Vielmehr gibt er mit der Idee, daß in modernen, komplex in autonome Handlungssphären ausdifferenzierten Gesellschaften Freiheit in der Wahrung von Rechten innerhalb der einzelnen Sphären besteht, die wir nur garantieren können, wenn wir der Logik dieser Sphären folgen, offensichtlich den Gedanken auf, der Weg der Transformation moderner Gesellschaften hin auf einen Zustand größerer Gerechtigkeit ließe sich im Lichte nur eines Prinzips - und sei es dem der politischen Demokratic oder der Umwälzung des Eigentums an Produktionsmitteln - beschreiben und projektieren. ${ }^{41}$ Damit gibt er zunächst dem liberalen Prinzip der

40 Dieser Gegeneinwand Walzer's ist ganz offensichtlich an die Adresse von John Rawls gerichtet. Dieser hat indes in den 80er Jahren, wohl auch unter dem Eindruck der kommunitaristischen Kritik, in einer Reihe von Aufsätzen seine Position so weit präzisiert, daß in dieser Frage keine fundamentale Differenz mehr zu erkennen ist: vgl. Rawls (1992).

41 Diese Kritik an der Idee einer monoperspektivischen Transformation moderner Gesellschaften hat er schon früh, in einem Aufsatz über sozialwissenschaftliche Modernisierungstheorien aus dem Jahr 1964, zum Ausdruck gebracht und sie seitdem als Kernbestandteil seiner Vorstellung eines »demokratischen Sozialismus «beibehalten. Dieser Aufsatz ist wiederabgedruckt in Walzer (1980: 189-200). 
Trennungen etwa von politischer Gemeinschaft und bürgerlicher Gesellschaft oder von Öffentlichkeit und Privatsphäre, die er durchaus als evolutionäre Errungenschaften verzeichnet, so weit nach, daß Politik nicht mehr als privilegierter Ort des guten Lebens erscheint: In diesem Sinne scheint sich auch der Anwendungsbereich demokratischer Regeln wie gleiches und geheimes Wahlrecht und öffentliche Argumentation auf die Verteilung und Legitimation des Gebrauchs von politischer Macht (Walzer, 1992: $430 \mathrm{f}$.) $\mathrm{zu}$ begrenzen, ohne daß diese darüberhinaus auch als übergreifende Modi staatsbürgerlicher Selbstbestimmung ausgezeichnet wären.

Indes läßt sich an dieser Stelle eine Gegenbewegung in Walzers Denken erkennen, die nicht in der liberalen »art of separation « (Walzer, 1984) aufgeht, sich jedoch gleichfalls aus der Idee komplexer Gleichheit speist: dieses fragile Arrangement bleibt stets internen wie externen Risiken der Ausbeutung und Überdehnung von aus einzelnen Verteilungspositionen sich ergebenden Ansprüchen ausgesetzt, denen nur durch dessen Verankerung in einer gemeinsamen Lebensform entgegengewirkt werden kann. Diese Nötigung bringt sich nun im wesentlichen in drei fundamentalen und miteinander verbundenen Anforderungen an den Prozeß der Ausgestaltung und Stabilisierung dieser Ordnung komplexer Gleichheit zur Geltung. Zum einen setzt die Idee distributiver Gerechtigkeit die Konstitution einer gemeinsamen (und wie Walzer hinzufügt: begrenzten) Welt in einem kooperativen Prozeß voraus, in dem sich Menschen als gleichwertig und gleichberechtigt auch erfahren können und in dem so jene Bindungen erzeugt werden, die zugleich als Projektionshorizont individueller Rechte und Verpflichtungen fungieren können (Walzer, 1992: 65 ff.). In dieser, aus der Vorstellung eines kooperativen Prozesses erwachsenden Fassung der Zugehörigkeit zu einer (politischen) Gemeinschaft, kommt dem Begriff der »membership« von vornherein auch die normative Funktion zu, den politischen Akt der Selbstbestimmung nach innen wie nach außen abzuschirmen: nach innen gegen die egoistische Ausbeutung kooperativer Arrangements (»free rider «) und die individualistische Auszehrung assoziativer Strukturen und gemeinwohlorientierter Handlungsdispositionen (Walzer, 1990a: 16); und nach außen gegen die universalistische, aber abstrakte Überformung der in gemeinsamen Erfahrungen und Traditionen wurzelnden kollektiven Identität (Walzer, 1981: 395). In diesem Zusammenhang hebt er dann zum zweiten hervor, daß Gerechtigkeit gerade im Sinne komplexer Gleichheit sich nicht nur institutionell produzieren und reproduzieren läßt. Vielmehr bedarf sie der Verankerung in individuellen Gerechtigkeitsüberzeugungen, die ihrerseits nicht nur rational motiviert sind, sondern sich aus den affektiven Bindungen speisen, die aus der Erfahrung gemeinsamen Handelns hervorgehen - dies jedenfalls scheint der Grund zu sein, von dem her Walzer die von ihm hervorgehobene Notwendigkeit auch der symbolischen und rituellen Reproduktion gesellschaftlicher Ordnung als einer gemeinschaftlichen Lebensform erschließt (Walzer, 1992: 281 ff.). ${ }^{42}$ Drittens schließlich rechnet Walzer durchaus

42 An diesem Gedanken hält Walzer fest, auch wenn er andererseits »patriotische Fieberanfälle kritisiert, die aus der Pathologie des nationalen Republikanismus entstehen. Aber damit hat er offensichtlich lediglich eine fehlgeleitete nationalstaatliche Projektion emotionaler Bindungen im Auge, die er in subnationalen, assoziativen Strukturen besser aufgehoben sieht. Vgl. Walzer (1990c: 612 f.). 
mit interessegeleiteten und konfligierenden Auslegungen der sozialen Bedeutung einzelner Güter und damit auch mit Dissens über die einschlägigen Verteilungskriterien - gerade deshalb rekurriert er auf Toleranz und auf eine dialogische Praxis als den Formen, in denen sich eine plurale Gesellschaft vermittelt (Walzer, 1992: 441).

Auf diese Weise verbindet er den Begriff einer gemeinsamen Lebensform eng mit seinem spezifischen Verständnis des demokratischen Prinzips, nach dem es nicht nur die »familiar products of their experience « sind, »that the people value, but the experience itself, the process through which the products were produced « (Walzer, 1981: 395). Mithin bezieht sich das Konzept der »shared understandings « in den drei Gestalten seiner Auslegung, die man als konstitutiv, affektiv und prozessual kennzeichnen könnte, ganz offensichtlich auf die Vorstellung einer politischen Gemeinschaft, die sich allein im Medium von Öffentlichkeit, verstanden als dialogische Praxis, reproduzieren kann - und gewinnt seinen spezifisch normativen Gehalt gerade nicht, wie liberale Kritiker des kommunitaristischen Ansatzes bei Walzer suggerieren, aus dem Bezug auf die Muster der Reproduktion partikularer Identitäten in »dichten Gemeinschaften«, sondern aus dem Bezug auf eine in einer demokratischen Lebensform verankerten kollektiven Identität. Dieser Zusammenhang tritt gerade dort besonders deutlich hervor, wo Walzer sich mit Fragen einer angemessenen Auslegung der amerikanischen Verfassungstradition auseinandersetzt und an dem Verhältnis der ursprünglichen sieben Verfassungsartikel, die sich auf die Einrichtung der Staats- und Regierungsgewalt beziehen, zu dem später angefügten Grundrechtsteil der »Bill of Rights« die Konkurrenz eines liberalen und eines republikanischen Rechtsverständnisses stilisiert (Walzer, 1991b). Danach ist zwar von vornherein durch die »Bill« ein individualistischer Zug in die gesamte Verfassungsordnung eingebaut, weil sich die subjektiv verstandenen Rechte wie konzentrische Kreise um das »geheiligte Zentrum « des Individuums legen, um es gegen tyrannische Übergriffe der Regierung und die Ansprüche demokratischer Mehrheiten abzuschirmen - dennoch können Individualrechte als Form der äußeren Beschränkung der Regierungstätigkeit durchaus als Komplementärstück zur institutionellen Regulierung der inneren Funktionsweise der Regierung fungieren (Walzer, 1991b: 115). Walzer kommt es nun aber im wesentlichen darauf an, zu zeigen, wie dieses Komplementärverhältnis dadurch aufgebrochen wird, daß das subjektive Rechtsverständnis den Keim einer Verrechtlichungsdynamik enthält, die nicht nur zu einer Juridifizierung des politischen Prozesses führt, sondern sich in einer Selbstblockade und Selbstentmächtigung kollektiven sozialen Handelns - und damit der politischen Gemeinschaft - bemerkbar macht (Walzer, 1991b: 117 ff.). Angesichts gerade der konservativen und privatisierenden Effekte, die von einer subjektiv-rechtlich ausgelegten Rechtsordnung ausgehen, unternimmt er es deshalb, die Individualrechte in den Zusammenhang einer objektiven Rechtsordnung zurückzustellen, die auf die Wahrung der Integrität einer politisch vermittelten, demokratischen Gesellschaft hin ausgelegt ist, um so den Sinn der ursprünglichen Verfassungsordnung zu restituieren (Walzer, 1991b: 121 f.). Damit legt sich Walzer nun aber nicht nur normativ auf ein republikanisches Modell der Demokratie fest, in dem der objektive Charakter der Rechtsordnung insgesamt vermittelt ist; vielmehr verbindet er mit dieser rationalen Rekonstruktion auch den Anspruch, den allgemeinen Kern der amerikanischen Tradi- 
tion, also den tieferen Gehalt der »shared understandings «, freigelegt zu haben: »Is there anything that is so importantly general, so deeply ours (Herv. d. Verf.), that we might for its sake discourage protest, separation, and privacy? ...I want to argue that a decent society requires not only individual rights but also group solidarities and the pluralist and democratic politics that groups make possible. Democracy itself is a value sufficiently general and sufficiently ours (Herv. d.V.) to warrant state action against the long-term effects of privatization« (Walzer, 1991b: 121 und 124).

Durch den Rekurs auf jene Strukturen also, die am sozialen Erzeugungszusammenhang politischer Ordnungen hervortreten und die eine gewisse Gewähr für die Reproduktion der Prozesse bieten sollen, in denen sich eine jede Gesellschaft autonom konstituiert, unterläuft Walzer den moralischen Partikularismus und Lokalismus, von dem seine Gerechtigkeitstheorie ihren Ausgang genommen hat. Dieses Gegenüber von Universalismus und Partikularismus möchte Walzer nun allerdings nicht als einen Widerspruch auffassen, sondern als eine Spannung, die er durch die Einführung des Begriffs des »reiterativen « Universalismus aufzulösen versucht. Danach unterscheidet sich dieser von einem »covering law «-Universalismus, den er durch den Anspruch kennzeichnet, »ein Gesetz, eine Gerechtigkeit, ein richtiges Verständnis des guten Lebens oder der guten Gesellschaft oder der guten Herrschaft « auszeichnen zu können (Walzer, 1991a: 8), gerade durch »seinen partikularen Fokus und seine pluralisierende Tendenz « (Walzer, 1991a: 10). Die in unserem Zusammenhang wichtige Pointe dieser Unterscheidung liegt nun darin, daß er die Anerkennung von Pluralität an eine Art integrativer Mechanik der Anerkennung von Andersheit zurïckbindet, also an die Tätigkeit der Moralbildung als einer andauernden und strittigen Praxis: "Die größte Anforderung der Moral, das Kernprinzip jedes Universalismus, ist demnach, daß wir einen Weg finden, uns auf diese Tätigkeit einzulassen, während wir in Frieden mit anderen Handelnden leben « (Walzer, 1991a: 24).

Dieser »reiterative « Universalismus bleibt also universalistisch darin, daß die sozialen Bedingungen und politischen Strukturen der Moralerzeugung eine eigene moralische Dignität und Unbedingtheit annehmen müssen. In dieser Form stellen sie jedenfalls allgemeine Ordnungsprinzipien dar, deren Geltung keineswegs an kulturellen Grenzen in oder zwischen einzelnen Gesellschaften endet, sondern diese vielmehr übergreift - Gesellschaften mit breiter Partizipation werden von ihm gewiß als gerechter beurteilt als solche ohne (vgl. Downing/Thigpen, 1986: 457). Sie fungieren so auch intern als Maßstäbe, die Walzer nicht nur in die Kritik der liberalen »art of separation « (Walzer, 1984: 324 f.) einfließen läßt, sondern die auch auf die Selektion angemessener materialer Gerechtigkeitsprinzipien in Fragen distributiver Gerechtigkeit durchgreifen. Dabei stellt sich der Zusammenhang zwischen dem Begriff der gemeinsamen Lebensform und einzelnen distributiven Praktiken über den Begriff des Staatsbürgers (»citizen«) im Sinne einer Staatsbürgerbefähigungspolitik her; mit der Frage danach, "what must citizens provide to one another if they are to have an inclusive common life « (Downing/Thigpen, 1986: 463) löst Walzer seine Interpretation dessen, was Gerechtigkeit erfordert, durchaus von gängigen und zumindest in den USA weit verbreiteten und weithin geteilten Überzeugungen ab (vgl. Thigpen, 1984 und Downing/Thigpen, 1986). 
c) Die interne Verklammerung einer kommunitaristischen Ethik mit einem normativen Begriff von Demokratie und die darin begründete Kritik kontraktualistischer Ansätze bedeutet nun indes nicht, daß Walzer seine politische Theorie im ganzen in den Zusammenhang der Tradition des Bürgerhumanismus oder des Republikanismus stellt. Tatsächlich hält er die Vorstellung, wie sie von »stärkeren « Kommunitaristen wie Sandel, MacIntyre oder Bellah u.a. vertreten wird, für obsolet, daß die einer modernen Gesellschaft abgeforderten Integrationsleistungen sich etwa noch in der Tugend des einzelnen, die ihren Halt an einer sittlich integrierten nationalen Gemeinschaft fände, vermitteln ließe. Gerade vor dem Hintergrund zunehmender kultureller Pluralisierung und komplexer Ausdifferenzierung ist dieser Republikanismus ein Trugbild, ein nationaler Kommunitarismus nicht wirklich mehr eine Option (Walzer, 1990c: 613): statt auf Fragen der Remoralisierung der Politik und einer darauf abgestimmten Kritik des Individualismus fokussiert er seine politische Theorie auf Fragen der Effektuierung des Kerngehalts des politischen Liberalismus, dem Strukturprinzip reflexiv aufeinander bezogener institutioneller Prozesse. In diesem Sinne ist denn auch die programmatische Formel zu verstehen, die sich am Ende seiner Überlegungen zu »Civility and Civic Virtue in Contemporary America « findet: »What we cannot have, and ought not to ask of one another, under present conditions, is civic virtue. For that we must first create a new politics« (Walzer, 1980: 72).

Die Konturen, die seine politische Theorie in der Perspektive der institutionellen Ermöglichung und Effektuierung demokratisch-partizipatorischer Willensbildung annimmt, lassen sich am besten erfassen, wenn man von den Spannungen ausgeht, die in seinen normativen Begriff von Demokratie eingelassen bleiben. Diese Spannungen werden im Kern dadurch erzeugt, daß er den Prozeß unter zusätzliche Rationalitätsanforderungen stellt, die sich nicht durch das normative Prinzip der Selbstbestimmung allein verbürgen lassen: die autonome Willensbildung darf im Ergebnis weder dazu führen, daß sie die demokratischen Rechte, auf denen sie selber aufruht, etwa suspendiert (vgl. Gill, 1987: 44 ff.), noch kann sie sich einfach kontingent gegenüber den kognitiven und Expertiseanforderungen verhalten, die in der inhaltlichen Ausgestaltung materialer Politiken gründen. ${ }^{43}$ Diese formale und materiale Qualifizierung der Willensbildung (der Wille muß allgemein sein, muß wollen, was richtig ist und muß die Garantie demokratischer Institutionen und Praktiken selber beinhalten: vgl. Walzer, 1981: 384) dient also einerseits gleichsam der Einschränkung des Risikos von Demokratie, das darin besteht, »that people have a right to act wrongly «(Walzer, 1981: 385). Andererseits bleibt es mit dem demokratischen Prinzip unvereinbar, sich diese Einschrän-

43 Dem scheint zunächst zu widersprechen, daß Walzer eine Unterscheidung zwischen dem »Recht, zu entscheiden« und dem »Wissen der richtigen Entscheidung « vornimmt (Walzer, 1981: 386). Sein Punkt ist an dieser Stelle jedoch lediglich der, daß Expertise dem Prozeß der demokratischen Willensbildung nicht vorgeschaltet oder übergeordnet werden darf, sondern sich innerhalb des Prozesses zur Geltung zu bringen hat (vgl. Walzer, 1981: 396). Allerdings ist einzuräumen, daß Walzer den zweiten Strang des Arguments kaum explizit aufgenommen und ausgearbeitet hat. Weitere Hinweise in diese Richtung lassen sich jedoch vor allem in seiner Diskussion von Expertise als Kriterium der Verteilung politischer Macht und in seiner Explikation von »office« finden (vgl. Walzer, 1992: 195-243 und 403-412). 
kung nach dem Muster externer constraints vorzustellen, die sich in Gestalt eines rechtlichen Paternalismus oder eines expertokratischen Autoritarismus wie ein Filter vor die demokratische Willensbildung schieben oder diese von außen durchdringen. ${ }^{44}$ Vielmehr muß es Walzer darauf ankommen zu zeigen, wie sich die geforderte Vernunft, diesseits einer Disjunktion von Wahrheit und Demokratie, im Innern der Prozesse selbst zur Geltung bringen läßt ${ }^{45}$ - vor diesem Hintergrund zielt Walzer auf etwas, was man als institutionelle Verbesserung der Chancen rationaler Willensbildung kennzeichnen könnte.

Den Bezugspunkt für entsprechende institutionelle Reformen bildet die mit dem Prinzip demokratischer Selbstbestimmung intim verknüpfte Idee der Herrschaft der argumentativer Vernunft (Walzer, 1992: 430), die allerdings in ihrer Übersetzung in eine argumentative Praxis selbst schon eine soziale Gestalt angenommen hat. Aus dieser Konzeptualisierung ergibt sich denn auch eine erste, noch negative Bestimmung adäquater institutioneller Mechanismen in dem Sinne, daß die extreme Privatisierung der demokratischen Willensbildung und die damit verbundene Entkopplung von Argument und Entscheidung im individualisierten Wahlakt wie in einer bloßen »Knopfdruckdemokratie « zu durchbrechen wäre: »Die zufällige oder willkürliche Ausübung von Macht erzeugt keine Selbstachtung - der Grund, weshalb eine auf der Basis von Knopfdruck-Partizipation betriebene Politik moralisch unbefriedigend bleibt. Der Bürger muß willens und fähig sein, zur gegebenen Zeit gemeinsam mit seinen Mitbürgern zu beratschlagen und nachzudenken, ihnen zuzuhören und von ihnen gehört zu werden und für das, was er sagt und tut, die Verantwortung zu übernehmen « (Walzer, 1992: 438). Positiv gewendet, läßt sich von diesem Zusammenhang auf die notwendige Rekontextualisierung der Willensbildung und damit auf solche Institutionen und organisatorischen Formen schließen, die geeignet sind, die zentrale Bedeutung argumentativer Praxis auch zur Geltung zu bringen. Während Walzer an dieser Stelle noch in einer ersten Annäherung am Beispiel der Organisationsform »politische Partei« auf die Momente von »Versammlung «, wechselseitiger Loyalität und Kooperation als notwendige Fermente argumentativer, gemeinwohlbezogener Willensbildung verweist (Walzer, 1992: 433 ff.), generalisiert er diese Perspektive später zum Konzept der »intimations of community «.

Mit diesem Konzept versucht er, die von anderen Kommunitaristen immer wieder artikulierte Kritik an der selbstdestruktiven Wirkung liberaler Institutionen auf ihre eigene moralische und soziale Infrastruktur aufzunehmen, ohne im Gegenzug der Suggestion zu erliegen, daß sich der gesellschaftliche Zusammenhang etwa unvermittelt in

44 Diese Pointe scheint Gill zu verfehlen, wenn sie gegen die liberalen Kritiker Walzer`s in einer zu liberalen Lesart diese Qualifizierungen gleichsam als Einhegungen demokratischer Freiheit begreift (vgl. Gill, 1987: 44 ff.).

45 Das ist im übrigen schon deshalb unvermeidlich, weil in praktisch-politischen Zusammenhängen auch mit Wahrheitsansprüchen ausgestattete Argumente selber in die politische Auseinandersetzung hineingezogen werden: »In the political arena, the philosopher's truths are likely to be turned into one more set of opinions, tried out, argued about, adopted in part, repudiated in part, or ignored. "(Walzer, 1981: $389 \mathrm{f}$.) 
einer direkt am allgemeinen Wohl orientierten individuellen Willensbildung, also gleichsam in einem Bewußtseinsakt, wieder herstellen ließe. Demgegenüber möchte er die produktiven Elemente sowohl des liberalen Denkens wie der kommunitaristischen Kritik bewahren und so zusammenführen, daß die differenzierte Struktur und das Netzwerk gesellschaftlicher Assoziationsverhältnisse als der primäre Ort gesellschaftlicher Synthese in den Blick kommt. Dabei läßt er sich von vier Gesichtspunkten leiten: erstens haben die Kommunitaristen recht, wenn sie auf der Notwendigkeit der Rückbindung von demokratischer Willensbildung an Gemeinschaftserfahrungen insistieren; zweitens aber gehen sie fehl, wenn sie diese Kritik im Gegenzug auf die Kontrastfolie einer mit der Gesellschaft koextensiven Gemeinschaft projizieren; drittens reaktiviert er alternativ den etwas kleinformatigeren Begriff der freiwilligen Assoziation und wendet sich viertens mit der Forderung nach einer aktiven staatlichen Politik der Dezentrierung gegen die Vorstellung des Nachtwächterstaates. Was er in dieser Perspektive von der liberalen »art of separation « zurückbehält, ist der Grundgedanke der institutionellen Befestigung und Absicherung ausdifferenzierter Handlungsbereiche; was ihn an der kommunitaristischen Kritik interessiert, ist die Einsicht, daß dieses System der Trennungen nicht in individueller Autonomie wurzeln und in der Garantie individueller Rechte allein verbürgt werden kann: »... The art of separation... is rooted in and warranted by social complexity. We do not separate individuals; we separate institutions, practices, relationships of different sort...We aim, or should aim, not at the freedom of the solitary individual but at what can best be called institutional integrity « (Walzer, 1984: 325). Vor diesem Hintergrund kann er schließlich sichtbar machen, daß das selbstdestruktive Moment der liberalen Praxis in der einerseits zu schwachen und andererseits zu starken Ausführung des Prinzips der Trennungen gründet. Zu schwach sind diese Trennungen dort, wo der Fokus auf das Prinzip individueller Freiheit nur sehr poröse Grenzziehungen zwischen einzelnen Handlungsbereichen erlaubt, die z.B. durchlässig bleiben für die Konversion von Reichtum in politische Macht; zu stark wirken sich diese Trennungen vor allem in der Dualisierung von bürgerlicher Gesellschaft und Staat aus, wodurch politisch gerichtete Vergemeinschaftungsformen auf der intermediären Ebene gesellschaftlicher Assoziationen, wo nicht vollständig aus dem Blick geraten, so doch in ihrer Bedeutung unterschätzt werden.

Dies ist für Walzer denn auch der Anlaß, die »liberale Kunst der Trennungen« in eine sozialistische resp. sozialdemokratische Perspektive zu rücken (Walzer, 1984: 318 und 1990: 6). D.h. zunächst, daß die liberale Fiktion der Neutralität des Staates überwunden werden muß, weil dem Staat nun grundsätzlich die reflexive Funktion sowohl der defensiven Wahrung und Verteidigung der institutionellen Integrität unterschiedlicher Handlungsbereiche als auch der Herstellung und Absicherung assoziativer Strukuren zukommen soll (Walzer, 1984: 327 und 1990a: 17/19). Im Unterschied zur Pluralismustheorie ist dies nicht im Sinne einer unterschiedslosen Förderung mehr oder weniger privater Vereine und Gruppen zu beliebigen Zwekken zu verstehen, und im Unterschied zur Korporatismustheorie ist dies nicht aus rein stabilitätsfördernen Gründen motiviert. Vielmehr hat Walzer hier, im Anschluß an Dewey (Walzer, 1990: 19), mit freiwilligen Hilfsorganisationen, Gewerkschaften, Nachbarschaftsgruppen o.ä. solche assoziativen Kontexte im Blick, die die gesellschaftliche Fähigkeit zu koo- 
perativer Problemlösung erhöhen. Ein instruktives Beispiel findet sich in seinem Aufsatz »Socializing the Welfare State« (1988a), in dem er zeigt, wie sich durch eine engere Anbindung von staatlichen Wohlfahrtsleistungen an lokale Kontexte und die Abschwächung der Trennung zwischen Wohlfahrtsverteilern und -empfängern sowohl die nachteiligen Wirkungen von Klientelisierung wie auch bürokratische Reibungsverluste vermeiden oder doch vermindern lassen.

Andererseits bleibt er sich der Risiken auch eines reflexiv ausgelegten Etatismus bewußt. Um den Gefahren eines autoritären Paternalismus entgegenzuwirken, gewinnt Walzer schließlich seiner Konzeptualisierung reflexiver Staatstätigkeit selbst noch einmal eine demokratische Wendung ab, wenn er mit der programmatischen Formel einer »Sozialisierung der Differenzierungsfrage« den Prozeß gesellschaftlicher Ausdifferenzierung einer vermeintlichen Naturwüchsigkeit entkleidet und die Bestimmung der genauen Grenzverläufe zwischen unterschiedlichen Handlungsbereichen wie den darauf bezogenen Umfang und Zuschnitt von Staatstätigkeit in den Zusammenhang einer assoziativ vermittelten, demokratischen Selbstbestimmung zurückstellt (Walzer, 1984: 328). Und es ist dieses reflexive Strukturarrangement, das sich vielleicht am ehesten noch mit dem Begriff eines »pluralistischen Republikanismus« belegen läßt.

d) Insgesamt geht es Walzer also darum, gegen die liberale Selbstbeschränkung des Projekts der Demokratie erneut die Einsicht zur Geltung zu bringen, daß eine freiheitliche Gesellschaft sich ohne die komplementäre Entwicklung der Fähigkeit zu bürgerlicher Selbstbestimmung und Selbstregierung auf Dauer nicht stabilisieren läßt. Einen kritischen Punkt erreicht die Demokratietheorie heute aber vor allem dort, wo sie jenseits eines bloßen Prozeduralismus erweiterte Beteiligungschancen mit der Erwartung einer substantiellen Verbesserung politischer Entscheidungsprozesse verknüpft und sich gesamtgesellschaftliche Rationalisierungseffekte von der Erhöhung der Interventionstiefe diskursiv erzeugter Gründe in die staatlich-administrative Entscheidungpraxis verspricht. Auf diese Funktionsbestimmung ist denn auch zunächst Walzers Forderung nach einer Ausdehnung einer von staatlichen Institutionen abgelösten öffentlichen Sphäre (Walzer, 1980: 70) zugeschnitten. Er plädiert in sachlicher Hinsicht für eine Erweiterung sowohl der Themen wie für eine Erhöhung der Eindringtiefe in politische Entscheidungen und die Verbesserung der strukturellen und institutionellen Bedingungen, die die Herrschaft des besseren Arguments gewährleisten sollen; in sozialer Hinsicht geht es ihm um die Erhöhung der Inklusivität, also der Verbesserung der strukturellen Beteiligungschancen; in der zeitlichen Dimension schließlich wird Öffentlichkeit zu einer Dauereinrichtung, die nicht von politischen Institutionen im engeren Sinne monopolisierbar und substituierbar ist (Walzer, 1980: 70 ff.; 1981: 395 und 1984: 326 ff.).

Gemessen an diesen Ansprüchen greift Walzers Konzept des Dialogs als Medium und Ferment politisch agierender Öffentlichkeiten aber freilich schon deswegen zu kurz, weil es zu eng auf den Modus der selbstbezüglichen Reproduktion der sozialen Praxis selber bezogen bleibt. In der Folge wird der öffentliche Dialog von ihm in seinen Strukturen von kognitiven Erwartungen und Zumutungen dermaßen sentlastet<, daß kaum noch zu sehen ist, wie es möglich sein sollte, etwa im gesellschaftlichen Diskurs den »Pool ausreichend guter Gründe« (Habermas), aus denen sich die politische 
Entscheidungspraxis dann versorgen kann, in demokratische Regie zu nehmen. Das wird deutlich, wenn er in Absetzung von Habermasschen Diskursbegriff seine Vorstellung des demokratischen Diskurses als eines »real talk « präsentiert (Walzer, 1990a). Real talk, das meint, daß Einverständnis in Demokratien unwahrscheinlicher ist als in allen anderen politischen Systemen; es meint, daß die Resultate der deliberativen Prozesse so unvorhersehbar wie widersprüchlich seien können; es meint, daß eine Prämie auf rhetorische Kompetenz ausgesetzt ist; es meint, daß Debatten chaotisch und ohne rechten Beginn und Ende vonstatten gehen; und es meint, daß sie eine so unabgeschlossene wie fallible Form der Kommunikation ist, die zuweilen ohne jeden sinnvollen Effekt betrieben wird: »the give and take of the conversation, the constant interruptions of one speaker by another, make it impossible for anyone to develop a persuasive argument, and people end where they began, voting their interest or defending an entrenched ideological position« (Walzer, 1990a: 189). Real talk, so Walzer, ist »unstable and restless « und letztendlich »more radical than ideal speech« (Walzer, 1990a: 195). Den Preis, den Walzer mit seiner Zelebrierung dieser Form der Kommunikation zahlt, ist beträchtlich: Er gibt den Anspruch auf, zwischen >real talk< und - um im Bilde zu bleiben - regressiven Formen von >baby talk < überhaupt noch sinnvoll unterscheiden zu können.

Verständlich wird diese sehr zurückgenommene Form der Konzeptualisierung demokratischer Öffentlichkeit überhaupt nur dann, wenn man sie auf Walzers strikte Unterscheidung von techné und praxis bezieht. Danach bemißt sich die spezifische Kompetenz des Staatsbürgers nicht an der Beherrschung und Produktion entscheidungsrelevanten Wissens, sondern an der Fähigkeit, »eine spezielle Beziehung zu einer bestimmten Gruppe von Menschen « (Walzer, 1992: 407) aufzubauen und zu erhalten. Das ist nun auch konzeptionell nicht etwa geringzuschätzen, insofern in diese Praxis die "principles of accomodation « (Gutmann/Thompson, 1990) eingelagert sind, die wenigstens eine gewisse Gewähr dafür bieten sollen, daß Konflikte überhaupt in der Form öffentlicher Diskurse und Debatten ausgetragen werden können. Problematisch wird diese Konzeptualisierung erst dadurch, daß Walzer die Unterscheidung von techné und praxis auf die (unaufhebbare) Differenz von Experten und Laienpublikum abbildet. Damit läuft er schließlich unvermeidlich in die Falle der Disjunktion von demokratischer Willensbildung und politischer Entscheidung, von wo aus er das Phänomen einer möglichen partizipatorischen Kompensation der Rationalitätsdefizite staatlichen Handelns kaum noch in den Blick bekommen und als demokratietheoretische Herausforderung begreifen kann. 


\section{Selbstgesetzgebung oder Selbstregierung?}

Wie wir gesehen haben, läßt sich Walzer, gleichsam verführt von der »liberalen Kunst der Trennungen $\ll$, am Ende dazu verleiten, dem Bereich einer auf politische Entscheidungen spezialisierten staatlichen Politik, in dem (institutionell und konstitutionell zwar eingehegte) Techniken des Machterwerbs und -erhalts wie der Interessenpolitik dominieren, eine zivilgesellschaftliche Praxis bloß gegenüberzustellen, ohne eine gesellschaftliche Form der Rationalisierung staatlicher Willensbildung im Ernst ins Auge zu fassen. In dieser Konstellation erhält die zivilgesellschaftliche Praxis ihre besondere Gestalt durch zwei miteinander korrespondierende Bestimmungen: Zum einen ist sie funktional auf die soziale Integration kollidierender Lebensformen hin ausgelegt und verweist insofem auf einen Begriff posttraditionaler Sittlichkeit (Honneth, 1992); zum anderen übersetzt er diese ethische Perspektive in die Vorstellung einer auf wechselseitige Anerkennung spezialisierten Form einer dialogischen Praxis, aus der (im Begriff des reiterativen Universalismus) jene >Kollisionsnormen ‘ erwachsen sollen, über die sich die soziale Integration vollziehen kann und durch die individuelle und kollektive Selbstbehauptungsanspriiche hindurch müssen. Die Grenzen der Leistungsfähigkeit dieses Arrangements sind offensichtlich und treten im Gegenlicht weitergehender demokratischer Forderungen nach einer institutionellen Verankerung von Mechanismen der Selbstregierung besonders markant hervor. Sie hängen intern mit den genannten konzeptuellen und begrifflichen Grundentscheidungen zusammen und lassen sich auf die Formel bringen, daß Walzer zugleich von einem zu engen und zu > weichen Begriff von Öffentlichkeit Gebrauch macht. Zu eng ist seine Vorstellung von Öffentlichkeit, weil er die netzwerkartige Struktur räumlich, sachlich und sozial differenzierter Öffentlichkeiten, ihre unterschiedlichen Funktionen, aber auch Überlappungen nicht in den Blick bekommt - schon dadurch verschenkt er m.E. Einsichten, die demokratietheoretisch fruchtbar zu machen sind. Zu >weich < ist seine Vorstellung, weil der von ihm favorisierte Kommunikationsmodus des »Dialogs « die argumentativen Züge vermissen läßt, die die gesellschaftliche Praxis mit der zusätzlichen Aufgabe einer problemlösungs- und entscheidungsbezogenen politischen Willensbildung vermitteln könnten. Dieses rationale Moment kommunikativer Praktiken ist aber nicht nur ein Reflex diskursiver Politik, sondem der »zwanglose Zwang des besseren Arguments « (Habermas) scheint darüber hinaus ein irreduzibles Ferment einer nicht mehr im ganzen über sittliche Orientierungen und individuelle, sozio-moralische Kompetenzen integrierbaren »politischen Gesellschaft«. Deshalb müssen gerade in demokratietheoretischer Hinsicht an beiden Grundentscheidungen Walzer's Korrekturen vorgenommen werden. Dem dienen die folgenden Überlegungen, mit denen ich in zwei Schritten zunächst einen Begriff »starker Öffentlichkeiten « herausarbeiten möchte (1), bevor ich mich dem Versuch von Habermas zuwende, der normativen Idee der demokratischen Selbstbestimmung im Modell deliberativer Politik einen angemessenen Ausdruck zu verleihen (2). 


\subsection{Zum Begriff politischer Öffentlichkeit}

Man wird heute kaum davon ausgehen können, daß sich die alltagssprachliche Verwendungsweise des Wortes Öffentlichkeit aus einem klar konturierten Begriff ergibt, der es erlaubte, die sich damit verbindenen Phänomene, Assoziationen und Erwartungen etwa in einem normativ und funktional ausgewiesenen wie institutionell, organsisatorisch und sozialstrukturell spezifizierten Konzept zu integrieren. Vielmehr scheinen die Konnotationen, die sich einstellen, zum Teil nur noch sehr locker verbunden mit dem aufklärerischen Kerngehalt einer in öffentlicher Argumentation vermittelten, kollektiven Willensbildung, die sich auf die Rationalisierung von Herrschaft beziehen sollte. Das gilt einerseits für die Unterscheidung von >privat< und >öffentlich $<$ und damit den Bezug auf `öffentliche Angelegenheiten<, die Vorstellung eines offenen, durch keinerlei soziale Barrieren verstellten Kommunikationszusammenhangs, die einer massenmedial verwalteten und häufig genug rein selbstbezüglichen Proliferation von »kommunikativen Kunstprodukten« (Sarcinelli 1990: 48) gegenübersteht. Und es gilt andererseits auch für die Kontrastierung der Idee der Publizität mit dem Phänomen einer querschnittig angelegten, diffusen und kognitiv relativ anspruchsarmen >öffentlichen Meinung<. Diese Unentschiedenheit ergibt sich ganz offensichtlich aus einer Spannung zwischen empirischen Beobachtungen und normativen Erwartungen, die es unklar erscheinen lassen, ob und wo ein anspruchsvoller Begriff von Öffentlichkeit »überhaupt einen Gegenstand findet « ${ }^{46}$ oder ob und wie weit die soziologisch beschreibbare Wirklichkeit von Öffentlichkeit zu jener ursprünglichen und immer wieder

46 So Gerhards/Neidhardt (1990: 5) in einer kritischen Wendung gegen den Habermasschen Begriffsgebrauch, der sich vor allem durch »eine nie aufgegebene Konfundierung empirischer und normativer Elemente« auszeichne. Insofern kann man auf der Grundlage empirischer Studien zu staatsbürgerlichen Einstellungen und Kompetenzprofilen oder mit Bezug auf die Wahl- und Medienforschung, die vor allem in den USA eine bis in die zwanziger Jahre zurückreichende Tradition haben (Lippmann, 1965) und eine Reihe von Daten und Einsichten erbracht haben, die gegen eine normative Überanstrengung der Idee der Öffentlichkeit sprechen, einige Gründe beibringen, die gegen eine allzu enge institutionelle Auslegung der Idee der Demokratie am Ideal der allgemeinen Partizipation sprechen. Andererseits bleibt es auch angesichts dieser eindrucksvollen Leistungen sehr die Frage, inwieweit die erhobenen Daten auf die theoretisch interessanten Fragen wirklich antworten. Diese gewiß triviale Feststellung sollte indessen Grund genug sein, zu versuchen, dem Phänomen demokratischer Öffentlichkeit(en) in einer engeren konzeptuellen Verzahnung normativer Argumente, theoretischer Konstruktionen und empirischer Forschung genauer nachzugehen. Genau dieser Anstrengung haben sich jüngst die in dem von Marcus und Hanson (1993) herausgegebenen Band versammelten Autoren unterzogen, mit einem vielleicht auch die empirische Forschung provozierenden Ergebnis: "Those content with bleak conclusions (aus dem nachweisbaren Desinteresse, der generellen Uninformiertheit und geringen staatsbürgerlichen Motivierung des durchschnittlichen Amerikaners, der Verf.) seem to us sadly mistaken about the problems and possibilities of democratic politics. Theories of democracy that focus on preference aggregation or the pluralistic clash of interests are portraits of a polity in trouble, not any kind of ideal worth affirming. The real hope lies in reforming our politics and practices, not in lowering our aspirations. Given what passes for democratic debate these days, we shouldn't be too surprised by the bleak empirical findings - by the clouds of disillusioning facts. Still it is not difficult to discern patches of blue sky, and not utopian to press for more (Kinder/Herzog, 1993: 373). 
aktivierten Idee aufschließen kann. Deshalb möchte ich zunächst einige neuere mediensoziologische Befunde Revue passieren lassen, die geeignet sein könnten, erste Korrekturen am Bild einer sich dem emphatischen Modell von Öffentlichkeit vollständig entziehenden Wirklichkeit der sich nach eigenen Gesetzen herausbildenden und reproduzierenden Medienöffentlichkeit anzubringen - interessant sind dabei in erster Linie solche empirischen Forschungen, die einen explizit heuristischen Gebrauch vom normativen Modell machen (a). ${ }^{47}$ Damit verlieren auch jene Ansätze an Plausibilität, die, gestïtzt auf allgemeine gesellschaftstheoretische Annahmen u.a. der Systemtheorie, die Relevanz normativer Elemente von Öffentlichkeit durch theoretische Annahmen und begriffliche Vorentscheidungen ausschließen oder aus dem Blick rücken - auch eine soziologische Theorie des Öffentlichkeitssystems muß der Tatsache einer Pluralität von Öffentlichkeitsformen, der Vielfalt des Medienangebots und der differenzierten Nutzung dieser Formen und Angebote im Prozeß der öffentlichen Meinungs- und Willensbildung Rechnung tragen (b). Vor diesem Hintergrund läßt sich dann auch der starke Gebrauch, den ich vom Konzept politischer Öffentlichkeiten machen möchte, rechtfertigen und gegen eine Konzeptualisierung von Öffentlichkeit im Sinne »schwacher Öffentlicheiten ${ }^{48}$ absetzen (c).

a) Der normative Gebrauch von Öffentlichkeit ist von der Erwartung bestimmt, daß es eine Sphäre gibt, in der sich die Mitglieder einer demokratischen politischen Gemeinschaft versammeln, um in ungezwungener, argumentativer Meinungs- und Willensbildung die im gemeinsamen oder allgemeinen Interesse dieser Gemeinschaft liegenden Angelegenheiten zu beraten und so zu entscheiden, daß sich die Orientierung am gemeinsamen Wohl aller gegen die bloß privaten Interessen einzelner durchsetzen kann. Dieser allgemeinen Funktionsbestimmung entsprechen die besonderen Kommunikationsformen, die den öffentlichen Raum konstituieren: Unter dem Gesichtspunkt von Gleichheit und Reziprozität wird der Zugang zur öffentlichen Kommunikation von Herkunft, Status, Vermögen, Ämtern, Bildungsqualifikationen abgelöst und einzig an die Kompetenz, sich in der Öffentlichkeit verständlich zu äußern, gebunden; entsprechend sollen keine Themen und Beiträge prinzipiell ausgeschlossen sein und ein Zwang wird lediglich bezüglich der Art ihrer Behandlung ausgeübt - er soll die sachliche Angemessenheit der Thematisierungsweisen verbürgen; darauf ist denn auch die Forderung nach einer dialogischen und diskursiven Struktur berechnet, die sicherstellen soll, daß die Akzeptanz von Problemdefinitionen und Lösungsvorschlägen nurmehr über den Gehalt von Argumenten vermittelt wird und sachliche Dissense nicht mit persönlichem Achtungsentzug quittiert werden (vgl. Peters, 1994: 46 f.).

Anders als Luhmann (1990: 172 f.) in seinem privatistischen Verständnis des Gebrauchs öffentlicher Kommunikationsfreiheiten unterstellt, wird man der Systemreferenz von Öffentlichkeit auf Gesellschaft nicht gerecht, wenn man die öffentliche Meinungsbildung ins-

47 Einen guten Überblick über den Stand der soziologischen Forschung zum Bereich Öffentlichkeit und öffentliche Meinung bietet neuerdings Neidhardt (1994).

48 Diese Unterscheidung von »strong « und »weak publics« findet sich bei Fraser (1992). 
gesamt als ein »Kommunikationsnetz ohne Anschlußzwang « konzipiert. ${ }^{49}$ Dieses normativ vollständig ausgebleichte Verständnis, mit dem Luhmann sich anschickt, wenigstens etwas aus der Tradition des Begriffs für die moderne Gesellschaftstheorie zu retten, verfehlt auch den funktionalen Sinn von Öffentlichkeit unter komplexen Bedingungen - nämlich den Adressatenkreis von politisch relevanten Informationen und Themen über den engen Kreis institutioneller Akteure hinaus zu erweitern und die Produkte einer aufgeklärten öffentlichen Meinungs- und Willensbildung als Legitimationsressourcen und Rationalisierungsreserven in die im engeren Sinne politische Entscheidungsfindung zurückzuspeisen. Das setzt umgekehrt allerdings voraus, daß die Chancen der Herausbildung relevanter und kommunikationsfähiger Öffentlichkeiten und der Übernahme jener Aktivitäten, die mit der Publikumsrolle verbunden sind (also etwa: Veranstaltungen aufsuchen, Medien nutzen, Sprechern Aufmerksamkeit zuwenden und Beiträge aufnehmen und verarbeiten - vgl. Neidhardt, 1994a: 317) besser erfaßt und ausgebaut werden. Dem scheinen die Kommunikationsbedingungen in heutigen Gesellschaften nun nicht unbedingt entgegenzukommen, und entsprechend beziehen sich Zweifel am normativen Modell sowohl auf mögliche trade-offs zwischen den einzelnen Anforderungen des Modells (etwa der zwischen gleicher Teilnahme und kompetenter Meinungsbildung - vgl. Peters, 1994: 51, Fn. 6) wie auf solche Einflußgrößen, die den Raum der Öffentlichkeit einengen oder intern fraktionieren könnten. Solche Gleichgewichtsstörungen im System öffentlicher Kommunikation können sich nun grundsätzlich aus drei Quellen speisen: Hinsichtlich der Gleichheitsforderung kann man etwa Asymmetrien in den Kommunikationsverhältnissen (i) ausmachen, die aus der ungleichen Verteilung der Chancen resultieren, sich vernehmbar zu machen, mit der eigenen Stimme auch Einfluß auszuüben und ihr durch den Rückgriff auf das erforderliche Wissen, das selber allerdings ungleich verteilt ist, auch das nötige Gewicht zu verleihen (Peters, 1994: 52); davon sind Einflüsse aus der gesellschaftlichen Umwelt von Öffentlichkeit zu unterscheiden (ii), die sich in Gestalt sozialer Stratifikations- und politischer Machtstrukturen zur Geltung bringen (Peters, 1994: 54 ff.); schließlich ist die interne Differenzierung und Stratifikation des Publikums mit der herausgehobenen Funktion von repräsentativen Sprecherrollen, Experten, Advokaten artikulations- und organisationsschwacher gesellschaftlicher Interessen und öffentlichen Intellektuellen in Rechnung zu stellen (Peters, 1994: 56 ff.), die ihre Reproduktionsbasis zu einem nicht geringen Teil im System der Massenmedien (Peters, 1994: 58 f.) hat, das aus darstellungs- und vermittlungstechnischen Gründen einen großen Bedarf an solchen öffentlichen Akteuren hat, die durch Prominenz und Prestige (vgl. Neidhardt, 1994a: 322 ff.) aus dem Strom der öffentlichen Meinungsbildung herausgehoben sind (iii).

Nun sollte man sich freilich die genaue Einschätzung der Chancen einer anspruchsvollen und inklusiven öffentlichen Meinungs- und Willensbildung auch unter Bedingungen einer hohen sachlichen Komplexität der Themen, der sozialen Heterogenität des Publikums

49 Auch wenn es dazu manchen Anlaß geben mag, etwa wenn man an jene monologischen Verlautbarungskommunikationen denkt, die sich medien- und vor allem fernsehgerecht so schön umsetzen lassen: hier scheinen medienspezifische Produktions- und Nutzungsformen eine Tendenz zur monadologischen Selbsteinkapselung von öffentlichen Akteuren und Publikum hervorzubringen oder zumindest zu akzentuieren. 
und der Fragmentierung der Öffentlichkeit in plurale Teilöffentlichkeiten nicht durch den Blick auf die Gesetze des Systems der massenmedial vermittelten Öffentlichkeit verstellen lassen. Auch die Massenmedien sind nur Teil einer insgesamt vielschichtigen Form der Organisation von Öffentlichkeit (darauf komme ich unter b) zurück), und sie werden zudem in ihrer Relevanz für die Meinungsbildung in politischen Fragen wie in ihrer Wirkungstiefe häufig genug überschätzt. Aus diesem Grund ist Kriesi denn auch am Beispiel der Willensbildung im Rahmen direkt-demokratischer Volksabstimmungen in der Schweiz der Frage genauer nachgegangen, »inwiefern die Medien die Qualität der politischen Beratschlagung der Bürger im Vorfeld der Volksabstimmungen beeinflussen « (Kriesi, 1994: 234), wobei diese Studie in unserem Zusammenhang ein besonderes Interesse schon deshalb verdient, weil sie sich explizit vom Ideal der deliberativen Demokratie leiten läßt und damit den Annahmen des normativen Modells von Öffentlichkeit auch eine heuristische Funktion zuweist. Insgesamt findet er wenig Anhaltspunkte für pessimistische Annahmen über eine grundlegende, mediengesteuerte Transformation der Öffentlichkeit und deren Konsequenzen für die Qualität der staatsbürgerlichen Meinungs- und Willensbildung und kann eine Revision gängiger diesbezüglicher Einschätzungen einleiten, die sich aus der stärkeren systematischen Berïcksichtigung von drei Bündeln von Faktoren ergibt: Nachfrageseitig hängen die Einflußchancen von Medien stark von der individuellen staatsbürgerlichen Kompetenz und der Ausprägung genereller politischer Identitäten ab - je kompetenter der Staatsbürger und je festgefügter seine politische Identität, umso weniger ist die individuelle Meinungsbildung durch Manipulationsversuche über die Medien zu beeinflussen (Kriesi, 1994: 240); auf der Angebotsseite nötigt schon die Pluralität der Medien und die Vielschichtigkeit der Informationsangebote zu einem selektiven Zugriff - dabei ergibt sich erstaunlicherweise, daß die »Hitliste der Medien« vom redaktionellen Teil der Presse, gefolgt von Fernsehen und Radio, offiziellen Broschüren, Standaktionen und >direct mailing a angeführt wird (Kriesi, 1994: 247); während schon dies darauf schließen läßt, daß sich qualitative Unterschiede im Informationsangebot auch in der Nutzungshäufigkeit niederschlagen, wird dieser Zusammenhang drittens noch durch die selektive Wirkung von Themen, die je nach dem Grad der Komplexität und ihrer »Alltagsferne« einen unterschiedlichen Informationsbedarf auslösen (Kriesi, 1994: 241), verstärkt. Vor diesem Hintergrund kann es kaum noch überraschen, wenn Kriesi bezüglich der Größenordnung von Medieneinflüssen auf die staatsbürgerliche Willensbildung feststellt, daß sie ganz allgemein sehr begrenzt sind und zudem kein einziges Medium, unabhängig vom Thema, einen stetigen, signifikanten Effekt erreichen kann (Kriesi, 1994: 253). Im Gegenteil zeigt sich, daß sowohl die oft gegen das normative Modell von Öffentlichkeit in Anschlag gebrachte Agenda-Hoheit der Medien übertrieben als auch deren meinungsprägende Wirkung überschätzt wird. ${ }^{50}$ Sie

50 So hält Brosius (1994: 279) als Ergebnis einer Überblicksstudie zur Agenda-Setting-Forschung fest, daß »die Medienagenda ... die Rezipientenagenda für einige Rezipienten (beeinflußt) , für andere nicht; bei einigen Themen, bei anderen nicht; zu einigen Zeitpunkten, zu anderen nicht (Herv. i.O.) «. Und Kriesi (1994: 255) kann in Beantwortung der Frage, auf welchem Wege dann letztlich die Meinungsbildung und Entscheidungsfindung der Bürger sich vollzieht, auf eine Umfrage nach der schweizerischen Abstimmung zum EWR-Abkommen am 6. Dezember 1992 verweisen, aus der hervorgeht, daß die Medien überhaupt nur für knapp ein Fünftel der Bevölkerung die hauptsächliche Einflußquelle darstellen. 
scheinen weniger als Gesprächsaktivitäten im persönlichen Umfeld, innerhalb »interpersonaler Netzwerke«, kognitive Wirkungen zu stimulieren und Einstellungen zu prägen, wobei es mehr als das Agenda-Setting durch die Massenmedien die individuelle Relevanz (»issue salience $\ll$ ) und die öffentliche Bedeutung von Themen (»community salience $\ll$ ) sind, die auch die Bereitschaft bestimmen, sich der Anstrengung deliberativer Praktiken auszusetzen (vgl. Schenk/Rössler, 1994: 293).

b) In dieser Perspektive haben die folgenden Überlegungen zunächst den Sinn, zu zeigen, $\mathrm{daß}$ das von Gerhards und Neidhardt ${ }^{51}$ vorgeschlagene kompakte, systemtheoretische Modell von Öffentlichkeit als eines relativ anspruchs- und voraussetzungslosen Kommunikationssystems (18) am Ende auf Grenzen stößt, die sichtbar machen, daß die korrespondierende, dominierende Form von Medienöffentlichkeit über sich hinausweist. Der Bezugs- und Ausgangspunkt dieses Modells ist die funktionale Ausdifferenzierung modemer Gesellschaften und die damit verbundene Frage nach dem Sinn, den Grenzen und möglichen Dysfunktionalitäten einer derartig hochgetriebenen Spezialisierung und selektiven Steigerung von (zum Teil inkompatiblen) Handlungsrationalitäten. Genauer: wenn man mit Gerhards/ Neidhardt davon ausgeht, daß eine der Möglichkeiten der Rückbindung und Reintegration funktional spezialisierter Handlungssysteme in der komplementären Institutionalisierung von Experten- oder Leistungsrollen einerseits und Klientenrollen andererseits (oder in wirtschaftlicher Analogie: von Produzenten- und Konsumentenrollen) besteht, dann bedarf es eines Handlungssystems (ökonomisch: der Markt), in dem sich die mit den Rollen gesetzten Verhaltensmuster durchdringen und so eine Zone der Interpenetration entsteht, in der über einen speziellen Mechanismus (im Markt: der Preis) Informationen entstehen, die für die Akteure in den komplementär ausdifferenzierten Handlungssystemen verwendbar, d.h. anschlußfähig, sind (8). Eine solche marktanaloge Funktion soll nun nach Überzeugung von Gerhards und Neidhardt das zwischen Politik und (Wahl-) Bürger sich ausdifferenzierende System der Öffentlichkeit übernehmen. Dabei ist in Rechnung zu stellen, daß das politische System aufgrund seiner gegenüber anderen Teilsystemen herausgehobenen Stellung, die aus der Spezialisierung auf die Bearbeitung von Externalitäten und den Möglichkeiten der Steuerung resultiert, sowohl besonders kontrollbedürftig (9) als umgekehrt auch erwartungssensibel ist: es ist (zumindest unter konkurrenzdemokratischen Bedingungen) in seiner Eigenreproduktion auch auf die Generierung extemer Ressourcen in Gestalt von Wählerstimmen und allgemeiner Zustimmung angewiesen. Mithin kommt der Öffentlichkeit selbst noch in ihrer Instrumentalisierung als »Beobachtung von Beobachtern « (Luhmann, 1990) in einem rekursiv geschlossenen politischen Machtsystem die Funktion eines Dependenzunterbrechers zu - die Beobachtung von Beobachtern hat einen systemischen Reproduktionswert nämlich nur dann, wenn die dabei gewonnenen Informationen in eine Adjustierung der politischen Handlungsprogramme auch umgesetzt werden (10 ff.).

In dieses Schema lassen sich dann alle weiteren Bestimmungen von Öffentlichkeit bezüglich ihrer Topographie, ihrer speziellen Funktionen und der darauf bezogenen Strukturmerkmale relativ problemlos eintragen: sie wird vorgestellt als ein thematisch

51 Gerhards/Neidhardt (1990). Die folgenden Seitenangaben (in Klammern) beziehen sich auf diesen Text. 
und sozial nicht abgeschlossenes, reines Kommunikationssystem, das sich zwischen Gesellschaft und Politik schiebt und nach beiden Seiten Orientierungs- und Kontrollfunktionen übernimmt, indem es eine ganz bestimmte Art von Wissen: nämlich öffentliche Meinung, erzeugt (12). Es ist denn auch dieser Begriff der öffentlichen Meinung, der so etwas wie den konzeptionellen Angelpunkt des vorliegenden Modells darstellt, indem er Anlaß gibt, die Erzeugungsregeln und sozialen Produktionszusammenhänge eines Wissens herauszuarbeiten, das nicht auf Wahrheit oder Vernunft abstellt, sondern auf Allgmeinheit i.S. einer Verbreitungs-, und d.ll. Resonanzfähigkeit (17 ff.), die ihrerseits einen technisch-organisatorischen und einen sozialen Aspekt hat. Unter dem erstgenannten Aspekt erweist sich dann die massenmedial hergestellte Öffentlichkeit als ein »relativ geschlossenes und damit unsensibles System « (24), das ständig Entscheidungen über Zugehörigkeit, Aufgabenverteilung und Autoritätsstrukturen trifft (29) und sich somit insbesondere über die Ausdifferenzierung von Darsteller- und Publikumsrollen wie die Installierung von "Gatekeeper-Rollen " (31) hierarchisch als grenzerhaltendes System reproduziert (30 ff.). Diese paradoxe Leistung eines auf Kommunikation spezialisierten Systems wird zudem gestützt durch die eigentümliche Art der Themenselektion, die vor allem über die Antizipation durchschnittlicher (und dabei selber konventionalisierter) Publikumswünsche gesteuert wird (Böckelmann 1975: 63 f.) und somit Themen präferiert, die sich in die Normalitätserwartungen und allgemeinen Deutungsraster »einhaken « lassen (41). Kurz: Massenmedial hergestellte öffentliche Meinung wirkt wie ein Selektionsfilter vor den autonomen Willens- und Meinungsbildungsprozessen sowie den damit gesetzten Vernunftansprüchen; und gerade darin soll, folgen wir den Autoren, die eigentliche, wenn auch paradoxe Leistung dieses evolutionär gegenüber schwächer institutionalisierten, aber offeneren Formen von Öffentlichkeit wie dem »encounter « (20 ff.) oder der »öffentlichen Veranstaltung « (22 ff.) in Führung gehenden Systems beruhen. ${ }^{52}$

52 Mittlerweile hat Gerhards auch den Typus der "Veranstaltungsöffentlichkeit « einer empirischen Untersuchung unterzogen. Auf den ersten Blick sind auch hier die Ergebnisse nicht besonders ermutigend, denn es zeigt sich, daß diese Form (im Vergleich zur Wirkungsbreite massenmedial hergestellter Öffentlichkeit) kleiner Öffentlichkeiten nach den Umfragedaten insgesamt nicht mehr als $15,2 \%$ der Befragten überhaupt erreichte und die Anzahl der Besucher in $62,7 \%$ der Fälle geringer als 101 Teilnehmer gewesen ist (Gerhards, 1992: 767). Nimmt man die hohe Selektivität dieser Öffentlichkeitsform bezüglich der Nachfrager - »Die Männer und höher Gebildeten, die Erwerbstätigen und die Mitglieder der Oberschicht, die neue Mittelschicht und die Personen, deren Bildung überproportional über ihrem Einkommen liegt...sind als Besucher öffentlicher Veranstaltungen deutlich überrepräsentiert « (768) - und die Zentrierung auf institutionalisierte Akteure der Interessenvermittlung (Verbände und Parteien) auf der Angebotsseite hinzu (773), wird deutlich, daß sie kaum als angemessene Organisationsform einer breiten, diskursiven Meinungs- und Willensbildung gelten können.

Auf den zweiten Blick könnte aber gerade in der 'Tatsache, daß »linke und postmaterialistische Interessenorganisationen « hier eine gewisse Marktführerschaft erlangt haben, einen Hinweis darauf enthalten, daß darin Möglichkeiten einer basisnäheren Meinungsbildung erschlossen werden können, die eine der Möglichkeiten darstellt, über die man durchaus Einfluß auf den politischen Entscheidungsprozeß nehmen kann (775). 
In ihrem Kern ist uns diese Botschaft natürlich vertraut, und es gibt keinen Anlaß, den (soziologischen) Boten für den Inhalt der Botschaft abzustrafen - wenn sie denn wahr wäre und wir es nicht auch mit einer ansatzspezifischen Vereinseitigung und teilweisen Verstellung des Gegenstandes zu tun hätten. Hier stellen sich aber nun Schwierigkeiten ein, die sich an internen Konstruktionsproblemen des Modells in drei Punkten wenigstens andeuten lassen:

- Zwar weisen die Autoren mit ihrer Unterscheidung von drei institutionellen Formen von Öffentlichkeit (Encounter, Versammlung und Massenmedien) selbst auf die interne Differenzierung des Gegenstandes hin. Aber sie schöpfen, obwohl sie im Prinzip von einer »Gleichrangigkeit « (25) dieser Formen ausgehen, das darin angelegte Deutungspotential $\mathrm{m}$.E. vor allem deshalb nicht aus, weil sie diese unterschiedlichen Formen als Ebenen der Erzeugung öffentlicher Meinung in eine hierarchische Ordnung bringen, die sich insgesamt aus den Eigengesetzlichkeiten massenmedialer Öffentlichkeit speist. Nun gibt es zwar Indizien dafür, daß sich der interne Zusammenhang von Öffentlichkeit auch über das Eindringen der o.g. Publizitätsregeln in primär stärker kommunikativ und diskursiv strukturierte Arenen herstellt. Aber es scheint dennoch unplausibel anzunehmen, daß sich Meinungsbildungsprozesse in dem Sinne > vertikalisieren< ließen, daß sie sich von dichteren Kommunikationstrukturen und den darin angelegten Rationalitätspotentialen vollständig abkoppeln ließen. Freilich geriete dann die Vorstellung einer im ganzen als System aufzufassenden Öffentlichkeit in Gefahr, und man müßte den Blick stärker auf Institutionen und Mechanismen richten, die eine intern nach unterschiedlichen Logiken differenzierte Öffentlichkeit vermitteln.

- Der zweite, damit zusammenhängende problematische Punkt wird sichtbar, wenn man von dem Postulat ausgeht, daß öffentliche Meinung auch Effekte auf das politische System haben soll, die sich idealerweise in einer Übersetzung von Informations- und Meinungssynthesen in Entscheidungen ausdrückt (14). Nun ist natürlich gerade nicht zu erwarten, daß die informationsarme Form einer im o.g. Sinne generaliserenden Meinungssynthese eine besondere Eindringtiefe in administrative Entscheidungsprozesse bezüglich Problemwahrnehmung und -bearbeitung hätte. Das tun natürlich auch die Autoren nicht - das Problem ist indes, daß unter diesem Gesichtspunkt die Funktionsbestimmung und die Strukturanalyse nicht besonders gut aufeinander abgestimmt sind: diese interne Spannung ließe sich nur auflösen, wenn man die in den letzten Jahren vielfältig entstandenen Formen einer partizipativen Bürgerkultur als wesentliche Teile von Öffentlichkeit stärker in den Mittelpunkt rückte.

- Dies verweist schließlich insgesamt auf die Notwendigkeit, die Organisationsformen institutionell vernachlässigter Meinungen (Böckelmann, 1975: $71 \mathrm{ff}$.) stärker einzubeziehen. Darauf verweisen am Ende Gerhards und Neidhardt zwar selber; aber entgegen der Anregung, dies als einen Wechsel von einem anspruchslosen in ein relativ anspruchsvolles Handlungssystem zu konzipieren (48) und sich so auf die Proliferation von Bereichstheorien der Öffentlichkeit einzustellen, wären diese Aspekte in einem qualifizierteren Modell zu integrieren. 
Will man die sich aus dieser Sichtweise erschließenden Möglichkeiten konstruktiv nutzen, ist allerdings das ohnehin diffus bleibende Bild einer massenmedial beherrschten politischen Öffentlichkeit in zweierlei Hinsicht zu ergänzen. Zum einen wird man der Tatsache Rechnung tragen müssen, daß Politik im Modus staatlich-administrativer Routinen nur einen geringen Aufmerksamkeitswert für massenmediale Berichterstattung besitzt und daß zudem die Aufmerksamkeitsspannen in der Regel zu kurz sind, um Entscheidungsverläufe so zu verfolgen, daß punktgenaue öffentliche Interventionen in die Entscheidungsroutinen angeregt und vermittelt werden könnten. Deshalb wird die Beantwortung der Frage nach dem massenmedial vermittelbaren Einfluß auf politische Entscheidungen nicht zuletzt auch von Charakter oder Typus dieser Entscheidungen abhängen, ohne daß der relative Medienwert schon eine verläßliche Auskunft über die politische Bedeutung des jeweiligen Entscheidungs- resp. Politiktypus beinhaltet: während »regulative« und »distributive« Politiktypen (also Regulierungen mit geringen Eingriffen in die bestehende Rechtslage oder einfache Leistungsgesetze) in aller Regel nur wenig Aufmerksamkeit der Medien auf sich ziehen dürften, ist das bei »prohibitiven«, »extensiven« oder »redistributiven« Maßnahmen, die sich auf eine Einschränkung oder Ausweitung geltender Rechte oder auf eine Umverteilung von Leistungen und Einkommen beziehen, anders (vgl. von Beyme, 1994: 332 f.) - aber auch in diesen Fällen kann man weder von einer Agenda-Dominanz der Medien noch von ihrer Meinungsführerschaft ausgehen, vielmehr werden sie auch hier im günstigsten Fall katalytische Funktionen für dic Ausbildung relevanter Öffentlichkeiten im Sinne spezifischer policy-communities ausüben. Und das führt zu einem zweiten wichtigen Punkt, weil man zum anderen davon ausgehen muß, daß die politische Öffentlichkeit selber keine homogene Organisationsform ausbildet, sondern, wie auch Habermas hervorhebt, als ein hochkomplexes Netzwerk aufzufassen ist, »das sich räumlich in eine Vielzahl von überlappenden internationalen, nationalen, regionalen, kommunalen, subkulturellen Arenen verzweigt; das sich sachlich nach funktionalen Gesichtspunkten, Themenschwerpunkten, Politikbereichen usw. in mehr oder weniger spezialisierte, aber für ein Laienpublikum noch zugängliche Öffentlichkeiten...gliedert; und das sich nach Kommunikationsdichte, Organisationskomplexität und Reichweite nach Ebenen differenziert « (Habermas, 1992: 452; vgl. auch Peters, 1994: 56). Damit bringt Habermas zwei wesentliche Aspekte moderner Öffentlichkeitsstrukturen bereits auf den Punkt, die im weiteren Gang der Argumentation noch eine entscheidende Rolle spielen werden: daß sich die Wirkungsbreite und -tiefe politischer Öffentlichkeiten durch funktionale Spezifizierung (und allerdings auch: bessere Institutionalisierung schon auf gesellschaftlicher Ebene) wesentlich verbessern läßt; und daß sich ein derartig modular aufgebautes, überlappendes, netzwerkartig integriertes und wechselseitig durchdringendes System politischer Öffentlichkeiten nicht von einer medial hergestellten Öffentlichkeit monopolisieren und durch deren Imperative kolonisieren läßt.

Das Problem der Öffentlichkeit liegt unter diesen Voraussetzungen nicht in der Unangemessenheit der normativen Erwartungen an sich, die sich mit der Idee der Publizität, der rationalisierenden Wirkung deliberativer Strukturen der Meinungs- und Willensbildung also, einstellen. Es liegt vielmehr in der räumlichen, zeitlichen und sachlichen Konzentration solcher Verfahren und in der Gewährleistung der anspruchsvollen 
motivationalen Voraussetzungen, unter denen eine diskursive, problembezogene Willensbildung zustande kommen kann. In beiderlei Hinsicht stellen Institutionalisierungen eine wesentliche Ressource dar, was indirekt auch durch Gerhards (1993) bestätigt wird, wenn er mit Blick auf Fragen der Entwicklung einer europäischen Öffentlichkeit resp. der Europäisierung nationaler Öffentlichkeiten institutionelle Anreizstrukturen in den Vordergrund rückt, die die Anstrengungen einer öffentlichen Meinungsbildung zu prämiieren hätten. M.a.W., es müssen institutionelle Kontexte geschaffen werden, die ausreichende Wirkungschancen für Öffentlichkeit vermitteln und insofern als Kristallisationskerne fungieren, die Öffentlichkeit anziehen und die Bildung spezialisierter Öffentlichkeiten nach sich ziehen. So stellt Gerhards mit Blick auf Europa, aber in durchaus generalisierbarer Perspektive fest: »Will man eine Europäisierung der nationalen Öffentlichkeiten herstellen, dann bedarf es institutioneller Reformen (Herv. d. Verf.), in der Hinsicht, daß die Entscheidungsträger unmittelbarer an die Bürger gekoppelt werden. Eine Europäisierung der nationalen Öffentlichkeiten wird dann gleichsam zwangsläufig eintreten « (Gerhards, 1993: 108).

Das Partizipationspotential, das thematisch spezialisierte Teilöffentlichkeiten im Gegensatz zu einer undifferenzierten großen Öffentlichkeit strukturell eröffnen, läßt sich nur durch institutionelle Arrangements auch aktualisieren, die die Anwendungsbedingungen diskursiver Prinzipien verbessern und die öffentliche Willensbildung und politisch-administrative Entscheidungsfindung besser miteinander verzahnen (vgl. Peters, 1994: 70). Diese Perspektive weist entschieden über den begrifflichen Bezugsrahmen für eine soziologisch gehaltvolle Theorie politischer Öffentlichkeit hinaus, wie er von Gerhards und Neidhardt vorgelegt worden ist - und dafür sprechen nicht nur normative, sondern zunehmend auch praktische Gründe. Dennoch bleiben auch in einer solchen Perspektive ihr Ansatz informativ, weil er die Anforderungen ziemlich genau markiert, denen ein normativ gehaltvolles Modell politischer Öffentlichkeit(en) unter modernen Bedingungen genügen können müßte. Dies gilt insbesonders für den herzustellenden und nachzuweisenden Zusammenhang von Funktionsbegriffen, Leistungserwartungen, Strukturmechanismen und institutionellen wie technisch-organisatorischen Voraussetzungen. Gerade dann, wenn man den Bezugspunkt der Verbesserung der Qualität politischer Entscheidungen wählt, wird man auf die Beantwortung von Fragen nach der Qualifizierung von Teilnahmebedingungen, von Schließungskomponenten, der institutionellen Binnenausstatung wie der institutionellen Verankerung im politischen System nicht verzichten können - diese Faktoren fungieren im folgenden als jedenfalls implizite Bewertungskriterien und Optimierungsgesichtspunkte.

c) Die normative Idee der Öffentlichkeit erschließt sich aus ihrer Bestimmung als Medium der autonomen Reproduktion des gesellschaftlichen Handlungszusammenhangs und der Rationalitätsimplikationen, die sich daraus ergeben. Unter dieser Voraussetzung kann man den konzeptionellen Aufbau unterschiedlicher Modelle von Öffentlichkeit grob schematisierend an Hand einer Baumstruktur rekonstruieren, die sich über Unterscheidungen im Begriff politischer Praxis aufbaut und sich im Kern daran orientiert, ob Praxis primär selbstreflexiv gefaßt wird oder aber die pragmatische Dimension der Verbesserung der Qualität politischer Entscheidungen mit aufnimmt: 
Für den Fall, daß die Bestimmung von »Öffentlichkeit«primär (selbst-) reflexiv auf die Reproduktion einer autonomen gesellschaftlichen Praxis bezogen bleibt, kann das aus dieser Entscheidung resultierende Modell entweder auf eine Grenzziehungsfunktion (bezogen auf die Unterscheidung von >privat $<$ und >öffentlich $<$ Benhabib, 1989 und 1991), auf die Funktion der konflikthaften Integration partikularisierter Lebensformen i.S. einer »Politik der Lebensstile « (Ritter, 1990; Dubiel, 1990) oder auf die Eröffnung von Räumen für den individuellen Selbstverwirklichungsanspruch (Expressionsfunktion: Rorty, 1989; Kateb, 1990 und Connolly, 1990) hin ausgelegt werden. Für den Fall, daß die öffentliche Willensbildung auch auf die Rationalisierung staatlich-administrativer Entscheidungen bezogen werden soll, ergeben sich wiederum zwei Möglichkeiten, die sich danach spezifizieren lassen, ob er sich in einer eher konstitutionellen Perspektive auf die Rationalisierung der Regeln des Zusammenspiels von Gesellschaft und Staat bezieht oder ob vielmehr ein direkter Policy- resp. Entscheidungsbezug hergestellt wird: auch letzterer kann sich schließlich unterschiedlich in Gestalt eines bloßen »Belagerungsmodells « oder eines Partizipationsmodells artikulieren.

Umgekehrt ist offensichtlich, daß diese Entscheidungen auch direkte Auswirkungen auf die Rationalitätsannahmen haben, die mit dem Konzept von »Öffentlichkeit« verbunden werden: je enger man in einer demokratisch-partizipatorischen Perspektive die gesellschaftliche Willensbildung mit der Idee der Rationalisierung staatlicher Politik i.S. einer Verbesserung der Qualität politischer Entscheidungen verklammert, desto anspruchsvoller werden die Rationalitätserwartungen, die man in den Strukturen öffentlicher Willensbildung unterbringen können muß. Unter Inkaufnahme der damit unvermeidlich verbundenen Abstraktionsverluste läßt sich daher so etwas wie eine Konstruktionslogik von Öffentlichkeitsmodellen ausmachen, die sich aus der Kombination von zwei grundlegenden Unterscheidungen (Praxis/Poiesis und kognitiv/nicht-kognitiv) ergibt und die zu vier Grundtypen der Konzeptualisierung von Öffentlichkeit führt:

$\begin{array}{lll} & \text { Poiesis } & \text { Praxis } \\ \text { nicht-kognitiv } & \begin{array}{l}\text { Interessenvermittlung } \\ \text { (pluralistische Option) }\end{array} & \begin{array}{l}\text { Selbstverwirklichung } \\ \text { (libertäre Option) }\end{array} \\ \text { kognitiv } & \begin{array}{l}\text { Selbstregierung (partizi- } \\ \text { patorische Option) }\end{array} & \begin{array}{l}\text { Selbstgesetzgebung } \\ \text { (liberale Option) }\end{array}\end{array}$

- Wenn man zunächst die Merkmale >Praxisbezug und >kognitivistische Auslegung von Politik< kombiniert, entsteht eine Vorstellung von Öffentlichkeit, die primär auf die verbindliche (und d.h. die argumentativ gültige) Regelung von Ordnungsproblemen in konstitutioneller Perspektive bezogen ist, für diese kognitive Orientierung aber zugleich bereit ist, den Preis der restriktiven Auslegung jener Fragen zu entrichten, die in diesem Sinne überhaupt einer verbindlichen Lösung zugänglich sind. Das ist im Kern offensichtlich die Strategie eines sich normativ verstehenden Liberalismus, die - bei allen verbleibenden Unterschieden - sowohl in der Rawlschen 
Gerechtigkeitstheorie (Rawls, 1992) wie im Neutralitätsprinzip Larmore's (1990) oder Ackerman's (1989) oder auch in Habermas' Vorstellung einer reflexiv gewordenen Idee der Volkssouveränität (1989) zum Ausdruck kommt.

- Wenn man dagegen in der Kombination der Merkmale >kognitiv und >Poiesis erster Linie auf die Verbesserung der Qualität politischer Entscheidungen durch die Erschließung kognitiver und moralischer Potentiale von Individuen abzielt, rückt Öffentlichkeit ein in die Funktion der Rationalisierung individueller und in der Folge kollektiver Willensbildung in sachlicher, zeitlicher und sozialer Hinsicht. Öffentlichkeit wird dann konzipiert als ein diskursives Medium der Entscheidungsverbesserung, das allerdings selbst auf die Absicherung in institutionellen Strukturen angewiesen bleibt, die auf diese Erschließungsfunktion ausgerichtet sind: in diese Richtung weisen vor allem die Vorschläge, die Offe und Preuß (1990), aber auch Joas (1990a) in den letzten Jahren entwickelt haben.

- Ein weiterer Grundtypus ergibt sich, wenn der Poiesis-Bezug zwar aufrechterhalten, die kognitiven und moralischen Ansprüche an den Prozeß der öffentlichen Willensbildung aber in Richtung auf eine weniger wahrheitsorientierte und mehr persuasive Deutung der Funktion von Deliberation zurückgenommen werden. Im Rahmen eines solchen Ansatzes, wie ihn vor allem Manin (1987) skizziert hat, bleibt Öffentlichkeit konzeptuell bezogen auf die etablierten Strukturen des politischen Vermittlungssektors wie Parteien und Verbände und ist so verbunden mit der Perspektive innerparteilicher Demokratisierung (Manin, 1987: 353 ff.): ein solches Modell scheint im Ansatz noch am ehesten kompatibel auch mit der dominierenden Gestalt von Medienöffentlichkeit, wie ich sie oben unter (a) kurz charakterisiert habe.

- Schließlich bleibt die Kombination der Merkmale snicht-kognitiv< und >Praxis<. Eine darauf aufbauende Deutung wird Öffentlichkeit primär als einen sozialen Raum konzeptualisieren, in dem sich auf der Basis der Erfahrung einer Differenz sich unvermittelt begegnender Lebensformen und -stile so etwas wie eine »integrative Mechanik der Differenzerfahrung (Dubiel, 1990: 140) entbinden soll. Damit erhält Öffentlichkeit den Status einer Instanz der Vermittlung eines konfliktorischen Vergesellschaftungszusammenhangs: dies sind Vorstellungen, die programmatisch vor allem mit der Idee der Zivilgesellschaft verbunden sind, die aber durchaus kompatibel bleiben mit den expressivistischen Grundintuitionen, wie sie etwa im Projekt eines »radikalisierten Liberalismus« (Connolly, 1985; 1988 und 1990) zum Ausdruck kommen.

Freilich sind diese Unterscheidungen, die insoweit nur eine erste Orientierungsfunktion haben können, in gewisser Weise etwas künstlich. Die »Macht von Öffentlichkeit« wird am Ende vielmehr von beidem abhängen: ob es gelingt, eine Sphäre der Vermittlung von Subjektivität, Erfahrung und Betroffenheit und Allgemeinheit gesellschaftlich zu organisieren und inwieweit es gelingt, einen Formtypus von Öffentlichkeit zu installieren, der die in unterschiedlichen Lebenszusammenhängen entbundenen Erfahrungen, Wünsche und Ansprüche auch in staatlichen Entscheidungsprozessen verankert. Diesen Zusammenhang möchte ich im folgenden durch die Einseitigkeiten hindurch sichtbar machen, die entstehen, wenn »Öffentlichkeit « primär mit Bezug auf die normativen Gesichtspunkte von Selbstverwirklichung und Selbstorganisation hin 
konzeptualisiert wird. Das von Stamm vorgeschlagene Modell authentischer Öffentlichkeit und Habermas Vorstellung einer reflexiv gewordenen Volkssouveränität kann man dann als nacheinandergeschaltete Stufen einer zivilen Vermittlung moderner Gesellschaften behandeln. So wird sichtbar, daß die politische Qualität von Öffentlichkeit solange problematisch bleiben muß, wie sie im Projekt einer Politik der Lebensstile hängenbleibt und sich lediglich als selbstreflexives Modell der Praxis alternativer Lebensformen (vgl. kritisch dazu auch Joas 1992: 358 ff.) versteht.

So zeichnet Stamm in seiner Arbeit über »Alternative Öffentlichkeit« (1988) den spannungsreichen und zum Teil widersprïchlichen Prozeß der Herausbildung eines neuen Typs von Öffentlichkeit nach, den er unter Bezug auf das herausragende Merkmal der Repolitisierung des Privaten im Zeichen einer durch Reflexion vermittelten Kollektivierung und Verallgemeinerung subjektiver Erfahrung als »authentisch« bezeichnet. Seine Rekonstruktion dieser Entwicklung besteht dann im wesentlichen aus drei Teilen: Zunächst zeigt er, $\mathrm{da} \beta$ sich die unterschiedlichen Typen von Öffentlichkeit, die sich in den letzten zwanzig Jahren herausgebildet haben - von der »Fanalöffentlichkeit« des linken Terrors über die »Produktionsöffentlichkeit der Erfahrung « der Alternativbewegung, die »Partizipationsöffentlichkeit« der Bürgerinitiativbewegung bis zur »Parteiöffentlichkeit« der Grünen (vgl. auch Stamm, 1989) -, im Kern aus der selektiven Aneignung und Institutionalisierung einzelner Momente des komplexen Öffentlichkeitsbegriffs der Studentenbewegung speisen; parallel dazu versucht er plausibel zu machen, daß das Scheitern dieser Versuche wesentlich in dem Auseinanderreißen der Momente von kollektiver Erfahrungsproduktion und der Partizipation an administrativer Politik begründet liegt; schließlich glaubt er Anzeichen dafür zu entdecken, daß diese Momente in einer neuen Form von »authentischer Öffentlichkeit « wieder zusammengebracht werden können.

Vor diesem Hintergrund sind nun vor allem die Punkte von Interesse, an denen einzelne Entwicklungen zum Stillstand kommen und die positiven Erfahrungsgehalte des einen gleichsam in ein neues Formexperiment überführt werden. Ohne auf die Charakterisierungen und begrifflichen Bestimmungen im einzelnen einzugehen, möchte ich zwei Beobachtungen herausgreifen, die im Gesamtzusammenhang besonders informativ sind. Die erste bezieht sich auf die komplementären Aspekte des Scheiterns des Öffentlichkeitsprojekts von Alternativ- und Bürgerinitiativbewegung. In der Alternativbewegung so Stamm (1988: 151 ff.) - komme vor allem ein Bedürfnis nach unvermittelter, alltäglicher Kommunikaton zum Ausdruck, das sich in lokaten Öffentlichkeiten zur Geltung bringt, die so für die Beteiligten einen direkten Gebrauchswert besitzen, aber andererseits vollständig abgekoppelt sind vom »System selber «. Diese Trennung macht er letztlich dafür verantwortlich, daß sich die alternativen Lebensformen ohne Bezug auf die Gesellschaft als ganze und auf eine allgemeine Lebensform in ihrer Partikularität einrichten das führt zu einem internen Spannungsverlust (Joas, 1992: $358 \mathrm{ff..),} \mathrm{der} \mathrm{seinerseits} \mathrm{in}$ eine selbstbezügliche »Intimisierung von Öffentlichkeit (Stamm, 1989: 7) mündet, an der das Projekt im ganzen zum Stillstand kommt. Komplementär dazu verhält sich seine Diagnose der Entwicklung einer Partizipationsöffentlichkeit im Zusammenhang der Bürgerinitiativbewegung (Stamm, 1988: 181 ff.). Für diese bleibt im Unterschied zur Alternativbewegung die Trennung von >privat< und >öffentlich< konstitutiv, die allerdings sowohl für den relativen Erfolg wie schließlich für die innere Auszehrung der Bewegung 
verantwortlich ist: der Erfolg der Thematisierung von verdrängten und nicht artikulierten Problemen und deren Einspeisung in administrative Zusammenhänge beruht zu einem Teil auch auf der Anpassung an organisatorische Zwänge, unter deren Druck egalitäre Kommunikations- und Handlungsstrukturen preisgegeben werden, über die sich eigene Identitäten generieren ließen. M.a.W., nimmt man beide Beobachtungen zusammen, dann drängt sich die Vermutung auf, daß in den komplementären Vereinseitigungen oder Spezialisierungen ein wesentlicher Grund für das Versagen liegt, ein Modell von Gegenöffentlichkeit, wie es die Studentenbewegung noch angezielt hatte, auch zu stabilisieren: in dieser Polarisierung läuft eine »Politik in der 1. Person « an ihrem fehlenden Allgemeinheitsbezug wie an ihrer Wirkungslosigkeit und Thematisierungschwäche auf, während sich im Gegenzug der partizipatorische Anspruch von genuinen Erfahrungsquellen und identitätsverbürgenden Kommunikationsstrukturen abschneidet und an administrative Wahrnehmungsmuster assimiliert.

Dieser Zusammenhang scheint sich in einer zweiten Beobachtung zu bestätigen, die die sog. »Parteiöffentlichkeit« der Grünen betrifft (Stamm 1988: 238 f.). Alle Indizien scheinen dafür zu sprechen, daß die Grünen es nicht geschafft haben, das Spannungsverhältnis zwischen diskursiv-egalitärer Willensbildung und deren auf Medien- und Parlamentarisierungszwänge hin ausgelegte parteiliche Überformung aufzulösen. Vielmehr scheinen sie letztlich doch Formen der Willensbildung ausgebildet zu haben, die sich kaum noch produktiv auf die Erfahrungen ihrer Mitglieder beziehen, sondern sich vielmehr wie ein Filter vor jene Diskurse schieben, die frei sind »von taktischen und ideologischen Erwägungen, (die) exponierte Positionen genauso berücksichtigen wie die Ideen von Querdenkem, Spinnem und Chaoten...«(Stamm, 1988: 239). Dieses Zitat kann durchaus als eine Kurzformel für den Typus authentischer Öffentlichkeit dienen, den Stamm als Synthese des von ihm nachvollzogenen Entwicklungsprozesses alternativer Öffentlichkeit im Auge hat. Indessen bleiben, entgegen seiner eher optimistisch n Annahme, was die Realisierungschancen eines solchen, von der Lebensweise der neuen Mittelschichten zu tragenden Projekts (Stamm, 1988: 283 ff.) angeht, gravierende Einwände bestehen. Diese hängen im Kem damit zusammen, daß die als ssubjektiver Erfahrungsbezug', >Allgemeinheit< und >Demokratisierung der Wissensgrundlagen politischer Entscheidungen< ausgezeichneten Strukturmomente doch konkurrierende Optimierungsgesichtspunkte für öffentliche Diskurse beinhalten - und dies vor allem deshalb, weil sich an individuellen Erfahrungen in komplexen Gesellschaften immer weniger allgemeine Gehalte entbinden lassen. So scheint es denn auch kein Zufall, daß Stamm die Funktion der neuen Öffentlichkeit am Ende eher an der inneren Konsolidierung partikularer Lebensformen ausrichtet (Stamm, 1988: 277) und sich auf einen Dualismus von Öffentlichkeiten einläßt (Stamm, 1988: 266 f.), ohne mit dem Konzept der authentischen Öffentlichkeit eine Perspektive zu eröffnen, die diesen Dualismus zu übergreifen in der Lage wäre.

\subsection{Das Modell deliberativer Politik bei Habermas}

Daß diese Einseitigkeit zu überwinden ist, wenn man den normativen Begriff der Öffentlichkeit für eine politische Theorie moderner Gesellschaften fruchtbar machen will, das ist 
die grundlegende Intuition, aus der heraus Habermas sein Diskursmodell radikaler Demokratie entwickelt. Dabei ist ihm von Anfang an klar, daß Öffentlichkeit beides ist: ein Medium der Selbstverständigung sozialer Akteure im Sinne einer "politics of identity « (Cohen/Arato, 1992: 510 ff.), ein Instrument aufgeklärter Meinungsbildung auf seiten des staatsbürgerlichen Publikums und eine Form der Rationalisierung der staatlich-politischen Willensbildung und Entscheidungsfindung. Das Problem ist dann, wie sich die lebensweltlich geprägte Praxis einer kulturellen Reproduktion kollektiver Identitäten mit der Aufgabe einer Demokratisierung staatlicher Politik so verklammern läßt, daß die von den reflexiven Lernprozessen der kollektiven Identitätsbildung ausgehenden Signale ankommen, Lernprozesse anregen und Entscheidungsprozesse umsteuern (Habermas, 1992: 451) können, ohne von den Aufgaben und Anforderungen administrativer Politik, von Entscheidungszwängen und komplexen Problemlösungsstrategien so durchdrungen und usurpiert zu werden, daß sie ihren eigenwilligen Charakter verlieren und ihre spezifische Rationalität preisgeben. Dieses Problem stellte sich Habermas schon im Zusammenhang mit der Frage, ob komplexe Gesellschaften überhaupt noch eine vernünftige Identität ausbilden könnten, die er in seiner Stuttgarter Hegel-Preis-Rede aufgegriffen hat (Habermas, 1976). Nachdem er hier, in einer Wendung gegen kollektive Identitätsfiktionen wie Staat, Nation oder Partei, ausdruicklich betont hat, daß »die kollektive Identität heute nur noch in reflexiver Gestalt denkbar (ist), nämlich so, daß sie im Bewußtsein allgemeiner und gleicher Teilhabe an solchen Kommunikationsprozessen begründet ist, in denen Identitätsbildung als kontinuierlicher Lemprozeß stattfindet« (Habermas, 1976: 116), stellte sich ihm das hier interessierende Problem dann in folgender Weise: »Woher nehmen wir aber die Überzeugung, daß die allgemeinsten kommunikativen Strukturen (in denen die Praxis einer reflexiven Identitätsbildung vermittelt ist, der Verf.) gleichsam von selbst, jedenfalls ohne ein strategisch gezieltes und organisiertes Handeln die Bedeutung einer Identitätsbasis erlangen werden?« (Habermas, 1976: 119).

Als Beispiel für die Verschränkung von administrativer Macht und kulturell erzeugtem Sinn diente ihm an dieser Stelle aus Gründen auch der damaligen Aktualität des Themas die Curriculumplanung, mit dem er seine schon in den »Legitimationsproblemen« (Habermas, 1973) aufgestellte These, daß es keine administrative Erzeugung von Sinn geben könne, illustrieren wollte (Habermas, 1976: 120). Die Vorstellung war zweifellos, daß sich dieser Zusamınenhang auch der staatlich-administrativen Entscheidungspraxis in Gestalt einer Nötigung zu einer diskursiven Öffnung der Willensbildungsprozesse mitteilen müßte; eine Vorstellung allerdings, die schon damals eigentümlich der an Luhmanns Systemtheorie gebildeten Auffassung von staatlicher Politik als eines selbstbezüglichen, medial über Macht vermittelten und systemisch integrierten Handlungszusammenhangs kontrastierte (vgl. zu diesem Punkt auch McCarthy, 1986). Die unvermeidliche Folge dieser konzeptuellen und begrifflichen Grundentscheidung war, daß nicht mehr recht sichtbar wurde, wie denn der kommunikative Modus der lebensweltlichen Reproduktion kollektiver Identitäten etwa in Forderungen nach staatsbürgerlicher Beteiligung an administrativen Planungsprozessen übersetzt werden sollte, ohne mit der aus der Logik komprehensiver Planung hervorgehenden Komplexität zu kollidieren (Habermas, 1973: 189). Hier konnte sich Habermas noch auf die Hoffnung zurückziehen, daß die vor dem Anspruch auf demokra- 
tische Beteiligung errichtete Komplexitätsschranke vielleicht zu überwinden wäre, wenn sich fehlende Beteiligung selber hemmend bezüglich einer weitergehenden internen Rationalisierung staatlich-administrativer Politik auswirkte (ebda.) - doch diese Aussicht mußte gemäß seinen eigenen Annahmen ungewiß genug bleiben, so da $\beta$ am Ende nur die Entschlossenheit blieb, den (aussichtslosen?) Kampf gegen die Verselbständigung eines gleichsam naturwüichsigen, systemischen Vergesellschaftungszusammenhangs wenigstens nicht aufzugeben (Habermas, 1973: 196).

Bekanntlich hat Habermas in der Folge dieses schon nicht sehr optimistische Szenario revidiert und auch die pathetischen Restbestände seiner Formulierung unter dem Eindruck eines Zusammenspiels zwischen einer skeptischer werdenden Zeitdiagnose einerseits und einer zunehmend positiven Würdigung der Systemtheorie andererseits immer mehr zurückgenommen. In der "Theorie des kommunikativen Handelns « (1981) läßt er den systemischen Eigensinn von Politik nun so weit hervortreten, $\mathrm{da}$ das politische System insgesamt als Funktion der manipulativen Sicherung von Massenloyalität (Habermas, 1981: II, 509) erscheint. Dem politischen System scheint es gelungen, die Staatsbürgerrolle in der »Münze der Gebrauchswerte, die die Staatsbürger als Klienten wohlfahrtsstaatlicher Bürokratien erhalten« (Habermas, 1981: II, 515), vollständig zu neutralisieren. Impulse für die Aktivierung kommunikativer Potentiale ergeben sich nicht mehr aus der Forderung nach demokratischer Teilhabe, sondern nur noch dann, wenn das System über die zwischen Lebenswelt und System verlaufende Frontlinie hinausgreift und Funktionen der symbolischen Reproduktion der Lebenswelt selber berührt sind (Habermas, 1981: II, 516). Als Folge dieser Kolonialisierungsthese erscheinen soziale Protestpotentiale und neue soziale Bewegungen als defensive Widerstands- und Rückzugsbewegungen, denen wenig emanzipatorisches Potential zukommt (Habermas, 1981: II, 578), die historische Vorläufer allenfalls in den sozialromantischen Bewegungen des Frühindustrialismus haben (Habermas, 1981: II, 577) und deren Versuche, mit Hilfe von Gegeninstitutionen »einen Teil der formal organisierten Handlungsbereiche (zu) entdifferenzieren, dem Zugriff der Steuerungsmedien (zu) entziehen und diese ‘befreiten Gebiete dem handlungskoordinierenden Mechanismus der Verständigung zurück(zu)geben« (Habermas, 1981: II, 582), als unrealistisch qualifiziert werden. ${ }^{53}$

Nicht zuletzt diese, in ihren demokratietheoretischen Implikationen weitreichende Zuspitzung hat ihm denn auch massive Kritik eingetragen, die sich vor allem auf die unnötige und zu weitreichende Assimilation seiner politischen Theorie an die systemtheoretischen Vorgaben Luhmanns (und Parsons) konzentrierte. ${ }^{54}$ Wohl auch unter

53 Von dieser Einschätzung nimmt er allerdings die Frauenbewegung aus, deren »Kampf gegen patriarchalische Unterdrückung und für die Einlösung eines Versprechens, das in den anerkannten universalistischen Grundlagen von Moral und Recht seit langem verankert ist", ihr die "Schubkraft einer offensiven Bewegung " verleiht (Habermas, 1981; II, 578).

$54 \mathrm{Vgl}$. insbesondere Honneth (1985), Joas (1986) und McCarthy (1986). Ich gehe an dieser Stelle auf diese Arbeiten nicht genauer ein, hole das aber in einem anderen Zusammenhang weiter unten (Kap. 5) nach, wo ich mich u.a. mit der Position von Joas ausführlicher auseinandersetze. 
dem Eindruck dieser Kritik hat Habermas dann ab Ende der achtziger Jahre seine Konzeptualisierung von Politik und politischem System unter Rückgriff auf Studien zur Rechtstheorie und eine Aktualisierung der normativen Kategorie der Öffentlichkeit einer erneuten Revision unterzogen. Dabei fällt insbesondere auf, daß er den Dualismus von System- und Handlungstheorie zugunsten einer eher institutionellen Betrachtungsweise des politischen Systems aufgibt, das nunmehr als Arrangement arbeitsteiliger, reflexiv aufeinander bezogener institutioneller Prozesse rekonstruiert wird. Das bietet ihm die Möglichkeit, eine Form der Verschränkung von kommunikativer und administrativer Macht ins Auge zu fassen, die er in der institutionellen Logik des liberalen und demokratischen Rechtsstaates selber verankert und die nicht mehr auf die äußerliche Konfrontation von System und Lebenswelt resp. Staat und Gesellschaft verwiesen ist. Im Zusammenhang damit kommt es dann auch zu einer (wenn auch vorsichtigen) Akzentverschiebung hinsichtlich der Einschätzung des politisch-emanzipatorischen Potentials neuer sozialer Bewegungen und zivilgesellschaftlicher Öffentlichkeiten: zum Angelpunkt seiner radikalisierten demokratietheoretischen Perspektive wird ein entsubstantialisierter Begriff der Volkssouveränität, nach dem sich staatliche Politik und demokratische Selbstbestimmungsansprüche über die prozedurale Rationalität diskursiver Verfahren vermitteln. Das daraus resultierende Modell deliberativer Politik stellt den m.E. komplexesten und am systematischsten ausgearbeiteten Beitrag zur modernen Demokratietheorie dar, hinter den man kaum mehr zurück kann, auch wenn die von ihm selber in Anspruch genommene Radikalität seiner Vorstellungen hinter manchen Erwartungen und, wie ich zu zeigen versuchen werde, hinter den gegebenen Möglichkeiten zurückbleibt. Ich werde diese Punkte im folgenden in der genannten Reihenfolge aufgreifen und jeweils knapp erläutern $(a-c)$. Schließlich werde ich die wichtigsten Einwände noch einmal kurz zusammenfassen, die dann den Anlaß bilden, mit Habermasschen Mitteln das Projekt der Demokratie von dem allzu engen und starren institutionellen Korsett der repräsentativen Demokratie zu befreien und der Idee einer auf Selbstregierung hin ausgelegten partizipatorischen Demokratie im Modell der reflexiven Demokratie neuen Halt zu geben (d) - diese Vorstellung werde ich im zweiten Abschnitt der Arbeit entwickeln.

a) Zur Rekonzeptualisierung der liberalen Gewaltenteilungslehre. ${ }^{55}$ Nachdem Habermas am Begriff des Rechts die irreduzibel öffentlichen und diskursiven Momente der Erzeugung legitimen Rechts herausgestellt hat, unternimmt er es in dem mich hier interessierenden Schritt, nunmehr auch den internen Zusammenhang von Recht und politischer Macht zu rekonstruieren; und zwar so, daß die bereits am Recht nachgewiesene Spannung zwischen Faktizität und Geltung auch an der politischen Macht sichtbar wird, die sich des Rechts zu eigenen Zwecken nicht mehr nur bedienen kann, sondern selber rechtlich konstituiert ist. Diesen Nachweis, der allerdings, wie Habermas selber einräumt, die empirischen Fälle der »verkehrten Faktizität einer dem Recht externen, das Recht instrumentalisierenden und insofern illegitimen Macht« (171) außer Be-

55 Die folgenden Seitenhinweise (in Klammern) beziehen sich, soweit nicht ausdrücklich anders ausgewiesen, alle auf Habermas (1992). 
tracht läßt, verteilt er auf vier demokratietheoretisch relevante Argumentationsschritte: Zunächst möchte er an Hand eines argumentationslogisch angelegten Prozeßmodells politischer Meinungs- und Willensbildung klären, wie sich die Verschränkung von administrativer und kommunikativer Macht beschreiben läßt; darauf bezogen kann er zweitens die fundamentalen Prinzipien des demokratischen Rechtsstaats erläutern, die - drittens - wiederum den Rahmen bilden, innerhalb dessen die Bestimmung der angemessenen Verfahren und organisatorischen Formen demokratischer Willensbildungsprozesse vorgenommen werden kann; in dieser Perspektive rückt er die politische Gesetzgebung in den Rang eines demokratischen Meta-Verfahrens, was ihn schließlich zu einer Rekonzeptualisierung der liberalen Idee der Gewaltenteilung veranlaßt. Damit möchte er verhindern, daß die diskurstheoretische Rekonstruktion der Funktionen der Gesetzgebung vorschnell in ein durch bestehende Institutionen okkupiertes Verständnis von Demokratie zurückgelenkt wird. Er versteht den gewählten Abstraktionsgrad der Analyse gleichsam als eine demokratische Öffnungsklausel wieviel diese am Ende wert ist, zeigt sich allerdings erst im Zusammenhang seiner Funktionsbeschreibung der Zivilgesellschaft und mit Blick auf sein Modell einer zweigleisigen, deliberativen Demokratie.

Dem Prozeßmodell der Verschränkung der Meinungs- und Willensbildung eines politischen Gesetzgebers ${ }^{56}$ mit der Erzeugung kommunikativer Macht liegt die zunächst analytisch gemeinte Unterscheidung von pragmatischen, ethisch-politischen und moralischen Fragen zugrunde, die inı Zuge der Behandlung regelungsbedürftiger Materien unterschiedlich stark hervortreten, aber jeweils spezifische Anforderungen an den Gebrauch der praktischen Vernunft stellen und unterschiedlichen Diskurstypen entsprechen. Pragmatische Fragen stellen sich danach »aus der Perspektive eines Handelnden, der bei gegebenen Zielen und Präferenzen geeignete Mittel für die Realisierung seiner Ziele sucht « (197) - dieser Aufgabe entsprechen »pragmatische Diskurse«, in denen Argumente den Ausschlag geben, »die empirisches Wissen auf gegebene Präferenzen und gesetzte Zwecke beziehen und die Folgen alternativer Entscheidungen...nach zugrundegelegten Maximen beurteilen« (198). Dagegen stellen sich ethisch-politische Fragen aus der Perspektive von Angehörigen einer politischen Gemeinschaft, »die sich in lebenswichtigen Fragen darüber klar werden wollen, welche Lebensform sie teilen, auf welche Ideale hin sie ihr gemeinsames Leben entwerfen sollen « (198) - behandelt werden Fragen dieses Typs in ethischen Diskursen, in denen Argumente den Ausschlag geben, »die sich auf eine Explikation des Selbstverständnisses

56 Man sollte von vornherein, um ein konkretistisches Mißverständnis zu vermeiden, darauf hinweisen, daß Habermas "politische Gesetzgebung» als eine allgemeine Funktionsbestimmung versteht, die nicht mit einer konkreten Form der Organisation von Gesetzgebungsprozessen (etwa in Gestalt der parlamentarisch-repräsentativen Beratung und Beschlußfassung) identifiziert werden sollte. Im Prinzip, so läßt dieser Vorbehalt erwarten, müßte die Aufgabe politischer Gesetzgebung auch basis- resp. anwendungsnah zu organisieren sein (vgl. Maus, 1992a), solange dezentrale Organisationsformen die Ansprüche an eine diskursive, auf allgemeine Geltung berechnete Gesetzgebung in sich aufzunehmen vermögen. Dagegen jedenfalls führt Habermas jeweils >nur technische Gründe ins Feld, die allerdings, wie noch zu zeigen sein wird, gravierende Wirkungen haben. 
unserer historisch überlieferten Lebensform stïtzen und in diesem Kontext Wertentscheidungen an dem für uns absoluten Ziel einer authentischen Lebensführung bemessen« (199). Während es also in pragmatischen Diskursen unter der Voraussetzung, daß fundamentale Werte nicht berührt sind, um die Wahl optimaler Strategien zur Erreichung gegebener Zwecke geht, wird in ethischen Diskursen thematisch, ob sich die gewählten Handlungsalternativen in Übereinstimmung mit den Werten befinden, die das Leben einer konkreten politischen Gemeinschaft bestimmen. Damit sind aber noch nicht alle möglichen Anforderungen an die Begründung von Entscheidungen abgedeckt, weil diese schließlich unter dem Aspekt der Gerechtigkeit in moralischen Diskursen auch darauf hin befragt werden können, ob eine daraus resultierende Praxis auch gleichermaßen gut für alle ist (200).

Diese Typen von Fragen beschreiben also gleichsam die Stufen, die ein Prozeß der Bildung eines politischen Willens durchlaufen können muß, der in einer allgemeinen Gesetzgebung terminieren soll. Damit aber stellt sich zum einen das Problem, daß innerhalb eines so integrierten Entscheidungsprozesses die rationalen Anforderungen, unter die sich die Beteiligten stellen müssen, wie der Kreis der an den Diskursen faktisch zu beteiligenden Betroffenen variiert. Das drückt Habermas so aus: »Je nach den pragmatischen, ethischen und moralischen Aspekten einer regelungsbedürftigen Materie wechseln also die Konstellationen von Vernunft und Wille. Aus diesen Konstellationen erklärt sich das Problem, von dem die diskursive Bildung eines gemeinsamen politischen Willens ausgeht« (202 f.). Freilich muß ein darauf berechnetes Prozeßmodell nicht nur eine angemessene Variabilität des Entscheidungsprozesses bezüglich der Wahl der Diskurstypen und der Inklusion Betroffener aufweisen, sondern es muß darüber hinaus eine Antwort auf die Frage bereithalten, wie die Übergänge gestaltet werden und wer die Pfade bestimmt, über die die Diskurse und Verhandlungen miteinander rückgekoppelt werden sollen (207).

Aus dieser Konstellation entwickelt Habermas die eigentliche Pointe seines Prozeßmodells, die in einer rekursiven Verfahrensanordnung besteht, nach der auf jeder Stufe der Willensbildung auch darüber entschieden werden kann und muß, auf welcher Ebene die spezifischen Kontroversen fortgesetzt werden sollen (203). In der folgenden Aufzählung der Alternativen nimmt er allerdings eine entscheidende Weichenstellung bezüglich der Organisationsform politischer Entscheidungsprozesse vor - neben der eingangs eingeführten Trias von Diskursen erscheinen nunmehr Verhandlungen als eine, mehr noch: als die eigentliche Normalform der Gesetzgebung in komplexen Gesellschaften: »In komplexen Gesellschaften wird aber selbst unter idealen Bedingungen oft weder die eine noch die andere Alternative (d.i. moralische resp. ethisch-politische Diskurse, der Verf.) offenstehen, nämlich immer dann, wenn sich herausstellt, daß alle vorgeschlagenen Regelungen vielfältige Interessen auf je verschiedene Weisen berüren, ohne daß sich ein verallgemeinerbares Interesse oder der eindeutige Vorrang eines bestimmten Wertes begründen ließen. In diesen Fällen bleibt die Alternative von Verhandlungen, die freilich die Kooperationsbereitschaft erfolgsorientiert handelnder Parteien erfordern« (204). Irritierend daran ist selbstverständlich nicht, daß Habermas auf diese Weise den Realitätsgehalt seiner Konzeptualisierung erhöhen will, zumal er unmittelbar im Anschluß zeigt, wie Verfahren der Kompromißbildung 
unter strategisch gesonnenen Akteuren auf das Diskursprinzip bezogen bleiben, »nämlich durch Verfahren, die die Verhandlungen unter Fairness-Gesichtspunkten regulieren « (205). Freilich ist diese Wirkung nur indirekt, und das Moment der Diskursivität bleibt dem Prozeß der Kompromißbildung äußerlich, weil er diesen so versteht, daß er sich ausschließlich im Modus strategischen, auf die Macht und Sanktionspotentiale der Parteien gestützten Handelns vollzieht (344). Damit verwischt er aber notwendige Unterscheidungen im Begriff der Verhandlung (etwa zwischen bargaining, negotiation, und Problemlösung), die sich daraus ergeben, in welchem Ausmaß diskursive Praktiken auch im Inneren von Verhandlungsprozessen aktiviert werden. Das aber hat für die Logik seines eigenen Arguments vor allem die mißliche Folge, daß er auf der Ebene von Verhandlungen keine Ansatzpunkte für die reflexiven Mechanismen mehr identifizieren kann, über die sich eine fortlaufende Verfahrenswahl im Prozeß der Gesetzgebung vollziehen soll: der Prozeß der autonomen Verschränkung und rekursiven Vernetzung von Diskursen und Verhandlungen, durch die sich eine vernünftige politische Willensbildung idealerweise auszeichnen sollte, wird unterbrochen und kann nurmehr von außen wieder in Gang gebracht werden.

Das Problem liegt also schon an dieser Stelle darin, daß Habermas die zunächst analytisch eingeführte Unterscheidung von Dimensionen der politischen Willensbildung (i.e. pragmatische, ethisch-politische und moralische Fragen) auf jeweils einsinnig spezialisierte Organisationsformen und Verfahren abbildet, die er dann in unterschiedlichen und nur lose miteinander verbundenen politischen Arenen situiert: staatlicherseits in Verwaltung und Parlament, auf der Seite der Gesellschaft in korporatistischen Arrangements und schwach institutionalisierten, zivilgesellschaftlichen Öffentlichkeiten (211 ff.). Nun entwickelt er in einem zweiten Schritt aus dieser Konstellation zwar die fundamentalen Prinzipien des demokratischen Rechtsstaats, die in einer prozedural ausgelegten Idee der Volkssouveränität ihren gemeinsamen Angelpunkt haben, nach der sich die kommunikative Macht der Staatsbürger in einer autonomen Gesetzgebung entfaltet, die die Bestimmung der Verfahren einer angemessenen politischen Problemlösung zum Inhalt haben. Andererseits sieht er sich gleich zu dem Eingeständnis genötigt, daß das Subjekt einer so verstandenen Gesetzgebung kollektiv gar nicht handlungsfähig ist und sich deshalb gleichsam in die Momente einer gewaltenteiligen Staatsorganisation auseinanderlegt. Daran ist gewiß zunächst einmal nichts auszusetzen, zumal er den Gedankengang in einer recht allgemein gehaltenen Formel zusammenfaßt, der man so leicht zustimmen kann: »Erst das Prinzip der Gewährleistung autonomer Öffentlichkeiten und der Grundsatz der Parteienkonkurrenz erschöpfen, zusammen mit dem parlamentarischen Prinzip, den Gehalt des Prinzips der Volkssouveränität. Es verlangt eine diskursive Strukturierung öffentlicher Arenen, in denen sich anonym verzahnte Kommunikationskreisläufe von der konkreten Ebene einfacher Interaktionen ablösen « (211). Daß sich dahinter auch ein nicht ganz triviales Problem verbirgt, zeigt sich erst, wenn man diese Bestimmung und das vierte von ihm hervorgehobene fundamentale Prinzip des demokratischen Rechtsstaats, die Trennung von Staat und Gesellschaft, ineinanderschiebt. Dieses Prinzip ist zwar darauf berechnet, die Entfaltung sozialer Macht so zu regulieren, daß »sie die Ausbildung staatsbürgerlicher Autonomie ermöglicht und nicht beschränkt (Herv. i.O.)《 (215), und damit zielt Habermas vor allem auf die Eindämmung der illegitimen Macht 
großer gesellschaftlicher Interessengruppen und korporatistischer Arrangements. Er übersieht aber, daß auch eine zum Grenzwächter zwischen Staat und Gesellschaft bestellte Staatsgewalt einen Filter bildet, in dem nicht nur partikulare, aber sozial mächtige Interessen hängenbleiben, sondern an dem (viel wahrscheinlicher) vor allem auch allgemeine Teilhabeansprüche einer breiteren, zivilgesellschaftlichen Öffentlichkeit abprallen - das aber bedeutet mindestens, daß sich die von ihm entwickelten Prinzipien nicht ganz so naht- und bruchlos zur "Architektur « des demokratischen Rechstsstaats zusammenfügen (217), wie er suggerieren möchte.

Während es also gute Gründe für die von Habermas vorgenommene Entsubstantialisierung des Begriffs der Volkssouveränität gibt, nach der das demokratische Verfahren der Gesetzgebung den Charakter eines Meta-Verfahrens annimmt, das die Einrichtung der für eine vernünftige politische Willensbildung erforderlichen Komunikationsformen und Verfahren reflexiv steuert (217 ff.), können diese Verfahren selber nicht ortlos bleiben. Diese Stelle der Macht muß besetzt werden, und die entscheidende Frage bleibt, welche Kandidaten dafür in Frage kommen. Bei Habermas scheint es so, daß, nachdem er, wie gezeigt, nacheinander die Kandidaten dezentraler Verfahren der politischen Problemlösung und die in dieser Hinsicht zu schwach institutionalisierten autonomen Öffentlichkeiten aus dem Felde geschlagen hat, nur noch der Staat als institutionelles Arrangement gewaltenteilig verschränkter Prozesse der Gesetzgebung, der Rechtsprechung und der Verwaltung übrig bleibt. Vor dieser Konsequenz allerdings schrickt er am Ende doch wieder zurück, wie sich an seiner Kritik einer bloß liberalen Lesart der Logik der Gewaltenteilung zeigt: »Argumentationslogisch betrachtet, ergibt sich die Kompetenztrennung zwischen gesetzgebenden, gesetzesanwendenden und gesetzesvollziehenden Instanzen aus der Verteilung von Zugriffsmöglichkeiten auf verschiedene Sorten von Gründen (Herv. i.O.) und aus der Zuordnung entsprechender Kommunikationsformen, die die Art des Umgangs mit diesen Gründen festlegen « ( 235 f.). Mit dieser formalen Bestimmung versucht er sich von einem Verständnis des demokratischen Prozesses abzulösen, das durch etablierte Formen der Institutionalisierung okkupiert und voreingenommen ist. Insofern fungiert diese Überlegung gleichsam als eine demokratische Öffnungsklausel, die den Blick auf dezentrale Formen der Willensbildung freigib ${ }^{57}$ und den Weg für eine Rekonzeptualisierung der arbeitsteiligen Funktionen staatlicher Institutionen wie für eine stärkere Institutionalisierung zivilgesellschaftlicher Formen der Politik freimachen könnte. In diese Richtung scheinen zunächst auch die Vorschläge zu weisen, die er am Ende ( 516 ff.) zum Zweck des konsequenten weiteren Ausbaus des demokratischen Rechtsstaats in komplexen Gesellschaften unterbreitet. Dazu zählt zum ei-

57 Das Beispiel, das Habermas selbst erwähnt, betrifft die kommunale Selbstverwaltung: »...unter funktionalen Gesichtspunkten betrachtet, ermöglicht die Dezentralisierung umfassender Befugnisse auf dieser basisnahen Entscheidungsebene eine organisatorische Verflechtung von Staatsfunktionen, die mit der Logik der Gewaltenteilung durchaus in Einklang steht...Die Legitimation durch allgemeine, personenbezogene Wahlen, die parlamentarische Form der Willensbildung, die ehrenamtliche Beteiligung von Laien usw. ermöglichen den Gemeindebürgern einen vergleichsweise starken Einfluß auf die Programme und den Ablauf einer Universalverwaltung, der über andere Modelle der Verwaltungsbeteiligung ... hinausgeht $\ll(237$, Fn. 62). 
nen eine Art reflexiver Parlamentsreform, die notwendig wird, weil »der politische Gesetzgeber je nach regelungsbedürftiger Materie zwischem formalem, materialem und prozeduralem Recht wählen « (528) muß - das »verlangt vom parlamentarischen Gesetzgeber zunächst Entscheidungen auf einer Metaebene - Entscheidungen darüber, ob er überhaupt entscheiden soll, wer an seiner Stelle entscheiden könnte und, falls er entscheiden will, welche Folgen sich für die legitime Verarbeitung seiner Gesetzesprogramme ergeben « (529). Diese allgemeine Partizipationschancen und -spielräume erweiternde Parlamentsreform muß zweitens aber durch eine »Demokratisierung der Verwaltung « (531) ergänzt werden, die in ihrem hoheitlichen Selbstverständnis einen ernstzunehmenden Flaschenhals für effektive Teilhabeansprüche auf der Ebene konkreter Problemlösungen und einzelner Politiken darstellt. Komplettiert wird dieses Neuarrangement aber erst dadurch, daß die aus der Zivilgesellschaft und den politischen Öffentlichkeiten hervorgehende kommunikative Macht auch in administrative Macht übersetzt werden kann - in diesem Zusammenhang rekurriert er auf die Einführung plebiszitärer Elemente wie basisdemokratischer Verfahren, und last, but not least drängt er auf eine stärkere »Konstitutionalisierung der Macht der Medien« (533).

Diese normativen Bestimmungen verbleiben andererseits aber in einem merkwürdigen Kontrast zu den sozialwissenschaftlichen Perspektiven, die er im Mittelteil von »Faktizität und Geltung « im Zusammenhang der selbst gestellten Aufgabe der Entwicklung einer soziologisch gehaltvollen Analyse von Chancen einer weitergehenden Demokratisierung entwickelt. Deshalb kann auf dieser Ebene noch nicht entschieden werden, welcher Status dieser normativen Perspektive auf den gewaltenteiligen Rechtsstaat demokratietheoretisch am Ende zukommen soll - das erschließt sich erst im Zusammenhang seiner genaueren Einschätzung zivilgesellschaftlicher Handlungspotentiale und der politischen Funktionsbestimmung autonomer Öffentlichkeiten.

b) Wenn wir Fragen der genauen Verortung der entsprechenden Diskurse noch einmal einen Moment lang zurückstellen, nimmt die diskursanalytische Rekonstruktion des Prinzips der Volkssouveränität bei Habermas etwa folgende Fassung an: Die Idee der Volkssouveränität realisiert sich im Modus von Selbstgesetzgebung, die über gesellschaftlich verallgemeinerte Rechtsdiskurse vermittelt ist und in einer politischen Gesetzgebung terminiert, die die Regelung der Verfahrensbedingungen zum Inhalt hat, unter denen konkrete politische Entscheidungsverfahren ablaufen, so daß ihnen Legitimität durch die Installierung und Gewährleistung angemessener Beteiligungs- und Kommunikationsformen zuwächst. Gegen diesen Typus reiner Verfahrensrationalität hat schon Peters eingewendet, $\mathrm{da} ß$ wir Verfahren in der Regel auch nach der Qualität der produzierten Ergebnisse bewerten, d.h., daß wir »die Rationalität unserer individuellen oder kollektiven Urteilsbildung ... in der Situation oder rückblickend primär davon abhängig machen (werden), ob die substantiellen Gründe gut genug waren, auf die wir uns gestützt haben « (Peters, 1991: 259) wenn wir aber einmal die Qualität der Ergebnisse als eigenständiges Legitimationskriterium anerkannt haben, müssen wir auch zugeben, daß wir gute Ergebnisse auf unterschiedlichen Wegen erreichen können, daß die Gegenstände der Entscheidungsfindung eine Selektivität bezüglich der geeignet erscheinenden Verfahren ausüben und daß schließlich Verfahren als solche und unabhängig von zusätzlichen substantiellen Entscheidungsgründen zwar rationalisierend wirken können, daß aber die Frage, »ob sie in dieser Weise ratio- 
nal legitimieren «(Peters, 1991: 269) von der Abstimmung von Merkmalen der Verfahren, der Handlungssituation und der Gegenstände der Entscheidung abhängen. ${ }^{58}$

Das erkennt Habermas zwar ausdrücklich an, indem er davon ausgeht, daß auch demokratische Verfahren einen internen Bezug auf Wahrheitssuche nicht preisgeben können (220) und ihre Rationalität daraus ableiten, daß sie die besseren Argumente zum Zuge kommen lassen und diesen Geltung verschaffen: »Die deliberative Politik gewinnt ihre legitimierende Kraft aus der diskursiven Struktur einer Meinungs- und Willensbildung, die ihre sozialintegrative Funktion nur dank der Erwartung einer vernünftigen Qualität (Herv. i.O.) ihrer Ergebnisse erfüllen kann« (369). Wenn er diesen Aspekt aber hervorhebt, kann er, und das hat Peters richtig gesehen (Peters, 1991: 269 f.), das Prinzip der Volkssouveränität kaum noch als zentrale Legitimationsformel moderner politischer Ordnungen restaurieren; ${ }^{59}$ sie erscheint vielmehr als eine regulative Idee, die in ihrer faktischen Auslegung unter den Vorbehalt gestellt werden muß, sich unmittelbar in Gestalt einer realen Beteiligung nur dort zur Geltung zu bringen, wo Beteiligung an sich als eigenständige Quelle der Rationalisierung von Entscheidungen fungieren kann. Deshalb sieht sich Habermas zu der Konzession genötigt, daß pragma-

58 Aus diesen Gründen sieht sich auch Röhl mit Blick auf die Procedural-Justice-Forschung in der Rechtssoziologie genötigt, eine Unterscheidung zu treffen zwischen der dienenden Funktion und dem Eigenwert des Verfahrens (Röhl, 1993: 6). Diese Unterscheidung zugrundelegend kann er sieben Variablen ausmachen, die sich für die Akzeptanz einer Entscheidung als bedeutsam herausstellen und von denen nur zwei den Typus prozeduraler Rationalität und Legitimität spiegeln, den Habermas im Auge hat: »das Ergebnis als solches, also seine Qualität als Belohnung oder Bestrafung (absolute outcome), das von den Beteiligten erwartete oder erhoffte Ergebnis (relative outcome), das von den Beteiligten unter dem Gesichtspunkt der Gleichbehandlung mit anderen erwartete Ergebnis (equality), das von den Beteiligten unter dem Gesichtspunkt der rechtmäßigen Behandlung erwartete Ergebnis (entitlement), das von den Beteiligten nach ihren eigenen Maßstäben als gerecht eingeschätzte Ergebnis (equity, distributive justice), die Legitimität der das Verfahren tragenden Organisation (legitimacy), die Fairness des zum Ergebnis führenden Verfahrens (procedural justice)« (Röhl, 1993: 8). Danach ist es zumindest eine empirisch offene Frage, inwieweit prozedurale Legitimität die aus der Sicht der Beteiligten oder Betroffenen vorzunehmende Bewertung und Akzeptanz der Ergebnisse substitutieren oder wenigstens beeinflussen kann.

59 Ganz andere Einwände gegen die Rekonstruktion des Systems der Rechte und des demokratischen Rechtsstaats aus der Idee der Volkssouveränität macht (aus liberaler Perspektive) Larmore (1993) geltend. Sein Bedenken gegenüber der in dieser Hinsicht radikaldemokratischen These Habermas' ist, "daß die angebliche Ableitung der subjektiven Rechte aus dem Begriff der Volkssouveränität in Wirklichkeit eher zirkelhaft ausfällt. Die Volkssouveränität, so wie sie von Habermas verstanden wird, entspringt selber der Anerkennung eines fundamentalen subjektiven Rechts «, das in einem moralischen Grundsatz gründet, »der schon als gültig angenommen werden muß: Niemand sollte durch Gewalt gezwungen werden, sich Handlungsnormen zu unterwerfen, wenn es ihm nicht möglich ist, deren Gültigkeit vernünftig einzusehen « (326 und 327). Daraus schließt er dann, da $\beta$ » >demokratische Autonomie< ... selber auf der Anerkennung eines subjektiven Grundrechts (beruht). Sie darf also nicht total sein. Radikale Demokratic ist nur als Liberalismus möglich« (327).

Dazu wäre anzumerken, daß Habermas zwar nicht auf der Ebene der Begründung, aber doch auf der Ebene der Organisation des demokratischen Rechtsstaats diesem Bedenken weitgehend entgegenkommt. 
tische und juristische Diskurse am Ein- und Ausgang des Prozeßmodells »noch am ehesten als Sache von Experten (Herv. d. Verf.) « (221) zu verstehen sind, wobei zu berücksichtigen ist, daß diese Diskurse den überwiegenden Teil der politischen Meinungs- und Willensbildung ausmachen. Das muß nicht notwendig eine Einschränkung der faktischen Bedeutung des Prinzips der Volkssouveränität nach sich ziehen, wenn und solange diese Ebenen der Willensbildung in einen mehrstufig-iterativen Prozeß der Selbstbestimmung eingebettet bleiben - einer solchen Auslegung entzieht sich Habermas indessen durch die Trennung von Staat und Gesellschaft und die komplementäre Stilisierung des Staates zum einzigen kollektiv handlungsfähigen Akteur.

Diesen radikaldemokratischen Weg wählt Habermas also nicht. Vielmehr führt er in der Folge, aus Gründen, die mit den technischen und organisatorischen Problemen der gesellschaftlichen Verallgemeinerung des Diskursprinzips zu tun haben, seine Vorstellungen wieder in die institutionellen Bahnen pluralistischer, liberal-repräsentativer Demokratien zurück. Diese entscheidende Weichenstellung vollzieht er unter dem dreifachen Eindruck der systemtheoretischen Differenzierungsthese, der kognitiven Überforderung deliberativer Politik angesichts der Komplexität des für politische Entscheidungen operativ notwendigen Wissens und der vergleichsweise schmalen Ressourcenbasis und Kompetenzaustattung des einzelnen Staatsbürgers: „Der demokratische Prozeß wird, wie die Entscheidungstheorie zeigt, > von innen < durch die Knappheit funktional notwendiger Ressourcen aufgezehrt; und snach außen< prallt er, wie die Systemtheorie behauptet, an der Komplexität undurchsichtiger und schwer beeinflußbarer Funktionssysteme ab« (390). Auch wenn er selber vor einem essentialistischen Mißverständnis einer solchen Projektion warnt, erkennt er darin doch ein Substrat »unvermeidlicher gesellschaftlicher Komplexiät« (392) und fährt fort: »In der Welt, wie wir sie kennen, besetzen Kommunikationen und Entscheidungen trivialerweise eigene Raum- und Zeitabschnitte, verbrauchen eigene Energie, erfordern einen eigenen Aufwand an Organisationsleistungen usw. Die Auswahl von Themen und Beiträgen, die unter Zeitdruck zustande kommt, verursacht überdies Kosten in terms versäumter oder verzögerter Entscheidungen. Ferner ergibt sich aus der arbeitsteilig organisierten Wissensproduktion eine ungleiche Verteilung von Kompetenzen und Kenntnissen... Zu diesen systemischen Beschränkungen kommt die zufällige Ungleichverteilung individueller Fähigkeiten hinzu. Die Ressourcen für eine Teilnahme an politischen Kommunikationen sind allgemein eng begrenzt, angefangen von der individuell verfügbaren Zeit und der episodischen Aufmerksamkeit für Themen mit eigensinnigen Karrieren, über die Bereitschaft und Fähigkeit, zu diesen Themen eigene Beiträge zu leisten, bis hin zu den opportunistischen Einstellungen, Affekten, Vorurteilen usw., die eine rationale Willensbildung beeinträchtigen« ( 395 f.).

Wer wollte diese Phänomene im Ernst leugnen? Die Frage ist nur, welche Bedeutung ihnen bezüglich Forderungen nach einer weitergehenden Demokratisierung tatsächlich zukommt. Muß man daraus wirklich den Schluß ziehen, daß kommunikative Vergesellschaftungsformen sich in die Institutionen des gewaltenteilig organisierten Staatsapparates einerseits und in die mehr oder weniger episodischen Politisierungsschübe pluraler und instabiler zivilgesellschaftlicher Öffentlichkeiten andererseits zurückziehen? Nun, ich denke nicht; und zwar dann nicht, wenn man sieht, daß die aufgezählten Defizite und Defekte des demokratischen Prozesses wenigstens zum Teil erst dann so dramatisch erscheinen, wenn man sie im (verzerrenden) Gegenlicht eines zu abstrakten (und sernantisch leeren) Kom- 
plexitätsbegriffs und einer institutionell auf den Staat verdichteten politischen Problemlösung erscheinen läßt. Dann verkennt man den modularen Aufbau des politischen Systems, die Aufstufung von Entscheidungsprozessen über viele Ebenen (lokal, regional, gesamtstaatlich) ebenso wie die vielfältigen subpolitischen Erscheinungsformen von Politik, die bessere Ansatzpunkte für eine breite und kompetente Beteiligung bieten, als sie sich Habermas zu erkennen geben - das Problem liegt dann nicht so sehr darin, daß es diese Beteiligungsformen nicht gibt oder daß sie den Anforderungen einer anspruchsvollen Willensbildung prinzipiell nicht genügen, sondern daß sie institutionell zu wenig erschlossen sind. ${ }^{60}$

Gerade diesen Weg verschließt sich Habermas aufgrund der konzeptuellen Weichenstellungen, die er an dieser Stelle vornimmt. Die Folgen dieser Entscheidung machen sich indessen unvermeidlich auch in seiner Funktionsbestimmung von Öffentlichkeit und der Charakterisierung der (bescheidenen) politischen Wirkungen der Zivilgesellschaft bemerkbar, mit denen Habermas (wie ich meine: voreilig) Reformperspektiven verschenkt, die sich aus seiner normativen Bestimmung des Modells deliberativer Politik ergeben könnten. Damit will ich nicht die oben erwähnten Spannungen leugnen, in die die Idee der Demokratie gerät, wenn man sie über Habermas hinaus zur Vorstellung gesellschaftlicher Selbstregierung zuspitzt; vielmehr steht dahinter die schwächere Behauptung, daß Habermas deshalb zu seinem demokratietheoretisch unbefriedigenden Ergebnis kommt, weil er, besorgt um den Realitätsgehalt seiner Vorstellung und gleichsam gebannt durch die Einwände der realistischen Tradition der Demokratietheorie, unvermittelt von der normativen Ebene zu wenig ermutigenden empirischen Bestandsaufnahmen übergeht, ohne den Zwischenschritt einer institutionellen Analyse und der entsprechenden Entwicklung institutioneller Reformvorstellungen zu unternehmen.

Diese Zurückhaltung hängt zweifellos aber auch mit der grundlegenden Funktionsbestimmung zivilgesellschaftlicher Öffentlichkeiten selber zusammen, in der sich unterschiedliche und nicht ohne weiteres miteinander kompatible Anforderungen kreuzen. Ihre Ressourcenbasis liegt in der spezifischen Sensibilität für lebensweltlich bestimmte Erfahrungen, sie bezieht »ihre Impulse aus der privaten Verarbeitung lebensgeschichtlich resonierender gesellschaftlicher Problemlagen« (442 f.): danach kann die Öffentlichkeit ihre Funktion nur in dem Maße erfüllen, » wie sie sich aus den Kommunikationszusammenhängen der potentiell Betroffenen bildet (441) und sich auf die »Allgemeinverständlichkeit der kommunikativen Alltagspraxis einstellı (436). In dieser Perspektive erscheint sie als ein sozialer Raum (ebda.), in den hinein sich eine Institutionalisierung organisierter Kommunikationsflüsse nur um den Preis einer Zerstörung der spontanen, aber fragilen Interaktionsnetze vorantreiben ließe. Andererseits müssen diese Öffentlichkeiten, wenn sie mehr als den bloßen Resonanzboden für Probleme beschreiben und politische Wirkung im Sinne einer Erhöhung des Problemdrucks auf das politische System entfalten sollen (435), auch einen spezifischen Konzentrations- und Verdichtungsgrad aufweisen können, der es erlaubt, ansonsten diffuse Aufmerksamkeiten und Energien so zusammenzufassen, daß sie »Probleme nicht nur wahrnehmen und identifizieren, sondern auch überzeugend und ein-

60 Darauf komme ich im zweiten und insbesondere im dritten Abschnitt der Arbeit ausführlich zurück. 
flußreich (Herv. i.O.) thematisieren, mit Beiträgen ausstatten und so dramatisieren, daß sie vom parlamentarischen Komplex auch übernommen und bearbeitet werden« (ebda.).

Diese Stilisierung legt jedenfalls nahe, daß man beides zugleich nicht haben kann; und das insbesondere dann nicht, wenn man verschärfend davon ausgeht, daß eine erfolgreiche Einflußnahme von Öffentlichkeiten auf den Komplex der parlamentarischen Willensbildung und administrativen Problembearbeitung sich nur dann einstellen wird, wenn es gelingt, die öffentliche Meinungsbildung und Problembearbeitung in sachlicher, zeitlicher und sozialer Hinsicht besser auf die staatlich-administrativen Entscheidungsroutinen abzustimmen: in sachlicher Hinsicht steigen die Wirkungschancen, wenn öffentliche Diskussionen sich auf Beiträge und Problemlösungen richten, die zu den staatlich-politisch zu behandelnden Problemen auch passen - wenn sie also thematisch interferieren; zeitlich gesehen müßte die Öffentlichkeit mit einem ausreichend langen Atem versehen werden, um den aufwendigen Prozeß einer anspruchsvollen Willensbildung gerade bei komplexen Problemlagen auch durchzuhalten; in sozialer Perspektive dürfte einiges davon abhängen, inwieweit es gelingt, unterschiedliche Akteure (Staat, Zivilgesellschaft, Verbände, Unternehmen, Interessengruppen o.ä.) in einen gemeinsamen Handlungszusammenhang von "policy-communities" einzubinden, die sich in einzelnen Politikbereichen wie um Einzelfallentscheidungen herum ausbilden. Vor diesem Gegenbild einer im ganzen politisch strukturierten zivilgesellschaftlichen Öffentlichkeit schreckt Habermas, wie gesagt, zurück und nimmt im Gegenzug dafür die Einschätzung in Kauf, daß »die Gruppierungen der Zivilgesellschaft zwar problemsensitiv (sind), aber die Signale, die sie aussenden, und die Impulse, die sie geben, im allgemeinen zu schwach (sind), um im politischen System kurzfristig Lemprozesse anzustoßen oder Entscheidungsprozesse umzusteuern (Herv. d. Verf.) (451). Der Grund für diese Entscheidung allerdings ist nicht recht einsichtig. Er kann nicht (oder jedenfalls nicht allein) darin liegen, daß er wegen der dann erforderlichen organisatorischen und institutionellen Strukturierung zivilgesellschaftlicher Handlungs- und Kommunikationszusammenhänge eine Unterbrechung des in spontanen öffentlichen Kommunikationen vermittelten lebensweltlichen Reproduktionszusammenhangs befürchten muß - hier könnte man ja eine (dezentrale) Institutionalisierungsebene für gesellschaftliche Willensbildungsprozesse ins Auge fassen, die eine gewisse auch räumliche Nähe zu lebensweltlichen Erfahrungen verbürgte. Vielmehr speist sich seine Skepsis, die Zivilgesellschaft als einen Fokus zu betrachten, »in dem sich die Strahlen einer Selbstorgansisation der Gesellschaft im ganzen konzentrieren « (449), wenn ich recht sehe, aus zwei miteinander verbundenen Quellen: er schreckt vor dem unmittelbaren Einfluß populistischer Bewegungen, vor einer Politik der Straße zurïck, die nicht mehr nur von emanzipatorischen Potentialen, sondern auch von »blinden«, regressiven Kräften (etwa: rechtsradikale soziale Bewegungen) ${ }^{61}$ getragen ist (449); und er behauptet deshalb den Primat einer staatlich konzen-

61 Insofern stimmt die Einschätzung gerade nicht, daß Habermas in seinem »Enthusiasmus « für die Kategorie der Zivilgesellschaft vergißt, »die demokratischen Impulse der Zivilgesellschaft wirksam vom Druck der Straße zu unterscheiden «(Dews, 1993: 362). Vielmehr läßt er sich von dieser Ambivalenz so sehr beeindrucken, daß er sich gezwungen sieht, eine sehr zurückhaltende Bestimmung der politischen Funktionen der Zivilgesellschaft vorzunehmen. 
trierten Entscheidungsfindung, weil ihm nur so zu gewährleisten scheint, daß die gesellschaftlichen Impulse durch die institutionellen Filter einer rechtsstaatlich gebundenen Politik hindurch müssen und einem Prozeß der kognitiven und moralischen Raffinierung ausgesetzt werden (439). Daß entgegen der Habermasschen Sichtweise das Moment einer institutionell ausgelegten Reflexivität demokratischer Prozesse nicht exklusiv an das staatliche Institutionensystem gebunden werden muß, sondern daß diese Reflexivität sich auf gesellschaftliche Beteiligungsformen durchaus »absenken« (Maus) läßt, möchte ich später zeigen. Zunächst ist bemerkenswert, daß es vor dem Hintergrund dieser Vorbehalte bei Habermas mehr oder weniger zwangsläufig zu einer eher äußeren Gegenüberstellung von spontaner Öffentlichkeit und zentralisierter, institutioneller Politik kommt, die schließlich auch die Art des Zusammenspiels beider Bereiche bestimmt: Nur unter der Bedingung krisenhafter Zuspitzungen können sich die Kräfteverhältnisse zwischen Staat, vermachteten (Medien-) Öffentlichkeiten und nicht-institutionalisierten öffentlichen Kommunikationen verschieben (461), während im Routinemodus von Politik diese Öffentlichkeiten gleichsam im Ruhe- oder Wartezustand verharren (458).

Unter diesen Vorzeichen ist es dann auch nicht mehr überraschend, daß der nurmehr sporadisch in die Gesellschaft und die öffentliche Debatte hinein verlängerte Prozeß der Rechtserzeugung in Gestalt des zivilen Ungehorsams (462 ff.) und eines historischen Verfassungsverständnisses (464 ff.) zum gewichtigsten Bezugspunkt der Explikation gesellschaftlicher Beteiligung wird: "Jede historische Verfassung hat einen doppelten Zeitbezug: als geschichtliches Dokument erinnert sie an den Akt der Gründung, den sie interpretiert...; zugleich besagt ihr normativer Charakter, daß sich die Aufgabe der Interpretation und Ausgestaltung des Systems der Rechte für jede Generation von neuem (Herv. i.O.) stellt...Unter diesem Aspekt eines auf Dauer gestellten Prozesses fortgesetzter (Herv. i.O.) Verfassunggebung gewinnt das demokratische Verfahren der legitimen Rechtsetzung einen ausgezeichneten Stellenwert. Deshalb drängt sich die Frage auf, ob und gegebenenfalls wie in komplexen Gesellschaften unseres Typs ein derart anspruchsvolles Verfahren so wirksam implementiert werden kann, daß sich ein rechtsstaatlich normierter Machtkreislauf im politischen System durchsetzt « (464 f.). An dieser Formulierung, mit der Habermas seinen demokratischen Erwartungen noch einmal einen kompakten Ausdruck verleiht, fällt indessen dreierlei auf, was ihren demokratietheoretischen Wert auch mindert: die Frequenz dieses Aktivierungsmodus demokratischer Politik bleibt durch ihre Ausrichtung am Generationenwechsel deutlich unterhalb der Schwelle kontinuierlicher und effektiver Teilhabeansprüche; er bleibt auf die Durchsetzung eines rechtsstaatlich normierten Machtkreislaufs im politischen System (d.i. der gewaltenteilige Rechtsstaat) begrenzt und umfaßt nicht eher mikrokonstitutionelle Prozesse der gesellschaftlichen Selbstorganisation politischer Entscheidungsprozesse; nur deshalb kann Habermas schließlich die selbst gestellte Frage nach den angemessenen Ebenen und Formen der Institutionalisierung entsprechender Verfahren offenlassen und sich im folgenden ( $465 \mathrm{ff}$.) erneut auf allgemeine Hinweise zur Bedeutung legitimen Rechts für die Operationsweise einer funktional spezifizierten Politik beschränken.

c) Man muß also letztlich mit einer gewissen Ernüchterung feststellen, daß Habermas das demokratische Prinzip der Volkssouveränität so durch mehrere, hintereinan- 
der gelegte Filter hindurchführt, an denen fast alle auf Selbstorganisation und Selbstregierung hin ausgelegten Aspekte der Idee der Demokratie hängenbleiben, daß er am Ende den Anspruch einer demokratischen Gestaltung von Politik in die institutionellen Bahnen einer liberalen, repräsentativen Demokratie zurückführt. Diese Filter werden gebildet durch eine wesentlich am Staat festgemachte »kollektive Handlungsfähigkeit«, zweitens durch die Anerkennung einer »unvermeidlichen« gesellschaftlichen Komplexität, an der, in Gestalt der Autonomie funktionaler Subsysteme, weiterreichende Teilhabeansprïche einfach auflaufen und drittens durch eine besonders im Gegenlicht einer anspruchsvollen, rationalen Problemlösung als mangelhaft erscheinende Kompetenz der einzelnen Staatsbürger. Diese Überlegungen bindet Habermas in einem »Schleusenmodell« demokratischer Politik, das er von Peters (1993: 344 ff.) übernimmt, noch einmal zusammen: »Nach diesem Vorschlag sind die Kommunikationsund Entscheidungsprozesse des rechtsstaatlich verfaßten politischen Systems auf der Achse Zentrum-Peripherie angeordnet, durch ein System von Schleusen strukturiert und durch zwei Arten der Problemverarbeitung gekennzeichnet« (429 f.).

Das Problem ist nun nicht, daß wir durch diesen rekonstruktiven Ansatz auf der deskriptiven Ebene wenig Neues erfahren. Hier erscheinen Verwaltung und Regierung, das Gerichtswesen und die parlamentarische Willensbildung (mit den zugehörigen Momenten politischer Wahlen und der Parteienkonkurrenz) als Kernbereich des politischen Systems, um den herum sich eine »innere Peripherie « solcher Institutionen ausbildet, die mit formellen Selbstverwaltungsrechten und delegierten Kontroll- oder Hoheitsfunktionen ausgestattet sind (Universitäten, Stiftungen, Wohlfahrtsverbände o.ä.). Darum herum legt sich dann eine »äußere Peripherie«, die von (korporatistischen) Verhandlungssystemen, Verbänden, Interessengruppen, medial vermachteten und eben spontanen, zivilgesellschaftlichen Öffentlichkeiten gebildet wird. Daran ist nichts auffällig, wenn man zum einen von der Frage absieht, ob die formale Unterscheidung von innerer und äußerer Peripherie auch der faktischen Gewichtung in den Strukturen der Willensbildung entspricht, und wenn man zum zweiten darüber hinwegsieht, daß mit der Unterscheidung der äußeren Peripherie in »Abnehmer« und »Zulieferer « schon eine gewisse Vorentscheidung über die Art und Qualität der gesellschaftlichen Einflußnahme auf die staatliche Politik vorgenommen wird. Abgesehen davon erhält dieses Bild seine eigentlichen Konturen erst durch die Einführung der erklärenden Momente des Schleusenmodells und zweier die Richtung der Kommunikationsflüsse bestimmenden Problemverarbeitungsmodi (431). Danach sind die Schleusen jene rechtsstaatlichen und demokratischen Verfahren, die von Entscheidungen passiert werden müssen, um Legitimität zu erhalten, und die Problemverarbeitungsmodi sind einerseits Handlungsroutinen, innerhalb derer Kommunikationen wesentlich vom Zentrum zur Peripherie verlaufen und andererseits der Modus der Problematisierung, in dem sich der Kommunikationsfluß umkehrt (432 f.). Das Ergebnis dieser Anordnung ist dann kurz gesagt folgendes: Es gibt wenig Anlaß, den Routinemodus von Politik einer grundlegenden institutionellen Revision zu unterziehen, solange die Schleusen des gewaltenteilig operierenden Rechtsstaats im Zentrum der staatlichen Willensbildung funktionstüchtig bleiben, denn »viele dieser (in Gegenrichtung zum offiziellen Machtkreislauf der Volkssouveränität, der Verf.) fließenden Kommunikationen dienen einer 
gleichsam unschädlich problemzerkleinernden Entlastung (!) des offiziellen Kreislaufs von unvermeidlicher Komplexität« (432). Schon dadurch wird die gesellschaftliche Meinungsbildung in eine Reservefunktion gerückt, die kaum mehr als eine Ausfallbürgschaft für den Routinemodus übernehmen kann. Darüber hinaus ist es dann nur noch diese enge Spezifizierung, der Habermas einen normativen Gehalt derart abgewinnen möchte, daß »(die Peripherie) diese starken Erwartungen nur in dem Maße (wird) erfüllen können, wie die Netzwerke der nicht-institutionalisierten öffentlichen Kommunikation mehr oder weniger spontane Meinungsbildungsprozesse ermöglichen « (434). Hiermit zielt er letztlich auf die Strukturen einer rationalisierten Lebenswelt und eine darin verankerte politische Kultur, die sich institutionell nicht erzeugen, sondern bestenfalls »stimulieren« läßt - damit entzieht er zwar Forderungen nach einer institutionellen Umsteuerung des demokratischen Prozesses nicht den Boden, aber er bricht ihnen doch die Spitze: Zwar müssen wir, wie Mouffe (1992: 293) zu Recht bemerkt, den fragilen Charakter politischer Institutionen in Rechnung stellen, die nicht im Boden einer demokratischen Kultur verankert sind; aber dieser Boden läßt sich nicht allein dadurch konsolidieren, daß wir das bestehende liberale Institutionensystem auf seine rationalen Grundlagen zurückführen, sondern in erster Linie dadurch, daß wir die institutionellen Praktiken, in die sie sich »einschreiben« können (Mouffe), vervielfältigen.

d) Wie wir gesehen haben, zielt Habermas' normatives Modell von Öffentlichkeit im Kern auf das Problem ab, wie der Zusammenhang zwischen der kulturellen Reproduktion pluralistischer Gesellschaften und der Rationalisierung einer nach wie vor staatlich konzentrierten politischen Willensbildung und Entscheidungsfindung zu begreifen ist. Dabei verbleibt er, geleitet von der Sorge um die rechtsstaatliche Qualität moderner Demokratien, allerdings im wesentlichen im Horizont der institutionellen Logik der repräsentativen Demokratie; und der normative Gehalt seiner politischen Theorie verdankt sich in erster Linie dem gerechtigkeitstheoretischen Anliegen, verbindliche Antworten auf die Frage zu geben, was gleichermaßen gut für alle ist und sich von Fragen des guten Lebens, nach der Legitimität individueller Glückserwartungen also, zu dispensieren (Habermas, 1990a: 118). Der normative Status seines Begriffs von Öffentlichkeit ergibt sich dann aber daraus, daß Antworten nurmehr im Rahmen einer realen argumentativen Praxis gefunden werden können, die zugleich die selbstbezügliche Funktion hat, sich selbst zu stabilisieren und mit »jedem zentralen Beitrag den Sinn einer unverzerrten politischen Öffentlichkeit überhaupt und das Ziel demokratischer Willensbildung selbst präsent (zu) halten« (Habermas, 1989: 30). Damit handelt er sich natürlich die Schwierigkeit ein, die Realitätsmächtigkeit dieses normativen Begriffs von Öffentlichkeit angesichts der Vernunftansprüche, die dem Prinzip der Publizität von vomherein anhaften wie zusätzlich jener durch den »Strukturwandel der Öffentlichkeit« aufgerissenen Probleme struktureller Realisierungshemmnisse auszuweisen und plausibel zu machen (Habermas, 1990: 33). Im Kern ging es dabei um die Behauptung der »Wahrheitsfähigkeit praktischer Fragen « (Habermas, 1973), um die Verklammerung diskursiver Praktiken mit dem demokratischen Wandel der Institutionen einer freiheitlichen Gesellschaft (Habermas, 1976) wie schließlich um die Lokalisierung und Erschließung der Rationalitätspotentiale, die in den Prozeß 
der vernünftigen kollektiven Willensbildung einzuspeisen sind (Habermas, 1981). Die entscheidende konzeptuelle Weichenstellung jedoch, mit der er die theoretischen Umstellungen eingeleitet hat, die jene nach eigener Auskunft im »Strukturwandel « offen gebliebenen Fragen lösen sollten (Habermas, 1990: 33-44), hat er mit dem Versuch unternommen, die normative Idee von Öffentlichkeit im kommunikativen Handeln als dem Modus der Reproduktion komplex ausdifferenzierter Gesellschaften selber zu verankern. Die Unterscheidung von Lebenswelt und System, die er in einer zweistufig und eben nicht dualistisch gemeinten Gesellschaftstheorie integriert hat, hatte von vornherein auch den Sinn, ein grundsätzliches Argument gegen die von manchen empirischen Evidenzen gestützte These aufzubieten, daß »die Öffentlichkeit in postliberalen Gesellschaften liquidiert wird « (Habermas, 1981: II, 571). Mit dieser Lösung ergeben sich jedoch sofort zwei Probleme: zum einen bleibt in die Vorstellung einer im Reproduktionsmechanismus der Lebenswelt im ganzen normativ integrierten Gesellschaft (d.i. die These der Zweistufigkeit) der Gegensinn einer eigenlogischen Reproduktion von Lebenswelt und System (d.i. die These vom Dualismus faktisch auseinandergetretener Handlungssphären) eingelagert, so daß die Frage entsteht, welche denn die Kanäle und Mechanismen sind, über die die diskursive Praxis der Öffentlichkeit in die staatlich-institutionelle Willensbildung und administrative Entscheidungsfindung eindringt; zum zweiten kommt verschärfend hinzu, daß die Idee der Öffentlichkeit im Zusammenhang der Kolonisierungsthese eine von vornherein defensive Auslegung erfährt, was in der Folge dazu führt, daß Öffentlichkeit primär als grenzerhaltendes, auf die formale, aber nicht die materiale Rationalisierung von Politik bezogenes Handlungssystem konzipiert wird.

Die Antwort, die Habermas auf das erstgenannte Problem gibt, lautet bekanntermaBen: Recht (Habermas, 1992: 151 ff.; vgl. aber schon Habermas, 1987 und 1989a). Das bietet sich deshalb an, weil Recht nicht nur das Medium der Transformation von Herrschaft in legitime Herrschaft und Instrument staatlicher Steuerung ist, sondern weil ihm ein Moment der Unverfügbarkeit und Soll-Geltung anhaftet, das nur dann nicht überstrapaziert wird, wenn es in den moralischen Überzeugungen der Gesellschaftsmitglieder verankert ist und sich offenhält für moralische Diskurse, in denen der Geltungsanspruch von Normen argumentativ geprüft werden kann. Damit ist das demokratietheoretisch dringende Problem der Durchbrechung eines selbstrekursiven Kreislaufs von Macht und Recht insofern gelöst, als sich aus der Doppelstruktur des Rechts die normative Forderung ableiten läßt, die Prozesse einer institutionellen Willensbildung offenzuhalten für eine gesellschaftliche, öffentliche Willensbildung, der zudem mit Blick auf die argumentativen Voraussetzungen moralischer Diskurse eine vernünftige, kognitive Struktur eingeschrieben werden kann (Habermas, 1989a: 152): das sind die guten Gründe, die von der Öffentlichkeit wie ein »Pool« verwaltet werden und aus denen sich die administrative Praxis, die sich ihre Legitimität nicht selbst besorgen kann, auch bedienen muß (Habermas, 1989: 31). Diese Gründe beziehen sich also nicht unmittelbar auf sachliche Fragen, auf die Inhalte und Ergebnisse politischer Entscheidungsprozesse, sondern sie zielen auf die Einrichtung von Verfahren, die die Legitimität solcher Entscheidungen erhöhen und die sich nach dem Muster indirekter Steuerung auswirken sollen (Habermas, 1989: 28). 
Diese Fokussierung auf das Recht bietet zunächst einmal den gewiß nicht zu unterschätzenden Vorteil, daß die liberale Disjunktion der Idee der Menschenrechte und des Prinzips der Volkssouveränität, der klassischen Freiheitsrechte und der politischen Bürgerrechte, mithin die Gegenüberstellung von privater und öffentlicher Autonomie überwunden werden kann (Habermas, 1994: 88 ff.) und zudem die Vermittlung von Faktizität und Geltung damit näher an die institutionelle Wirklichkeit der Gesellschaft herangeführt wird, als es im abstrakten Licht eines stark idealisierenden Begriffs politischer Öffentlichkeiten möglich ist. Dieser progressiven Tendenz wird freilich dann die Spitze genommen, wenn die Konzentration auf die Verfahrensform durch das Absehen von inhaltlichen und substantiellen Fragen, von an die Verfahrensergebnisse anzulegenden materialen Gütekriterien, die zugleich die Akzeptanz von Verfahren beeinflussen und ein wichtiges Motiv für Verfahrensinnovationen bilden, erkauft wird (vgl. auch Angehrn, 1993: 260). An dieser Stelle muß dann Habermas' Vorschlag der Aufspaltung der unterschiedlichen Formen der politischen Willensbildung entlang der Einteilung politischer Fragen in pragmatische, ethisch-politische und moralisch-praktische Fragen eine besonders unglückliche Wirkung entfalten, weil sie zum einen die Angriffsflächen kommunikativer Macht im Zustand der bloßen Belagerung des politisch-administrativen Systems ein weiteres Mal reduziert. Zum anderen handelt er sich durch dieses »terminologische fiat«, wie Kettner zutreffend hervorhebt, ein »problemsorting-problem《 derart ein, daß die »...taxonomy of pragmatic, `ethical< and `moral discourses, though heuristically useful, has no rational credentials to offer to parties who may want to employ it in a dispute whenever the issue is such that already the way to sort the problem, or to sort sub-problems within an agreed common ground of a problem area, is part of the dispute « (Kettner, 1995: 13) - ein immerhin in politischen Prozessen der Problemlösung nicht gerade seltenes Phänomen. Dieser Einsicht aber müßte man, über Habermas Empfehlungen hinaus, durch solche Verfahrenskriterien Rechnung tragen, die eine rekursive Verfahrensanlage nahelegen und einen besseren Substitutions- oder Ausdruckswert für materiale Gütekriterien enthalten. So hat etwa Schmidt (1993: 94 f.) sechs in diesem Zusammenhang einschlägige Kriterien zusammengestellt: Danach fordert das Kriterium der Vollständigkeit, daß die Entscheidungsregeln gewährleisten, daß die für »einen gegebenen Problemkomplex relevanten normativen und instrumentellen Gesichtspunkte auch tatsächlich auf die Agenda gelangen und angemessene Berücksichtigung finden«; unter »Offenheit für Information« ist gefaßt, daß die Verfahren die Berücksichtigung eines Maximums an Informationen gewährleisten, während »voice « dafür steht, »daß die von einer Entscheidung direkt oder indirekt Betroffenen Gelegenheit erhalten, ihre spezifischen Sichtweisen, Anliegen, Interessen und Gerechtigkeitsvorstellungen mit einer realistischen Aussicht, den Entscheidungsprozeß zu beeinflussen, zur Geltung bringen können «; das macht Reversibilitätsregeln erforderlich, die gegebenenfalls eine Korrektur von Entscheidungen und Entscheidungsregeln ermöglichen sollen; daneben treten schließlich unterstützend Transparenzregeln und die Institutionalisierung von Rechenschaftspflichtigkeit.

Zwar können Verfahren auch in dieser qualifizierten Form keine Gewähr dafür bieten, daß am Ende gute, sachlich angemessene und normativ richtige Entscheidungen stehen - auch weil eine verfahrensunabhängige Bestimmung der Güte von Entschei- 
dungen keine politische, und schon gar keine demokratische, Option darstellt; aber hier verzahnt sich enger als bei Habermas die rationalisierende Wirkung mit einem demokratisch-partizipatorischen Verfahrensformat, und es wird eine gesellschaftsweite Dislozierung auch von entscheidungsbezogenen Verfahren möglich, die sie aus dem engen Fokus staatlicher Politik und staatlicher Institutionen herausführen. Ein darauf bezogenes institutionelles Design hätte aber nicht nur Verständigungspotentiale zu fördern und zu hegen, sondern die Chancen für ein konsensorientiertes, ergebnis- und entscheidungsbezogenes Handeln gesellschaftlicher Akteure zu verbessern. Diese Perspektive einer weitergehenden Vergesellschaftung des Staates läßt den m.E. neuralgischen Punkt moderner Demokratietheorie deutlich hervortreten, an dem sich der Anspruch auf erweiterte Partizipation mit den Anforderungen einer problem- und ergebnisbezogenen, oft expertiseabhängigen Politik verbinden muß - aber auch hier stellen die Öffentlichkeit und für allgemeine Teilhabeansprüche offene Strukturen unverzichtbare, wenn auch noch wenig erschlossene Ressourcen dar. Das ist offensichtlich auch der Grund, der Habermas dazu veranlaßt, die prozeduralen Momente eines Modells deliberativer Politik stark in den Vordergrund zu rücken, die ja zugleich die Nötigung wie die Chance für die Beteiligten beinhalten, sich der konstitutionellen Aspekte von Politik und damit auch der Bedingungen anzunehmen, unter denen ein problembezogener Informationszufluß und eine sachgerechte Verarbeitung von Informationen in demokratischen Entscheidungsprozessen gewährleistet werden können (Habermas, 1992: 360). Freilich läßt er sich in seinen Erläuterungen zu diesem Modell m.E. noch zu sehr von der Vorstellung eines gegenläufigen Kommunikationsflusses zwischen der Peripherie pluraler gesellschaftlicher Öffentlichkeiten und dem politisch-administrativen Zentrum leiten. Diese Gegenläufigkeit ergibt sich für ihn aus der Hierarchie moralischer, ethischer und pragmatischer Fragen einerseits, über die sich die Öffentlichkeit, vermittelt in der Idee und Praxis des Rechts, einen Zugang ins Zentrum der politischen Entscheidung verschaffen kann und der unvermeidlichen Abstufung von Entscheidungs- und Problemlösungskompetenzen vom Zentrum zur Peripherie andererseits (Habermas, 1992: 431 ff.). Beide Prozesse interferieren nun aber nur außerhalb der Routinen des politischen Alltags in außerordentlichen, konstitutionellen Momenten, in denen die moralische Regelung von Konflikten und die ethische Sicherung von Identitäten und Lebensformen selber auf dem Spiel stehen (Habermas, 1992: 388). Darin artikuliert sich sicherlich auch ein berechtigter Vorbehalt gegenüber der Überstrapazierung komplexer, diskursiver Meinungs- und Willensbildungsverfahren; entscheidend aber ist, daß sich Habermas durch diese strikte Funktionstrennung von den mikrokonstitutionellen Aspekten auch normaler Politik und damit der integrierten Bearbeitung von normativen, Wert- und Sachfragen und der horizontalen Zusammenführung von Akteuren in wichtigen Politikarenen auch ablenken läßt, die einen, wie ich meine, besseren Ansatzpunkt für die Konzeptualisierung eines Modells deliberativer Politik bilden. 


\section{II}

Das Modell der »reflexiven Demokratie« 
Wie wir gesehen haben, hat Habermas in »Faktizität und Geltung « den systematischen und breit angelegten Versuch unternommen, das Verständnis des modernen demokratischen Gemeinwesens auf den Modus einer normativen Vergesellschaftungsform zu beziehen, die er zehn Jahre zuvor im Begriff des kommunikativen Handelns expliziert und entfaltet hatte. Gewiß waren einige der Weichenstellungen, mittels derer er die Verschränkung von Handlungs- und Demokratietheorie vorzubereiten gedachte, schon damals erkennbar (vgl. Scheit, 1987). Das betrifft vor allem die grundlegende Intuition, daß der demokratische Prozeß als Modell des Projekts der Moderne fungieren könne, nämlich die Einheit der Vernunft in der sich prozessual verschränkenden Vielheit ihrer Stimmen zum Ausdruck zu bringen. Andererseits blieb angesichts der binären Kontrastierung von $>$ System $<$ und $>$ Lebenswelt $<$ und der daraus resultierenden Ambivalenz der Kolonialisierungsthese noch unklar, welchen Status er dem Modus der kommunikativen Vergesellschaftung wirklich einräumen wollte. An dieser Stelle hat er nun, wie gezeigt, Klarstellungen vorgenommen, mit denen er sich nach beiden Seiten hin absichern will: gegen den Verdacht einer vollständigen systemischen Absorption von Politik einerseits und den sich dazu spiegelbildlich verhaltenden Vorwurf einer unrealistischen, letztlich utopischen Überzeichnung der Kraft und Wirkungschancen des diskursiven, konsensorientierten Handelns andererseits. Zu diesem Zweck nimmt er zum einen Differenzierungen im Begriff des politisch-administrativen Systems vor, das nun nicht mehr als festgefügter Block aus Imperativen instrumentellen und strategischen Handelns erscheint, sondern als arbeitsteiliges Zusammenspiel von Parlament, Verwaltung und Judikative, in dem moralische, ethische und pragmatische Fragen wie die darauf bezogenen Modi des Vernunftgebrauchs ihr Eigengewicht behalten und sich zugleich verschränken; vor diesem Hintergrund kommt er auch zu einer Neueinschätzung der politischen Funktion gesellschaftlicher Öffentlichkeiten und der neuen sozialen Bewegungen. Zum zweiten tritt der Begriff des Rechts in seiner Scharnierfunktion zwischen dem Modell kommunikativer Vergesellschaftung und der soziologischen Analyse der Integration komplexer Gesellschaften deutlicher hervor: gerade das legitimationsanfällige, vollpositivierte Recht kann seine Geltung nur durch den Rückbezug auf den gesellschaftlichen Erzeugungszusammenhang, in dem es sich im Modus argumentativ einzulösender Geltungsansprüche reproduziert, behaupten - in diesem Zusammenhang ist Habermas Entscheidung zu sehen, die Geltung subjektiver Rechte im Prinzip der Volkssouveränität zu begründen (kritisch dazu: Larmore, 1993: 325 ff.).

Dieses Dreiecksverhältnis von Recht, zivilgesellschaftlicher Öffentlichkeit und einer reflexiv ausgelegten, arbeitsteiligen staatlichen Politik dient ihm nunmehr als guter Ansatzpunkt für eine soziologische Übersetzung des Modells deliberativer Politik. Dabei wird vor allem die Rekonstruktion der reflexiven Logik des staatlichen Institutionensystems zum Bezugspunkt einer immanenten Kritik der repräsentativen Demokratie; allerdings mit der Konsequenz, daß diese dabei eine im Prinzip so überzeugende Gestalt annimmt, daß die Erweiterung der repräsentativen zu einer partizipatorischen, zivilgesellschaftlichen Demokratie nicht nur als weitgehend unrealistisch, sondern auch im Ganzen als unnötig erscheint.

Die daraus resultierenden perspektivischen Beschränkungen des Projekts der Demokratie sind denn für Cohen und Arato auch der Anlaß, die Rolle der Zivilgesell- 
schaft im Zusammenhang der politischen Vermittlung moderner Gesellschaften noch einmal zu überdenken und hinsichtlich einer gesellschaftlichen Form der Selbstorganisation und Selbstinstituierung aufzuwerten (Kap. 4). Dieser Impuls bleibt aber schließlich dadurch stecken, daß sie den Prozeß der gesellschaftlichen Differenzierung selber system- und nicht handlungstheoretisch begreifen. Durch diese begriffliche Entscheidung wird aber von vornherein die Reichweite und Tiefenwirkung möglicher Demokratisierungsprozesse erheblich beschränkt. Darauf beziehen sich denn auch die Modifikationen, die ich bezüglich der Grundannahmen und Aufgabenbeschreibung des Projekts einer zivilgesellschaftlich erweiterten Demokratie vornehmen werde (Kap. 5), um dann den Vorschlag zu machen, die Vorstellung einer reflexiven Fortsetzung des Projekts der Demokratie unter Bezug auf die Idee einer reflexiven Demokratie zu radikalisieren (Kap. 6). Das hat selbstverständlich wichtige institutionelle Implikationen, die insgesamt einen Funktionswandel staatlicher Institutionen nahelegen, der sich allerdings über Modifikationen und Ergänzungen des institutionellen Repertoires der repräsentativen Demokratie vollziehen kann, ohne mit der darin angelegten Logik brechen zu müssen (Kap. 7). 


\section{Zum Konzept der »Civil Society«}

Die Attraktivität des demokratietheoretischen Paradigmenwechsels zum Modell der deliberativen Demokratie verdankt sich zweifellos auch des besonderen historischen Umstands des Endes der kommunistischen Welt, das zudem mit ausführlichen Besinnungen auf das Erbe der französischen Revolution und ihrer zweihundertjährigen Geschichte zusammenfiel. Diese führten zu einer auffälligen Revitalisierung des Konzepts der Bürgergesellschaft und einer (zumindest versuchsweisen) Wiedereinsetzung des Bürgers »als zentraler Akteur in allen gesellschaftlichen Lebensbereichen «, womit, wie Preuß zu Recht hervorhebt, eine doppelte Stoßrichtung verbunden war: »gegen alle philosophischen Doktrinen, die das individuelle Selbstinteresse zur normativen Grundlage der Sozialpflichten des Individuums erklären « und zum anderen dagegen, »daß das Individuum als bestimmender gesellschaftlicher Akteur zunehmend an den Rand gedrängt wird ...« (Preuß, 1994: 130). Und jenes machte auf die politische Bedeutung sozialer Bewegungen und außerinstitutioneller Formen politischer Meinungs- und Willensbildung aufmerksam, so daß beides in der "suggestiven Formel « (Dubiel) einer zivilgesellschaftlichen Erneuerung der Politik zusammengeschlossen werden konnte. An diese Projektion hefteten sich dann schnell (trotz oder gerade wegen der durchaus auffälligen begrifflichen und konzeptuellen Unschärfen) weitere Motive an: der Suche nach einem Ersatzkandidaten für das aufgegebene Projekt einer revolutionären Eroberung des Staates auf seiten der Linken und neuer Perfektionsbegriffe für politische Ordnungen jenseits von liberaler Demokratie und »totalitärem« Sozialismus, einem Bestreben, dem die gleichzeitige Diskussion um die (Neu)Begründung der Idee des politischen Liberalismus zusätzlich ein Stück weit entgegenkam (vgl. Dubiel, 1994: 68 f.).

Weniger eindeutig als diese Motivlage freilich war (und ist) der begriffliche und normative Status des Konzepts der Zivilgesellschaft. Die Kategorie der »Civil Society«, so hebt Tester in seiner ideengeschichtlich angelegten Rekonstruktion der Genese des Konzepts vor allem im 17. und 18. Jahrhundert hervor, bezeichnete nie eine klar umrissene, gesellschaftliche Wirklichkeit. Sie war (und ist) in dem genauen Sinne eine Idee, die auf die Frage antworten sollte, wie die autonome Produktion und Reproduktion einer Gesellschaft von (individualisierten) Fremden möglich sein könnte: »Hence, and to put it all extremeley schematically, the imagination of civil society is best interpreted as a modern social and historical attempt to understand the possibility of the reproducibility of society in situations where the natural artifice had been drastically deconstructed « (Tester, 1992: 35). ${ }^{62}$ Sie ist, so die in Anlehnung an Castoriadis akzentuierte These, die Reflexionsform einer modernen Ordnung, die ihre Stabilität und Legitimität aus sich selber, und d.h. aus den Interaktionsbeziehungen der sie konstituierenden individuellen Subjekte hervorbringen muß, ohne auf transzendente Ordnungsgarantien zurückgreifen zu können. 
Zweifellos ist dies genau die Intuition, von der sich auch Rödel u.a. (1989) zu ihrer Rekonzeptualisierung der autonomen Gesellschaft als eines selbstbezüglichen, zivilgesellschaftichen Handlungszusammenhangs anregen lassen. Was sie dabei allerdings aus den Augen verlieren, ist der andere Teil der Botschaft, den die Ideengeschichte des Konzepts der Zivilgesellschaft auch enthält: daß die autonome Praxis nur gelingen kann, wenn sich der Prozeß der Produktion und Reproduktion gesellschaftlicher Ordnung unter allgemeine Normen stellen kann, die ihm selber in gewisser Weise unverfügbar bleiben. Diese Stelle kann, und darauf machen so unterschiedliche Traditionen wie der bürgerhumanistische Tugenddiskurs, die Naturrechtskonstruktion Lockes oder die vernunftrechtlichen Strategien Rousseaus oder Kants aufmerksam, nicht leer bleiben, weil die basale Selbstbezüglichkeit der gesellschaftlichen Praxis für sich genommen deren Zivilität nicht anregen oder verbürgen kann. Deshalb wird sie auf eine moralische Ordnung projiziert, die die Aufrechterhaltung der gemeinsamen Praxis zum Inhalt hat und über moralische Gefühle, die sich von der eingelebten Sittlichkeit konkreter Lebensformen nicht ablösen lassen, auch im Inneren der Subjekte reproduziert werden muß: »Indeed, it is quite impossible to appreciate the complexity and subtlety of civil society if a great deal of attention is not paid to how it was taken to involve the imposition or inculcation of moral regulation in the relationship between the individual subjects of society « (Tester, 1992: 149). Diese Nötigung hinterläßt ihre Spuren auch im Begriff der bürgerlichen Gesellschaft, der im Kern das Programm der sozialen und politischen Integration der nachständischen Gesellschaft und die bürgerlichen Emanzipationshoffnungen in sich aufnimmt und dabei u.a. auf das Moment der Realisierung von Freiheit und Gleichheit im vernunftbestimmten Zusammenleben der Menschen abhebt - zu seinen Instrumenten gehören deshalb zentral, neben der Kodifizierung des öffentlichen und privaten Rechts oder der parlamentarischen Demokratie, auch Konzeptionen der Bildung, die wesentlich zur sozialen Formierung des Bürgertums beitragen (vgl. Haltern, 1993: $103 \mathrm{f}$. und 124).

Diese knappen Andeutungen sollen hier nur einen wesentlichen Punkt illustrieren, daß und weshalb im Konzept der Zivilgesellschaft von Anfang an Spannungen enthalten sind, die man im Versuch der Aktualisierung nicht einfach ignorieren kann. Diese

62 Diesen vorsoziologischen Status des Konzepts als einer im Kern »moralischen Vision« hebt auch Seligman hervor, wenn er darauf hinweist, daß über weite Strecken der Ideengeschichte die Lösung des Problems »of how to posit a social whole beyond the particular interests that define individual existence $(1993$ : 155) auf anthropologisch (so in der schottischen Moralphilosophie) oder sozial tiefsitzende moralische Gefühle wechselseitiger Anerkennung zurückgefühtt wurde: «What was unique was precisely the coupling of a vision of society with that moral field implied by the term civil society, while, at the same time, rooting this field in an innerworldly logic and not in a transcendent reality ... What the idea of civil society meant to the thinkers of the Scottish Enlightenment was primarily a realm of solidarity held together by the force of moral sentiments and natural affections (1993: 146). Diese Fassung scheint nicht so weit entfernt zu sein von dem Gebrauch, der auch heute von dem Konzept (etwa bei Honneth oder bei Rödel u.a.) gemacht wird - wobei allerdings übersehen wird, daß diese fragile Synthese letztlich kaum in der Lage war, die Prozesse gesellschaftlicher Desintegration im Zeichen systemischer Differenzierung und Individualisierung zu bändigen. 
Spannungen betreffen zum einen das Verhältnis des Zivilgesellschaftskonzepts zur Idee der Demokratie; zum anderen artikulieren sie sich im Widerspruch zwischen einem vernunftrechtlichen Universalismus einerseits und dem sittlichen Partikularismus, aus dem sich auch die zwischenmenschlichen, solidarischen Bande einer zivilen Gesellschaft weben, andererseits (vgl. Seligman, 1992: 15 ff.). Des zweiten Problems, dem ich hier nicht systematisch nachgehen kann, hat sich in den letzten Jahren vor allem Honneth angenommen (vgl. Honneth, 1992: bes. 274 ff. und 1993). Ihm geht es mit dem Konzept der »posttraditionalen Gemeinschaft« genau darum, eine Explikationsbasis für die Norm der Solidarität zu finden, die einen Ersatz bieten kann für einen seiner Objektivität und unverbrüchlichen Geltung beraubten gesellschaftlichen Wertekosmos, über den sich die wechselseitige Anerkennung und soziale Wertschätzung der Mitglieder einer bestimmten Gemeinschaft traditional vermitteln konnte: Die wechselseitige Wertschätzung von Personen, über die sich die soziale Integration von Gemeinschaften vollzieht, kann nach der radikalen Öffnung des ethischen Werthorizontes nur noch die Form annehmen, »daß jedes Mitglied einer Gesellschaft in die Lage versetzt wird...so in seinen Leistungen und Fähigkeiten anerkannt zu werden, daß es sich selber wertzuschätzen lernt $\ll$. Das impliziert, daß Solidarität »unter diesen Bedingungen an die Voraussetzung von sozialen Verhältnissen der symmetrischen Wertschätzung zwischen individualisierten (und autonomen) Subjekten gebunden « ist; und zwar derart, daß darin nicht nur eine passive Toleranz gegenüber den anderen zum Ausdruck kommt, sondern »in dem ich aktiv dafür Sorge trage, daß sich ihre mir fremden Eigenschaften zu entfalten vermögen « (Honneth, 1993: 269). Nun mag man darin die zivile Grundlage dafür erkennen, daß wir als politische Gemeinschaft die uns gemeinsamen Ziele verwirklichen können. Allerdings könnte es sehr wohl sein, daß diese Form der solidarischen Integration pluraler Gesellschaften einerseits zu schwach ist, um uns auf gemeinsame Ziele überhaupt verpflichten zu können; ${ }^{63}$ andererseits ist sie in dem Sinne zu weit oder zu unspezifisch, als daß sie die Konstitution eines bestimmten (und nach außen abgrenzbaren) politischen Handlungszusammenhangs und dessen institutionelle (demokratische) Konsolidierung wirklich informieren könnte. Kurz, diese Form der Akzentuierung des Moments der »Zivilitä « am Begriff der Zivilgesellschaft führt zu einer Konzeptualisierung von Zivilgesellschaft als eines auf Fragen der kulturellen Reproduktion moderner Gesellschaften spezialisierten, selbstbezüglichen Hand-

63 Ob Konflikte tatsächlich die paradoxe Wirkung zeitigen, die zivilen und solidarischen Bande zwischen den Gesellschaftsmitgliedern zu stärken und somit als Bindemittel zu wirken, oder ob Konflikte nicht doch eher ein Lösungsmittel bilden, hängt nicht zuletzt, worauf Hirschman aufmerksam macht, vom vorherrschenden Konflikttypus ab: Konflikte des »more or less «-Typs sind gewiß besser als Konflikte des »either or «-Typs geeignet, als Beleg für die Pazifizierungs- und Zivilisierungsthese zu dienen (vgl. Hirschman, 1994: 209 ff.). Wie dem auch sei, scheint in beiden Fällen die Bildung sozialer, gemeinschaftlicher Bande und solidarischer Einstellungen den Konflikterfahrungen eher vorauszuliegen als das sie in und durch Konflikte hervorgebracht werden - die Reproduktionsbasis ziviler Orientierungen ist jedenfalls eher in stabilen gesellschaftlichen Assoziationsverhältnissen zu finden, in denen Individuen »ais participants in a common life ... learn to deliberate, argue, make decisions and take responsibility« (Walzer, 1994: 189). 
lungszusammenhangs (vgl. Rödel, 1992), dessen politik- und demokratietheoretische Relevanz zumindest offen ist.

Das zeigt sich besonders gut, wenn man das Konzept der Zivilgesellschaft auf den Dualismus von Staat und bürgerlicher Gesellschaft bezieht und fragt, welche Ansätze zu einer Überwindung dieser Disjunktion sich auf dieser konzeptuellen Grundlage erschließen lassen. Ein häufig nicht ganz zu Unrecht geäußerter Verdacht besteht denn auch darin, daß sich der Zivilgesellschaftsdiskurs faktisch in diesem Dualismus einrichtet, obwohl er seine ursprüngliche Attraktivität der Propagierung der Überwindung dieser Differenz verdankt: Es sollte ja gerade gezeigt werden, daß sich die Gesellschaft die im Staat entäußerten Potenzen der Selbstorganisation und Selbstregierung angesichts der abnehmenden Leistungsfähigkeit des modernen Staates und des wachsenden Unbehagens an der aus der funktionalen Differenzierung erwachsenden korporatistischen Dezentrierung des Politischen wieder aneignen kann und muß (vgl. Angehrn, 1993: 147 f.). In dieser Perspektive allerdings erscheint die Zivilgesellschaft dann eher als eine Sphäre sozialer Assoziationen und Organisationen, die dadurch auf den Staat einwirken, daß sie nun selber die Funktion der Konstituton eines Allgemeinen annehmen. Dann aber erfährt der Begriff der Zivilgesellschaft Bestimmungen, die über die oben genannten hinausweisen: er nimmt die Gestalt einer Forderung nach direkter Demokratie an, die sich über eine Dezentralisierung von Meinungsbildungs- und Entscheidungsprozessen und eine Verbesserung des Gemein- oder Bürgersinns wie der individuellen Kompetenzen, Kenntnisse und Einflußmöglichkeiten realisieren soll (vgl. Angehrn, 1993: $153 \mathrm{ff}$.).

Das ist in etwa die Konstellation, in der Cohen und Arato den Versuch unternehmen, die unterschiedlichen Fäden des Zivilgesellschaftsdiskurses aufzunehmen und zu einer Theorie demokratischer Politik in komplexen Gesellschaften zu verweben, indem sie auf der Grundlage der Habermasschen Theorie des kommunikativen Handelns Elemente eines deliberativen, liberalen und republikanischen Modells von Politik zusammenzufügen und miteinander zu verbinden trachten. In diesem Zusammenhang dient der enge Bezug ihrer politischen Theoric auf die neuen sozialen Bewegungen vor allem dazu, die republikanische Tradition der Selbstregierung in den modernen politischen Prozeß hinein zu vermitteln. Diese Strategie wird im Zuge der Entwicklung ihres Arguments vor allem unter dem Druck ihrer modernisierungstheoretischen Differenzierungsthese letztlich aber so weit reduziert, daß sie das Modell deliberativer Politik fast vollständig an eine liberale Perspektive assimilieren und auch insoweit Habermas eher folgen, als über seine Vorgaben wirklich hinauszukommen. Ich werde im folgenden ihrem Argumentationsgang zunächst bis an den Punkt folgen, an dem spezifische »trade-offs « zwischen den kultur-, differenzierungstheoretischen und demokratietheoretischen Annahmen sichtbar werden (a - c), um dann einen Vorschlag zu machen, wie man dieser Falle entkommen könnte.

a) Zunächst aber sehen sich Cohen und Arato (1992: $410 \mathrm{ff}$. und $468 \mathrm{ff}$.) durch den Anspruch einer »reflexiven Fortsetzung des Projekts der Demokratie« genötigt, drei große Aufgaben unmittelbar anzugehen: Die Demokratie muß zwischen den Klippen einer blaß und unplausibel gewordenen elitären Demokratie einerseits und einer mit 
unrealistischen Erwartungen zu einem allgemeinen demokratischen Formprinzip generalisierten Idee der direkten Demokratie andererseits hindurchgesteuert werden; es muß, zweitens, eine Antwort auf die bürokratische Erstarrung und auf die von Legitimationsverlusten begleitete Entwicklung des Wohlfahrtsstaatsmodells gefunden werden, ohne der neoliberalen Suggestion der Weckung der Heilkräfte des Marktes auf dem Wege der vorangetriebenen Deregulation zu erliegen; und es muß, drittens, eine Perspektive angeboten werden, in der sich die liberale These des Vorrangs des Rechts mit der Idee der demokratischen Selbstbestimmung so vermitteln lassen, daß die Idee des Rechts von der Vorstellung isolierter, atomisierter Individuen einerseits und eines unvermeidlichen staatlichen Paternalismus andererseits abgelöst und in den Zusammenhang der Reproduktion einer politischen Ordnung zurückgestellt werden kann, ohne die individuellen Freiheitsansprüche zu untergraben (Cohen/Arato, 1992: 4 ff.).

Auf die Beantwortung dieser Fragen sind denn auch die fünf zentralen Theorieentscheidungen zugeschnitten, mit denen Cohen und Arato hoffen, dem Konzept der »Civil Society « eine auch im ideengeschichtlichen Kontext distinkte, aktuelle Fassung zu geben, in der es so etwas wie einen Orientierungsrahmen für weitergehende Demokratisierungsprozesse bereithalten kann. ${ }^{64}$ Zum einen muß, weil der ursprünglich exklusive Bezug auf soziale Bewegungen und informelle soziale Netzwerke im Zuge der osteuropäischen und lateinamerikanischen Transformationserfahrungen an Plausibilität verloren hatte, der Anschluß an das klassische Konzept der bürgerlichen Gesellschaft als einer rechtlich ausdifferenzierten Sphäre des privaten Verkehrs zwischen Individuen wieder hergestellt, aber zugleich politisch gewendet werden - dem dient die Unterscheidung von Zivilgesellschaft als Bewegung und als Institution, wobei mit dem Brückenkonzept des zivilen Ungehorsams der Zusammenhang zwischen dem Gebrauch und der Einforderung subjektiver Rechte und einer institutionellen Erweiterung der politischen Handlungssphäre in gesellschaftliche Assoziationen, soziale Bewegungen und Netzwerke hinein hergestellt werden soll. In der Folge dieser ersten Entscheidung stellt sich aber heraus, daß der Begriff der »civil society « zu amorph wurde, weil er zu viele eigen- und z.T. gegensinnige Handlungszusammenhänge umgreifen mußte. Deshalb bringen sie zweitens Unterscheidungen im Begriff der Zivilgesellschaft an, die nunmehr in ihre Komponenten einer ökonomischen, politischen und zivilen Gesellschaft auseinandergelegt wird, wobei dieser Differenzierungsgewinn allerdings nur realisiert werden kann, wenn zugleich der Einheitsfokus der Zivilgesellschaft deutlicher hervortritt. Diesem Zweck dient dann drittens die normative Auszeichnung eines übergreifenden Modus der kommunikativen Handlungskoordination, der die Grundlage für die Einheit der Kategorie der »civil society « bilden soll - ein normativer Zugriff, der indessen erneute Bedenken sowohl bezüglich der soziologischen Relevanz der Kategorienbildung wie bezüglich seiner demokratietheoretischen Stoßrichtung aufkommen läßt: insbesondere bleibt - so der vierte Schritt - unklar, wie Cohen und Arato in dieser Habermas nachempfundenen, unter dem Druck verallgemeinerter Rechtsdiskurse entstehenden Verbindung von Liberalismus und Demokratie, über dessen demokra-

64 Vgl. zum folgenden Arato (1994: 2 ff.) 
tische Reformperspektive in partizipatorischer Absicht hinauskommen wollen; was schließlich dadurch nur unterstrichen wird, daß sie die Schlüsselkategorie einer inklusiven, politisch fungierenden Öffentlichkeit auf Kontexte der Medien und der Universitäten(!) zurücknehmen.

Damit sind die m.E. wesentlichen Elemente benannt, die dann konstitutiv in die von Cohen und Arato postulierte »reflexive Fortsetzung des Projekts der Demokratie« einfließen, auf das nunmehr etwas genauer einzugehen ist. Die Erwartungen, die sie mit dieser reflexiven Wendung der Demokratietheorie verbinden, lassen sich in einem ersten Zugriff recht gut mit Blick auf die drei genannten Aufgaben erläutern. Darin sind ganz offensichtlich die Unterscheidungen von Staat und Gesellschaft, Staat und Markt und Individuum und Gemeinschaft in der Absicht aufgenommen, sie aus ihrer polaren Gegenüberstellung zu rükken, die sich erst ergibt, wenn man die zugrundeliegenden subsystemisch spezifizierten Integrationsprinzipien von Macht, Geld und Solidarität zu einem jeweils die ganze Gesellschaft umgreifenden Integrationsprinzip generalisiert und totalisiert. Wenn es einerseits dieser Fehler der Generalisierung subsystemisch gebundener, relativ eigensinniger gesellschaftlicher Handlungslogiken über alle Sphären der Gesellschaft ist, der in der Fortsetzung des Projekts der Demokratie zu vermeiden ist, so wird umgekehrt von diesen Unterscheidungen gerade die Anerkennung des Faktums der gesellschaftlichen Differenzierung zurückbehalten, um sie in einem zweiten Schritt mit der Idee des »self-limited radicalism« der demokratischen Transformation zu verbinden, nach der die ausdifferenzierten Handlungsbereiche und die mit ihnen institutionalisierten Handlungslogiken jeweils unterschiedliche Optionen für die weitergehende Demokratisierung von Staat, Gesellschaft und Gemeinschaft eröffnen: Die Pointe gegenüber Theorien der direkten Demokratie besteht in einer nurmehr spezifizierten und selektiven Anwendung dieses Formprinzips.

In einem genaueren Sinne bedeutet »Reflexivität« die Anwendung eines Prinzips auf sich selbst - hier also der Demokratie auf die Demokratie. Damit rückt die »civil society « als ein spezifisch kommunikativ strukturierter Handlungszusammenhang und damit als der Ort, der sich für allgemeine Partizipationsansprüche am aufnahmefähigsten erweist, in den Mittelpunkt: Sie erscheint von daher als ein gleichsam kommunikativ-argumentativ strukturiertes, reflexives Steuerungszentrum der Gesellschaft (Frankenberg/Rödel/Dubiel, 1989: 164 f.), und das auf zweierlei Weise. Zum einen werden in der öffentlichen Debatte und Auseinandersetzung Fragen der Demokratie im Sinne einer differentiellen Anwendung der unterschiedlichen Organisationsformen von Demokratie selber thematisch und die Frage der Demokratisierung in die Regie einer deliberierenden Öffentlichkeit genommen; zum anderen sollen hier in sachbezogenen, argumentativen Auseinandersetzungen die Gründe produziert und »verwaltet« werden, die über das politische Vermittlungssystem von Parteien und Parlament direkt in die Entscheidungszusammenhänge des ausdifferenzierten politischen Systems eindringen sollen (Habermas, 1989: 31).

Damit ist aber zunächst nur eine recht allgemeine Funktionsbestimmung erreicht. Was genauer ist die »civil society «, die sich aufgrund ihrer Strukturen, Handlungslogik und sozialen Infrastruktur als für diese Funktionszumutung besonders aufnahmefähig erweisen soll? Die erste Schwierigkeit, die sich einer solchen Bestimmung entgegen- 
stellt, liegt schon in der spezifischen Unschärfe des Begriffs selber, der ja in der Ideengeschichte ganz unterschiedliche Inhalte und Bedeutungen angenommen hat. Das liegt u.a. daran, daß er als Infrastrukturbegriff gleichsam die Eigenschaften in sich aufzunehmen hatte, die ihm im Rahmen der Gesamtarchitektur der Theorien, in deren Kontext er verwendet wurde, zugewiesen wurden (Bobbio, 1989; Taylor, 1993a). Gemeinsam ist diesen Bestimmungen indes zunächst, daß die zivile Gesellschaft »sowohl den Raum von (zwischen)menschlichen Vereinigungen, die nicht erzwungen sind, als auch das Ensemble jener Beziehungsnetzwerke, die um der Familie, des Glaubens, der jeweiligen Interessen und einer bestimmten Ideologie willen gebildet worden sind und diesen Raum ausfüllen...: Gewerkschaften, Kirchen, politische Parteien und Bewegungen, Kooperativen, Nachbarschaften, Denkschulen, Gesellschaften zur Förderung oder Verhinderung dieser oder jener Sache « (Walzer, 1992: 65) bezeichnet. Bei genauerem Hinsehen erweist sich dieser Hinweis auf eine Vielzahl von gesellschaftlichen Assoziationsverhältnissen als zu unspezifisch, um von daher den Bereich der Gesellschaft, der mit dem Begriff der civil society (in seinen Bedeutungsvarianten der societas civilis, der bürgerlichen Gesellschaft und eben der modernen Zivilgesellschaft) abgesteckt ist, genauer zu charakterisieren. 65

So scheint es sinnvoll, diese infrastrukturelle Perspektive mit einer theoriesystematischen Fragestellung zu verbinden, in der man dann grob drei Bedeutungsvarianten des Begriffs unterscheiden kann: die »civil society « als Bereich des Nicht-Staatlichen erscheint dann einmal als ein vorstaatlicher, als ein anti-staatlicher oder als ein poststaatlicher Integrationszusammenhang (Bobbio, 1989: 23 f.). Dieser Ambivalenz versuchen Cohen/Arato nun durch die Verfeinerung der Topographie des zivilgesellschaftlichen Moments im Zusammenhang der Gesamtgesellschaft zu entkommen. Die moderne »civil society « wird im Rahmen eines als drei- resp. vierstufig konzipierten gesellschaftlichen Vermittlungszusammenhangs sowohl gegen den Staat und den Markt, aber auch gegen die »political society « des institutionalisierten politischen Vermittlungssystems repräsentativer Demokratien abgehoben und mit Hilfe der Unter-

65 Diese Ambivalenzen kann auch Diamond (1994: 6) in seinem ansonsten sehr instruktiven Versuch, etwas größere Klarheit in den Gebrauch der Kategorie der »civil society « zu bringen, nicht vollständig umgehen. Das zeigt sich etwa, wenn feststellen muß, daß die »civil society encompasses a wide array of organizations, formal and informal « und dann Assoziationen im Bereich der Ökonomie ("productive and commercial associations and networks«) neben kulturelle und issue-orientierte Organisationen wie Bürgerrechtsbewegungen stellt. Allerdings nimmt er dann doch Unterscheidungen bezüglich der Orientierung und internen Struktur spezifisch zivilgesellschaftlicher Assoziationsformen vor, die diese Beliebigkeit eindämmen und zu einem genaueren Merkmalsprofil führen: Danach sind zivilgesellschaftliche Organisationen dadurch charakterisiert, daß sie partiale Zwecke verfolgen und den Prinzipien von Pluralität und Diversität in der Weise verpflichtet sind, daß sie nicht versuchen, den politischen Raum zu monopolisieren und daß zivilgesellschaftliches Handeln primär an öffentlichen und nicht privaten Zwecken orientiert ist; daß es sich zwar auf den Staat bezieht, aber nicht auf die Erringung formeller Machtpositionen ausgelegt ist ( 6 f.) - und sie können diese Funktionen umso eher ausfüllen, je deutlicher sich diese Orientierungen auch in einem demokratischen Strukturaufbau der Organisationen selbst spiegeln (11 f.). 
scheidung von >privat< und >öffentlich ` gegen den Privatbereich einer alltäglichen Lebenswelt differenziert. Was dabei zuriickbleibt, ist ein Komplementärbegriff zu den von Habermas im Rahmen seines Konzepts einer post-traditionalen, rationalisierten Lebenswelt erschlossenen institutionellen Strukturkomponenten der Kultur, der sozialen Integration und der Sozialisation, der schließlich mit Blick auf Mechanismen der sozialen Integration und kulturellen Reproduktion fast auschließlich auf eine im Netzwerk sozialer Bewegungen konstitutierte Öffentlichkeit fokussiert wird und so als privilegierter Ort der Austragung von Auseinandersetzungen über die genauen Formen des sozialen und politischen Lebens erscheint (Walzer, 1992: 79 ff.).

Diese Art der Einbindung des Konzepts der Zivilgesellschaft birgt nun allerdings eine demokratietheoretisch nicht unerhebliche Weichenstellung, insofern die Idee der Öffentlichkeit und die sie begleitenden Vorstellungen von diskursiven und deliberativen politischen Praktiken nurmehr als rationalisierendes und pazifierendes Ferment einer konflikthaften zivilgesellschaftlichen Praxis selber erscheinen. Das Prinzip der öffentlichen Deliberation wird so in die Nähe eines rein selbstbezüglichen zivilgesellschaftlichen, d.i. lebensweltlichen, Reproduktionszusammenhangs gerückt, der außerhalb dieser eng umgrenzten Handlungssphäre, also vor allem auch in den Strukturen einer dezisiv orientierten, auf Problemlösungen und Entscheidungen ausgerichteten staatlichen Politik, bestenfalls kontingente Wirkungen erzeugen kann (ähnlich auch der Einwand von Baynes, 1993: 546 f.). ${ }^{66}$ Während sich damit dieser Vorschlag im Prinzip im tradierten Dualismus von Staat und bürgerlicher (Zivil-) Gesellschaft (oder von dezisiver und deliberativer Politik - vgl. Kleger, 1992) einrichtet, ließe sich demgegenüber eine demokratietheoretisch bedeutsame Resultatverbesserung dann erzielen, wenn man sich von der Idee der Zivilgesellschaft als eines "post-staatlichen« (Bobbio, 1989) Integrationszusammenhangs leiten ließe. In dieser Perspektive käme es gerade auf eine engere Verklammerung und Vermittlung der unterschiedlichen Politikbereiche wie -stile in dem Sinne an, daß die Vorbereitung, Planung, Gestaltung und Durchführung materialer und thematisch spezifizierter Politiken (policies) in den Horizont einer allgemeinen, offenen Willensbildung zurückgestellt werden. ${ }^{67}$

66 Dem scheinen Cohen und Arato zunächst mit einer Unterscheidung von vier grundlegenden Modi der Politik neuer sozialer Bewegungen (»politics of identity«, »politics of inclusion«, »politics of influence « und »politics of reform« - vgl. Cohen/Arato, 1992: 526), die zu der Differenzierung eines auf Fragen der kulturellen Reproduktion spezialisierten zivilgesellschaftlichen Handlungszusammenhangs gegen die politische Gesellschaft der Parteien, Interessengruppen und Verbände querliegt, entgegenwirken zu wollen. Diesen Vorteil verschenken sie m.E. jedoch dadurch, daß sie an einer dualistischen Konzeptualisierung von ziviler und politischer Gesellschaft festhalten. Das führt im Ergebnis dazu, daß ihre Vorstellung einer Politik institutioneller Reform einseitig den zivilgesellschaftlichen Perspektiven einer Politik der Identität und der Inklusion verhaftet bleibt: sie konzentrieren sich zu sehr auf die Eingabeseite des politischen Prozesses und vernachlässigen die Strukturen des >Throughputsı von Interessen und Bedürfnissen wie jene Faktoren, die die Qualität politischer Entscheidungen auf der Output-Seite beeinflussen (Cohen/Arato, 1992: 555 ff. und 562).

67 Diesen Aspekt der rationalen Problemverarbeitung und der dazu notwendigen Kopplung zivilgesellschaftlicher und staatlicher Willensbildung hebt auch Staff in ihrer Bestimmung der Funktionen einer neu zu konstitutierenden Bürgergesellschaft hervor (vgl. Staff, 1993: 919). 
b) Die Schwierigkeiten, in die Cohen und Arato auf diese Weise geraten, hängen zum einen zweifellos mit den weit gesteckten und zum Teil disparaten Ansprüichen selber zusammen, denen das Konzept genügen soll. Es geht ja nicht nur um eine auf die Politik neuer sozialer Bewegungen abgestimmte Reformulierung der Idee partizipatorischer Demokratie. Sondern es geht um die Frage, wie entscheidungs- und problemlösungsbezogenes politisches Handeln in eine Praxis der kulturellen Reproduktion moderner Gesellschaften unter Bezug auf das Ideal einer post-traditionalen Sittlichkeit (vgl. Honneth, 1992 und 1993) so eingebettet werden kann, daß sich diese Orientierungen nicht wechselseitig blockieren. Darüber hinaus haben die Probleme, die zunächst vorhandenen Erwartungen und Hoffnungen auch einzulösen, im Kern mit der normativen Unterbestimmtheit des Begriffs der bürgerlichen Gesellschaft selber zu tun (Taylor, 1991 und 1993a), der ideengeschichtlich mindestens drei unterschiedliche, miteinander nicht ohne weiteres kompatible Fassungen angenommen hat: ${ }^{68}$ Einmal in der Gestalt einer vorpolitischen Vergesellschaftung von Privaten qua Markt und Recht; zum anderen in der Form einer sich aus der Privatsphäre herauslösenden Öffentlichkeit, in der eine auf allgemeine Fragen der politischen Ordnung bezogene Willensbildung ihren Ort und ihr Medium findet; schließlich im Sinne einer in dezentralen Entscheidungsstrukturen im ganzen politisch-institutionell strukturierten Gesellschaft, die den Staat tendenziell in sich zurücknimmt. Diese Ambivalenzen treten deutlich hervor, wenn man den Begriff der bürgerlichen Gesellschaft unmittelbar für demokratietheoretische Zwecke in Anspruch nehmen will, so daß der Bezug auf die Civil Society den angemahnten, theoretischen Entscheidungsbedarf in drei grundlegenden Dimensionen zunächst nicht recht zu decken vermag.

In der kontraktualistischen Tradition wird die Idee individueller Autonomie und Freiheit an das Konzept eines »spatial self« (Warren, 1989: $525 \mathrm{ff}$.), also eines sich wesentlich über Besitz definierenden, vorsozialen Individuums assimiliert. In der Konsequenz erscheint die bürgerliche Gesellschaft primär in der Perspektive eines staatlich regulierten Nebeneinanders von Privatpersonen, um die sich - wie in konzentrischen Kreisen - ein zunehmend ausgebautes und verfeinertes Netz von Individualrechten legt, um sie gegen staatliche Herrschaftsansprüche wie allerdings auch gegen die $\mathrm{Zu}$ mutungen und Zudringlichkeiten einer horizontalen, demokratischen Willensbildung abzuschirmen. Zweifellos stellt sich der zivilgesellschaftliche Diskurs da, wo es im Horizont eines normativen Begriffs radikaler Pluralität und eines Rechts auf Besonderheit vor allem um Transformation kommunikativ erzeugter Macht in neue Rechtsansprüche, um das Recht also, Rechte zu haben, geht, auch in diese liberale Tradition einer »relentless translation of wants into rights « (Elshtain, 1991: 78). Andererseits wird die Gefahr der dissoziativen Konsequenzen, die eine solche Entwicklung birgt, durchaus gesehen, zumal dieser Typus von Rechten destruktiv auf die Strukturen der kommunikativen Erzeugung von Macht selber zurückwirkt. Deshalb wird immer wieder versucht, diesen kontraktualistischen Ansatz mit einer zivilrepublikanischen Deutung von Rechten zu verbinden, in dem Rechte dann primär die Gestalt politischer Freiheits-

$68 \mathrm{Vgl}$. zum folgenden auch Schmalz-Bruns (1992) 
rechte annehmen, die ihre normative Dignität nicht aus dem Bezug auf das Individuum, sondern die Gemeinschaft von Staatsbürgern erhalten. ${ }^{69}$ Diese additive Strategie übersieht jedoch ein Problem, auf das Walzer jüngst mit Blick gerade auf die amerikanische Verfassungstradition aufmerksam gemacht hat: der dominante Bezug auf die individuellen Freiheitsrechte in der Tradition der »Bill of Rights « saugt eben auch den politischen Gehalt der demokratischen Rechte auf, weil die Übersetzung von materialen Konflikten in justiziable Rechtsansprüche in der Tendenz zu einer Usurpation der öffentlichen Debatte durch die Gerichte führt (Walzer, 1991b: 118 ff.; vgl. auch Maus, 1991). Anders als der Titel des von Rödel herausgegebenen Bandes »Autonome Gesellschaft und libertäre Demokratie« (Rödel, 1990) suggerieren möchte, weist das libertäre Moment, das im Kern der kontraktualistischen Tradition verhaftet bleibt, keine Wahlverwandtschaft mit der republikanisch inspirierten Idee einer autonomen, politisch gerichteten sozialen und demokratischen Praxis auf: hier wird man sich also entscheiden müssen, und dies nicht zuletzt auch deshalb, weil »die aktuellen Tendenzen einer beschleunigten Individualisierung « jedenfalls dem Theoretiker auch Anlaß zur Sorge geben sollten, der sich die Zivilgesellschaft als eine politische Gemeinschaft vorstellt, die sich ohne ein gewisses $\mathrm{Maß}$ einer in einer öffentlichen Moral gegründeten Tugend gar nicht reproduzieren und zur Geltung bringen kann (Honneth, 1992b: 66; vgl. auch Münkler, 1991).

Vor diesem Hintergrund stellen sich auch bezüglich des normativen Begriffs von Demokratie selber Unklarheiten ein, die sich nicht schon durch den Rekurs auf die These der vollständigen Säkularisierung der Legitimitätsgrundlagen politischer Herrschaft aufhellen lassen: Wenn man die demokratische Frage nicht nur als Problem der äußeren Rationalisierung und elektoralen Rückbindung politischer Herrschaft begreift, sondern sie auf das Problem der institutionellen Mechanismen der partizipatorischen Öffnung und der sachlichen Verbesserung politischer Entscheidungsfindung bezieht, dann kann man die Frage nicht übergehen, wie sich denn eine zivilgesellschaftlich in pluralen, nicht-institutionalisierten Öffentlichkeiten diffundierte Volkssouveränität in Zusammenhängen der politisch-administrativen Willensbildung noch zur Geltung bringen kann. Jedenfalls scheint es unplausibel, diese Zumutung angesichts der inversen Entwicklung von Staatsaufgaben und staatlicher Steuerungsfähigkeit mit dem Hinweis zurückzuweisen, daß Kritierien der Effizienz und sachlichen Angemessenheit von Entscheidungen keine genuin politischen Kriterien darstellen.

Dieses Desinteresse scheint auch damit zusammenzuhängen, daß die Neigung besteht, die Demokratietheorie insgesamt in der Perspektive von Bewegungsakteuren als den primären Trägergruppen weitergehender Demokratisierungsprozesse zu konzipieren. Das ist verständlich, wenn man bedenkt, daß der Civil Society-Diskurs, in dem zunächst die Bestrebungen der Reform des Staatssozialismus und der weitergehenden Demokratisierung $»$ real existierender Demokratien« (Arato, 1990: 110) zusammengeführt werden sollten, in nicht unbeträchtlicher Weise von den Hoffnungen zehrte, die dadurch entstanden, daß Bürgerbewegungen in der Lage zu sein schienen, den öffent- 
lichen Raum wiederzuerobern und mit einigen eigenwilligen institutionellen Erfindungen (»Runde Tische«) so auszugestalten, daß sie den Prozeß der Transformation und politischen Neukonstitution tatsächlich in die »eigene Regie « (Habermas) nehmen konnten. Nun hat sich indes schnell gezeigt, daß die Akteure, die man dabei vor allem im Auge hatte, dieses große »Politikspiel « auch deswegen verloren, weil sie die Erwartungen der eigenen Bevölkerung nicht bedienen konnten: der Prozeß der deutschen Vereinigung z.B. mündete entgegen den anfänglichen Erwartungen schnell in einen Triumph der großen Parteien, der Ministerialbürokratien und der etablierten Interessenverbände, weil allein diese ressourcenstark genug waren (Nullmeier, 1991; Lehmbruch, 1991), die Aufgabe einer gleichzeitigen politisch-institutionellen und ökonomischen Transformation so zu bewältigen, daß die in diese Gleichzeitigkeit eingelagerten Spannungen wenigstens zum Teil auch absorbiert werden konnten. ${ }^{70}$ Unabhängig von einer genaueren Einschätzung dieses Prozesses sowohl unter normativen wie unter Effizienzgesichtspunkten, gibt dies Anlaß zu der grundsätzlicheren Erwägung, wie weit man der in der linken Tradition tief verwurzelten Neigung weiterhin nachgeben kann, die Demokratietheorie durch einen engen Bezug auf bestimmte Gruppen von Akteuren zu präjudizieren. Mit Blick auf die vorangetriebenen Prozesse der soziokulturellen und funktionalen Differenzierung spricht vielmehr einiges dafür, mit Emanzipations- und Veränderungspotentialen zu rechnen, die von sozialen Bewegungen zu politischen Parteien und Verbänden und zu staatlichen Instanzen und von dort wieder zurückwandern können (Nullmeier, 1991: 23 f.). Das aber hieße, daß sich die Demokratietheorie auf vielfältige Formen horizontaler Selbstkoordination in sozialen Bewegungen und in korporativen Verhandlungssystemen (Scharpf, 1991) wie auf deren Vermittlung mit Formen zentraler staatlicher Steuerung und Willensbildung einzustellen hätte, indem sie sich stärker auf die institutionellen Voraussetzungen der Ausschöpfung der darin angelegten Potentiale konzentriert (vgl. Buchstein, 1992).

Freilich bedeutet das keineswegs, daß das Konzept der »Civil Society« sich etwa nicht in Zusammenhängen einer stärker entscheidungsbezogenen und institutionell gerichteten Explikation demokratischer Willensbildung zur Geltung bringen ließe. Vielmehr kann man beobachten, daß sich der Civil Society-Diskurs entlang der bezeichneten Alternativen intern ausdifferenziert. Das Problem liegt nun auf konzeptioneller Ebene vor allem darin, daß diese Vorstellungen jeweils spezialisierte, nur auf ganz be-

70 Deshalb quittiert auch Dubiel (1994: 78 ff.) der antitotalitären Theorie der zivilen Gesellschaft eine gewisse sozialwissenschaftliche Naivität, insbesondere in bezug auf deren Rolle nach der demokratischen Revolution und hebt hervor, daß vor allem die Schwierigkeiten übersehen wurden, die sich im Zusammenhang der Konstitutionalisierung politischer Freiheitsrechte im Rahmen einer posttotalitären Konkurrenzdemokratie und der gleichzeitigen Errichtung von Marktwirtschaften stellen (was Offe als das Dilemma der Gleichzeitigkeit apostrophiert hat - vgl. Offe, 1994). Weil sich gerade an Übergangsgesellschaften ganz generell die hervorragende Bedeutung politischer Institutionalisierungen nachweisen läßt, muß sich die Unterbelichtung der institutionellen Aspekte der demokratischen Konsolidierung und weitergehenden Demokratisierung in den meisten zivilgesellschaftlichen Ansätzen als gravierender Mangel herausstellen (vgl. dazu auch O'Donnell, 1994; Diamond, 1994 und Kumar, 1993). 
stimmte Probleme hin orientierte Problemlösungsstrategien beinhalten, die nicht immer kombinierbar sind und sich z.T. wechselseitig verstellen. Je nachdem, welche der oben erwähnten Problembeschreibungen in den Vordergrund treten, nimmt auch die »Civil Society « eine andere Gestalt an: Läßt man sich von Fragen der Erzeugung einer kollektiven Identität unter Bezugnahme auf die normative Idee radikaler Pluralität leiten, wird die »Civil Society« zur Projektionsfläche einer primär kulturellen Praxis der autonomen Vermittlung von »Andersheit« (Connolly, 1990 und 1991); rückt man dagegen das Problem der politischen Konstitution einer funktional differenzierten und kulturell fragmentierten Gesellschaft in den Vordergrund, entsteht das Bild eines zivilgesellschaftlichen Liberalismus, in dem sich ein »demokratischer Legalismus « mit der normativen Idee von Öffentlichkeit verbindet (vgl. Benhabib, 1991); orientiert man sich schließlich i.S. eines "zivilgesellschaftlichen Interventionismus« (Nullmeier, 1991: 17) primär an der Frage, wie sich die Idee partizipatorischer Demokratie institutionell mit der Anforderung einer Verbesserung der Qualität politischer Willensbildung vermitteln ließe, dann paßt darauf besser die Vorstellung einer in unterschiedlichen assoziativen Strukturen institutionell verfaßten Zivilgesellschaft.

c) So weit bisher zu erkennen, lassen sich die Empfehlungen zu einer weitergehenden Demokratisierung »real existierender Demokratien « (Arato, 1990: 110) im wesentlichen auf drei Elemente zurückführen: Erstens hält der Civil Society-Ansatz an der liberalen Trennung von Staat und Gesellschaft schon deswegen fest, weil die Demokratisierung der bürgerlichen Gesellschaft auf die sanktionsbewehrte Garantie individueller und politischer Freiheitsrechte angewiesen bleibt - das impliziert die Anerkennung der auf die Rechtserzeugung bezogenen Mechanismen des Parlamentarismus und des Parteienwettbewerbs (Held, 1989: 181); diese Entscheidung ist zweitens mit der Diagnose verbunden, daß weder die Gesellschaft Strukturen für effektive Partizipation bereithält noch der Staat auf die effektive Kontrolle sozialer Macht hin ausgelegt ist - dies führt zu der Empfehlung einer Doppelstrategie der komplementären Demokratisierung von Staat und Gesellschaft, die sich davon leiten läßt, nicht nur die Legitimitätsgrundlagen der Staatswillensbildung zu verbessern, sondern vor allem die Interventionstiefe staatlicher Steuerung durch die interne Demokratisierung gesellschaftlicher Organisationen zu erhöhen (Held, 1989: 182); schließlich soll darauf geachtet werden, daß das prekäre Gleichgewicht zwischen demokratischen Selbstbestimmungsrechten einerseits und individuellen Abwehr- und Anspruchsrechten wie der Eigensinn ausdifferenzierter Handlungsbereiche andererseits erhalten bleibt, an dem sich die konkreten Formen der Demokratisierung bemessen lassen müssen.

Die Frage ist indessen, ob sich unter der Voraussetzung der Fixierung auf die liberale Trennung von Staat und Gesellschaft und die Kautele des »self-limited radicalism $\ll,{ }^{71}$ in der sich die Anerkennung der Effektivitäts- und Effizienzvorteile funktional ausdifferenzierter Gesellschaften zur Geltung bringen soll, die in dieser Idee angelegten Demokratisierungpotentiale wirklich ausschöpfen lassen. Denn zum einen

71 Mit dieser Formel kennzeichnen Cohen und Arato ein zentrales Anliegen ihrer politischen Theorie: vgl. Arato (1990), Arato/Cohen (1988), Cohen/Arato (1989) und Cohen (1990). 
bleibt die liberale Optik unempfindlich gegenüber der faktischen Diffusion staatlicher Souveränitätsansprüche in korporative Politiknetzwerke: um diesem Effekt der schleichenden Grenzverschiebung mit seinen entdemokratisierenden Folgewirkungen zu entgehen, wäre das liberale Prinzip der Trennungen (von Staat und Gesellschaft, privat und öffentlich, Recht und Moral) dadurch zu demokratisieren, daß die Bestimmung des genauen Grenzverlaufs in den Horizont einer deliberativen gesellschaftlichen Praxis zurückgestellt wird (vgl. Walzer, 1984). Zum anderen muß man - im Blick auf die Formen und Folgen sozialer Differenzierung - sicher den Eigensinn und -wert unterschiedlicher Handlungsrationalitäten in Rechnung stellen, an denen Demokratisierungsimpulse auch ihre Grenze finden können. Dennoch besteht umgekehrt kein Anlaß, einen bestimmten Typus funktionaler Differenzierung zu substantialisieren: Differenzierungen sind keine Naturtatsache, sondern sie entstehen erst durch die institutionelle Abschirmung eigensinniger Handlungsformen, die prinzipiell reversibel bleibt - in diesem Bewußtsein aber kann die konkrete Form gesellschaftlicher Kooperation i.S. einer »Demokratisierung der Differenzierungsfrage « reflexiv zum Gegenstand selbstbestimmter Koordination werden (Joas, 1990a: 20 ff.; Demirovic, 1991a und $b$ ).

Diese Entscheidung, an der »liberalen Kunst der Trennungen « (Walzer, 1984) festzuhalten und sie differenzierungstheoretisch sogar noch zu radikalisieren, ist überhaupt nur vor dem Hintergrund plausibel, $\mathrm{da} B$ Cohen und Arato die Zivilgesellschaft im Kern als selbstbezüglichen Reproduktionszusammenhang kollektiver Identitäten begreifen. Entgegen dieser Auslegung, die letztlich zu einer Art Selbsteinkapselung des zivilgesellschaftlichen Handlungszusammenhangs führen muß, wäre an einer politisch-institutionellen Fokussierung festzuhalten: Zum einen soll die Tiefe demokratischer Willensbildung dadurch verbessert werden, daß man die politische Entscheidungsfindung in einen intermediären Sektor vernetzter Assoziationsverhältnisse (Offe, 1989) verlagert, der sich aus der Privatsphäre und den staatlichen Institutionen ausdifferenziert; diese Einbindung hat zweitens aber auch die Funktion, die Politisierung des Privaten und Subjektiven institutionell zu kanalisieren und in anspruchsvolle Formen kollektiver Willensbildung einzubinden; nur vor diesem Hintergrund kann drittens plausibel gemacht werden, daß auch die Reichweite demokratischer Willensbildung durch die Politisierung von Fragen einer kollektiven Identität, der gesellschaftlichen Differenzierung und schließlich der unterschiedlichen Organisationsformen von Demokratie selber erhöht werden kann.

In dieser Perspektive bilden die Gesichtspunkte der Freiheit, Gleichheit (Inklusion), Kompetenz und Effektivität resp. Effizienz nur noch die Eckpunkte eines »magischen Vierecks « der Demokratietheorie, die man zu unterschiedlichen Demokratiemodellen verbinden kann. Nun ist es gewiß keine neue Beobachtung, daß erhebliche Spannungen zwischen diesen Optimierungsgesichtspunkten bestehen, die sich nur selektiv in unterschiedlichen Formen institutionalisieren lassen: Formen repräsentativer Demokratie führen zu einer Mediatisierung individueller und kollektiver Willensbildung, partizipationsoffene Verfahren sind ergebnisoffen und führen zu Selbstblockaden der Willensbildung nach dem Motto »Wenn sich alle auf die Zehenspitzen stellen... « und expertiseorientierte Verhandlungssysteme sind in aller Regel repräsentationsschwach 
und legitimationsarm (vgl. Offe/Preuß, 1991: 162ff.). Worin könnte angesichts dieser Lage nun die spezifische Pointe eines zivilgesellschaftlichen Ansatzes bestehen? Hier genügt es m.E. nicht, die Not zu einer Tugend zu machen und die bloße Pluralität von Formen der Demokratie schon als Versprechen der Chance allgemeiner und bedeutungsvoller Partizipation zu interpretieren (Cohen, 1990: 100). Vor allem wird der vermeintliche Bedeutungsgehalt von Öffentlichkeit und Partizipation auf der Ebene der Zivilgesellschaft durchaus zweifelhaft, wenn sie an gleicher Stelle mit der einsinnigen Zuordnung von unterschiedlichen Beteiligungsformen zu den ausdifferenzierten Handlungsbereichen von Staat, Gesellschaft und Ökonomie verbindet (Cohen, 1990: 100). Aussichtsreicher erscheint mir demgegenüber eine Überlegung, die an dem metapolitischen Charakter des Streits etwa darüber ansetzt, wie, im Zusammenhang der Entwicklung und Implementation neuer Technologien, hinsichtlich dieser Entwicklungen ein Klärungsprozeß überhaupt beschaffen sein muß, wie entsprechend die Verfahren der Entscheidung und Implementation zu gestalten sind (Kleger, 1992: $121 \mathrm{ff}$;; vgl. auch Burns/Ueberhorst, 1988). Hier haben wir es also mit öffentlichen Auseinandersetzungen über die Frage einer situationsspezifischen und problembezogenen Zuordnung von demokratischen Verfahren und einzelnen Politiken zu tun, und insofern stellt Öffentlichkeit eine Ressource dar, die durch die direkte Einbindung in den Policy-Zyklus so zu institutionalisieren wäre, daß die Möglichkeit eröffnet würde, institutionelle Verkrustungen aufzubrechen und gleichsam reflexiv zu verflüssigen.

Aber diesen Weg wählen Cohen und Arato eben nicht. Ihrem Versuch einer reflexiven Fortsetzung des Projekts der Demokratie wird vielmehr dadurch die Spitze genommen, daß sie drei sich wechselseitig verstärkende Grundentscheidungen treffen, an denen Überlegungen bezüglich einer weitergehenden Demokratisierung von vornherein abprallen müssen: Besorgt um die Vitalität eines zivilgesellschaftlichen Handlungszusammenhangs sind sie genötigt, die rechtlichen, institutionellen und Kompetenzanforderungen an die Entfaltung staatsbürgerlichen Engagements möglichst gering zu halten - deshalb erschließen sie den nicht oder schwach institutionalisierten Öffentlichkeiten ein Betätigungsfeld, das sie im Vorhof staatlicher Macht und entscheidungsbezogener Willensbildungsprozesse lokalisieren; dadurch reduziert sich die Politik der Zivilgesellschaft auf den öffentlichen Streit um kollektive Identitäten im Zusammenhang einer "post-traditionalen « (Honneth) Gemeinschaftsbildung - diese Politik läßt sich nur sich indirekt in administrative und staatliche Entscheidungsprozesse hinein vermitteln und erzeugt dort bestenfalls kontingente Wirkungen; ist dies schon insofern ein Problem, als sich weitergehende Gestaltungsansprüche auch kollektiver gesellschaftlicher Akteure frustiert sehen könnten, wird selbst diese Option noch zusätzlich dadurch restringiert, da $B$ mit Bezug auf ein Modell systemischer Differenzierung wichtige gesellschaftliche Handlungsbereiche gegen Demokratisierungsforderungen überhaupt abgeschirmt werden. Doch unbeschadet dessen rückt die Idee einer Revitalisierung der Bürgergesellschaft in einer zeitgemäßen Form nicht zufällig in das Zentrum der Bestrebungen zur Erneuerung der Demokratie - nicht zufällig deshalb, weil das Konzept eines privilegierten (staatlichen) Zentrums, das mit zwangsbewehrten rechtlichen Normen die gesellschaftliche Ordnung aufrechterhalten und alle relevanten politischen Kommunikationen problemgerecht fokussieren und zu effektiven und sachlich 
angemessenen Entscheidungen bündeln kann, immer weniger überzeugt. Als Ersatzkandidat für diese integrativen Leistungen steht nur die Bürgergesellschaft »als Form des institutionalisierten Zwangs zur Kommunikation und Reflexion « zur Verfügung, und was deshalb vom Zivilgesellschaftsdiskurs auf jeden Fall zurückzubehalten und aufzunehmen ist, ist die Idee, daß »gewissermaßen die Intelligenz, das Wissen und die kommunikativen und kooperativen Fähigkeiten der Individuen und der Gruppen mehr und mehr an die Stelle des staatlichen Zentrums « (Preuß, 1994: 156 f.) rücken könnten. Dies dürfte freilich ohne eine stärkere organisatorische Bündelung und Konzentration des gesellschaftlichen Reflexionspotentials und die Verankerung von Lernfähigkeit im »Normalbetrieb der Institionen « (Preuß) kaum zu haben sein, und dafür reichen die vielfach apostrophierten Mechanismen subjektiver Rechte und der Gruppengesellschaft (vgl. Preuß, 1994: $160 \mathrm{ff}$.) nicht aus: hinzutreten müssen partizipationsoffene Strukturen der politischen Willensbildung und Entscheidungsfindung, die die gesellschaftlichen Energien aufnehmen und effektiv kanalisieren können. Kurz, wenn man das Projekt der Demokratie wieder auf den Weg bringen will, sind an den Grundentscheidungen und Weichenstellungen, die Cohen und Arato vornehmen, noch einmal entschiedene Revisionen vorzunehmen. 


\section{Ansätze zu einer Radikalisierung des Modells zivilgesellschaftlicher Politik}

Zweifellos gibt es einen intimen Zusammenhang zwischen dem Projekt einer reflexiven Radikalisierung der Demokratie, einer (unvermeidlichen) Subjektivierung von Steuerungs- und Integrationsleistungen und steigenden Anforderungen an den Staatsbürger. Genau diese Konstellation hat auch Münkler im Blick, wenn er darauf verweist, daß eine theoretisch konsistente und empirisch gehaltvolle Explikation der Demokratie ohne den Rückgriff auf den republikanischen Tugenddiskurs schwer zu haben sein dürfte. Seine These ist, daß »politische Tugend, verstanden als nicht erzwingbare Intention der Orientierung unserer Handlungen am Gemeinwohl... der Zentralbegriff der Selbstexplikation einer Gesellschaft (ist), welche die Ideale von Freiheit und Toleranz weniger mit dem Imperativ ihrer institutionell gebundenen Verstetigung als vielmehr dem ihrer Regenerations- und Anpassungsfähigkeit unter den Bedingungen traditionelle Werte konsumierender und/oder Normen generierender gesellschaftlicher und technologischer Entwicklungen zu kombinieren sucht (Münkler, 1992: 28). Nehmen wir diesen Gedanken ernst, dann erscheint politische Tugend gleichsam als Substitut für den im Zusammenhang der ökologischen Krise weggebrochenen Fortschrittsoptimismus, als Wertebasis und Motivationsquelle eines Handelns, das den Verzicht auf die Steigerung von Optionen (Offe, 1986) durch die reflexive Kontrolle der eigenen Wünsche und Bedürfnisse am Gemeinwohl einzulösen sucht.

Diesen Hinweis auf ein irreduzible subjektives Moment im Prozeß gesellschaftlicher Modernisierung und Demokratisierung möchte ich zum Anlaß nehmen, um wenigstens kurz ein staatsbürgerliches Kompetenz- und Qualifikationsprofil nachzuzeichnen, wie es sich aus zwei mit dem Konzept der »civil society« verbundenen Anforderungen ergibt: das sind zum einen Anforderungen, die sich aus dem Problem der autonomen Reproduktion einer konflikthaften Praxis ergeben, die eine moralischreflexive Kompetenz gerade angesichts der zunehmenden Moralisierung politischer Fragen in besonderer Weise herausfordert; das sind zum anderen Anforderungen an die Ausbildung auch sachlich und zeitlich reflexiver Fähigkeiten des einzelnen, die durch dessen stärkere Inanspruchnahme in partizipatorisch geöffneten Entscheidungszusammenhängen entstehen.

Den ersten Gesichtspunkt kann man auch als Frage nach dem Zuschnitt der Tugenden aufnehmen, die im Zusammenhang thematisch nicht restringierter öffentlicher Diskurse zu mobilisieren wären. Dieser Frage nehmen sich in einem instruktiven Aufsatz Gutman und Thompson (1990) in einer Auseinandersetzung mit dem liberalen Prinzip der Neutralität an. Zu diesem Zweck müssen sie den klassischen Dreischritt liberaler Theorie vom Skeptizismus zum Neutralitätsprinzip und zur Entpolitisierung (»method of avoidance $\ll$ ) schon an der Stelle unterbrechen, wo sich die Frage der Se- 
lektivität der "principles of preclusion « stellt, die sich aus Sorge um die Vernünftigkeit öffentlicher Deliberation wie ein Filter vor die Öffentlichkeit schieben und nur jene, prozedural auf die Einrichtung einer gerechten Ordnung bezogenen Fragen durchlassen, auf die überhaupt allgemeine und verbindliche Antworten gegeben werden können. Denn eine solche Strategie läuft im Kern darauf hinaus, die Konfliktdynamik, die aus der öffentlichen Behandlung substanzieller und kontroverser Themen erwachsen könnte, dadurch stillzustellen, daß man den Raum einer vorstaatlichen, zivilpolitischen Handlungssphäre mit dem institutionellen Mittel der Trennung von Staat und bürgerlicher Gesellschaft gleichsam thematisch austrocknet. Wenn man nun im Gegenzug in demokratischer Perspektive auf eine Repolitisierung der bürgerlichen Gesellschaft setzt, wird man das Problem, das den Liberalismus zu seiner klassischen institutionellen Antwort motiviert, natürlich nicht los. Vielmehr stellt es sich in einer anderen Weise: die Strategie der Einhegung von Konfliktdynamiken muß durch Mechanismen der autonomen Konfliktbändigung ersetzt werden. Auf diese Aufgabe sind ganz offensichtlich die »principles of accomodation« zugeschnitten, die sie aus den internen Bedingungen entwickeln, die den argumentativen Charakter öffentlicher Debatten selbst sichern sollen. Zu diesem Zweck unterscheiden sie schließlich zwei Sorten derartiger Prinzipien; zum einen solche, die Fragen der moralischen Integrität betreffen wie das Prinzip der Vermeidung von Opportunismus, das Konsistenzprinzip oder das Prinzip der Betrachtung aller relevanten Umstände und Folgen; zum anderen solche, die auf die Herausbildung demokratischer Charaktermerkmale wie Toleranz und wechselseitigen Respekt zielen - dazu zählen die Bereitschaft, anderen Positionen nicht von vornherein den moralischen Ernst abzustreiten und das Bestreben, die Gründe für die wechselseitige Zurückweisung von Auffassungen zu minimieren.

Die mit dem Tugendbegriff verbundene Idee der »individual excellence (Galston, 1988) ist natürlich der klassischen liberalen Theorie keineswegs fremd. Im Gegenteil spielt sie da eine bedeutsame Rolle, wo sie nicht so sehr auf das Ideal der individuellen Vervollkommnung als vielmehr funktional auf die Reproduktion der gesellschaftlichen und politischen Ordnung und der demokratischen Institutionen bezogen sind. Ganz in diesem Sinne hat Galston einen Katalog zusammengestellt, den ich an dieser Stelle einmal unkommentiert vorstellen möchte. Er unterscheidet dabei allgemeine Tugenden, in denen sich generell der Zusammenhang von individuellem Charakter und institutioneller Ordnung zum Ausdruck bringt, wie Legalitätsglaube und den Respekt vor den Rechten anderer von solchen Tugenden, die den sozialen Integrationsprozeß sichern wie Loyalität, Treue, Solidarität und Toleranz. Davon setzt er schließlich noch einmal im engeren Sinne politische Tugenden ab wie die "capacity to discern the character and talent of people vying for office «, die kognitive Kompetenz »to form a common purpose " und die allgemeine, moralisch-reflexive Disposition »to engage in public discourse « (Galston, 1988: 1282 ff.): die Arenen der Einübung solcher Tugenden sind dann nicht nur die Familie, die Schule oder die politischen Institutionen, sondern auch und wesentlich die politische Praxis einer dialogischen Begegnung mit anderen (Galston, 1988: 1288).

Zweifellos setzt also gerade das Projekt der Radikalisierung der Demokratie eine hohe Prämic auf die Bildung und Artikulationsfähigkeit des Staatsbürgers aus, und es 
tendiert dazu, jene, die diese Voraussetzungen nicht mitbringen, stärker zu benachteiligen, als dies in anspruchsloseren Formen repräsentativer Demokratie der Fall ist. Insofern ist das demokratische Staatsbürgerideal auch ein erzieherisch anspruchsvolles Ideal, weil wir uns nicht darauf verlassen können oder sollten, daß sich die erforderlichen Einstellungen und Kompetenzen einfach als Folge von Demokratisierungsprozessen einstellen: politische Bildung i.S. der Kultivierung der staatsbürgerlichen Tugenden, des Wissens und der Fertigkeiten, die in den politischen Prozeß notwendig eingehen, hat so gesehen den moralischen Primat über andere Aufgabenstellungen der öffentlichen Erziehung in einer demokratischen Gesellschaft (Gutmann, 1987: 287). Diese Dispositionen jedenfalls bilden insgesamt ein kaum reduzierbares individuelles Ferment einer demokratischen Gesellschaft, und sie sind - weder institutionell noch prozedural vollständig substituierbar. Dies rechtfertigt den Bezug auf Tugend als eines eigenständigen und explikationsbedürftigen Phänomens (Taylor, 1989: 3 ff.), auch dann, wenn dieser Zusammenhang in modernen Theorien in der Regel eher stillschweigend übergangen wird. Gewiß sollten wir weder in der Theorie noch mit Blick auf die demokratische Praxis unsere diesbezüglichen Erwartungen überziehen und solchen institutionellen Strukturen den Vorrang geben, die moralische Einstellungen zwar ermöglichen und stützen, aber doch ohne allzu heroische Tugendunterstellungen auskommen können. Aber staatsbürgerliche Moral und politische Institutionen stehen andererseits auch nicht in einem Konkurrenzverhältnis zueinander, sondern sie sind in einen wechselseitigen Reproduktionszusammenhang eingebunden (Gutmann, 1987: 287).

Vor diesem Hintergrund möchte ich nunmehr an drei Punkten Revisionen des grundbegrifflichen Rahmens vorschlagen, innerhalb dessen, wie oben gezeigt, Cohen und Arato ihre politische Theorie der Zivilgesellschaft mit insgesamt mäßigem Erfolg (vgl. Ely, 1992) entfaltet haben. Das betrifft zum einen Klarstellungen hinsichtlich des Begriffs der Politik (a), zum zweiten eine Neuakzentuierung der Idee partizipatorischer Demokratie, wie sie Offe und Preuß vorbereitet haben (b) und zum dritten die handlungstheoretische Auflösung der eher unglücklichen Verbindung von Funktionalismus und Demokratietheorie, die Joas angemahnt hat und über das Konzept der »Kreativität des Handelns« vollziehen möchte (c).

a) Das westliche politische Denken ist über weite Strecken, wenn auch mit charakteristischen Ausnahmen, motiviert vom Ideal politischen Handelns, das auf die Einrichtung einer gerechten institutionellen Ordnung und die Formen der kooperativen Lösung jener Probleme zielt, die sich der Realisierung eines guten Lebens entgegenstellen oder sich auf diesem Wege einstellen. Dieses Ideal einer autonomen Praxis war zudem von Anfang an logisch mit der Idee der Vernunft oder Rationalität verknüpft, die, wo sie diesem Prozeß nicht selber sein Maß und sein Ziel vorgab, doch die Funktion hatte, den Menschen die zur Erreichung ihrer Ziele notwendigen und unverzichtbaren Mittel an die Hand zu geben: Politik und politisches Handeln sind ein Reflex der Immanenz und Autonomie sozialer und gesellschaftlicher Ordnung, aber sie sind aus dem gleichen Grunde auch nicht autark gegenüber rationalen Annahmen und Unterstellungen, die das Medium und Ferment einer solchen Praxis bilden. Das Problem besteht nun in dem Doppelstatus der reklamierten Vernunfteinsichten als Bedingungen 
und Produkt der Praxis, auf die sie sich beziehen sollen; und der Verdacht, der sich an dieser Stelle leicht einschleichen kann, insbesondere vermittelt über szientifische $\mathrm{Zu}$ spitzungen und instrumentelle Vereinseitigungen des ursprünglichen Konzepts praktischer Vernunft (Spragens, 1990: 14 ff.), ist nicht nur, daß die Vernunft selber der Praxis als äußere Macht gegenübertreten könnte, sondern daß sie, auf ihren konstruktivistischen Grund und illusionären Charakter hin durchschaut, auch ihrer Funktion im Rahmen einer autonomen Praxis nicht mehr gerecht werden könne. Dieser Verdacht kann nun allerdings auf unterschiedliche Weise aufgegriffen und politiktheoretisch umgesetzt werden. Zum einen ist er Gegenstand einer dekonstruktivistisch verfahrenden Vernunftkritik, die die Vernunftideen allein auf ihren illusionären Charakter als Produkte eines logozentrischen Denkens hin durchsichtig machen will, das seine Macht- und Herrschaftsinteressen nun nicht mehr verbergen kann: politische Gestalt gewinnt er im ästhetischen Ideal der Selbsterschaffung des Subjekts, dem ein Perspektivenwechsel von Problemen kollektiven Handelns und der Integration von Gesellschaften auf eine emphatische Betonung von radikaler Pluralität und die `Sorge um Andersheit (White, 1988: 191 ff.) im Kontext einer Politik der Differenz entspricht (Young, 1990; Connolly, 1991; Rorty, 1989). Zum anderen wird er von einer politisch inspirierten Kritik aufgenommen, die sich mit dem Argument der ontologischen Differenz zwischen Wissenschaft und Politik nurmehr gegen die szientifische, objektivistische Überformung von Politik in epistemischen Modellen der Politik wendet. Die Gründe dafür werden etwa an Barber's Definition des Politischen sichtbar, die ein soziales Beziehungsgeflecht kennzeichnet, das aus einer »necessity for public action, and thus for reasonable public choice, in the presence of conflict and in the absence of private or independent grounds for judgment « erwächst (Barber, 1984: 120). Diese Sichtweise läßt als Inbegriff einer politischen Konstellation das Bild einer Praxis erscheinen, die, von einer irreduziblen, durch > Wahrheit $<$ nicht domestizierbaren Konflikthaftigkeit geprägt, sich nur in fragilen Formen wechselseitigen Verständnisses und wechselseitiger Anerkennung reproduzieren kann: Politik bezeichnet dann nicht einen besonderen Gegenstandsbereich sozialen Handelns, sondern primär einen dialogischen Kommunikationsmodus, der nicht so sehr auf rationale Konfliktregulierung oder Problemlösung, sondern auf die Zivilisierung der Konfliktaustragung eingestellt ist. Gleichwohl hinterläßt diese ontologische Entzweiung von Politik und Vernunft empfindliche Lücken in der politischen Praxis wie in einem angemessenen Verständnis moderner Politik, so daß schließlich dem oben aufgeworfenen Verdacht auch durch eine weitergehende Immanentisierung und Soziologisierung des Vernunft- und Erkenntnismodells und eine Rekonstruktion von Politik als einer rationalen Praxis entgegengewirkt werden könnte.

Jene, die in der Folge Hannah Arendts im Politischen eine besondere Form nicht durch Gründe domestizierbaren und nur von wechselseitigem Respekt und wechselseitiger Anerkennung als Freie und Gleiche getragenen sozialen Zusammenhandelns beschreiben, bauen ihr Argument normalerweise in drei Schritten auf: am Anfang steht in der Regel die deskriptiv gemeinte Diagnose einer zunehmenden und in der vollständig säkularisierten Welt des Sozialen unvermeidlichen Politisierung aller individuellen und kollektiven Existenz- und Überlebensfragen - in diesem Zusammenhang stellt >Politi- 
sierung eine Reaktion auf die mit steigender Pluralisierung und Individualisierung wachsende Konflikthaftigkeit sozialer Beziehungen selber dar; mit der Säkularisierungsthese verbindet sich die Annahme, daß das Vernunftdenken »im Säurebad der Modernisierung « (Greven, 1992: 199) so vollständig zersetzt worden ist, daß nunmehr auch die Formen und Gestalten praktischen und theoretischen Wissens, über die sich eine konflikthafte Praxis vermitteln sollte, selber in den Strudel der Auseinandersetzungen hineingezogen werden und keine verbindliche und verbindende Qualität mehr gewinnen können; vor diesem Hintergrund hebt sich drittens das normative Ideal einer dialogischen, nicht diskursiven Praxis ab, der allein noch zugetraut wird, ein nicht-teleologisches, allein aus der gemeinsamen Sorge um die öffentlichen Angelegenheiten sich webendes Band zwischen den Bürgern zu stiften. Nun sind die Schwächen einer solchen Vorstellung ebenso offensichtlich wie bekannt. Dazu zählen nicht nur die Bereinigungen am Begriff der Politik, die allein eine um Interessen und instrumentelle wie teleonomische Aspekte reduzierte Vorstellung des Politischen zurücklassen, in der nur noch die Energiezufuhr durch große, konstitutionelle Momente die Bürger zu gemeinsamem Handeln im öffentlichen Raum zusammenführt. Vielmehr sind es die Unschärfen im Konzept einer von kognitiven Elementen diskursiver Praktiken befreiten dialogischen Praxis, die dem Aufschluß zu den Phänomenen und Erfahrungen moderner Politik im Wege stehen (Warren, 1990: 26): durch die Hintertür dieser Trennung wird unvermeidlich ein entschieden dezisionistisches Verständnis von Politik wieder eingeführt.

Diese Konsequenz hat denn auch Greven ${ }^{72}$ in einem jüngeren Aufsatz gezogen, in dem er gerade dem Faktum des unvermeidlichen und irreduziblen Dezisionismus eine demokratische Pointe abzugewinnen sucht. Zu diesem Zweck geht er zunächst den Gründen nach, die den Dezisionismus-Verdacht trotz der allgemein anerkannten Tatsache, daß »im politischen Prozeß entschieden werden (muß) und zwar ohne, daß für diese Entscheidungen allgemein anerkannte Geltungsgründe... vorhanden wären, aus denen die Inhalte konkreter Entscheidungen lediglich deduziert zu werden brauchten « (196), seine Wirkung verleihen, um dann über die Unterscheidung eines »emphatischen « und eines "pragmatischen « Dezisionismus seine Konsequenz eines »demokratischen Dezisionismus « vorzubereiten. Dabei bemerkt er völlig zu Recht, daß die Skandalisierung des Dezisionismus nicht etwa über die Unterscheidung »Entscheidung - Nichtentscheidung « läuft, sondern über den Gegensatz von »Begruindung Willkür« (197 f.). An dieser Stelle könnte man die Angelegenheit dadurch zu Ende bringen, daß man den unterschiedlichen Kanälen und Mechanismen nachspürte, über die Gründe in den Entscheidungsprozeß eindringen und zu einer Rationalisierung des Entscheidungsverhaltens beitragen. Diesen Weg indessen geht Greven nicht. Vielmehr bringt er nunmehr die sehr allgemein gehaltene These der rationalitätzersetzenden Wirkung des Säkularisierungsprozesses ins Spiel, die den berechtigten Ausgangs- und Angelpunkt des »emphatischen Dezisionismus« in seiner Schmittschen Prägung ausmachte (199). Damit greift er auch hinter seine kritisch gemeinte Unterscheidung von Begründung und Willkür zurück, so daß am Ende, trotz der Abwehr des emphatischen

72 Die folgenden Seitenangaben (in Klammern) beziehen sich alle auf Greven (1992). 
Dezisionismus als einer »Theorie der Politik als Existenzialanalyse vor metaphysischem Hintergrund « (198) und der Kritik der strukturkonservativen Wirkungen eines ganz auf Routineentscheidungen abgestellten pragmatischen Dezisionismus Lübbescher Provenienz (199ff.), die Grundzüge eines existentialistischen Politikverständnisses auch in sein Konzept eines demokratischen Dezisionismus eindringen: »In der Politik geht es insgesamt um soziale Geltung kraft Entscheidung und nicht um Wahrheit « (Greven, 1992: 204). Damit aber reflektiert der demokratische Dezisionismus nicht mehr bloß eine faktische Entkopplung von Wahrheit und Entscheidung, eine deskriptiv gemeinte Feststellung, die sich ja selber der Verdunklung der rationalen Motive und Mechanismen im politischen EntscheidungsprozeB verdankt. Das Problem besteht m.E. im Kern darin, daß Greven in gleichem Maße die Folgen unterschätzt, die eine vollständige Entkopplung für die Demokratie haben müßte, so daß auch die partizipatorische Öffnung von Entscheidungsprozessen keine Antwort mehr auf die selbstgestellte Frage bereithielte, ob die Übel des Dezisionismus denn vermieden oder wenigstens gemildert werden könnten. Die Gründe dafür sind leicht zu sehen: erstens führt Partizipation als solche nicht aus dem Entscheidungsdilemma heraus, sondern verstärkt dieses nur; zum zweiten bleibt gerade unter Bedingungen von allgemeiner Partizipation die Anwendung von Entscheidungsregeln einem besonderen legitimatorischen Streß ausgesetzt, der nur über die Inanspruchnahme von der Entscheidung vorausliegenden diskursiven Verfahren abgebaut werden kann.

Insofern sind diese sehr zugespitzten Überlegungen Grevens auch wiederum sehr informativ, weil sie die mißlichen Konsequenzen und die konzeptuellen Schwächen eines politischen Anti- oder Arationalismus deutlich hervortreten lassen. Diese Schwächen resultieren insgesamt daraus, daß drei notwendige Unterscheidungen unsichtbar gemacht werden: Zum einen wird selten genau genug unterschieden zwischen dem (unhaltbaren) Anspruch einer Determinierung von Politik durch (Vernunft-) Gründe einerseits und einem Gebrauch von Gründen in der politischen Praxis andererseits das aber wirkt destruktiv auf das demokratische Ideal selber zurück; zum zweiten sitzt die Kritik an epistemischen Modellen der Politik der Assimilation von Rationalität an objektivistische und instrumentell enggeführte Vernunftbegriffe auf und versperrt sich so den Zugriff auf die kognitiven Potentiale einer rationalen (oder genauer: rationalisierten) politischen Praxis (Warren, 1990: 20 ff.); drittens macht sich der Dezisionismus in seinen unterschiedlichen Spielarten selbst eines objektivistischen Mißverständnisses schuldig, insofern er politische Praxis allein aus der systemischen Perspektive eines Beobachters, nicht aber in der Perspektive von Beteiligten rekonstruiert. Eine derartige Perspektive müßte sich sensibilisieren für die »irreducible activity of agents in sustaining the mutual intelligibility of their interactions « (McCarthy, 1991: 29), und sie würde, entgegen einer einseitigen Abrechnung mit dem illusorischen Charakter von Vernunftideen, den Zugang zu dem pragmatischen Gebrauch eröffnen, den Akteure von Ideen normativer Richtigkeit und theoretischer Wahrheit machen, um sich wechselseitig als für ihre Handlungen verantwortliche Subjekte zu erkennen und anzuerkennen und um Kritierien der Lösung von Interaktionskonflikten zur Verfügung zu halten.

An dieser Stelle sind nun vor allem die politisch-institutionellen Implikationen dieser pragmatistischen Reformulierung der Idee des Guten als nachmetaphysische Be- 
gründung und Rechtfertigung von Demokratie von Interesse. Dabei treten drei Aspekte in den Vordergrund: zum einen fungieren >Partizipation $<$ und das >Interesse an der Qualität von Ergebnissen< als gleichrangige institutionelle Kriterien einer demokratischen Ordnung, die sich nicht gegeneinander ausspielen lassen, sondern mit Blick auf die Anforderungen materialer Politiken sorgfältig balanciert werden sollten; zum zweiten ist offensichtlich, daß diese Balance nur gelingen kann, wenn wir darüberhinaus ein Interesse an der Qualität der staatsbürgerlichen Willensbildung auch institutionell dadurch zum Ausdruck bringen, daß Strukturen der Willensbildung vorzusehen sind, die eine stärker reflexive Willensbildung ermöglichen und stabilisieren; drittens nötigt der veränderte Fokus auf Problemlösung auch dazu, unterschiedliche Formen und Aggregationsstufen öffentlicher Willensbildung füreinander durchlässiger zu machen und besser aufeinander zu beziehen. Bevor ich aber diesen Argumentationsfaden mit Blick auf einen Begriff des kreativen Handelns, wie ihn Joas entwicket hat, wieder aufnehme, möchte ich an Hand der Überlegungen Offes und Preuß' kurz andeuten, welche Implikationen die Idee der Qualitätsverbesserung von Politik für das Verständnis einer partizipatorischen Demokratie enthält.

b) Wie wir oben gesehen haben, resultierte Habermas' (über-) vorsichtige Einschätzung der Möglichkeiten kollektiver Willensbildung, der Cohen und Arato dann im wesentlichen gefolgt sind, aus der Kombination von drei sich wechselseitig verstärkenden Grundentscheidungen. Habermas konzentriert sich in legitimationstheoretischer Perspektive auf die Bedingungen rationaler Regelbefolgung oder eines rational motivierten Gesetzesgehorsams (Offe/Preuß, 1991: 157) - und damit auf die Output-Seite des politischen Entscheidungsprozesses, dessen Unzulänglichkeiten, interne Widersprüche und Irrationalitäten gleichsam mit der Unterstellung einer kompakten bürokratischen Rationalität zugedeckt werden; darüberhinaus gilt sein Interesse vor allem den Strukturen, die dem »besseren « Argument zu Anerkennung und Geltung verhelfen und übersieht die Frage, ob und inwieweit demokratisch-rechtsstaatliche Verfahren auch in der Lage sind, hinreichend gute Argumente zu erzeugen (Offe 1989: 757 f.); schließlich möchte er vermeiden, der Demokratietheorie eine kognitiv zu anspruchsvolle Fassung zu geben, die dazu tendierte, die individuellen und kollektiven Rationalitätsressourcen überzustrapazieren (vgl. Lindner, 1990: 154 ff.). Das ist nun freilich eine empirische Frage, deren Beantwortung theoretisch nicht präjudiziert werden kann; jedenfalls gibt es auch keinen Grund, angesichts der vielfältig zu belegenden Thematisierungs- und Problemlösungsleistungen, die gesellschaftliche Akteure im Bereich von Mikro-Entscheidungen und auf dezentraler Ebene erbringen (Ostrom, 1989 und 1990), das von der frühen amerikanischen Einstellungsforschung im wirkungsvollen Kontrast zu demokratischen Idealen gezeichnete Bild des »unsophisticated citizen « in bezug auf politisches Interesse, Informiertheit und kognitive Kapazitäten zu reproduzieren (Dalton, 1988: 18-33). Wie dem auch sei, so viel läßt sich mit Bestimmtheit sagen: wenn die Becksche Diagnose der zunehmenden Selbsterzeugung von Gefahren im Medium eines generalisierten Autismus (von Systemen, Kollektiven und Individuen) zutrifft und damit die Lücke zwischen der »Design-Komplexität « gesellschaftlicher Steuerungsobjekte und der staatlichen Steuerungsfähigkeit größer wird (Wiesenthal, 1989: 138 f.), dann wird man die Probleme nur am Ort ihrer gesellschaftlichen 
Genese behandeln können - die Steuerungsleistungen wären gleichsam zu »subjektivieren « (Offe, 1989: 743).

Und das ist dann der Punkt, an dem Offe und Preuß mit der einfachen Überlegung einsetzen, daß, wer die Rationalität kollektiver Entscheidungen erhöhen will, an der Verbesserung der kognitiven wie moralischen Qualität der individuellen Präferenzen auf der Input-Seite des politischen Entscheidungsprozesses ebenso ansetzen muß ${ }^{73}$ wie an den Strukturen und institutionellen Mechanismen, die den Throughput, also den Grad der Berücksichtigung von Interessen, Informationen und Erkenntnissen bestimmen. Damit sind die beiden Richtungen angedeutet, in die die partizipatorischen Strukturelemente liberaler Demokratien sowohl ausgeweitet wie intern radikalisiert werden sollen: zum einen geht es Offe und Preuß i.S. einer "Staatsbürgerqualifikationspolitik « (Preuß, 1990a: 126) um die Verbesserung der subjektiven Voraussetzungen einer vernünftigen kollektiven Willensbildung; zum anderen geht es um das Design von Institutionen, die größere Anreize bieten, von vorhandenem moralischen und theoretischen Wissen wie von Informationen auch tatsächlich Gebrauch zu machen, anstatt diese Ressourcen durch Institutionen, die wesentlich auf die Mediatisierung des Staatsbürgers angelegt sind, trockenzulegen (Offe/Preuß, 1991: $165 \mathrm{ff}$.).

Es ist also sicherlich kein Zufall, daß das Bestreben der Demokratisierung des Liberalismus von einer teilweisen Rückwendung auf Tugendideen und implizite Erziehungsideale begleitet ist. ${ }^{74}$ In welcher Weise, das wird etwa schon sichtbar, wenn Preuß die Möglichkeiten der normativen Rechtfertigung des Wohlfahrtsstaates im Rahmen einer »Staatsbürgerqualifikationspolitik « untersucht (Preuß, 1990a: 124 ff.). Seine entscheidene Prämisse ist, daß heute neben die Freiheits- und Gleichheitsrechte ein weiteres Moment staatsbürgerlicher Qualifizierung tritt, das er im Blick auf ein gesellschaftliches Interesse an der »Qualität der politischen >outcomes< kollektiver Entscheidungen « (Preuß, 1990a: 125) so beschreibt: »... die demokratische Gesellschaft (ist) insgesamt darauf angewiesen..., daß die durch Bürger gefällten kollektiven Entscheidungen eine - wie immer definierte - Qualität haben. Damit ist sie auch an der guten Qualität der Staatsbürger interessiert: ihre Informiertheit, ihre Fähigkeit zur Reflexion unter Berücksichtigung der Folgen ihrer politisch relevanten Entscheidungen, ihrem Willen, ihre Interessen im Hinblick auf die Interessen ihrer Mitbürger ebenso wie der künftiger Generationen zu formulieren und durchzusetzen...« (Preuß, 1990a: 125 f.) - wobei die Pointe in der Unterstellung liegt, daß »die ungleiche Verteilung von Lebensgütern... die Qualität der staatsbürgerlichen Gütemerkmale und damit im Ergebnis auch die erreichbare Rationalität kollektiver Entscheidungen (mindert)«

73 Diese Idee findet sich bei J.S. Mill, und sie ist in der amerikanischen Debatte zwischen Liberalen und »Communitarians « vor allem von jenen wieder aufgegriffen worden, die den selbstdestruktiven Tendenzen eines politischen Liberalismus durch strukturelle »intimations of community entgegenwirken wollen (vgl. Sandel, 1984 und Walzer, 1990)

74 Besonders deutlich wird dies in der amerikanischen Diskussion, wo sich zeigt, daß kommunitaristisch inspirierte Positionen regelmäßig eine besondere Affinität zu Fragen der Erziehung und politischen Bildung aufweisen. Vgl. etwa die Studien von Bellah et al. (1987 und 1991). 
(Preuß, 1990a: 126). Aber nicht diese wohlfahrtsstaatliche Selbstimplikation des gesellschaftlichen Interesses an der Qualität politischer Entscheidungen interessiert mich hier, sondern es sind die institutionellen Implikationen dieser These eines wachsenden Bedarfs an »verantwortungsethischen Massenorientierungen « (Offe, 1989: 758) - institutionelle Strukturen sollen die Funktion der Ermutigung, der Ermöglichung und des Schutzes moralisch-reflexiver Dispositionen vor der Ausbeutung durch »moralische Trittbrettfahrer« übernehmen.

In der Konzeptualisierung eines solchen Modells nun rückt der Begriff der Öffentlichkeit unvermeidlich in eine zentrale Stellung, und zwar in räumlicher, sozialer und sachlicher Hinsicht: Räumlich gesehen geht es um die Entzerrung und Entlastung der Strukturen staatlicher Entscheidungsprozesse (Offe, 1987), und zwar nicht (oder nicht nur) i.S. von Dezentralisierung, sondern in Richtung auf eine Generalisierung von Partizipationsrechten. Dazu gehört auch, daß der Raum einer vorstaatlichen Willensbildung konstitutionell besser erschlossen und für die Rationalisierung von Entscheidungsprozessen fruchtbar gemacht wird (das ist, wenn ich es recht verstehe, der Sinn der Preußschen Formel des »moralisch-reflexiven Konstitutionalismus « (Preuß, 1990: 78 ff.). In sozialer Hinsicht vermittelt Öffentlichkeit die Reziprozität der individuellen Interessenbefriedigung (Preuß, 1989: 10) und greift mindestens insofern auch auf die Genese von Präferenzen durch, als sie die innere Spannung zwischen unterschiedlichen Präferenzen, zwischen stark und schwach bewerteten Wünschen und Bedürfnisssen (Taylor, 1988: 9 ff.) oder zwischen Präferenzen und Meta-Präferenzen hervortreten läßt und deren moralische Regulierung oder Auflösung anregt. In sachlicher Hinsicht schließt Öffentlichkeit den Aspekt der Verbesserung der kognitiven Angemessenheit der individuellen Willensbildung mit jenem der Wirkung von guten Argumenten in Entscheidungsprozessen zusammen und vermittelt so nicht nur kollektive Lernprozesse, sondern auch die Motive, sich diesen zu öffnen.

Mit dieser Konstruktion soll es auch in ideengeschichtlicher Perspektive gelingen, die kontraktualistische Tradition mit der demokratisch-republikanischen so zu verbinden, daß das Interesse nicht mehr nur als Geburtshelfer einer im Recht wohlgeordneten Gesellschaft erscheint, sondern selbst zum Gegenstand der Rationalisierung mit Bezug auf ein allgemeines Interesse wird: über diese Vorstellung eines reflexiven "preference learning « soll die Idee der Tugend in der Idee deliberativer, öffentlicher Willensbildung so aufgehoben werden, daß man ohne einen totalisierenden Rekurs auf substantiierte Gemeinwohlvorstellungen auskommen kann (Offe/Preuß, 1991: 167 f.). Gleichwohl nimmt das allgemeine Interesse eine doppelte Gestalt an. Zunächst erscheint es in der formal-reflexiven Fassung eines Interesses an nun nicht lediglich rationalen Formen der Konfliktregulierung, sondern an Institutionen der rationalen Problemlösung, das auch unterhalb der konstitutionellen Fragen auf der Ebene der Policy-Formierung angreift. Gleichzeitig wird durch den Bezug auf Problemlösung zumindest implizit nahegelegt, daß wir von der Rationalisierung der kollektiven Willensbildung im Ernst nur dann reden können, wenn sie zu Ergebnissen führt, die den sachlich ausweisbaren Anforderungen an $>$ gute $<$ Problemlösungen entsprechen oder wenigstens nahe kommen. M.a.W. ist anzunehmen, daß das allgemeine Interesse im Lichte hinreichend guter Gründe jeweils so substantiierbar oder spezifizierbar ist, daß es auch eine orientierende 
Wirkung und motivierende Kraft im Zusammenhang der individuellen Präferenzgenese entfalten kann - dies scheint mir jedenfalls durch die Forderung nahegelegt, daß jeder einzelne sich selbst gegenüber auch die Haltung des Experten einnehmen und die eigenen Interessen in sachlicher, sozialer und zeitlicher Hinsicht validieren können soll (Offe, 1989: 758).

Das setzt natürlich voraus, daß man ein generell nicht erzwingbares Interesse an der gemeinwohlbezogenen Aufklärung und Raffinierung des individuellen Interesses nachweisen und lokalisieren kann. Diesem Zweck dient zunächst der Versuch, die Spannung zwischen partikularen und allgemeinen Interessen gleichsam zu subjektivieren und auf die heterogene Präferenzstruktur des »multiplen Selbst« abzubilden, in der die hierarchische Ordnung von Präferenzen und Metapräferenzen dafür sorgt, daß das Individuum seine Präferenzen erster Ordnung im Lichte seiner Interessen zweiter Ordnung einer »Selbstreinigung « unterziehen kann. ${ }^{75} \mathrm{Zum}$ anderen aber, und darin liegt die entscheidende institutionelle Wende, die sie ihrem Argument geben, sollen die unvermeidlich entstehenden Motivationsprobleme durch assoziative Grundstrukturen der gesellschaftlichen Willensbildung, durch öffentliche Argumentationen und durch In-

75 Diese präferenztheoretische »Wende« mag eng mit der Konzentration auf wohlfahrtsstaatliche Politiken zusammenhängen, die in besonderem Maße interessensensibel sind (vgl. Offe, 1987b und Thompson, 1988). Ein anderes Bild ergibt sich indes schon, wenn man sich z.B. der Technologiepolitik zuwendet, wie Wiesenthal am Beispiel des »Sozialverträglichkeitsdiskurses « zeigt (1989). Kritisch gegen diese Programmatik der Subjektivierung des Allgemeininteresses wendet sich auch Habermas (1990b: $62 \mathrm{f}$.).

Dieser Weg einer präferenztheoretischen Reformulierung des Problems ist mit einigen charakteristischen Schwierigkeiten belastet. Denn selbst wenn nun nichts gegen die Annahme spricht, daß wir solche unterschiedlichen Interessen wirklich haben, ist damit noch nichts darüber gesagt, ob und inwieweit sie in einem internen Verhältnis der Rationalisierung schwächer bewerteter (egoistischer) zu stärker bewerteten (sozialen) Interessen stehen. Gegen diese optimistische Annahme hat etwa Scharpf in einer spieltheoretischen Rekonstruktion der Rationalitätsstruktur der Auflösung dilemmatischer Handlungssituationen vor allem am Beispiel des »Battle of the Sexes « darauf aufmerksam gemacht (1991: $72 \mathrm{f}$.), daß wir eher mit einer dualistischen als mit einer hierarchischen Präferenzstruktur rechnen sollten. Danach besteht die wahrscheinliche Form der Auflösung der Spannung zwischen partikularen und allgemeinen oder Kooperationsinteressen darin, die Problemlösung in Fragen der Konfliktregulierung einerseits und in Verhandlungen über materiale Fragen so aufzuspalten, daß die Lösung dieser Fragen nicht mit Fragen der Erzeugung von Kooperationsregeln kontaminiert und belastet wird. Das aber hat nun im günstigsten Fall die Wirkung, $\mathrm{daB}$ die Reziprozitätsbedingungen der Befriedigung primärer Interessen deutlicher hervortreten (und auch das würde das substantielle Interesse selber zunächst unangetastet lassen, jedoch kreative Lösungen i.S. neuer Interessendefinitionen erleichtern); im schlechteren Falle würde die Erfahrung, daß sich eine Befriedigung des substantiellen Interesses auch unter Bedingungen von Kooperation nicht einstellt, sogar umgekehrt zu einer Unterminierung eben der Kooperationsmoral führen. Kurz: die erwarteten Wirkungen einer präferenztheoretischen Umformulierung des allgemeinen Zusammenhangs und Zusammenspiels von individuellem Interesse, allgemeinem Interesse und vernünftiger kollektiver Willensbildung scheinen sich nicht einmal theoretisch sicher nachweisen zu lassen, und das hat primär damit zu tun, daß sich reflexive Meta-Präferenzen in erster Linie gar nicht auf niederrangige Interessen beziehen, sondern auf die Kontexte, in denen diese zur Geltung gebracht werden können. 
stitutionen aufgefangen werden, die dafür Sorge zu tragen haben, daß die Meinungsund Willensbildung gegen egoistische Regressionen der Interessenbildung einerseits und gegen die Ausbeutung durch strategisch gesonnene Akteure abgeschirmt wird. Diese konzeptionelle Stoßrichtung spiegelt sich schließlich auch in den Vorschlägen, mit denen Offe und Preuß ihre Vorstellung einer Radikalisierung der Idee demokratischer Partizipation illustrieren. Sie sind vor allem darauf bezogen, sei es in Gestalt der Einfügung von Elementen statistischer Repräsentation, des Voucher-Systems (Preuß, 1989: 11 f.) oder im Rückgriff auf Überlegungen zum öffentlichen Wahlrecht, die Repräsentativität der Interessenartikulation auf der Eingabeseite des politischen Prozesses zu verbessern, stärker deliberative Elemente in den Proze $\beta$ der Interessenvermittlung einzubringen und so die Aussicht auf eine Erhöhung der Qualität der politischen Entscheidungen zu begründen. ${ }^{76}$

c) In viel radikalerer Weise als Cohen und Arato führen Offe und Preuß also die Defizite moderner Politik auf die liberale Auslegung des politischen Prozesses und dessen institutionellen Zuschnitt zurück. Daraus resultiert dann die plausible Erwartung, durch institutionelle Reformen auf Seiten der Bürger jene moralischen Ressourcen und kognitiven Kompetenzen erschließen zu können, auf die man nicht verzichten kann, wenn man der republikanischen Idee der Selbstregierung unter Bedingungen gesellschaftlicher Komplexität wenigstens einige Plausibilität verleihen will. Damit unterlaufen sie die Selbstbeschränkungsformel, soweit sie auf eine Diagnose der Überforderung diskursiver Prozesse und des Staatsbürgers zurückzuführen ist. Davon bleibt das zweite entscheidende Argument, mit dem Cohen und Arato (aber nicht nur sie: in der Anlage ähnlich argumentieren auch Rödel, Frankenberg und Dubiel) in ihrer Sicht unrealistische Erwartungen bezüglich einer weitergehenden Demokratisierung von Politik und Gesellschaft zurückweisen, zunächst unberührt: eine strukturelle Grenze für Demokratisierungsprozesse bilden danach die Logik der gesellschaftlichen Differenzierung und die eigenlogische Reproduktion ausdifferenzierter Handlungszusammenhänge in Politik und Ökonomie. Will man diesem, in funktionalistischer, systemtheoretischer Perspektive gewonnenen Argument nicht vorschnell nachgeben, dann muß man sowohl die Frage nach der Rationalisierung des Zusammenspiels eigenlogisch differenzierter Teilsysteme (vgl. Offe, 1986) als auch insbesondere jene nach dem Modus von sozialen Prozessen der Differenzierung und Entdifferenzierung stellen.

Das ist nun genau der Punkt, an dem Joas Überlegungen einsetzen, ob sich die bei Habermas analytisch und methodisch in Handlungs- und Systemtheorie auseinandergelegte Gesellschaftstheorie nicht doch innerhalb eines einheitlichen handlungstheore-

$76 \mathrm{Da}$ es mir an dieser Stelle nur auf die allgemeine Charakterisierung des Arguments ankommt, kann ich es bei dieser programmatischen Zuspitzung belassen und komme auf Einzelheiten genauer erst weiter unten (Kap. 7.2) zu sprechen. 
tischen Bezugsrahmens rekonstruieren läßt. ${ }^{77}$ Diese Überlegung entfaltet er grob in drei Schritten: zunächst weist er auf dem Weg einer immanenten Kritik den Anspruch funktionalistischer Ansätze zurück, eine angemessene Explikation und Erklärung von Prozessen gesamtgesellschaftlicher Integration und Ordnungsbildung gewährleisten zu können; nachdem er sich auf diese Weise den für die Entfaltung einer handlungstheoretischen Alternative notwendigen Raum geschaffen hat, kann er im Zusammenhang von Konstitutionstheorien der Gesellschaft sein Modell kreativen Handelns einführen; dies ermöglicht es ihm schließlich, die soziale und politische Demokratie als Form der (institutionellen) Selbstbeschreibung der konstitutiven Praxis plausibel zu machen und die Möglichkeit eines demokratischen Zugriffs auf Prozesse der gesellschaftlichen Differenzierung und Entdifferenzierung zu erschließen.

Zweifellos ist Joas Argumentationsgang von vornherein durch den normativen Bezug auf die Idee der Demokratie informiert. Das zeigt sich besonders an der Stelle (Joas, 1992: 319), an der er auf seine frühere Auseinandersetzung mit Habermas` »Theorie des kommunikativen Handelns « zurückblickt (Joas, 1986) und das Motiv seiner Kritik mit dem von McCarthy zur Dekkung bringt: »McCarthy hat die Unvereinbarkeit dieser Fülle von Zielen (die Habermas mit der Unterscheidung von sLebenswelt und sSystem< verbindet: die Differenz von Teilnehmer- und Beobachterperspektive, die Differenz einer sozialen Integration über Handlungsorientierungen gegenüber einer Integration über Handlungsfolgen, die Differenz der Bereiche symbolischer und materieller Reproduktion u.a., d. Verf.) eindrucksvoll demonstriert. Er weist insbesondere nach, daß Habermas mit dem Systembegriff versucht, auf politischem Gebiet Forderungen nach Demo-

77 Zwar möchte Joas die »Kreativität des Handelns« nicht als normativen, sondern eher als deskriptiven oder explikativen Begriff verstanden wissen und macht erst im Schlußteil seiner Arbeit auch einen normativen Gebrauch von seinen rekonstruktiven Analysen. Ich kann an dieser Stelle die weitgespannten Überlegungen und Untersuchungen nicht im einzelnen nachvollziehen, die Joas unternimmt, um dieser anspruchsvollen Fragestellung gerecht zu werden (vgl, jetzt zusammenfassend Joas, 1992). Sie führen uns über eine Kritik funktionalistischer und neo-funktionalistischer Ansätze zurück zu Theorien der normativen Integration von Gesellschaften (wobei er dem Werk Durkheims besondere Aufmerksamkeit schenkt), um von da aus eine handlungstheoretische Alternative zu entwikkeln. Auf diesem Weg sind dann vor allem die von ihm sog. »Konstitutionstheorien « der Gesellschaft von Interesse, Theorien also, die auch makro-gesellschaftliche Prozesse aus dem Handeln der Individuen zu begreifen versuchen (Joas, 1992: 337), wie er sie etwa in den Werken von Etzioni, Giddens, Touraine oder Castoriadis vorgebildet sieht. Seine besondere Aufmerksamkeit gilt dabei insbesondere einem Typus von Konstitutionstheorien, die er in der Perspektive der Kreativität des Handelns faßt und deren Grundzüge er am amerikanischen Pragmatismus (Mead und Dewey) entwickelt. Auf dieser Grundlage kann er schließlich versuchen, Spuren der Kreativität des Handelns unter systematischen Gesichtspunkten (Ausdruck, Produktion, Revolution, Leben, Intelligenz und Reproduktion) durch die soziologische Theoriengeschichte hindurch zu identifizieren, um am Ende alle diese Fäden zu einer Theorie der »kreativen Demokratie « (Dewey) auf praxistheoretischer Grundlage wenigstens programmatisch zu verknüpfen (vgl. dazu auch Münch, 1993).

Angesichts dieser Lage muß ich mich darauf beschränken, die strategisch entscheidenden Argumentationsschritte zu markieren, die ihn schließlich zu der für unsere Überlegungen einschlägigen Formel einer »Demokratisierung der Differenzierungsfrage« führen. 
kratisierung von Staat und Ökonomie metatheoretisch aus dem Felde zu schlagen ${ }^{78}$ Nun ist andererseits aber klar, daß normative Gründe nicht dazu taugen, theoretische Modelle gegen analytische Anforderungen und empirische Einsichten zu imprägnieren. Deshalb unternimmt es Joas denn auch in seinem ersten Schritt, die funktionalistische Perspektive auf Fragen der Handlungskoordination und Prozesse der Herstellung gesellschaftlicher Ordnung aus immanenten Gründen zurückzuweisen. Maßgeblich sind dabei insbesondere zwei Argumente, von denen eines auf das Problem der deskriptiven Angemessenheit, das andere mit Blick auf methodische Probleme der nicht-willkürlichen Beschreibung von Sollwerten und Bestandsschwellen sozialer Systeme auf den Objektivitätsanspruch funktionaler und systemtheoretischer Ansätze zielt. Die entsprechenden Argumente lassen sich wie folgt resümieren. In Übereinstimmung mit der gängigen Funktionalismuskritik, die auf die Schwierigkeiten abzielt, Funktionen als Bewirkung der Voraussetzungen des Bestandes von Handlungssystemen zu definieren, wenn diese nicht auf eine bestimmte Identität festgelegt sind und unklar ist, was das z.B. in der Biologie relativ eindeutig faßbare Problem des Todes im Zusammenhang sozialer Systeme bedeuten soll, geht er dann genauer den Lösungen nach, die Luhmann sukzessive für dieses Problem erarbeitet (Joas, 1992: 309 ff.): Weil Luhmann durch eine einfache Temporalisierung des Bestandsproblems, d.h. durch eine Verschiebung der Problematik vom Bestand eines Systems auf die Erhaltung von Prozessen der Strukturierung, das Problem der Wahl eines Bezugspunkts, an dem sich kontrollieren ließe, ob ein Reproduktionsprozeß unterbrochen oder abgebrochen wurde, nicht los wird, zieht er sich schließlich auf die Formel der Reduktion von Weltkomplexität zurück; diese Formel aber bleibt so lange semantisch leer, wie man die Handlungsprobleme, auf die Strukturerfindungen berechnet sind, nicht genauer identifziert (Joas, 1992: $314 \mathrm{f}$.) - das ist die Lücke, die Joas mit der pragmatistischen Vorstellung des Problemlösungshandelns als eines situativ-kreativen Aktes der reflexiven Zielbestimmung durch Akteure schließen möchte (vgl. Joas, 1986: 151).

Auf diese Weise kann Joas den von Luhmann und Habermas übereinstimmend vertretenen Objektivitätsanspruch systemtheoretischer Beschreibungen zurückweisen, der ja wesentlich auf der Annahme gründet, daß es Systeme in genau dem Sinne gibt, daß sie »objektiv gestellte Probleme durch übersubjektive Lernprozesse lösen können« (Habermas, 1970: 271). Gegen die deskriptive Verwendung eines systemtheoretischen Modells hat Joas indessen keine grundsätzlichen Einwände, verweist aber auf die Notwendigkeit einer vorgängigen Klärung des »degree of systemness «, den die zu analysierenden Handlungszusammenhänge tatsächlich aufweisen: »In dieser Perspektive gibt es zwar Syste-

78 Zwar hat Habermas, wie oben gezeigt, seit der »Theorie des kommunikativen Handelns (1981) und insbesondere in »Faktizität und Geltung « (1992) vor allem die analytische Perspektive auf das politische System stark (gleichsam institutionentheoretisch) modifiziert, indem es nun nicht mehr als ein- und eigensinniges, mediengesteuertes (Macht) Subsystem erscheint, sondern als Zusammenhang reflexiv aufeinander bezogener, institutioneller Prozesse der Legitimation, Machterzeugung und -anwendung. Gleichwohl bleiben die demokratietheoretischen Konsequenzen dieses Neuansatzes hinsichtlich einer Öffnung dieser Strukturen für gesellschaftliche Prozesse öffentlicher Meinungs- und Willensbildung hinter einigen Erwartungen zurïck (vgl. oben Kap. 3.2). 
me, aber keineswegs erfüllt jedes soziale System die Anwendungsbedingungen der Systemtheorie. In vielen Fällen sind diese nur zu einem so geringem Grade gegeben, daß die funktionale Analyse gegenstandsverzerrend wirken muß«(Joas, 1992: 320). Und genau diese voraussetzungsvollen Anwendungsbedingungen scheinen weder in der Politik noch in der Ökonomie im ganzen gegeben zu sein. Dabei sind es im Falle des politischen Systems nicht allein Bedenken bezüglich der normativen Unangemessenheit einer systemtheoretischen Bschreibung, wie sie McCarthy auf den Punkt gebracht hat: "Wenn Selbstbestimmung, politische Gleichheit und die Beteiligung der Staatsbürger an den Entscheidungsprozessen die Merkmale wirklicher Demokratie sind, dann kann eine demokratische Regierung kein politisches System (Herv. i.O.) im Sinne von Habermas sein, das heißt, ein Handlungsbereich, der von allen anderen Teilen der Gesellschaft abgespalten ist und seine Autonomie ihnen gegenüber dadurch aufrecht erhält, daß er seinen Austausch mit ihnen über entsprachlichte Steuerungsmedien wie Geld und Macht reguliert « (McCarthy, 1986: 198). Aber auch McCarthy bringt an dieser Stelle nicht nur normative Kriterien zur Beurteilung der deskriptiven Angemessenheit systemtheoretischer Modelle in Anschlag. Vielmehr fragt auch er sich, inwieweit wir faktisch davon ausgehen können, daß Interaktionen in der politischen Sphäre eher systemisch als sozial integriert sind. Um diesen Punkt zu erhellen, genügt es, die Frage nach den Formen zu stellen, in denen sich das Handeln in diesen Bereichen organisiert und dann einen Blick auf das >Innenleben< formaler Organisationen und Unternehmen zu werfen, um festzustellen, daß auch hier das Handeln kaum ausschließlich und vielleicht nicht einmal in erster Linie über formale, mediale Mechanismen der Verknüpfung von Handlungsfolgen strukturiert ist. ${ }^{79}$

Nachdem er den analytischen Anspruch systemtheoretischer Modelle so weit reduziert resp. spezifiziert hat, wendet sich Joas dann dem »Kernstück « funktionalistischer Theoriebildung, der Theorie der Differenzierung, zu (Joas, 1992: 326 ff.), was ihm eine exemplarische Überprüfung des gesellschaftstheoretischen Anspruchs des Funktionalismus ermöglichen soll. Auch hier kann er unter sechs Gesichtspunkten (vgl. Joas, 1992: $329 \mathrm{ff}$.), die ich ebenfalls nur nennen kann, zeigen, daß der Anspruch der Substitution von Handlungstheorie auch auf gesellschaftstheoretischer Ebene unbegründet ist: Zum ersten bleibe der logische Status des Begriffs der Differenzierung fragwürdig, weil nicht klar ist, ob es sich um ein bloßes Deskriptionsschema oder um ein Erklärungsgesetz handelt; m.a.W., »ist ein Differenzierungsprozeß schon erklärt, wenn er sich als solcher beschreiben läßt « (Joas, 1992: 329)? Diese Ambivalenz trete zweitens auch hervor, wenn man sich der Frage nach den Ursachen von Differenzierungsprozessen zuwendet; auch hier haben Erklärungen, die Differenzierung auf einen Gewinn an Leistungsfähigkeit oder auf evolutionäre Mechanismen eines gerichteten Anpassungsprozesses an innere und äußere Problemlagen resp. auf Komplexitätssteigerung zurückführen, zunächst einmal nur einen heuristischen Wert, kei-

79 Bezüglich der Organisationsform »Unternehmen« vgl. die instruktiven Überlegungen Bergers (1992); daß man den »degree of systemness « im Organisationshandeln nicht überschätzen sollte, hat Türk (1989) in einem systematischen Überblick über neuere Entwicklungen in der Organisationstheorie gezeigt: danach erscheint die Formalität des Organisationshandelns bestenfalls als (immer noch) wirksamer und gut behüteter Mythos, über den Organisationen ihre Legitimationsanspriiche sozial vermitteln. 
nesfalls aber können heuristische Annahmen stillschweigend kausal umgedeutet werden. Dieser Einwand wiederum verknüpft sich drittens mit der Frage nach den Trägern von Differenzierungsprozessen in der Weise, daß wir fragen müssen, ob man sich diese Prozesse so vorstellen kann, daß sie durch die Orientierungen und Intentionen von Handelnden hindurchgreifen; und wenn nicht, ob man die Differenzierungsgesichtspunkte (Effizienz, evolutionäre Anpassung, Komplexitätssteigerung) auch als konkrete Handlungsziele von Beteiligten nachweisen kann? Wie immer die Antworten auf diese und ähnliche Fragen im Einzelfall ausfallen mögen, sicher scheint zu sein, daß man sie nur stellen muß, um den weitreichenden Anspruch systemtheoretischer Modelle zurückzuweisen und vor allem den substantialistischen, ontologisierenden Implikationen, die sich gleichsam gegen die ungesicherte methodologische Ausgangsbasis verselbständigen, entgegenzusteuern.

Während Joas auf diese Weise sein Beweisziel nur indirekt erreichen kann, hängt im weiteren alles von dem Ausbau des Instrumentariums einer Handlungstheorie ab, die die aufgetane Lücke im gesellschaftstheoretischen Erklärungszusammenhang auch füllen kann. Schon in seiner Habermas-Kritik (1986) hatte er zu diesem Zweck eine Erweiterung der Handlungstypologien eingeklagt. Diese Anregung greift er nunmehr in seinem zweiten zentralen Argumentationsschritt auf, dessen Kernstuick die Plausibilisierung eines Modells kreativen Handelns ausmacht. Den systematischen Ausgangspunkt dafür bietet ein Rückgriff auf Durkheims Studie über die Arbeitsteilung, was insofern naheliegt, als für Durkheim der Zusammenhang zwischen Arbeitsteilung (Differenzierung) und Moral, verstanden als situativ-reflexive Einsicht in die Erfordernisse kooperativen, problemlösenden Handelns, konstitutiv ist: »Bei einer solchen Kooperationsmoral handelt es sich weder um eine von Herrschern auferlegte Zwangsmoral noch um eine freiwillige Vereinbarung von Subjekten in die ihnen akzeptabel scheinenden Bedingungen des Umgangs miteinander, sondern um eine reflexiv gewinnbare Einsicht in die funktionalen Erfordernisse egalitärer Kooperation « (Joas, 1992: 90 f.). Was ihn daran interessiert, ist einerseits die Form einer »selbstreflexiven und insofern sekundären Vergegenwärtigung eines Handlungsgeschehens in Situationen« (Joas, 1986: 151), also die Zurückführung von Regeln der Arbeitsteilung und Kooperation auf intentionale Akte; zum anderen die Tatsache, daß sich im Lichte einer solchen Beschreibung die Sicht auf das zweck- oder erfolgsorientierte menschliche Handeln selber verändert, insofern Zwecksetzung als kontinuierlicher, situativ-reflexiver (und mithin: kreativer) Prozeß sichtbar wird. Diese Konsequenz zieht er ausdrücklich auch hinsichtlich des Gegenstandes einer makrosoziologischen Theoriebildung: »Das Streben nach solcher makrosoziologischen Theoriebildung lenkt ihren (Konstitutionstheorien, der Verf.) Blick auf die kreative Dimension des Handelns, die implizit auch in anderen Handlungsmodellen steckt. Selbst innerhalb eines als Nutzenverfolgung gedachten Handelns tritt ja Kreativität auf, da die geeigneten Handlungsmittel oft nicht zuhanden sind, sondern erst geschaffen werden müssen, und da auch zur Konzipierung einer geschickten Strategie schöpferische Eigenleistungen erforderlich sind. Auch innerhalb des normativen Handelns läßt sich Kreativität nachweisen, da sich situationsadäquates normkonformes Handeln nicht deduktiv aus Normen erschließen läßt, sondern riskante Entwürfe nie begangener Handlungspfade erfordert...All diese Resultate der Kreativität: erzeugte Handlungsmittel, neue Handlungsstrategien, kultu- 
relle Innovationen und Bindungswirkungen kultureller Gehalte - lösen sich ab vom Akt ihrer Kreation und werden zu Ressourcen neuen Handelns « (Joas, 1992: 342).

Den Grundgedanken des aus dieser Überlegung resultierenden Modells kreativen Handelns kann man nun kurz folgendermaßen umreißen: Zunächst wird der Begriff des Handelns prinzipiell aus der Perspektive der Anwendung (kollidierender) Handlungsnormen in problematischen Situationen und nicht in der Perspektive der Normbegründung erschlossen; zweitens kann kreatives Handeln im Zusammenhang von Normanwendung und angemessener Problemlösung nicht solipsistisch verstanden werden - ihm bleibt eine moralische Dimension durch die intersubjektive Orientierung von Kreativität selbst eingeschrieben; damit kann dieses Verständnis in eine partizipatorische Auffassung von Demokratie insoweit eingepaßt werden, als Mechanismen der objektivistischen Überformung von Handlungszusammenhängen durch eine institutionell zu sichemde »Kooperationsmoral « substitutiert werden sollen (Joas, 1990b: 8). Diesen Grundgedanken versucht er dann unter Aufnahme der Maslowschen Unterscheidung von primärer, sekundärer und integrierter Kreativität zu präzisieren, in der kreatives Handeln als ein dreistufiger sozialer Problemlösungsprozeß erscheint (Joas, 1990a: 13 f.). Auf der ersten Stufe primärer Kreativität werden »individuelle Vorstellungskraft, Momente des Spielerischen und der Enthusiastik « freigesetzt, die auf der zweiten Stufe rationalisierenden Perfektionskriterien ausgesetzt werden, so daß die unterschiedlichen Gestalten der Ausprägung menschlicher Vernunft in der Lösung konkreter Probleme zusammengeführt und die »Offenheit der Selbstartikulation mit Verantwortungshaftigkeit und Selbstkontrolle zusammengedacht« werden können (Joas, 1990b: 8). Dieses Modell integrierter Kreativität steht ersichtlich im Zusammenhang eines pragmatistischen Sozialmodells von Wissen und Rationalität, das zwar das »effective working of an idea« zum Bezugspunkt der Explikation von Wahrheit schlechthin macht, das aber, anders als es etwa in sozialtechnologischen Vorstellungen aufgenommen wird, auf die demokratischen Selbstimplikationen pragmatischer Wissenserzeugung und -anwendung (also: rationaler Problemlösung) zielt und so auf die zentrale Stellung und Bedeutung der Idee von Öffentlichkeit in einem solchen Proze $\beta$ verweist: "Truth telling has always been a matter of adaptation to a social audience (Kaufman-Osborn, 1985: 842).

Eine gesellschaftstheoretisch wichtige Implikation dieses Handlungsbegriffs liegt zweifellos darin, daß er die Projektion des Gesellschaftsbegriffs auf das territorial abgegrenzte Gebilde des modernen Staates etwa unterbricht und einige Skepsis gegenüber der Vorstellung einer normativen Integration von Gesellschaften provoziert. Vielmehr wird an die Stelle »einer nie stabilisierbaren Interessenbalance rationaler Akteure oder die nie erreichbare weiträumige normative Integration...die Vorstellung von Netzwerken der Handlungsverknüpfung (gesetzt), die in unterschiedlichem Maße Raum und Zeit uiberbrücken« (Joas, 1992: 343). Erst mit dieser Generalisierung des Modells kreativen Handelns zu der Vorstellung eines gleichsam modularen ${ }^{80}$ Aufbaus moderner Gesellschaf-

80 Dieser Begriff stammt von Herbert Simon und wird zur Kennzeichnung des Aufbaus komplexer Systeme über tief staffelbare System-Subsystem-Beziehungen verwandt (zit. bei Willke, 1992: 63). Trotz dieser ganz anderen Herkunft scheint er mir gut geeignet, auch das aus dem handlungstheoretischen Ansatz von Joas folgende Organisationsmodell moderner Gesellschaften zu erfassen. 
ten, setzt sich Joas erntzunehmenden Einwänden aus. Zum einen kann diese Vorstellung schon deshalb nicht einfach an die Stelle normativer Ordnungen treten, deren Hauptmerkmal, wie Münch (1993: 295) zu Recht hervorhebt, ja darin besteht, daß sie auf einem Konsens über die moralische Dignität und Autonomie des Individuums aufruhen, dessen Möglichkeit und Zustandekommen auch erklärt werden können muß. Zum anderen läuft Joas Gefahr, sich mit der pragmatistischen Handlungstheorie unterhalb der Ansatzhöhe der kritisierten funktionalistischen und systemtheoretischen Paradigmen einzurichten (vgl. Münch, 1993: $303 \mathrm{f}$.), wenn er die Vorstellung einer normativen Integration vollständig aus dem Felde schlägt, weil die Stelle der Mechanismen der autonomen Vernetzung modular gedachter Einheiten zunächst unbesetzt bleibt.

An dieser Stelle ist er schließlich zu einem theoriestrategisch folgenreichen, leider aber nur knapp angedeuteten dritten Argumentationsschritt genötigt - demokratische Formen der Selbstregierung und Selbstbestimmung sollen nicht nur den internen Aufbau unterschiedlicher Handlungszusammenhänge regulieren, sondern darüber hinaus die Art ihrer Verknüpfung, mithin Fragen der Differenzierung und Entdifferenzierung in die eigene Regie nehmen: "Die Konstitutionstheorien können der Aufgabe einer normativen Reflexion auf die Idee der Demokratie nicht entgehen, in der die Idee der Selbstkonstitution auf die Bedingungen einer differenzierten modernen Gesellschaft hin zu konkretisieren ist « (Joas, 1992: 348). Für diese Synthese von Konstitutions- und Differenzierungstheorien schlägt er deshalb die Formel einer »Demokratisierung der Differenzierungsfrage « vor, die ihren Ausgangspunkt in der Einsicht hat, daß alle sozialen Prozesse in modernen Gesellschaften politisch vermittelt sind. Mit dieser Formel versucht er Möglichkeiten für die Steigerung der Chancen moderner Gesellschaften, auf sich selbst und ihre Entwicklung einzuwirken, zu eröffnen, ohne sich etwa Münchs (1984) Vertrauen in die Interpenetration aller Subsysteme überlassen zu müssen - das freilich setzt auch einige Phantasie auf dem Wege einer institutionellen Konkretisierung dieser Idee voraus. Die Suche nach entsprechenden institutionellen Formen, die Joas selber nur anregt, aber nicht selber durchführt, müßte grundsätzlich in drei Richtungen vorangetrieben werden (vgl. auch Giegel, 1992: 96 ff.): in Richtung funktionsspezifischer Teilsysteme, die schon von sich aus in der Regulierung ihrer Interaktionsbeziehungen eine gewisse Affinität zu Formen der kommunikativen, argumentativen Vernetzung aufweisen; zweitens in Richtung auf Formen der Assoziierung und Gemeinschaftsbildung auf den unterschiedlichen Ebenen des politischen Prozesses und drittens in Richtung auf fokale Strukturen der gesellschaftlichen und politischen Problemlösung, in denen Akteure `systemübergreifend k kommunizieren können und müssen. 


\section{Die Idee der reflexiven Demokratie}

Einen wichtigen Schritt in die angedeutete Richtung einer gesellschaftlichen Konkretisierung der Idee der partizipatorischen Demokratie haben bereits Cohen und Rogers (1992) unternommen, indem sie im Rahmen eines egalitären Verständnisses von Demokratie $^{81}$ die Bedeutung gesellschaftlicher Gruppen bei der Beförderung einer intelligenten, ergebnisorientierten und effizienten Politik der Problemlösung hervorheben. Ihre diesbezüglichen Erwartungen lassen sich in vier Punkten zusammenfassen (Cohen/Rogers, 1992: 424 f.). Zunächst wird die staatliche Politik im Zuge der Ausweitung und Intensivierung regulativer Politiken anfälliger für Probleme, die sich im Zusammenhang der Beschaffung notwendiger Informationen einstellen - hier können gesellschaftliche Gruppen schon aufgrund ihrer häufig größeren Problemnähe eine wichtige Zuliefererfunktion übernehmen. Darüber hinaus sollte eine intensivierte und strukturell in den institutionellen Entscheidungszusammenhang inkorporierte Gruppenbildung den herrschenden Asymmetrien im System der Interessenrepräsentation entgegenwirken können - sie erlauben es auch ressourcenschwachen Individuen, ihre Ressourcen zu »poolen « und Interessen zu artikulieren, die auf der Basis eines primär territorialen Organisationsprinzips von Politik schlecht erfaßt werden können. Erst eine derartig aktivierte und effektuierte staatsbürgerliche Teilhabe erschließt drittens auch Anreize für den einzelnen, eine entsprechende Kompetenz, das nötige Selbstvertrauen und ein breiteres Spektrum an Interessen auszubilden, als es in einem fragmen-

81 In Konkretisierung des abstrakten Ideals einer demokratischen Gesellschaft als einer Gesellschaft von Gleichen, die zugleich durch und für ihre Mitglieder regiert wird, zeichnen sie sechs spezifische Bedingungen aus, die diesem Ideal Substanz verleihen sollen. Es sind dies die Prinzipien der Volkssouveränität, der politischen Gleichheit und der distributiven Gerechtigkeit, die sich nur realisieren lassen, wenn sich die politische Ordnung insgesamt auf ein ausgeprägtes und hinreichend verbreitetes staatsbürgerliches Bewußtsein stützen kann, wenn die ökonomische Leistungsfähigkeit einer an allgemeiner Wohlfahrt orientierten Gesellschaft bewahrt wird und wenn schließlich die Staatstätigkeit auf die Effektuierung öffentlicher Deliberation hin ausgelegt ist (Cohen/Rogers, 1992: $417 \mathrm{ff}$.). Der Sinn der letztgenannten Bedingungen erschließt sich vor allem in Bezug auf ihre allgemeine Prämisse, daß $»$ political decision making must be deliberative... and public initiatives are defended ultimately by reference to an sopenly acknowledged conception of the public interest « (Cohen/Rogers, 1992: 420).

Von Bedeutung ist dieser Ansatz deswegen, weil er geeignet ist, über Habermas' Auslegung der radikalen Demokratie in Richtung auf das Ideal der Selbstregierung hinauszugreifen: anders als im »Belagerungsmodell« wird eine Organisationsform »kommunikativer Macht « angestrebt, die es erlaubt, »picking up some of the work of the administrative state, not simply posing a siege upon it« - ein wichtiger Grund dafür ist, daß sich Cohen und Rogers weniger als Habermas von der vermeintlich eigensinnigen inneren Funktionslogik bürokratischer Apparate beeindrucken und ablenken lassen (vgl. Cohen/Rogers, 1994: 137, Fn 8). 
tierten politischen System der Fall ist. Insofern können schließlich die gesellschaftlichen Gruppen und Assoziationen nicht nur als »Schulen der Demokratie « fungieren, sondern sie sind auch der Ausdruck einer anderen Form der Regierung - »(they) figure more as problem solvers than simply as representatives of their members to authoritative political decision makers, pressuring those decision makers on behalf of their interests. They help to formulate and execute public policies and take on quasi-public functions that supplement or supplant the state's more directly regulatory actions « (Cohen/Rogers, 1992: 425).

Kurz, was sie hier im Auge haben, ist ein Projekt der Rekonstruktion einer politischen Gemeinschaft (Streeck, 1992: 513), in dem gesellschaftliche Assoziationsstrukturen die Aufgabe übernehmen, Ungleichgewichte in der Interessenrepräsentation auszutarieren, dem herrschenden Gruppenpartikularismus und -egoismus durch die Ermutigung deliberativer Praktiken entgegenzuwirken und die staatliche Politik dort zu ersetzen, "where their participation could improve the effectiveness of government programs « (Cohen/Rogers, 1992: 425 f.). Freilich können wir nicht davon ausgehen, daß gesellschaftliche Gruppen und Assoziationen in ihren Organisationsstrukturen, -prinzipien und -zielen diesen Anforderungen immer genügen. Vielmehr bedarf es einer gezielten Anstrengung, adäquate Gruppenbildungsprozesse anzuregen und zu unterstützen. Das wird von Cohen und Rogers auch eingeräumt, wenn sie notieren, daß »the art of associative democracy (Herv. d. Verf.) consists in matching group characteristics with assigned functions and - now admitting the fact of artifactuality - cultivating those characteristics appropriate to functions consistent with the norms of egalitarian democracy « (Cohen/Rogers, 1992: 428). Selbst unter diesen Voraussetzungen wird man allerdings davon ausgehen müssen, daß sich die erwarteten Effekte nur einstellen, wenn man eine demokratische Gruppenpolitik in einem System der politischen Willensbildung verankern kann, das die Willensbildungsströme nicht mehr nur auf das staatliche Zentrum hin institutionell kanalisiert, sondern in die Kapillaren eines Netzwerks gesellschaftlicher Assoziationen umlenkt. Das nötigt aber, wie ich meine, zu einer viel weitergehenden Umgestaltung des gesamten Systems der institutionellen Politikvermittlung als sie Cohen und Rogers an dieser Stelle vorsehen (vgl. auch Hirst, 1992: $476 \mathrm{ff} .{ }^{82}$

Vor diesem Hintergrund zeichnen sich die politischen und metapolitischen Implikationen der Wendung von einer "reflexiven Fortsetzung des Projekts der Demokratie« zu einem, wie ich es nennen möchte, Projekt der reflexiven Demokratie nunmehr deut-

82 Das räumen Cohen und Rogers mittlerweile auch ein, wenn sie wenigstens andeuten, daß im Unterschied zu einer minimalen Auslegung des Projekts der assoziativen Demokratic, in der es gleichsam kompensatorisch in die Funktionslücken staatlicher Politik treten soll, auch eine maximale Auslegung möglich ist, nach der eine neue Form der politisch-konstitutionellen Ordnung insgesamt ins Auge zu fassen wäre (vgl. Cohen/Rogers, 1994: $138 \mathrm{f}$.). Obwohl sie dieser Andeutung dann doch nicht genauer nachgehen, spricht einiges dafür, daß sich erst in einer solchen Perspektive das Potential einer auf die Erneuerung der moralischen und solidarischen Grundlagen moderner Politik gerichteten normativen Rechtfertigung und funktionalen Begründung der assoziativen Demokratic auch ausschöpfen ließe (vgl. Cohen/Rogers, 1994: $150 \mathrm{ff}$.). 
licher ab. Wenn aus Gründen der politischen Gleichheit und der Effektivität repräsentative Organisationsformen der Demokratie durch direktdemokratische Formen nicht einfach ersetzt werden können; wenn aber durch die Mediatisierung der Staatsbürger andererseits auch jene Ressourcen zunehmend verschüttet wurden, auf die man für Zwecke einer gesellschaftlich vermittelten Rationalisierung der Politik dringend angewiesen ist, dann müssen Perspektiven entwickelt werden, die es erlauben, die Demokratie zwischen den Klippen einer blaß und unplausibel gewordenen elitären Demokratie einerseits und einer mit unrealistischen Erwartungen zu einem verbindlichen Formprinzip generalisierten Modell direkter Demokratie hindurchzuführen. Die Antwort auf das damit gestellte Problem liegt nun im Kern in der Radikalisierung und Erweiterung des reflexiven Mechanismus aufeinander bezogener, arbeitsteiliger Prozesse der Gesetzgebung, Regierung und Rechtsprechung, wie er im Modell der horizontalen und vertikalen Gewaltenteilung und -verschränkung bereits vorgebildet ist (Maus, 1992 und 1992a).

Komplementär zur Idee der vernünftigen Selbstbeschränkung des demokratischen Prinzips erhält die Vorstellung einer reflexiven Demokratie den Charakter einer metapolitischen Radikalisierung partizipatorischer Demokratie: die Struktur einer institutionell befestigten Aufspaltung von Demokratie in unterschiedliche und nur lose und z.T. widersprüchlich verbundene Organisationsformen wäre durch eine Politisierung und Demokratisierung des Zusammenspiels unterschiedlicher Formen von Demokratie aufzubrechen und zu prozessualisieren; darüberhinaus muß sich die Demokratietheorie unmittelbar der Fragen und Probleme annehmen, die sich im Zusammenhang der Rationalisierung staatlicher Politik auf der Ebene materialer Einzelpolitiken mit Blick auf die Verbesserung der Qualität und nicht nur der Legitimität von Entscheidungen stellen. Diese Perspektive einer weitergehenden Vergesellschaftung des Staates läßt den m.E. neuralgischen Punkt moderner Demokratietheorie deutlich hervortreten, an dem sich der Anspruch auf erweiterte Partizipation mit den Anforderungen einer problemund ergebnisbezogenen, oft expertiseabhängigen Politik verbinden muß - aber auch hier stellen deliberative Öffentlichkeit und für allgemeine Teilhabeansprüche offene Strukturen unverzichtbare, wenn auch noch wenig erschlossene Ressourcen dar.

Den leitenden Gesichtspunkt einer darauf bezogenen Modellvorstellung bildet die Frage, wie sich das Interesse an der Verbesserung der demokratischen Legitimitätsgrundlagen der Politik mit dem Interesse an der Verbesserung der Qualität der Ergebnisse von Politik verbinden läßt; eine Frage, die sich indessen nicht ohne ein adäquates Konzept des Staatsbürgers beantworten läßt, das ein entscheidendes Scharnier zwischen institutioneller Analyse und materialer Politik bildet - hier teile ich die Überzeugung Schmitter's »that any viable institutional (re)design should be aimed at expanding this crucial property intrinsic to all types of democracy. Not only would this engender a properly generic sense of empowerment, but it just might encourage individuals to use whatever powers are accorded to them in a more civic or other-regarding way « (Schmitter, 1992: 512, Fn. 4). Eine solche Perspektive der Verbesserung der Effizienz und Effektivität von demokratischer Teilhabe nötigt dazu, die institutionellen Mittel selber, mittels derer die Gesellschaft auf sich als ganze einwirken kann, unmittelbar zum Gegenstand der öffentlichen Willensbildung zu machen. Das impliziert nicht nur eine öffentliche 
Dauerreflexion auf die thematische und gesellschaftliche Reichweite und Wirkung demokratischer Verfahren, sondern es sollte zu einer Selbstqualifizierung der Demokratie in vor allem drei Richtungen führen. Zum einen ist die Idee der Demokratie faktisch in unterschiedliche Muster einer repräsentativen, direkt-majoritären und partizipatorischdeliberativen Organisationsform diffundiert und in unterschiedlichen Handlungsbereichen wie auf unterschiedlichen Ebenen der Willens- und Meinungsbildung segmentär institutionalisiert. Dieses Bild einer fragmentierten Struktur der politischen Meinungs- und Willensbildung in modernen, repräsentativen Demokratien läßt nun selber zwei unterschiedliche Deutungen zu. Man kann, im Rahmen eines Kreislaufmodells (vgl. March/ Olsen, 1989: 117 ff.), das periodische Aufbrechen von Forderungen nach stärker direktdemokratischen Elementen als notorischen Ausdruck einer Unzufriedenheit mit den repräsentativen Institutionen werten, also als Protestphänomen, aus dem sich keine alternativen Grundstrukturen gewinnen lassen - diese Interpretation ist zugleich eine der gängigen Deutungsvorgaben für das Auftauchen und den Lebenszyklus von sozialen Bewegungen. Das gleiche Phänomen läßt sich aber auch als Ausdruck eines strukturellen Differenzierungsprozesses deuten, wonach die Praktiken neuer sozialer Bewegungen zu einer irreduziblen Pluralisierung politischer Entscheidungsverfahren führen, die dann gleichsam ein Reservoir an demokratischen Formelementen bilden, aus dem sich politische Willensbildungs- und Entscheidungsprozesse nach Maßgabe der differentiellen Leistungsfähigkeit der einzelnen Verfahren versorgen könnten. ${ }^{83}$ Das freilich setzt Formen der demokratischen Beteiligung voraus, die geeignet sind, die Allokation von Ent-

83 Eine solche Deutung des demokratischen Entwicklungsprozesses vor dem Hintergrund eines strukturellen Differenzierungsmodells wird auch von Kitschelt (1993) favorisiert. Er unterscheidet zunächst eine liberale von einer organisationalen und einer partizipatorischen Sichtweise des demokratischen Prozesses, um diese dann hinsichtlich der relevanten Akteurkonzeptionen, des Begriffs von »citizenship«, der zentralen institutionellen Charakteristika und des zugrundeliegenden Interessebegriffs zu vergleichen und daraus ein differentielles Leistungsprofil zu gewinnen. Auf diese Weise bereitet er seine eigentliche These vor, daß »different democratic choice procedures are better or worse equipped to handle certain classes of collective choice problems « (Kitschelt, 1993: 24) - d.h. er möchte einen Allokationsmodus für demokratische Entscheidungsverfahren plausibel machen, der sich an allgemeinen Charakteristika kollektiver Entscheidungsprobleme orientiert. Zu diesem Zweck arbeitet er schließlich vier Aspekte heraus, an Hand derer sich kollektive Entscheidungsprobleme beschreiben lassen und die, schon für sich genommen, eine bestimmte Form der (prozeduralen) Bearbeitung nahelegen: "In substantive respects, political issues may present discrete or interdependant problems of choice...In temporal respects, political issues may require permanent attention by democratic decision makers and a continous demand for collective decision, or they may require intermittent attention and decisions « (ebda.).

Damit ist sicherlich ein Kriterium gewonnen, an Hand dessen man die Allokation von Entscheidungsverfahren so steuern kann, daß eine optimale Nutzung des vorhandenen demokratischen Formreservoirs möglich wird. Andererseits sagt er wenig darüber, an welchem Ort von wem und mit welchen Mitteln die Entscheidungen über die Allokation von Entscheidungsverfahren selber vorgenommen werden könnten. Dies mag damit zu tun haben, daß dieses Differenzierungsmodell seinen Rückhalt an einer selber noch zu objektivistischen Differenzierungslogik von Entscheidungsproblemen gewinnt und damit wenig aufnahmefähig ist für das Phänomen der konflikthaften, kollektiven Form der Problemdefinition. 
scheidungsverfahren selber zu steuern und einer demokratischen Kontrolle zu unterwerfen. Ein schwieriges Problem bildet schließlich die Frage, wie eine solche metapolitische Funktion zu institutionalisieren ist, und ein möglicher Ansatzpunkt hierfür ist die Überlegung zu einem reflexiven Funktionswandel des Parlaments. Damit werden aber zweitens auch die Strukturen einer angemessenen Genese der Volkswillens thematisch - in diesem Sinne bedeutet »demokratischer Autopaternalismus« einen Vorrang für solche institutionellen Arrangements, die an der Verbesserung der individuellen Meinungserwerbs-, Artikulations- und Wirkungschancen ansetzen. Drittens müßte auch der Selbstüberforderung partizipatorischer Potentiale und Energien dadurch entgegengewirkt werden, daß selektive, aber gleichwohl offene und effektive Mobilisierungsmechanismen besser und breiter institutionalisiert werden - hier könnte man etwa an die grundsätzliche Öffnung von Policy-Arenen denken, die als Kristallisationskerne für flottierende Teilhabeansprüche fungieren sollten. Schließlich sollte es auf diese Weise möglich sein, dem konkurrenzdemokratisch induzierten Flaschenhalseffekt einer kurzfristig und querschnittig orientierten "positionellen Politik « (Ueberhorst, 1986) mit Blick auf ein vernünftiges Zusammenspiel gesellschaftlicher und staatlicher Politik dadurch auszuweichen, daß man konstitutionell-reflexive Funktionen, administrative Aufgaben und sachliche Entscheidungskompetenzen stärker auseinanderzieht. Und das nicht zuletzt auch deshalb, weil auch die staatliche Politik einen Anspruch auf einen institutionellen Schutz vor sich selber hat.

Entsprechend lassen sich die groben Konturen eines Modells reflexiver Demokratie folgendermaßen umreißen:

- Zunächst ist davon auszugehen, daß das »entscheidende Problem der Demokratietheorie das Entscheidungsproblem « (Zilleßen/Barbian, 1992:14) ist, weil politische Entscheidungen aufgrund ihrer Diffusions- wie technisch-wissenschaftlich potenzierten gesellschaftlichen Tiefenwirkung eine neue Qualität angenommen haben, die nunmehr die Qualität dieser Entscheidungen selber in den Mittelpunkt rückt und die bestehenden Entscheidungsstrukturen auf eine ernste Probe stellt (King/Schneider, 1992). Den Bezugspunkt bilden mithin kollektive Handlungsprobleme und die Bereitstellung demokratischer Mittel der Selbsteinwirkung, wobei die Ideen der Selbstbeschränkung, der Verklammerung unterschiedlicher Formen von Demokratie und der tiefen Staffelung entscheidungsbezogener Willensbildung in den Vordergrund rücken. Das läuft darauf hinaus, dem demokratischen Prozeß insgesamt eine reflexivere Gestalt zu geben, die jeweils spezifizierte Antworten auf die Grundfragen nach dem »Wer « der Beteiligung, dem »Wie« des Problemlösungs- und Entscheidungsverfahrens und dem $»$ Was « der legitimen Reichweite politischer Entscheidungen erlauben (vgl. auch March/Olsen, 1989: 118 und Offe, 1992: 127);

- unter Gesichtspunkten des »Wer verlangt das Problem der horizontalen Diffusion von Entscheidungswirkungen vor dem Hintergrund einer sich beschleunigenden Globalisierung wie der zunehmenden Selbstformatierung relevanter Policy-Netzwerke eine institutionelle Reaktion derart, daß eine Flexibilisierung der Zuschreibung von Teilhaberechten und Entscheidungskompetenzen quer zur nationalstaatlichen Engführung des Legitimitätsprinzips möglich wird. D.h., wir benötigen eine »variable Geometrie ( (Streeck, 1992: 517) assoziativer Strukturen, die eine variable 
Organisation von Politik in unterschiedlichen funktionalen Bereichen, auf unterschiedlichen Ebenen und in einer Vielzahl von Bezugssystemen bereithält, derer sich soziale Akteure in der Verfolgung ihrer Anliegen und Interessen flexibel bedienen können;

- unter dem Gesichtspunkt des »Wie« wäre in Rechnung zu stellen, daß sich die demokratische Willensbildung auch unmittelbar auf Verfahren beziehen muß, die eine gewisse Gewähr für die Vernunft von Ergebnissen bieten: damit treten Fragen nach den Formen der angemessenen Genese des Volkswillens gleichrangig neben Fragen der Verbesserung der Meinungsartikulations- und -wirkungschancen;

- das impliziert, daß man von der Vorstellung einer institutionell konzentrierten und homogenisierten Willensartikulation Abschied nehmen muß, und statt dessen tief gestaffelte, mehrstufig aufeinander bezogene Prozesse der Willensbildung vorsieht;

- erst eine solche Vorstellung erlaubte es schließlich, sich in durchaus kritischer Absicht von dem Gesichtspunkt der entscheidungsbezogenen Effektuierung demokratischer Teilhabe leiten zu lassen und Fragen der Verbesserung der politischen Problemlösungskapazität und der Qualität der Ergebnisse politischer Prozesse in den Vordergrund zu rücken, ohne die zivilgesellschaftliche Ressourcenbasis differenzierter Willensbildungsprozesse überzustrapazieren und den Eigensinn und Eigenwert eines autonomen zivilgesellschaftlichen Handlungszusammenhangs zu unterminieren;

- freilich bedarf eine solche variable konstitutionelle Geometrie der Politik in erhöhtem Maße auch des Rückhalts in den Einstellungen und Orientierungen gesellschaftlicher Akteure. Nun ist in der Gesellschaft der Individuen und Gruppen aber gerade nicht mehr zu erwarten, daß sich ein entsprechendes allgemeines Interesse auf die bestimmten Interessenlagen homogener, organisations- und konfliktfähiger gesellschaftlicher Großgruppen projizieren läßt. Vielmehr wird man damit rechnen müssen und können, daß, wie etwa Schmitter (1994: 170 f.) hervorhebt, die soziale Trägerschaft an diffuse Akteure (»diffuse agency «) übergeht, die für die politische Bewältigung der Herausforderungen an die Entwicklung moderner Gesellschaften (von Verteilungsfragen über Fragen der Technikentwicklung und Umweltpolitik), denen sie auch in ihrer konkreten Lebensführung konfrontiert sind, neue integrative Mechanismen und politische Strukturen suchen und finden müssen: diesem generischen Kontext dürften Formen der »projektiven Integration « besser entsprechen, die daran anknüpfen und »aus den drängenden Zukunftsfragen neue, politisch offene Bindungs- und Bündnisformen zu schmieden« versuchen (Beck/Beck-Gernsheim, 1994: 35).

Kurz, was gesucht ist, ist ein Verbindungsstück zwischen dem intuitiven Ideal demokratischer Assoziation und der substantielleren Vorstellung deliberativer, gemeinwohlorientierter Entscheidungsverfahren. Genau hier setzt das Modell der reflexiven Demokratie an, indem es auf das Problem einer notwendigen qualitativen und metapolitischen Zuspitzung der Idee demokratischer Selbstbestimmung reagiert: die Struktur einer institutionell befestigten Aufspaltung von Demokratie in unterschiedliche und nur lose und z.T. widersprüchlich verbundene Organisationsformen wäre durch eine Politisierung und Demokratisierung des Zusammenspiels unterschiedlicher Formen 
von Demokratie aufzubrechen. M.a.W., was wir sehen, ist, daß die Idee der Demokratie faktisch in unterschiedliche Muster einer repräsentativen, direkt-majoritären und partizipatorisch-deliberativen Organisationsform diffundiert und in unterschiedlichen Handlungsbereichen wie auf unterschiedlichen Ebenen der Willens- und Meinungsbildung segmentär institutionalisiert ist. Dieser vorhandene Formenreichtum kann umgekehrt den Ausgangspunkt einer differentiellen Einschätzung der spezifischen Leistungsfähigkeit dieser Formen in unterschiedlichen Kontexten bilden, die wiederum Voraussetzung für eine demokratische Steuerung der >gesellschaftlichen Allokation von Demokratie`wäre. Den institutionellen Implikationen eines solchen reflexiven Arrangements werde ich im folgenden nun etwas ausführlicher nachgehen. 


\section{Institutionelle Implikationen}

Die reflexive Demokratie ist also zunächst einmal eine »starke « Demokratie in dem Sinne, daß sie auf eine unmittelbare Selbstregierung durch eine engagierte Bürgerschaft zielt - eine Idee, die, wie Barber zu Recht hervorhebt, zwar einer attraktiven Tradition des politischen Denkens entspringt, aber kaum eine überzeugende, moderne Praxis hervorgebracht hat: "In der Tat«, so Barber, "galt die Moderne häufig als ihr schlimmster Feind: Größe und technologischer Charakter moderner Gesellschaften werden oft als unüberwindbare Hindernisse für ihre praktische Durchführung angesehen« (Barber, 1994: 233 f.). Derartige Bedenken bilden regelmäßig das Einfallstor für Vorschläge zu einer demokratietheoretischen Diät im Namen eines Realismus, die freilich ebenso regelmäßig auch die normativ gehaltvollen Präsuppositionen der Idee der Demokratie angreift. Dabei wird allerdings vergessen, daß sich die Gründe, die zu einer solchen Abmagerungskur Anlaß geben sollen, auch der Tatsache verdanken, daß sich direktdemokratische Praktiken in einer institutionellen Umwelt bewähren müssen, die ihr nicht unbedingt entgegenkommt, ihr teilweise sogar entgegensteht und jedenfalls den anspruchsvollen Bedingungen, unter denen sich eine staatsbürgerliche Urteilskompetenz, das direktdemokratische Handeln und Entscheiden entfalten kann, nicht in ausreichender Weise Rechnung trägt. Deshalb nimmt die Entwicklung eines institutionellen Rahmens auch in Barbers Programmatik der »starken Demokratie« einen breiten Raum ein, den er durch zwölf detaillierte Vorschläge ausfüllt, die folgenden Kriterien genügen sollen (vgl. Barber, 1994: 234 f.): sie sollen den »besonderen Forderungen starker Demokratie als einer Theorie des Sprechens, Urteilens und öffentlichen Wahrnehmens Ausdruck verleihen « und dabei insofern realıstisch und praktikabel sein, als sie "mit den Hindernissen fertigwerden, die der Partizipation aus den modernen Verhältnissen zu erwachsen scheinen: nämlich Größe, Technologie, Komplexität und das Paradox des Provinzialismus«; dazu gehört auch, daß sie liberalen Sorgen hinsichtlich der Tendenz partizipatorischer Gemeinschaften zu »Irrationalismus, Vorurteil, Gleichförmigkeit und Intoleranz« Rechnung tragen und in den repräsentativen Rahmen großflächig organisierter politischer Gemeinschaften einzupassen sind. Daran sind dann die einzelnen Vorschläge zu messen, die er in den Dimensionen der »Institutionalisierung starkdemokratischen Sprechens« (u.a. Nachbarschaftsversammlungen, Fernseh-Bürgerversammlungen und generell die Nutzung der Telekommunikationstechniken zu einer adäquaten, spezifischen Informationsversorgung - vgl. Barber, 1994: 241 ff.), der »Institutionalisierung starkdemokratischer Entscheidungsprozesse « (u.a. nationale Volksbegehren, elektronische Abstimmungen vermittelt durch interaktive Video-Kommunikation, Wahl durch Losverfahren - Barber, 1994: $257 \mathrm{ff}$.) und der »Institutionalisierung starkdemokratischen Handelns « in Gestalt eines allgemeinen Bürgerdienstes oder mittels einer stärker kontextualisierten Willensbildung (vgl. Barber, 1994: 281 ff.) unterbreitet. 
Obwohl im einzelnen keineswegs neu, sind diese Vorschläge gerade in ihrer systematischen Verzahnung ${ }^{84}$ informativ und insofern durchaus geeignet, die Entwicklung demokratischer Reformperspektiven aus den engen institutionellen Bahnen der repräsentativen Demokratie hinauszuführen. Ihre Grenzen liegen denn zum einen auch eher $\mathrm{da}$, wo es um Fragen der genauen Einpassung in den normativen Rahmen der liberalen Demokratie, um die Vermittlung mit den funktionalen Erfordernissen moderner Politik sowie der sachlichen Leistungsfähigkeit direktdemokratischer Institutionen geht. So wäre unter Gesichtspunkten der Kompatibilität etwa zu prüfen, ob und inwieweit man sich vom Prinzip der Gewaltenteilung dispensieren kann, wie das Majoritätsprinzip mit dem Grundrechtsschutz auch (und gerade) für Minderheiten auszutarieren ist und inwieweit der rechtsstaatlichen Gesetzesbindung der (staatlichen) Gewalten auch dann Geltung verschafft werden kann, wenn das Volk selbst als Organ handelt; und unter Gesichtspunkten der Leistungsfähigkeit ist darauf zu achten, daß direktdemokratische Formen der Willensbildung und Entscheidungsfindung tatsächlich als Korretiv für die diagnostizierten Schwächen des repräsentativen Systems staatlicher Politik fungieren und etwa die Rationalität, Effizienz und Transparenz der politischen Entscheidungsprozesse verbessern. ${ }^{85}$ Zum anderen treten natürlich im Gegenlicht des anspruchsvolleren demokratischen Ideals der Selbstregierung auch die Schwachstellen einer partizipatorischen Form besonders deutlich hervor: Motivationsprobleme, die starke Strapazierung und Inanspruchnahme kognitiver und moralischer Ressourcen auf seiten der Beteiligten (Lindner, 1990: 153 ff.), die mögliche Schadenswirkung informationsarmer Formen der Urteilsbildung (Offe, 1992: 140) und die paradoxen Effekte einer bloß kakophonen Vielstimmigkeit sind gewiß ernstzunehmende Probleme. Aber sie stellen andererseits auch keine gleichsam natürlichen Attribute partizipatorischer Willensbildung überhaupt dar, sondern sind, wenigstens z.T., auch Reflexe zu stark mediatisierter und hoch aggregierter institutioneller Formen der Meinungsbildung und artikulation. Beide Aspekte hat jüngst Offe noch einmal aufgegriffen, als er mit Blick auf mögliche institutionelle Reformen die Fiktivität, die Fehlbarkeit und die Manipulierbarkeit des Volkswillens in Erinnerung gebracht hat. Danach muß der Volkswille fiktiv bleiben, weil er in der Regel zu vage ist, um politische Entscheidungen wirklich

84. Vgl. dazu genauer auch Buchstein/Schmalz-Bruns (1994).

85 Von diesen Gesichtspunkten läßt sich auch Stelzenmüller in einer breit angelegten Untersuchung zur Praxis der direkten Demokratie in Amerika leiten, die zu dem insgesamt wenig ermutigenden Ergebnis führt, daß allein verfahrenstechnisch den Engpässen direktdemokratischer Willensbildung, die sie wesentlich in der individuellen Motivation und »maximalen Entscheidungskapazität« verortet, nicht beizukommen ist (vgl. Stelzenmüller, 1994: $34 \mathrm{ff}$. und $285 \mathrm{ff}$.). Freilich ist dieses generelle Urteil zum einen hinsichtlich der Entscheidungsebenen (national, einzelstaatlich, kommunal) wie hinsichtlich der Dimensionierung und des Inhalts der Themen (Fragen der Exekutive, Jurisdiktion oder der Legislative, letztere zu unterscheiden nach verfassungsgesetzlichen resp. einfachgesetzlichen Entscheidungen) zu differenzieren. Zum anderen ergibt sich eine Beschränkung auch aus der Konzentration auf plebiszitäre Mechanismen und drittens macht sie selber abschließend darauf aufmerksam, daß eine verläßliche Einschätzung der Funktionsfähigkeit Fragen der Gewährleistung materieller Vorbedingungen nicht außer acht lassen kann. 
zu informieren, oder weil die Effizienz und Effektivität des Volkswillens eine unrealistische Bündelung vorhandener Aufmerksamkeitsenergien voraussetzt; fehleranfällig wird der Volkswille insgesamt dadurch, daß schon die Strukturen einer weitgehend privatisierten individuellen Meinungsbildung der Komplexität von Sachfragen kaum angemessen sind; dies induziert eine enorme "Hilfsbedürftigkeit«, die ihrerseits der Manipulation Tür und Tor öffnet (Offe, 1992: 127 ff.).

Auch wenn Offe am Ende seiner Diagnose zu dem Schluß kommt, dem Volkswillen bei allen Schwächen wenigstens den Kraftakt abzuverlangen, »sich selbst unter einen rauto-paternalistischen< Vorbehalt zu stellen und demgemäß auf die Möglichkeit zu verzichten, sich im Gesetzgebungsprozeß zu allen Themen und zu jedem Zeitpunkt Gehör zu verschaffen (Herv. i. O.) (Offe, 1992: 141) ${ }^{86}$ dann führt er die Idee der Demokratie nicht einfach umstandslos in bestehende repräsentative Formen zurück. Diese Formulierung macht vielmehr nur Sinn, wenn man mit der (institutionell zu konkretisierenden) Möglichkeit rechnet, daß ein über seine Leistungsgrenzen aufgeklärter Volkswille die Bestimmung seiner angemessenen Form in die eigene Regie nehmen könnte. Mit dieser auf die Optimierung und nicht auf die Maximierung von demokratischer Teilhabe (Spescha, 1992: 104) hin ausgelegten reflexiven Wende könnte man die Ansätze zu einer institutionellen Reform denn auch nicht nur an den Untiefen plebiszitärer, direktdemokratischer Elemente (Kriesi, 1992) vorbeisteuern. Vielmehr bietet sich zugleich die Möglichkeit, der Idee der Demokratie zwischen den gleichermaBen problematischen und sich spiegelbildlich zueinander verhaltenden Alternativen eines technokratischen Paternalismus der »vielspurigen Demokratie« (Wehner 1992: $79 \mathrm{ff}$.) und einer sich in zivilgesellschaftlichen Handlungszusammenhängen gleichsam selber einkapselnden Politik schwach organisierter, multipler Öffentlichkeiten einen

86 Diese notwendige Skepsis bezüglich der Bereitschaft und Fähigkeit breiter Bevölkerungskreise, aktiv und kompetent an Politik teilzunehmen, sollte indessen nicht dazu führen, die soziale Exklusivität politischer Willensbildungs- und Entscheidungsprozesse generell noch etwa dadurch zu erhöhen, daß man die Bemühung um Einbindung jener aufgibt, die aus vermeintlich subjektiv-rationalem Kalkül von sich aus und bewußt darauf verzichten. Diese Konsequenz hat Schatz im Auge, wenn er vorschlägt, »über tragende Säulen unseres Politikmodells ganz radikal nach(zu)denken, z.B. über das allgemeine Wahlrecht, jedenfalls über eines, das ohne weitere Qualifikationen ausgeübt wird «, um hinzuzufügen, daß »wenn Spezialisierung das Kennzeichen moderner. Gesellschaften ist, dann paßt so etwas wie die allgemeine Partizipation an Politik nicht mehr in den Trend der Zeit" (so Heribert Schatz in einer Diskussionsbemerkung in Sarcinelli, 1994: 123). Diese Schlußfolgerung scheint, um das mindeste zu sagen, auch in einer rein effizienzorientierten, technokratischen Perspektive voreilig, weil man mit guten Gründen dagegenhalten kann, daß der Verlust an Leistungsfähigkeit moderner Politik, den Schatz durch Verzicht auf das Gleichheitsprinzip und eine weitergehende Spezialisierung beheben möchte, im Kern gerade auf die schon jetzt weit fortgeschrittene soziale, sachliche und zeitliche Entfremdung des Bürgers von der (staatlichen) Politik zurückzuführen ist. 
neuen Halt zu geben. ${ }^{87}$ Kurz, was gesucht ist, ist ein Verbindungsstück zwischen dem intuitiven Ideal demokratischer Assoziation und der substantielleren Vorstellung deliberativer, gemeinwohlorientierter Entscheidungsverfahren (1). Vor diesem Hintergrund drängen sich Modifikationen an der institutionellen Logik staatlicher Politik wie Ergänzungen zum bestehenden institutionellen Repertoire auf (2), die ihrerseits auf impliziten Annahmen beruhen, die keineswegs selbstverständlich sind und deshalb abschließend wenigstens ansatzweise plausibilisiert werden sollen (3).

\subsection{Die Balancierung von demokratischer Legitimität und politischer Effektivität}

Ein solches Prinzip, das als normatives Kriterium institutionell regulierter Entscheidungsverfahren fungiert - und insofern nicht, wie Habermas (1992: 369) suggeriert, der falschen Totalität »einer im ganzen deliberativ gesteuerten und insofern politisch konstituierten Gesellschaft« aufsitzt - und das die tiefe Staffelung aufeinander bezogener diskursiver Willensbildungsprozesse institutionell abzubilden erlaubt, hat Cohen mit dem »idealen deliberativen Verfahren « vorgeschlagen (Cohen, 1989: $17 \mathrm{f}$.). Dieses Verfahren soll nun auf den drei Ebenen des Agenda-Setting, der diskursiven Erörterung alternativer Problemlösungen und der Bestimmung der angemessenen Entscheidungsregeln selber zur Geltung gebracht werden und umfaßt im wesentlichen folgende Bestimmungen: Das Entscheidungsverfahren wird dem Postulat der Autonomie und der Freiheit dadurch gerecht, daß sich die Beteiligten nur durch die Ergebnisse ihrer gemeinsamen Beratungen gebunden fühlen und daß der argumentative Charakter der Entscheidungsfindung deren Legitimität ausreichend verbürgt; dieses ideale Verfahren ist vernünftig, weil außer der Kraft des besseren Arguments keine Macht ausgeübt wird. Darüber hinaus impliziert die Idee der Vernünftigkeit, daß kollektive Entscheidungen

87 In der Kontrastierung dieser so unterschiedlichen Konzeptualisierungen des Projekts der Demokratie werden die komplementären Vereinseitigungen, die entstehen, wenn man sich entweder nur an der Zivilgesellschaft oder nur an den Anforderungen an ein verbessertes Problemlösungsverhalten staatlicher Politik orientiert, besonders gut sichtbar. So schlägt Wehner im Rahmen einer » vielspurigen Demokratie« vor, einzelne ordnungspolitische Bereiche zum Zweck der Effizienzsteigerung aus der parlamentarischen Willensbildung herauszulösen (etwa: Ökologie, Bevölkerungspolitik, Sozialpolitik, Finanz- und Haushaltspolitik) und neue ordnungspolitische Instanzen in parallel geschalteten Fachparlamenten zu institutionalisieren. Der Sinn dieser segmentären Differenzierung der Politik besteht darin, das spezifische Verhältnis von Beteiligungsformen und ordnungspolitischen Zielen besser auszutarieren und und das Gewicht demokratischer Teilhabeansprüche an den Effizienzkriterien der Ordnungspolitiken zu relativieren (Wehner, 1992: $79 \mathrm{ff}$. und $104 \mathrm{f}$.).

Komplementär dazu verhält sich die Vorstellung einer ganz auf Fragen der kulturellen Reproduktion spezialisierten zivilgesellschaftlichen Demokratie (Cohen/Arato, 1992: $423 \mathrm{ff}$.). Darin spiegelt sich zweifellos die nunmehr reifizierte analytische Unterscheidung von System und Lebenswelt, was zur mißlichen Konsequenz einer Befestigung des Dualismus von Staat und Gesellschaft führt, weil eine von schwachen, subalternen Gegenöffentlichkeiten (Fraser, 1992: 122 ff.) getragene Politik der Lebensweise und der Lebensstile bestenfalls noch kontingente und indirekte Außenwirkungen hat. 
grundsätzlich auf deliberativem Wege zustande kommen sollen und die Adaption an vorhandene Wählerpräferenzen für sich genommen kein ausreichender Entscheidungsgrund ist; die Beteiligten sind in formaler und substantieller Hinsicht gleich, insofern die Verfahrensregeln nicht zum Ausschluß bestimmter Individuen oder Gruppen führen dürfen und insofern bestehende Machtungleichgewichte nicht auf die Chance der Beteiligung am deliberativen Prozeß durchschlagen dürfen; schließlich sind diese Verfahren zwar auf einen rational motivierten Konsens hin orientiert, ohne ihn indes gewährleisten zu können: deshalb können Abstimmungen durchaus notwendig werden, aber sie strukturieren nicht von vornherein die Interaktion und sind selbst Gegenstand argumentativ herbeizuführender Entscheidungen (Cohen, 1989: 22 f.; Miller, 1992: 60).

Dieser so weit plausible Vorschlag beruht also auf der Transformation des Ideals demokratischer Öffentlichkeit in institutionelle Strukturen deliberativer Enscheidungsfindung. Er läßt indes noch nicht ohne weiteres erkennen, wodurch die deliberativen Verfahren intern mit der substantielleren Idee einer gemeinwohlorientierten Politik verknüpft sind; und er läßt offen, worin die Rationalitätsvorteile deliberativer gegenüber aggregativen Formen der Bestimmung des Gemeinwohls liegen. Um diesen Schritt zu tun, reichen deliberative Verfahren für sich genommen nicht aus, weil sie bei den Beteiligten eine rationale Motivation, eben den Willen, die eigenen Präferenzen und Überzeugungen einer reflexiven Revision zu unterziehen und Argumentationen nicht strategisch zu mißbrauchen, bereits voraussetzen. Diesen Motivationsproblemen können institutionelle Strukturen dann entgegenwirken, wenn sie auf Mechanismen der externen Unterminierung der Autonomie der Beteiligten zurückzuführen sind. Cohen unterscheidet mit »adaptive « und »accomodationist preferences « zwei Formen, in denen die subjektive Anpassung an die Umwelt daraus resultiert, daß entweder Unklarheit über die rationale Motivation Dritter besteht oder daß Zweifel über die normative Gültigkeit des Autonomieideals selber bestehen. In beiden Fällen, so zeigt Cohen, können Institutionen wichtige autonomiefördernde und -ermöglichende Funktionen erfüllen: »The phenomenon of adaptive preferences underlines the importance of conditions that permit and encourage the deliberative formation of preferences; the phenomenon of accomodationist preferences indicates the need for favorable conditions for the exercise of the deliberative capacities « (1989:25) - genau diese Anforderungen sollten institutionelle Strukturen erfüllen können, die das ideale deliberative Verfahren so weit als möglich widerspiegeln. Nachdem also deliberative Verfahren insgesamt günstigere Bedingungen gemeinwohlorientierten Handelns bereitstellen, wird nun auch sichtbar, inwiefern sich Rationalitätsvorteile des deliberativen gegenüber dem aggregativen Verfahren bezüglich der Bestimmung des Gemeinwohls einstellen. Dabei kann man drei Aspekte unterscheiden (Miller, 1992: 60 ff.). Zum einen wirken deliberative Kontexte unmittelbar auf die Präferenzgenese ein - kognitiv, indem sie dazu beitragen, auf falschen empirischen Annahmen aufruhende Präferenzen auszuscheiden und moralisch, indem sie ethische Einstellungen freilegen und zur Thematisierung moralisch relevanter Handlungsfolgen nötigen. Auf diese Weise tragen sie auf der Seite des Individuums zur Klärung der Ordnung und Hierarchie subjektiv gehaltener Präferenzen bei und verengen mit Blick auf kollektive Entscheidungsprozesse das Spektrum an Präferenzen, die in das Aggregat des Gemeinwohls einzuspeisen sind. Darüberhinaus ermöglichen es delibera- 
tive Verfahren, die durch aggregative Verfahren induzierte, zu starke Amalgamierung von unterschiedlichen Dimensionen eines Entscheidungsproblems rückgängig zu machen und so auseinanderzuziehen, daß sie nacheinander, im Rahmen eines stufenförmigen Prozesses der Willensbildung behandelbar werden; und das erlaubt es nicht zuletzt, unterschiedliche Entscheidungskriterien wie Mehrheit, Durchschnittsnutzen oder sachliche Richtigkeit und normative Geltung themenspezifisch einzusetzen.

Diese Überlegungen zeigen so weit, daß das ideale deliberative Verfahren das gesuchte Brückenprinzip liefert und daß die daran orientierte Konstruktion den Belastungen, denen es ausgesetzt ist, auch standhalten kann. Es bleiben jedoch noch zwei wesentliche Probleme offen. Das eine betrifft die Frage, ob das Problem der politischen Gleichheit wirklich schon angemessen thematisiert ist - dies läuft auf die Frage nach der Relationierung von Deliberation, Partizipation und Repräsentation hinaus; das andere betrifft den ungeklärten Zusammenhang von entscheidungsorientierter, politisch-institutioneller Willensbildung einerseits und zivilgesellschaftlichen Meinungsbildungsprozessen andererseits (Habermas, 1992: 372 f.). Dem ersten Problem möchte ich mich nunmehr mit Blick auf einige institutionelle Reformvorschläge, die sich aus den Debatten um eine Verfassungs- und Parlamentsreform herausschälen lassen, zuwenden; den zweiten Problemkomplex behandele ich dann ausführlich im abschließenden dritten Abschnitt der Arbeit.

\subsection{Institutionelle Reformperspektiven}

Daß diese Herausforderungen an die Reform des demokratischen Prozesses auch im Parlament und den politischen Parteien nicht gänzlich ohne Resonanz geblieben sind, zeigt u.a. die Arbeit der vom Bundestag und Bundesrat eingesetzten Gemeinsamen Verfassungskommission (GVK). Diese hat gewiß nicht die zum Teil weitgesteckten Erwartungen erfüllt, von denen der Proze $B$ der Verfassungsreform begleitet war und wie sie etwa aus dem Entwurf einer »Verfassung für Deutschland « (vgl. Guggenberger/Preuß/Ulmann, 1991) hervorgehen. Dort wurde in der dem Verfassungsentwurf vorangestellten Denkschrift mit Blick auf das Demokratieprinzip eine aktivere Rolle des Staatsbürgers gefordert: „Die Möglichkeit dazu wird vor allem durch Grundrechte garantiert, z.B. durch die Meinungs- und Informationsfreiheit, Versammlungs- und Vereinigungsfreiheit. Doch über diese klassischen demokratischen Mitwirkungsrechte im Staate hinaus bedarf es heute der gesonderten Sicherung von Mitwirkungsrechten überall dort, wo der Mensch Ordnungen unterworfen ist, die ihn entmündigen oder seine Handlungs- und Entscheidungsfreiheit einschränken könnten. Deshalb sieht der Verfassungsentwurf in Artikel 2 Absatz 3 ein allgemeines Recht auf demokratische Teilhabe in Staat und Gesellschaft vor « (Guggenberger/Preuß/Ulmann, 1991: 48). Dieser Grundsatz wird dann im weiteren dahingehend präzisiert, daß die Verfahren des Volksbegehrens und der Volksgesetzgebung auszubauen sind (ebda. $68 \mathrm{ff}$.) und daß es im Rahmen einer Parlamentsreform vor allem zur Stärkung des Parlaments und zu einer Stärkung der Rechte der Opposition und des einzelnen Abgeordneten kommen müsse (ebda. $74 \mathrm{ff}$.). 
Solche Erwartungen sind unter dem Druck einer rigiden institutionellen Regie der Verfassungsreformdiskussion schnell reduziert worden. ${ }^{88}$ Dennoch haben sie, wenn auch in einer grundsätzlich abgeschwächten Form, die Arbeit der GVK zumindest auf der Ebene verfassungskonzeptueller Erwägungen beeinflußt. Das wird an drei Eckpunkten deutlich, mittels derer beispielsweise Peschel-Gutzeit (1994) die Beratungen der GVK charakterisiert. Dabei hebt sie zum einen hervor, daß an den Ausführungen zum Thema »Bürgerbeteiligung e eine gewisse Unsicherheit im Umgang mit der normativen Idee der Volkssouveränität deutlich wurde. Diese Unsicherheit resultierte im Kern aus der offenen Frage, wie man diese Idee in konkrete und institutionell verbürgte Teilhabeansprüche so übersetzen kann, daß sich eine Steigerung von Partizipationschancen mit der Steigerung staatsbürgerlicher Verantwortung und den Imperativen der Wahrung der Stabilität und Rationalität der liberalen, rechtsstaatlichen Ordnung kombinieren und vermitteln läßt. Den zweiten Eckpunkt beschreibt die Überlegung, daß ein bloß liberales, auf die Sicherung subjektiver Abwehrrechte gegen den Staat kapriziertes Verfassungsverständnis mit der Entwicklung der Staatstätigkeit, der ausgreifenden Politisierung von Fragen der gesellschaftlichen Entwicklung und der gesellschaftlichen Diffusion staatlicher Entscheidungsprozesse nicht mehr Schritt halten könne. An dieser Stelle wurde zwar versucht, erweiterte Teilhabeansprüche durch das Angebot eines staatszielbezogenen Verfassungsverständnisses zu kompensieren. Die Ambivalenz dieser Strategie wird aber spätestens dann sichtbar, wenn die Einsicht eingeklagt wird, daß die Wirksamkeit und Stabilität von Verfassungsordnungen von motivationalen Voraussetzungen abhängt, die sich in erster Linie im demokratischen, zivilgesellschaftlichen Handeln der Bürger reproduzieren müssen. Das ergibt zusammengenommen ein recht gutes Bild der in dieser historischen Situation verpaßten (oder planmäßig verspielten) Chancen. Deshalb möchte ich im folgenden, ohne Anspruch auf Vollständigkeit und Originalität im einzelnen, in fünf Punkten versuchen, eine auch normativ einigermaßen integrierte institutionelle Reformperspektive zu eröffnen, die auf eine bewußtere Nutzung und den Ausbau reflexiver Strukturen und Mechanismen zielt und von daher die Chancen für die vernünftige und sachlich angemessene Lösung kollektiver Handlungs- und Entscheidungsprobleme unter breiter Beteiligung von Betroffenen zu verbessern sucht. Dabei komme ich zunächst, unter Beschränkung auf eher allgemein gehaltene, noch nicht sehr detaillierte Hinweise, auf Strukturveränderungen zu sprechen, die sich mit der Einrichtung von Parallelinstitutionen verbinden (a), um diese dann auf der Ebene des Parlaments (b), der Parteien (c) und der Verwaltung (d) zu verfolgen und abschließend eine zusammenhängende Deutung dieser Veränderungen im Sinne einer reflexiven Institutionenpolitik (e) zu geben.

88 Vgl. auch Busch, Zapfe, Fischer u.a. (1993) und die an gleicher Stelle abgedruckten Empfehlungen der Gemeinsamen Verfassungskommission zur Änderung und Ergänzung des Grundgesetzes sowie die Überblicksdarstellungen von Berlit (1994), Neumann (1994) und zu Aspekten einer Reform des Parlamentsrechts die Studie von Sannwald (1994). Obwohl (oder gerade weil) die Arbeit der GVK jeweils Themen von grundlegender Bedeutung für das gesellschaftliche Zusammenleben und die Strukturierung und Orientierung staatlicher Macht berürte, sind die Ergebnisse bescheiden. Ein wesentlicher Grund dafür dürfte schon in der Art der Kommissionsbildung, ihrer parteipolitischen Einbindung und Zusammensetzung, wie in der frühzeitigen Festlegung auf das Quorum einer Zwei-Drittel-Mehrheit für ihre Empfehlungen zu finden sein (vgl. Berlit, 1994: $77 \mathrm{f}$.). 
a) Parallelinstitutionalisierungen. Das ideale deliberative Verfahren, wie es Cohen vorgestellt hat, unterstellt einfach, daß die drei fundamentalen, in die Idee der Demokratie eingelagerten Prinzipien der Gleichheit, Freiheit und Deliberation in die gleiche Richtung weisen und sich in einem einsinnigen Institutionalisierungspfad zusammenbinden ließen. Dies ist jedoch alles andere als selbstverständlich. So üben partizipatorische Strukturen in Verbindung mit dem deliberativen Prinzip eine eigene Selektivität dadurch aus, daß sie jene begünstigen, die über ausreichend Aufmerksamkeitsenergie, Zeit und kognitive Kompetenz verfügen und insofern die Idee politischer Gleichheit tendentiell unterlaufen. Demgegenüber sind direkt-majoritäre Verfahren zwar besser geeignet, Gleichheit zu gewährleisten; sie haben jedoch den Nachteil, daß sie eine Übertragung von Kompetenzen vornehmen, ohne gleichzeitig angemessene Anforderungen an die Art der Meinungs- und Willensbildung mitzuinstitutionalisieren, also dazu tendieren, unreflektierte Präferenzen des Massenpublikums bloß zu messen, statt die Reflexivität einer kognitiv und moralisch raffinierten Form der Präferenzgenese zu optimieren (Fishkin, 1991: 4) - sic sind insofern nicht nur extrem anfällig gegen Demagogie, sondern können eben aus diesem Grunde auch mit der Idee der Freiheit und rechtsstaatlichen Prinzipien der Freiheitssicherung in Konflikt geraten (Fishkin, 1991: 21). Schließlich sollten repräsentative Institutionen in Verbindung mit konstitutionellen Selbstbeschränkungen zwar der Idee nach die Prinzipien der Gleichheit (Wahl), der Deliberation (parlamentarische Beratung) und der rechtsstaatlichen Freiheitssicherung zur Geltung bringen können; sie führen jedoch andererseits zu einer tiefen Spaltung zwischen inkompetentem Publikum und kompetenten Eliten. Kurz: diese Dilemmata scheinen uns lediglich die einfache, aber unbefriedigende Wahl zwischen der Qualitätssteigerung von Politik über ein Elitenmodell der Demokratie und der Inkaufnahme der Oberflächlichkeiten massendemokratischer Strukturen zu lassen (Fishkin, 1991: 4). An dieser Stelle nun setzt Fishkins Vorschlag zu einer institutionellen Reform im Rahmen einer grundsätzlich repräsentativen Ordnung an, der es erlauben soll, die drei genannten Bedingungen simultan zu erfüllen. Dieser Vorschlag orientiert sich im Kern an den Anforderungen, wie sie sich aus seinem spezifischen Verständnis des Gleichheitsprinzips ergeben, daß die Bedingungen für angemessene Meinungserwerbs-, Artikulations- und Wirkungschancen einschließt: $\gg B y$ political equality I mean the institutionalization of a system which grants equal consideration to everyone's preferences and which grants everyone appropriately equal opportunities to formulate preferences on the issues under consideration (Herv. im Orig.). Because granting equal consideration has two components, the full notion of political equality yields three separate requirements. First, there must be formal equality granting equal weight to peoples' preferences...Second, there must be guarantees that the political process has not been interfered with by irrelevant factors... Third, there must be adequate opportunities for voters to form preferences « (Fishkin, 1991: 30 f.). Das läuft auf eine Institutionalisierungsform hinaus, die formale Gleichheit sichert, die die Meinungsbildung hinreichend gegen spezifische soziale Interessen und Machtungleichgewichte abschottet und die für eine effektive Einspeisung der Ergebnisse in den Prozeß parlamentarischer Willensbildung Sorge trägt. Das Verfahren nun, daß diesen Gesichtspunkten gerecht werden soll, ist das »deliberative opinion poll «, das die Aufgabe hat, zu simulieren, was 
die demokratische Öffentlichkeit denken würde, wenn sie eine bessere Chance hätte, über die anstehenden Probleme intensiv nachzudenken (Fishkin, 1991: 1). Die Idee, die eine gewisse Ähnlichkeit mit Dahls »Minipopulus« (Dahl, 1992; 1989: 340 f.; 1987) aufweist, besteht darin, eine repräsentative Auswahl von Bürgern über mehrere Tage an einem Ort zu versammeln, um sie in persönlichem Kontakt mit den Kandidaten der Parteien über die relevanten politischen Sachfragen diskutieren zu lassen. Am Ende des Prozesses sollen dann Meinungsbilder erstellt werden, die sich sowohl auf die Optionen der Behandlung der politischen Sachfragen wie auf die Kandidaten beziehen.

Die Einzelheiten der Ausführungsbestimmungen dieses Vorschlags (Fishkin, 1991: 81 ff.) brauchen hier nicht zu interessieren. Auch wenn es stark auf die Bedingungen des amerikanischen politischen Systems und auf die Verbesserung des Selektionsverfahren der Primaries abgestellt ist, enthält es durchaus Aspekte, die in Überlegungen zur Demokratisierung der Willensbildung und Personalpolitik politischer Parteien auch westeuropäischen Typs aufgegriffen werden könnten (Offe, 1992: 138 f.). Darüberhinaus könnten dieses oder ähnliche Verfahren durchaus als Kristallisationspunkte der Ausbildung themen- und problemzentrierter Arenen der öffentlichen Willensbildung fungieren, die die häufig stark korporativ vermachteten Policy-Netzwerke von innen her auflockern. In dieser Perspektive hat das Modell sicherlich den zusätzlichen Vorteil, daß es ohne zu großen Aufwand und ohne die institutionelle Logik der parlamentarischen Demokratie grundsätzlich in Frage zu stellen, realisiert werden könnte. Indessen ist nicht zu übersehen, daß sich dieser auf den ersten Blick günstige Eindruck auch nicht ausgewiesenen konzeptionellen Lücken verdankt, die sich an den Schnittstellen mit der Willensbildung in gesellschaftlichen Organisationen wie im politisch-administrativen System einstellen und so die durchaus offene Frage der Tiefen- und Breitenwirkung dieser in gewisser Weise doch sexotischen $<$ Institutionalisierung überspielen. Hier läßt sich jedoch durch einen ersten weiterführenden Schritt, der noch in der Logik dieses Modells verbleibt, Abhilfe schaffen, indem man sich etwa auf die bekannten Schwachstellen auf der Input-Seite des politischen Entscheidungsprozesses, auf die Strukturen der Problembearbeitung und Konfliktregulierung im Laufe dieses Prozesses und auf notwendige Verbesserungen der Output-Kontrolle konzentriert. Darauf gerichtete institutionelle Reformen liätten sich von der Überlegung leiten zu lassen, daß es darauf ankommen muß, die langfristigen Interessen des Gemeinwesens gegenüber den kurzfristigen und partikularen Interessen stärker zur Geltung zu bringen; $\mathrm{da} ß$ die Berücksichtigung der Interessen Betroffener im Entscheidungsprozeß verbessert werden muß und daß schließlich die Entscheidungsstrukturen besser auf komplexe Problemstrukturen abzustimmen wären (Zilleßen, 1993: 32). Entsprechende Effekte ließen sich u.a. durch die kombinierte Einrichtung nationaler Politikforen, die Einführung von Mediationsverfahren in den Policy-Prozeß und die Institutionalisierung von unabhängigen Sachverständigengremien mit aufschiebenden Veto-Rechten gegenüber parlamentarischen Entscheidungen erreichen, die insgesamt sicherzustellen hätten, daß die grundsätzlichen und langfristigen Fragen und Themen auch auf die politische Agenda gesetzt werden und daß das Risiko von Entscheidungen gerade mit langfristigen Folgewirkungen wenigstens eingedämmt werden kann (Zilleßen, 1993: 34 ff.).

Damit kommt man nun zwar der Beantwortung der mit Blick auf das ideale deliberative Verfahren noch offengebliebenen Frage nach der Relationierung partizipatori- 
scher, deliberativer und repräsentativer Strukturen schon etwas näher. Andererseits ist nicht zu übersehen, daß solche Vorschläge doch mit herrschenden Vorstellungen über den Status und die Funktion parlamentarischer Beratungen sowie dem Selbstverständnis staatlich-politischer Akteure kollidieren. Daraus resultieren Schnittstellenprobleme zwischen den unterschiedlichen Foren der Willensbildung und Entscheidungsfindung, die zum Teil dadurch behoben oder wenigstens gemildert werden können, daß im inneren des parlamentarischen Prozesses selbst entsprechende Umstellungen oder Akzentverschiebungen vorgenommen werden.

b) Parlamentsreform. Um die Idee der Demokratie vor einer illusionären Selbstüberanstrengung in Schutz zu nehmen, hat Ingeborg Maus (1992: 191 ff.) die alte Unterscheidung von Selbstgesetzgebung und Selbstregierung mit dem Ziel wieder aktiviert, die Idee der Volkssouveränität primär unter Bezug auf die jurisgenerative Funktion demokratischer Öffentlichkeiten zur Geltung zu bringen: damit möchte sie Fragen der Selbstregierung aus dem Zusammenhang demokratischer Selbstbestimmung herauslösen und die Funktionstrennung von administrativem Staat (Regierung) und Öffentlichkeit (ziviler Gesellschaft) restaurieren, ohne das Prinzip der Volkssouveränität zu beschädigen. Dahinter steht die Vorstellung, den demokratischen Machtkreislauf unter der Voraussetzung hinreichend über den rechtsstaatlichen Mechanismus der Gesetzesbindung von Regierung, Verwaltung und Justiz sicherstellen zu können, daß die Gesetzgebung selber aus dem selbstbezüglichen Machtkreislauf staatlicher Politik herausgehoben und für gesellschaftliche Rechtsdiskurse weiter geöffnet wird. So sollte einerseits eine selbstbezügliche Einkapselung gesellschaftlicher Akteure in einen bloß zivilgesellschaftlichen Handlungszusammenhang (Rödel, 1992) vermieden werden können, in dem das Interesse an Autonomie durch ein Desinteresse an »administrativer Partizipation « erkauft wird. Andererseits sollte auch das Interesse an administrativer Partizipation so kanalisiert werden, daß es nicht unvermeidlich zu einer Selbstiuberanstrengung zivilgesellschaftlicher Handlungsmotive und -ressourcen führt: »Aber auch Partizipationsmodelle, die genau diesen Einfluß bezwecken und durch Bürgerbeteiligung eine Demokratisierung von Exekutiv- und Administrationsfunktionen erreichen wollen, scheitern an einem Moment des Illusionären, das in die Sachlogik von Selbstregierung eingebaut ist. Bürgerbeteiligungen dieser Art können zwar in Einzelfällen Einflußchancen gewähren, aber insgesamt nicht die Form generalisierter Kontrolle der Exekutive und Administration ersetzen, die in der Verpflichtung aller gesetzesanwendenden Instanzen auf die >Selbstgesetzgebung $<$ des Volkes einmal intendiert war $\ll .{ }^{89}$

89 Maus (1992: 201 f.). Diese Beobachtung ist zwar richtig, sie sollte aber nicht dazu herhalten, >Selbstgesetzgebung und >Selbstregierung gegeneinander auszuspielen. Zum einen kann man auf die Option wadministrativer Partizipation « auch in einer generalisierten Perspektive nicht verzichten, weil die konkreten Entscheidungsebenen und -inhalte in einzelnen Politikbereichen von allgemeinen Gesetzen häufig genug entweder nicht erreicht werden oder zumindest unterbestimmt bleiben (vgl. van den Daele, 1993 und 1994). Zum anderen muß »administrative Partizipation « im kooperativen Verwaltungshandeln nicht notwendig die Form einer korporatistischen »Refeudalisierung « der Gesellschaft annehmen, wie Maus an gleicher Stelle befürchtet - ich werde weiter unten (im dritten Abschnitt der Arbeit) zu zeigen versuchen, daß es dazu durchaus demokratische Alternativen gibt (vgl. auch Zweck, 1993). 
Aber auch dann ist in Rechnung zu stellen, daß die für parlamentarische Systeme konstitutiven Prinzipien der Repräsentation und der Gewaltenteilung nur sekundäre Prinzipien oder institutionelle Mechanismen darstellen, die funktional auf das normativ vorrangige Prinzip einer allgemeinen, möglichst inklusiven und diskursiven Willensbildung und Entscheidungsfindung bezogen sind: »die zentrale Chance von Repräsentation liegt diskurstheoretisch betrachtet darin, auch in großen politischen Gemeinwesen Entscheidverfahren zu ermöglichen, in denen gemeinsame Probleme diskursiv erörtert werden (Herv. i.O.) «, und die Gewaltenteilung ist kein primär reaktives Prinzip gegen Machtkumulation, sondern erfordert eine »Organisation der Organe und Zuständigkeiten im Staat auf eine Weise, die permanent Chancen oder sogar Zwänge zur diskursiven Auseinandersetzung und Verständigung schafft «. ${ }^{90}$ Damit macht auch Müller die Qualität des Parlaments davon abhängig, inwieweit die Wahlverfahren wie die internen Strukturen der Willensbildung »den elementaren Forderungen diskurstheoretischer Art standhalten «, was insbesondere bedeutet, daß die Diskurse im Parlament die Vermutung stützen müssen, daß »echte, nicht täuschende Konsense und Kompromisse zustandekommen « (Müller, 1993: 163 und 164). In dieser Perspektive hängt dann allerdings einiges davon ab, ob es gelingen kann, die demokratische Qualität des Gesetzgebungsprozesses selber zu verbessern, und d. h., die Rolle des Parlaments als Form einer deliberativen Vermittlung von Politik aufzuwerten und die parlamentarische Beratung enger mit dezentralen gesellschaftlichen Rechtsdiskursen zu verknüpfen. Deshalb faßt Maus an dieser Stelle einen reflexiven Funktionswandel des Parlaments ins Auge, den sie auf das Prinzip der reflexiven Ausdifferenzierung von Verfassung und Gesetzgebung zurückführt, das nunmehr in einer »Arbeitsteilung innerhalb der Gesetzgebung « radikalisiert werden soll: Aufgabe der parlamentarischen Beratung wäre danach in erster Linie, Entscheidungen darüber herbeizuführen, welche Regelungsmaterien zentral und welche dezentral zu bearbeiten sind sowie die Verfahrensbedingungen vorzuhalten und zu gewährleisten, die die demokratische Qualität dezentraler Rechtsdiskurse verbürgen sollen. Auf diese Weise würde es möglich, konkrete Regulierungsvorhaben situationsspezifischer und kontextsensibler auszugestalten, die Gesetzgebung also insgesamt näher an die Bedürfnisse und Interessen von Betroffenen heranzurücken, ohne die generalisierende Perspektive der Rechtsform selber preisgeben zu müssen (vgl. Maus, 1991: 149 f.). Innerhalb dieses Rahmens eines reflexiven Funktionswandels des Parlaments wären dann Reformakzente so zu setzen, daß der Kommunikationsfluß zwischen Wählern und Abgeordneten verbessert (i), das Interessenberücksichtigungspotential erhöht (ii) und schließlich die deliberativen Anteile in der parlamentarischen Willensbildung aufgewertet werden (iii).

(i) Ein erster Schritt in diese Richtung könnte dadurch unternommen werden, daß man den Repräsentationsgedanken selber dynamisiert und dialogisiert. Da die Zeitstrukturen von Präferenzen und langfristig angelegten Politiken auseinanderfallen, man

90 Müller (1993: 157 und 168). Müller unterstreicht diesen Zusammenhang zusätzlich noch dadurch, daß er Repräsentation und Gewaltenteilung ausdrücklich den Rang normativer Prinzipien vorenthält und im einen Fall von »Notbehelf « (155) spricht, im anderen den instrumentellen Charakter (167) hervorhebt. 
aber andererseits Präferenzen nur unter hohen (jedenfalls momentanen) Legitimationskosten institutionell mediatisieren kann, könnte eine Lösung darin bestehen, die Präferenzbildung mit der politischen Willensbildung und Entscheidungsfindung prozessual zu verkoppeln (Thompson 1988). Der Kerngedanke eines entsprechenden Modells ist, daß man sich die Herausbildung eines allgemeinen Willens als einen iterativen, vierstufigen Prozeß vorstellen kann: Repräsentanten bringen zunächst partikulare Interessen in die parlamentarische Willensbildung ein, die unter dem Eindruck konfligierender Interessen im Lichte allgemeiner Arguınente modifiziert und in dieser Gestalt der Bewertung des Wählers ausgesetzt werden, so daß hier der Prozeß, ausgehend wiederum von einem nunmehr argumentativ aufgeklärten Wählerinteresse, erneut beginnen würde. Ein solches Arrangement hätte den Vorteil, daß es die für die Herausbildung allgemeiner Interessen - i.S. einer »politics of the common good « (Mansbridge, 1988: 61) - unverzichtbaren deliberativen Momente in der institutionellen Willensbildung gegenüber bloßen bargaining- oder Verhandlungsprozessen stärken könnte. ${ }^{91}$

(ii) Ein auf diese Weise intensivierter Kommunikationsfluß soll die Rationalität kollektiver Willensbildungsprozesse nach beiden Seiten hin sichern: gegen die Verzerrungen eines vernünftigen Allgemeinwillens, die aus der mangelhaften Berücksichtigung und Inklusion von Interessen und Bedürfnissen wie aufgrund asymmetrisch verteilter Zugangsund Einflußchancen auf die parlamentarische Willensbildung entstehen, einerseits; und gegen interessenegoistische Regressionen der individuellen Willensbildung andererseits. Worauf es ankommt, ist zum einen »die Wiedergewinnung des Politischen aus der Reflexionsfähigkeit der Individuen - und diese verlangt in erster Linie einen durch das Recht institutionell geschützten Raum ihrer Entfaltung « (Preuß, 1989: 11); zum anderen aber müßten Mechanismen vorgesehen werden, die eine Gewichtung und Balancierung der unterschiedlichen Intensitäten von Interessen, die in einen kollektiven Willensbildungsund Entscheidungsprozeß eingehen, erlauben. Für beide Probleme kann man sich nun Lösungen vorstellen, die nicht in Konkurrenz zum Repräsentationsgedanken treten, sondern lediglich bestimmte Schwächen des bestehenden Systems kompensieren.

Nach dieser Maßgabe muß die Strategie zunächst darin bestehen, der reflexiven Fähigkeit der Individuen auf der Ebene der individuellen wie der kollektiven Willensbildung überhaupt »eine Stimme zu verleihen« - mit dieser interessanten Begründung schlägt Preuß an dieser Stelle die Einführung von »vouchers « vor: Jedem Bürger wäre ein Gutschein über einen bestimmten Betrag zuzuweisen, »über den er zugunsten eines (nach einem bestimmten Verfahren akkreditierten) Verbandes verfügen kann; damit soll ein gewisser Ausgleich dagegen geschaffen werden, daß das gegenwärtige System der

91 Diese Unterscheidung legt Mansbridge (1988: 62 f.) ihren Überlegungen zugrunde, wie sich die Chancen deliberativer Praktiken im Zusammenhang parlamentarischer Willensbildung verbessern ließen: die Dynamisierung der Repräsentation wäre dann ein institutioneller Mechanismus, mit dem sich die von ihr ausgewiesenen Motivationsquellen deliberativer Praktiken (»the desire to make good policy... the motives to matter, to earn the respect of one's peers, and to learn and then to act on what one has learned«) auch erschließen ließen (Mansbridge 1988: $80 \mathrm{ff}$.). 
Interessenrepräsentation im wesentlichen die ungleiche Verteilung von Ressourcen in der Gesellschaft lediglich abbildet und reproduziert. Verbände, die schwer organisierbare, sog. >diffuse $<$ Interessen vertreten - Interessen also, die wenig Gehör und noch weniger Berücksichtigung finden -, sollen dadurch die Chance einer erhöhten Professionalität ihrer Vertretung erhalten « (Preuß, 1989: 11 f.). Dies ist sicherlich eine Möglichkeit, den repräsentativen Verzerrungen einer auf das allgemeine Wohl berechneten kollektiven Willensbildung entgegenzuwirken. Was immer man sonst dagegen einwenden mag, ist allerdings wichtig zu sehen, daß es sich hierbei im wesentlichen um ein Mittel der »Stimmverstärkung « handelt, das seine angenommene Wirkung nur entfalten kann, wenn auch die individuelle Präferenzbildung schon unter Bedingungen stattfindet, die eine Entfaltung der vorhandenen kognitiven Potentiale, des Verantwortungsgefühls und solidarischer Einstellungen auch prämiiert und befördert. Kurz, Gewichtsveränderungen im System der politischen Repräsentation müssen durch Maßnahmen ergänzt werden, die die Reflexivität der individuellen Präferenzbildung erhöhen - hier wäre auf die Vermutung zugunsten einer rationalisierenden Wirkung des Prinzips der Publizität zu rekurrieren, mit der spezifischen Folge etwa, auch die monologische und privatistische Abschließung des Wahlaktes durch Rückgriff auf Modelle der öffentlichen Wahl zu überwinden. ${ }^{92}$

Zum anderen wäre der durch die Mehrheitsregel strukturierte parlamentarische Entscheidungsprozeß für die unterschiedlichen Intensitäten zu sensibilisieren, mit der Entscheidungsträger und Betroffene ihre jeweils involvierten Interessen und Präferenzen versehen. Wenn man nämlich die Bedingungen, unter denen Mehrheitsentscheidungen von allen als legitim und bindend akzeptiert werden können, auf das Prinzip der politischen Gleichheit zurückführt, so ergeben sich drei Möglichkeiten der Auslegung dieses Gleichheitsgrundsatzes (vgl. Offe, 1984: 175). Die erste, gängige und anspruchsloseste Auslegung betrifft die "Gleichheit der Verfahrensbeteiligung«, die den Nachteil hat, die für Fragen der Legitimation wichtige Dimension der Verfahrensergebnisse außer Acht zu lassen. Dem kann man begegnen, wenn man zweitens den Gleichheitsgrundsatz nach der Maxime der Gleichheit des Einflusses auf das Ergebnis auffaßt - aber auch dieses Arrangement ignoriert noch das Phänomen, daß verschiedene Entscheidungsthemen und ergebnisse die Beteiligten und Betroffenen in ganz unterschiedlicher Weise berührt. Dieses Intensitätsproblem kann man dadurch in Rechnung stellen, daß man die Gleichheit der Verfahrensbeteiligung in Richtung einer gewichteten Gleichheit des Einflusses auf die Verfahrensergebnisse radikalisiert: den daraus resultierenden Schwierigkeiten (im Kern: das Problem einer nicht-subjektivistischen Definition von >Betroffenheit) ( versucht Offe dann durch eine komplementäre Einschränkung und Ausdehnung des Anwendungsbereichs der Mehrheitsregel entgegenzuwirken (Offe, 1984: 178 ff.). Die Pointe seiner Überlegung liegt in dem Vorschlag, die Mehrheitsregel auf sich selber anzuwenden, d.h. eine reflexive Schleife in die Entscheidungsverfahren einzuziehen, in »der die Gegenstände, Modalitäten und Grenzen der Anwendung des Mehrheitsprinzips« selber thematisch und zum Gegenstand einer Mehrheitsentscheidung werden (Offe, 1984: 179).

$92 \mathrm{Vgl}$. Buchstein (1993 und 1994). In eine ähnliche Richtung weisen bereits die Überlegungen von Offe und Preuß (1991: 170). 
Diese Lösung ist im Prinzip von ähnlichen Überlegungen inspiriert wie der oben unterbreitete Vorschlag einer reflexiven Wendung des Demokratieprinzips. Sie setzt allerdings voraus, $\mathrm{da} \beta$ sich durch das Auseinanderziehen und den reflexiven Bezug einzelner Verfahrensschritte tatsächlich Rationalitätsvorteile einstellen, daß also die Verfahrenswahl zumindest nicht vollständig durch Ergebnisinteressen präjudiziert wird - dafür spricht in erster Linie, daß für die Verfahrenswahl unter Gesichtspunkten der Gerechtigkeit, Angemessenheit und Fairness andere Gründe mobilisiert werden müssen als auf der materialen Verfahrensebene (vgl. Offe, 1984: 180). Dennoch bleibt die Verfahrenswahl selbstverständlich in die materialen Interessenkonflikte eingespannt und entsprechend strategieanfällig. ${ }^{93}$ Aus diesem Grund könnte es sinnvoll sein, das reflexive Verfahrensarrangement durch eine Entspannung des Problems struktureller Minderheiten und des Intensitätsproblems auf der Ebene des inhaltlichen Entscheidungsverfahrens zu ergänzen. Dies setzt voraus, daß man gleiche, aber unteilbare Stimmen durch einen jedem Beteiligten zuzuweisenden, festen Betrag "politischen Geldes« ergänzt, der nach Maßgabe der spezifischen Interessiertheit am Ergebnis in das Entscheidungsverfahren investiert werden kann: »...Consider that each legislator is not provided with a vote on each issue as it arises, but with an account of $>$ political money<, which I will give a name: not dollars, pounds, or Deutschmarks, but >kaldors a after the inventor of the compensation principle. The kaldors in a legislator's account are fungible; they can be used on any legislation as it arises. As a bill arises, each legislator places a $>$ bid $<$ in kaldors on that legislation, pro or con. After all bidding is in, the bill passes if more kaldors have been bid positively than negatively, and fails otherwise. If the bill passes, those who bid against it are compensated, each by the number of kaldors he has bid. If the bill fails, compensation occurs in the reverse direction « (Coleman, 1991: 25). Ohne das Argument hier ausführlich würdigen zu können, scheint mir ein solches Verfahren, auch wenn es zunächst nicht von der sachlichen Gütequalität der Resultate her informiert ist, drei entscheidende Vorteile gegenüber der Zählung von Stimmen zu bieten. Es erhöht, ohne den Gleichheitsgrundsatz zu verletzen, die Kosten für die Durchsetzung einer Mehrheitsmeinung und bietet den jeweiligen Minderheiten Kompensationen, die »kapitalisierbar « sind und rigide Mehrheiten- $/$ Minderheiten-Positionen aufbrechen; und es vermittelt über die entstehenden Kosten

93 Die Dominanz strategischer Handlungsdispositionen führt zweifellos zu einer gewissen Unsicherheit und Instabilität, die das reflexive Arrangement insgesamt unterminieren könnten. Dies legt eine Klärung des Verhältnisses der Kommunikationsmodi >Arguing، und >Bargaining in Kontexten der Verfahrenswahl (oder genereller: im Zusammenhang von »constitutional choice«) nahe: darauf komme ich weiter unten (Kap. 7.3) sowie im letzten Abschnitt der Arbeit (Kap. 9.2) zurïck. 
eine stärkere Konsensorientierung, die ihrerseits Anreize zu einer Aufwertung deliberativer Verfahrensmomente enthält. ${ }^{94}$

(iii) Dieser letztgenannte Aspekt sollte schließlich als dritter wichtiger Bezugspunkt einer Strukturreform der parlamentarischen Prozesse fungieren. Innerhalb des parlamentarischen Systems kommen den Parlamenten, wenn auch in unterschiedlichem Ausma $\beta$ und in unterschiedlicher relativer Gewichtung, vier allgemeine Funktionen zu: sie haben eine »Kreationsfunktion« hinsichtlich der Regierung, eine »Gesetzgebungsfunktion«, eine »Kontrollfunktion« und schließlich eine »Öffentlichkeits- oder Forumsfunktion« (Hoffmann-Riem, 1993: 23). Nachdem ich oben insbesondere auf die Gesetzgebungsfunktion schon eingegangen bin, interessiert mich an dieser Stelle vor allem die Öffentlichkeits- oder Forumsfunktion, deren Bedeutung im Gegenzug zur Diffusion politischer Steuerung in Politiknetzwerke, in denen staatliche Institutionen nurmehr als Kooperationspartner neben anderen gesellschaftlichen Akteuren fungieren, eher noch zunimmt (vgl. Hoffmann-Riem, 1993: 29 f.). Und dies vor allem aus zwei Gründen. Zum einen führt der Bedeutungszuwachs vor allem korporatistisch vermachteter Verhandlungssysteme dazu, daß Probleme, deren Lösung nicht im strikten Sinne der Regulierung distributiver Folgewirkungen »verhandelbar « ist, tendenziell eher liegenbleiben. Zum anderen aber auch deshalb, weil derartige Netzwerke nicht durch einen unmittelbaren Legitimationsentzug bedroht und deswegen für Thematisierungssignale und -ansprüche einer breiteren Öffentlichkeit weniger empfänglich sind. Dem kann man zwar auch durch eine Funktionserweiterung von Verhandlungssystemen zu Arenen einer rationalen Problemlösung, durch deren partizipatorische Öffnung und interne Demokratisierung entgegenwirken. ${ }^{95}$ Zweifellos kommt aber auch den staatlichen Institutionen, und hier insbesondere dem Parlament, unter diesen Bedingungen die Aufgabe zu, sich stärker "gesellschaftlich zunächst konkurrenzlosen Themen « (Böhret, 1992: 123 f.) zu widmen. D.h., vor allem das Parlament sollte darauf vorbereitet sein und institutionell in die Lage versetzt werden, diffuse öffentliche Thematisierungsschübe aufzugreifen, zu verstärken und ggf. zu behandlungs- und entscheidungsfähigen Vorlagen zu verdichten.

Das aber setzt voraus, daß die parlamentarische Beratung sich den Diskussionen in der politischen Öffentlichkeit weiter öffnet und einen direkten, nicht durch die Willensbildung in den Parteien mediatisierten Einfluß öffentlicher Thematisierungswünsche auf die Agenda ermöglicht; andererseits müßte Öffentlichkeit in den parlamentarischen Beratungen hergestellt und gesichert werden, in denen, anders als im Plenum, häufig ausführlich und sachbezogen diskutiert wird - also vor allem in den Ausschüs-

94 Man muß allerdings sehen, daß es sich beim voucher-System, das eine Marktlösung kollektiver Entscheidungsprobleme anbietet, im Prinzip um eine Alternative zum Modell deliberativer Politik handelt. Dennoch kann man beide Vorstellungen dann zusammenbinden, wenn man darauf achtet, daß Mechanismen der Kapitalisierung von Stimmrechten und der Ausdruck von Intensitäten politische Diskurse nicht ersetzen, sondern anregen: sie sollen lediglich dazu dienen, Entscheidungen in Situationen einer strukturellen Verfestigung von Mehrheiten-/Minderheiten-Positionen für diskursive Verfahren wieder zu öffnen (vgl. auch Cohen/Rogers, 1992: 470, Fn. 64).

$95 \mathrm{Vgl}$. dazu unten Kap. 9. 
sen, Untersuchungsausschüssen und Enquête-Kommissionen (vgl. Hoffmann-Riem, 1993: 63 ff. und 281 f.). ${ }^{96}$ Bezogen auf diese Punkte hat jüngst die Enquête-Kommission »Parlamentsreform« der Hamburger Bürgerschaft Vorschläge unterbreitet, von denen ich an dieser Stelle nur einen abschließend hervorheben möchte. Um der Öffentlichkeit bessere, institutionalisierte Einflußkanäle auf die Themengestaltung der parlamentarischen Beratungen zu eröffnen, hat die Kommission die Einführung des Instruments der Volkspetition vorgeschlagen. Die Überlegung ist, daß dieses Instrument, dem ein höherer Aufmerksamkeitswert zukommt als dem allgemein im Grundgesetz verankerten Petitionsrecht, gleichsam eine »seismographische« Funktion übernehmen könnte, indem es die Möglichkeit eröffnet, das Parlament unmittelbar für die Öffentlichkeit bewegende Themen zu sensibilisieren und eine entsprechende Öffnung der Willensbildung zu bewirken. Wichtig ist dabei, daß die Volkspetition rechtlich von weiterreichenden plebiszitären Instrumenten des Volksbegehrens und des Volksentscheids abgekoppelt werden soll, es also nicht mit einer Entscheidungsfunktion belastet wird. Damit kommt dieser Vorschlag sowohl den oben geäußerten Bedenken entgegen, daß Plebiszite unter Gesichtspunkten der Selbstregierung wegen ihres punktualistischen Charakters und ihrer kaum kontrollierbaren Anfälligkeit für populistische Strategien kein besonders geeignetes Mittel der Verbesserung staatsbürgerlicher Teilhabe darstellen. Unterhalb dieser Schwelle können sie aber sehr wohl die Responsivität staatlicher Institutionen gerade deshalb erhöhen, weil sie durch niedrig zu haltende Quoren keine allzu engmaschigen Filter zwischen die öffentlichen Debatten und die parlamentarische Beratung schieben (vgl. Hoffmann-Riem, 1993: 250 ff.; siehe auch Blankart, 1992). ${ }^{97}$

Diese hier nur angedeuteten Reformen verlangen, je für sich genommen, kaum dramatische Veränderungen (was nicht bedeutet, daß sie schon deshalb leichter zu realisiercn wären). Im Zusammenhang sollten sie aber dennoch geeignet sein, staatlicher-

96 Auch dieses Thema war, neben Fragen der Stärkung der Oppositionsrechte, der Stellung der Opposition in Ausschüssen und der Erweiterung der Informationsrechte des Parlaments gegenüber der Regierung Gegenstand der Beratungen der GVK - aber auch im Bereich des Parlamentsrechts hat sich die Verfassungskommission nicht auf eine Änderung oder Ergänzung des Grundgesetzes verständigen können (vgl. Sannwald, 1994).

97 Eine weitergehende Auslegung der Volksabstimmung als »institutionalisierende Form des Diskurses auf der Ebene der Gesamtgesellschaft « fassen demgegenüber Frey und Kirchgässner (1993: 139 ff.) ins Auge, wobei sie die rational motivierende Wirkung dieser Diskursform von ihrem Sach- und Entscheidungsbezug abhängig machen. D.h., es muß der »Schleier der Insignifikanz« (so Baurmann/Kliemt, 1993) gelüftet werden, um einen rationalisierenden Einfluß öffentlicher Erörterungen auf individuelle Präferenzen auszuüben doch auch in dieser Perspektive, die ihren methodischen Reiz zusätzlich aus der Verschränkung von Diskurstheorie und Politischer Ökonomie erhält, rücken Fragen des Designs institutioneller Arrangements in den Vordergrund, die geeignet sein könnten, den o.g. unter den Stichworten der Fiktivität, Fehlbarkeit und Manipulierbarkeit des Volkswillens bezeichneten Problemen entgegenzuwirken (zur demgegenüber konventionell-abschlägigen Behandlung dieses Themas in der GVK vgl. auch Fischer, 1993: 16 ff.). Eine breitangelegte vergleichende Untersuchung zu Formen und Wirkung direktdemokratischer Verfahren im Kontext der Institutionen westeuropäischer Demokratien bietet jetzt auch Luthardt (1994). 
seits die Voraussetzungen für eine bessere Verklammerung zentraler staatlicher und dezentraler zivilgesellschaftlicher Willensbildungsprozesse zu schaffen. In einer darüber hinausgreifenden Perspektive wäre allerdings auch dafür Sorge zu tragen, daß die genaue Justierung institutioneller Vermittlungsmechanismen selber zum Gegenstand der Willensbildung in partizipationsoffenen Verfahren werden kann.

c) Parteien. Von einer solchen Akzentverschiebung in der Funktionsbestimmung der parlamentarischen Gesetzgebung kann auch die Rollenbeschreibung und das Selbstverständnis politischer Parteien als den Hauptakteuren im politischen Vermittlungssystem nicht unberührt bleiben. In dieser Perspektive wird dann gerade zum Problem, was jüngst Fuchs mit Blick auf die klassische Parteientheorie noch einmal in Erinnerung gerufen und normativ festzuzurren versucht hat: daß die wesentliche Funktion der Parteien in der Mobilisierung politischer Unterstützung für das Handeln des Regierungssystems in Form von Wählerstimmen besteht und daß sie sich zu diesem Zweck in erster Linie personalpolitischer und programmatischer Mechanismen bedienen - personalpolitisch soll es darum gehen, »den Staatsbürgern Angebote [zu] machen über die Politiker, die die Entscheidungspositionen besetzen sollen«, und programmatisch geht es um eine Selektion und Transformation der im Öffentlichkeitssystem artikulierten Ansprüche, um eine effektive Entscheidungstätigkeit des Regierungssystems zu ermöglichen (Fuchs, 1993: $45 \mathrm{f}$. und $50 \mathrm{ff}$.) ${ }^{98}$ Das sind nun zweifellos wichtige Funktionen, die Parteien wahmehmen müssen. Was an dieser Bestimmung indessen irritiert, ist zum einen die etatistische Verschmelzung der Rekrutierungs-, Mobilisierungs- und Transformationsfunktion, die dazu führt, daß Parteien aus der Perspektive von Teilhabern an administrativer Macht die politische Öffentlichkeit nurmehr instrumentell als eine zu steuernde Umwelt wahrnehmen, aus der sie sich Massenloyalität beschaffen; zum anderen bleibt deshalb zugunsten der Transformationsfunktion unterbelichtet, daß Parteien insofern Teil des »Publikumssystems « bleiben, als sie an der allgemeinen politischen Meinungs- und Willensbildung mitwirken und in diesem Zusammenhang eher als Katalysatoren denn als Transformatoren fungieren sollen (vgl. auch Habermas, 1992: 533 f.).

Hinter diesen Bedenken steht nun mehr als der Versuch, erneut geläufige normative und verfassungsrechtliche Vorbehalte gegen die parteienstaatliche Usurpation der politischen Willensbildung zur Geltung zu bringen, die in gewisser Weise ja nur das Gegenstïck zu den Erwartungen eines weitgehend entpolitisierten staatsbürgerlichen Publikums bildet. Was im Lichte der bisherigen Argumentation hervorgehoben werden

98 Für diese konventionellen Annahmen bezüglich der Rolle der Parteien kann Fuchs (1993: 51) zweifellos genïgend theoretische wie empirische Referenzen beibringen, die durchaus geeignet sind, Zweifel an dieser spezifischen Leistungsfähigkeit der Parteien auszuräumen (vgl. in vergleichender Perspektive etwa Budge/Keman, 1990). Andererseits gerät dieser klargeschnittenen Systemoptik, die mit der Unterscheidung von Regierungssystem, intermediärem System und Publikumssystem die Verstaatlichung der Parteien normativ bestätigt, aus dem Blick, daß die politische Öffentlichkeit mehr ist als eine (feindliche?) Umwelt des Vermittlungssystems - dieser Sichtverengung scheint sich wesentlich der ebenso häufig notierte Verlust der Leistungsfähigkeit wie der Resonanz und Akzeptanz politischer Parteien zu verdanken. 
soll, ist vielmehr der Gesichtspunkt, daß im Zuge der institutionellen Entdifferenzierung zwischen den einzelnen Funktionen die Leistungsfähigkeit der Parteien insgesamt sinkt, weil etwa die Fehlsteuerung der Personalrekrutierung durch eingefahrene Rituale der internen Faktionierung nicht nur die Repräsentativität mindert und den Weg zu einer »weitergehenden Professionalisierung des Berufs zur Politik zu einer Laufbahn für politische Verantwortung « (Willke, 1993: 80) blockiert, sondern weil dieses Rekrutierungsmuster zugleich die Responsivität reduziert und individuelle Kompetenzprofile prämiiert, die auf Machterwerb und -erhalt, nicht aber auf die Fähigkeit ausgelegt sind, »in komplexen Entscheidungslagen zu adäquat komplexen und der Kompliziertheit des Problems angemessenen Entscheidungen zu kommen « (Willke, 1993: 79). Solche funktionsübergreifenden Struktureffekte einer basalen Selbstbezüglichkeit limitieren den Spielraum für vielfach (palliativ) bekundete Reformbereitschaften, und sie lassen es als wenig aussichtsreich erscheinen, daß sich unterhalb der Schwelle einer institutionellen (Re)Differenzierung der unterschiedlichen Funktionen die Ziele einer Öffnung der Parteien gegenüber der Gesellschaft, der Etablierung neuer Konsensverfahren in der Problemlösung und der verbesserten Ausschöpfung des weitgehend brach liegenden Potentials an sozialer Kompetenz und Kreativität erreichen lieBen (vgl. Leif, 1993: $24 \mathrm{f}$. und 33). Deshalb erscheint es notwendig, die Wahrnehmung der Vermittlungsleistungen gegenüber der Gesellschaft und damit die Funktion der Parteien als Katalysatoren und Mediatoren einer staatsbürgerlichen Meinungs- und Willensbildung aus dem staatlich-administrativen Selbstverständnis wieder herauszulösen und auch organisatorisch stärker zu akzentuieren. Dies würde den oben angesprochenen reflexiven Funktionswandel des Parlaments im Sinne des Leitbilds einer »demokratischen Kommunikationspartei« aufgreifen und verstärken und könnte durch vier Reformschritte eingeleitet werden: ${ }^{99}$

- Unter der Vorgabe einer »Öffnung der Parteien von außen nach innen « muß es darum gehen, Kommunikationsstrukturen vorzuhalten, die dem Formwandel des gesellschaftlichen Interesses und Engagements Ausdruck verleihen, indem Projektgruppen zu einzelnen Themen gebildet werden, die für Nichtmitglieder offen sind und deren Ergebnisse die parteiliche Willensbildung erkennbar beeinflussen - unter dieser Voraussetzung könnten Parteien ihrem Selbstaufbau entsprechende Organisationshilfen für ein erweitertes staatsbürgerliches Engagement auf den unterschiedlichen Ebenen der Politik anbieten und dafür sorgen, daß die Ergebnisse der Willensbildung einer erweiterten politischen Öffentlichkeit effektiver in die staatlichen Entscheidungsprozesse hinein kanalisiert werden;

- dem müßte - zweitens - auch eine »Öffnung von innen nach außen « entsprechen. Das läuft auf eine Änderung oder zumindest Ergänzung des Selbstverständnisses und der Praxis von Parteien als Forum und Faktor gesellschaftlicher Diskurse und gezielter Politikdialoge hinaus, nach dem sie sich explizit als Katalysatoren, Initiatoren und Moderatoren gesellschaflicher Politik verstehen;

99 Ich folge hier einem Vorschlag, den Meyer (1994: 233 ff.) unterbreitet hat. 
- diesem Interesse der politischen Öffentlichkeit an einer Nutzung der von den Parteien vorgehaltenen organisatorischen Infrastruktur sollte das Interesse der Parteien entgegenkommen, in der "fallweisen Organisation themenbezogener Koalitionen « ein Substitut für den Mechanismus einer weitgehend symbolischen Lagerformierung und Mobilisierung gesellschaftlicher Unterstützungspotentiale an die Hand zu bekommen;

- das kann schließlich nur gelingen, wenn sie sich auch im Inneren so öffnen, daß sie phantasievollere und vielfältigere Formen der innerparteilichen Kommunikation entwickeln und auch die Parteiapparate sich mehr als Dienstleistungszentren verstehen, die durch Informations-, Sach- und Organisationshilfen diese neuen kommunikativen Strukturen aktiv fördern.

d) Verwaltung. Auch für die Verwaltung kann es nicht folgenlos bleiben, daß die »längst eingetretene Säkularisierung der geistigen Grundlagen staatlicher Gewalt an einem Vollzugsdefizit (leidet), daß durch eine weitergehende Demokratisierung ausgeglichen werden muß« (Habermas, 1992: 534). Und was die Chancen der Einlösung dieser Forderung angeht, so erschöpfen sie sich nicht in der Form einer demokratischen Belagerung der »Festung des Staatsapparats« (Habermas, 1992: 531). Vielmehr hat sich die Verwaltungspraxis in den letzten Jahren nicht zuletzt aufgrund eines steigenden Effizienz- und Kostendrucks (vgl. auch Jürgens/Naschold, 1994: 252 ff.) ein Stück weit vom Modell eines konditional programmierten, einseitig-hoheitlichen Staatshandelns abgelöst und für neue Praktiken des informellen, kooperativen und konsensualen Verwaltungshandelns geöffnet (vgl. auch Schulze-Fielitz, 1993; Dreier, 1993 und Hoffmann-Riem, 1990), wodurch sich bessere interne Anknüpfungspunkte einer demokratischen Beteiligung und Kontrolle ergeben, die sich nicht mehr auf Formen der gesetzlichen Programmierung der Verwaltung und eine rechtsstaatliche Verfahrenskontrolle zurückziehen muß (und kann). Für diesen »Gestaltwandel« der Verwaltung hin zu mehr informellen und kooperativen Praktiken im Sinne von Vorverhandlungen, Absprachen, Agreements zwischen Beteiligten und Betroffenen in bezug auf konkrete Einzelprojekte gibt es sachliche Gründe, die mit der veränderten Gesamtkonstellation des Staatshandelns zusammenhängen (vgl. oben Kap. 1.1) und die Fähigkeit des Gesetzgebers zur präzisen Determination des Verwaltungshandelns insbesondere bei komplexen, gestaltenden und verteilenden Aufgaben prinzipiell begrenzen. ${ }^{100}$

In einer solchen Situation bietet der Auf- und Ausbau von Verhandlungssystemen und informellen Abstimmungsverfahren zunächst deutliche Vorteile, weil dadurch die bei allen Beteiligten ansonsten aus der Unübersichtlichkeit, Vagheit und Offenheit vieler Normen und der entsprechenden generalklauselartigen Tatbestandsformulierungen wie Ermessensspielräume resultierende Rechtsunsicherheit abgebaut, die Informati-

100 Vgl. Dreier (1993: 658 f.) Zu diesen Gründen sind u.a. zu zählen: eine »schwache legislatorische Programmierung (und Programmierbarkeit, der Verf.) der Verwaltung, hohe Komplexität des Entscheidungsgegenstandes, knappe Ressourcen, Ungewißheit uiber den Ausgang einer rechtsförmlichen (Gerichts-) Entscheidung sowie andere Unsicherheitsfaktoren, schließlich der Zeitdruck und über Tauschmacht verfügende Beteiligte... « (Dreier, 1993: 659). 
onslage verbessert sowie die Flexibilität und das Innovationspotential erhöht werden kann. Dem stehen aber auch spezifische Nachteile gegenüber, insofern es im Zuge von informellen Prozessen und Verhandlungen zu einer »Niveausenkung normativer Standards« oder zu einer Gefährdung der Rechtspositionen Dritter kommen kann, so daß Informalisierung für sich genommen noch keine Gewähr für verbesserte demokratische Teilhabe und Kontrolle bietet; ja diese sogar einschränkt, wenn sie zu einer AuBerkraftsetzung jener rechtlichen Schutzmechanismen führt, die »eine umfassende, objektive, in der Sache nicht präjudizierte und alle betroffenen Interessen berücksichtigende Rechtsanwendung durch die Verwaltung sicherstellen sollen « (Dreier, 1993: 661). Hier kündigt sich ein Strukturierungsbedarf an, dem man schon in einer entsprechenden Ausgestaltung des Verwaltungsverfahrensrechts entgegenkommen könnte, das die Entscheidungsbeteiligung von Betroffenen sicherzustellen und Modifikationen am Verfahrensablauf in Gestalt der Einführung von Mediation und Negotiation oder der Aktivierung von Ombudsleuten o.ä. vorzunehmen hätte. ${ }^{101}$ Um solche oder ähnlich gerichtete Innovationen wirklich zur Geltung zu bringen, bedürfte es darüber hinaus wohl eines neuen Perfektionsmodells der Verwaltung, das es erlaubt, das Verwaltungshandeln besser auf das Aufgabenprofil einer netzwerkartigen Organisation moderner Politik abzustimmen. Einen ersten, in diese Richtung weisenden Vorschlag hat jüngst Ladeur (1993) unterbreitet, und ich möchte den Argumentationsgang, der zur Vorstellung eines »administrativen Netzwerks « als Alternative zum hierarischen Modell der Verwaltung führt, an dieser Stelle wenigstens knapp rekapitulieren.

Auch Ladeur geht davon aus, daß die Probleme der modernen Leistungsverwaltung ziemlich genau die Herausforderungen spiegeln, vor die sich der funktionale Staat angesichts der »Pluralisierung politischer Funktionen, Kompetenzen und Verfahren sowie des Auseinandertretens von formaler Entscheidungsbefugnis und informalen Machtkreisläufen« (Ladeur, 1993: 137) gestellt sieht. Um nun die Genese dieser Problematik sichtbar zu machen und angemessene Lösungen vorzubereiten, wählt er von vornherein eine kognitivistische Perspektive, in der sich das sukzessive Auseinandertreten der wesentlichen Funktionsbestimmung des Staates und seines Selbstbildes wie seiner organisatorischen Form besser beleuchten lassen: erst aus einer Perspektive, »die in der Generierung von Wissen und in der Erhaltung von Handlungskoordination ermöglichenden Werten ihren Bezugspunkt sucht « (Ladeur, 1993: 139) lassen sich, so die Annahme, die Entwicklung von einer Gesellschaft der Individuen und der Organisationen zu einer netzwerkgerechten kognitiven und normativen Infrastruktur sowie die sie begleitenden Staats- und Verwaltungsmodelle genauer erfassen - wobei er die Übergänge zwischen diesen Formationen nach dem Muster einer jeweils prekären Balancierung der kognitiven Struktur der Gesellschaft und der Mechanismen der Herstellung von Erwartungssicherheit modelliert. In diesem Licht soll die Freisetzung des Prinzips der (Rechts-) Subjektivität in der Gesellschaft der Individuen zunächst »eine bestimmte Selbstwahrnehmung der Individuen und damit auch eine beweglichere kognitive Struktur der Gesellschaft insgesamt durchsetzen« (Ladeur, 1993: 140), wäh- 
rend der hoheitlichen Verwaltung die Aufgabe zukommt, über die Implementation vertikaler Rechtsregeln eine stabile Koordination der »horizontalen, an ein Netzwerk von Beziehungen gebundenen zerstreuten Wissensbestände« (Ladeur, 1993: 145) zu ermöglichen. Dieses Prinzip muß aber zweitens dann versagen, wenn es zu einer zunehmend materialen Intervention des Staates in die Gesellschaft kommt: nunmehr kommt den gesellschaftlichen (Groß-) Organisationen die Funktion zu, gleichsam als Vorstufe der staatlichen Einheitsbildung, jene Werte und Wissensbestände zu reproduzieren, die eine gesellschaftliche Ordnungsbildung ermöglichen sollen - damit läuft die pluralistische Verwaltung gleichzeitig aber Gefahr, sich zu sehr von den orientierungsbildenden Wissens- und Wertsynthesen korporativer Netzwerke abhängig zu machen und in die sich öffnende Schere zwischen Aufgabenwachstum einerseits und abnehmender Durchsetzungsfähigkeit aufgrund eines Verlustes an »konventionalisierten Folgebereitschaften « andererseits zu geraten (Ladeur, 1993: 149 ff.). Diese Krise wird zusätzlich dadurch verstärkt, daß die Bindungskraft der Organisationen selber und damit ihre Fähigkeit zur horizontalen Herausbildung von verläßlichen Wissens- und Wertsynthesen wieder abnimmt. Mit dieser Einsicht bereitet Ladeur schließlich eine Lösung vor, die das notwendige Komplementärstück zu einer immer stärker netzwerkartigen, horizontalen Selbstkoordination der Gesellschaft in einem »post-pluralistischen « Verwaltungsmodell entdeckt, das nunmehr die Wahrnehmung und Konstruktion von Verwaltungsaufgaben auf die »Influenzierung von Netzwerken« (Ladeur, 1993: 162) konzentrieren soll: »Deshalb käme es darauf an, offene Formen einer heterarchischen prozeduralen, auf Selbstrevision und experimentierendes Abtasten von Koordinationsmöglichkeiten in Beziehungsnetzwerken angelegten Selbststeuerung zu konzipieren, über die durch gemeinsames Lernen variable Konventionen generiert werden und damit neue Anschlußmöglichkeiten verfügbar werden. Ein solches Lernen hätte die Rationalität des Verwaltungsentscheidens auf die den einzelnen ausdifferenzierten Praxisfeldern und deren Eigenkomplexität implizit bleibenden Wissensbestände einzustellen« (Ladeur, 1993: 158).

Während sich in diese Bestimmung die oben erwähnten Ansätze zu einer inneren Demokratisierung der Verwaltung m.E. gut einfügen lassen, versieht sie diese Reformen - und darauf kommt es an - zugleich mit einem deutlich reflexiven Richtungssinn: die eigenständige Funktion der öffentlichen Verwaltung bestünde dann primär darin, eine netzwerkgerechte kognitive, normative und materielle Infrastruktur zu gewährleisten, die auf die Ermöglichung, Vermittlung und Abstützung neuer Kooperationsformen zwischen den an gesellschaftlichen Problemlösungen in den unterschiedlichen Politikbereichen und auf unterschiedlichen Ebenen beteiligten Akteuren zielt.

e) Reflexive Institutionenpolitik. Die Behebung der eingangs erwähnten Schwachstellen staatlicher Politik und die bessere Verklammerung der unterschiedlichen Dimensionen und Ebenen der politischen Willensbildung erfordert nun über Korrekturen im Detail hinaus auch ein neues »Perfektionsmodell «(Willke) von Politik, in dem sich die Erweiterung von demokratischen Teilhaberechten und die Verbesserung von effektiven Partizipationschancen in einzelnen Politik- oder Handlungsbereichen mit der Verbesserung des Zusammenspiels der dann entstehenden Teilordnungen zusammenschließen läßt. Zur Erläuterung dieser Perspektive bietet sich grundsätzlich ein Modell 
reflexiver Politik (vgl. auch Beck, 1993: 206 ff.) an, innerhalb dessen sich die bisherigen Überlegungen sowohl rekapitulieren als auch mit einem neuen Akzent versehen lassen.

- In einem ersten Schritt zu einer insgesamt dreistufig anzulegenden Transformation des politischen Institutionensystems ginge es um eine durchaus selbstkritische Demokratisierung der internen Strukturen bestehender Institutionen, Parteien, Verbände o.ä. Diese Demokratisierung hätte sich, und darin liegt ihr selbstreflexiver Charakter, an der Balancierung von Teilhabe- und Kompetenzansprüchen zu orientieren und die Frage, wer in welcher Weise an der Bearbeitung und Entscheidung welcher Themen zu beteiligen wäre, auch auf unvermeidliche Kompetenzanforderungen und die Verbesserung der Meinungserwerbs- und -artikulationschancen hin auszulegen (March/Olsen, 1989: 118 und 133) - dieses Problem staatsbürgerlicher Kompetenz (Dahl, 1992) ist ein Engpaß, durch den normativ begründete Teilhabeansprüche hindurchgeführt werden müssen.

- Darüber hinaus wäre zweitens der weitgehend nicht- oder nur schwach institutionalisierte Raum politischer Meinungsbildung in den pluralen gesellschaftlichen Öffentlichkeiten besser zu erschließen und effektiver mit institutionalisierten Formen politischer Willensbildung und Entscheidungsfindung zu verklammern. Ein Schritt in diese Richtung könnte in Form der Einrichtung von Parallelinstitutionen erfolgen, etwa in der Gestalt nationaler, deliberativer Politikforen (Fishkin, 1991), in Form von Mediationsverfahren im Bereich einzelner Politiken oder von Sachverständigengremien mit aufschiebenden Veto-Rechten gegenüber der parlamentarischen Willensbildung (Zilleßen, 1993: 34 ff.). Diese Vorschläge orientieren sich insgesamt daran, daß es darauf ankommen muß, die langfristigen Interessen des $\mathrm{Ge}-$ meinwesens gegenüber den kurzfristigen und bloß partikularen besser zur Geltung zu bringen und setzen daher an den oben identifizierten Schwachstellen staatlichpolitischer Entscheidungsprozesse auf Input-, Throughput- und Outputseite des Entscheidungsprozesses an: in dieser Perspektive erweisen sich vor allem einzelne Policies und die Strukturen des Policy-Zyklus immer mehr als besonders gut geeignete Kristallisationskerne effektiver und effizienter Partizipation.

- Ein solches Muster institutioneller Differenzierung erzeugt aber schließlich Probleme an den Schnittstellen der einzelnen Bereiche und Ebenen der Willensbildung, die u.a. thematische Interferenzen und Fragen der jeweiligen Prärogativen und Legitimation betreffen. Andererseits ist kaum zu erwarten, und im Zusammenhang dieser Modellvorstellung nicht einmal wünschenswert, daß die erforderliche Verklammerung einem festen Muster folgen kann. Vielmehr wäre die Bearbeitung der Schnittstellenproblematik selber zu prozeduralisieren (van den Daele, 1991: 27) d.h. es wären Foren und Verfahren der 'konstitutionellen< Dauerreflexion zu finden und einzurichten, die eine fallweise Adjustierung und Balancierung von Teilhabeansprüchen, Themen und Entscheidungsprozeduren vorzunehmen hätten. Diese Aufgabe könnten zum einen die auch von Bellah et al. (1991) schon ausgemachten und empfohlenen »fokalen Strukturen« gesellschaftlicher Verhandlungssysteme mit übernehmen, in denen gesellschaftliche Gruppen, Organisationen und Verbände wie staatliche Akteure zu einer kooperativen Problemlösung zusammengeführt 
werden, wenn man ihnen zugleich eine gewisse Autonomie im Bereich regelsetzender oder -verändernder Politik einräumte.

Auch derartige mikrokonstitutionelle, gesellschaftliche Dauerreflexionen auf eine ständige Neujustierung und wechselseitige Abstimmung von Teilhabeansprüchen, Kompetenzanforderungen, Verfahrensregeln und Themen stehen freilich unter einem doppelten Vorbehalt. Zum einen dürfen allgemeine Verfassungsnormen nicht zu einer bloßen Verfügungsmasse von Tagespolitik reduziert werden; dies nicht zuletzt deshalb, weil auch mikrokonstitutionelle Prozesse anfällig für die Ausbeutung durch strategisch motiviertes Interessehandeln bleiben. Zum anderen müssen sie, um wenigstens eine gewisse Stabilität, Regelmäßigkeit und Effizienz zu gewährleisten, selber institutionell abgesichert werden. Eine solche Institutionalisierung von »Institutionspolitik« (Benz, 1990) könnte, parallel zu mikrokonstitutionellen Arrangements, auch über die Einrichtung eines permanenten Verfassungsrates erreicht werden (Wehner, 1993: 27 ff.).

Dieses mit einer eigenständigen demokratischen Legitimität auszustattende Organ könnte - so Wehners Vorstellung - gleichsam als ein »demokratisches Notstromaggregat « fungieren, aus dem sich die Verfassungsordnung mit der notwendigen Antriebsdynamik für konstitutionelle Änderungen und Anpassungen versorgt, die bisher weitgehend durch das institutionelle Eigeninteresse derjenigen blockiert ist, die solche Veränderungen zu beschließen hätten. Dabei sollte es sich, im Sinne der Demokratisierung der Institutionenpolitik und der Umgehung allzu paternalistischer Strukturen, nur um eine Ergänzung, nicht aber um einen Ersatz für die oben angesprochenen Formen eines gesellschaftlichen Mikrokonstitutionalismus mit eher moderierenden und koordinierenden Funktionen handeln.

\subsection{Institutionen als Mittel staatsbürgerlicher Selbstqualifikation?}

Wer eine demokratische Antwort auf die Leistungsschwächen moderner Politik geben will, so lassen sich die bisherigen Überlegungen im Kern zusammenfassen, muß das Interesse an der Verbesserung der Qualität politischer Entscheidungen verbinden mit einem Interesse an der moralischen Qualität der staatsbürgerlichen Meinungsbildung und der kollektiven Willensbildung, woraus schließlich auch ein Interesse an der Qualität politischer Institutionen resultiert, die moralische Dispositionen reflektieren und moralisches Handeln stützen und motivieren können sollten.

Der Grund für die Zuspitzung der demokratischen Frage auf die Bedingungen, unter denen Akteure zu einer gemeinwohlbezogenen, deliberativen Raffinierung ihrer Interessen und Präferenzen bereit und in der Lage sind und unter denen politische Institutionen die notwendige, zivilisierende Wirkung auch entfalten können, liegt darin, daß anders das fundamentale Rätsel der modernen Massendemokratie, wie denn kollektiv rationale Entscheidungen auf demokratische Weise zustandekommen sollen, kaum gelöst werden kann: »The conundrum of generating what are assumed to be collectively rational decisions without first generating citizens who are inspired by the desire for promoting the common good (or the common interest in the conditions of the pursuit 
of private interests) can be compared to the task of creating a desired effect in the absence of the necessary cause " (Offe/Preuß, 1991: $162 \mathrm{f}$.). Offe und Preuß weisen an gleicher Stelle jedenfalls zu recht darauf hin, daß die repräsentative Auflösung dieses Rätsels, die Mediatisierung des Staatsbürgers zum Wahlbürger und die Konzentration der Willensbildung bei politischen Eliten, kaum noch eine zureichende Antwort auf Probleme kollektiver Entscheidungsfindung darstellt - jedenfalls dann nicht, wenn die Implementation politischer Entscheidungen auf das bewußte Entgegenkommen von Individuen und gesellschaftlichen Gruppen angewiesen ist und die Vermutung zugunsten einer rationalen Überlegenheit einer staatlich konzentrierten Willensbildung selber begründeten Zweifeln ausgesetzt ist. Unter diesen Bedingungen, so die These von Offe und Preuß, müssen die in den repräsentativen Mechanismus eingebauten zeitlichen, sachlichen und sozialen Entfremdungen - zeitlich die Entscheidungsferne des Wahlaktes, sozial durch die Herausbildung einer gut abgeschotteten politischen Klasse, sachlich durch die wachsende Distanz zwischen Alltagswissen, -werten und -erfahrungen und politischer Expertise - zu einer selbstdestruktiven Erschöpfung der moralischen Ressourcen des Staatsbürgers, zu einem moralischen und politischen »deskilling « des Elektorats führen (Offe/Preuß, 1991: 164 f.). Aus dieser zugespitzten Krisendiagnose ziehen sie dann den Schluß einer notwendigen Radikalisierung des Prinzips demokratischer Partizipation: "This radicalization would amount to a third step to follow the two that have already been taken by previous waves of democratic movements and democratic reforms (d.i. die Wahlrechtsreform und die Demokratisierung auch gesellschaftlicher Lebensbereiche, der Verf.)...(This step) would consist in enfranchising, as it were, the various preferences that exist within (Herv. der Verf.) individual citizens/voters so as to organize an orderly social conflict not just between majorities and minorities...but, in addition, an inner conflict < between what individuals experience as their more desirable and their less desirable desires. Such a radicalization ... would amount to the introduction of procedures (Herv. d. Verf.) that put a premium upon the formulation of carefully considered, consistent, situationally abstract, socially validated and justifiable preferences«(Offe/Preuß, 1991: 167).

Vor diesem Hintergrund habe ich zu zeigen versucht, daß die institutionelle Ordnung moderner Demokratien diesem erweiterten Anspruch und den damit verknüpften Erwartungen nur dann entsprechen kann, wenn die vorhandenen Mechanismen einer moralischen Selbstadaptation ausgebaut und durch eine demokratische, deliberative Praxis der reflexiven Institutionenwahl ergänzt werden. Dahinter stehen nun freilich Annahmen, die nicht selbstverständlich sind, sondern vielmehr selber kontrovers diskutiert werden. Das betrifft zum einen die Frage, ob im Zuge der institutionellen Dauerreflexion und Dauerrevision institutioneller Arrangements nicht die Funktionstüchtigkeit einer konstitutionellen Ordnung selber riskiert wird, die auch darauf beruht, daß grundlegende Regeln des politischen Prozesses diesem selber entzogen bleiben oder jedenfalls nicht zur Disposition tagespolitischer Bedürfnisse stehen dürfen. Diesem Einwand kann man dadurch begegnen, daß Verfassungen ohnehin Revisionsregeln vorsehen und Revisionsprozesse institutionalisieren, was der Vorstellung von einer Verfassungsordnung als einer aufgegebenen und nicht ein für alle Mal realisierten Ordnung entspricht - in diesem Sinne können die individuellen und politischen Freiheits- 
rechte als reflexive Rechte verstanden werden, die die Bürger in Anspruch nehmen, um, neben den staatlichen Institutionen, Einfluß auf die Fortbildung der institutionellen Ordnung auszuüben (vgl. Habermas, 1992: 639 f.). Ein zweiter Einwand könnte sich gegen die Erwartung richten, daß sich durch das Auseinanderziehen von (konstitutionellen) Verfahrensfragen und Sachthemen in konkreten Entscheidungszusammenhängen überhaupt moralische Ressourcen erschließen lassen, die eine rationalisierende und zivilisierende Wirkung im Prozeß der Problemlösung oder Konfliktregulierung entfalten könnten. Der Einwand bezieht sich auf das Verhältnis von strategischem und kommunikativem Handeln und lautet, daß Verfahren der Institutionenwahl aufgrund des hohen Einsatzes die Prämien für strategisches Handeln eher erhöhen. Dies muß nicht bestritten werden - aber: die erfolgreiche Behauptung von Interessen kann sich auf dieser Ebene nur über eine Sorte von Gründe vollziehen, die einen allgemeinen Geltungsanspruch erheben - Interessen müssen sich insoweit einem argumentativen Gestaltwandel unterziehen, der im Sinne einer »zivilisierenden Kraft der Heuchelei« (Elster) auch dann nicht ohne Folgen bleibt, wenn die Argumente strategisch motiviert sind. Damit zusammenhängend mag drittens schließlich bezweifelt werden, daß sich im Zuge der Erweiterung von Partizipationschancen zwangsläufig auch der Effekt der staatsbürgerlichen Selbstverbesserung einstellt. Dieser Erwartung könnte die pessimistische Prognose entgegengehalten werden, daß Beteiligung auch korrumpierende Wirkungen haben kann, insofern sie die strategische Ausgangslage zur Durchsetzung egoistischer Interessen verbessert (vgl. Offe/Preuß, 1991: 162). In einer weniger extremen Fassung besagt dieser Einwand dann schlicht, daß demokratische Verfahren und institutionelle Strukturen moralische Dispositionen nicht erzeugen, sondern vielmehr voraussetzen. Einen Einwand beinhaltete diese Feststellung aber nur dann, wenn sie die weitergehende Behauptung einschließt, daß moralische Intuitionen (mindestens im Zusammenhang politischen Handelns) keine oder keine nennenswerte Rolle spielen. Wenn das nicht gemeint ist, was selbst utilitaristische Ansätze nicht unterstellen, dann gibt es keinen Grund, demokratische Institutionen von der Aufgabe zu dispensieren, moralische Haltungen, wo nicht zu erzeugen, so doch zu reflektieren, zu stützen und zu ermutigen.

Ich möchte, wegen des Gewichts dieser Einwände, aber ohne ihnen im einzelnen nachzugehen, zunächst wenigstens kurz erläutern, wie politische Institutionen eine moralisierende Wirkung in der Politik entfalten können, ohne daß man dazu auf weiterreichende (und vielleicht zu weitgehende) Annahmen einer kollektiven Selbstveredelung zurïckgreifen muß (a). Abschließend komme ich dann noch einmal auf die Frage zurück, ob demokratische Partizipation nicht doch eher einen positiven Einfluß auf das moralische Selbstverständnis von Akteuren hat (b).

a) Die Einlösung der Forderungen der Moral ist ganz offensichtlich der Preis, der für die Möglichkeit einer politischen Integration von Gesellschaften zu entrichten ist. Die Einsicht in diesen konstitutiven Zusammenhang ist der politischen Theorie seit ihren klassischen Ursprüngen vertraut, so daß der paradigmenbildende Streit in erster Linie immer wieder um die Frage ging, an wen diese Forderungen zu adressieren wären: an den einzelnen Bürger in Form von Tugenderwartungen und -zumutungen, oder an 
institutionelle Mechanismen der Ordnungsbildung, über die zumindest moralanaloge Funktionsprinzipien implementiert werden sollten, die den Vorteil hätten, den einzelnen von allzu großen moralischen Kompetenzerwartungen zu entlasten und die politische Theorie von der Nötigung zu befreien, sich allein auf zu heroische Annahmen über die gesellschaftliche Verteilung moralischer Kompetenzen verlassen zu müssen. Freilich war diese elegante institutionelle Lösung, der der politische Liberalismus viel von seiner Attraktivität verdankte und verdankt, immer auch von einer Konzentration und (staatlichen) Kondensation des Politischen abhängig - eine Voraussetzung, die unter Bedingungen einer zunehmenden Politisierung des Sozialen und der sukzessiven Ausdehnung des Kreises der Teilhabebrechtigten kaum aufrechtzuerhalten war. Aus diesem Grund mutet die Demokratie den Mitgliedern des Gemeinwesens erhebliche persönliche Kompetenzen zu, und Müller hat sicher Recht, wenn er in diesem Zusammenhang feststellt, daß ohne die persönlichen Voraussetzungen der »Bereitschaft zu Reflexion und einfühlendem Nachvollzug der Interessen anderer « konsensstiftende Diskurse als »eigentlich tragendes Element der politischen Gemeinschaft « keine reale Chance haben und auch die »ausgefeiltesten Verfahren der Entscheidbildung keine hinreichende Garantie für Demokratie « bieten (Müller, 1993: 205). Umgekehrt dürfte aber auch gelten, daß sich derartige moralische Einstellungen und Haltungen kaum naturwüchsig reproduzieren und in ihrer Verbreitung und Verankerung auf entgegenkommende institutionelle Kontexte angewiesen sind, die sie schützen, ermutigen und stabilisieren, so daß es im Kern um die genaue Verzahnung von Personmerkmalen mit der Funktionsweise des politischen Systems geht. Dieser Frage ist jüngst NunnerWinkler (1994) mit dem Ergebnis noch einmal systematisch nachgegangen, daß unter vier Modellen der Zurechnung von Moral und Politik (i.c. Moral allein als Frage der Person, allein des Systems, > weder noch < und >sowohl als auch <) allein das >sowohl als auch<-Modell eine tragfähige Grundlage demokratischer Politik bereithält. Dabei gewinnt sie zunächst die Gründe, die für das Systemmodell sprechen, primär aus der kognitiven Dimension von Politik, in der es darum geht, »Materien, von denen mehrere Subjekte betroffen sind, so zu regeln, daß das wohlverstandene langfristige Eigeninteresse jedes Einzelnen an Schadensminderung unparteilich gesichert und dementsprechend das gleiche Recht auf Interessenberücksichtigung operationalisiert wird (Nunner-Winkler, 1994: 138) - in dieser Sicht liefert die begrenzte kognitive Fähigkeit der einzelnen, alle Folgen und Nebenfolgen von Entscheidungen absehen zu können, den Anlaß dafür, Öffentlichkeit als sozialstrukturellen Ort realer Diskurse zu institutionalisieren (Nunner-Winkler, 1994: 139 f.). Während dies der Grundstruktur einer gerechten demokratischen Ordnung insgesamt eingeschrieben werden muß und politische Moral insofern als Systemeffekt zu konzeptualisieren ist, weist sie aber unter motivationalen Aspekten gleichzeitig darauf hin, daß diese Institutionen auf Dauer nur funktionsfähig bleiben können, »wenn die große Mehrheit der Individuen intrinsisch - i.e. sanktionsunabhängig - zum sinngemäßen (und nicht bloß buchstabengetreuen) Regelgehorsam motiviert ist und dies auch allen anderen (zumindest der überwältigenden Mehrheit) unterstellt (Nunner-Winkler, 1994: 141) - in diesem Sinne bilden persönliche Tugenden wie Solidarität, Toleranz und Vertrauen die nicht-substituierbare moralische Infrastruktur moderner Politik, deren Reproduktion ihrerseits freilich deutlich 
mit der effektiven Inklusion der Bürger in die Regelung der öffentlichen Angelegenheiten und damit mit horizontalen Kooperationsstrukturen korreliert (Nunner-Winkler, 1994: 143).

Wenn es also gute Gründe gibt, gerade für Demokratien eine Kongruenz von Moral und Politik sowohl bezüglich der Verfahren wie der Inhalte theoretisch zu unterstellen, dann müßte es sich lohnen, etwas ausführlicher der Frage nachzugehen, wie institutionelle Mechanismen mit moralischen Gefühlen und Intuitionen verklammert sind und durch welche Strategien es möglich ist, moralische Gefühle, über die jedenfalls die meisten von uns in wenn auch rudimentärer Form (die »Goldene Regel «) aus ihren alltäglichen Handlungszusammenhängen heraus verfügen (Goodin, 1992; vgl. auch Wilson, 1993), auch in der Politik besser zur Geltung zu bringen. Unter der Einschränkung, daß es nicht darum gehen kann, den empirischen Grenzfall auch jener "harten $\mathrm{Nuß}$ «u knacken, » who really wants to behave badly. My suggestion is simply that we not waste quite so much time trying. To do so simply misallocates our moral energies...« (Goodin, 1992: 138), identifiziert Goodin drei Strategien der Förderung moralischen Verhaltens in der Politik (Goodin, 1992: $151 \mathrm{ff.}$ ):

- „Codetermination«. Diese Strategie ist darauf gerichtet, die motivationale Kluft zwischen moralischen Überzeugungen und moralischem Handeln zu überbrücken. Dabei geht es nicht darum, die normative Lücke zwischen der Begründung allgemeiner moralischer Normen und Regeln und ihrer situationsangemessenen Anwendung zu schließen. Das Problem, das Goodin hier im Blick hat, erwächst vielmehr aus der wechselseitigen Unsicherheit von Akteuren bezüglich der Reaktionen auf die eigenen moralischen Vorleistungen: wird moralisches Handeln mit moralischem Handeln beantwortet oder wird es strategisch ausgebeutet? Auf dieses Problem gibt es zwei mögliche Antworten, von denen Goodin an dieser Stelle nur eine in Betracht zieht, nämlich den Fall vorsichtig moralischen Verhaltens nach der Regel >Wie-du-mir-so-ich-dir ( $>$ Tit-for-Tat $)$, unter der sich das gesollte Verhalten egos erst im Handlungsvollzug als Reaktion auf die Handlungsweise von alter erschließt. ${ }^{102}$ Während diese Strategie immerhin einen gewissen Ansatzpunkt für die Moralisierung politischen Verhaltens bietet, bleibt sie aber doch zu anspruchslos, um den unbedingten Charakter moralischer Normen auch nur ansatzweise reflektieren zu können: dem würde eine Strategie besser gerecht, die auf die Definition solcher (institutionellen) Kontextbedingungen zielt, die einen gewissen Moralisierungsdruck auf alle Beteiligten ausüben und auf diese Weise die Aktualisierung moralischer Orientierungen gegen Ausbeutung schützt und damit ermutigt.

102 In leichter Abwandlung der >Tit-for-Tat<-Strategie haben Vanberg/Congleton (1992) auf der Basis spieltheoretischer Simulationen zeigen können, daß die Strategie der "prudent morality « (ein Akteur wählt immer dann, wenn er spielt, eine Kooperationsstrategie, weigert sich aber mit jenen überhaupt zu spielen, die in der Vergangenheit nicht-kooperatives Verhalten gezeigt haben) unter der Bedingung vorhandener exit-Optionen insgesamt erfolgreich ist: "All in all, the simulation results suggest that a strategy of cooperating with those who have cooperated in the past and avoiding those who have defected in the past is eminently viable and is robust over a wide range of community compositions« (Vanberg/ Congleton, 1992: 421 und 427). 
- »Ratcheting up«. Diese Strategie nimmt ihren Ausgangspunkt in vorhandenen, aber auf partikulare Handlungskontexte bezogenen, starken moralischen Intuitonen der Menschen und versucht, deren Geltungsbereich über die engen intuitiven Anwendungsbereiche hinaus zu generalisieren. Als Beispiel dienen ihm hier die moralischen Gefühle, die wir aufgrund ihrer Schutzbedürftigkeit und Verletzlichkeit gegenüber Kindern entwickeln (vgl. Wilson, 1993) und die nach der Maxime "protecting the vulnerable« von dieser spezifischen Situation abgelöst und generalisiert werden können. Der politische Mechanismus, über den sich eine Generalisierung dieser moralischen Gefühle über ihren engen Entstehungszusammenhang hinaus erreichen ließe, ist das Recht: während subjektive und politische Rechte auf solche moralischen Gefühle zurückgeführt werden können, entfalten sie eine eigene Dynamik und binden uns anschließend auch in Handlungszusammenhängen, zu denen wir über moralische Gefühle nicht mehr aufschließen können - das historische Beispiel, das Goodin zur Illustration dieses Generalisierungsmechanismus wählt, ist der Prozeß der Wahlrechtserweiterung (Goodin, 1992: 85 ff.).

- "Bridging down «. In gewisser Weise stellt diese indirekte Form der Moralisierung von Politik auch eine Antwort auf das oben angedeutete Problem dar, wie moralische Wirkungen erzielt werden können, ohne daß in bestimmten Handlungssituationen unmittelbar moralische Motive vorausgesetzt werden müssen. Verbürgte Rechtsansprüche bilden so gesehen auch ein relativ robustes Gegenmittel gegen Versuchungen zur einseitigen Aufkündigung moralischer Erwartungen; aber sie bleiben empfindlich gegenüber den Modi der Rechtserzeugung selber. Bereits auf dieser Ebene muß der Gehalt moralischer Gefühle in geeigneten Verfahren der Rechtserzeugung gleichsam gebunden werden: »Thus we are forced, ultimately, back to questions of how to make mass publics more tolerant - or, more precisley, how to tap (Herv. der Verf.) their deeper, latent values in support of tolerance for purposes of more day to day political affairs « (Goodin, 1992: 169) - die im ganzen gesehen erfolgreiche Standardlösung für dieses Problem ist der Konstitutionalismus.

Damit ist der Punkt erreicht, an dem der erste zentrale Einwand nun aufgenommen werden kann, daß Prozesse der Verfassunggebung aufgrund ihres hohen Stellenwertes selber besonders anfällig für strategisches Verhalten und die strategische Ausbeutung argumentativer, verständigungsorientierter Kommunikationsformen sind. M.a.W. wäre im Gegenzug zu zeigen, daß konstitutionelle Situationen gleichsam selbstselektiv auf die kommunikativen Modi der Erzeugung anerkennungswürdiger und stabiler Verfahrensordnungen oder -regeln einwirken. Eine Antwort auf dieses Problem kann in zwei Schritten erfolgen. Zunächst ist es ein charakteristisches Merkmal konstitutioneller Situationen, daß die Beteiligten ihr Denken und die Bewertung ihrer Präferenzen in Zeithorizonten organisieren müssen, die die Perspektive einer bloß kurzfristigen Optimierung aktueller Interessen überschreitet: »What I would emphasize about constitutional deliberations is just this. When asked to choose fundamental laws and basic structures for their society, people are perforce contemplating schemes designed to persist into the indefinite future; when doing so, they are forced to extend their time horizons, thinking in terms of further futures than they would ordinarily have any rea- 
son to contemplate; and the further into the future they project their deliberations, the greater will be the uncertainties surrounding their own fate... The greater the uncertainty the greater the consequent impartiality with which even the most purely prudential actor will be forced to reflect upon the possible plights of all people in general « (Goodin, 1992: 104). Die in konstitutionellen Situationen akzentuierte, endemische Unsicherheit über die Bedingungen der Realisierung egoistischer Interessen übt danach einen doppelten Rationalisierungsdruck aus: einerseits nötigt sie auch rein strategisch motivierte Akteure, ihre momentanen Interessen in bezug auf den Entwurf möglicher Zukünfte zu diskontieren; andererseits hängt die Verläßlichkeit solcher Antizipationen auch von der Qualität der Informationen über die Interessen, Ziele und Werte ab, die die aktuell oder potentiell Beteiligten ihrerseits einbringen - m.a.W. sie müßten aus Eigenintersse Kommunikationsformen präferieren, die ihrerseits die Vermutung einer unverzerrten Darstellung begründen können.

Von diesem Argument bleibt allerdings die Frage zunächst unberührt, warum egoistische und strategisch gesonnene Akteure sich überhaupt Situationen aussetzen sollten, die eine so weitreichende Selbsttransformation dann erforderlich machen. Wieso also lassen sie sich auf den Prozeß 3 der Verfassunggebung überhaupt ein? ${ }^{103}$ Eine Antwort könnte darin bestehen, den Spieß umzukehren und das Faktum des Konstitutionalismus als Indiz dafür zu werten, daß die Individuen über höherrangige und niederrangige Präferenzen verfügen, die in einem reflexiven Verhältnis zueinander stehen, so daß sie nach Möglichkeiten und Mechanismen suchen, den Vorrang ihrer höheren Interessen zu sichern. In diesem Sinne manifestiert und reflektiert der Konstitutionalismus moralische Orientierungen, ohne diese indessen selber hervorbringen resp. ihnen eine situationsangemessene, spezifische Gestalt geben zu können (vgl. Goodin, 1992: 123 und 112). Genau dies

103 So bezweifelt auch etwa Michael Taylor (1993) die internalistische Position, daß man einen intrinsischen Zusammenhang zwischen moralischen Überzeugungen und der Motivation zu moralischem Handeln unterstellen kann. Nach seiner Auffassung sind moralische Überzeugungen motivational »inert«, so daß er auch die kognitivistische Annahme, »that we can form a new desire or suppress an existing one or make one of our desires the motivationally effective one purely by the cognitive process of deliberation and evaluation « (Taylor, 1993: 81) zurückweist - deshalb erscheinen auch reflexive Metapräferenzen als »desire for a particular first order desire « nicht als Produkt deliberativer Handlungssituationen, sondern bleiben diesen motivational vorausgesetzt $(82 \mathrm{f}$.). Freilich kann er diese externalistische Sicht am Ende nicht durchhalten, wenn er die Bergung des moralischen Kapitals, über das die Individuen auch in seiner Sicht in Gestalt geltender moralischer Überzeugungen verfügen, vom Gehalt moralischer Normen ablösen und in motivierende Kontexte sozialer Anerkennung verschieben will: soziale Kontexte der Anerkennung im Allgemeinen wie diskursive Praktiken im Besonderen bilden nicht nur die soziale Außenseite moralischer Normen und sind insofern auch nicht bloß kontingent mit den Gehalten dieser Normen verbunden, sondern sie bilden ihren prinzipiellen Kern. Die externalistische Sichtweise zieht also zu starke Konsequenzen aus der ansonsten richtigen und produktiven Einsicht, daß die Wirkung moralischer Überzeugungen in konkreten Handlungssituationen von instrumentellen oder strategischen Orientierungen überlagert werden kann - produktiv ist diese Einsicht deshalb, weil sie den Blick auf institutionelle Mechanismen lenkt, mit denen man diesem Effekt entgegensteuern kann: auf dieser pragmatischen Ebene treffen die Argumentationslinien von Goodin und Taylor wieder zusammen. 
wäre aber i.S. des von Goodin herausgestellten Mechanismus des »bridging down« erforderlich; die wechselseitige Akkomodierung von Interessen bezogen auf ein kollektives oder Allgemeininteresse ist aber ein sozial und kognitiv anspruchsvoller Prozeß, der Kommunikationsformen prämiiert, die selber schon eine Nötigung zur internen Verschränkung von Perspektiven enthält. Der systematisch gesehen entscheidende Punkt zugunsten der Behauptung der Nicht-Substitutierbarkeit einer deliberativen Praxis in »konstitutionellen Momenten ${ }^{104}$ liegt darin, daß wir es mit einer Handlungssituation zu tun haben, in der gerechte Verfahren der Herstellung eines allgemeinen Interesses definiert werden müssen, ohne auf ein substantiierbares Allgemeininteresse schon rekurrieren zu können - in diesem Fall müssen die Formen der Interaktion selber unmittelbar jene Gesichtspunkte der Gerechtigkeit, des gleichen Respekts und des wechselseitigen Vorteils reflektieren. M.a.W., »the concern with justice and the common good are ensured by the very idea of such an interchange, properly conceived « (Gauthier, 1993: 315) - dieser Anspruch aber ist nur im Modus einer deliberativen Politik und nicht in strategischen Interaktionsformen einzulösen, in dem Ergebnisse nur aus dem kontingenten Zusammenspiel individueller Interessen erwachsen.

Kurz, dieser Prozeß kann sich nur im Modus einer vom Prinzip der Publizität inspirierten argumentativen Praxis vollziehen: »In what sense then might the actions that people take, knowing that they will have to defend those actions in public, be more moral...? The general idea, in other words, seems to be that the necessity of defending your position in public rules out any special form of pleading " (Goodin, 1992: 132). Nun mögen allerdings die rationalen Nötigungen nicht stark genug sein, um im Einzelfall die Beteiligten auch zu einem tatsächlich moralischen Verhalten zu motivieren. Aber auch dieser Motivationsschwäche wirkt das Prinzip der Publizität schließlich entgegen: Die Bedingungen, unter denen der Verallgemeinerungszwang auch aktualisiert und implementiert wird, können eher pragmatischer Natur sein (i.e. die Suche nach »argumentativen Verbündeten«, die Überzeugung Dritter); sie resultieren, grundsätzlicher, aber auch aus dem spezifisch intersubjektiven Charakter moralischen Verhaltens, denn erst die Nötigung, sich öffentlich zu erklären und zu verteidigen, führt zu einer auch im psychologischen Sinne wirksamen Internalisierung der Sichtweisen, Interessen und Bedürfnisse anderer - motivierend wirkt dann das Gefühl der Verlegenheit angesichts der offenbar werdenden Unangemessenheit egoistisch-strategischen Verhaltens in der Öffentlichkeit (vgl. Goodin, 1992: 134 f.).

b) Auch wenn man auf dem vorgeschlagenen Weg zeigen kann, daß Individuen gemeinhin über mehr moralische Ressourcen verfügen, als insbesondere individualisti-

104 Der Begriff des »konstitutionellen Moments« (Ackerman) soll hier lediglich zur Bezeichnung einer spezifischen Handlungssituation dienen und sagt nichts über deren Häufigkeit: während Ackerman den Modus öffentlicher, deliberativer Politik für jene historischen Ausnahmesituationen der revolutionären Umwälzung der Ordnung politischer Gemeinwesen reservieren möchte, spricht nichts dagegen, diese Idee mit Blick auf die autonome Regulierung von Verfahren der politischen Problemlösung in einzelnen Politikbereichen gewissermaßen zu veralltäglichen. $\mathrm{Zu}$ »mikrokonstitutionellen « Lösungen kollektiver Handlungsprobleme vgl. Ostrom (1989 und 1990). Ich komme darauf im 3. Abschnitt der Arbeit (Kap. 9) zurück. 
sche Konzeptualisierungen des politischen Prozesses anzunehmen bereit sind; und wenn plausibel ist, daß institutionelle Kontexte sich mehr oder weniger günstig auf die Erschließung solcher Ressourcen und auf die Absicherung moralischer Handlungsdispositionen auswirken können, könnte es immer noch ein Gebot der Klugheit sein, eher von einer Knappheit an moralischen Ressourcen und "verantwortungsethischen Masseneinstellungen « (Offe) auszugehen und jedenfalls nicht zu weitreichende diesbezügliche Erwartungen schon in die demokratietheoretischen Grundentscheidungen einzubauen. Zwar habe ich mit dem Modell der reflexiven Demokratie grundsätzlich versucht, diesem Bedenken in der doppelten Perspektive einer Radikalisierung und Selbstbeschränkung der demokratischen Idee der Beteiligung Rechnung zu tragen, aber es ist doch unvermeidlich, daß mit der erweiterteten Inanspruchnahme des Staatsbürgers auch die Anforderungen an seine kognitiven Kompetenzen und reflexiven Fähigkeiten wachsen: die Frage ist dann im Kern, inwieweit in das konstitutive Verständnis des modernen Selbst schon Züge eingelassen sind, auf die man rekurrieren kann ${ }^{105}$ und ob man den Prozeß der moralischen Verbesserung als heroischen Akt der Selbsttransformation oder als in die Strukturen politischer Interaktion eingelassenes Moment verstehen kann. ${ }^{106}$

Es sind normalerweise im wesentlichen drei Annahmen, auf die sich die Forderung nach einer weitergehenden Demokratisierung liberaler politischer Ordnungen zurückführen läßt: Die erste ist die Erwartung, daß eine breitere Partizipation in Angelegenheiten des öffentlichen Lebens dazu beiträgt, die primäre Orientierung an individuellen Interessen durch eine Orientierung am Gemeinwohl oder zumindest den kollektiv gemeinsamen Interessen zu ersetzen oder reflexiv zu ergänzen; die zweite hängt damit zusammen und betrifft die Vorstellung, daß sich im Zuge der Minderung des Konfliktpotentials zwischen konkurrierenden Interessen die kollektive Willensbildung für Prozesse einer argumentativen Raffinierung und kognitiven Anreicherung der Präferenzgenese aufschließen läßt, so daß der Einsatz von Macht als Medium politischer Interaktion reduziert werden kann; drittens ist schließlich auch die Überzeugung maßgeblich, daß die partizipatorische Demokratie die angemessenere Form der Realisierung des Wertes der Autonomie darstellt (8). Die damit verbundenen moralischen Erwartungen an das Individuum sowie die ethisch relevanten Aspekte des politischen Prozesses treten nun im Gegenlicht liberaler Standardannahmen besonders deutlich hervor (Warren, 1992: $9 \mathrm{ff}$.).

Liberale politische Theorien, mindestens insoweit sie sich auf eine individualistische Ontologie stützen (vgl. dazu Taylor, 1993), zeichnen Individuen als rationale Maximierer vorpolitischer, monologisch generierter Interessen. Aus dieser Konstellation entsteht ein Bild von Politik als eines Verteilungskampfes um knappe Ressourcen, in dem sich die Beteiligten im Rahmen instrumenteller und strategischer Handlungsdispositionen wechselseitig lediglich als Objekte wahrnehmen können. Der entscheidende Punkt ist, daß unter solchen Bedingungen pazifizierende und die Konfliktdynamik

105 Das ist die Strategie, die Ch. Taylor (1992) wählt, um den Zusammenhang zwischen dem ethischen Ideal individueller Authentizität und der Idee der partizipatorischen Demokratie zu erläutern. Vgl. dazu weiter oben das Kapitel über den »Kommunitarismus«.

$106 \mathrm{Vgl}$. zum folgenden Warren (1992). 
zumindest zivilisierende Wirkungen nur von außen auf die Interaktionen einwirken können; und zwar entweder durch staatlich sanktionierte Freiheits- und Autonomierechte, die der wechselseitigen Instrumentalisierung der Individuen Grenzen setzen, oder durch eine weitgehende Entpolitisierung möglichst vieler Sphären des gesellschaftlichen Lebens in der Einschätzung, daß die größte Bedrohung der individuellen Autonomie und Souveränität aus politischen Phänomenen der Majorisierung der Willensbildung erwächst. Nun schätzen auch Demokraten den freiheitsverbürgenden Charakter liberaler Rechte nicht gering, aber in ihrer Sicht übernehmen Rechte eher die Funktion einer Art Ausfallbürgschaft für interne Mechanismen der Vermittlung von wechselseitiger Anerkennung, Respekt und Toleranz, die nicht im ganzen rechtlich zu substituieren sind. Um diese alternative Sichtweise zu plausiblisieren, muß dann aber insbesondere gezeigt werden, daß partizipatorische Arrangements den genannten $\mathrm{Ge}-$ fährdungen des politischen Prozesses von sich aus entgegenwirken, indem sie die Beteiligten in ihrer individuellen Willensbildung für allgemeine Belange sensibilisieren und daß demokratische Erfahrungen zur Entwicklung wechselseitigen Respekts und der Anerkennung von Pluralismus führen.

Gewiß kommt diese demokratische Gegenthese nicht ohne einen Rekurs auf moralische Kompetenzen und die Unterstellung der individuellen Bereitschaft zu moralischem Verhalten aus. Doch das nötigt nicht, wie ich meine, das von liberalen Kritikern in der Regel anvisierte extreme Gegenbild eines vollständig sozialen, diskursiv konstituierten und moralisch homogenen Selbst tatsächlich zu entwerfen (Warren, 1992: 13 ff.), nach dem sich ein demokratischer Handlungszusammenhang nur unter der permanenten moralischen Anstrengung vollständig tugendhafter Bürger reproduzieren ließe. Vielmehr eröffnen sich Optionen diesseits dieser extremen (und unrealistischen) Sichtweise, die sich knapp auf drei Thesen zurückführen lassen. Zum einen verkennt die liberale Theorie der Politik als eines wesentlich aggregativen Prozesses das Ausmaß, in dem soziale und institutionelle Kontexte bereits auf die Genese individueller Interessen und Präferenzen durchgreifen - deshalb ist ein wichtiges Ziel der partizipatorischen Demokratie, diesen Zusammenhang auch institutionell zur Geltung zu bringen und nicht lediglich die individuelle Autonomie in der Befriedigung von Interessen zu sichern, sondern grundsätzlicher die Autonomie kollektiver Prozesse der Interessenerzeugung (Sunstein, 1991: 12). Damit zusammenhängend übersieht die liberale politische Theorie, daß die Entwicklung der moralischen Kompetenzen und politischen Fertigkeiten durch institutionelle Kontexte selber zurückgehalten oder befördert werden kann: In diesem Sinne sind $\gg$ the selves that often seem endemic to liberal democracies - selves characterized by selfishness, apathy, alienation, lack of knowledge, and prejudice - ... reflections as much of limited means for meaningful political discourse and participation as of more general limits to the capacities of citizens for selfgovernance (Warren, 1992: 11) - m.a.W. ist das Arrangement liberaler politischer Institutionen häufig eher die Ursache als die Therapie für die herausgestellten Übel des politischen Prozesses. Aus diesem Verständnis von Politik und der Wirkungsweise politischer Institutionen folgt dann zum dritten, daß es darauf ankommen muß, »to design institutions that encourage discourse, which, in turn, is necessary to identify and distinguish plural, common and emergent interests (Warren, 1992: 12). Insgesamt ist es 
also weniger die (vorpolitische) moralische Exzellenz einzelner, auf die Demokratisierungsbestrebungen zurückgeführt werden sollen, als vielmehr ein irreduzible deliberatives Ferment der Vermittlung kollektiven Handelns und der politischen Willensbildung. Diesen Zusammenhang hat Sunstein in vier Punkten auf den Begriff gebracht: »First, the collective character of politics, which permits a response to collective action problems, is critical here. People may not want to implement their considered judgments, or to be altruistic, unless there is assurance that others will be bound to do so as well...Second, the collective character of politics might overcome the problem...of preferences and beliefs that have adapted, at least to some extent, to an unjust status quo or to limits in available opportunities...Third, social and cultural norms might incline people to express aspirational or altruistic goals more often in political behavior than in markets. Such norms may press people, in their capacity as citizens, in the direction of a concern for others and the public interest...Fourth, the deliberative aspects of politics, bringing additional information and perspectives to bear, may affect preferences as expressed through the governmental processes« (Sunstein, 1991: $16 \mathrm{f})$.

107 Informativ ist in diesem Zusammenhang auch der theoretische Kontext, aus dem heraus Sunstein sein Ideal einer »Republic of Reasons « (vgl. jetzt auch Sunstein, 1993: $17 \mathrm{ff}$. und 162 ff.) entfaltet: er argumentiert gegen subjektivistische Nutzentheorien libertärer Provenienz und genauer gegen den Versuch, am Begriff der Präferenzautonomie eine normative Basis für eine strikte Neutralitätsverpflichtung staatlicher Politik zu gewinnen. Die Grenzen eines solchen Ansatzes lassen sich unter dem Eindruck von drei grundlegenden Argumenten genauer bestimmen, von denen zumindest das zweite und dritte auch in unserem $\mathrm{Zu}$ sammenhang aufschlußreich sind: Der erste Einwand gegen eine Neutralitätsverpflichtung der Politik gegenüber individuellen Präferenzen besteht in dem Nachweis, daß die Bildung von Präferenzen und ihre spezifische Verteilung dem politischen Prozeß keineswegs vorgelagert sind, sondern auf kollektive Entscheidungen in Form institutioneller Regeln und rechtlich verbürgter Ansprüche zurückgehen - dieser »endowment effect « (Sunstein, 1993: $166 \mathrm{ff}$.) rückt aber zugleich die Frage nach der moralischen und ethischen Legitimität von durch den Begriff der individuellen Autonomie normativ imprägnierten Präferenzen wieder in den Mittelpunkt; das ist umso entscheidender, wenn man damit rechnet, daß die rationale Bewertung subjektiver Präferenzen unter Umständen ein moralisch und kognitiv so anspruchsvolles Unterfangen ist, daß man sich über seine Präferenzen leicht täuschen kann; für diesen Fall verleiht auch der Begriff der Autonomie keine hinreichende normative Dekkung mehr, der sich nicht sinnvoll von der reflexiven Kompetenz des Subjekts ablösen läßt, seine Präferenzen in sachlicher, zeitlicher und sozialer Hinsicht zu validieren und gegebenenfalls zu ändern (vgl. auch Gillroy/Wade, 1992: 242 ff.).

Mit diesen Argumenten gegen den theoretischen Agnostizismus bezüglich der sachlichen, sozialen und zeitlichen Qualität der in den politischen Prozeß einzubringenden individuellen Präferenzen führt Sunstein, wie gesehen, zu einem Modell deliberativer Politik hin, dessen hier relevante Pointe in einer Radikalisierung des Prinzips der individuellen Präferenzautonomie derart liegt, daß subjektive Werte und Interessen, die in die kollektive Willensbildung und Entscheidungsfindung eingehen, nicht mehr als gegeben und statisch, sondern als im Lichte einer permanenten selbstkritischen Überprüfung in Richtung auf ihre Verallgemeinerbarkeit, sachliche Angemessenheit und Zukunftsfähigkeit rational veränderbare Einstellungen begriffen werden - dies aber ist ohne eine entsprechende Veränderung des Modus der Genese von Präferenzen wie der strukturellen und institutionellen Bedingungen der Stabilisierung eines solchen neuen Modus nicht zu haben. 
Mit diesen knappen Bemerkungen kann ich hier nur andeuten, daß sich zumindest theoretisch gute Gründe für die Vermutung finden lassen, daß im Zuge einer weitergehenden Demokratisierung der politischen Willensbildungs- und Entscheidungsverfahren nicht nur die Ansprïche an die moralischen und kognitiven Kompetenzen der Beteiligten wachsen, sondern daß eine breitere und effektivere Institutionalisierung diskursiver Praktiken im Zusammenhang eines deliberativ orientierten Modells politischer Entscheidung zugleich in der Lage sein sollte, diese Ansprüche aufzufangen, weil sie die Bedingungen verbessert, unter denen sich die geforderten Kompetenzen aktualisieren lassen und reproduzieren können. ${ }^{108}$ Damit verliert dann auch ein zweiter Einwand, der aus der Kritik an der Selbstverbesserungsthese folgt, einiges an Gewicht: der empirische Einwand nämlich, daß sich selbst unter günstigen Bedingungen die Schere zwischen dem durch Demokratisierung erzeugten Bedarf an ethischen und moralischen Masseneinstellungen einerseits und dem >Angebot an solchen Orientierungen weiter öffnen wird - daß, m.a.W., »an increase in the number of associations would only stretch out the competent people, more and more thinly (Walzer, 1994: 190). Auch diesem Einwand kann man nunmehr die mindestens ebenso plausible, "angebotstheoretische« Annahme entgegensetzen, daß die Erhöhung des Bedarfs auch eine ressourcenerschließende Wirkung aufweist: "Multiply the call for competent people, and the people will appear. Multiply the opportunities for action-in-common, and activists will emerge to seize the opportunities. Some of them, no doubt, will be narrow-minded and bigoted, but the greater their number and the more diverse their activities, the less likely it is that narrow-mindedness and bigotry will prevail « (Walzer, 1994: 190). Nach dieser Lesart des Knappheitsphänomens hängt es dann primär an der Breite und Qualität institutionell verbürgter Beteiligungschancen, ob der Politik die für die Selbststeuerung moderner Gesellschaften dringend benötigten moralischen und kognitiven Ressourcen tatsächlich zugeführt werden können; und zwar ohne in die Falle zu unrealistischer Erwartungen an eine durchgreifende Selbstmoralisierung individueller Interessen zu laufen.

108 Für diese Vermutung sprechen mittlerweile auch spieltheoretische Analysen. So können Bohnet und Frey auf Ergebnisse von Experimenten mit 340 Studierenden der Ökonomie an der Universität Zürich verweisen, die am Beispiel von Gefangenendilemma- und FairneßSpielen zeigen, daß sowohl anreizorientierte Regeln in Form monetärer Sanktionen, aber auch insbesondere kommunikative Praktiken sowie fest verankerte und internalisierte, gemeinschaftlich geltende Normen »das Verhalten der Individuen verändern und zu erhöhter Kooperation bei der Erstellung öffentlicher Güter und bei Verteilungsfragen führen « (Bohnet/Frey, 1994a: 455 ff.). Über dieses Ergebnis hinaus hat sich in experimentellen Analysen auch die Evidenzbasis für die Annahme verbreitern lassen, daß Kommunikationschancen nicht nur generell die Kooperationsbereitschaft erhöhen, sondern daß »discussion seems to induce moral behavior (and) improves cognitive capabilities « (Bohnet/Frey, 1994b: 343). Deshalb können Bohnet und Frey an dieser Stelle auch folgern, daß »introducing communication possibilities into minimal contribution games increases the accuracy of the decisions taken by the players by minimizing the over- and underprovision of public goods...In these experiments, communication-groups, therefore, always provide the public good in a nearly optimal manner $\ll$. 
Schließlich wird man aber selbst unter dieser doppelten Voraussetzung, daß die angespannte Ressourcenlage der Politik im Kern auf eine kumulative sachliche, zeitliche und soziale Entfremdung des Bürgers von der Politik durch die aggregativen Mechanismen der repräsentativen Wettbewerbsdemokratie zurückzuführen ist und daß dieser Engpaß durch institutionelle Reformen, die sich an einem stärker deliberativen Modell von Politik orientieren, aufgehoben werden kann, nicht davon ausgehen können, daß es sich dabei um einen sich vollständig selbsttragenden und selbststabilisierenden Prozeß handelt (vgl. auch Knight/Johnson, 1994: 287 ff.). Dagegen spricht nicht nur die einfache Einsicht, daß institutionelle Reformen regelmäßig (Macht-) Verteilungskonflikte implizieren, sondern auch, daß die in die bestehende institutionelle Ordnung eingelassene Spannung zwischen liberalen und demokratischen Grundnormen, zwischen individueller Freiheit und kollektiver Selbstbestimmung und zwischen Gleichheit und vernünftiger Selbstbestimmung also, zunächst deutlicher hervortritt und akzentuiert wird. Die Frage ist dann, ob es Kerne einer solchen deliberativen Praxis in anspruchsvollen politischen Handlungszusammenhängen mit einem deutlichen Entscheidungsbezug gibt, die sich institutionell (gleichsam experimentell) so ausbauen lassen, daß ihre Stellung im politischen Prozeß insgesamt schrittweise verstärkt werden kann. Wenn es dabei gleichzeitig darauf ankommt, die Legitimität und die Effizienz demokratischer Willensbildung zu stärken; und wenn vermieden werden soll, für die Erhöhung der Autonomie und Selbstorganisationsfähigkeit der Gesellschaft den Preis eines »administrativen Desinteresses « (Maus) zu entrichten, dann müßten sich entsprechende Ansatzpunkte vor allem in funktional konstituierten Handlungszusammenhängen. der kollektiven Problemlösung finden lassen (vgl. auch Warren, 1993: 226 ff.). Diesem Gedanken möchte ich im folgenden wenigstens ein Stück weit nachgehen. 
III

Jenseits von Staat und Gesellschaft:

Zur assoziationspolitischen Modernisierung der Demokratie 
Verstreut über ein breites Feld von Forschungen u.a. zur Analyse risikogesellschaftlicher Strukturen, zu Fragen der Regierbarkeit moderner Gesellschaften im Kontext der Korporatismusforschung oder des Neo-Institutionalismus in der Policy-Forschung und damit zusammenhängend der neueren Staatstheorie, ${ }^{109}$ sind in den letzten Jahren insgesamt beeindruckende Evidenzen dafür zusammengetragen worden, daß sich die moderne Gesellschaft nur durch einen fundamentalen Wandel ihrer Architektur und eine tiefgreifende Reform ihres Systems der politischen Willensbildung und Entscheidungsfindung auf die zunehmend wissensbasierte Lösung der Probleme ihrer sozialen, technischen und ökologischen Reproduktion wird einstellen können. Dabei ist weitgehend unbestritten, daß vor allem die Ökologieproblematik und die Umweltpolitik wegen ihrer Folgenträchtigkeit und ihrer sachlich, zeitlich und sozial ausgesprochen anspruchsvollen Problemstruktur so etwas wie einen »Lackmustest « für institutionelle Reformvorhaben darstellt: ${ }^{110} \gg$ Die bequeme Vorstellung, der Markt sorge für eine optimale Allokation >privater ‘ Güter und die Politik für diejenige > kollektiver < Güter, führt dort in die Irre, wo moderne Gesellschaften ihre Potentialität und ihre Riskiertheit gleichermaßen verdichten: an den Orten jener komplexen Problemstellungen, die in vielfältiger Verschachtelung sachlicher, sozialer, zeitlicher, operativer und kognitiver Dimensionen und Wertigkeiten keine eindeutigen, einfachen oder einseitigen Lösungen zulassen, sondern responsive und revisible Prozesse der Entscheidungsfindung erfordern« (Willke, 1992: 59).

Diese Problemstruktur legt es nun nahe, auch die Frage der Angemessenheit hierarchischer Steuerung und einer auf die parlamentarische Beratung und Staatswillensbildung bloß zulaufenden und in der zentralen Gesetzgebung terminierenden öffentlichen Willensbildung mit größerem Nachdruck zu stellen. Für Willke und für Beck jedenfalls ist die Frage entschieden: der hierarchische Staat stirbt ab und muß als »ziviler « Staat im Rahmen eines reflexiven Modells von Politik neu erfunden werden (Beck, 1993: 214); denn es sind die aus der Verbindung von liberaler (repräsentativer) Demokratie und hierarchisch-administrativer Steuerung resultierenden strukturellen Restriktionen der Problemlösungsfähigkeit, die jene Räume schaffen, in denen sich horizontal ausgelegte und diskursiv vermittelte Formen demokratischer Politik ausbreiten können. Die begrenzte Leistungsfähigkeit einer Politik, die von den komplementären Schwächen der Wettbewerbsdemokratie einerseits und des administrativen Staates andererseits bestimmt ist, wird schon in einem flüchtigen Blick auf die allgemeinsten Merkmale dieser Arrangements deutlich (vgl. Dryzek, 1992: 21 ff.). Bestimmt durch die adverseriale Mechanik des politischen Wettbewerbs und die binäre Logik von Regierung und Opposition sowie die Trennung von Staat und Gesellschaft, die gesellschaftliche Gruppen und Assoziationen zur strategischen Verfolgung partikularer Interessen freisetzt und die Entfaltung so-

109 Zum Komplex Risikogesellschaft vgl. u.a. Beck (1986, 1988 und 1993); zum Korporatismus siehe etwa Williamson (1989), zum Neo-Institutionalismus vgl. March/Olsen (1989) und Schmalz-Bruns (1989 und 1990); Grundzüge einer neuen Staatstheorie werden reflektiert u.a. bei Offe (1986 und 1990), bei Scharpf (1992), Böhret (1990 und 1992) sowie bei Willke (1992) und Beck (1993).

110 Dryzek (1992: 18); vgl. auch v. Prittwitz (1993), Zilleßen/Dienel/Strubelt (1993) und Dekker (1994). 
zialer Macht zur politischen Beförderung dieser Interessen prämiiert, zeitigt die liberale Demokratic mindestens vier Struktureffekte, die sich negativ auf die kollektive Handlungsfähigkeit der Gesellschaft auswirken: erstens verstärkt sie die ungleiche Verteilung sozialer Macht und enthält aufgrund primär zweiseitiger und segmentär ausgelegter Kommunikationen kaum Anreize zur gemeinwohlbezogenen Raffinierung von Interessen; ${ }^{11}$ dies überträgt sich zweitens auf eine fragmentierte Identifikation und Wahrnehmung von allgemeinen Problemen, die sich primär an der unterschiedlichen Stimmächtigkeit betroffener Gruppen und damit an der Optik partikularer Interessen orientiert - ein Effekt, der im übrigen durch die Ressortierung der Regierungsorganisation noch verstärkt wird; in die gleiche Richtung wirkt drittens die Logik des Tauschs von Stimmen gegen fühlbare Leistungen oder »Belohnungen«, die nicht nur zu einer Strapazierung der Finanzkraft des Staates durch querschnittige Verteilungsmuster führt, sondern zu einer Invisibilisierung entstehender Kosten nötigt, die der Wahmehmung und Lösung komplexer Probleme eher im Wege steht; daraus resultiert schließlich eine Verkürzung auch des Zeithorizonts der Politik, der sich mehr an der Vertaktung (Böhret) des politischen Systems durch Wahlperioden als an der Art der zu lösenden Probleme ausrichtet.

Auf der anderen Seite bildet das administrative System staatlicher Steuerung kaum ein Gegengewicht gegen diese Tendenzen, auch wenn es sich zunächst auf eine andere Rationalität der Problemwahmehmung, auf ihre Gemeinwohlverpflichtung und Expertise sowie auf die rechtlich geschützte Autorität zur notfalls zwangsbewehrten Durchsetzung rationaler Entscheidungen berufen kann. Demgegenüber ergeben sich wesentliche Beschränkungen der Handlungs- und Problemlösungsfähigkeit der Verwaltung schon auf der Ebene der Handlungsprogramme, durch ihre Adressatenbindung und den durch hierarchische Organisationsprinzipien und ein Modell instrumenteller Rationalität bestimmten Routinemodus bürokratischen Handelns. Kurz: programmierte Handlungsroutinen führen zur Problemzerstückelung und unterlaufen eine komplexe Problemwahrnehmung und -bearbeitung, sie können sich schlecht auf sich schnell ändernde Problemumwelten einstellen, und hierarchische Organisationsformen kanalisieren den Fluß von Informationen so, daß eine erfolgreiche Lösung von Nicht-Routine-Problemen schon im Ansatz verhindert wird. ${ }^{112}$

111 Dieses Problem reproduziert sich in gewisser Weise auch über das Institut der geheimen Wahl, das, auch wenn es sich gewiß auf gewichtige normative Gründe der Freiheit und Gleichheit stützen kann, stark privatisierende Effekte auf den Akt der individuellen Wahlentscheidung ausübt. Vgl. dazu Buchstein (1993).

112 Diese allgemeine Feststellung wird von soziologischen Untersuchungen zum konventionellen und unkonventionellen Lernverhalten von Organisationen gut bestätigt. In Auswertung seines Literaturberichts kommt Wiesenthal zu Antworten auf die Fragen nach dem Durchschnittslernverhalten von Organisationen und nach ihrer Fähigkeit zur Erfüllung externer Ansprüche (etwa an den Grad ihrer kooperativen Problemlösungsbereitschaft) durch reflexives Strukturlernen, die die hier vertretene Sicht insgesamt bestätigen: Weil als erste Antwort auf Umweltherausforderungen zunächst nur die Aktivierung simpler Lernroutinen zu erwarten ist, erfordert die effektive Berücksichtigung externer Anforderungen (i.e. Gemeinwohlorientierungen) die Herstellung von »Anschlußstellen im Orientierungsrahmen«, die als interne Rezeptoren und »Speicher« für solche Ansprüche fungie- 
Nimmt man nun diese beiden Formprinzipien staatlicher Politik zusammen, so ergibt sich ein spezifisches Bild, das die Leistungsschwächen dieser Politik gegen die im wesentlichen unstrittigen Erfordernisse einer anspruchsvolleren Politik der Problemlösung konturiert: Da ist zunächst (i) ein Phänomen, das man als Wahrnehmungsschwäche staatlicher Politik beschreiben kann - hierbei geht es um einen durch den bürokratisch-administrativen Routinemodus staatlicher Politik verursachten Sensibilitätsverlust gegenüber neuen Themen und Problemen, deren Bearbeitung und Lösung Strategien erfordert, die zum konkurrenzdemokratischen Schematismus einer klientelistischen Interessenpolitik querliegen (Peters, 1993: 346ff.). Damit hängt (ii) eine gewisse Konzentrationsschwäche des Staates zusammen, und zwar in einem doppelten Sinne: zum einen zwingt die »Vertaktung « der Politik über relativ kurze Legislaturperioden und die schnelle Aufeinanderfolge von Wahlen auf den unterschiedlichen Ebenen die politische Bearbeitung von Themen in Zeithorizonte, die der Langfristigkeit und Schwierigkeit der Probleme nicht angemessen sind; zum anderen lenkt die »Querschnittigkeit« (Böhret) der Anlage von Normalpolitik von einer an sich notwendigen Entlastung und Konzentration im Aufgabenbereich ab (Böhret, 1992: 123 f.; March/Olsen, 1989: 139; Beck, 1993: 217 f.). Darüberhinaus muß (iii) eine staatliche Politik, die sich nach wie vor von einem Modell hierarchischer Steuerung leiten läßt, mit Rationalitätsverlusten rechnen, weil sie, gleichsam geblendet von einem »dominanten Interesse an der Staatswillensbildung und hierarchischen Willensdurchsetzung (Scharpf, 1992: 103), die Leistungsfähigkeit von Verhandlungssystemen nicht anerkennen und ausnutzen kann. Schließlich (iv) führen diese Strukturvorgaben auch zu einer spezifischen Ressourcenschwäche, weil Sachwissen und Sachverständnis wie reflexive Fähigkeiten gerade nicht zu den prämiierten Kompetenzen eines auf Machterhalt spezialisierten politischen Akteurs gehören.

Während sich diese Diagnosen einer im wesentlichen strukturbedingten Leistungsschwäche staatlicher Politik und die daraus resultierenden Empfehlungen einer stärkeren Dezentralisierung, Entstaatlichung, Entparlamentarisierung und Vergesellschaftung von Politik im Kern einem zunehmenden Interesse an den Inhalten von Politik und der Verbesserung der sachlichen Gütequalität politischer Entscheidungen verdanken, gibt es andererseits auch gute Gründe, dieses politikinhaltliche Interesse nicht umstandslos in Empfehlungen zu radikalen Umbauten am bestehenden System der politischen Institutionen umzusetzen und so den Versuch zu unternehmen, das System einfach auf die Notwendigkeiten materialer Politiken zuzuschneiden (Decker, 1994: 254 ff.). In diesen Gründen vermischen sich historische, pragmatische, strategische und normative Aspekte. Zum einen muß man sicherlich der Tatsache Rechnung tragen, daß die Rationalisierung der Politik in konstitutionellen Bahnen sich im wesentlichen als Prozeß der reflexiven Selbstrationalisierung von Politik vollziehen muß - oder m.a.W.: institutionelle Reformen müssen durch den Flaschenhals einer an dem eigenen Machterhalt orientierten »positionalen« Politik (Ueberhorst) hindurch (vgl. auch Moe, 1990: 215 f.). Was den staatlichen Akteuren also abverlangt wird, ist nichts weniger als der Einsatz ihrer institu-

ren - solche unkonventionellen Lernformen gehen auf Strukturreformen zurück, die u.a. qua »Externalisierung von Mitgliedschaftsentscheidungen« die Bedingungen für organisationsinterne Dissidenz, für die Kopräsenz externer Orientierungen und für die Ausbildung multipler Organisationsidentitäten schaffen müssen (vgl. Wiesenthal, 1993: 24 ff.). 
tionell verbürgten Machtmittel zum Zweck der Selbstentmachtung; und es ist deswegen kaum verwunderlich, daß entsprechende Handlungsdispositionen eine ausgesprochen knappe Ressource darstellen. Insofern ist es denn auch verständlich, wenn mit Blick auf realistische Handlungsalternativen immer wieder nahegelegt wird, im Zuge der Entwicklung von Reformvorstellungen die Anforderungen an ein neues institutionelles Design möglichst gering zu halten (Decker, 1994: 255 f.). So werden denn gerade im Namen eines »aufgeklärten Institutionalismus «, der sich mit Blick auf die Pfadabhängigkeit der Entwicklung von Institutionensystemen, auf die fragile, aber wenigstens eingespielte $\mathrm{Ba}$ lance des Systems der Gewaltenteilung und -verschränkung vor allem über die »Grenzen institutioneller Reform « (Scharpf, 1985) aufklären soll, eher inkrementale Verbesserungen im Rahmen der bestehenden Institutionen nahegelegt. Im Gegenzug gibt es nun aber durchaus Hinweise darauf, daß die zunehmend prekären Bedingungen staatlicher Machterhaltung und -entfaltung, das Gefühl, wie Beck (1993: $210 \mathrm{ff}$.) notiert, nur noch die Fassaden eines im Inneren längst entkernten Machtgebäudes zu verteidigen, in den Handlungsstrategien staatlicher Akteure ihre Wirkung entfalten: der Rückgriff auf konkordanzdemokratische und korporatistische Formen des Aushandelns von Politik in Politiknetzwerken und Verhandlungssystemen, Versuche der Deregulierung durch Umstellung von >Staat auf >Markt ‘ wie schließlich die Ansätze der Umstellung auf eher kooperative Formen des Verwaltungshandelns (vgl. Hoffmann-Riem, 1990) sind allesamt Indikatoren für eine »staatliche Politik der Staatsentlastung « (Offe, 1987: 317), an die Strategien einer weitergehenden Demokratisierung anschließen können sollten.

Selbst vor diesem Hintergrund aber muß die Empfehlung einer stärkeren gesellschaftlichen Allokation von politischen Entscheidungsrechten und Verantwortlichkeiten nicht nur mit Hinweisen auf die mögliche Fragmentierung, Segmentierung und Selbstblockade der politischen Willensbildung im Zuge einer Dezentralisierung und partizipatorischen Öffnung politischer Entscheidungsstrukturen rechnen (Wiesenthal 1989 und 1990); vielmehr ist auch nicht auszuschließen, daß eine asymmetrisch verteilte soziale Macht, die durch die Trennung von Staat und Gesellschaft und die gewaltenteilige Balance des staatlichen Institutionensystems auch eingehegt und diszipliniert werden kann, sich nur ungehinderter entfaltet und unmittelbarer in politische Entscheidungen umsetzt. Hinter diesem Hinweis steht die gewiß nicht unberechtigte Sorge (vgl. Habermas, 1992: 215 ff.), daß das parlamentarische Prinzip, in dem sich die Idee der Publizität historisch materialisiert hat und das zusammen mit der Gewährleistung autonomer Öffentlichkeiten und dem Organisationsmittel der Parteienkonkurrenz die Idee der Volkssouveränität zum Ausdruck bringen soll (Habermas, 1992: 211), unterlaufen wird, ohne daß ein adäquater Ersatz zur Verfügung stünde. Zusammen mit »technischen " Gründen (Habermas, 1992: 224) schließlich, die auf die Notwendigkeit von face-to-face Interaktionen im Rahmen einer entscheidungsorientierten, diskursiven politischen Praxis verweisen, sieht sich Habermas deshalb - wie gezeigt zu einer weitgehenden Assimilation des Prinzips deliberativer Politik an die Formen repräsentativer, parlamentarischer Willensbildung veranlaßt. Diese technischen Gründe erhalten insoweit den Charakter eines Sach- oder Organisationszwangs, vor dessen Hintergrund die Auslagerung politischer Entscheidungen in die unterschiedlichen Assoziationen und Willensbildungsstrukturen einer fragmentierten Öffentlichkeit, die ge- 
sellschaftliche Allokation von Entscheidungsrechten leicht den Charakter einer (schlechten) Utopie der Stilisierung des »Volkswillens « zu einem homogenen, kollektiven Subjekt demokratischer Politik annimmt. Deshalb hält er daran fest, daß sich die Meinungsbildung in einer nicht institutionalisierten und insgesamt auch nicht institutionalisierbaren Öffentlichkeit nur indirekt, über die Kanäle des etablierten Vermittlungssystems von Parteien und Verbänden, auf die parlamentarische Willensbildung auswirken, die in der allgemeinen Gesetzgebung terminiert.

M. E. läßt sich Habermas hier allzu sehr von der rechtlichen Qualität von Politik, einer in der Gesetzgebung terminierenden Idee der Selbstbestimmung und mithin von der allgemeinen Form des Gesetzes beeindrucken. Dies verleitet ihn zu einer - wie ich meine: voreiligen - Adaptation der demokratischen Idee der Selbstgesetzgebung an eine körperschaftliche, zentralisierte Form der allgemeinen Gesetzgebung. Nun muß Politik keineswegs immer in einer allgemeinen Gesetzgebung terminieren; und das Parlament ist keineswegs die einzige Form der technischen Umsetzung der interaktiven Anforderungen an eine deliberative Politik - hier kommen dezentrale, fokale Strukturen, wie sie in Verhandlungssystemen, Politik-Netzwerken oder hybriden Organisationen des Dritten Sektors auf lokaler Ebene oder im Zusammenhang einzelner Politikbereiche entstehen, ebenso in Betracht. Auch wenn diese Arenen der Problemlösung und politischen Entscheidungsfindung eine größere Autonomie erhalten, sind sie, insofern sie auf rechtlich verbürgte Freiheiten konstitutiv angewiesen bleiben, ja nicht autark gegenüber den Anforderungen und Zumutungen einer allgemeinen, vernünftigen Gesetzgebung und damit den Institutionen des liberalen Rechtsstaates. Insofern läßt sich die hier eingenommene Perspektive einer reflexiven Demokratisierung auch gegen realistische Einwände und eine nicht unbegründete normative Skepsis durchaus verteidigen: Verbesserungen materialer Politik lassen sich ohne Verletzung der normativen Präsuppositionen des liberalen Rechtsstaates dann erreichen, wenn man gleichgerichtete, integrierte Strukturreformen auf den unterschiedlichen Ebenen und Aggregationsstufen des politischen Prozesses vornimmt. Die allgemeine Logik, die hinter der Idee einer Radikalisierung der im Prinzip der institutionellen Gewaltenteilung und -verschränkung bereits angelegten Reflexivität politischer Prozesse steht, hatte ich im letzten Kapitel im Rahmen eines Stufenmodells institutioneller Reform bereits angedeutet. Das Problem, das sich auch angesichts der soeben noch einmal aufgenommenen Einwände jetzt stellt, ist die Frage, wie sich diese Reflexivität auf die Ebene konkreter Entscheidungen in Policy-Arenen oder in dezentralen, lokalen Zusammenhängen der politischen Problemlösung absenken läßt (Maus, 1992), um so der Idee einer deliberativen Politik einen über die Form repräsentativen Parlamentarismus hinausweisenden demokratischen Handlungsrahmen zu erschließen.

Die generelle Richtung, in die uns diese Fragestellung führt, haben Cohen und Rogers mit dem Projekt einer assoziationspolitischen Modernisierung der Demokratie bereits vorgegeben. ${ }^{113}$ Es verdankt seine Relevanz der ausdrücklichen Verschränkung von normativen Annahmen und Gesichtspunkten der Effizienz und Effektivität demo-

113 Dieses Modell habe ich in seinen Grundzügen weiter oben (Kap.6) bereits rekapituliert. 
kratischer Beteiligung im Modell deliberativer Politik, indem es eine strukturpolitische Reaktion auf vier Klassen von Handlungsproblemen einklagt, denen sich (staatliche) Politik unter Bedingung einer zunehmenden Wissensbasierung politischen Handelns ausgesetzt sieht: Dabei haben sie vor allem solche Situationen im Auge, (i) in denen der Staat zwar die Kompetenz besitzt, Regulationsnormen in Kraft zu setzen, in denen aber aufgrund der Vielzahl, der Dispersion und der Unterschiedlichkeit der Regulationsobjekte eine entsprechende zentrale Implementationskontrolle schwierig ist (Beispiel: Arbeitsplatzregulierungen); in denen er (ii) zwar die Normsetzungskompetenz besitzt, die Implementation aber genaue Kenntnisse der örtlichen Gegebenheiten voraussetzt (Beispiel: Umweltregulierungen); in denen (iii) die Bestimmung von Regulierungszielen nur in enger Kooperation mit dezentralen, auch nicht-staatlichen Akteuren erreicht werden kann; in denen sich (iv) die Problemdefinition und -bearbeitung dem Zuschnitt konventioneller Politikbereiche entzieht und die bereichsübergreifende Kooperation mit unterschiedlichen Akteurgruppen notwendig wird (Cohen/Rogers, 1994: 146 f.). In diesen Situationen entzicht sich die Lösung von Problemen typischerweise der kompartmentalisierten Organisationsstruktur des staatlich-administrativen Apparates ebenso wie sie die Leistungsfähigkeit des Systems der pluralistischen Interessenrepräsentation oder der korporatistischen Form der Interessenvermittlung übersteigt (vgl. Schmitter, 1994: $160 \mathrm{f}$.): »In consequence, adressing such problems requires coordination within the state across its formal decision-making or administrative machinery in different policy domains, and agreement on that coordination with the relevant - and mutually distant - private actors affected by each. To solve such problems, routinely (Herv. d. Verf.) what is needed ... is some institutionalized learning capacity - a capacity especially to identify new problems and experiment with solutions that disrespect existing organizational boundaries and competences « (Cohen/Rogers, 1994: 153 f.). Auf diese Herausforderung hat die Politikwissenschaft nun in den letzten Jahren vor allem durch eine konstruktive Verbindung von Netzwerkanalyse einerseits und der Theorie von Verhandlungssystemen andererseits bereits reagiert, ${ }^{114}$ und was beide Perspektiven miteinander verbindet, ist die Einsicht, daß sich ein legitimationswirksamer, effektiver und effizienter Gebrauch von solchen neuen Politikinstrumenten nur machen läßt, wenn sie in einer neuen Form der »sekundären Staatsbürgerschaft« (Schmitter, 1994: 162) vermittelt sind, die es diffusen Akteuren (Individuen wie Organisa-

114 Vgl. dazu neuerdings auch Jansen/Schubert (1995) und Schubert (1995: 234 ff.), der vor allem die »Innovationslogik « von Netzwerken hervorhebt und darauf aufmerksam macht, daß »Netzwerke « mehr als eine beschreibbare Struktur, eine »gestaltbare Größe« sind, weil sie nicht als Selbstzweck entstehen, sondern »opportunity structures« bilden, die den Akteuren Möglichkeiten bieten, unkonventionelle, häufig sachangemessenere und innovative Problemlösungen zumindest vorzubereiten, wo nicht zu implementieren. Insofern bilden sie zumindest potentiell ein wichtiges Ferment einer assoziationspolitischen Modernisierung der Demokratie - darauf komme ich weiter unten (Kap. 9) zurück. 
tionen) erlaubt, in den Raum der Vorbereitung und Durchführung einzelner materialer Politiken vorzudringen. ${ }^{115}$

Diese thematischen und konzeptuellen Markierungen stecken denn auch in etwa den Argumentationsrahmen für die folgenden Überlegungen ab, die den Zweck haben, die Formveränderungen materialer Politik aufzuspüren und konzeptionell zu integrieren, die jenseits des Dualismus von Staat und Gesellschaft angesiedelt sind und insoweit der hier vertretenen reflexiven Auslegung der Idee der Demokratie schon entgegenkommen. Dabei gehe ich zunächst den Implikationen der »dritten demokratischen Transformation « (Dahl), also der zunehmenden Wissensbasierung und Expertiseabhängigkeit moderner Politik, für den Funktionsbegriff und die Formbestimmung politischer Öffentlichkeit nach und versuche an Hand der programmatischen Fortentwicklung der Policy-Analyse zu einer Demokratiewissenschaft einen Eindruck von den Anforderungen zu gewinnen, denen sich die neue Balance zwischen Expertisebedarf und erweiterten Teilhabeansprüchen ausgesetzt sieht (Kap. 8). Diese Nötigung zu einer deliberativen Selbstadaptation des institutionellen Rahmens moderner Politik ist schließlich keinesfalls auf einzeIne Politikbereiche wie die Umwelt- und Technologiepolitik begrenzt. Vielmehr greift die materiale Politisierung der gesellschaftlichen Entwicklung auch auf klassische Bereiche distributiver und redistributiver Politiken (z.B. in der Sozial-, Arbeitsmarkt- und Industriepolitik - vgl. Zapf/Dierkes, 1994) über, so daß auf einiger Breite die Erprobung neuer Formen der Problemlösung auf dem Wege einer horizontalen Selbstkoordination von Akteuren bereits eingesetzt hat: gerade netzwerkartig organisierte Verhandlungssysteme mit einem flexiblen Mix an Formen der Koordination, in denen unterschiedliche Kommunikationsmodi des Bargaining, des politischen Tauschs und der argumentativen Problemlösung miteinander verschränkt werden können, sind demokratietheoretisch ernstzunehmen und konzeptionell so zu adaptieren, daß deliberative Arenen in Gestalt verständigungsorienter Politikdialoge (Ueberhorst), von diskursiven Verfahren der Technikfolgenabschätzung oder der Mediation mehr darstellen können als (entscheidungsferne) Inseln einer partizipatorischen Praxis im Meer einer adverserialen, kompetitiven Politik (Kap. 9).

115 Freilich bedarf es zu diesem Zweck des gezielten Ausbaus der rechtlichen, finanziellen und politischen Infrastruktur, um dieses Ziel einer möglichst breiten Inklusion unterschiedlicher Akteure in funktional spezialisierte Handlungskontexte zu erreichen. Zu diesem Zweck hat Schmitter (1994: $163 \mathrm{ff}$.) vorgeschlagen, 》(1) the establishment of a semi-public status for interest associations; (2) the financing of these associations through compulsory contributions; and (3) the distribution of these funds by means of citizen vouchers « ins Auge zu fassen. Die zentrale Idee, die hinter der Einführung eines halb-öffentlichen Status steht, ist »to encourage associations to become better citizens, i.e. to treat each other on a more equal basis and to respect the interests of the public as a whole « (164), während die Erhebung von Zwangsbeiträgen eine Finanzierungsmethode für öffentliches Handeln sicherstellen soll, die unabhängig von der individuellen Zahlungsbereitschaft und -fähigkeit ist (165); schließlich soll durch die Verteilung über »citizen vouchers « vor allem eine Verbesserung der Repräsentativität wie eine Lösung des Intensitätsproblems auf eine Weise erreicht werden, die zugleich Anreize für eine reflektierte Präferenzartikulation auf seiten der Bürger und die Erhöhung der Verantwortlichkeit (accountability) auf seiten der Verbände und Vereinigungen vermittelt (166 f.). 


\section{Perspektiven einer »dritten demokratischen Transformation«}

Die bisherigen Überlegungen sollten genug Gründe dafür beigebracht haben, daß es lohnen könnte, sich nach Konzepten für eine sich zur Gesellschaft hin öffnenden, rationalen politischen Praxis umzusehen, die das Projekt einer zwischen dem Souveränitätsverlust des Staates, einer weitgehend korporatistisch aufgenommenen gesellschaftlichen Diffusion von Staatlichkeit, wachsenden Teilhabeansprüchen einer breiteren Öffentlichkeit und den sich verschärfenden Ansprüchen an die moralische Qualität und sachliche Angemessenheit von Politik eingeklemmten partizipatorischen Demokratie wieder mit plausiblen Perspektiven versorgen. Einen solchen Ansatz finden wir in John Deweys Versuch einer nachmetaphysischen Rechtfertigung der Demokratie bereits vorgebildet, der den Vorzug hat, die für den weiteren Gang der Argumentation wichtige Verschränkung der Gesichtspunkte von allgemeiner Partizipation, öffentlicher Deliberation und einem problemlösungsbezogenen politischen Handeln grundsätzlich vorzubereiten. Wegweisend ist in diesem Zusammenhang vor allem seine Entscheidung, die gesellschaftstheoretische Frage nach der Differenzierung moderner, komplexer Gesellschaften in der Entfaltung seines spezifischen Begriffs von Staat und Öffentlichkeit in einen grundsätzlich handlungstheoretischen Begriffsrahmen zurückzustellen.

Damit bietet er eine Perspektive an, deren Vorzüge sich gerade demokratietheoretisch in dreierlei Hinsicht bemerkbar machen: er löst die Vorstellung kreativen Handelns von der expressivistischen, romantisierenden Vorstellung individueller Exzellenz nach dem Modell des künstlerischen Schaffens ab und rekonstruiert sie als soziale, komunikative Praxis (vgl. dazu Alexander, 1987: 151 ff. und Joas, 1992: 286 ff.); diese Sicht kann er dann zweitens auch auf die Erzeugung demokratischer Institutionen übertragen, die nun nicht mehr lediglich als Produkt großer außeralltäglicher, dramatischer Ereignisse (constitutional moments) erscheinen, sondern als Ergebnis eines kumulativen Prozesses der reflexiven Bearbeitung von Handlungsfolgen im Zusammenhang der Problemlösung auf den unterschiedlichen Ebenen von Politik (vgl. Joas, 1992: 96); drittens schließlich kann er auf diesem Wege die demokratietheoretisch ungünstige Aufspaltung von Handeln in kommunikatives Handeln einerseits und instrumentelles Zweckhandeln andererseits vermeiden - daraus ergibt sich ein Verständnis von Demokratie, für das er programmatisch den Titel der »kreativen Demokratie« (Joas, 1992: 290; vgl. auch Burns/Ueberhorst, 1988) in Anspruch nimmt (1). Während in seinen Überlegungen zu einem nachmetaphysischen Konzept des Staates zunächst noch Fragen der politischen Demokratie und der Abwehr elitistischer Repräsentationsmodelle im Mittelpunkt stehen, rückt er im Fortgang der Argumentation mit seinem Begriff der Öffentlichkeit zunchmend Aspekte der sozialen Demokratic in den Vordergrund: dadurch, daß er sich nunmehr primär für die Möglichkeiten der Demokratisierbarkeit von Handlungszusammenhängen interessiert, in denen die Bewältigung von Handlungsproblemen die Vermittlung von Werten, Fakten- und theoretischem Wissen 
verlangt, wirft er das Problem der Sozialisierung und Demokratisierung von Expertise auf. An die darauf gerichteten Überlegungen Deweys kann dann Dahl anknüpfen, für den die Überwindung der expertokratischen Entfremdung des staatsbürgerlichen Publikums und ineins damit die Frage der Verbesserung der staatsbürgerlichen Kompetenz den Dreh- und Angelpunkt seiner Forderung nach einer »dritten demokratischen Transformation « bilden. In diesem Horizont stehen denn auch seine exemplarischen Überlegungen etwa zu den Chancen und Bedingungen von innerbetrieblicher Demokratie, zur Teledemokratie, zur Einrichtung von Wissenschaftsräten oder zur Schaffung nationaler Foren der Meinungsartikulation und staatsbürgerlichen Willensbildung. Diese technischen Visionen könnten, was auch Habermas moniert (Habermas, 1992: 386), den Eindruck erwecken, daß Dahl sich zu weit von den tatsächlichen Strukturen der Willensbildung und Entscheidungsfindung entfernt, um den notwendigen Anschluß an die politische Realität halten zu können; der Defekt liegt indes, anders als Habermas vermutet, nicht in den Unzulänglichkeiten seiner Sozialstrukturanalyse, sondern weniger grundsätzlich eher schon darin, daß Dahl es versäumt, seine Vorstellungen mit Blick auf relevante Strukturen und hybride Organisationsformen, die sich im Bereich des Designs und der Implementation materialer Politiken ausmachen lassen, zu explizieren. M.E. lassen sich aber gerade hier Möglichkeiten zur Erweiterung des demokratischen Handlungsrahmens erkennen (2).

\subsection{Politische Öffentlichkeit(en) in der »kreativen Demokratie«}

»The Public and Its Problems « (1927) ist zweifellos die gewichtigste unter den Arbeiten, mit denen Dewey seinen radikaldemokratischen Intuitionen einen systematischen Ausdruck zu geben versucht. Damit reagiert er auch auf einen immer skeptischer werdenden Zeitgeist, der vor allem unter dem Eindruck empirischer Wahlstudien, an denen die Vorstellungen vom engagierten und rationalen Bürger zunehmend zerbrachen, den Konsens aufkündigte, dem die amerikanische Politikwissenschaft in der Verbindung von demokratischen Werten und objektiver Wissenschaft ihre Entstehung verdankte. ${ }^{16}$ Wenn Dewey diesem von empirischen Studien gestützten Zeitgeist widerstehen wollte, so mußte es ihm vor allem darauf ankommen zu zeigen, daß nicht die Anthropologie oder Psychologie für die Erklärung des konstatierten Niedergangs einer demokratischen Kultur verantwortlich zeichnen, sondern daß es vor allem die bestehenden Institutionen und die etablierten Interaktionssysteme sind, auf die der unübersehbare Fehlschlag demokratischer Aspirationen zurückzuführen ist. So war es unter den Realisten der zwanziger Jahre vor allem Walter Lippmann, dessen Arbeiten für Deweys eigene Argumentation stilbildend wirkten, und zwar deshalb, weil er sich in

$116 \mathrm{Vgl}$. dazu und zum folgenden auch Westbrook (1991: $280 \mathrm{ff}$.). Daneben bieten vor allem die Arbeiten von Damico (1978) und Alexander (1987) einen guten Überblick über Dewey als Demokratietheoretiker und die systematische Verknuipfung seiner demokratischen Ideale mit seiner Philosophie insgesamt. Zu diesem Problemkomplex vgl. auch die Studien zum kreativen Handeln von Joas (1992). 
seinem Realismus weniger auf psychologische und behavioralistische Annahmen verließ, sondern, ähnlich wie Dewey, das »Problem des Wissens « und der staatsbürgerlichen Kompetenz zum Angelpunkt seiner Überlegungen machte. Es sind vor allem drei miteinander verbundene Annahmen, auf denen Lippmann seine Skepsis gegenüber einer massendemokratischen Bewältigung der Probleme komplexer Gesellschaften des Industriezeitalters gründete: Weil Deweys Arbeit bis in den Aufbau der Argumentation hinein diesen Vorgaben folgt, ist es informativ, sich zunächst kurz der Thesen Lippmanns zu versichern, bevor ich dann Deweys Antwort etwas ausführlicher skizziere.

In seiner Analyse der "öffentlichen Meinung « von 1922 entfaltet Lippmann sein Plädoyer für eine elististische Version der repräsentativen Demokratie in drei Schritten: in einem ersten, erkenntniskritischen Schritt wirft er einen Blick auf jene Strukturen der Genese von Erfahrungen und der Meinungsbildung, die auf der Seite des Individuums zu unvermeidlichen, systematisch verzerrten Wahrnehmungen der politischen Umwelt führen; dann macht er deutlich, daß die Strukturen einer primär massenmedial vermittelten Öffentlichkeit diese Defekte nicht nur nicht beseitigen, sondern vielmehr noch verstärken; so bereitet er schließlich seine expertokratische Lösung des Problems des Wissens vor, die in der Empfehlung einer Entwicklung der Sozialwissenschaften zu objektiven »policy sciences « kumuliert, die die Willensbildung des Staatsbürgers nicht ergänzen oder informieren, sondern ersetzen sollen. Den Ausgangspunkt dieser Argumentationskette bildet mithin die einfache Feststellung, daß Menschen ihre Umwelt nicht direkt, sondern vermittelt über Vorstellungen über diese Umwelt wahrnehmen. Diese an sich noch unverfängliche Einsicht wird ihm erst dadurch zum Problem, daß traditionale lebensweltliche, kulturell fest verankerte Wahrnehmungsmuster immer weniger zu der industriegesellschaftlich induzierten Dynamik einer auch politisch relevanten Umwelt aufschließen können und daß in der Folge der individuelle Zugriff auf für die Meinungsbildung relevante Umwelten und Umweltdaten in einer Weise beschränkt ist, die zu erheblichen Verzerrungen der Wahrnehmung führen muß, die begrenzt ist durch »... artificial censorships, the limitations of social contact, the comparatively meager time available each day for paying attention to public affairs, the distortions arising because events have to be compressed into very short messages, the difficulty of making a small vocabulary express a complicated world, and finally the fear of those facts which would seem to threaten the established routine of men's lives « (Lippmann, 1965: 18).

Mit diesen Überlegungen, die bis heute wohl den harten Kern der Überzeugungen von Vertretern einer realistischen Demokratietheorie umschreiben, leitet Lippmann direkt zu seinem zweiten Punkt über, der Frage nämlich, ob die öffentliche Meinung diese im individuellen Weltbild entstehenden Lücken schließen könnte. Auch hier ist seine Antwort unzweideutig: während Demokraten das Problem des begrenzten Wissens des Staatsbürgers schon theoretisch nie befriedigend lösen konnten, verließen sie sich in der Praxis allzu sehr auf die Zeitungen, die die Aufgabe übernehmen sollten, den Bürger in Kontakt zu einer für ihn unsichtbaren und unverständlichen, aber doch relevanten Welt zu bringen. Dieser Erwartung stünden jedoch letztlich sowohl ökonomische Zwänge, die, vermittelt über das für die Erhaltung von Zeitungen notwendige Anzeigenaufkommen, direkt an der Nachrichtenselektion und -gestaltung angreifen und 
eine wahrheitsgetreue Berichterstattung wo nicht unterminieren, so doch erschweren, als auch der extrem ereignisabhängige Charakter einer Nachricht selber entgegen (vgl. Westbrook, 1991: 297). Deshalb sieht sich Lippmann schließlich genötigt, die Erzeugung funktional notwendigen Wissens allein sozialwissenschaftlichen Experten zu überlassen, die in interesseloser Einstellung die Tatsachen finden und formulieren, die in die Entscheidungen der politisch Verantwortlichen eingehen und die notwendige Rationalität politischer Entscheidungung verbürgen sollen. Während Lippmann diesen szientifischen Optimismus durchaus mit Dewey teilt und für diesen gerade dadurch zu einer Herausforderung wird, möchte er, anders als Dewey, die öffentliche Willensbildung der Staatsbürger durch die Organisation von sozialwissenschaftlicher Intelligenz im wesentlichen substituieren: Der Zweck von Expertise ist es dann nicht mehr, »to burden every citizen with expert opinion on all questions, but to push that burden away from him towards the responsible administrator...(and) the broad principles on which the action of the public can be continous are essentially principles of procedure « (Lippmann, 1965: 250 f.).

a) Gegenüber diesem emphatischen Plädoyer für ein elitistisches Modell der repräsentativen Demokratie kann Dewey sein Ideal der partizipatorischen Demokratie nur behaupten (und gerade das verbürgt auch die Aktualität seiner Überlegungen), wenn er von vornherein die Erzeugung anspruchsvollen, relevanten Wissens als einen interaktiven Prozeß der kollektiven Problemlösung sichtbar machen kann; wenn er Strukturen von Öffentlichkeit identifizieren kann, die sich weitgehend unabhängig von massenmedialen Vermittlungsagenturen einrichten lassen, und wenn er schließlich plausibel machen kann, daß die Bedingungen der Erzeugung handlungsrelevanten politischen Wissens die Demokratisierung von Expertise selber nahelegen. Das ist nun im Kern die

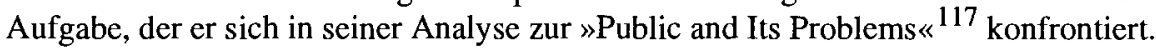
Den Ausgangspunkt dieses weitgespannten Unternehmens bildet dabei die Frage, wie sich die überkommene republikanische Tradition lokaler Demokratie auf die Effekte einstellen könnte, die sich aus der fortschreitenden Industrialisierung für die Gesellschaft insgesamt und die Formen ihrer politischen Vermittlung im besonderen ergeben. Er war überzeugt (und darin folgen ihm seine kommunitaristischen Nachfolger im wesentlichen: vgl. etwa Bellah et al., 1991), daß die einzig erfolgversprechende Remedur der individualistischen und liberalen Reduktion der Bedeutung von Demokratie in der Transformation der »Great Society « in die »Great Community« (325) liege. Dieses Argument führt er dann im wesentlichen in vier Schritten durch.

Er beginnt mit einer handlungstheoretischen Reformulierung des Konzepts des Staates, um den Begriff des Staates von dessen teleologischen und metaphysischen Konnotationen zu entlasten und zu zeigen, in welchem Sinne der Staat als Produkt der kooperativen Aktivitäten gesellschaftlicher Akteure aufgefaßt und sichtbar gemacht werden kann. Der Kern dieses Arguments, das dann die ganze weitere Diskussion bestimmt, ist die These, daß »human acts have consequences upon others, that some of these consequences are perceived, and that their perception leads to subsequent effort

117 Die folgenden Seitenangaben (in Klammern) beziehen sich alle auf Dewey (1984). 
to control action so as to secure some consequences and to avoid others « (243). Diese These hat nun ihrerseits zwei Konsequenzen. Die eine ist seine Folgerung, daß von politischer Öffentlichkeit im eigentlichen Sinne erst dann gesprochen werden kann, wenn sie ein Bewußtsein ihrer selbst als ein Ganzes ausbildet und ihre Aufmerksamkeit auch auf solche Handlungsfolgen richtet, deren Wirkung sich auch aktuell nicht Beteiligten mitteilt (243f.), und wenn sie darüberhinaus Kriterien und Mittel der Bearbeitung dieser Handlungsfolgen institutionalisiert (249); die andere ist, daß dies in dem Maße drängender wird, in dem das soziale Komplexitätsniveau durch die sich beschleunigende Individualisierung und die Verbreitung unpersönlicher und i.S. Durkheims mechanischer Formen der sozialen Integration gesteigert wird. Von diesem Ausgangspunkt her ist er dann zweitens in der Lage, die Beziehung zwischen Öffentlichkeit, Staat und Regierung in der Weise zu rekonzeptualisieren, daß der Staat nurmehr als eine »sekundäre Assoziationsform« (279) erscheint, die es der Öffentlichkeit ermöglicht, auf sich selbst als ganze über das institutionelle Mittel der Regierung einzuwirken. Drittens legt er sich dann die Frage vor, weshalb das allgemeine Phänomen der »invasion of community by the new and relatively impersonal and mechanical modes of combined human behavior « - i.e. das Maschinenzeitalter, das ihm als die Signatur des Zeitalters schlechthin gilt (296) - zunehmend ausgerechnet mit den Mitteln einer individualistischen Philosophie reflektiert wird: die Antwort findet er in der Erschließung menschlicher Kräfte, die sich, verbunden mit dem Ideal einer demokratischen Öffentlichkeit, zu einer kreativen menschlichen Praxis entfalten könnten. Erst gegen diesen Hintergrund kann er schließlich die Entwicklungen absetzen und sichtbar machen, die sich der Entfaltung einer demokratischen Öffentlichkeit entgegenstellen - und dabei rücken Phänomene der technokratischen und szientistischen Entfremdung von Politik in den Vordergrund (312 f.).

Der Staat ist also die Form, in der die Öffentlichkeit ein Bewußtsein ihrer selbst zum Ausdruck bringen kann und in der sie sich eine handlungsfähige Gestalt gibt; und die Öffentlichkeit ist definiert als all jene, die von den indirekten Konsequenzen von Transaktionen in einem Maße betroffen sind, das es nahelegt, sich um diese Konsequenzen in systematischer Weise zu kümmern. Durch diese interne Relationierung des institutionellen Systems der Regierung mit gesellschaftlichen Praktiken und Verkehrsformen, auf deren Integration jenes berechnet ist, gelingt es Dewey, die Vorstellung vom Staat zu historisieren und zu dynamisieren, insofern sich die $\gg$ Regierungsmaschine « stets von neuem auf die gesellschaftlichen Entwicklungen einzustellen hat, wie sie u.a. durch das Industriesystem und technologische Entwicklungen ausgelöst werden (254). Daraus resultieren aber auch Probleme, die zum einen in der Logik der Selbstadaptation politischer Institutionen begründet liegen, zum anderen darin, daß die Öffentlichkeit als Insgesamt der von der Entwicklung neuer gesellschaftlicher Formen der Arbeitsteilung und Kooperation Betroffenen zunächst nur einen virtuellen Status hat, sich also allererst zu beschreiben und ihre potentiellen Interessen zu definieren hat: "The new public which is generated remains long inchoate, unorganized, because it cannot use inherited political agencies. The latter, if elaborate and well institutionalized, obstruct the organization of the new public. They prevent that development of new forms of the state which might grew up rapidly were social life more fluid, less 
precipitated into set political and legal molds. To form itself, the public has to break existing political forms. This is hard to do because these forms are themselves the regular means of instituting change $(254 \mathrm{f}$.).

Dieses Moment institutioneller Beharrung ist zunächst eine Erklärung dafür, weshalb historisch ein Wandel von Staatsformen häufig nur auf dem Wege von Revolutionen zu bewirken war. Es enthält aber auch bereits den Grund dafür, daß Dewey den unabschließbaren experimentellen Prozeß der ständigen Neuerfindung des Staates (256) in die Regie von Betroffenen stellen möchte, die mit der Unterstützung von politischer Philosophie und Wissenschaft für eine Verstetigung dieses Prozesses aus praktischen Handlungszusammenhängen heraus Sorge tragen können, wenn methodisch angeleitete Beobachtungen der Bedingungen und Folgen ihres Handelns das Experimentierverhalten weniger blind, weniger zufallsgesteuert und somit intelligenter gestalten (257). Von daher rückt das Zusammenspiel von sozialwissenschaftlicher Expertise und allgemeiner Öffentlichkeit im Prozeß der öffentlichen Selbstaufklärung in den Mittelpunkt seines Interesses, zumal, wie er einräumt, »the machine age has so enormously expanded, multiplied, intensified and complicated the scope of indirect consequences, has formed such immense and consolidated unions in action, on an impersonal rather than a community basis, that the resultant public cannot identify and distinguish itself...The problem of a democratically organized public is primarily and essentially an intellectual problem, in a degree to which the political affairs of prior ages offer no parallel « (314). Diese Zustandsbeschreibung einer demokratischen Öffentlichkeit des Industriezeitalters im Werden ist zugleich sein wesentliches Argument gegen die empirischen Grundlagen der realistischen Demokratietheorie und die elitistischen Folgerungen, die sie aus ihren Momentaufnahmen zum Wählerverhalten gewinnen: sie beziehen sich eben auf eine noch unorganisierte Öffentlichkeit, die ihre neuen Artikulationsformen noch nicht gefunden hat und spiegeln insoweit lediglich die Spannungen, in die das überkommene System politischer Institutionen gegenüber einer sich rapide verändernden gesellschaftlichen Handlungsbasis geraten ist (318 und 320). Sie nötigt ihn aber andererseits auch, Wege aufzuzeigen, auf denen sich die Öffentlichkeit erneut als handlungsfähiger politischer Akteur konstituieren kann.

Der Bewältigung dieser Aufgabe dienen nun der dritte und vierte oben angedeutete Argumentationsschritt, in denen er zwei Probleme zugleich angehen muß: die Transformation der »Great Society « in die »Great Community « verlangt die Lösung des Problems des Wissens auf eine Weise, die die Aufspaltung der Öffentlichkeit in Experten und ein mediatisiertes Laienpublikum verhindert; und sie macht eine Neudefinition jener fokalen Interaktionstrukturen, wie sie früher lokal definierte Gemeinschaften bereithielten, erforderlich. Der Lösung des ersten Problems widmet er sich mit einiger Ausführlichkeit. Zu diesem Zweck kritisiert er den vorherrschenden individualistischen Wissensbegriff, der von der Vorstellung ausgeht, daß »each individual is of himself equipped with the intelligence needed, under the operation of self-interest, to engage in political affairs, and that general suffrage, frequent elections of officials and majority rule are sufficient to ensure the responsibility of elected rulers to the desires and interests of the public« (334). Dieser Vorstellung, die aus sich heraus die im Gegenzug von den »Realisten« heftig attackierte Omnikompetenzvorstellung des Bürgers 
erst erzeugt, setzt er seinen intersubjektiven Begriff des Wissens als einer Funktion von Assoziation und Kommunikation entgegen (ebda.), um von daher dann die elitäre Aufspaltung der Staatsbürger in (wissenschaftliche) Experten und Laien, die für ihn das drängenste Problem des demokratischen Staates darstellt, aufzugreifen.

Die Diskussion dieser Frage eröffnet er dann mit einer eher rhetorischen Feststellung: »The important governmental affairs «, so notiert er, »are also technically complicated matters to be conducted properly by experts. And if at present people are not educated to the recognition of the importance of finding experts and of entrusting administration to them, it may plausibly be asserted that the prime obstruction lies in the superstitious belief that there is a public concerned to determine the formation and execution of general social policies « (312). Faktisch gibt er diesem technokratischen und elitistischen Einwand gegen die Möglichkeit von Demokratie nur Raum, um es dadurch zurückzuweisen, daß er zeigt, daß es selber auf zwei Bedingungen aufruht, die solange nicht erfüllt sein können, wie man Experten dem staatsbürgerlichen Publikum bloß gegenüberstellt - daß nämlich Expertenpolitik grundsätzlich weise und wohlwollend ist. Interessant ist nun der Grund, den er dafür angibt, daß diese Bedingungen unter den charakterisierten Umständen gar nicht erfüllt sein können. Er liegt nicht primär im Eigeninteresse der Experten, und auch nicht in ihrer Verführbarkeit oder Manipulierbarkeit - dies gewiß auch. Entscheidend ist für ihn vielmehr, und hier bringt sich der grundlegend demokratische Charakter des pragmatistischen Denkens zur Geltung, daß es so etwas wie einen eingebauten Mechanismus der Selbstentwertung von Expertise gibt, die sich von dem Wissen und den Bedürfnissen derjenigen abschneidet, denen sie dienen soll (364). Darüberhinaus zeigt er, daß die Artikulation von Bedürfnissen bereits in der Formierung adäquaten Wissens aus dem Grund eine irreduzible Rolle spielt, daß die Definition dessen, was als angemessenes Wissen zu gelten hat, ohne den Bezug auf die zu lösenden Handlungsprobleme gar nicht möglich erscheint. Dieses Argument führt ihn schließlich zu der Schlußfolgerung, daß wissenschaftliche Expertise und demokratische Öffentlichkeit in der Erzeugung und Distribution relevanten Wissens zur Lösung gemeinsamer Probleme eng verzahnt bleiben müssen (344). In diesem Licht erweist sich dann umgekehrt, daß eine Verbesserung der Qualität der Politik ohne eine Verbesserung der Methoden und Bedingungen öffentlicher Debatten und Diskussionen nicht zu haben sein dürfte - und diese Verbesserung »... is the problem of the public (Herv. i. O.) « (365).

Der entscheidende Schritt, den Dewey hier unternimmt, um aus der demokratietheoretischen Falle einer Disjunktion von >Wahrheit< und >Politik < herauszukommen, besteht also darin, daß er erstens Politik primär im Horizont problemlösungsbezogener, materialer Politiken konzeptualisiert; daß er zweitens die objektivistischen Selbsttäuschungen eines szientifischen Wissens- und Wissenschaftsverständnisses unterläuft, indem er vor allem auf den praktischen Erzeugungszusammenhang relevanten Wissens abstellt und so drittens Wissenschaft wie Politik als rationale, über die Mechanismen diskursiver Verständigung regulierte Praktiken rekonstruiert und füreinander öffnet. Dabei erweist sich das pragmatistische Prinzip der Problemlösung als entscheidendes Gelenkstiick, über das die wissenschaftliche wie politische Praxis mit einer nun allerdings: schwachen - teleologischen Struktur versorgt und der Rationalitätsbe- 
griff aus der demokratietheoretisch gleichermaßen nicht adaptierbaren Gegenüberstellung von szientifischem Reduktionismus einerseits und kognitivem und moralischem Skeptizismus und Relativismus andererseits herausgeführt wird. Allerdings bleibt das zweite oben genannte Problem, das der Neudefinition von fokalen Strukturen, an die sich eine im Medium von Argumentation und in face-to-face Interaktionen sich bildende und artikulierende Öffentlichkeit effektiv ankristallisieren kann, weitgehend ungeklärt, obwohl die pragmatischen Bezugspunkte seines Denkens wenigstens in die Richtung deuten, in der entsprechende Ansätze gefunden werden könnten. Hier kommt man schon einen wichtigen Schritt weiter, wenn man zunächst auf einen Operationalisierungsvorschlag zurückgreift, mit dem Dahl seine Vorstellung einer $»$ dritten demokratischen Transformation « umzusetzen sucht.

b) Die wesentliche Aufgabe, der sich die moderne Demokratie so gegenübersieht, wenn sie mit institutionellen und edukativen Mitteln der Entfaltung von spezifischen Ungleichheitsrelationen, die das demokratische Prinzip zu unterminieren drohen, entgegenwirken will, stilisiert Dahl noch einmal am evolutionären Übergang zwischen drei Modellen der Polyarchie (Dahl, 1989: 336, 338 f.). Während mit der Anwendung der Idee demokratischer Selbstbestimmung auf die Regierung eines nationalen Flächenstaates das Prinzip der Versammlungsdemokratie schon von differenzierteren polyarchischen Institutionen abgelöst werden mußte, konnten auf dieser frühen Stufe der »Polyarchie I« die wesentlichen politischen Entscheidungen noch im Zusammenspiel von (Wahl-) Bürgern und politischen Repräsentanten getroffen werden, ohne auf die Leistungen eines ausdifferenzierten und spezialisierten administrativen Apparates zurückgreifen zu müssen. Diese Konstellation ändert sich entscheidend in dem Maße, wie im Zuge der Entwicklung der Gesellschaft und der zunehmenden Internationalisierung der Politik nicht nur die Zahl der politisch zu bearbeitenden Probleme wuchs, sondern sich auch die interne Komplexität der einzelnen Politiken rasch steigerte. In dieser Situation wird nunmehr eine zusätzliche Erschließung von Rationalitätsressourcen notwendig, aus denen sich die Politik zu Zwecken einer angemessenen Entscheidungsfindung zu versorgen hat - die Verwaltung übernimmt jetzt auch die Funktion der Mobilisierung spezialisierter Intelligenz und Kompetenz. Wenn dieses bürokratische Modell der »Polyarchie II im ganzen recht erfolgreich war, so hatte es doch auch eine weitgehende Mediatisierung wenn nicht schon der politischen Repräsentanten, so doch der breiteren Öffentlichkeit der Staatsbürger zur Folge: die $»$ Polyarchie III « resultiert dann aus dem Versuch, diese Lücke zwischen Experten und Laien dadurch zu schlieBen, daß Institutionen geschaffen werden, die eine gewisse Gewähr für effektive Teilhabeansprüche auf der Ebene der Formulierung und Implementierung einzelner Politiken bieten und die andererseits für eine entsprechende Ausbildung der staatsbürgerlichen Kompetenz sorgen.

Mit dieser Zuspitzung signalisiert Dahl bereits, daß es ihm nicht primär um Modifikationen am Institutionengefüge der liberalen Demokratic in ihrer indirekten, repräsentativen Form geht, sondern daß es ihm um die Verbesserung der Entfaltungsbedingungen einer im Kern deliberativen politischen (Alltags-) Praxis geht. Darauf sind dann sowohl seine Kriterien zur Bestimmung eines demokratischen Prozesses wie sei- 
ne Vorstellungen zur Lösung des drängenden Kompetenzproblems berechnet. Zunächst beschreibt er die Struktur eines politischen Entscheidungsprozesses, der die Prinzipien der individuellen Autonomie, der kollektiven Selbstbestimmung und der politischen Gleichheit (Dahl, 1989: $97 \mathrm{ff}$.) gleichermaßen erfüllen kann und somit im gleichen Interesse aller liegt, nach vier Gesichtspunkten. Danach muß (i) die Inklusion und effektive Partizipation der Betroffenen gewährleistet werden: »Throughout the process of making decisions, citizens ought to have the opportunity, and an equal opportunity, for expressing their preferences as to the final outcome. They must have adequate and equal opportunities for placing questions on the agenda and for expressing reasons for endorsing one outcome rather than another « (Dahl, 1989: 109). Insofern aber partizipationsoffene Strukturen durch die sozial ungleiche Streuung von materiellen und kognitiven Teilhabevoraussetzungen in der Regel eine eigene Selektivität erzeugen, ist (ii) politische Gleichheit dadurch sicherzustellen, daß »at the decisive stage of collective decisions, each citizen must be ensured an equal opportunity to express a choice that will be counted as equal in weight to the choice expressed by any other citizen. In determining outcomes at the decisive stage, these choices, and only these choices, must be taken into account « (ebda.). Interessant und innovativ ist an dieser Stelle aber, daß er durch diese Maßgabe den Politikprozeß weder auf allen Stufen noch hinsichtlich der Konstitution des jeweils relevanten Demos oder der Wahl der Entscheidungsregeln präjudizieren möchte: vielmehr schreibt er dem Prinzip der allgemeinen und gleichen Wahl oder Abstimmung insofern eine reflexive Struktur ein, als der Demos auch über die relative Gewichtung von Individual- oder Gruppeninteressen auf den vorgängigen Stufen des Entscheidungsprozesses entscheiden, daß er bestimmte Entscheidungen delegieren und schließlich auch über die Entscheidungsregeln selber disponieren kann (Dahl, 1989: 110).

Darüber hinaus muß das allgemeine demokratische Entscheidungsverfahren (iii) gewährleisten, daß alle Beteiligten im Lichte hinreichender Informationen und guter Gründe ein aufgeklärtes Verständnis der regelungsbedürftigen Sachfragen und der involvierten Interessen ausbilden können (Dahl, 1989: 112; vgl. auch Habermas, 1992: 383) und entsprechend (iv) die Agendahoheit verantwortlich wahrnehmen können: "The demos must have the exclusive opportunity to decide how matters are to be placed on the agenda of matters that are to be decided by means of the democratic process « (Dahl, 1989: 113). Diese Prinzipien, in denen sich die Idee der Volkssouveränität ihre Gestalt gibt, sind nun aufgrund vor allem der Veränderung der Reichweite und der internen Komplexität einzelner Politiken (vgl. dazu Dahl, 1992: 49 ff.) zweifellos erheblichen Belastungen ausgesetzt, auf die der Demos zum einen dadurch reagieren kann, daß er sich selber gleichsam unter den autopaternalistischen Vorbehalt stellt, nicht zu jeder Zeit und nicht zu jedem Thema die faktische Entscheidung an sich ziehen zu müssen (vgl. Offe, 1992: 141). Gefordert ist nicht die umfassende Kompetenz in allen Sachfragen, sondern vielmehr die reflexive Kompetenz, sich fallweise über die Grenzen der eigenen Leistungsfähigkeit und Zuständigkeit aufzuklären: »Thus the criterion of final control does not presuppose a judgment that the demos is qualified to decide every question requiring a binding decision. It does presuppose a judgment that the demos is qualified to decide (1) which matters do or do not require binding deci- 
sions, (2) of those that do, which matters the demos is qualified to decide for itself, and (3) the terms on which the demos delegates authority « (Dahl, 1989: 114).

Mit dieser Fassung des Prinzips der Volkssouveränität, das nicht mehr den omnikompetenten Bürger, sondern einen »good-enough or adequate citizen « (Dahl, 1992: 48) voraussetzt, kann Dahl, wie ich meine, den realistischen Einwänden, mit denen sich schon Dewey auseinandersetzen mußte, besser als dieser entgegentreten. Andererseits, und das ist entscheidend, zieht sich die Volkssouveränität nicht in die rationale Struktur ausdifferenzierter und reflexiv aufeinander bezogener Verfahren des gewaltenteiligen, liberalen Rechtsstaates allein zurück. Vielmehr soll sie sich, gestützt durch ihre reflexive Struktur, auch im Inneren solcher Verfahren, in der Lösung kognitiv anspruchsvoller Probleme und der Entscheidung von Sachfragen, zur Geltung bringen. Das setzt nun aber, in Ergänzung der Prinzipien des demokratischen Verfahrens, eine Verbesserung der Meinungserwerbs-, Artikulations- und Durchsetzungschancen der allgemeinen oder sich fallweise um einzelne Politiken herum konstituierenden Öffentlichkeiten voraus - diesem Ziel dient Dahl's Rückgriff auf die technischen Möglichkeiten der interaktiven Telekommunikation. Zweitens braucht gerade eine als deliberative Praxis rekonstruierte Politik einen konkreten Ort, an dem sie sich in engem Kontakt zu den zu lösenden Problemen und mit einer hinreichenden, institutionell zu verbürgenden Wirkungschance, entfalten kann. In diesem Zusammenhang zieht er zum einen die Erweiterung der politischen zu einer sozialen Demokratie in Betracht und erörtert die Chancen und Bedingungen innerbetrieblicher Demokratie (Dahl, 1985 und 1987: 195 ff.). Zum anderen plädiert er dafür, die Chancen zu nutzen, die sich aus einer weitergehenden Dezentralisierung der Politik für die Verbesserung der Bürgerpartizipation ergeben (Dahl, 1992: 55) und macht schließlich einen Vorschlag, wie bezüglich lokale Horizonte übergreifender allgemeiner oder politikbereichsspezifischer Fragen auf der nationalen Ebene die Partizipationschancen durch die Einrichtung von Bürgerforen im Sinne eines »Minipopulus « verbessert werden können (Dahl, 1987: 205 f. und 1989: 340 f.).

Die interaktive Telekommunikation soll die Öffentlichkeit von den Unzulänglichkeiten ihrer massenmedial geprägten Infrastruktur unabhängiger machen und das notwendige Zusammenspiel von wissenschaftlicher Expertise und einer breiteren Meinungsund Willensbildung verbessern. Gestützt auf die Arbeit unabhängiger wissenschaftlicher Beratergremien könnte sich dieser Prozeß grob in zwei Schritten vollziehen: $\mathrm{Zu}$ nächst kann man sich durch die Anwahl eines menügesteuerten Informationskanals Informationen über die relative Bedeutung einzelner politischen Fragen besorgen, wie sie sich etwa in der Sicht einer Zufallsauswahl von Bürgern, nach sozialen Kriterien des Berufs, des Einkommens, der Ausbildung, des Geschlechts oder der Ethnizität spezifizierten Sichtweisen oder in der Optik wissenschaftlicher Experten darstellen; vor diesem Hintergrund, der zunächst wichtige Auskünfte über Interessenlagen und -konflikte bereithält, können dann in einem zweiten Schritt genauere, nach Niveau und Form differenzierte Sachinformationen abgerufen werden (Dahl, 1987: $204 \mathrm{f}$.).

Ohne auf diese Idee hier genauer einzugehen, lassen sich doch zwei wesentliche Schwachstellen eines solchen Modells sowohl auf der Eingabeseite als auch auf der Empfängerseite ausmachen: die demokratische Kontrolle der Expertise einerseits und die Privatisierung der Informationsaufnahme und -verarbeitung andererseits. Beides 
steht den Erwartungen und Ansprüchen an eine deliberative Politik, die sich gerade über das Wechselspiel von Argumenten in face-to-face Interaktionen reproduziert, eher entgegen. Aus diesen Gründen muß die erweiterte Nutzung technischer Möglichkeiten in deliberative Kontexte eingebettet bleiben, die themenfokussierte Interaktionen unter Anwesenden tatsächlich ermöglichen - diesem Zweck könnte die Einrichtung von »Minipopuli«, Bürgerforen oder »citizen juries « auf den unterschiedlichen Ebenen der Politik parallel zu den klassischen Vermittlungs- (Parteien) und Entscheidungsinstitutionen (Parlament) dienen. 118

Diese Verfahrensvorschläge, die auf der Diagnose beruhen, daß das Problem des Wissens und die Behinderung des demokratischen Prozesses durch die Entstehung "paternalistischer Wissensmonopole « (Habermas) zum entscheidenden Engpaß werden, durch den das Projekt der Demokratie hindurchgeführt werden muß, sind $\mathrm{m}$. E. schon ein Schritt in die richtige Richtung. Aber sie geben den Innovationsperspektiven, die sich im Lichte dieser Diagnose einstellen, noch keine befriedigende Fassung. Dazu bedarf es vielmehr einer anderen Einstellung der Optik weg von den übergreifenden, allgemeinen Strukturen der demokratischen Polity hin auf die kapilaren Ströme alltäglicher Politik (policies). Der Vorteil dieses Perspektivenwechsels liegt u.a. darin, daß Fragen des Designs wie der Implementation materialer Politiken und die sich in diesem Zusammenhang ausbildenden Strukturen einer horizontalen Kooperation staatlicher und unterschiedlicher gesellschaftlicher Akteure etwa in Bereichen der Umwelt-, Technologie-, Sozial- oder Gesundheitspolitik häufig genug querliegen zur Logik eines hierarchisch gestuften Modells staatlicher Politik. Sie bilden so gerade wegen ihres vielfach selbstsektorierenden und selbstformatierenden Charakters einen wichtigen weiteren Fokus für die Bündelung demokratischer Energien und die Effektuierung von allgemeinen Teilhabeansprüchen.

\subsection{Policy-Analyse als Demokratiewissenschaft}

Freilich haben wir schon bei Dewey gesehen, daß sich die Lösung des Problems des Wissens, der staatsbürgerlichen Kompetenz und der Verschränkung von wissenschaftlicher Expertise mit dem Prozeß der argumentativen Selbstaufklärung und Selbstbestimmung einer breiteren Öffentlichkeit vor dem Hintergrund eines objektivistischen Wissenschaftsverständnisses und einer rein instrumentellen Auslegung der Rationalität des Handelns (vgl. Dryzek, 1993) kaum erreichen läßt. Das hängt einerseits mit der von einem solchen (Miß)Verständnis der politischen Rolle und Funktion von Wissen vorangetriebenen Entfremdung zwischen Experten und »Laien « zusammen, die dann eine Kommunikationsschwelle errichtet, die durch Forderungen nach gleichberechtigter Teilhabe anschließend nur noch schwer zu überwinden ist. Andererseits weist ein positivistisches Modell politischer Problemlösung gerade dann auch immanente Schwächen und Mängel auf, wenn es einem besonderen Typus von heiklen ( $»$ wicked «) Problemen konfrontiert wird (vgl. Fischer, 1993: 456 ff.). Diese Sorte von Problemen unterscheidet sich von

118 Vgl. Dahl (1987: 205 f.; 1989: 340 f. und 1992: 54 ff.) 
»leichten« Problemen grundsätzlich dadurch, daß sie nicht vorwiegend technischer Natur sind, sich deshalb auch nicht für eindeutige und schlüssige Definitionen und Umschreibungen eignen und dementsprechend keine klaren Kriterien enthalten, an Hand derer Lösungen beurteilt werden könnten. Sie zeichnen sich vielmehr durch eine enge Verzahnung von Problemdefinition und Problemlösung aus, wobei die Problematik der Definition eines Problems aus der irreduziblen Verschränkung von normativen Kriterien (Ziele, Standards, Regeln etc.) und empirischen Situationen und Bedingungen resultiert - kurz: »Ein Problem ist nicht ein Faktum, das durch die Außenwelt gesetzt wird; vielmehr ist es ein soziales Konstrukt. Ein Policy-Problem impliziert daher erstens eine Diskrepanz zwischen einem Standard und einer empirischen Situation; zweitens ist weder der Standard noch die Situation - und daher rührt die Diskrepanz - als eine objektive Gegebenheit zu begreifen, die außerhalb der sozialen Akteure liegt « (Fischer, 1993: 457). ${ }^{119}$ Damit ist eine Spur gelegt, die schließlich zu einer Neukonzeptualisierung der Policy-Analyse als Demokratiewissenschaft führt, ${ }^{120}$ in der sich »epistemische « Überlegungen zur argumentativen Wende des Policy-Prozesses (a) mit einem Wandel des Funktions- und Formverständnisses politischer Öffentlichkeiten (b) verbinden.

a) Von der irreduziblen Verschränkung normativer und sachlicher Fragen mit der strategischen Ausgangslage beteiligter Akteure und deren Interessen kann die Stellung wissenschaftlicher Experten und der Geltungsanspruch methodisch erzeugten, wissenschaftlichen Wissens im Policy-Prozeß grundsätzlich nicht unberührt bleiben. Vielmehr drängt sich in einer soziologischen und politikwissenschaftlichen Perspektive ein Problem auf, das Saretzki mit Blick auf Fragen der Technikfolgenabschätzung und Risikoimplementation folgendermaßen formuliert: »Unter welchen sozialen und institutionellen Bedingung erhält das wissenschaftliche >Berechenbarkeitsproblem lenwert für die politische Konfliktregelung bei kontroversen Technologien? Dies scheint in erster Linie dann der Fall zu sein, wenn die wissenschaftliche Risikoanalyse und die damit beauftragten Experten selbst zugleich eine zentrale Bedeutung und institutionell fixierte Funktion für die Risikoregulation haben. Damit wären aus einer sozialwissenschaftlichen Perspektive aber zunächst einmal die Strukturen und Prozesse näher zu untersuchen,

119 Ein deutliches Indiz für die damit verbundenen Schwierigkeiten bildet das Nimby (Not in my backyard)-Syndrom, das sich immer mehr als zentrales Hindernis für die Lösung einer wachsenden Zahl von Umweltproblemen herausstellt (vgl. Fischer, 1993: $458 \mathrm{ff}$.). Dieser Einsicht in die konstruktivistische Natur sozialer und politischer Probleme scheint mittlerweile auch die Politikwissenschaft mit einer Profilierung interpretativer Ansätze in der Policy-Forschung entgegenzukommen (vgl. Nullmeier, 1994), ein Vorgehen, das sich nicht nur in der Analyse umweltpolitischer Prozesse, sondern auch im Bereich der Sozialpolitik zu bewähren scheint (vgl. Nullmeier/Rüb, 1993). Die Pointe dieser Entwicklung liegt dann nach Ansicht vieler Beobachter darin, daß die Antwort auf dieses Problem in einer argumentativen Wende der Policy-Praktiken bestehen könnte (vgl. Fischer/Forester, 1993), über die schließlich Forderungen nach einer weitergehenden Demokratisierung des PolicyZyklus von Problemdefinition, -lösung, Politikimplementation und Kontrolle vermittelt sind.

$120 \mathrm{Vgl}$. auch Héritier (1993: 21 f.). Dieses Programm einer Policy-Analyse als Demokratiewissenschaft wird vor allem verfolgt in Fischer/Forester (1993) und Dryzek/Torgerson (1993). 
die dazu führen, daß (nicht beliebige, sondern meist bestimmte) Expertengruppen die Definitionsgewalt über angemessene Risikobewertung und Risikoregulation zugewiesen bekommen oder sich aktiv aneignen können « (Saretzki, 1993: 11). In dem Maße, in dem man dieser Empfehlung folgt (und gestützt auf eine zumindest gesellschaftlich wirkungsvolle Selbst-Dementierung des absoluten Geltungsanspruchs wissenschaftlich-objektiven Wissens über die vielzitierten »Expertenstreite «) wird auch die Annahme fragwürdig, daß die bessere wissenschaftliche Beschreibung eines Problems auch zu einer besseren Politik führt: und dies, weil erstens selbst eine erfolgreiche wissenschaftliche Reduzierung von Unsicherheit nicht automatisch auch zu einer Konfliktreduzierung führt; weil zweitens unter Bedingungen einer hohen gesellschaftlichen Polarisierung und eines adverserialen politischen Regulierungsmodus auch die wissenschaftliche Expertise unvermeidlich polarisiert wird; weil es drittens unter diesen Bedingungen von wissenschaftlicher Unsicherheit einerseits und politischem Entscheidungsdruck andererseits zu einer erzwungenen Ehe zwischen Wissenschaft und Politik kommt, in der Expertise auch ihre Eigenständigkeit und Unabhängigkeit, die zur Untermauerung der erhobenen Geltungsansprüche eingesetzt werden könnten, preisgeben muß (vgl. Jasanoff, 1990: 7 ff.).

Auf diese Phänomene hat Nullmeier jüngst mit der These reagiert, daß man, um Politikprozesse und -ergebnisse angemessen erklären zu können, verstärkt auf Wissenssysteme und Deutungskonflikte zwischen unterschiedlichen Wissensarten im jeweiligen Handlungskontext rekurrieren muß. Wissen wird in der intimen Verschränkung mit politischen Prozessen der Wissenserzeugung variabel, "wählbar«: »Mit dieser Verschiebung des Wissens in den Bereich des Intentionalen und Entscheidbaren muß sich der Prozeß $\beta$ der Handlungserklärung verändem: er wird dreistufig. Auf einer ersten Stufe findet die Filterung jener Präferenzen, Kriterien und Wissenssysteme statt, die die Auswahl oder Akzeptanz eines handlungsrelevanten Wissens steuern. Die zweite Stufe erfaßt die Filterungsprozesse der als legitim erachteten Deutungen über Situation, Handlungsalternativen, Präferenzen und Normen (Deutungswahl), bevor auf einer dritten Stufe die Festlegung auf genau eine Handlungsalternative erfolgt (Handlungswahl)« (Nullmeier, 1993: 186). Damit erfaßt Nullmeier zweifellos bedeutsame Aspekte des Prozesses der Politisierung von Expertise und eröffnet somit auch Perspektiven für einen bewußten, konstruktiven Umgang mit der einhergehenden Kontingenzerfahrung. Gleichwohl unterscheidet er nicht genau genug zwischen der Entwertung des absoluten Geltungsanspruchs eines auf seine soziale und politische Erzeugung hin durchsichtig gemachten Wissens einerseits und den Geltungsansprüchen, die auch in den sozialen ProzeB der Erzeugung von Argumenten eingelassen bleiben. Durch diese Fixierung überspielt er für sich genommen weniger problematische Konflikte, die durch die Konkurrenz unterschiedlicher Tatsachenbehauptungen einerseits oder durch konkurrierende Geltungsansprüche (Wahrheit, normative Richtigkeit u.a.) erzeugt werden. Dadurch vergibt er m.E. die Chance eines rationalen Umgangs mit Problemen der Deutungs- und Handlungswahl, so daß ihm schließlich nur der Rekurs auf Rhetorik bleibt, die er zwar von dem Verdacht einer bloß manipulativen Kunstlehre befreien möchte, die aber auch in seiner auf Aristoteles zurückgreifenden Fassung lediglich das sozial vermittelnde Gegenstück der Dialektik, zum Arsenal »metaphorischen Wissens « also, bildet (Nullmeier, 1993: 187 ff.). 
Vor allem kann er aus dieser relativistischen Position heraus kaum die Bedingungen aufklären, unter denen Akteure in dem Versuch der Lösung von Interaktionskonflikten einen pragmatischen Gebrauch von kontroversen, aber eben einlösbaren Geltungsansprüchen machen. Vor diesem Hintergrund wird eine ganz andere Lösung für eine auf das Problem der Politisierung von Expertise reagierende Expertisepolitik interessant, wie sie Fischer (1990) vorgeschlagen hat. Er ist vor dem Hintergrund einer Fallstudie zum »Head Start«-Programm, einem Modellversuch der kompensatorischen Erziehung benachteiligter Kinder in den USA, entstanden und war ursprünglich zur Verbesserung des methodischen Arsenals einer emanzipatorischen "policy science of democracy « (Lasswell, 1951) gedacht. ${ }^{121}$ Das Projekt wurde Mitte der sechziger Jahre gestartet und wurde im Rahmen des »War on Poverty « zunächst von hohen Erwartungen begleitet. Diese schienen alsbald im Lichte wissenschaftlicher Begleitstudien, die einen kompletten Fehlschlag des Programms nachweisen zu können glaubten, korrigiert werden zu müssen. In diesem Sinne hatte auch Richard Nixon die Studie als Beleg seiner politischen Ziele verstanden und aufgenommen. Was darauf tatsächlich folgte, war eine intensive öffentliche Debatte, in deren Verlauf dann entweder die Evidenz der von der Studie beigebrachten Daten in Frage gestellt oder darauf verwiesen wurde, daß die Ergebnisse auf falschen Evaluationskriterien beruhten; schließlich wurden auch Kritiken laut, daß, unabhängig von einzelnen Ergebnissen und Konsequenzen, Fragen von herausragender moralischer und ethischer Bedeutung überhaupt nicht hinreichend mit Bezug auf empirische Daten beurteilt werden könnten ( $242 \mathrm{ff}$.).

Von dieser Debatte konnte auch das methodische Selbstverständnis der Policy-Forschung nicht unbeeindruckt bleiben. Die folgende innerwissenschaftliche Diskussion löste sich indessen bald von der in der öffentlichen Auseinandersetzung vorherrschenden Frage nach der einen, richtigen methodischen Orientierung und ging zu der Frage über, welche Beziehungen es zwischen den unterschiedlichen methodischen Orientierungen gibt und wie man diese in ein umfassendes Rationalitätskonzept einbinden könnte. ${ }^{22}$ Vor diesem Hintergrund nun entfaltet Fischer seinen Vorschlag zur methodischen Reintegration auch normativer Fragen in die Policy-Forschung. Er beruht im Kern auf einer Projektion der Argumentationslogik Toulmins in einen rekursiven, sozialen Prozeß der Erzeugung handlungs- und entscheidungsrelevanten Wissens. Nach Toulmin setzt sich ein Argument zusammen aus einer problematischen Äußerung (data), für die, vermittelt über eine Schlußregel (warrant) und unter bestimmten Bedingungen (qualifier) ein Geltungsanspruch erhoben wird (claim). Die Schlußregel ihrerseits kann sich auf verschiedene Evidenzen stützen (backing) und muß gegebenenfalls (rebuttal) eingeschränkt oder zurückgenommen werden (vgl. auch Habermas, 1981: I, 48 f.). Diese formale Struktur übersetzt Fischer nun in ein Vier-Phasen-Modell einer kritischen Evaluationsforschung: »Specifically, this range of questions is structured around four phases that interrelate two fundamental levels of evaluation. First-order discourse, consisting of verification and validation, involves decision-making based on

$121 \mathrm{Vgl}$. zum folgenden Fischer (1990).

122 Folgt man Fischer, so war es in diesem Zusammenhang, daß Habermas' Theorie erstmals auch in den USA beträchtliche Aufmerksamkeit auf sich ziehen konnte. 
principles fixed in the value system governing the particular decision-making process in question. In second-order discourse, composed of vindication and rational social choice, evaluation turns to questions about the acceptability of the value system itself. Each of the four phases has specific requirements that must be fulfilled in making a complete justification of a value judgment. For a reason to be considered a >good reason $<$ it must meet all of the requirements of the four-phased probe« $(248 \mathrm{f}$.).

Unter Gesichtspunkten der empirischen Verifikation von Policy-Zielen sind danach etwa folgende Fragen zu stellen: Erreicht das Programm seine selbstgesetzten Ziele? Lassen sich unvermutete, kontraintuitive Sekundäreffekte nachweisen? Sind die vorgeschlagenen Mittel auch effizient oder gibt es Alternativen? Darüber hinaus bedarf es aber auch einer Klärung der Situationsangemessenheit der Policy-Ziele und ihrer Einpassung in ein übergeordnetes gesellschaftliches Wertesystem, während auf einer weiteren Stufe der Erörterung dieses Wertsystem selbst problematisiert werden kann. Auf dieser Stufe des Policy-Diskurses sind dann Fragen des Typs zu stellen, ob »the fundamental ideals that organize the accepted social order provide a basis for the equitable resolution of conflicting judgments? « Und wenn nicht, und die soziale Ordnung sich als unfähig erweist, Konflikte zwischen unterschiedlichen Wertsystemen zu regulieren, gibt es dann andere soziale Ordnungsmodelle, »(that) equitably prescribe for the relevant interests and needs that the conflicts reflect « (255)?

Für die Zwecke meines Arguments ist es hier nicht notwendig, weiter in die Details zu gehen. Interessant an diesem Modell sind hier vor allem zwei Punkte. Zum einen zeigt es, daß konkretes Problemlösungshandeln auf z.T. sehr weitreichenden Voraussetzungen und Annahmen aufruht, die jederzeit zu einem eigenständigen Thema im Zuge der diskursiven Bearbeitung von Problemen gemacht werden können müssen und insofern im Verfahrensaufbau und -ablauf selber zu reflektieren sind. Vor allem aber zeigt es, daß die Erzeugung handlungsrelevanten Wissens aus systematischen Gründen nicht einzelnen Experten oder Expertenkulturen überlassen bleiben kann: es nötigt, wie ich meine, dazu, eine Demokratisierung von Expertise ins Auge zu fassen. Den Ansatzpunkt dafür liefert die sichtbar gewordene intime, wechselseitige Verschränkung von Bedürfnissen, Interessen, Normen, Werten, Problemwahrnehmungen und der Aufklärung über relevante Daten. Unter dieser Voraussetzung möchte ich abschließend wenigstens stichwortartig drei Aspekte unterscheiden (vgl. auch Fischer, 1990: 355 ff.):

- Zunächst rückt Expertise in die Funktion der Erhöhung der Kompetenz und der Vermittlung der Selbstrationalisierung des Staatsbürgers ein. Zu diesem Zweck wären etwa Institutionen vorzusehen, die auf die problemspezifische Aufbereitung des zur Verfügung stehenden relevanten Wissens spezialisiert sind (etwa in Gestalt unabhängiger, interdisziplinär besetzter ständiger Expertenkommissionen); darüberhinaus wäre eine technische Infrastruktur zu schaffen, die nicht nur die ständige, auch individuelle Verfügbarkeit dieses Wissens garantiert, sondern die zugleich Voraussetzungen für die Entwicklung und Adjustierung dieses Wissens in einem Dialog zwischen Experten und »Laien« schafft (vgl. Dahl, 1987 und Barber, 1984).

- Dieser Vorschlag wäre dann zweitens in sozialer Hinsicht dahingehend zu ergänzen, daß das hierarchische Verhältnis von Experten und Laienpublikum in egalitärhorizontale Strukturen übersetzt wird, wie sie etwa durch ein kontextspezifisches, 
pragmatisches Problemlösungshandeln induziert werden. Das zielt durchaus auch darauf, das technokratische Selbstmißverständnis von Expertise und deren enge Verbindung mit staatlicher Macht aufzubrechen.

- Schließlich, und vor allem, wäre Expertise gleichsam auch intern zu demokratisieren, indem auf die sozialen Aspekte der Erzeugung anwendungsrelevanten Wissens selber abgestellt wird. Diese Vorstellung erhält jedenfalls dann eine gewisse Plausibilität, wenn man berücksichtigt, daß Policies in der Regel auf ein Wissen angewiesen sind, in dem sich disziplinäres Spezialwissen, normative Fragen und soziale Fragen der Implementation amalgamieren. D.h., daß schon die Wissenserzeugung selbst auf kooperative Strukturen einer »participatory research « (Fischer, 1991) verwiesen ist, in denen die Kompetenzen von »Experten des Alltags « für eine angemessene Problemwahrnehmung, -bewertung und -lösung erschlossen werden können.

b) Diese Einsicht hat dann aber auch Folgen für die Modellierung entsprechender Beteiligungsverfahren. Ein solcher Versuch hätte sich von drei grundlegenden Gesichtspunkten leiten zu lassen: Den Ausgangspunkt bildet die Intuition, daß die Effektivität materialer Politiken im Kern von der Partizipation Betroffener sowohl im Design- wie im Implementationsprozeß, also von Kritikoffenheit, horizontalen Interaktionsstrukturen (in die auch Experten eingebunden bleiben) und demokratischen Implementationsverfahren abhängen (Dryzek, 1990: 147; vgl. auch Majone, 1993). ${ }^{123}$ Darauf bezogen hätte sich eine institutionelle Präzisierung des Prozesses partizipatorischer Policy-Formierung von drei grundlegenden Gesichtspunkten leiten zu lassen: der Herstellung und Sicherung eines »strong democratic discourse« (Barber, 1984), der An- und Einbindung von Expertenwissen und der Sicherung von Strukturen, die hinreichend Anreize dafür bieten, daß sich die beteiligten Akteure der Zumutung der »Verfeinerung « ihrer ursprünglichen Interessen und Präferenzen auch aussetzen (Dryzek, 1990: 126 ff.). Nun haben sich Praktiken in unterschiedlichen Kontexten ausgebildet, die diese Anforderungen, wenn z.T. auch durchaus selektiv, bereits aufnehmen (»regulatory negotiation «, »policy-dialogue «, »principled negotiation « und »problem-solving-workshops « im Zusammenhang internationaler Konfliktregulierung), an die man anschließen kann, um so etwas wie ein Grundmuster einer Problemlösungspraxis zu erstellen. Eine solche Praxis zeichnet sich dann dadurch aus, daß sie

- auf Kontexte bezogen ist, in denen die Lösung eines drängenden Problems im gemeinsamen Interesse aller Beteiligten liegt und die

- ein anfängliches Konfliktpotential enthalten, das aus den negativen externen Effekten zusammenhängender, aber unverbundener individualistischer Optimierungsstrategien hervorgeht;

123 Dryzek liefert in diesem Buch, das eine Reihe von Aufsätzen aus den letzten Jahren zum Problemkreis »Discursive Democracy zusammenfaßt, eine Vielzahl von Beispielen und empirischen Belegen, die sich gut für eine Illustration der hier auf ihren programmatischen Charakter verkürzten Überlegungen eignen. Darauf kann ich allerdings aus Raumgründen an dieser Stelle nicht weiter eingehen. 
- eine neutrale dritte Partei installieren, der die Aufgabe zukommt, Diskussionen in Gang zu setzen und die Einhaltung formaler Regeln zu überwachen;

- die face-to-face Diskussionen so lange fortgesetzt werden, bis ein handlungsleitender Konsens erreicht ist und

- daß sie schließlich eng an die problematische Situation gebunden bleiben und jedenfalls keine Institutionalisierungen vorsehen, die den Situationskontext übergreifen (Dryzek, 1987: 438).

Dieses Grundmuster partizipatorischer Problemlösung kann einigen Einwänden, wie sie typischerweise gegen Partizipationsmodelle immer wieder erhoben werden (vgl. Lindner, 1990), durchaus begegnen. So geht es nicht darum, daß Rationalitätsgewinne allein schon über Mechanismen der Inklusion erzielt werden sollen - vielmehr zielt die charakterisierte Praxis sowohl auf Mechanismen der kognitiven Anreicherung von Entscheidungsprozessen als auch auf die Selbstrationalisierung der Beteiligten; auch der Komplexitätseinwand kann insofern aufgenommen werden, daß eine der komplexen Problemstruktur angemessene Design-Komplexität gerade davon profitieren soll, daß so viele Informationen wie möglich aufgenommen und integriert werden sollen - dem liegt darüber hinaus die Annahme zugrunde, daß Komplexität die Leistungsfähigkeit kommunikativer Strukturen eher deutlicher hervortreten läßt und daß sie zudem dem einzelnen einen Anreiz vermittelt, sich auf kooperative Strategien einzulassen. Von diesen Gegeneinwänden bleibt allerdings ein Punkt unberührt, der darauf hinausläuft, daß partizipatorische Strukturen in der Regel auf die Optimierung bloß lokaler Optima hin ausgelegt sind. Dies gibt Anlaß, die sich bei Dryzek zur Forderung einer vollständigen Entstaatlichung von Policies ausweitende Entgegenstellung von Öffentlichkeit und staatlichen Instanzen in der Perspektive eines Modells noch einmal zu überprüfen, das die diskursive Öffnung und Rejustierung staatlicher Steuerung selbst ins Auge faßt.

Eine solche Perspektive zwingt aber dann auch dazu, den Institutionalisierungsgrad von Öffentlichkeit insgesamt zu erhöhen, und das schon deshalb, um so wenigstens eine gewisse Gewähr dafür zu bieten, daß öffentliche Willensbildungsprozesse nicht letztlich in dem bloß kontingenten Zusammentreffen von administrativen Entscheidungsmaterien, öffentlichen Thematisierungsschüben und öffentlicher Wissenserzeugung leerlaufen und marginalisiert werden. Die Schwierigkeiten, die dann entstehen und für die m.E. eine institutionelle Lösung vorgesehen werden muß, lassen sich gut an dem Problem der Rationalisierung des Zusammenspiels von Expertise und demokratischer Willensbildung exemplifizieren, weil sich hier unterschiedliche Prozesse der Erzeugung von Wissen, der administrativen Verwendung von Wissen sowohl aus sachlichen wie legitimatorischen Gründen und der horizontalen Vernetzung kontextualisierter Willensbildung verschränken. Ein solcher Rationalisierungseffekt könnte sich grundsätzlich auf zwei Ebenen erschließen lassen: auf der Ebene des unmittelbaren Problem!ösungshandelns durch eine »Demokratisierung der Expertise « und auf der reflexiven Ebene einer »Metapolicy «, die als »policy on how to make a policy« (DeSario/Langton, 1987: 210) zu definieren wäre. Beide Vorschläge laufen im wesentlichen auf die Befestigung und den Ausbau der Funktionen und Strukturen öffentlicher Deliberation hinaus. Den erstgenannten Aspekt werde ich weiter unten (Kap. 9.3) aufgreifen. Es ist aber schon an dieser Stelle wichtig zu sehen, daß Ansätze zu einer inter- 
nen Rationalisierung von policy-bezogenen Entscheidungsprozessen nur dann wirklich zum Tragen kommen können, wenn sie von gleichgerichteten Reformen einer Flexibilisierung und Demokratisierung der Arenapolitik selber begleitet und ergänzt werden. Die Modellierung einer solchen weiteren reflexiven Wendung der Idee demokratischer Selbstbestimmung (vgl. Burns/Ueberhorst, 1988) hätte sich dann an drei Gesichtspunkten zu orientieren: Zum ersten wäre der strukturellen Querschnittigkeit und Kurzfristigkeit des konkurrenzdemokratischen Modus der Erzeugung von Politik entgegenzuwirken, der insgesamt nicht besonders gut auf die kognitiven und legitimatorischen Anforderungen einer mit langen Zeitperspektiven arbeitenden Technologiepolitik abgestimmt ist (Burns/Ueberhorst, 1988: 93); zum zweiten müßten spezifische Kompetenzen auch gesellschaftlicher Akteure besser genutzt werden und zugleich institutionelle Kontexte und Mechanismen vorgehalten werden, die eine Selbstrationalisierung der individuellen Willensbildung ermöglichen und prämiieren; drittens schließlich wären partizipatorische Potentiale auf der gesamten Breite ausdifferenzierter Assoziationsverhältnisse in der bürgerlichen Gesellschaft, unter Einschluß auch von Parteien, Verbänden und Gewerkschaften also, zu erschließen.

Nach diesen Maßgaben bietet es sich an, sich im institutionellen Design partizipatorischer Politik in den Grundziigen zunächst am Modell des Policy-Zyklus (WindhoffHéritier, 1987: 64 ff.) zu orientieren. Dieser ist dann allerdings an drei entscheidenden Stellen zu durchbrechen oder zu erweitern, um die rigide Institutionalisierung von Policies im Rahmen hoch vermachteter korporativer Arrangements reflexiv aufzulockern. Dann erhalten öffentliche Diskurse schon in der Konstitutionsphase von Policies die Funktion, die institutionellen Arrangements und damit die Akteurkonfigurationen zu bestimmen, innerhalb derer der weitere Prozeß einer diskursiven Policy-Formierung ablaufen soll (Burns/Ueberhorst, 1988: 100); zum zweiten wäre dieser Prozeß insofern zu entstaatlichen, als die Initiativfunktion nicht an staatliche Instanzen gebunden bleibt, sondern auch von gesellschaftlichen Organisationen, von kollektiven Akteuren wie sozialen Bewegungen und lokalen Bürgerinitiativen ausgeübt werden kann; drittens soll die Reflexivität institutioneller Prozesse selber auch dadurch erhöht werden, daß eine Entscheidung über die anzuwendende Entscheidungsregel vorgesehen ist. Der spezifisch problem- und entscheidungsbezogene »demokratische Diskurs « im engeren Sinne umfaßt dann sechs Phasen: die Problemdefinition; die Klärung moralisch relevanter Aspekte; die Spezifizierung der Kosten, der möglichen Folgen wie der Wertberücksichtigungspotentiale alternativer Entwicklungspfade; die Perspektivenverschmelzung zwischen den beteiligten Akteuren im Medium eines kollektiven Lernprozesses; schließlich in einer fünften Phase die Festlegung der Entscheidungsregeln selber und sechstens Entscheidung und Implementation (Burns/Ueberhorst, 1988: 104 ff.).

Dieses Modell umreißt wenigstens näherungsweise die institutionellen Strukturen, an denen demokratische Öffentlichkeiten, die nicht mehr nur auf die Reproduktion einer zivilgesellschaftlichen Praxis bezogen sind, sondern die entscheidende Bereiche der institutionell ausdifferenzierten Staatstätigkeit in die eigene Regie zurückzunehmen versuchen, einen gewissen Halt finden könnten. Darüberhinaus werden daran aber auch allgemeinere Gesichtspunkte, an denen sich die institutionellen Reformen im Rahmen 
einer Radikalisierung der partizipatorischen Komponente moderner Demokratien orientieren müßten, sichtbar. Ich möchte abschließend vier hervorheben. Es geht u.a. darum,

- die Effizienz der demokratischen Willensbildung durch eine bessere Verzahnung mit administrativen Entscheidungsmaterien und besonderen Problemlagen zu verbessern;

- in diesem Zusammenhang müssen Mechanismen vorgesehen werden, die geeignet sind, durch verbesserte Meinungserwerbs- und -bildungschancen auf Seiten aller Beteiligten auch die Qualität der politisch relevanten Entscheidungen zu verbessern;

- drittens kommt es darauf an, unrealistische Erwartungen an den Beteiligungswillen und die zeitlichen und sachlichen Ressourcen der Staatsbürger zu vermeiden - diesem Bedenken gegenüber Formen generalisierter Partizipation kann man dadurch entgegentreten, daß policies gleichsam als Kristallisationskerne fungieren, an die sich fallweise Beteiligungswünsche und ein öffentliches Engagement der Staatsbürger effektiv anlagern können;

- schließlich müssen es solche Strukturen erlauben, ohne die Projektion eines vernünftigen und homogenen Volkswillens auszukommen und die interesseninduzierte, grundlegende Konflikthaftigkeit des Prozesses der Definition allgemeiner Interessen zu berücksichtigen und in Rechnung zu stellen und durch mehrstufige, aufeinander bezogene Verfahren zu kanalisieren. ${ }^{124}$

124 Eine diesen Anforderungen angenäherte Vorstellung haben Renn u.a. (1993) mit dem Modell eines dreistufigen, iterativen Verfahrens der Entscheidungsfindung entwickelt. Auch sie gehen davon aus, daß es darauf ankommt, unterschiedliche Arten von »Wissen (»knowledge based on common sense and personal experience, knowledge based on technical expertise, and knowledge derived from social interests and advocacy : 190) über spezielle »Trägergruppen « (»stakeholder groups « im Sinne sozial organisierter Betroffenengruppen, Wissenschaftler als Vertreter unterschiedlicher wissenschaftlicher Disziplinen und Ansätze und »randomly selected >Citizen-panels< for Policy Evaluation and Recommendation «) in den Entscheidungsprozeß einzuspeisen und dort zu vermitteln (190 ff.). Allerdings vertreten sie aus Gründen der Einpaßbarkeit des Modells in bestehende Strukturen eine eher minimale Auslegung der Funktion von »citizen-panels «, die staatlich-administratives Handeln nicht ersetzen, sondern (entscheidungsvorbereitend) lediglich ergänzen sollen. Für diese Option machen sie Probleme der Gewährleistung von Verantwortlichkeit in langfristigen Planungszusammenhängen wie Repräsentationsprobleme in der Bearbeitung von Fragen überregionaler Reichweite und Wirkung geltend (207 ff.).

Auf der anderen Seite muß man freilich Motivationsverluste in Rechnung stellen, die sich als Reaktion auf eine mangelnde Effektivität der Bürgerbeteiligung und einer lediglich kontingenten Wirkung auf die staatlich-administrative Entscheidungspraxis einstellen können. In Auswertung einer Fallstudie zur Bürgerbeteiligung mit Hilfe von »citizen survey panels« (hier im Rahmen der regionalen Verkehrswegeplanung in Boulder, Colorado) machen Kathlene und Martin (1991: 47 f.) denn auch grundsätzlich auf drei Typen von Einflußfaktoren aufmerksam, von denen die Effektivität einer erweiterten Bürgerbeteiligung in politischen Planungszusammenhängen abhängig ist: zum einen sind es Begrenzungen der Beteiligungsbereitschaft, die sich auf ein ungünstiges Kosten-Nutzen-Kalkül bezüglich der individuellen Beteiligung ergeben, wobei auf der Nutzenseite der tatsächliche Einfluß auf kritische Punkte im Entscheidungsablauf, auf der Kostenseite vor allem der Aufwand zur Erlangung relevanter (offizieller und technischer) Informationen zu bewerten ist; zum anderen sind es institutionelle Faktoren, die eine Art Legitimitätsbalance zwischen 
Solche Strukturen lassen sich nun gewiß nicht auf einmal und auf ganzer Breite institutionalisieren. Aber es gibt doch auch Hinweise darauf, daß sich die Einsicht in die wachsende Bedeutung von reflexiven Strukturen der Willensbildung gerade unter Bedingungen des vorherrschenden Problem- und Entscheidungsstresses staatlicher Politik verbreitert. Dennoch müssen solche Versuche, auch da, wo sie zu Ergebnissen führen, immer noch durch den Flaschenhals einer von den konkurrenzdemokratischen Mechanismen induzierten positionalen Politik hindurch. Deshalb ist es unverzichtbar, realistische Anknüpfungspunkte, an denen ein so relativ anspruchsvolles Modell seinen Halt finden könnte, genauer zu identifizieren. Hier kommen vor allem jene Strukturmerkmale moderner Politik in Betracht, die aus der Logik des konkurrenzdemokratischen Modells und einer hierarchischen, bürokratischen Steuerung bereits ausgewandert sind und sich fest etabliert haben, ohne allerdings auf die Anforderungen demokratischer Legitimität, der individuellen Autonomie, der Gleichheit und der kollektiven Selbstbestimmung also, immer schon besonders gut abgestimmt zu sein.

staatlich-administrativer Prärogative einerseits und einer breiten öffentlichen Willensbildung herstellen müssen; das führt schließlich dazu, daß dem genauen Design des Beteiligungsprozesses selber eine nicht zu unterschätzende Bedeutung für dessen Effektivität zuwächst. Dem kann man nun durch eine Anlage des »citizen panels« entgegenwirken, die folgendes sichersteltt: »(1) lowering the costs of participation for citizens by providing information and access to the points in time when the decisions are made; (2) overcoming political limitations by greatly reducing the policy makers' time dedicated to gathering citizen opinion while simultaneously increasing the number of citizens who have input, as well as expanding the breadth of issues to be considered by citizens; and (3) addressing design limitations by opening the process to a true cross section of the community participating in the creation of the master plan from the beginning to the end « (Kathlene/Martin, 1991: 50). Unter diesen Voraussetzungen kann das Instrument des »citizen panels« ein durchaus wirkungsvolles Mittel staatsbürgerlicher Beteiligung im Rahmen eines kooperativen Problemlösungshandelns zwischen staatlich-administrativen Akteuren und Bürgern darstellen. 


\section{Zur Erweiterung des demokratischen Handlungsrahmens: Netzwerke, Verhandlungssysteme und »deliberative Arenen «}

Die Entzauberung des Staates und die daran anschließende Forderung nach einer demokratischen Modernisierung politischer Gemeinwesen, der Vorschlag also, aus der Not des Staates eine demokratische Tugend zu machen, ist nicht nur in einer immanenten Kritik der bestehenden Institutionen im Lichte der Ideale eines unverzerrten Begriffs der Selbstbestimmung und Selbstgesetzgebung normativ verankert, sondern sie ist zugleich im materiellen Charakter moderner Politiken begründet. Nirgends läßt sich dies deutlicher demonstrieren als etwa im Bereich der Umwelt- und Technologiepolitik und einer darauf bezogenen übergreifenden ökologischen Modernisierung der gesellschaftlichen und politischen Strukturen. Hier gibt es manche Anzeichen dafür, daß moderne Gesellschaften im Zuge der deutlicheren Akzentuierung und Dramatisierung von Gefahren und Risiken in einen Prozeß der materialen Politisierung der gesellschaftlichen Evolution hineingezogen werden, der sich mit den institutionellen Mitteln der repräsentativen Demokratie allein nicht mehr beherrschen läßt (1). Vor diesem Hintergrund dürfte es sich lohnen, einen Blick auf die Veränderungen des Rahmens von Politik zu werfen, die den daraus erwachsenden Ansprüchen bereits entgegenkommen. In diesem Zusammenhang signalisiert die Verbreitung politischer Netzwerke, wie Mayntz hervorhebt, bereits eine tatsächliche Veränderung in den politischen Entscheidungsstrukturen, die sich immer weniger dem klassischen (und stereotypen) Bild einer klaren Trennung von Staat und Gesellschaft fügen wollen (Mayntz, 1993: 40) - in ihnen bringt sich gleichzeitig das verstärkte Interesse gesellschaftlicher Akteure an einer effektiven Teilhabe am politischen Prozeß und das Interesse des Staates an der Rückgewinnung politischer Steuerungsfähigkeit im Sinne der »Produktion « gemeinwohlorientierter Problemlösungen zum Ausdruck (vgl. auch Scharpf, 1994: 381 f.). Freilich können sie nur dann als Indikator und Mechanismus gesellschaftlicher und politischer Modernisierung gelten, wenn sie »die Fähigkeit, ohne Zwang verantwortungsbewußt zu handeln « (Mayntz, 1993: 43) und mithin eine »Handlungslogik« institutionalisieren, die auf integrierte Problemlösungen, also auf die Herstellung möglichst problemadäquater Ergebnisse im gemeinsamen, aufgeklärten Interesse aller gerichtet ist. Diesen Anforderungen dürften die Koordinationsmechanismen des (generalisierten) Tauschs oder des Bargaining kaum genügen, so daß auch die Interaktionsbeziehungen im Inneren von Verhandlungssystemen stärker durch eine Logik des >arguing (Elster) charakterisiert und bestimmt sein sollten (2). Schließlich vermitteln Erfahrungen mit diskursiven Verfahren der Technikfolgenabschätzung wie der Mediation einen Eindruck von der Leistungsfähigkeit deliberativer Praktiken der Problemlösung; freilich hängt der Einfluß, den solche »deliberativen Arenen « auf die Anhebung des gesellschaftlichen Diskursniveaus und die Rationalisierung der Grundlagen politischer Steuerung und kollektiver Entscheidungen 
tatsächlich ausüben können, auch davon ab, inwieweit sich die davon ausgehenden Impulse auch in eine strukturelle Transformation des Gesamtzusammenhangs der demokratischen Willensbildung übersetzen lassen (3). ${ }^{116}$

\subsection{Zur materialen Politisierung der gesellschaftlichen Entwicklung}

Für die auch strukturell und institutionell wachsende Bedeutung der Umweltpolitik gibt es mehrere Gründe, die Jänicke (1993: 20 f.) zusammengefaßt hat. Zunächst gibt es in wohl keinem anderen Politikfeld so regelmäßige Testfälle für die Interventionsbereitschaft und -fähigkeit des Staates und der staatlichen Verwaltung. Daran treten dann nicht nur die von Luhmann immer wieder herausgehobenen Kommunikationsschwierigkeiten zwischen gesellschaftlichen Funktionssystemen wie dem Staat und der Ökonomie hervor, sondern es zeigt sich, daß die ökologische Problematik in die Fissuren des politischen Systems selber eindringt und dadurch auf und zwischen den einzelnen Ebenen der Politik Interessengegensätze und -konflikte hervortreibt, die die Handlungsfähigkeit des Staates beeinträchtigen: so muß die »ökologische Handlungsmotivation im Staat selbst gegen widerstrebende Motive und Policies durchgesetzt werden «; so wird der partielle Souveränitätsverlust des Nationalstaates vom ökologischen Lokalismus-Globalismus-Konnex noch akzentuiert und es kommt zu Konkurrenzen zwischen zentralen und dezentralen Interventionen. Schließlich läßt auch die Verlagerung des Zeithorizontes und die Akzentuierung von zukünftigen, nicht immer absehbaren Folgen gegenwärtigen Handelns die Schwächen eines primär reaktiven, auf die nachsorgende Kompensation bereits eingetretener Folgen spezialisierten Modus distributiver Politik unübersehbar werden.

Wie unzureichend die vorhandenen institutionellen Strukturen der Willensbildung auf diese Anforderungen eingestellt sind, läßt sich gut an der alltäglichen Anarchie des politischen Entscheidungsprozesses illustrieren, wie sie etwa im garbage-can-Modell der Analyse administrativen Entscheidungshandelns zum Ausdruck gebracht wird (Cohen/March/Olsen, 1972). Der Inhalt dieser »Mülltonne « besteht aus den Komponenten >Probleme <, >Problemlösungen $<$ und `Politik $<$, und die Erfahrung lehrt, daß Entscheidungen nur möglich sind, wenn Problemkonjunkturen, vorhandene Problemlösungen und politische Bedingungen interferieren und sich sog. "policy-windows « öffnen, die einen historisch zufälligen, günstigen Moment der Amalgamierung und Verdichtung dieser Komponenten zu politischen Entscheidungen kennzeichnen. Gleichwohl scheint der Normalfall eher der zu sein, daß zwar entweder krisen- und er-

116 Insofern geht das Denken in Kategorien der Verhandlungsdemokratie zwangsläufig mit einer reflexiven Neubestimmung der Funktion des Staates einher (vgl. oben Kap. 7), die auf die, wie Kleger (1995: 1) formuliert, "praktische Immanenz des Staates in der Gesellschaft « reagiert. Diese Vorstellung ist gleich weit von libertären (und unrealistischen) Minimalstaatsvorstellungen und der Mystifikation des Staates als Handlungszentrum der Gesellschaft entfernt und hat ihren Ausgangspunkt in der Bestimmung von >Staat< als einer reflexiven Leitidee der Politik der Bürgergesellschaft ( 5 ff.). 
eignishaft verdichtete Problemlagen und ein politischer Entscheidungsbedarf vorhanden sind, daß aber die Wissenschaft über keine gesicherten Perspektiven der Problemlösung verfügt; oder daß die Komponenten Problemlösung und Politik sich verbinden, daß aber die entsprechenden öffentlichen Aufmerksamkeitswerte fehlen, die einen Handlungsbedarf signalisieren; schließlich ist es durchaus vorstellbar, daß zu den drängenden Problemen auch Lösungen vorhanden sind, während sich die Politik als entscheidungsunfähig oder -unwillig erweist (Mucciaroni, 1992: 460 f.). Gleich, wo man die Blockaden im Zusammenspiel dieser irreduziblen Komponenten des politischen Prozesses lokalisiert, ist doch unübersehbar, daß sie auf unterschiedliche Handlungslogiken und institutionell vermittelte Handlungschancen der beteiligten Akteure zurückzuführen sind.

In dieser Perspektive liegt es dann nahe, nach institutionellen Mechanismen Ausschau zu halten, mit denen diese Blockaden überwunden werden können; und eine Möglichkeit, die insbesondere die politikwissenschaftliche Policy-Forschung mit der Beschreibung und Modellierung von Politik-Arenen und Policy-Zyklen aufgegriffen hat, besteht in der Einrichtung von Handlungszusammenhängen, die querliegen zu der institutionellen Logik der Differenzierung von Staat und Gesellschaft. Die Rationalitätsvorteile, die stärker horizontal ausgelegte Handlungszusammenhänge im Prinzip erschließen, machen sich vor allem dort bemerkbar, wo es in besonderer Weise darauf ankommt, die Aufgaben der Problemwahrnehmung, der Erarbeitung von Handlungsalternativen, der Festlegung öffentlicher Handlungsprogramme, der Implementation und Wirkungskontrolle wie schließlich der Handlungskorrektur aufgrund problembezogenen Lernens in einem zyklisch-iterativen Prozeß der Entscheidungsfindung zusammenzuführen. Das ist im Zusammenhang der hier angestellten Überlegungen insbesondere deshalb bemerkenswert, weil es zugleich die Möglichkeit eröffnen sollte, die Mechanismen und Formelemente der Repräsentation, Öffentlichkeit und Partizipation je nach ihrer spezifischen Leistungsfähigkeit in den unterschiedlichen Phasen des Policy-Zyklus zur Geltung zu bringen (von Prittwitz, 1990: $171 \mathrm{ff}$.).

Allerdings wird dieser Vorteil sofort wieder verspielt, wenn man, wie von Prittwitz, den Policy-Zyklus auf einen »Demokratie-Zyklus« so abbildet, daß Öffentlichkeit und partizipatorische Strukturen vor allem in den Vorstadien und Nachphasen des eigentlichen Entscheidungsstadiums angreifen, in dem repräsentative Mechanismen ihre uiberragende Bedeutung behalten sollen (von Prittwitz, 1990: 178). Was er in dieser einsinnigen Zuordnung übersieht, ist, daß er dadurch einer kontraproduktiven Gegenläufigkeit von öffentlicher und administrativer Macht Raum gibt, die zu einer Entwertung der öffentlichen Problematisierungsleistungen und partizipatorischen Kontrollstrukturen tendiert, weil diese nicht wirklich auf das korporative Zusammenspiel von Verwaltung und gesellschaftlichen Interessenverbänden in der Entscheidungsfindung durchgreifen. 117

117 Dies kann man u.a. sehr gut an der fragwürdigen Rolle und der unzureichenden rechtlichen Absicherung z.B. von öffentlichen Anhörungsverfahren im Rahmen technischer Großprojekte sehen (vgl. Ueberhorst, 1983: 42ff. und 142ff.). 
Das ist ganz zweifellos umgekehrt auch der Grund dafür, daß institutionelle Fragen, in denen die Teilhabeansprüche und Mitwirkungsrechte geklärt werden und die insofern die Durchsetzungschancen materialer Interessen stark beeinflussen, regelmäßig besonders heftige Konflikte in dezentralisierten Verfahren der Problemlösung auslösen (Ueberhorst, 1992a: 38 ff.). Andererseits sind es unübersehbare Legitimitäts- wic Effizienzdefizite, die den Staat veranlassen, staatliche Entscheidungen oder Entscheidungsvorbereitungen in gesellschaftliche Verhandlungssysteme auszulagern. Die staatliche Logik, die hinter diesem Vorgehen steckt, ist leicht erkennbar, sobald man sieht, daß die staatliche Steuerung vor allem dort mit Effizienzproblemen konfrontiert ist, wo der Staat - wie häufig im Bereich der Umweltpolitik - in nur schwach oder nicht organisierte Bereiche hineinwirken muß (Offe, 1990: $187 \mathrm{ff}$.). Dies legt es nahe, durch dezentralisierte Verfahren "gewissermaßen die Schnittstelle zum Normadressaten (zu prozeduralisieren)«, wobei »Prozeduralisierung« hier zunächst nur meint, daß »Probleme, deren Lösung nicht definiert ist, an Verfahren delegiert werden« (van den Daele, 1991: 26 f.). Bringt sich so zunächst nur ein Interesse des Staates an seiner eigenen Entlastung zur Geltung, so lösen sich die Verfahren doch auch von den Strukturen staatlicher Willensbildung ab (mit der Chance, transformierend auf diese zurückzuwirken), weil sie Interaktions- und Kommunikationsstrukturen herausbilden müssen, die aus komplexen Problemlagen resultierende Sachstands-, Wert- und Problemlösungskonflikte aufnehmen können und die, ohne den Rückgriff auf überlegene Wahrheiten, konsensuelle oder zumindest kompromißfähige Lösungen möglich machen sollen, auch wenn dabei Kriterien der Wahrheit, der Objektivität und der Kausalität durchaus ihren pragmatischen Handlungssinn behalten (Fietkau/Weidner, 1992: 28 f.). Damit haben wir es im Kern mit deliberativen Prozessen zu tun, die die metapolitische Funktion der Konsensplanung annehmen (Majone, 1989) und, noch vor der Lösung von materialen Sachproblemen und Norm- resp. Wertfragen, eine reflexive Verständigung, mithin eine Verständigung über Verständigungsaufgaben, zum Ziel haben (Ueberhorst/de Man, 1990: 81).

Wie anspruchsvoll dieser Verständigungsproze $B$ ist und welchen Belastungen die Strukturen und das institutionelle Design standhalten können müssen, kann man sich schnell klarmachen, wenn man einen Blick auf die Sorten von Verständigungsaufgaben wirft, die sich aus der Verschränkung von kognitiven, institutionellen und prozessualen Elementen in diesen mikrokonstitutionellen Situationen ergeben. Zunächst einmal müssen solche Verfahren sich gleichsam selber sektorieren, indem sie sich Fragen des Typs vorlegen, zu welchen Themen überhaupt längerfristige Mehrheiten angestrebt, weshalb eine breitere Verständigung erreicht werden sollte und zu welchen konkreten Dialogaufgaben das führt (Ueberhorst, 1992: 6). Erst wenn dies geklärt ist, macht es Sinn, sich den sachlichen und normativen Fragen zuzuwenden, die aufgrund des Komplexitätsniveaus der Entscheidungsprobleme ebenfalls zunächst nur eine reflexive Fassung annehmen. Vorstellbar etwa ist der folgende Katalog: Was wollen wir wissen? Was wollen wir tun? Was wissen wir über die Risiken, die mit den angestrebten Entscheidungen verbunden sind, und mit welcher Genauigkeit? Wie genau ist genau genug? und schließlich: Wer soll diese Fragen mit welcher Legitimation beantworten? (Ueberhors//de Man, 1990: 84). Die letzte Frage weist schon auf einen dritten 
Problemkomplex, der die Beteiligten dazu nötigt, sich auch reflexiv auf die institutionellen Strukturen zu beziehen, in denen sie den Problemlösungsprozeß organisieren wollen. In diesem Zusammenhang wäre dann zunächst zu klären, ob überhaupt eine eigenständige Politik für den in Rede stehenden Themenbereich ausdifferenziert werden sollte und wie die Schnittstellen zu bestehenden Formen institutioneller Willensbildung und informeller öffentlicher Meinungsbildung ausgestaltet werden könnten; das wiederum hätte Implikationen für die Anforderungen an demokratischer Legitimation und die Repräsentation von Expertise, unter die man die Verfahren stellt usw. (Ueberhorst/de Man, 1992: 39 f.; vgl. auch Majone, 1989: 95 ff.). ${ }^{118}$

Als instruktives Beispiel auch für institutionelle Reformen, die damit induziert sind, kann der auf diesen Überlegungen basierende Versuch Ueberhorsts gelten, eine Initiative des Bundeswirtschaftsministeriums zu gesellschaftlichen Verständigungsprozessen in der Energiepolitik in der schon erwähnten "Planungsstudie zur Bildung und Arbeitsplanung einer unabhängigen Kommission zur Förderung energiepolitischer Verständigungsprozesse« (1992) aufzugreifen. Als entscheidend steltt er dabei von Anfang an ein Planungsverständnis heraus, daß an einer »fairen und rationalen Klärung gesellschaftlicher Verständigungsaufgaben « (Ueberhorst, 1992: 3) orientiert ist. Vor dem Hintergrund dieser Maßgabe stellt sich schnell heraus, daß der Erfolg verständigungsorientierter Prozesse entscheidend davon abhängt, daß es gelingt, die argumentationslogische Verschränkung von Sach-, Norm- und Wertfragen in den konstitutionellen Selbstaufbau des Prozesses einfließen zu lassen und gewissermaßen zu

118 Ähnlich auch Miller (1992: $50 \mathrm{ff}$.). Am Beispiel einer diskurslogischen Untersuchung eines Expertenstreits über die Wiederaufarbeitungsanlage Wackersdorf kommt er zu dem Schluß: "Zugleich liefert dies jedoch einen Hinweis darauf, daß die Möglichkeit der Ezeugung eines rationalen Dissenses in solchen Konflikten nicht mehr lediglich durch den Zwang einer mehr oder weniger informellen Öffentlichkeit..., sondern nur noch durch strukturell komplexe institutionelle Formen einer Konfliktaustragung sichergestellt werden kann. Dies legt zumindest die Hypothese nahe, daß Konflikte in der modernen Gesellschaft wegen der hohen Interdependenz systemspezifischer Referenzen tendenziell vor der Wahl stehen, in unendliche Konflikte überzugehen oder aber einen normativen Wandel hinsichtlich der institutionellen Strukturen und Verfahren öffentlicher Entscheidungsprozesse auszulösen, in denen es um die Herausarbeitung entscheidungsfähiger Differenzen geht « 55 f.). Anders als Miller allerdings suggerieren möchte, kann ein in diesem Sinne rationaler Dissens Mechanismen der Generierung rationaler Konsense nicht ersetzen - die Erzeugung rationaler Dissense ist in der hier vertretenen Sicht lediglich eine notwendige Stufe im Rahmen kollektiver Prozesse der Problemlösung.

Dann aber macht die Gegenüberstellung von Konsens und Dissens keinen Sinn, denn »argumentativer Konsens bedeutet die Lösung eines vorangegangenen Dissenses, der jedoch offen bleibt für neue Kritiken und Problematisierungen. Und wo Konsens nicht denkbar ist oder als unerwünscht gilt, kann man auch von Dissens nicht reden: denn kontroverse Argumentation macht nur Sinn, wo die Möglichkeit gegenseitiger Überzeugung vorausgesetzt wird. Nicht erst der Konsens, schon der Dissens bzw. Disput (im Gegensatz zum bloßen Konflikt) sind >unwahrscheinlich < - nämlich angewiesen auf eine eingeübte Praxis wechselseitigen Respekts. Nicht einfach die `Zähmung`, sondern die Fruchtbarmachung von Konflikt durch Verwandlung in Dissens ist eine entscheidende, wenn auch stets gefährdete Errungenschaft der Moderne« (Peters, 1994: 68). 
institutionalisieren. Dabei ist allerdings in Rechnung zu stellen, daß die beteiligten Akteure auch unterschiedliche Vorstellungen über den Sinn solcher Verfahren schon einbringen, die in dann nur noch schwer miteinander vermittelbare Verfahrenskonzepte einfließen. 119

Das impliziert auf einer ersten Stufe die Aufgabe, überhaupt einen Konsens über das Ziel einer konsensualen Energiepolitik zu erreichen und auf Fragen des Typs »Zu welchen energiepolitischen Themen sollte längerfristig eine breite Mehrheit angstrebt werden?«, »Warum sollte eine breite Mehrheit erreicht werden? « und "Welche sind die Bedingungen der Möglichkeit einer erfolgreichen Bildung und Arbeit einer Kommission zur Förderung energiepolitischer Konsense? « eine Antwort zu finden (Ueberhorst, 1992: 6). Dieses Auseinanderzichen von in dem allgemeinen Verständigungsziel implizierten partiellen Verständigungsaufgaben ist deshalb wichtig, weil so (konstitutionell gesprochen) durch die auf den unterschiedlichen Ebenen des Klärungsprozesses erreichten Ergebnisse (Selbst-) Bindungen erzeugt werden, die ihre Bindungswirkung sowohl zeitlich als auch auf den nachgelagerten Ebenen entfalten können - und diese Bindungswirkung beruht vor allem darauf, daß jeweils unterschiedliche Sorten von Gründen mobilisiert werden müssen, die dann durch das gesamte Verfahren hindurch ihre Geltung behalten und jedenfalls nicht problemlos im Lichte möglicherweise entgegenstehender Interessen dementiert werden können. Eine so verstandene Kommissionsarbeit ist nicht nur offen für unterschiedliche gesellschaftliche Teilhabeanspriiche; sie macht vielmehr eine Vernetzung der Kommissionsarbeit mit öffentlichen Prozessen der Meinungs- und Willensbildung zwingend erforderlich. So nimmt schließlich der Modus diskursiver Problemlösung auch einen mikrokonstitutionellen Charakter an, dessen Autonomie gegenüber den herkömmlichen Strukturen der Politikvermittlung und der Regierung zu gewährleisten wäre. M.a.W. spiegeln sich in diesem reflexiven Modus rationaler Problemlösung, in dem es zugleich um Sachfragen wie um die

119 Bora etwa unterscheidet drei Ausprägungen solcher Verfahrenskonzepte (wissenschaftlicher Diskurs, politischer Diskurs und Verfahrensdiskurs) und erläutert sie folgendermaßen: »Eine Variante stellt nur auf die Sachebene ab; eine andere betrachtet zwar Sach- und Sozialdimension, geht aber davon aus, sie seien zu einer einheitlichen Sach-Interessen- und Bewertungsebene verknüpft; eine dritte schließlich hält Sach- und Bewertungsebene für gleichermaßen relevant, trennt sie systematisch und versucht sie prozedural zu integrieren « (Bora, 1993: 72). Das Problem, das nun auftritt, besteht darin, daß sich diese Verfahrenskonzepte nicht nach Maßgabe nur eines Diskurstyps integrieren lassen - auch eine Prozeduralisierung erhöht den Bindungsgrad zwischen den Diskursen nicht, solange es kein integratives Verfahrenskonzept gibt. Boras Frage ist dann, wie dieses Paradox bewältigt werden kann; und er schlägt vor, Prozeduralisierung durch Hierarchisierung in sozialer, sachlicher und zeitlicher Hinsicht zu ersetzen - durch die Auszeichnung einer Instanz, die Verfahrensregeln setzt und überwacht; durch die Hierarchisierung von diskurstypischen Regelsystemen und durch eine zeitliche Staffelung von Problembeschreibung, Informationsbeschaffung und -bewertung (Bora, 1993: $76 \mathrm{ff}$.). Auch wenn Bora hier einen wichtigen Punkt getroffen hat, kann seine Lösung der Hierarchisierung kaum überzeugen, weil nicht recht zu sehen ist, wie sich wert- und interessenbesetzte, konfligierende Verfahrensinterpretationen auf diese Weise schlichten lassen sollten - Hierarchisierungen müssen im Gegenteil eher konfliktverschärfend und damit desintegrierend wirken. 
Bedingungen der Möglichkeit rationaler Problemlösung geht, Anforderungen, die allgemeiner auch in einem Neuarrangement des Verhältnisses von staatlicher und gesellschaftlicher Politik eingelöst werden müßten. Eine entsprechende Generalisierung des von Ueberhorst ins Auge gefaßten Katalogs mikrokonstitutionell zu bearbeitender Fragen bietet sich m.E. jedenfalls geradezu an: Sollen Mitglieder der Kommission bestimmte Themen tabuisieren können; welche Zeitvorgaben für die Erarbeitung welcher Art von Ergebnissen sollte die Kommission entwickeln; wie soll mit Beschlußlagen von Parteien und Organisationen umgegangen werden; welche Anreize für die Mitwirkung welcher Akteure müssen mitinstitutionalisiert werden und welche Bedeutung hat wissenschaftliche Expertise im Zusammenhang des Konsensfindungsprozesses u.a. (Ueberhorst, 1992: $87 \mathrm{f}$.)?

Gewiß bilden solche Verfahren der mikrokonstitutionellen Selbstorganisation gesellschaftlicher Foren problemlösungsbezogenen politischen Handelns noch einen Fremdkörper im institutionalisierten System der Politikvermittlung, deren Erfolgschancen im Augenblick noch nicht zu übersehen sind. ${ }^{120}$ Andererseits sind sie aber auch nicht vollständig ortlos, insofern es sich zum einen um gleichsam partizipatorisch zugespitzte Formen der Problembewältigung handelt, für die in den etablierten Verfahren z.B. der Sozial- und Umweltverträglichkeitsprüfungen in Fragen der Technologiepolitik bereits Ansatzpunkte vorhanden sind: So kommt es »im Legitimationsschatten des unabweisbaren Informationsinteresses zu einer Eskalation von Forderungen, die die Teilhabeaspekte des Verfahrens (der Umwelt- und Sozialverträglichkeitsprüfung, d. Verf.) verstärken. Einschlägige Themen sind etwa die Mitwirkung bei der Festlegung des Untersuchungsrahmens und der Auswahl der Gutachter, die Überprüfung von Informationen einschließlich der Option (und den Ressourcen) zur Erstellung von >Gegenexpertisen «, das Recht auf Sondervoten. Die Standards des Verfahrens sind mitlau-

120 Anders als in den USA etwa, wo solche Praktiken seit fast zwanzig Jahren im Bereich von »public policies « erprobt werden und mittlerweile einen im administrativen Selbstverständnis wie in entsprechenden gesetzlichen Bestimmungen gut verankerten Stil konsensueller Konfliktregulierung und Problemlösung zum Ausdruck bringen (vgl. etwa HoffmannRiem, 1990; Reich, 1988; Susskind/Cruikshank, 1987 und Bingham, 1986), bilden sie unter den institutionell anders gelagerten Bedingungen des deutschen politischen Systems immer noch die Ausnahme. Andererseits sind, auch wenn die Erfahrungsbasis noch relativ schmal ist, erste sozialwissenschaftliche Projekte bereits angelaufen, in denen der Versuch einer systematischen Evaluation der vorliegenden Erfahrungen wie der Perspektiven mittlergestützter Verfahren der gesellschaftlichen Problemlösung unternommen wird (vgl. etwa Zilleßen/Barbian, 1992; Fietkau/Weidner, 1992 und van den Daele, 1991). Daß sich mit dem verstärkten Einsatz solcher Praktiken einige Erwartungen verbinden, kann man schon an der leitenden Fragestellung erkennen, in der van den Daele die Absicht eines WZB-Forschungsprogramms zur »Normbildung und Umwelt« zusammenfaßt: »Die leitende Fragestellung der Untersuchung ist, ob unter den Bedingungen des Verfahrens (mittlergestützter Verhandlungen, d. Verf.) ... Lernprozesse unvermeidlich sind, also konvergierende Situationsdefinitionen, Problemwahrnehmungen und Bewertungen erzwungen werden « (van den Daele, 1991:5) und mithin die sachliche, soziale und zeitliche Reflexivität und damit die Rationalität von Umweltpolitik erhöht und verbessert werden kann. 
fende latente Themen des Verfahrens, die jederzeit aktiviert werden können « (van den Daele, 1993: 239).

Zwar bleiben, anders als hier intendiert, solche Verfahren, auch wenn sie durch diskursive Interaktionsmodi aufgewertet werden, im Kern »bloße Untersuchungsstrategien, die als solche mit mehr oder weniger großer Distanz zur Entscheidung operieren« (van den Daele, 1993: 241). Sie können aber auch in dieser demokratietheoretisch noch sehr zurückgenommenen Gestalt schon als Indikator dafür gelten, daß die Grundprobleme der gesellschaftlichen Entwicklung die bestehenden Möglichkeiten und Spielräume staatlicher Politik überfordern; und das deshalb, weil die problemgenerierende Seite der Ausdifferenzierung funktional spezifizierter und in ihren Grenzen innovativer Sozialsysteme in Wissenschaft und Wirtschaft nunmehr selber in den Blick tritt. Zugespitzt haben wir es hier im Kern mit einem (vermutlich irreversiblen) Prozeß der materialen Politisierung der gesellschaftlichen Evolution zu tun, insofern nun die strukturellen und institutionellen Rahmenbedingungen des Entwurfs möglicher gesellschaftlicher Zukünfte zum Thema werden: In dieser Perspektive werden Sozial- und Umweltverträglichkeitsprüfungen zu institutionell auszubauenden »Foren des allgemeinen Diskurses der Gesellschaft über angemessene kulturelle Orientierungen, über wünschenswerte und notwendige Ziele und die Grenzen der institutionalisierten Politik « (van den Daele, 1993: 245).

Diese Projektion der Technikfolgenabschätzung zu einem diskursiven Instrument der gesellschaftlichen Vermittlung von Umwelt- und Technologiepolitik (van den Daele, 1994; vgl. auch Zweck, 1993) reagiert bereits auf die intime Verschränkung von Norm-, Wert- und Sachfragen, die für komplexe Politikmaterien insgesamt typisch ist. So zeigt sich die Abhängigkeit der Umweltpolitik von einer rationalen Bearbeitung normativer Fragen erstens daran, daß der Verbrauch und die Zerstörung der Umwelt auch Folge eines durch bestehende Normen und weitgehend akzeptierte Werte gedeckten Verhaltens ist; daß zweitens erst die Veränderung von Zielen oder normativen Erwartungen Veränderungen der Umwelt von bloßen Sachverhalten in zu lösende Probleme transformiert und daß drittens Normbildung qua Rechtsetzung eine unverzichtbare Strategie der politischen Verarbeitung von Umweltproblemen darstellt (van den Daele, 1991: 9). Zwar bilden die mit Gesetzgebung und kultureller Selbstverständigung markierten Formen der Normbildung bloß die Eckpunkte auf einem Kontinuum von Normbildungsprozessen, die füreinander gerade wegen ihrer komplementären Stärken und Schwächen durchlässig bleiben müssen. Doch wenn Durchlässigkeit nur meint, daß die gesetzestechnische Feinregulierung von Verhalten im Rahmen des positiven Rechts sich nicht vollständig ablösen kann von allgemeineren normativen Erwartungen, so ist das sicherlich zu wenig, weil es in den hier interessierenden Handlungszusammenhängen mit Blick auf konkrete Regelungsmaterien vielmehr auf die genaue und kontrollierte Übersetzung allgemeiner normativer Erwartungen in Handlungsvorschriften geht. Deshalb dürfte es auch nicht ausreichen, wenn man, wie $\mathrm{Ha}$ bermas etwa, unter Bezug auf Fragen der Form und Organisation entsprechender Verfahren, auf mehr oder weniger gut eingespielte, arbeitsteilige Beziehungen zwischen allgemeinen, gesellschaftlichen Selbstverständigungsdiskursen, der zentralen, körperschaftlich organisierten Gesetzgebung und einer rechtsstaatlich rückgebundenen Ver- 
waltung verweist (Habermas, 1992: $187 \mathrm{ff}$. und $197 \mathrm{ff}$.). Die freiheitverbürgende und demokratische Legitimität sichernde Reflexivität der institutionellen Ordnung des liberalen Rechtsstaates jedenfalls, die Habermas hier ganz offensichtlich im Auge hat, ist viel zu hoch angesiedelt, um sich in dezentralen Kontexten der Willensbildung, Entscheidung und Handlungsplanung auszuwirken. Nun muß man Habermas an dieser Stelle, an der er die grundlegende Unterscheidung von moralischen, ethischen und pragmatischen Diskursen in eine Rekonstruktion der repräsentativen Demokratie und damit der Funktionstrennung von staatlich-institutioneller Politik einerseits und zivilgesellschaftlichen Öffentlichkeiten andererseits überführt, ja nicht folgen. Zum einen, weil die Gründe für diese >liberale< Wende primär defensiver Natur sind: er möchte dem Modus deliberativer Politik in Gestalt von gesellschaftlichen Rechtsdiskursen und der parlamentarischen Gesetzgebung einen Ort zuweisen, an dem er von den Einwänden realistisch gesonnener Kritiker nicht so leicht zu erreichen ist und beschränkt sich darüber hinaus auf die Klarlegung, wie sich die diskursive Rationalität dem bürokratischen Routinemodus von Politik und der Kompromißbildung zwischen unterschiedlichen Interessen wenigstens indirekt über Verfahrensnormen mitteilt - das realistische - Gegenbild von Interessepolitik ist indessen lediglich ein anderes, mit mehr oder weniger guten Gründen verteidigtes Modell demokratischer Politik, dessen empirischer Gehalt nicht so selbstverständlich ist, wie Habermas unnötigerweise unterstellt. Zum anderen spricht nichts dafür, daß man dem Sinn der dimensionalen Unterscheidung von moralischen, ethischen und pragmatischen Aspekten politischer Fragen nur räumlich durch die institutionelle Spezifizierung unterschiedlicher Diskurstypen entsprechen kann: man kann sie auch sequentiell auffassen, dann beschreiben sie unterschiedliche Stufen eines Willensbildungs- und Entscheidungsprozesses - in einem solchen Verständnis kann sie als Modell für die Absenkung der erforderlichen Reflexivität auf die Ebene einzelner Entscheidungsprogramme fungieren. Es spricht also einiges dafür, sich auf die Beschreibung und Identifikation solcher Formen der politischen Willensbildung und Entscheidungsfindung zu konzentrieren, die der faktischen Verschränkung von normativen, Wert- und Sachfragen auch durch eine tatsächliche Verklammerung der entsprechenden Diskurse und der Integration unterschiedlicher gesellschaftlicher und staatlicher Akteure in einen themenfokussierten Interaktionszusammenhang entsprechen können; und dies nicht zuletzt auch deshalb, weil nur in fokalen Interaktionsstrukturen die kommunikativen Voraussetzungen einer angemessenen Problemlösung wenigstens im Prinzip zu gewährleisten sind.

Vor diesem Hintergrund kann man die zivilgesellschaftlichen Foren autonomer Politikplanung, wie sie Ueberhorst im Auge hat, und Diskurse, die sich um Fragen der Sozial- und Umweltverträglichkeitsprüfungen herum ausbilden, als rudimentäre, aber doch ausbaufähige Kristallisationskerne demokratischer Politik identifizieren. Sie bilden Formen einer horizontalen, zivilgesellschaftlichen Praxis der Selbstkoordination, die nicht in der Logik der Selbstkoordination gesellschaftlicher Funktionssysteme aufgehen, die Willke (1992) als Antwort auf die Krise der "präzeptoralen « Staates stilisiert; das ist deshalb entscheidend, weil sie sozial weniger exklusiv sind als Formen der korporatistischen Integration und weil sie nicht die demokratieaversen Effekte zeitigen, die sich in der Perspektive weitgehend normfreier, rein an funktionalen Gesichts- 
punkten orientierter Mechanismen der Systemintegration einstellen. Andererseits liegen sie aber auch quer zu einer eher hierarchisch ausgelegten Integrationsmechanik der repräsentativen Demokratie und können, was Habermas entgeht, den Modus deliberativer Politik und die reflexiven Grundsätze des liberalen Rechtsstaates zur Geltung bringen, ohne auf der Trennung zwischen Staat und Gesellschaft und der Präponderanz staatlicher Politik bestehen zu müssen.

Kurz: die organisatorischen und institutionellen Fragen einer Modernisierung der Demokratie stellen sich etwas anders, als sie allein in der Perspektive der horizontalen Selbstkoordination von Funktionssystemen einerseits und in einer primär um die liberale Qualität des demokratischen Rechtsstaates besorgten Optik des Modells deliberativer Politik andererseits erscheinen. Um diese Frage nach einer leistungsfähigen Infrastruktur partizipatorischer Politik zu beantworten, die den Kriterien der Effizienz, Effektivität und demokratischen Legitimität zugleich genügen kann, muß man sich an grundbegrifflichen Problemvorgaben beider Sichtweisen orientieren und die daraus erwachsenden Vorschläge integrieren. In diesem Zusammenhang sind es zunächst drei miteinander zusammenhängende, von Willke in seinem Versuch der Neubestimmung des Staates entwickelte Vorschläge zur genaueren Bestimmung der Integrationsproblematik moderner Gesellschaften, die mich hier interessieren. Da ist zum einen sein Vorschlag, auf das sich verschärfende »Ignoranzrisiko" moderner Politik mit der Schaffung einer wissensbasierten Infrastruktur $\mathrm{zu}$ reagieren; deren Herstellung wie effiziente Nutzung hängen zweitens davon ab, daß gesellschaftliche Akteure wie Funktionssysteme ihre Interaktionen und Austauschbeziehungen unter Gesichtspunkten von Autonomie, unvermeidlicher Interdependenz und notwendiger Independenz selber regulieren; diesen sozialen Konstitutionalismus einer »verfaßten Gesellschaft « möchte er neben den Verfassungsstaat stellen - so etwas wie eine Grammatik subsystemischer Interaktionen wenigstens im Ansatz zu entwerfen, die jene allgemeinen Regeln enthält, die den Prozessen der Selbstverfassung von einzelnen Interaktionszusammenhängen vorausliegen, diese bestimmen und ermöglichen.

Wie der Rechtsstaat aus der asymmetrischen Verteilung sozialer Macht und der Notwendigkeit erwächst, den von den gewaltsamen Folgen der ungleichen sozialen Machtverteilung Betroffenen das kompensatorische Machtmittel staatlich sanktionierter Rechtsansprüche an die Hand zu geben; wie der Sozial- und Wohlfahrtsstaat aus einem Mangel an gesellschaftlicher Solidarität resultiert, so »muß man heute feststellen, daß ein Mangel an Wissen eine neue Staatsfunktion fordert, einen supervidierenden Staat, weil mit der Ausbreitung wissensbasierter Technologien das individuelle und kollektive Risiko eines unkontrollierten Wissens selbstdestruktiv wird «(Willke, 1992: 268). Die Argumente, die Willke für seine Forderung nach einer neuen Staatsfunktion beibringt und die Beschreibung einer entsprechenden wissensbasierten Infrastruktur, die er im wesentlichen am Modell der Fraunhofer-Gesellschaft entwickelt (Willke, 1992: 270 ff.), müssen nicht im einzelnen interessieren - sie weichen auch von den hier schon angestellten Überlegungen nicht wesentlich ab. Wichtig ist an dieser Stelle nur, daß er die Lösung des Ignoranzproblems durch Erzeugung eines spezifischen Wissens, das der Kontrolle der Gefährdungen der Bürger durch wissensbasierte Technologien dient, eng mit der reflexiven Form und Funktion des Supervisionsstaates verbindet: 
»Die Aufgabe des Staates ist eine bloß subsidiäre und supervisorische...Ausdrücklich und dezidiert geht es mithin nicht um staatliche Wissenschaft, sondern darum, die infrastrukturellen Voraussetzungen für die zivilisierte, d.h.: das öffentliche Wohl einbeziehende, Kontrolle wissensbasierter Technologien zu schaffen « (Willke, 1992: 290). Freilich erschöpft sich der Sinn der Rede von der Zivilisierung, wie in dieser Formulierung noch nahegelegt, keineswegs darin, dem Wissenschaftssystem substantiierte, ethische Reflexionsbezugspunkte extern vorzugeben. Vielmehr drängt Willke, weil Reflexion ein für systemische Operationsmodi generell höchst anspruchsvoller und prekärer Prozeß ist, darauf, daß interne Strukturen vorzuhalten sind, die der sachlichen, zeitlichen und sozialen Selbstvalidierung subsystemischer Operationen dienen. M.a.W. kann die Forderung nach Reflexion nur über Strukturen und Mechanismen der Selbstreflexion vermittelt werden, und sie verlangt deshalb »vorausschauende Investitionen in Einrichtungen der Selbstaufklärung über systemexterne Wirkungen der Handlungsweise eines Teils. Und sie verlangt Investitionen in einen reflexiven Steuerungsmodus, der es dem System insgesamt ermöglicht, im Hinblick auf eine zukünftige Identität kontrollierte Veränderungen in Gang zu setzen « (Willke, 1992: 307).

Auf diese Aufgabe hin ist dann zweitens sein Modell der verfaßten Gesellschaft ausgelegt. Darin bringt er die Nötigung zum Ausdruck, die moralisch-reflexive Struktur des modernen Verfassungsstaates auf die Ebene der Gesellschaft und der diese konstituierenden Funktionssysteme und Assoziationen abzusenken. Dabei geht es nunmehr nicht allein um den Schutz der Autonomie von Individuen und die Regulierung der friedlichen Koexistenz vor dem Hintergrund der Achtung einer irreduziblen Pluralität von Weltbildern, kulturellen Orientierungen und kollektiven Identitäten; diese Perspektive auf den Bürger als natürliche Person soll vielmehr erweitert werden auf ihre Organisationen, korporativen Akteure und Funktionssysteme. Damit erfährt der Verfassungsstaat zwei wesentliche Erweiterungen: Zum einen ist nun eine »innere Konstitutionalisierung aller Funktionssysteme und korporativen Akteure « gefordert; zum anderen »verlangt sie eine Konstitutionalisierung der Beziehungen zwischen den organisierten sozietalen Akteuren, um ihre Autonomie zu schützen und ihre Gemeinverträglichkeit zu sichern « (Willke, 1992: 357 f.). Zwar räumt Willke selber zu Recht ein, daß die Idee der inneren Konstitutionalisierung keineswegs neu ist. Beispiele für derartige Versuche reichen von der Forderung nach sozialer Demokratie, von Verbände- und Parteiengesetzen über betriebliche Mitbestimmungsregelungen bis hin zur Beteiligung von Eltern und Schülern an schulischen Angelegenheiten. Dennoch moniert er, ebenfalls zu Recht, daß diese inneren Konstitutionalisierungen selten ausreichend Sorge dafür getragen haben, daß in die internen Willensbildungs- und Entscheidungsprozesse zugleich auch reflexive Kapazitäten eingebaut werden, die »über den Aspekt der inneren Ordnung hinaus auch die Frage einer geeigneten Identität des Funktionssystems im Kontext der Gesellschaft insgesamt in den Blick bringt (Willke, 1992: 359).

Diese Verbindung von innerer und äußerer Konstitution geht schließlich in die Bestimmung jener Regeln ein, die so etwas wie eine Tiefengrammatik der Interaktionen organisierter sozialer Akteure beschreiben. Diese sollen als allgemeine Erzeugungsregeln von Informationen durch die auf der Performanzebene jeweils ausgebildeten Spezialsemantiken hindurchgreifen und für die wechselseitige Verstehbarkeit von syste- 
mischen Informationen sorgen. Vor diesem Hintergrund unterscheidet Willke dann im einzelnen (Willke, 1992: 343 ff.) »Präferenzregeln«, welche die internen Operationen eines Systems nach Maßgabe spezifischer leitender Gesichtspunkte, Kriterien, Maßstäbe, Kontrollparameter und Standards regulieren; daneben treten sog. »Inferenzregeln«, nach denen Systeme die jeweils für sie relevante Umwelt selegieren und zurechtlegen und auf die Außenbeziehungen berechnete »Transferenzregeln «, die, vergleichbar den Kollisionsnormen im Recht, das Zusammenspiel unterschiedlicher systemischer wie intersystemischer Regeln bestimmen sollen. Weil sich diese Regeln noch aus der Binnenperspektive eines jeweiligen Systems ergeben und auch Austauschrelationen primär selbstbezüglich bestimmen, kommen viertens »Konferenzregeln « ins Spiel, die nicht mehr in Subsystemen verankert sind, sondern die aus dem aktiven und absichtsvollen Zusammenspiel der unterschiedlichen Teile des gesellschaftlichen Ganzen entstehen.

So weit der Vorschlag Willkes. Ich möchte nun nicht im Detail auf seine Überlegungen eingehen; an dieser Stelle sollen drei eher allgemein gehaltene Anmerkungen genügen. Zunächst ist seiner allgemeinen Problembeschreibung und der Strategie zuzustimmen, im Licht der diagnostizierten Probleme staatlicher Politik die Bedingungen und Chancen gesellschaftlicher Selbstkoordination und Selbstorganisation genauer zu bestimmen: dann liegt es auch nahe, den allgemeinen Mechanismus der verfassungsrechtlichen Selbsteinhegung und -rationalisierung von Politik auch in diesen Kontexten zur Geltung zu bringen und die Perspektive des liberalen Verfassungsstaates durch jene eines sozialen Konstitutionalismus zu ergänzen (vgl. auch Sabel, 1993). Genau an dieser Stelle stellen sich zwei Probleme ein, die aus der spezifischen Fassung resultieren, die Willke diesem Argument letztlich gibt. Zum einen bezieht Willke, wie gesehen, die Vorstellung einer verfaßten Gesellschaft primär auf die Anforderungen einer funktionalen (Selbst-) Koordination selbstreferentiell geschlossener Subsysteme instrumentellen Handelns und behandelt entsprechend auch Fragen der Integration dieser Teile in ein größeres, emergentes Ganzes in einer rein funktionalen Einstellung. Hier ist Habermas zuzustimmen, wenn er moniert, daß damit gesellschaftliche Funktionssysteme aus ihrer instrumentellen Rolle entlassen werden, zu einem Selbstzweck avancieren und mit der Idee des autonomen Individuums und der Volkssouveränität auch die Legitimationsgrundlage des demokratischen Rechtsstaates unterminiert wird (Habermas, 1992: 425 und 424). Dieser von Habermas befürchtete Effekt stellt sich aber nur ein, wenn man der Idee des sozietalen Konstitutionalismus die radikale Fassung gibt, nach der dieser den demokratischen Rechtsstaat ersetzen würde. Willke selber ist in dieser Frage nicht eindeutig und legt in seinen Formulierungen einmal die Vorstellung einer Substition, dann aber auch wieder die einer Komplementarität von demokratischem Verfassungsstaat und verfaßter Gesellschaft nahe. Wie immer indessen Willke sich entscheiden mag, ist evident, daß sich schon aus systematischen Gründen die radikale Fassung gar nicht halten läßt: der Grund dafür ist schlicht, daß die Erzeugung der von Willke typisierten Regeln der Koordination und Integration sich gar nicht anders als im Modus der konstitutionellen Deliberation unter Beteiligten vollziehen kann - ein solcher Prozeß aber bedarf zumindest der Absicherung durch und der Verankerung in verfassungsstaatlich verbürgten, individuellen Freiheitsrechten. Wenn man 
dies voraussetzt, verliert die Vorstellung des sozialen Konstitutionalismus einiges von ihrem verfassungsstaatlichen Schrecken - wir haben es dann mit in gesellschaftliche und potentiell demokratische Regie genommenen Prozessen der permanenten Selbstadaptation einer Verfassungsordnung zu tun: "...just as the constitution anticipates the transformation of the groups in the polity, so it anticipates that those groups, once transformed, may amend the constitutional rules to conform to their new relations. The process by which identities are changed through the accomodation of different interests is called deliberation; the institutional arrangements that in their ensemble encourage this are called the constitution« (Sabel, 1993: 101).

Das zweite Problem hängt mit der Wahl des Bezugspunktes für den sozietalen Konstitutionalismus eng zusammen. Der Bezug auf die Abstimmungsprobleme von Funktionssystemen legt es zumindest nahe, daß Willke sich auch die Abstimmungsprozesse nach dem Muster korporativer Arrangements vorstellt, was dann die Frage der demokratischen Legitimation in den Vordergrund rückt: von der wenigstens indirekt demokratisch legitimierten hierarchischen staatlichen Willensbildung vollständig entkoppelte korporatistische Verhandlungssysteme, die in eigener Regie die Gefahren der gesellschaftlichen Desintegration bewältigen, unterbrechen den ohnehin gestörten Machtkreislauf der repräsentativen Demokratie ein weiteres Mal und verschärfen Legitimationsprobleme eher als daß sie sie eindämmen (Habermas, 1992: 423). Andererseits ist auch an dieser Stelle unklar, ob Willke die ihm von Habermas unterstellte Perspektive wirklich einnehmen möchte. Die empirische Referenz jedenfalls, die er an der entscheidenden Stelle in Anspruch nimmt (Willke, 1992: 359), ist der Verweis auf "Verhandlungssysteme", die Habermas seinerseits recht einseitig und einsinnig als korporativ vermachtet auffaßt. Verhandlungssysteme aber müssen, wenn man der Unterscheidung etwa von Scharpf (1993: 36 ff.) folgt, nicht die Form korporatistischer Arrangements annehmen; sie können sich auch in Gestalt offenerer, pluraler PolitikNetzwerke etablieren. Vor diesem Hintergrund scheinen Willkes Vorschlag und Habermas Kritik letztlich in der auch für den hier vorgestellten Argumentationszusammenhang wichtigen Frage zu konvergieren, welche Ansatzpunkte und Chancen einer weitergehenden Demokratisierung sich mit Blick auf bestehende Formen der Kontextsteuerung, wie sie in unterschiedlich strukturierten Verhandlungssystemen zum Ausdruck kommen, erschließen lassen.

\subsection{Politik in Verhandlungssystemen}

Es ist zwar klar, daß man das politische System nicht im ganzen auf die speziellen Anforderungen eines einzelnen (wenn auch bedeutsamen) Politikbereichs einstellen kann. Aber insofern hieran Anforderungen deutlich werden, die sich auch in anderen Bereichen aufgrund von Phänomenen der Internationalisierung einerseits wie der zunehmenden Individualisierung, der Differenzierung von Lebenslagen und der kulturellen Pluralisierung andererseits in allgemein wachsenden Komplexitätsvorgaben für Politik spiegeln, sollte dies doch zu einer Verbesserung der politischen Innovationschancen führen. Markant sind in diesem Zusammenhang Entwicklungen weg von einer regula- 
tiven und hin zu einer auf Kontextsteuerung ausgelegten Politik, vom »präzeptoralen « (Willke) hin zum kooperativen Staat (vgl. etwa Hesse, 1990; Jänicke, 1993: 24 und Decker, 1994: 170 ff.). So ist es denn auch kein Zufall, daß Willke zu Zwecken einer Illustration der Logik horizontaler Selbstkoordination gerade auf Verhandlungssysteme rekurriert. Sie drängen sich in seiner Sicht, wiewohl nicht optimal oder manchmal sogar schlecht funktionierend, als jedenfalls ausbaufähige Kristallisationskerne des von ihm favorisierten Integrationsmodus moderner Gesellschaften geradezu auf. Der Grund dafür ist zunächst schlicht ein empirischer: sie bilden, sei es in Gestalt internationaler Verhandlungsregimes oder auf innerstaatlicher Ebene in Form von konkordanzdemokratischen Elementen, der föderalen Politikverflechtung, der neokorporatistischen Konzertierung oder von pluralistischen Politik-Netzwerken (Scharpf, 1992a: $30 \mathrm{ff}$.) längst eine gut etablierte Alternative oder Ergänzung zu »einer alt gewordenen hierarchischen Struktur « (Willke, 1992: 359 f.) des politischen Vermittlungssystems.

Darüber hinaus gibt es aber auch einen systematischen Grund für einen entsprechenden, auch von Scharpf (1992: 107) geforderterten, demokratietheoretischen Perspektivenwechsel: Es läßt sich in vielen Politikbereichen wie etwa der regionalen Wirtschaftspolitik, der Raumordnungspolitik und eben der Umweltpolitik (Hesse, 1990: 102 ff.) zeigen, daß die Veränderungen der Rahmenbedingungen staatlichen Handelns und der daraus resultierende Wechsel von hierarchischen zu eher kooperativen Formen der Implementation politischer Programme auch Strukturveränderungen nach sich ziehen, die eine bessere Möglichkeit bieten, kommunikative und reflexive Formen des Handelns und der Steuerung aufzugreifen (Hesse, 1990: 108). Nun macht es gewiß wenig Sinn, eine »gesellschaftliche Rationalitätssteigerung (von Politik, der Verf.) zu empfehlen, ohne die damit wachsenden Kosten der Konsensfindung zu berücksichtigen, integrierte Problemlösungen durch einen Abbau politisch-administrativer Arbeitsteilung anzustreben, ohne die informatorischen und konsensbezogenen Vorteile der Arbeitsteilung in Rechnung zu stellen, dezentrale Selbststeuerung zu propagieren, ohne zu erkennen, daß ausdifferenzierte Gesellschaften und pluralistisch-fragmentierte Institutionensysteme einen wachsenden Kollektivbedarf der Steuerung, Planung und Konsensbildung erzeugen « (Hesse, 1990: 108 f.). Aber gerade in dieser Hinsicht scheinen horizontal gelagerte Verhandlungssysteme doch auch spezifische Vorteile zu bieten. In sachlicher Hinsicht bieten sie eine Antwort auf die Schwierigkeiten, die sich einstellen, wenn man umfassende Willensbildungs- und Entscheidungsprozesse jeweils für alle relevanten Akteurgruppen öffnen möchte - sie ermöglichen eine Zerlegung und bereichsspezifische Öffnung des Problemlösungsprozesses, der eher geeignet sein könnte, funktionalen wie normativen Erfordernissen gerecht zu werden. In zeitlicher Hinsicht scheinen sie die Chance zu eröffnen, komplexe Entscheidungsmaterien in einer Sequenz von aufeinander bezogenen Einzelentscheidungen innerhalb eines übergreifenden Entscheidungszusammenhangs zu bearbeiten, der die faktische Interdependenz von unterschiedlichen Handlungsträgern, Akteuren und Interessen organisatorisch wahren kann. Und in sozialer Hinsicht schließlich eröffnen sie die Möglichkeit, wachsende Interessen- und Wertberücksichtigungsansprüche anders als über Rechtsstreitigkeiten (Litigation) durch konkrete Teilhaberechte zu kanalisieren (vgl. Hesse, 1990: 109 f.). 
Gleichwohl ist diese Entwicklung praktisch und theoretisch häufig durch den Rückgriff auf korporatistische Arrangements enggeführt und fehlgeleitet worden. Diese weisen indessen, trotz der nicht zu leugnenden Rationalitätsvorteile, die in ausgehandelten Problemlösungen, Absprachen und Vereinbarungen zwischen einer begrenzten Zahl staatlicher und gesellschaftlicher Akteure liegen können (vgl. Scharpf, 1992), doch auch erhebliche spezifische Nachteile auf. Sie können zunächst bezüglich der inhaltlichen Qualität der Problemlösungen entstehen: gleich, ob Zugeständnisse hinsichtlich der Regelungsabsicht durch Kompensationen oder durch Abstriche am Regelungsgehalt »erkauft« werden, bleiben die Ergebnisse von Absprachen zumindest nominell hinter den Möglichkeiten einer rechtlichen Regulierung zurück. Durch Bargaining-Prozesse vermittelte Absprachen haben selbst unter der günstigen Voraussetzung einer etwa gleichen Verteilung des Macht- und Drohpotentials (Exit-Drohungen) die Tendenz zur Bestätigung und Sicherung des status quo und entfalten selten verhaltensändernde Wirkungen. Zudem läßt sich in solchen Konstellationen zwischen einem strategischen und einem verständigungsorientierten Gebrauch von Argumenten, Zusagen und Versprechungen nur schlecht unterscheiden - das aber hat erhebliche Folgen für die Stabilität von Absprachen und ihre zukünftige Einhaltung. Schließlich sind häufig genug nicht nur die Macht, sondern auch das Wissen und die Informationen unter den Akteuren ungleich verteilt: Akteure aber, die nicht nur aus der Optimierung des eigenen Nutzens, sondern auch aus dem Nutzenverlust der anderen Beteiligten einen Gewinn ziehen, haben wenig Anreize, diese auf die Handlungschancen sich negativ auswirkende asymmetrische Verteilung von Informationen durch deren Preisgabe zu überwinden, wenn sie für sich davon Nachteile erwarten müssen. ${ }^{121}$

Diese Schwierigkeiten und Defekte ergeben sich nun primär daraus, daß in Verhandlungen, die auf Interessenausgleich und Kompromißbildung spezialisiert sind, der »äußeren Form der Kommunikation keine innere Form der Argumentation« entspricht. Wenn, m.a.W., die Beantwortung der pragmatischen Frage, was wir in Hinblick auf konkrete Aufgaben tun können, abhängt von aufeinander bezogenen Antworten auf die moralisch-praktische Frage, wie wir gerechterweise handeln sollen, auf die ethisch-politische Frage, wer wir sind und wer wir ernstlich sein wollen und die praktische Frage, wie wir konkurrierende Interessen miteinander in Einklang bringen können (Habermas, 1992: 218 und 222), dann muß es zu Rationalitätsverlusten führen, wenn dieser Zusammenhang nicht auch durch den Gebrauch angemessener Kommunikationsfor-

121 Keck (1993) jedenfalls versucht theoretisch zu zeigen, daß dieses Dilemma auch durch eine Inaussichtstellung von Kompensationen für den Nutzenverlust durch Informationspreisgabe nicht zu überwinden ist und demonstriert das eindrücklich in empirischen Studien zur Kernenergiepolitik in den USA, in Großbritannien, Frankreich und Deutschland. 
men im Rahmen des Verhandlungsprozesses gewahrt bleibt. ${ }^{122}$ Bezüglich der dominanten Auslegung von Verhandlungssystemen als Formen des korporatistischen Interessenausgleichs stellen sich mithin zwei Probleme ein, die besonders deutlich hervortreten, wenn sie als Mechanismen der horizontalen Selbstkoordination und -organisation der Gesellschaft verstanden werden sollen und wenn der Anspruch der Problemlösung neben distributiven auch sachliche und legitimatorische Fragen aufwirft: Zum einen das Problem der Repräsentation und Inklusion, der differentiellen Zugangschancen und der asymmetrisch verteilten Machtressourcen (a); zum anderen Probleme, die sich aus der Kombination des Situationsmerkmals $»$ Nicht-Öffentlichkeit« mit dem Kommunikationsmodus des »Bargaining ${ }^{123}$ (b) verbinden (vgl. auch Decker, 1994: $183 \mathrm{f}$.).

a) Es kann mittlerweile als gesichert gelten, daß institutionelle Strukturen einen erheblichen Einfluß auf die Qualität materialer Politiken haben. Diese Qualität kann man grob daran messen, inwieweit in sozialer Hinsicht unterschiedliche institutionelle Arrangements sicherstellen, daß die Interessen, die von einer bestimmten Politikwahl objektiv berührt sind, auch faktisch Berücksichtigung finden - ihnen also gleichsam eine Stimme verliehen wird; in der zeitlichen Dimension sind Institutionen danach zu beurteilen, inwieweit sie es erlauben, aktuelle Interessen auf zukünftige ohne gravierenden Legitimitätsverlust zu diskontieren; in sachlicher Hinsicht schließlich besteht das wesentliche Merkmal der Effektivität von Institutionen in dem Ausmaß, in dem sie in der

122 Diesen Aspekt hebt auch Mansbridge hervor. Sie geht von einer grundsätzlich positiven Rolle von Verhandlungssystemen im Zusammenhang einer demokratischen Willensbildung aus, denn »Interest groups not only collect information, mobilize support, and submerge disagreement (presumably against the interests of those whose views are submerged); they also distill and order individual preferences by encouraging their members to think about, talk about, and bring to the point of individual decision considerations on various sides of an issue « (Mansbridge, 1992: 501). Diese positiven Effekte neokorporatistischer Verhandlungssysteme stellen sich aber auch in ihrer Sicht nur dann ein, wenn die Verhandlungen unter Bedingungen stattfinden, »that redress to some extent the imbalances of the laissez-faire war of all against all. By >neocorporatism< I mean a system with three attributes. First, it values interest groups as ongoing institutional mechanisms for representing interests not easily represented in the territorial representative process. Second, it attempts to bring the laissez-faire system of interest representation partly under public control. Third, it looks beyond traditional economic and sectoral interests for the interests that should be represented « (495). Wenn dies zu gewährleisten ist, können die auf dem Verhandlungswege zu erreichenden Übereinkünfte vier Formen annehmen: sie können als Kompromiß, als »trade-off« und als Kompensation erscheinen, oder sie führen zu einer Reorientierung "where both factions abandon their initial positions to adopt a fundamentally new alternative $\ll(505$, Fn. 21$)$.

Der letztgenannte Effekt ergibt sich, wie van den Daele betont, daraus, daß in Diskursen »niemand das Schicksal seiner Argumente vollständig in der Hand (hat). Argumente führen ein Eigenleben; sie wirken auch wider Willen« (van den Daele, 1994: 27).

123 Diese Unterscheidung von institutionellen Kontexten von Kommunikation (öffentlich vs. nicht-öffentlich) einerseits und Handlungsorientierungen in der Kommunikationssituation selber (diskursiv vs. bargaining) findet sich bei Elster (1992). Vgl. dazu auch Saretzki (1994) und Buchstein (1992) - ich komme auf diesen Punkt weiter unten zurück. 
Lage sind, unterschiedliche Rationalitätsressourcen zu erschließen und in Prozessen kollektiver Problemlösung zusammenzuführen (Scharpf 1991: 56). Andererseits wissen wir auch, daß es nicht institutionelle Regulierungen allein sind, die den tatsächlichen Charakter materialer Politiken bestimmen (Scharpf 1987). Unter den Faktoren, die dabei eine zusätzliche, gewichtige Rolle spielen, treten vor allem in Hinblick auf Fragen der Steigerung von Sachangemessenheit unterschiedliche Entscheidungsstile wie Konfrontations-, Bargaining- und »Problemlösungsstrategien« (Scharpf 1991: 62 ff.) in den Blick, die einen eigenständigen normativen und kognitiven Status haben und sich mit Bezug auf das Problem der Verbesserung von Politikergebnissen zur Geltung bringen: Konfrontations- und Bargaining-Strategien, die Ergebnisse produzieren, die wesentlich von mobilisierbaren Machtressourcen abhängig sind, bleiben kognitiv unterbestimmt; allein Problemlösungsstrategien, die durch gemeinsame Ziele und die darauf bezogene kooperative Suche nach den besten Lösungen definiert sind (Scharpf 1991: 63), bieten ausreichend Chancen, moralische Orientierungen und kognitive Potentiale zu erschließen. Und darin drückt sich der normative Gehalt des Entscheidungsstils "Problemlösung « aus, daß er die institutionellen Arrangements auszeichnet, die am ehesten in der Lage sind, diese Bedingungen zu erfüllen. ${ }^{24}$

Kurz: Scharpf möchte die Kriterien der demokratischen Authentizität einerseits und der Effektivität und sachlichen Angemessenheit von Willensbildungs- und Entscheidungsprozessen andererseits gleichsam als Sonde benutzen, mit der sich geeignete Strukturentwicklungen auffinden und aus der breiten und bunten Vielheit von Formen der Politikvermittlung, der Policy-Formierung und -Implementation besser herausheben lassen. Und dies aus gegebenem Anlaß; denn, wie er zu Recht bemerkt, haben sich "nicht nur die politische Diskussion, sondern auch die politikwissenschaftliche Demokratietheorie ....auf die Realität der vielfach vernetzten und durch Verhandlungen handelnden Politik noch nicht einstellen können. Sie schreiben den politisch verantwortli-

124 Scharpf arbeitet vier Idealtypen von Verhandlungen heraus, indem die Merkmalsdimensionen "Umverteilung von Vorteilen und Lasten: $\mathrm{ja}$ /nein« und »Produktion neuer Lösungen: $\mathrm{ja}$ /nein « miteinander kombiniert. Dadurch erhält er die reinen Typen der negativen Koordination, der distributiven Verhandlung, der integrativen Verhandlung und der positiven Koordination (Scharpf, 1994: 391 ff.), die die Gemeinwohlorientierung des Handelns der Beteiligten auf unterschiedliche (und von 1 nach 4 zunehmend anspruchsvolle) Weise vermitteln. Fraglos tragen die Typen der positiven Koordination und der integrativen Verhandlung der kognitiven Dimension der Gemeinwohlproblematik noch am ehesten Rechnung; allerdings macht Scharpf auch auf ihre Grenzen aufmerksam, die vor allem in z.T. prohibitiv hohen Transaktionskosten liegen, denen man andererseits durch die Kombination von negativer und positiver Koordination entgegenwirken kann (398 ff.). Damit vertritt er allerdings eine minimale Auslegung der Logik von Verhandlungssystemen, die aus seiner Sicht durch den Zwang zur Einpassung dieser Form horizontaler Koordination in die Mechanismen adverserialer und pluralistischer Interessenpolitik gerechtfertigt ist, die gleichsam den Engpaß bilden, durch den modernisierende Strukturreformen hindurch müssen. Eine maximale - und demokratietheoretisch interessantere - Auslegung müßte demgegenüber eine Durchdringung und sukzessive Substitution der dominanten Typen negativer Koordination und distributiver Verhandlungen durch integrative Verhandlungen und positive Koordination im Rahmen eines Modells deliberativer Politik ins Auge fassen. 
chen Funktionsträgern weit mehr Ereignisbeherrschung zu, als diese auch unter günstigsten Umständen haben könnten - und sie tendieren umgekehrt dazu, alle Verhandlungszwänge auch als Demokratiedefizit zu registrieren« (Scharpf, 1992: 107).

Nun habe ich oben bereits anzudeuten versucht, daß die Sorge um das Demokratiedefizit mit Blick auf die korporatistische Auslegung solcher Verhandlungen ja nicht unberechtigt ist - sie bergen die deutliche Gefahr einer Kolonisierung des Staates (was Scharpf auch einräumt - 1993b: 36 ff.) und einer Usurpation der gesellschaftlichen Willensbildung. Diese bedenkliche Schlagseite läßt sich indessen korrigieren, wenn man die etwas andersartige, emergente Realität von Politik-Netzwerken in Rechnung stellt, die eine pluraler und inklusiver angelegte Form »gesellschaftlicher Regierung « vermitteln sollen (vgl. Kenis/Schneider, 1991). Der praktische Bezugspunkt für diese in den letzten Jahren auch theoretisch besser elaborierte Perspektive ist die Beobachtung der Herausbildung fokaler, problemzentrierter Interaktionszusammenhänge, von »policy communities«, die sich um kontroverse Politiken herum ausbilden, um den problematischer werdenden Anforderungen bezüglich des Designs, der Formulierung und Implementation von Politik besser gerecht werden zu können: »The core of this perspective is a decentralized concept of social organization and governance: society is no longer exclusively controlled by a central intelligence (e.g. the State); rather, controlling devices are dispersed and intelligence is distributed among a multiplicity of action (or >processing ) units « (Kenis/Schneider, 1991: 26).

Solche Arrangements lassen spezifische Vorteile erwarten. Nicht nur ermöglichen sie eine bessere Erschließung breit gestreuter und jedenfalls beim Staat knapper werdender politischer Ressourcen zur Lösung von Problemen. Sie können sich darüber hinaus auf Beteiligungsansprüche einstellen, die aus tatsächlicher Betroffenheit erwachsen, ohne im Gegenzug zu einer partizipatorisch induzierten »Übervölkerung « der einzelnen Politik-Arenen zu führen. Zudem wirken sie dadurch, daß die sachlichen Auseinandersetzungen und Interessenkonflikte in ein aus gemeinsamen Interaktionserfahrungen gewebtes Netz persönlicher Beziehungen eingebettet bleiben, auch den Belastungen und Dilemmata entgegen, wie sie typischerweise kooperativen Bestrebungen aus strategischen Handlungsorientierungen erwachsen. Daraus resultiert schließlich, daß der erhöhte Aufwand und die steigenden Kosten der Politikformulierung durch entsprechend geringere Kosten auf der Implementationsseite kompensiert werden können - m.a.W., sie sind, unter Bedingungen von hoher Interdependenz der Akteure und der durch diese vermittelten Problemperspektiven sowie einer breiten Streuung notwendiger politischer und kognitiver Ressourcen, im Prinzip effizienter und effektiver als hierarchische Formen der Steuerung (Kenis/Schneider, 1991: 43).

Inwieweit sich diese Vorteile im einzelnen auch wirklich einstellen (vgl. Mayntz, 1993: 48 ff.), hängt sicher zum einen von den sozialen Mechanismen ab, die in Verhandlungssystemen wirksam sind und die schon für sich genommen durch Interaktionserfahrungen, Vertrauensbildung und den Austausch von Informationen zu einer Transformation des Eigeninteresses der Beteiligten führen und ihre Kooperationsbereitschaft fördern; zum anderen aber auch von der Existenz von Regeln, die, unabhängig von ihrer spezifischen Orientierung an einem fairen Austausch, an Reziprozität, einer gerechten Verteilung von Kosten und Nutzen oder der sachangemessenen Lösung 
von Problemen, in jedem Fall den Beteiligten eine aufgrund ihrer wechselseitigen Geltung zumutbare Handlungsbeschränkung auferlegen. Entscheidend aber dürften schließlich die Bedingungen sein, unter denen der Typus der produktiven Problemlösung den bloßen Interessenausgleich und das Prinzip des Tauschs ${ }^{125}$ als Handlungsorientierung dominieren kann: dazu zählt zum einen (im Fall korporativer Akteure) die Ablösung des Selbstverständnisses der Beteiligten von den Eigeninteressen der entsendenden Organisationen (u.a. auf der Basis einer professionellen Identität) - ein Prozeß, der von der »Mehrebenenstruktur « korporativer Organisationen, die eine Differenzierung der Identifikationsebenen für Organisationsmitglieder als sog. »locals « und »cosmopolitans « ermöglicht, unterstützt wird; andererseits könnten Konsenschancen mindernde, gegnerschaftliche Orientierungen durch die Erhöhung der Wahrscheinlichkeit einer folgenreichen Beteiligung i.S. von Meinungserwerbs-, Artikulations- und Wirkungschancen so abgebaut werden, daß, wie Scharpf vorsichtig schließt, die institutionellen Bedingungen einer Einigungsbereitschaft wenigstens nicht strikt entgegenstehen (Scharpf, 1993b: 40). Davon einmal abgesehen, haftet jedoch auch diesen Arrangements noch ein bestimmtes demokratisches Risiko an, das sich in der Tendenz zur Selbstsektorierung und Selbstformatierung solcher Netzwerke und ihrer problematischen Vermittlung in den übergreifenden Gesamtzusammenhang der demokratischen Willensbildung zur Geltung bringt. Hier wird zum Problem, was sich bezüglich der internen, kooperativen und integrativen Handlungsorientierungen noch als Vorteil herausgestellt hatte: in dem Maße, in dem die interne Kohäsion wächst und sich im günstigen Fall ein wechselseitiges Verständnis und sogar gemeinsame Situationsdeutungen und Handlungsorientierungen ausbilden, werden die »externen« Beziehungen der Beteiligten zu den von ihnen repräsentierten Gruppen strapaziert; zudem sind »policy communities « vor dem Hintergrund der sie konstituierenden besonderen (Konflikt-) Biographie und besorgt um die Stabilität der gefundenen Arrangements eben auch anfällig für Tendenzen zur sozialen Schließung der Interaktionszusammenhänge (vgl. Scharpf, 1993b: 41).

Politik-Netzwerke, denen demokratietheoretisch gesehen ja die Funktion einer sozialen, sachlichen, zeitlichen und räumlichen Konzentration und Verdichtung der Willensbildung einer breiteren, aber nicht als solche institutionalisierbaren demokrati-

$125 \mathrm{Daß}$ indessen auch die Logik des »generalisierten Tauschs « nicht allein in der Rationalität individualistischer Nutzenkalküle verankert werden kann, zeigt sich schon daran, daß es gleichsam eines »institutionalisierten Gedächtnisses « (Benz, Scharpf) bedarf, um Koppelgeschäfte, bei denen sich die Tauschvorgänge über längere Zeiträume erstrecken und lokale resp. regionale Partialnutzenorientierungen übergreifen, zu ermöglichen. Darüber hinaus weist Mayer darauf hin, daß Institutionalisierungen, die diesen Tauschgeschäften eine gewisse Stabilität und Dauer vermitteln und die Kooperationsbereitschaft durch reiterative Interaktionen erhöhen sollen, allein nicht ausreichen, um das notwendige Vertrauen in die Ausgleichsleistungen anderer herzustellen und das free-rider-Problem zu überwinden: dies verlangt, statt einer egoistisch-rationalen Nutzenmaximierung, die Konzentration auf eine problemorientierte Globalausrichtung, die durch die zeitliche Vertaktung der Politik iiber (relativ) kurze Wahlperioden und die Bindung politischer Akteure an lokale oder regionale Elektorate nicht unbedingt gefördert wird (vgl. Mayer, 1994: 454 ff. und 466 f.). 
schen Öffentlichkeit zukommt, weisen mithin gerade in ihren Beziehungen zur demokratischen >Basis< eine gewisse Störanfälligkeit auf. Diese resultiert daraus, daß hier die Unzulänglichkeit der klassischen Mechanismen zur Überbrückung dieser Lükke besonders markant hervortritt: während die Verhandlungsfähigkeit (und damit die Effizienz der Verhandlungen) der an Verhandlungen Beteiligten nur gesichert werden kann, wenn der Anspruch demokratischer Legitimation auf die Delegation von Vertrauen reduziert wird, führen stärkere Rückbindungen etwa in Form eines simperativen Mandats zu Optionsverlusten, die den Verhandlungsprozeß schnell zum Stillstand bringen können und dessen Effizienz und Effektivität gefährden. Beide Lösungen sind defizitär, weil sie zu einem wechselseitigen Verbrauch dringend benötigter Optionalität führen - wenn es aber nichts zu entscheiden oder aber nichts zu verhandeln gibt, laufen das Kriterium demokratischer Legitimität und Authentizität und das ebenfalls wichtige Kriterium der Effektivität leer (vgl. Scharpf, 1993b: 41 f.).

Weil aber gleichzeitig die demokratische Öffentlichkeit als Quelle politischer Legitimität kein kollektiv handlungsfähiges Subjekt darstellt, muß an dieser Stelle dem demokratischen Verfahren eine insgesamt reflexivere Struktur eingeschrieben werden: Während die Delegation von spezifischen Entscheidungskompetenzen selbst auf diskursive Prozesse einer breiteren Öffentlichkeit zurückgehen kann, muß sich auch der >demokratische Souverän < unter den »autopaternalistischen« (Offe) Vorbehalt stellen, nicht zu jeder Zeit und zu jedem Thema die Entscheidungshoheit an sich ziehen zu wollen. Diese reflexive Orientierung kann zusätzlich dadurch gestützt werden, daß man anders als die beiden o.g. Lösungen es vorsehen, Strukturen vorhält, über die sich eine Vermittlung der internen und externen Perspektiven und Situationsdeutungen vollziehen kann. Beides zusammengenommen könnte zu einer Form der »integrativen Vermittlung « führen, von der sich auch Scharpf erhofft, daß dann »die jeweilige Basis die Chance erhielte, die kognitiven und evaluativen Lernprozesse der Verhandlungsführer mitzuvollziehen « und die Meinungen der Basis als revidierbare, »vorläufige Meinungen lern- und verständigungsbereiter Personen behandelt werden « (Scharpf, 1993b: 42 f.). Die vorausgesetzte Bereitschaft zur Selbstaufklärung eines breiteren $\mathrm{Pu}$ blikums dürfte sich aber umgekehrt erst unter der Voraussetzung einstellen, daß die Willensbildung in den ausdifferenzierten Handlungszusammenhängen auch von Politik-Netzwerken grundsätzlich offengehalten werden, um den Meinungsbildungsprozessen in den unterschiedlichen Öffentlichkeiten eine gewisse Wirkungschance zu vermitteln.

b) Mit plural zusammengesetzten Politik-Netzwerken haben sich also bereits demokratisch ausbaubare Strukturen ausdifferenziert, die im Prinzip der Forderung nach einer stärkeren Vergesellschaftung von Politik schon entgegenkommen, ohne den Preis eines groben Effizienzverlustes von Politik entrichten zu müssen. Und sie scheinen, jedenfalls in der Fassung als integrierte Vermittlungssysteme, den anspruchsvollen Voraussetzungen einer horizontal gelagerten gesellschaftlichen Praxis der Selbstkoordination entsprechen zu können. Wir haben aber auch gesehen, daß diese Leistung davon abhängen wird, inwieweit es gelingt, dem Prinzip der Öffentlichkeit Geltung zu verschaffen. Und zwar nicht nur in Richtung einer breite Beteiligung ermöglichenden Öff- 
nung der politischen Meinungs- und Willensbildungsmechanismen (Jänicke, 1993: 27) in Gestalt von Informationssystemen, politischen Parteien, Politikarenen und binnenpluralen Policy-Netzwerken; sondern auch im Sinne einer stärkeren diskursiven Zentrierung der Interaktionsformen in diesen Kontexten politischen Problemlösungshandelns. Das wird plausibel, wenn man Elsters Versuch einer Rekonstruktion der Prozesse und Ergebnisse der historischen amerikanischen und französischen Verfassungsdebatten im Lichte der Unterscheidung der Kommunikationsmodi von >Arguing und > Bargaining < in den Blick nimmt. ${ }^{126}$

Elster verbindet mit seiner Arbeit von vornherein ein über den unmittelbaren Anlaß der vergleichenden Beschreibung der Verfassungsgebungsprozesse hinausgreifendes, weit gestecktes Ziel (Elster, 1991: 2 ff.). Er möchte erstens in historischer Perspektive die fundamentalen anthropologischen Prämissen und institutionellen Leitideen herauspräparieren, die nicht nur in die unterschiedlichen Designs der Verfassungsordnung selber einfließen, sondern vielmehr auch die spezifische Form der historischen Beratungspraxis und Entscheidungsfindung bestimmen. Mit Bezug auf den erstgenannten Aspekt und die Frage der Stabilität von Verfassungsordnungen ist die Botschaft eindeutig, aber nicht eben überraschend: »The Americans designed their constitution on the worst-case assumption that human motivations will remain self-interested. The French believed that they could design a constitution that would change human motivations for the better. These two ideas need not be incompatible. But to design a constitution that will work only (Herv. i.O.) if it succeeds in changing motivations, is to court disaster « (Elster, 1991a: 33). Ein eigenes Gewicht gewinnt diese Feststellung aber zweitens erst dadurch, daß Elster die historische Einschätzung mit der soziologischen Frage nach verallgemeinerbaren Kontextbedingungen einer in diesem Sinne gelingenden Beratungspraxis verknüpft: hier ist seine These, daß die Instituierung der Verfassungsberatungen in Gestalt nicht-öffentlicher, »geheimer « Verhandlungen die Rationalität und Stabilität der Ergebnisse eher fördert (Elster, 1991: 98). Nachdem diese Entscheidung getroffen ist, richtet sich sein Blick dann drittens auf die konzeptuelle Frage der internen Relationierung der Kommunikationsmodi von >Arguing < und $>$ Bargaining « und des ergebnisbezogenen Gewichts argumentativer, konsensorientierter Verhaltensdispositionen im Verhältnis zu eigeninteressierten, strategisch orientierten Einstellungen: an dieser Stelle weist er zumindest eine gewisse Überlegenheit von >Arguing nach, die sich sowohl der spezifischen Stärken dieses Kommunikationsmodus wie der relativen Schwächen von >Bargaining verdankt (Elster, 1991: 88 ff.). Kurz: was Elster am Beispiel des anspruchsvollen Prozesses der Verfassunggebung entwikkelt, ist ein allgemeines Modell rationalen, ergebnis- und entscheidungsbezogenen politischen Handelns, das auf kontraintuitive Weise die Momente von Deliberation und Nicht-Öffentlichkeit verbindet.

126 Jon Elster: Arguing and Bargaining in two Constituent Assemblies (1991). Eine erste Fassung dieses Papiers, auf die ich mich ebenfalls bezichen werde, hat Elster unter dem Titel »Arguing and Bargaining in the Federal Convention and the Assemblée Constituantes (1991a) vorgelegt. 
Elster unterscheidet nun die beiden Kommunikationsmodi unter den Gesichtspunkten der jeweils in Anspruch zu nehmenden Motive und Akteurqualifikationen, der erschließbaren Ressourcen, der Kontextbedingungen und der vorherrschenden Ergebniserwartungen. Daraus ergibt sich zunächst so etwas wie ein differentielles Leistungsprofil, das sich grob folgendermaßen beschreiben läßt. ${ }^{127}$ Das Ziel von >Arguing< ist es danach, andere zu überzeugen und sich selbst plausiblen Gegenargumenten angesichts strittiger normativer und Tatsachenbehauptungen nicht zu verschließen - zählen soll, und hier übernimmt Elster die Formulierung von Habermas, allein die Kraft des besseren Arguments. Demgegenüber besteht das Ziel bei >Bargaining «-Prozessen in der Machterhaltung resp. der relativen Machtsteigerung - was jetzt zählt, sind Machtressourcen, mit denen Akteure ihren wechselseitigen Drohungen und Warnungen eine gewisse Glaubwürdigkeit verleihen können. Deshalb unterscheiden sich auch die Motive und Akteurqualifikationen, die in beiden Kommunikationsmodi vorausgesetzt sind. Das >Arguing< ist von der Bereitschaft zur reflexiven Selbstdistanzierung der Akteure genauso abhängig wie von der logischen und moralischen Widerspruchsfreiheit ihrer Interssen, wozu nicht zuletzt gehört, keine zeitlich inkonstanten Präferenzen zu entwickeln und sich nicht opportunistisch oder taktisch, sondern authentisch zu den eigenen Präferenzen zu verhalten; demgegenüber stellen sich Akteure im Modus des $>$ Bargaining< generell wechselseitig von moralischen Anforderungen frei, erwartet wird lediglich die Bereitschaft und Fähigkeit, den subjektiv erwarteten Nutzen mit Mitteln der Verschleierung, des Rückgriffs auf externe Ressourcen und der Drohung wie Warnung zu maximieren. Dieses Muster der Kontrastierung anspruchsarmer, aber realistischer und anspruchsvoller, aber unwahrscheinlicher Dispositionen setzt sich bezüglich der Kontextbedingungen und der Ergebnisse fort. Danach sind Argumentationen prinzipiell auf Handlungssituationen angewiesen, die sich durch eine hohe sachliche, soziale und zeitliche Durchlässigkeit auszeichnen und das Verfahren mithin nicht von vornherein unter den Druck enger zeitlicher Begrenzungen setzen, während der Modus der >Bargaining < dann in Führung geht, wenn Entscheidungsstreß vorherrscht, die Komplexität der zu behandelnden Fragen eher gering ist oder sich auf Verteilungsfragen reduzieren läßt und wenn sich ein sozial exklusiver Handlungszusammenhang unter nach außen durchsetzungsstarken Akteuren etablieren läßt. Dementsprechend gilt als Gütekriterium relevanter Ergebnisse einerseits ein machtneutralisierender, sachlicher Konsens über strittige Fragen und andererseits ein machtteilender Kompromiß.

M.a.W. liegen die Vorteile des >Bargaining < darin, daß das Verfahren nicht auf unwahrscheinliche oder zumindest nicht sicher erwartbare Motivationen angewiesen ist, $\mathrm{da} ß$ der Zeitverbrauch vergleichsweise gering ist und daß Ergebnisse erzielt werden können, ohne daß man sich auf die Gründe, die zu dem Ergebnis führen, auch einlassen muß. Dem stehen nun aber auch spezifische Nachteile gegenüber, die vor allem darin bestehen, daß die durch den Einsatz von Machtmitteln wie Drohungen und Warnungen

$127 \mathrm{Vgl}$. zum folgenden Saretzki (1994: $8 \mathrm{f}$.). Saretzki bezieht sich an dieser Stelle seinerseits auf einen mündlichen Vortrag Offes auf einer Tagung zur »Macht der Öffentlichkeit - Öffentlichkeit der Macht« vom Juni 1991 in Bad Homburg. 
bestimmten Ergebnisse insgesamt kognitiv unterbestimmt bleiben; daß eine endemische Neigung zur strategischen Fehlrepräsentation von Präferenzen und die $»$ Kündbarkeit « von Kompromissen im Lichte der Neubewertung der je eigenen, kurzfristigen Interessen auch die Stabilität der erreichten Absprachen gefährdet - kurz: die Gewinne durch möglicherweise niedrigere Entscheidungsfindungskosten können leicht auf Kosten einer angemessenen Problembewältigung erkauft werden (Saretzki, 1994: 15).

Der Nachweis der begrenzten Leistungsfähigkeit von `Bargaining‘-Prozessen bildet indessen noch keinen unmittelbaren Einwand gegen das Argument Elsters, der ja die differentielle Leistungsfähigkeit der beiden Kommunikationsmodi gerade zum Anlaß genommen hatte, auf die Notwendigkeit des stärkeren Einbaus diskursiver Formen in unvermeidlich immer auch strategisch bestimmte Interaktionszusammenhänge zu verweisen. Daraus entstehen jedoch Probleme eigener Art, die vor allem damit zu tun haben, daß die Akteure in Kontexten des >Bargaining $<$ nicht wirklich die Option haben, aus dem Sprachspiel von Drohung, Warnung und Versprechen auszusteigen und auf den verständigungsorientierten Modus des >Arguing $<$ umzusteigen, weil in Kontexten strategischen Handelns der jederzeit mitlaufende Verdacht eines nur strategischen Gebrauchs von Argumenten prinzipiell nicht auszuräumen ist (Elster, 1991: 85 ff.; vgl. auch Saretzki, 1994: 18). In dieser mißlichen Konstellation muß es Elster deshalb darauf ankommen, Bedingungen freizulegen, unter denen ein strategisch motiviertes Interesse an >Arguing unter der Hand zu einem tatsächlichen Wechsel des dominanten Sprachspiels führt - womit er rechnet, ist so etwas wie die »zivilisierende Kraft der Heuchelei« (Elster, 1991: 7), die sich auf unterschiedliche Weise bemerkbar machen kann. Zum einen kann die rationale Praxis des Argumentierens eine Schutzfunktion für die Akteure annehmen, die ansonsten nur über geringe Verhandlungsmacht verfügen - diese werden, so die Annahme, auf eine vorgängige wechselseitige Verpflichtung auf den Modus des `Arguing « drängen. Zum zweiten macht es der Gebrauch von Argumenten im Gegensatz zur offenen Artikulation von eigennützigen Interessen den Betroffenen und einer breiteren Öffentlichkeit schwerer, die wirklichen Effekte der Absprachen auch zu erkennen. Während hier Argumente nur so etwas wie einen Schleier bilden, hinter dem sich die eigentlichen Absichten umso besser und ungestörter entfalten können, ist es drittens selbstverständlich nicht auszuschließen, daß beteiligte Parteien einen ernsthaften Gebrauch von Gründen machen, um etwa neutrale Dritte auf ihre Seite zu ziehen und von ihrem Anliegen zu überzeugen. Schließlich können sich auch Akteure, die primär an der Maximierung oder komparativen Optimierung des eigenen Vorteils interessiert sind, der sozialen Norm, die besagt, $\mathrm{da} ß »$ no one should take a position that cannot be justified in terms of benefits of the collectivity« (Elster, 1991: 90), nicht vollständig entziehen. Faktisch hängt nun die rationalisierende Wirkung dieser Motivlagen von Bedingungen ab, die gerade in Verhandlungen nicht als regelmäßig gegeben angesehen werden können und auf deren Herstellung deshalb zu dringen wäre: sie wird letztlich über die Präsenz wirklich unabhängiger, neutraler Akteure im Verhandlungssystem wie über die Einbettung von Verhandlungen in Foren öffentlicher Willensbildung vermittelt. ${ }^{128}$

128 Auf beide Aspekte komme ich weiter unten (Kap. 9.3) noch ausführlicher zurück. 
Dies ist aber schließlich die Stelle, an der sich Elsters konzeptioneller Vorschlag tatsächlich ernsthaften Einwänden aussetzt. Wie schon erwähnt, operiert Elster eigentlich mit zwei Unterscheidungen, von denen sich die eine auf institutionelle Kontexte der Kommunikation (öffentlich vs. nicht-öffentlich resp. »geheim«), die andere auf die Orientierungen in der Kommunikationssituation (`Arguing $<$ vs. >Bargaining $<$ ) bezieht. Auf diese Weise bereitet er seine Pointe vor, daß gerade nicht-öffentliche Kommunikationssituationen bessere Bedingungen für die interne Entfaltung einer rationalen, argumentativen Praxis bereithalten, weil Anreize zur Verschleierung tatsächlicher Präferenzen und zur bloß rituell-formelhaften Bedienung des Prinzips der Publizität entfallen. Diese Effizienzvermutung kann allerdings vier Einwänden, die in der Perspektive der Inklusion, der Legitimation, der Problemdefinition und der Präferenzgenese erwachsen, nicht standhalten. ${ }^{129}$

In Hinblick auf diese Dimensionen rationaler Problemlösung und Konfliktregulierung stellt Öffentlichkeit insgesamt eine nicht substituierbare Kommunikationsbedingung dar. Generell ist davon auszugehen, daß die Rationalität einer Problemlösung sozial von der vorgängigen Berücksichtigung aller einschlägig berührten Interessen und sachlich von der angemessenen Repräsentation der relevanten Problemperspektiven wie der unterschiedlichen Problemaspekte abhängig ist. Die Lösung dieser Repräsentationsaufgabe ist aber gerade unter Bedingungen hoher sachlicher Komplexität und der komplexen Vernetzung einzelner Politikmaterien wesentlich auch sozial vermittelt: hier übernimmt eine nicht nur begrifflich mit Offenheit korrelierte Öffentlichkeit die wichtige Funktion der Erzeugung oder Entdeckung faktischer Betroffenheit, auf die sich dann Teilhabeansprüche auch normativ stützen. Dieser sachlich motivierten und normativ begründeten Forderung der Inklusion aller Betroffenen wirkt aber der Zwang zur Abgrenzung von funktionstüchtigen Entscheidungszusammenhängen jedenfalls dann entgegen, wenn man lediglich auf implizite oder explizite, aber nur intern verhandelte »boundary rules « rekurriert - die Zustimmungsfähigkeit solcher SchlieBungsregeln läßt sich nicht im Lichte der monologisch in Anspruch genommenen Vernünftigkeit simulieren, sondern sie bleibt von der faktischen, rational motivierten $\mathrm{Zu}$ stimmung aller Betroffenen abhängig. Natürlich ist nicht auszuschließen (und darüber hinaus häufig der Fall), daß Betroffene die Ausübung ihrer Teilhabeansprüche unter den autopaternalistischen Vorbehalt der Vermeidung von Selbstüberforderung stellen. Die für die Legitimität von Verhandlungssystemen entscheidende Reflexivität des demokratischen Prozesses insgesamt wird jedoch unter Bedingungen von Nicht-Öffentlichkeit an entscheidender Stelle unterbrochen, weil die Entscheidung über eine mögliche (und möglicherweise vernünftige) soziale, sachliche und zeitliche Konzentration und Kondensation von Prozessen der Entscheidungsfindung und die Frage der Delegation von Teilhaberechten resp. Verantwortlichkeiten der demokratischen Willensbildung entzogen wird. Diese Defizite machen sich schließlich auch darin bemerkbar, daß Elster für seine Behauptung der Überlegenheit von hinter verschlossenen Türen sich entfaltenden Argumentationen den Preis einer Reduzierung der diskursiven Kompo-

129 Im folgenden beziehe ich mich wiederum auf Saretzki (1994: $22 \mathrm{ff}$.). 
nente auf die Ebene sachlicher Fragen und pragmatischer Erwägungen entrichten muß. Das ist aber schon für sich genommen eine unangemessene Verkürzung der Willensbildung, »weil die Frage nach der normativen Qualität des Wollens oder Sollens gar nicht mehr gestellt wird. Wenn ein Akteur vor einem Problem steht, dann stellt sich die klassische Frage: was soll ich tun? ... auf dreierlei Weise: als pragmatische Frage nach dem Wollen, als ethische Frage bedingten Sollens im Rahmen einer konkreten sittlichen Lebensform und als moralische Frage nach der Gerechtigkeit« (Saretzki, 1994: 28). Diese drei Aspekte individueller Handlungsorientierung aber müssen auch auf der Ebene der kollektiven Willensbildung in geeigneten Mechanismen und Verfahren ihre Entsprechung finden. Das aber heißt, daß Öffentlichkeit ein kaum reduzierbares Ferment nicht nur der demokratischen Praxis der Selbstbestimmung schlechthin, sondern auch der rationalen Problembewältigung in einzelnen Bereichen politischen Handelns darstellt.

\subsection{Politische Problemlösung in deliberativen Arenen}

Diese unvermeidliche Verschränkung der Idee einer rationalen, argumentativen Praxis mit der Idee der Öffentlichkeit müßte also auch mit Blick auf die Einrichtung und institutionelle Ausgestaltung ausdifferenzierter Verhandlungssysteme besser zur Geltung gebracht werden. Genau auf diesen Punkt zielen etwa die Vorstellung diskursiver Planungsprozesse ${ }^{130}$ und Verfahren der Mediation, die vor allem in den USA in den letzten Jahren über ein breites Spektrum materialer Einzelpolitiken mit durchaus einigem Erfolg Anwendung gefunden haben. ${ }^{131}$ Wie oben schon angedeutet, verdanken sich diese Verfahrensinnovationen im Bereich der Politikformulierung und -implementation den besonderen Schwierigkeiten und Anforderungen, denen sich die politische Regulierung und Lösung von Konflikten zunächst im Bereich der Umweltpolitik konfrontiert sah. Die in diesem Zusammenhang wesentlichen Aspekte haben Magidan, Susskind und Weinstein folgendermaßen auf den Punkt gebracht: »Als Besonderheiten für die Beilegung von Umweltstreitigkeiten lassen sich insbesondere benennen: die Existenz von irreversiblen ökologischen Effekten; die Art, die geographischen Gren-

130 Auf Anforderungen und Möglichkeiten der diskursiven Ausgestaltung von gesellschaftlich notwendigen Verständigungsprozessen im Bereich der Umwelt- und Technologiepolitik hatte ich oben unter Rückgriff auf Überlegungen Ueberhorsts schon hingewiesen.

131 Auch in der deutschen Diskussion und Verwaltungspraxis wird inzwischen vermehrt auf diese Konzepte der Konfliktbewältigung durch mittlerunterstützte Verhandlungen zurückgegriffen, obwohl dem die ganz andere deutsche Verwaltungstradition zunächst entgegengestanden haben mag. Vgl. Hoffmann-Riem/Schmidt-ABmann (1990), van den Daele (1991), Zilleßen/Barbian (1992), Fietkau/Weidner (1992) und Zilleßen/Dienel/Strubelt (1993). Für die USA vgl. insbesondere Bingham (1986), Susskind/Cruikshank (1987), Reich (1988), Susskind/MacMahon (1990), Magidan/Susskind/Weinstein (1990) und Ozawa/Susskind (1990). Instruktive Überlegungen zu einer breiteren und effektiven Beteiligung gesellschaftlicher Gruppen an Prozessen kollektiver Problemlösung sowohl auf nationaler, regionaler oder lokaler Ebene finden sich auch bei Cohen/Rogers (1992: $434 \mathrm{ff}$.). 
zen, die Teilnehmer und die Kosten von Eingriffen in die Umwelt sind häufig nur schwer abschätzbar; die betroffenen Parteien nehmen oft in Anspruch, daß sie ein weitgefaßtes Allgemeinwohlinteresse (einschließlich der Interessen der leblosen Natur, der wild lebenden Tiere und der zukünftigen Generationen) vertreten und die Implementation der von den betroffenen Parteien ausgehandelten Vereinbarungen ist schwierig. Die Durchführung von mittlergeschützten Aushandlungsprozessen wird überdies durch die Einschätzung einiger Entscheidungsträger und weiter Teile der Öffentlichkeit erschwert, Konflikte um einen notwendigen Umweltschutz seien im wesentlichen ein Streit um ihre richtige wissenschaftliche Beurteilung...Wir sind demgegenüber der Auffassung, daß die Auseinandersetzungen im Umweltschutzbereich mindestens ebenso eine Kontroverse über die richtige technische Entscheidung wie über unterschiedliche Wertvorstellungen ist« (1990: 158).

Kurz: hier verbinden sich die für sich genommen schon schwierige Beantwortung kognitiver und evaluativer Fragen mit Problemen der Abgrenzung von Entscheidungsarenen einerseits und der Kompetenzverteilung zwischen staatlichen Entscheidungsträgern, wissenschaftlicher Expertise und staatsbürgerlicher Öffentlichkeit andererseits. Diesen Anforderungen sind die klassischen Strukturen staatlicher Politik und die Mechanismen hierarchischer Steuerung ganz augenscheinlich nicht gewachsen. Und das hat nicht nur mit der für sachliche Einzelfragen unsensiblen, zeitlich strukturierten Periodizität von Wahlen und Abstimmungen, den spezifischen Unzulänglichkeiten der Mehrheitsregel, den kurzfristigen Handlungsorientierungen der politischen Entscheidungsträger oder dem >winner-takes-it-all-Charakter konkurrenzdemokratischer Mechanismen zu tun (vgl. Susskind/Cruikshank, 1987: 39 ff.). Darauf haben westliche politische Systeme durch einen mehr oder weniger intensiven und mehr oder weniger formalisierten Rückgriff auf horizontal gelagerte, tripartistische Verhandlungssysteme zwischen dem Staat (der staatlichen Verwaltung) und gesellschaftlichen Großverbänden in gewisser Weise schon reagiert. Aber auch diese bleiben wegen ihrer sozialen Exklusivität und den auf Verteilungskompromisse spezialisierten, rein instrumentellen Praktiken der Interessenvermittlung resp. der Netto-Nutzen-Maximierung hinter den Anforderungen und Möglichkeiten zurïck (vgl. Reich, 1988: 129 ff.). Dies vor allem deshalb, weil keine dieser Techniken Anreize für eine reflexive Überprüfung bestehender Präferenzen (also kollektives Lernen) und für das Auffinden innovativer Problembeschreibungen und -lösungen enthält: "...neither (of these techniques, der Verf.) creates an opportunity for the public to deliberate about what is good for society. Yet it is through such deliberation that opinions can be revised, premises altered, and common interests discovered « (Reich, 1988: 144).

Aus diesen Gründen optiert Reich denn auch an gleicher Stelle sowohl für eine gröBere interne Pluralität von Verhandlungssystemen als auch für eine stärker diskursive Zentrierung der Verfahren und Konfliktlösungsstrategien. Davon erwartet er sich im einzelnen folgende Vorteile: Zunächst bietet sich die Chance, das zu verhandelnde Problem im Lichte gemeinsamer Interessen genauer zu definieren und Interessenkonflikte so in ein Projekt zu transformieren, daß alle Beteiligten unterstützen können; darüber hinaus sollten deliberative Prozesse die wechselseitige Anerkennung aller Beteiligten und ihrer legitimen Interessen befördern und im Lichte einer sich einstellenden Multi- 
perspektivität die Neubewertung und -formulierung eigener Präferenzen erleichtern; schließlich können auch tieferliegende Konfliktstrukturen, die gerade dann, wenn sie unerkannt bleiben, Einigungschancen vermindern, besser hervortreten und so zu einer Konzentration der Beratungen auf die bedeutungsvollen und entscheidenden Fragen führen. Dies verbürgt, für sich genommen, selbstverständlich nicht, daß konsensuelle Lösungen für anstehende Probleme auch erreicht werden; aber öffentliche, deliberative Prozesse bieten immerhin die Möglichkeit, auch gemeinsame Werte und Interessen zu entdecken: »Deliberation does not automatically generate these public ideas, of course: it simply allows them to arise (Reich, 1988: 144 ff. und 146). Vor diesem Hintergrund kommt der staatlichen Politik, auch wenn die allgemeine Gesetzgebung dann nicht mehr der alleinige Adressat für Forderungen nach einer Verbesserung der inhaltlichen Qualität der Ergebnisse von Politik ist, die Aufgabe zu, durch geeignete Maßnahmen das »Niveau der Diskursivität in der Gesellschaft« zu heben und mit der gezielten Einrichtung deliberativer Arenen in die »Handlungsfähigkeit der Gesellschaft« zu investieren (van den Daele, 1994: 195). In diesem Sinne kann man beispielsweise Mediationsverfahren (a) und diskursive Verfahren der Technikfolgenabschätzung (b) als Formen der periodischen Herstellung effektiver politischer Öffentlichkeiten verstehen, die, wenn sie in neue Muster horizontaler Selbstkoordination, wie sie politische Netzwerke im Prinzip bereithalten, eingepaßt werden, als Kristallisationskerne einer graduellen Transformation der Politik nach dem Prinzip der Selbstregierung fungieren können.

a) Konturiert gegen die Unzulänglichkeiten staatlicher Politik und programmatisch bezogen auf die Überwindung der Blind- und Schwachstellen der Standardverfahren zur politischen Konfliktregulierung besteht die besondere Rationalität mittlergestützter, diskursiver Verfahren in der innovativen Suche nach Problemdefinitionen und -lösungen, die für alle Beteiligten und Betroffenen akzeptabel sind. Dieser Weg führt über das wechselseitige Ausloten von Handlungsspielräumen zur Suche nach neuen Lösungen im Medium eines fairen Dialogs sowie unter Einbezug auch der Personen und Gruppen, die in bisherigen, förmlichen Verwaltungsverfahren keine oder nur schwache Beteiligungsrechte haben (vgl. Fietkau/Weidner, 1992: 27): »Die Konfliktmittlung ist ein Verfahren, in dem diejenigen, die an dem Konflikt beteiligt sind, gemeinsam versuchen, ihre Streitigkeiten zu erkunden und beizulegen. Der Konfliktmittler (Mediator, d. Verf.) hat keine Autorität, den Konfliktparteien eine Lösung aufzuzwingen. Seine Stärke liegt in der Fähigkeit, den Parteien bei der Lösung ihrer eigenen Streitigkeiten zu helfen. Ein Konflikt ist dabei als beigelegt anzusehen, wenn die Parteien eine Übereinkunft erzielt haben, die sie selbst als eine arbeitsfähige Konfliktlösung bezeichnen (Cormick, 1978: 2; zitiert nach Magidan/Susskind/Weinstein, 1990: 153). Danach zeichnet sich diese Form der Konfliktregulierung vor allem durch drei Elemente aus. Erstens suchen alle von einer Entscheidung Betroffenen oder am Ergebnis Interessierten gemeinsam nach einer Problemlösung - weil dies nur über geordnete Verfahren der Beteiligung erreichbar ist, impliziert es die Vorstellung einer umfassenden demokratischen Kompetenz des Bürgers, mindestens seine Repräsentanten in diesem Verfahren auch selber zu bestimmen. Zweitens zielt der Verhandlungsprozeß auf einen vernünftigen Konsens, der im gleichmäßigen Interesse aller liegt, so daß gleichzeitig auch ein stabiles Interesse an der faktischen Implementation der Ergebnisse er- 
zeugt wird. Das setzt drittens voraus, daß Fragen der (autonomen) Verfahrensdefinition mindestens ebenso viel Beachtung finden wie der eigentliche Konfliktinhalt (vgl. Zilleßen/Barbian, 1992: 16). ${ }^{132}$ Der Innovationsgrad dieser Praxis wird insbesondere dann deutlich, wenn man die konstitutiven Merkmale dieses konsensorientierten Verfahrens jenen konventioneller Ansätze gegenüberstellt (Susskind/Cruikshank, 1987: 78)

\begin{tabular}{|c|c|c|}
\hline Attributes & Conventional Approaches & Consensual Approaches \\
\hline Outcomes & $\begin{array}{l}\text { Win-lose; impaired } \\
\text { relationships }\end{array}$ & $\begin{array}{l}\text { All-gain; improved } \\
\text { relationships }\end{array}$ \\
\hline Participation & Mandatory & Voluntary \\
\hline Style of interaction & Indirect & Direct (face-to-face) \\
\hline Procedures & $\begin{array}{l}\text { Same ground rules and } \\
\text { procedures apply designed } \\
\text { in all cases }\end{array}$ & $\begin{array}{l}\text { New ground rules and } \\
\text { procedures } \\
\text { for each case }\end{array}$ \\
\hline $\begin{array}{l}\text { Methods of reaching } \\
\text { closure }\end{array}$ & $\begin{array}{l}\text { Imposition of a final } \\
\text { acceptance of a } \\
\text { determination by a judge or } \\
\text { an official }\end{array}$ & $\begin{array}{l}\text { Voluntary } \\
\text { final decision by the parti }\end{array}$ \\
\hline Roles of inter-mediaries & $\begin{array}{l}\text { Unassisted; } \\
\text { no roles for intermediaries }\end{array}$ & $\begin{array}{l}\text { Assisted or unassisted; } \\
\text { various roles for interme- } \\
\text { diaries }\end{array}$ \\
\hline Cost & $\begin{array}{l}\text { Low to moderate in the } \\
\text { short term; } \\
\text { potentially very high in the } \\
\text { long term }\end{array}$ & $\begin{array}{l}\text { Moderate to high in the } \\
\text { short term; } \\
\text { low in the long term if suc- } \\
\text { cessful }\end{array}$ \\
\hline Representation & $\begin{array}{l}\text { General-purpose elected or } \\
\text { appointed officials }\end{array}$ & $\begin{array}{l}\text { Ad-hoc; specially selected } \\
\text { for each negotiation }\end{array}$ \\
\hline
\end{tabular}

Der besondere Reiz dieses Verfahrensmodells liegt nun im argumentativen Zusammenhang unserer Überlegungen zweifellos darin, daß es mit wesentlichen Formprinzipien der Idee der reflexiven Demokratie zusammenstimmt: die Idee einer rationalen demokra-

132 Darüber hinaus kommt der Frage der Ressourcengerechtigkeit eine wichtige Bedeutung für die Akzeptanz solcher Verfahren und die Bindungswirkungen, die sie entfalten, zu. Gerade ressourcenschwache Teilnehmer sind darauf angewiesen, daß ausreichend Mittel für die Bestellung von Gutachten oder die Kompensation individueller Aufwendungen insbesondere bei denen zur Verfügung stehen, die ehrenamtlich, freiberuflich oder durch Spenden finanziert arbeiten müssen (vgl. van den Daele, 1994: 14 ff.). 
tischen Praxis wird gleichzeitig unter Legitimitäts- wie Effektivitätsgesichtspunkten entfaltet; die deliberativen Prozesse weisen einen deutlichen Entscheidungsbezug auf und sind offen für eine fallspezifische Justierung unterschiedlicher demokratischer Teilhabeformen; schließlich werden Fragen des Arenazuschnitts und des Designs der Verfahren in die Praxis demokratischer Selbstbestimmung zurückgestellt, was zu einer internen Differenzierung der Problemlösung nach der Behandlung pragmatischer, ethischer und moralischer Fragen im Rahmen eines mehrstufigen Verfahrens der Relationierung aufeinander abgestimmter Willensbildungsprozesse führt. Deshalb sind die aus der praktischen Anwendung dieses Modells resultierenden Erfahrungen und institutionellen Innovationen auch in besonderer Weise instruktiv, insofern sie einen genaueren Blick auf die sich einstellenden Probleme und ihre Lösungsperspektiven ermöglichen. So kann man in vorsichtiger Verallgemeinerung drei Faktorenkomplexe unterscheiden, von denen der Erfolg von Verfahren der Mediation abhängt: dies sind parteienbezogene, prozeß- und kontextbezogene wie sach- und themenbezogene Faktoren, deren Berücksichtigung eine insgesamt reflexivere Verfahrensstruktur nahelegen (vgl. Bingham, 1986: $96 \mathrm{ff}$. ).

Grenzziehungen und die Verteilung von Teilhaberechten sind dabei von vorrangiger Bedeutung, weil die Beurteilung der Richtigkeit von Ergebnissen am Ende auch davon abhängen wird, inwieweit alle möglicherweise Betroffenen eine faire Chance hatten, ihre Interessen und Gesichtspunkte im Laufe des Verfahrens auch zur Geltung zu bringen. Nun ist die Identifizierung möglicher Betroffener gerade in komplexen Handlungssituationen mit nicht immer überschaubaren Wirkungen einzelner Maßnahmen für sich genommen schon nicht leicht. Aus verschiedenen Gründen kann darüber hinaus die genaue Form der Beteiligung problematisch werden: so, wenn zu fragen ist, wie unterschiedliche Interessen überhaupt effektiv repräsentiert werden können - und dies vor allem dann, wenn der vorgängige Organisationsgrad dieser Interessen eher niedrig ist; oder wenn die an einer Konfliktregulierung interessierten Parteien an unterschiedlichen Stellen des Verfahrens involviert werden; oder wenn schließlich ein Konflikt so viele potentiell Betroffene involviert, daß aus pragmatischen Erwägungen der begrenzten Aufnahmefähigkeit diskursiver Verfahren heraus einfach nicht alle zu jeder Zeit auch effektiv beteiligt werden können. Für all diese Fragen und Probleme gibt es ganz offensichtlich keine allgemeinen, durch institutionelle Regeln vorentscheidbare Lösungen, so daß es Aufgabe des Mediators und letztlich der Betroffenen bleiben muß, möglichst faire, paßgenaue und prinzipiell revisionsoffene Regelungen zu finden und zu implementieren (Bingham, 1986: 96 f.; vgl. auch Susskind/MacMahon, 1990: 71 f.).

$\mathrm{Zu}$ den prozeßbezogenen Erfolgsbedingungen gehört sicherlich auch, daß die Parteien genug Anreize haben, sich auf einen unter diesen Bedingungen zunächst schwierigen, zeitraubenden und auch kostenträchtigen Prozeß überhaupt einzulassen. Hier kommt die Erwägung komparativer Kosten, wie sie im Modus einer eher adverserialen Konfliktregulierung (etwa juristische Auseinandersetzungen) entstehen, genauso ins Spiel wie die Antizipation langfristig sinkender Kosten durch die konsensgestützte Überwindung von Blockaden der Ergebnisimplementation (Bingham, 1986: $108 \mathrm{ff}$.). Während diese Erwägungen eine Schwelle markieren, die überwunden werden muß, damit konsensorientierte Verfahren überhaupt in Gang kommen, treten im weiteren Verlauf Fragen des Einbaus von Expertise und der Repräsentation in den Vordergrund. 
Hierbei dürfte es zum einen entscheidend sein, den unvermeidlichen Rückgriff auf Experten so zu organisieren, daß auch hier unterschiedliche wissenschaftliche Meinungen zur Geltung kommen, ohne daß der Expertendialog oder -streit die demokratische Willensbildung insgesamt überspielt; zum anderen ist die effektive Kommunikation zwischen den unterschiedlichen Basisgruppen und ihren Verfahrensrepräsentanten sicherzustellen, was gerade mit Blick auf ad hoc-Gruppen oder diffuse Interessenlagen nicht ganz einfach sein dürfte (vgl. Bingham, 1986: 105 ff.). Eine dritte Sorte von Erfolgsbedingungen bilden endlich die themen- und sachbezogenen Faktoren. Zwar findet Bingham keine direkten empirischen Anhaltspunkte für eine signifikante Beziehung zwischen der Art der Themen und dem Erfolg der von ihr ausgewerteten Verfahren. Dennoch gibt es eine Beziehung derart, daß die Erfolgswahrscheinlichkeit steigt, wenn Fragen der Problemdefinition und des Agenda-Setting ausdrücklich zum Gegenstand direkter Gespräche und Verhandlungen gemacht werden: $\gg$ This probably increased the chances of success in this effort because ... the parties had to agree on the problem before they could agree on a solution (Herv. $\mathrm{d}$. Verf.) (Bingham, 1986: $117 \mathrm{ff}$. und 119).

Diese hier nur andeutungsweise sichtbar gemachten Verfahrensvoraussetzungen und -implikationen machen deutlich, daß mittlergestützte, problemlösungsorientierte Verhandlungssysteme den Charakter mikrokonstitutioneller Arrangements annehmen müssen, wenn sie die erwartete Legitimität und Effizienz erreichen wollen. D.h., es handelt sich um politische Handlungssysteme, die sich ihre Regeln nicht nur selber geben müssen, sondern Verfahren der prozeßbegleitenden Beobachtung, Adaptation und Revision dieser Grundregeln einrichten müssen. Diese selbstreflexive, rekursive Prozeßorientierung kann näherungsweise in ein Drei-Phasen-Modell der Konfliktmittlung übertragen werden, wie es etwa Magidan, Susskind und Weinstein (1990: $166 \mathrm{ff}$.) entwickelt haben. In einer ersten Phase der »Vorverhandlungen « sind danach folgende Probleme zu lösen: Erstens sind die am Verfahren interessierten und von möglichen Ergebnissen betroffenen Gruppen und Personen zu ermitteln, glaubwürdige Repräsentanten zu bestimmen und für funktionstüchtige Kommunikationsstrukturen zwischen den >Basisgruppen< und deren Verfahrensrepräsentanten zu sorgen. Zweitens sind der Konfliktmittler auszuwählen und drittens die grundlegenden Verfahrensregeln zu entwickeln. Viertens ist eine Liste der Streitgegenstände zu erstellen und fünftens sind finanzielle Ressourcen zur Durchführung der Verhandlungen zu erschließen. Sechstens sind, unter der Einbeziehung der notwendigen Expertise, Informationen zu sammeln und daran anschließend dann siebtens die für die Konfliktlösung als bedeutsam geltenden Tatsachen gemeinsam festzustellen. Achtens sind alle Teilnehmer aufgefordert, ihre Positionen darzulegen und die Probleme zu bestimmen, die sie zunächst bearbeitet wissen möchten.

Erst wenn diese Vorverhandlungen für alle Beteiligten zufriedenstellend abgeschlossen sind, kann die Phase der eigentlichen Verhandlungen und der Konsensbildung beginnen. Auch diese vollzieht sich über mindestens vier Schritte, wobei es wesentlich darauf ankommt, daß sich die Parteien wechselseitig für eine Unterscheidung ihrer eingenommenen Positionen von ihren Interessen sensibilisieren. Die Annahme ist dabei, daß die artikulierten Positionen häufig nur eine unter mehreren Möglichkeiten darstellen, mit denen den zugrundeliegenden Interessen Rechnung getragen werden kann - dies eröffnet nicht nur Chancen für die Entdeckung von Kompromißzonen, son- 
dern bildet den Ansatzpunkt für eine diskursiv orientierte, kognitive Anreicherung des Verfahrens und damit für kollektive Lemprozesse. Erst vor diesem Hintergrund sind dann auch Verhandlungspakete zu schnüren und distributive Probleme auf dem Wege von Kompensationszahlungen zu lösen. Diese Ergebnisse können dann in einer schriftlichen Vereinbarung festgehalten werden, die ihrerseits die Grundlage für die Phase der »Nachverhandlungen« bildet, in der Fragen der angemesseneren Umsetzung und Implementation zu klären sind. Dazu gehört, daß die Übereinkünfte mit formellen, rechtsförmigen Handlungen u.a. der Träger hoheitlicher Gewalt verknüpft und Mechanismen der Überwachung und Implementation der Ergebnisse in Gang gesetzt werden. Der letzte Schritt bestünde schließlich in einer allgemeinen Verfahrensevaluation auch in der Perspektive aktuell nicht am Verfahren beteiligter Gruppen und Personen, die gegebenenfalls Anlaß zur Wiederaufnahme des Verfahrens an unterschiedlichen Punkten bietet, zumindest aber dazu dienen kann, über das aktuelle Verfahren hinaus Verbesserungen für zukünftige Verfahren ins Auge zu fassen.

Das ist gewiß ein sehr suggestiver Vorschlag, der zudem den Vorteil hat, aus den Erfahrungen einer langjährigen Praxis von >public policies< in den USA zu erwachsen. Freilich ist andererseits auch nicht zu übersehen, daß sich die suggestive Kraft der Überlegungen auch der Tatsache verdankt, daß die Handlungs- und Verfahrensprobleme primär aus der Binnenperspektive einzelner Policy-Dialoge oder lokaler Verhandlungssysteme wahrgenommen werden. Das wirft indessen zusätzliche Fragen nach der möglichen Independen $z$ und der notwendigen Interdependenz solcher Arrangements im Gesamtzusammenhang unterschiedlicher Politiken ebenso auf wie Probleme der Einpasssung in etablierte Strukturen der politischen Willensbildung und Politikvermittlung. Diese Schnittstellenproblematik tritt auf der Konstitutionsseite markant etwa an Fragen der Formierung der spezifischen Politikarenen hervor; im Inneren des Verfahrens stellt sie sich mit Blick auf die Wahl zwischen unterschiedlichen, gleichwohl aber gut etablierten Techniken der Konfliktregulierung und des Verhältnisses von demokratischer Selbstbestimmung und wissenschaftlicher Expertise ein; auf der Implementationsseite ist die Verknüpfung dieser innovativen Praktiken mit der vorherrschenden Verwaltungspraxis und den rechtlichen Rahmenbedingungen des Verwaltungshandelns unvermeidlich. ${ }^{133}$

133 Deshalb bildet das Verfahren der mittlergestützten, diskursiven Problemlösung auch nur einen, und dazu sehr voraussetzungsreichen, Mechanismus der Konfliktregulierung. Daneben existieren weitere, konventionelle wie alternative Verfahren, u.a. das gegnerschaftliche Modell der gerichtlichen Entscheidung, das nicht auf Problemlösung, sondern auf Machtsteigerung und Interessendurchsetzung ausgelegte $>$ Bargaining ` sowie problemlösungsorientierte Verfahren der »non-assisted negotiation « (Susskind/Cruikshank, 1987: 80 ff.; vgl. auch Zilleßen/Barbian, 1992: 16). Sie gehen von unterschiedlichen Voraussetzungen aus, unterscheiden sich nach ihrer jeweiligen Kostenstruktur und sind auf unterschiedliche Ergebniserwartungen gerichtet - kurz: insofern sie als Verfahrensoptionen zur Verfügung stehen, resultiert für die spezifische 'policy community ein Optimierungsproblem derart, daß sie eine zielbezogene Wahl der geeigneten Verfahrensmittel vornehmen muß (vgl. Vidmar, I993: 42 ff.). Angesichts der Konfliktintensität einer Verfahrenswahl, die ja auch eine Bestimmung verfügbarer Machtmittel und eine relative Gewichtung vorhandener Machtressourcen beinhaltet und insoweit die wahrscheinlichen Ergebnisse des Prozesses nicht unwesentlich beeinflußt, dürfte es sinnvoll sein, diese Wahl selber in einem geordneten Verfah ren zu institutionalisieren. Diese Funktion könnte etwa ein »multifaceted 
b) Diese Fragen können hier weder in ihrer ganzen Breite noch mit der im einzelnen notwendigen Tiefenschärfe aufgenommen werden. ${ }^{134}$ Das gilt insbesondere für Probleme im Zusammenhang des deutschen Verwaltungsverfahrensrechts, das aber insgesamt der Implementation alternativer Formen der Problemlösung und Konfliktregulierung wenigstens nicht strikt entgegenzustehen scheint (vgl. Hoffmann-Riem, 1990: 33 ff.). Das gilt aber auch für Fragen nach verbesserten rechtlichen Bedingungen einer demokratischen Steuerung der gesellschaftlichen Entwicklung. Diese hätten sich generell an fünf Voraussetzungen zu orientieren, die Ueberhorst (1990: 150) am Beispiel von Technologiepolitik expliziert hat. Um demokratischen Verfahren überhaupt einen sinnvollen Angriffspunkt in der Entscheidung über technische Entwicklungspfade zu eröffnen, muß die Möglichkeit bestehen, zwischen der Nicht-Nutzung oder Nutzung einer bestimmten Technik oder zwischen funktional äquivalenten Alternativen überhaupt zu wählen; eine solche Wahl kann nur unter Bezug auf Werte stattfinden, die die jeweiligen Folgen auch unter normativen Gesichtspunkten beschreibbar machen; dies setzt wiederum die möglichst weitgehende Kenntnis der Folgen voraus; die Wahrscheinlichkeit einer inklusiven Wertberücksichtigung und angemessenen Folgenwahrnehmung hängt ihrerseits von einer breiten öffentlichen Erörterung der Alternativen ab; das soltte schließlich zu Regelungsprogrammen führen, deren Beachtung und Überprüfung in der Wirklichkeit erneut mit dem ersten Schritt zur Eröffnung neuer Altemativen führt. Unter allen diesen Gesichtspunkten weisen die Standardverfahren gravierende Mängel auf (Ueberhorst, 1990: 150 ff.), die von juristischer Seite dadurch zu beheben wären, daß die eben genannten Verfahrensanforderungen in rechtliche Gebote umgesetzt werden (Ueberhorst, 1990: 158). Das allerdings setzt dann auch voraus, daß sich die Rechtswissenschaft insbesondere von drei Fiktionen verabschiedet: daß die Aufgabe der Rechtserzeugung allein auf Justiz und Parlament konzentriert werden könne - diese muß an gesellschaftliche Diskurse zurückgebunden bleiben (Ueberhorst, 1990: 149, vgl. auch Habermas, 1992); daß der vielzitierte »Stand der Wissenschaft« als hinlänglicher normativer Orientierungspunkt fungiere oder daß sich Bür-

dispute resolution center« übernehmen, daß an die Stelle des herkömmlicher Gerichte tritt: »Instead of just one door / leading to the courtroom, such a comprehensive justice center would have many doors through which individuals might pass to get the most appropriate process. Among the doors might be ones labeled sarbitration<, >mediation< and >minitrialk. Provision might also be made for channeling disputes into specialized tribunals « (Sander, 1990: 145) Die Vorzüge dieses Modells, das gleichsam einer Initialzündung auch kollektiver Prozesse der Konfliktregulierung und Problemlösung dient, liegen zum einen darin, daß Konflikte je nach den Charakteristika der Konfliktmaterie in die zur Lösung des Problems am besten geeigneten Verfahren kanalisiert werden: »For example if we were dealing with a complex environmental tort case a minitrial ... might be employed. A multiparty siting dispute might well be sent to mediation, as the best way to sort out the interests of the various players. But if a case presented novel issues of statutory or constitutional interpretation, then it should go to court for a definitive ruling « (Sander, 1990: 145). Zum anderen erlaubt es eine prozeßbezogene Sequentialisierung, Stufung oder Ineinanderschaltung von Verfahrensalternativen, die je nach dem Typus der anstehenden Fragen, seien sie pragmatischer, ethischer oder moralischer Natur, aktiviert werden können und zugleich reflexiv aufeinander bezogen bleiben.

134 Die Richtung, in welche die Lösung der Schnittstellenproblematik weisen könnte, habe ich oben (Kap. 7.1 und 7.2) unter Bezug auf die Idee einer tiefen Staffelung und Sequentialisierung unterschiedlicher Formen der demokratischen Willensbildung anzudeuten versucht. 
ger mit ihren Meinungen in politische Willensbildungsprozesse und projektgebundene Beteiligungsprozesse ohne weiteres einbringen könnten - hier kommt man ohne eine rechtliche Verbesserung der Informations-, Meinungserwerbs- und Artikulationschancen nicht aus.

Es spricht also, genährt auch von vergleichenden empirischen Untersuchungen zu den Bedingungen einer erfolgreichen Umweltpolitik, einiges für die Vermutung, daß sich die Legitimität, Effizienz und Effektivität politischer Entscheidungen unter Risikobedingungen, also in Situationen, in denen sich die Unsicherheit über die Folgen des Handelns als kognitiver Dissens über die Wissensgrundlagen für politische Entscheidungen und als normativer Dissens über die Ziele gesellschaftlicher Entwicklung artikuliert, nur erhöhen läßt, wenn die Beteiligungschancen einzelner Bürger wie gesellschaftlicher Gruppen strukturell verbessert werden (vgl. Jänicke/Weidner, 1995: 21 ff.). Allerdings ist dann darauf zu achten, daß die Mobilisierung der Zivilgesellschaft nicht zu den komplementären Problemen einer Überlastung der motivationalen, assoziativen und rechtlichen Infrastruktur der Zivilgesellschaft einerseits und einer zu weitgehenden Irritation der staatlichen, administrativen und rechtlichen Entscheidungsroutinen andererseits führt. Auch letzteres könnte, wie Bora (1994) jüngst am Beispiel des Rechtssystems gezeigt hat, dysfunktionale und kontraintuitive Effekte derart auslösen, daß das Rechtssystem entweder durch zunehmende nichtrechtliche Interventionen in das Recht in Gestalt einer erweiterten Öffentlichkeitsbeteiligung seine Funktionsfähigkeit zu verlieren und zu »explodieren« droht, weil es genötigt wird, »seine Komplexität an die externen Ansprüche anzupassen und damit über die Obergrenze adäquater Komplexität zu steigern « (Bora, 1994: 147); oder aber es kommt zu Abwehrreaktionen einer Delegitimierung solcher Formen der Kommunikation, die sich nicht am Code des Rechts orientieren, mit der Folge, daß diese gleichsam ausgefiltert und vom Entscheidungsprozeß ferngehalten werden. Dieses Dilemma entsteht also dadurch, daß dem Recht, wie etwa im Falle der rechtlichen Steuerung der Entwicklung von neuen und riskanten Technologien, Entscheidungen zugemutet werden, die es nicht selber verantworten kann, so daß die Verantwortung an andere gesellschaftliche Teilsysteme (z.B. mit der Formel »Stand der Forschung « an die Wissenschaft) weitergereicht werden muß, die Normbildung also externalisiert wird. In diesem Zusammenhang rückt dann auch die Öffentlichkeitsbeteiligung in die Funktion einer Restabilisierung der kognitiven und normativen Entscheidungsgrundlagen - dies allerdings um den Preis der Mobilisierung von Sorten von Gründen, die rechtlich nicht mehr unmittelbar adaptierbar sind. ${ }^{135}$

135 So hat Bora an den »Problemzonen von Erörterungsterminen « fünf Arten von Argumenten herausgearbeitet, mit denen rechtliche Entscheidungsinstanzen in solchen Situationen konfrontiert werden können, von denen insbesondere die beiden letzten als problematisch anzusehen sind: wissenschaftliche, materiellrechtliche, verfahrensrechtliche, substitutive und methodologisch-evaluative (Bora, 1994: 139 ff.). Nach dieser Unterscheidung zielen substitutive Argumente auf die Ersetzung des Rechtscodes »Recht/Unrecht « durch Kriterien wie Moral oder Politik und bedrohen so die strukturelle Identität des Rechstssystems, während methodologisch-evaluative Argumentationen, die er unter den Stichworten des »hypothetischen Risikos«, der »Wissenschaftskritik «, der »Nutzen-Bewertung « und von »Ethik als Abwägungskriterium« erläutert, geeignet sind, die Spielräume der Gesetzesauslegung zu überdehnen und eine Flexibilität zu reklamieren, die die interne Konsistenz der Rechtsprechung bedrohen 
Aus dem Auftreten solcher (hier nur beispielhaft angedeuteter) Schwierigkeiten folgt nun nicht, daß Partizipationsforderungen generell wieder weiter zurückgedrängt werden müssen. Vielmehr legt auch diese Diagnose einen Bedarf an neuen Mechanismen der Kopplung gesellschaftlicher, staatlich-administrativer und rechtlicher Diskurse nahe, die geeignet sein könnten, die wechselseitigen Irritationen an den Schnittstellen solcher Diskurse einzudämmen und die notorische Unsicherheit vor allem bezüglich der Wissensgrundlagen einer politischen Steuerung und Gestaltung der technischen Entwicklung ein Stück weit abzubauen. Einen solchen Mechanismus können Verfahren zur Technikfolgenabschätzung unter der Voraussetzung bilden, daß sie nicht szientistisch mißverstanden werden und sich programmatisch wie konzeptuell doppelt reflexiv auf das Verhältnis objektiver Problemlagen und gesellschaftlich-politischer Problemwahrnehmungen beziehen: ${ }^{136}$ zwar ist einerseits davon auszugehen, daß es ein objektives Substrat technischer Entwicklungen und der Beschreibung ihrer Folgen gibt, allerdings ohne daß solche Beschreibungen gesellschaftliche Prozesse der Normbildung und der Festlegung von Entwicklungszielen, in deren Licht Folgen erst bewertet werden können, substituieren könnten; andererseits müssen sie sich dann auf der Ebene von Problemwahrnehmungen darauf einstellen, den grundsätzlich sozialen Prozeß der Erzeugung von Problemen intern abzubilden und selber diskursiv zu vermitteln (vgl. auch Gloede, 1991: 314). Dieses grundlegende Anforderungsprofil einer wechselseitig argumentativen Durchdringung von (gesellschaftlicher, politischer und rechtlicher) Normbildung und wissenschaftlich-technischem Wissen (vgl. auch van den Daele, 1991) enthält bereits Implikationen für die konzeptionelle Umsetzung von Verfahren der Technikfolgenabschätzung, die sich knapp in sieben Punkten resümieren lassen (Petermann, 1991: 273 f.): Sie werden ihre Konsensbildungs- und Regulierungsfunktion nur wahrnehmen können, wenn sie (i) auf eine systematische Identifikation möglichst vieler gesellschaftlich relevanter Auswirkungen einer technischen Entwicklung zielen und dies (ii) mit einer antizipativen Orientierung im Sinne eines »Frühwarnsystems « verbinden; deshalb sollte die Analyse schwerpunktmäßig auch bei den nicht unmittelbar erkennbaren Folgen ansetzen (iii), um so - in interdisziplinärer Einstellung (iv) - eine möglichst breite Bewertung gesellschaftlicher Chancen und Risiken oder alternativer Entwicklungspfade und -szenarien vorzubereiten (v); dies ist ohne eine breite Einbeziehung betroffener Individuen oder gesellschaftlicher Gruppen in die Analyse wie Wertung nicht zu haben (vi), für deren Motivation schließlich die

136 Auch Bora verweist an dieser Stelle darauf, daß Technikfolgenabschätzungen und »Runde Tische« grundsätzlich besser als die Erörterungstermine im Rechtsverfahren geeignet sein könnten, den entstehenden Kommunikationsbedarf und die Forderung nach allgemeiner Partizipation aufzunehmen - so weit kann ich Bora folgen. Skeptisch bin ich vor allem bezüglich seines diskurstheoretischen Konzepts, mit dem er diesen Vorschlag abstützen möchte: wenn er den Diskursbegriff nicht konsenstheoretisch im Sinne von Habermas (oder Apel), sondern differenztheoretisch und konstruktivistisch im Sinne Foucaults auslegt, kann er kaum mehr plausibel machen, worin denn die eigentümliche Leistung von Diskursen bestehen soll, wenn nicht darin, problematische Geltungsansprüche nach konsentierten Geltungskriterien zu bewerten und so gesichertes, wenn auch immer fallibles »Wissen « zu erzeugen, das als kollektive Handlungsgrundlage fungieren kann (vgl. Bora, 1994: 148 f.). 
Anwendungs- und Entscheidungsorientierung des Verfahrens konstitutiv sein dürfte (vii).

Insofern geht das Konzept des TA-Verfahrens davon aus, daß die Technikfolgenabschätzung eine deliberative Arena bietet, in der »die gesellschaftspolitischen Konflikte um die Einführung einer neuen Technik exemplarisch dargestellt und bearbeitet werden können « und in dem es generell darum geht, »die Rationalität und Legitimität von Entscheidungen über Technikentwicklung zu erhöhen... Alle modernen Gesellschaften sehen sich mit dem Problem konfrontiert, technische Dynamik öffentlich transparent und politisch gestaltbar zu machen, also Handlungsfähigkeit zu bewahren... TA-Verfahren sollen Wege weisen, die zwischen der bloßen Anpassung an einen naturwüchsigen Innovationswettlauf und einer unproduktiven Blockade der weiteren Entwicklung hindurchführen. Von ihnen wird sowohl ein analytischer Beitrag (Informationsbeschaffung), wie auch ein politischer Beitrag (Konfliktbearbeitung) erwartet (Herv. d. Verf.) (van den Daele, 1994a: 2 f.). Diese doppelte Orientierung, die van den Daele auch für das vom WZB durchgeführte Verfahren zur »Technikfolgenabschätzung des Anbaus von Kulturpflanzen mit gentechnisch erzeugter Herbizidresistenz « noch einmal ausdrücklich reklamiert hat, weil so eine durch diskursive Kommunikation vermittelte Loyalität der Beteiligten gegenüber dem Verfahren und seinen Ergebnissen aufgebaut werden sollte, von der die politische und gesellschaftliche Wirksamkeit des Verfahrens am Ende abhängig ist, macht nun gleichzeitig auch die Risiken sichtbar, denen sich die unterschiedlichen Akteure durch Beteiligung an dem Verfahren aussetzen. Dieses Risiko besteht darin, daß »die politischen Interessen, mit denen die Beteiligten in ein TA-Verfahren hineingehen, ... im Verfahren den Filter der Informationsorientierung passieren (müssen) und sich dem Risiko der Information aussetzen. Es ist geradezu der Sinn einer TA, daß dabei die >Gefahr< entsteht, daß griffige Behauptungen, mit denen man in der Öffentlichkeit trefflich Reklame für die Technik machen oder umgekehrt Widerstand gegen sie provozieren kann, sich als unbeweisbar, schlecht begründet oder falsch erweisen« (van den Daele, 1994a: 8). Sie verzichten, m.a.W., auf eine politische Kontrolle der Ergebnisse; und genau dieses Problem (das sich jedenfalls in der Deutung van den Daeles in dem Rückzug der Umweltgruppen aus dem Verfahren manifestierte) und seine mögliche Bearbeitung macht dieses spezielle Verfahren so instruktiv für die Beantwortung der allgemeineren Frage nach den Bedingungen, Möglichkeiten und Grenzen diskursiver Politik. An dieser Stelle kann man, wie van den Daele, informiert durch die besonderen Bedingungen eines kognitiv orientierten Verfahrens, Zweifeln an der politischen Attraktivität diskursiver Konfliktregulierung Raum geben und einen prinzipiellen trade-off zwischen Diskursorientierung und Entscheidungsbezug (van den Daele, 1994: 153) vermuten, der dem Modell deliberativer Politik enge Anwendungsgrenzen setzte. Oder aber man nimmt das mit dem Austritt der Umweltgruppen verbundene politische Scheitern des Verfahrens zum Anlaß, diesseits dieser grundsätzlichen Schwelle Schwachstellen in der Verfahrensanlage zu identifizieren und diese durch eine stärkere Nutzung reflexiver Mechanismen eventuell zu beheben. In jedem Fall haben wir es hier, wie Saretzki (1994a: 61) zu Recht vermutet, gleichsam mit einem »Grundkurs über diskursive Demokratie « zu tun, der in der Art eines kontrollierten Experiments die Chancen und Bedingungen einer partizipatorischen Transformation moderner Politik noch einmal hervortreten läßt. 
Den Angelpunkt einer solchen konstruktiven Rekonstruktion ${ }^{137}$ der partizipatorischen, diskursiv orientierten Technikfolgenabschätzung, die ich abschließend noch einmal in knappen Stichworten andeuten möchte, bildet das auch von van den Daele herausgestellte Diskursrisiko der Virtualisierung von Interessenstandpunkten und des damit verbundenen Verlustes der »politischen« Kontrolle über Verfahrensergebnisse. Insbesondere dann, wenn man die Verfahrensumwelt der politischen Institutionen und der Organisationen, die ihre Vertreter in das Verfahren entsenden, mit in den Blick nimmt, zeigt sich, daß die diskursive Orientierung im Verfahren grundsätzlich von zwei Seiten in die Zange genommen wird. So entsteht ein Motivationsproblem dann, wenn der Entscheidungsbezug des Verfahrens eher gering und nicht ohne weiteres erkennbar ist: Warum soll man überhaupt an einem zeit- und arbeitsaufwendigen Verfahren teilnehmen, wenn nicht gewährleistet ist, daß die Ergebnisse in unmittelbar zu implementierende Steuerungsstrategien umgesetzt werden (Saretzki, 1994a: 55). Selbst wenn es nun gelingt, das Interesse des Staates an der Entlastung seiner majoritären Entscheidungsmechanismen aufzugreifen und einen starken Entscheidungs- und Umsetzungsbezug des Verfahrens herzustellen, und wenn das Problem der Legitimation, also die Frage nach der Verbindlichkeit der TA-Ergebnisse für Dritte, durch breite Inklusion mindestens gemildert werden kann, dann könnte sich nunmehr ein Diskursproblem einstellen: Je stärker der Entscheidungs- und Umsetzungsbezug, »desto eher ist mit einer Zunahme instrumentellstrategischer Kalküle und mit einer Abnahme diskursiver Orientierungen zu rechnen« (Saretzki, 1994a: 55), weil dadurch Anreize vermittelt werden, sich den Rückgriff auf externe Macht- und Drohpotentiale nicht voreilig argumentativ abschneiden zu lassen.

Aus diesem Dilemma hat nun van den Daele den Schluß gezogen, daß der Wahrung des spezifisch diskursiven Verfahrenscharakters der Vorrang einzuräumen ist. Freilich ruht diese Entscheidung auf einer Auslegung der >principal-agent<-Problematik (vgl. dazu auch Mayntz, 1993: 50 ff.) besonders mit Blick auf die beteiligten Umweltgruppen, die die Komplexität der Organisationsmotive und -ziele bezüglich einer Verfahrensbeteiligung unterschätzt, die man besser »als Ausdruck eines gestuften oder konditionierten Forderungsprogramms erklären (kann), bei dem die organisationsbezogenen und schließlich die organisationsinternen Aspekte praktisch zunehmende Bedeutung erhalten « (Saretzki, 1994a: 59 f.): Danach kann man annehmen, daß gerade die Umweltgruppen zunächst einen starken Entscheidungsbezug fordern, weil sie dadurch einen gegenüber den institutionalisierten Prozessen politischer Entscheidung deutlich verbesserten Einfluß auf Politikergebnisse erhalten; erst wenn das nicht zu haben ist, erscheint der Preis, den man an das Verfahren in Gestalt der Schwächung externer Ressourcen und Mobilisierungschancen entrichten muß, als zu hoch, so daß man an zweiter Stelle auf eine Optimierung der Mobilisierungsmöglichkeiten setzt, für die ein Abbau der internen Konsenszwänge notwendig ist; deshalb stellt drittens die Forderung (vor allem seitens der Umweltverbände) nach einer Kompensation ungleicher Ressourcenausstattung auch

$137 \mathrm{~lm}$ folgenden lehne ich mich eng an Überlegungen Saretzkis an, der das WZB-Verfahren sowie die Schlußfolgerungen der wissenschaftlichen Begleitforschung durch die WZBGruppe einer detaillierten und für die Zwecke der vorliegenden Arbeit ausgesprochen instruktiven Kritik unterzogen hat: vgl. Saretzki (1994a: bes. 53 ff.). 
nicht lediglich eine »Verschiebung « (displacement) der Begründung von Konsensverweigerung von einer sachlichen auf eine politische Ebene dar, sondern bildet so etwas wie »bottom-line « eines organisationsbezogenen Kosten-Nutzen-Kalküls. Wie dem auch sei, entscheidend ist für das Verfahrensdesign nun nicht so sehr, welche dieser Deutungen tatsächlich zutrifft, sondern vielmehr, daß die Klärung dieser (und ähnlicher) Fragen zu einem eigenständigen Thema des Verfahrens wird, was im Gegenzug eine deutlichere Akzentuierung reflexiver Prozesse nahelegt. In diesem Zusammenhang sind dann fünf Aspekte hervorzuheben (vgl. Saretzki, 1994a: 61 ff.):

- Unter Bezug auf den Entscheidungs- und Umsetzungsbezug wäre darauf zu achten, daß reflexive Schleifen in das Verfahren eingebaut werden, in denen die Möglichkeiten und Grenzen der TA im Verhältnis zur Verfahrensumwelt thematisiert werden - ein expliziter Konsens über die Art und das Ausmaß des Umsetzungsbezugs jedenfalls könnte deutlich konfliktmindernde Wirkungen haben;

- unter Aspekten der internen Verfahrensgerechtigkeit ist darüber hinaus die Frage klärungsbedürftig, nach welchem Modus die eventuellen Lücken eines argumentativ nicht vollständig bestimmbaren Konsenses geschlossen und ein verbindliches Ergebnis erreicht werden soll;

- drittens wäre unter Gesichtspunkten der Ressourcengerechtigkeit eine gezielte Verbesserung der Partizipationsfähigkeit der weniger organisations- und konfliktfähigen Gruppen anzustreben - was gerade dann unvermeidlich erscheint, wenn es um die effektive Teilhabe der Gesellschaft an einer gemeinwohlorientierten Form der Techniksteuerung geht;

- wenn es viertens pragmatisch vorteilhaft ist, nicht von der Vorstellung einer vollständig horizontalen Selbststeuerung des Verfahrens durch die Beteiligten auszugehen und einer dreidimensionalen Struktur mit übergeordneten neutralen Instanzen den Vorzug zu geben, dann sollte die genaue Form der inneren Gewaltenteilung explizit zum Gegenstand eines konstitutionellen Konsenses werden, der dann nicht mehr beliebig revozierbar wäre;

- schließlich sollte sich die reflexive Thematisierung des Verfahrens, wegen der groBen Bedeutung, die der Festlegung des sachlichen Untersuchungsrahmens zukommt, auch auf die ausführliche Diskussion der Untersuchungskonzepte, auf die jeweils erkenntnisleitenden Analyse- und Bewertungskriterien selber erstrecken.

Diese Punkte sind im einzelnen sicher präzisierungsbedürftig. Sie sollten aber hier nur plausibel machen, daß die Erwartung, durch den gezielten Einsatz reflexiver Mechanismen in der sachlichen, sozialen und normativen Dimension von TA-Verfahren die Effizienz, Effektivität und Legitimität diskursiv vermittelter politischer Partizipation zu verbessern und sie damit auf die Anforderungen einzustellen, die sich aus der Übernahme demokratischer Verantwortung für die bewußte Entwicklung und Steuerung moderner Gesellschaften ergeben, nicht vollkommen unrealistisch bleiben muß. In dieser Gestalt bilden sie denn auch ein wichtiges, konstitutives Element des institutionellen Gesamtaufbaus einer reflexiven Demokratie. 


\section{Literaturverzeichnis}

Acham, Karl (1992): Struktur, Genese und Funktion von Institutionen aus sozialwissenschaftlicher Sicht. In: Gert Melville (Hg.), Institution und Geschichte. Köln/ Weimar/Wien. 25-71.

Ackerman, Bruce (1989): Why Dialogue? In: Journal of Philosophy 86. 5-23.

Ackerman, Bruce (1990): Neutralities. In: R. Bruce Douglas/Gerald M. Mara/Henry S. Richardson (Hg.), Liberalism and the Good. N.Y./London (Routledge). 29-43.

Ackerman, Bruce (1991): We the People. Vol. I: Foundations. Cambridge/Mass./London (Harvard University Press).

Ackerman, Bruce (1994): Political Liberalisms. In: The Journal of Philosophy 91 (No.7). 364-386.

Alexander, Thomas M. (1987): John Dewey's Theory of Art, Experience, and Nature. The Horizons of Feeling. New York (State University of New York Press).

Anderson, Charles W. (1979): The Place of Principles in Policy Analysis. In: APSR 73. 711-723.

Anderson, Charles W. (1990): Pragmatic Liberalism. Chicago (The University of Chicago Press).

Angehrn, Emil (1993): Zivilgesellschaft und Staat. Anmerkungen zu einer Diskussion. In: Volker Gerhardt/Henning Ottmann/Martyn P. Thompson (Hrsg.), Politisches Denken. Jahrbuch 1992. Stuttgart/Weimar. 145-158.

Angehrn, Emil (1993a): Das unvollendete Projekt der Demokratie. In: Philosophische Rundschau 40 (H. 4). 257-264.

Arato, Andrew (1990): Revolution, Civil Society und Demokratie. In: Transit. Europäische Revue H.1. 110-126.

Arato, Andrew (1994): The Rise, Decline and Reconstruction of the Concept of Civil Society, and Directions for Future Research (Ms). New York/Budapest.

Arato, Andrew/Cohen, Jean (1988): Civil Society and Social Theory. In: Thesis Eleven No.21. 40-64

Arneson, Richard J. (1993): Liberal Democratic Community. In: John W. Chapman/ Ian Shapiro (Hg.), Democratic Community (Nomos XXXV). New York (New York University Press). 191-227.

Arneson, Richard J. (1993a): Democratic rights at national and workplace levels. In: David Copp/Jean Hampton/John E. Roemer (Hg.), The Idea of Democracy. Cambridge (Cambridge University Press). 118-148.

von Arnim, Hans Herbert (1993): Staat ohne Diener. Was schert die Politiker das Wohl des Volkes. München.

Avineri, Shlomo/de-Shalit, Avner (Hg.), (1992): Communitarianism and Individualism. Oxford (Oxford University Press). 
Barber, Benjamin (1989): Liberal Democracy and the Costs of Consent. In: Nancy L. Rosenblum (Hg.): Liberalism and the Moral Life. Cambridge/Mass (Harvard University Press). 54-68.

Barber, Benjamin (1994): Starke Demokratie. Hamburg.

Baurmann, Michael/Kliemt, Hartmut (1993): Volksabstimmungen, Verhandlungen und der Schleier der Insignifikanz. In: Analyse \& Kritik 15 (H. 2). 150-167.

Baynes, Kenneth (1990): The Liberal/Communitarian Controversy and Communicative Ethics. In: David Rasmussen (Hg.): Universalism vs. Communitarianism. Contemporary Debates in Ethics. Cambridge/Mass (MIT Press). 61-81.

Baynes, Kenneth (1991): Liberal Neutrality, Pluralism, and Deliberative Politics. Berlin (Ms).

Baynes, Kenneth (1993): Book Review: Jean Cohen and Andrew Arato, Civil Society and Political Theory. In: Political Theory 21 (No.3). 544-547.

Beck, Ulrich (1993): Die Erfindung des Politischen. Frankfurt a.M.

Beck, Ulrich/Beck-Gernsheim, Elisabeth (1994): Individualisierung in modernen Gesellschaften - Perspektiven und Kontroversen einer subjektorientierten Soziologie. In: Ds. (Hg.), Riskante Freiheiten. Frankfurt a.M. 10-39.

Bellah, Robert N. (1991): Citizenship, Diversity, and the Search for the Common Good. In: Robert E. Calvert (Hg.), »The Constitution of the People«. Reflections on Citizens and Civil Society. Lawrence/Kansas (University Press of Kansas). 47-63.

Bellah, Robert N./Madsen, Richard/Sullivan, William M./Swidler, Ann/Tipton, Steven M. (1991): The Good Society. N.Y. (Alfred A. Knopf).

Bellah, Robert N./Richard Madson/William M.Sullivan/Ann Swidler/Steven M.Tipton (1987): Gewohnheiten des Herzens. Individualismus und Gemeinsinn in der amerikanischen Gesellschaft. Köln.

Benhabib, Seyla (1991): Modelle des öffentlichen Raums. Hannah Arendt, die liberale Tradition und Jürgen Habermas. In: Soziale Welt 42 (H.2). 147-165.

Benhabib, Sheyla (1989): Autonomy, Modernity, and Community. In: Axel Honneth/ Thomas McCarthy/Claus Offe/Albrecht Wellmer (Hg.), Zwischenbetrachtungen. Im Prozeß der Aufklärung. Jürgen Habermas zum 60. Geburtstag. Frankfurt a.M. 373-394.

Benhabib, Sheyla (1992): Kritik, Norm und Utopie. Frankfurt a.M.

Benz, Arthur (1990): Institutionspolitik. In: Jahrbuch zur Staats- und Verwaltungswissenschaft 4. 359-374.

Benz, Arthur (1993): Commentary on O'Toole and Scharpf: The Network Concept as a Theoretical Approach. In: Fritz W. Scharpf (Hg.), Games in Hierarchies and Networks. Analytical and Empirical Approaches to the Study of Governance Institutions. Frankfurt a.M., Boulder/Col. 167-175.

Berger, Johannes (1986): Gibt es ein nachmodernes Gesellschaftsstadium? Marxismus und Modernisierungstheorie im Widerstreit. In: Ds. (Hg.), Die Moderne - Kontinuitäten und Zäsuren. Göttingen: Soziale Welt (Sonderband 4). 79-96.

Berger, Johannes (1992): Der Konsensbedarf der Wirtschaft. In: Hans-Joachim Giegel (Hg.), Kommunikation und Konsens in modernen Gesellschaften. Frankfurt a.M. 151-196. 
Berlit, Uwe (1994): (K)eine neue Verfassung für das geeinte Deutschland? Eine Zwischenbilanz nach Abschluß der Beratungen der Gemeinsamen Verfassungskommission. In: Prokla. Zeitschrift für kritische Sozialwissenschaft 24 (Nr. 1). 65-86.

Bermbach, Udo (1991): Demokratietheorie un politische Institutionen. Opladen.

Beyme, Klaus von (1991): Theorie der Politik im 20. Jahrhundert. Von der Moderne zur Postmoderne. Frankfurt a.M.

Beyme, Klaus von (1994): Die Massenmedien und die politische Agenda des parlamentarischen Systems. In: Friedhelm Neidhardt (Hg.), Öffentlichkeit, öffentliche Meinung, soziale Bewegungen (KZfSS Sonderheft 34). Opladen. 320-336.

Bingham, Gail (1986): Resolving Environmental Disputes. A Decade of Experience. Washington/D.C. (The Conservation Foundation).

Blankart, Charles B. (1992): Bewirken Referendum und Volksinitiative einen Unterschied in der Politik? In: Staatswissenschaft und Staatspraxis 3 (H.4). 509-523.

Bobbio, Noberto (1989): Civil Society. In: Ds., Democracy and Dictatorship. The Nature and Limits of State Power. Cambridge (Polity Press). 22-43.

Böckelmann, Ernst (1975): Theorie der Massenkommunikation. Frankfurt a.M.

Böhret, Carl (1990): Folgen. Entwurf für eine aktive Politik gegen schleichende Katastrophen. Leverkusen.

Böhret, Carl (1992): Zur Handlungsfähigkeit des funktionalen Staates der spätpluralistischen Industriegesellschaft. In: Beate Kohler-Koch (Hg.), Staat und Demokratie in Europa. Opladen. 116-129.

Böhret, Carl (1993): »Globalisierung « von Folgen der Technologisierung. Eine Herausforderung für zukunftsorientierte Politik. In: Ds./Göttrik Wewer (Hg.), Regieren im 21. Jahrhundert - zwischen Globalisierung und Regionalisierung (Festgabe für Hans-Hermann Hartwich zum 65. Geburtstag). Opladen. 31-61.

Bohman, James F. (1990): Communication, Ideology, and Democratic Theory. In: APSR 84. 93-109.

Bohmann, Gerda (1993): Paradigmata im Verständnis des Wohlfahrtsstaates. Zum Wiederaufleben der Staatstheorie in den Sozialwissenschaften. In: Österreichische Zeitschrift für Politikwissenschaft 22 (H.1). 5-22.

Bohnet, Iris/Frey, Bruno S. (1994a): Kooperation, Kommunikation und Kommunitarismus. Eine experimentelle Analyse. In: KZfSS 46 (H. 3). 453-463.

Bohnet, Iris/Frey, Bruno S. (1994b): Direct-Democratic Rules: The Role of Discussion. In: Kyklos 47 (Fasc. 3), 341-354.

Bora, Alfons (1993): Gesellschaftliche Integration durch Verfahren - Zur Funktion von Verfahrensgerechtigkeit in der Technikfolgenabschätzung und -bewertung. In: Zeitschrift für Rechtssoziologie 14 (H.1). 55-79.

Bora, Alfons (1994): Grenzen der Partizipation? Risikoentscheidungen und Öffentlichkeitsbeteiligung im Recht. In: Zeitschrift für Rechtssoziologie 15 (H. 2). 126152.

Brandt, Reinhard (1990): Die politische Institution bei Kant. In: Gerhard Göhler/Kurt Lenk/Herfried Münkler/Manfred Walther (Hg.): Politische Institutionen im gesellschaftlichen Umbruch. Ideengeschichtliche Beiträge zur Theorie politischer Institutionen. Opladen. 335-357. 
Brosius, Hans-Bernd (1994): Agenda-Setting nach einem Vierteljahrhundert Forschung: Methodischer und theoretischer Stillstand? In: Publizistik 39 (H. 3). 269288.

Brower, Bruce W. (1994): Limits of Public Reason. In: The Journal of Philosophy 91 (No. 1). 5-26.

Brumlik, Micha (1991): Was heißt »zivile Gesellschaft «? Versuch, den Pudding an die Wand zu nageln. In: Blätter für deutsche und internationale Politik 36 (H.8). 987993.

Brumlik, Micha (1992): Gleichheit und Bürgerstolz. Michael Walzers nachegalitäre Theorie der Gerechtigkeiten. In: Blätter für deutsche und internationale Politik 37 (H.4). 482-490.

Brumlik, Micha/Brunkhorst, Hauke (Hg.), (1993): Gemeinschaft und Gerechtigkeit. Frankfurt a.M.

Brunkhorst, Hauke (1994): Demokratie und Differenz. Vom klassischen zum modernen Begriff des Politischen. Frankfurt a.M.

Bryant, Christopher G. A. (1993): Social self-organization, civility and sociology: a comment on Kumar's >Civil Society<. In: The British Journal of Sociology 44 (No. 3). 397-400.

Buchstein, Hubertus (1991): Varianten im Verhältnis von Macht und Öffentlichkeit Die Argumente für das öffentliche Stimmrecht in der deutschen Wahlrechtsdebatte. Berlin (Ms).

Buchstein, Hubertus (1992): Perspektiven Kritischer Demokratietheorie. In: Prokla. Zeitschrift für kritische Sozialwissenschaft 86. 115-136

Buchstein, Hubertus (1993): Public Voting: Bringing Political Competence and Morality Back In (Paper presented at the Conference on »Philosophy and the Social Sciences - Rethinking Subjectivity: Modernity and the Self « in Prague, May 1.-8.).

Buchstein, Hubertus (1994): Selbstbindung als verfassungstheoretische Figur. In: Jürgen Gebhardt/Rainer Schmalz-Bruns (Hg.), Demokratie, Verfassung und Nation. Baden-Baden. 231-252.

Buchstein, Hubertus/Schmalz-Bruns, Rainer (1994): Republikanische Demokratie. In: Benjamin Barber, Starke Demokratie. Hamburg. 297-323.

Budge, Ian/Keman, Hans (1990): Parties and Democracy. Coalition Formation and Government Functioning in Twenty States. Oxford (Oxford University Press).

Burnheim, John (1987): Über Demokratie. Alternativen zum Parlamentarismus. Berlin.

Burns, Tom R./Dietz, Thomas (1992): Institutionelle Dynamik: Ein evolutionärer Ansatz. In: Journal für Sozialforschung 32 (H. 3/4). 283-306.

Burns, Tom R./Ueberhorst, Reinhard (1988): Creative Democracy. Systematic Conflict Resolution and Policymaking in a World of High Science and Technology. New York u.a. (Praeger).

Busch, Eckart u.a. (1993): Zusammenfassung und Diskussion der Ergebnisse der Gemeinsamen Verfassungskommission. In: Aus Politik und Zeitgeschichte B 52-53. 7 48. 
Castoriadis, Cornelius (1989): Psychoanalyse und Politik. In: Lettre International (Herbst). 68-70.

Cladis, Mark S. (1992): Durkheim Among a Company of Critics: Rawls, Walzer, MacIntyre, and Rorty. In: Ds., A Communitarian Defense of Liberalism - Emile Durkheim and the Contemporary Social Theory. Stanford. 256-286.

Cohen, Jean (1990): Discourse Ethics and Civil Society. In: David Rasmussen (Hg.), Universalism vs. Communitarianism. Contemporary Debates in Ethics. Cambridge/ Mass. (MIT Press). 83-105.

Cohen, Jean/Arato, Andrew (1989): Politics and the Reconstruction of the Concept of Civil Society. In: Axel Honneth/Thomas McCarthy/Claus Offe/Albrecht Wellmer (Hg.), Zwischenbetrachtungen. Im Prozeß der Aufklärung. Jürgen Habermas zum 60. Geburtstag. Frankfurt a.M. 482-503.

Cohen, Jean/Arato, Andrew (1992): Civil Society and Political Theory. Cambridge/ Mass. (MIT Press).

Cohen, Joshua (1986): Book Review »Michael Walzer: Spheres of Justice«. In: The Journal of Philosophy 83. 457-468.

Cohen, Joshua (1989): Deliberation and Democratic Legitimacy. In: Alan Hamlin/Philip Pettit (Hg.), The Good Polity. Oxford (Blackwell). 17-34.

Cohen, Joshua (1989a): Democratic Equality. In: Ethics 99. 727-751.

Cohen, Joshua (1989b): The Economic Basis of Deliberative Democracy. In: Social Philosophy and Policy 6 (No.2). 25-50.

Cohen, Joshua (1993): Moral pluralism and political consensus. In: David Copp/Jean Hampton/John E. Roemer (Hg.), The Idea of Democracy. Cambridge (Cambridge University Press). 270-291.

Cohen, Joshua/Rogers, Joel (1992): Secondary Associations and Democratic Governance. In: Politics and Society 20 (No.4 - Special Issue). 393-472.

Cohen, Joshua/Rogers, Joel (1994): Solidarity, Democracy, Association. In: Wolfgang Streeck (Hg.), Staat und Verbände (PVS Sonderheft 25). Opladen. 136-159.

Cohen, M. D./March, James G./Olsen, Johan P. (1972): A Garbage Can Model of Organizational Choice. In: Administrative Science Quaterly 17 (No.1). 1-25.

Coleman, James S. (1991): The Design of Constitutions in the 1780s and 1990s (The Tocqueville Lecture). Bayreuth und München.

Connolly, William E. (1985): Taylor, Truth and Otherness. In: Political Theory 13 (No.3). 365-376.

Connolly, William E. (1987): Politics and Ambiguity. Oxford (Blackwell).

Connolly, William E. (1988): Political Theory and Modernity. Oxford (Blackwell).

Connolly, William E. (1990): Identity and Difference in Liberalism. In: R. Bruce Douglass/Gerald M. Mara/Henry S. Richardson (Hg.): Liberalism and the Good. New York/London (Routledge). 59-85.

Connolly, William E. (1991): Identity Difference. Democratic Negotiations of Political Paradox. Ithaca/N.Y. (Cornell University Press).

van den Daele, Wolfgang (1991): Zum Forschungsprogramm der Abteilung Normbildung und Umwelt. Berlin (WZB FS II 91-301). 
van den Daele, Wolfgang (1993): Sozialverträglichkeit und Umweltverträglichkeit. Inhaltliche Mindeststandards und Verfahren bei der Beurteilung neuer Technik. In: PVS 34 (H.2). 219-248.

van den Daele, Wolfgang (1994): Die "Bewahrung der Schöpfung « als Staatsaufgabe? In: Wolfgang Zapf/Meinolf Dierkes (Hg.), Institutionenvergleich und Institutionendynamik (WZB Jahrbuch 1994). Berlin. 134-158.

van den Daele, Wolfgang (1994a): Technikfolgenabschätzung als politisches Experiment (WZB FS II 94-301). Berlin.

van den Daele, Wolfgang (1994b): Natur und Verfassung. Zum Versuch, dem Umweltschutz mit einer Staatszielbestimmung auf die Sprünge zu helfen. In: Jürgen Gebhardt/Rainer Schmalz-Bruns (Hg.), Demokratic, Verfassung und Nation. BadenBaden. 364-384.

Dahl, Robert A. (1985): Controlling Nuclear Weapons: Democracy versus Guardianship. Syracuse (Syracuse University Press).

Dahl, Robert A. (1987): Sketches for a Democratic Utopia. In: Scandinavian Political Studies 10. 195-206.

Dahl, Robert A. (1989): Democracy and Its Critics. New Haven/Conn. (Yale University Press).

Dahl, Robert A. (1992): The Problem of Civic Competence. In: Journal of Democracy 3. 45-59.

Dalton, Russell J. (1988): Citizen Politics in Western Democracies. Public Opinion and Political Parties in the US, GB, West Germany, and France. Chatham/N.J. (Chatham House Publishers).

Damico, Alfonso J. (1978): Individuality and Community. The Social and Political Thought of John Dewey. Gainesville (University Presses of Florida).

Decker, Frank (1994): Umweltschutz und Staatsversagen. Eine materielle Regierbarkeitsanalyse. Opladen.

deLeon, Peter (1993): Demokratie und Policy-Analyse: Ziele und Arbeitsweise. In: Adrienne Héritier (Hg.), Policy-Analyse. Kritik und Neuorientierung (PVS Sonderheft 24). Opladen. 471-485.

Demirovic, Alex (1991): Zivilgesellschaft, Öffentlichkeit, Demokratie. In: Das Argument 33 (H.1). 41-55.

Demirovic, Alex (1991a): Ökologische Krise und die Zukunft der Demokratie. In: Prokla 21 (H.3). 443-460.

Demirovic, Alex (1992): Freiheit oder die Dekonstruktion des Politischen. Ein Plädoyer für Kritik. In: Jutta Georg-Lauer (Hg.), Postmoderne und Politik. Tübingen. 121-143.

Demirovic, Alex (1992a): Ökologische Krise und moderne Demokratie. In: Widerspruch 12 (H.4). 62-71.

Deppe, Rainer/Dubiel, Helmut/Rödel, Ulrich (Hg.), (1991): Demokratischer Umbruch in Osteuropa. Frankfurt a.M.

DeSario, Jack/Langton, Stuart (1987): Toward a Metapolicy for Social Planning. In: Ds. (Hg.), Citizen Participation in Public Decision Making. New York u.a. (Greenwood Press). 205-221. 
Dewey, John (1984): The Public and Its Problems. In: Jo Ann Boydston (Hg.), John Dewey: The Later Works, Vol. II: 1925-1927. Carbondale/Ill. (Southern Illinois University Press). 235-375.

Dews, Peter (1993): Faktizität, Geltung und Öffentlichkeit. In: Deutsche Zeitschrift für Philosophie 41 (H.2). 359-364.

Diamond, Larry (1994): Rethinking Civil Society. Toward Democratic Consolidation. In: Journal of Democracy 5 (No. 3). 4-17.

Downing, Lyle A./Robert A. Thigpen (1986): Beyond Shared Understandings. In: Political Theory 14. 451-472.

Döbert, Rainer (1993): »Handlungs-/Partizipationskosten « und die Reproduktion neokonstruktivistischer Relativismen - Ein Blick auf ein erhellendes Ende einer Technikfolgenabschätzung. Berlin (Ms).

Dreier, Horst (1993): Informales Verwaltungshandeln. In: Staatswissenschaft und Staatspraxis 4 (H. 4). 647-681.

Dryzek, John S. (1987): Complexity and Rationality in Public Life. In: Political Studies 35. 424-442.

Dryzek, John S. (1990): Discursive Democracy. Cambridge u.a. (Cambridge University Press).

Dryzek, John S. (1990a): Designs for Environmental Discourse: The Greening of the Administrative State? In: Robert Paehlke/Douglas Torgerson (Hg.), Managing Leviathan. Environmental Politics and the Administrative State. Lewiston, NY (broadview press). 97-111.

Dryzek, John S. (1992): Ecology and Discursive Democracy: Beyond Liberal Capitalism and the Administrative State. In: Capitalism, Nature, Socialism 3 (No.2). 1842.

Dryzek, John S. (1992a): How Far is it from Virginia and Rochester to Frankfurt? Public Choice as Critical Theory. In: British Journal of Political Science 22 (No.4). 397-418.

Dryzek, John S. (1993): Policy Analysis and Planning: From Science to Argument. In: Frank Fischer/John Forester (Hg.), The Argumentative Turn in Policy Analysis and Planning. London (UCL Press). 213-232.

Dryzek, John S./Berejikian, Jeffrey (1993): Reconstructive Democratic Theory. In: APSR 87 (No. 1). 48-60.

Dryzek, John S./Torgerson, Douglas (1993): Editorial: Democracy and the policy sciences: A Progress report. In: Ds. (Hg.), Democracy and the Policy Sciences (=Policy Sciences 26, No. 3: Special Issue). 127-137.

Dubiel, Helmut (1986): Autonomie oder Anomie. Zum Streit über den modernen Sozialcharakter. In: Johannes Berger (Hg.): Die Moderne - Kontinuitäten und Zäsuren. Göttingen: Soziale Welt (Sonderband 4). 263-281.

Dubiel, Helmut (1990): Zivilreligion in der Massendemokratie? In: Soziale Welt 41 (H.2). 125-143.

Dubiel, Helmut (1994): Ungewißheit und Politik. Frankfurt a.M.

Dunn, John (1993): Conclusion. In: Ds. (Hg.), Democracy. The Unfinished Journey 508 BC to AD 1993. Oxford (Oxford University Press). 239-266. 
Durkheim, Emile (1991): Physik der Sitten und des Rechts. Vorlesungen zur Soziologie der Moral. Frankfurt a.M.

Dworkin, Ronald (1983): To Each His Own. In: The New York Review of Books. 14. April 1991. 2-4.

Dworkin, Ronald (1989): The Liberal Community. In: California Law Review 77. 479504

Eder, Klaus (1985): Geschichte als LernprozeB? Zur Pathogenese politischer Modernität in Deutschland. Frankfurt a.M.

Eder, Klaus (1993): Reflexive Institutionen? Eine Untersuchung zur Herausbildung eines neuen Typus institutioneller Regelungen im Umweltbereich (Antrag auf Finanzierung eines Forschungsprojekts im Schwerpunktprogramm »Theorie politischer Institutionen «). Ms.

Eisenstadt, Shmuel N. (1992): Introduction. In: Ds. (Hg.), Democracy and Modernity. Leiden u.a. (E.J. Brill). VII-XIII.

Elkin, Stephen (1993a): Constitutionalism's Successor. In: Ds./Karol Edward Soltan (Hg.), A New Constitutionalism. Designing Political Institutions for a Good Society. Chicago/London (The University of Chicago Press). 117-143.

Elkin, Stephen L. (1993): Constitutionalism: Old and New. In: Ds./Karol Edward Sol$\tan$ (Hg.), A New Constitutionalism. Designing Political Institutions for a Good Society. Chicago/London (The University of Chicago Press). 20-37.

Ellwein, Thomas/Hesse, Joachim Jens (1994): Der überforderte Staat. Baden-Baden.

Elshtain, Jean Bethke (1991): »In Common Together «: Unity, Diversity, and Civic Virtue. In: Robert E. Calvert (Hg.), »The Constitution of the People«. Reflections on Citizens and Civil Society. Lawrence/Kansas (University Press of Kansas). 64-84.

Elster, Jon (1991): Arguing and Bargaining in Two Constituent Assemblies (The Storrs Lectures, Yale Law School).

Elster, Jon (1991a): Arguing and Bargaining in the Federal Convention and the Assemblée Constituante. Chicago (Ms.).

Ely, John (1992): The Politics of »Civil Society《. In: Telos (No.93). 173-191.

Etzioni, Amitai (1988): The Moral Dimension: Toward a New Economics. New York (The Free Press).

Etzioni, Amitai (1990): Liberals and Communitarians. In: Partisan Review 57 (No.2). 215-227.

Etzioni, Amitai (1993): The Spirit of Community. Rights, Responsibilities, and the Communitarian Agenda. New York (Crown Publishers).

Etzioni, Amitai (1993a): Über den Eigennutz hinaus. In: Josef Wieland (Hg.), Wirtschaftsethik und Theorie der Gesellschaft. Frankfurt a.M. 109-133.

Evers, Adalbert (1992): Explaining and Conceptionalizing the »Third Sector« - Three Different Approaches. Wien (Europäisches Zentrum für Wohlfahrtspolitik und Sozialforschung).

Evers, Adalbert (1992a): Soziale Bewegung und soziale Ordnung im Konzept des Wohlfahrtsmix. In: Forschungsjournal NSB 5 (H.4). 49-58. 
Fietkau, Hans-Joachim/Weidner, Helmut (1992): Mediationsverfahren in der Umweltpolitik. Erfahrungen in der Bundesrepublik Deutschland. In: Aus Politik und Zeitgeschichte B 39-40. 24-34.

Fischer, Frank (1990): Technocracy and the Politics of Expertise. Newbury Park/London/New Delhi (Sage).

Fischer, Frank (1991): Risk assessment and environmental crisis: toward an integration of science and participation. In: Industrial Crisis Quaterly 5 (No.2). 113-132.

Fischer, Frank (1993): Bürger, Experten und Politik nach dem »Nimby «-Prinzip: Ein Plädoyer für die partizipatorische Policy-Analyse. In: Adrienne Héritier (Hg.), Policy-Analyse. Kritik und Neuorientierung. Opladen (PVS-Sonderheft 24). 451-470.

Fischer, Frank (1993a): Citizen participation and the democratization of policy expertise: From theoretical inquiry to practical cases. In: John S. Dryzek/Douglas Torgerson $(\mathrm{Hg}$.), Democracy and the Policy Sciences (=Policy Sciences 26, No. 3: Special Issue). 165-187.

Fischer, Frank/Forester, John (Hg.), (1993): The Argumentative Turn in Policy Analysis and Planning. London (UCL Press).

Fischer, Wolfgang (1993): Formen unmittelbarer Demokratie im Grundgesetz. In: Aus Politik und Zeitgeschichte B 52-53. 16-18.

Fishkin, James S. (1991): Democracy and Deliberation. New Directions for Democratic Reform. New Haven/Conn. (Yale University Press).

Forester, John (Hg.), (1985): Critical Theory and Public Life. Cambridge/Mass, London (MIT Press).

Forst, Rainer (1993): Kommunitarismus und Liberalismus - Stationen einer Debatte. In: Axel Honneth (Hg.), Kommunitarismus. Frankfurt a.M., New York. 181-212.

Forst, Rainer (1994): Kontexte der Gerechtigkeit. Frankfurt a.M.

Fowler, Robert Booth (1991): The Dance with Community. The Contemporary Debate in American Political Thought. Lawrence, Kansas (University Press of Kansas).

Frankenberg, Günter/Rödel, Ulrich/Dubiel, Helmut (1989): Die demokratische Frage. Frankfurt a.M.

Fraser, Nancy (1992): Rethinking the Public Sphere. In: Craig Calhoun (Hg.), Habermas and the Public Sphere. Cambridge/Mass. (MIT Press). 109-142.

Frey, Bruno S./Kirchgässner, Gebhard (1993): Diskursethik, Politische Ökonomie und Volksabstimmungen. In: Analyse \& Kritik 15 (H. 2). 129-149.

Fuchs, Dieter (1993): Eine Metatheorie des demokratischen Prozesses (WZB FS III 93-202). Berlin.

Furubotn, Eirik G./Richter, Rudolf (Hg.), (1993): The New Institutional Economics. Recent Progress; Expanding Frontiers. In: Journal of Institutional and Theoretical Economics 149 (H.1). 1-10.

Galston, William A. (1988): Liberal Virtues. In: APSR 82. 1277-1289.

Galston, William A. (1989): Community, Democracy, Philosophy. In: Political Theory 17. 119-130.

Gauthier, David (1993): Constituting Democracy. In: David Copp/Jean Hampton/John E. Roemer (Hg.), The Idea of Democracy. Cambridge (Cambridge University Press). 314-334. 
Gebhardt, Winfried (1992): Individualisierung, Pluralisierung und institutioneller Wandel. Für eine »kritische« Theorie der Institutionen. In: Der Staat 31 (H.3). 347365 .

Gerber, Elisabeth R./Jackson, John E. (1993): Endogeneous Preferences and the Study of Institutions. In: APSR 87 (No. 3). 639-656.

Gerhards, Jürgen (1992): Politische Veranstaltungen in der Bundesrepublik. Nachfrager und wahrgenommenes Angebot einer »kleinen« Form von Öffentlichkeit. In: KZfSS 44 (H.4). 766-779.

Gerhards, Jürgen (1993): Westeuropäische Integration und die Schwierigkeiten der Entstehung einer europäischen Öffentlichkeit. In: ZfS 22 (H.2). 96-110.

Gerhards, Jürgen (1994): Politische Öffentlichkeit. Ein system- und akteurstheoretischer Bestimmungsversuch. In: Friedhelm Neidhardt (Hg.), Öffentlichkeit, öffentliche Meinung, soziale Bewegungen (KZfSS Sonderheft 34). Opladen. 77-105.

Gerhards, Jürgen/Neidhardt, Friedhelm (1990): Strukturen und Funktionen moderner Öffentlichkeit. Fragestellungen und Ansätze. Berlin (WZB FS III). 90-101.

Gerstenberg, Oliver (1994): Zur Verfassungsdebatte in den USA - Konstitutionalismus im Liberalismus/Kommunitarismus. In: Jürgen Gebhardt/Rainer Schmalz-Bruns (Hg.), Demokratie, Verfassung und Nation. Die politische Integration moderner Gesellschaften. Baden-Baden. 151-168.

Giddens, Anthony (1994): Beyond Left and Right. The Future of Radical Politics. Oxford (Polity Press).

Giegel, Hans-Joachim (1992): Diskursive Verständigung und systemische Selbststeuerung. In: Ds. (Hg.), Kommunikation und Konsens in modernen Gesellschaften. Frankfurt a.M. 59-112.

Giegel, Hans-Joachim (1993): Demokratie in der Krise. In: Vorgänge 32 (H. 3). 44-53.

Giesen, Bernhard/Michael Schmid (1990): Symbolische, institutionelle und sozialstrukturelle Differenzierung. Eine selektionstheoretische Betrachtung. In: Hans Haferkamp (Hg.): Sozialstruktur und Kultur. Frankfurt a.M. 95-123.

Gill, Emily (1987): Walzer's Complex Equality: Constraints and the Right to be Wrong. In: Polity 20. 32-56

Gillroy, John Martin/Wade, Maurice (1992): Introduction. In: Ds. (Hg.), The Moral Dimensions of Public Policy Choice. Beyond the Market Paradigm. Pittsburgh/London (University of Pittsburgh Press). 237-249.

Gloede, Fritz (1991): Rationalisierung oder reflexive Verwissenschaftlichung? Zur Debatte um die Funktionen von Technikfolgen-Abschätzung für Technikpolitik. In: Thomas Petermann (Hg.), Technikfolgen-Abschätzung als Technikforschung und Politikberatung. Frankfurt a.M./New York. 299-328.

Göhler, Gerhard (Hg.), (1987): Grundfragen der Theorie politischer Institutionen. Opladen.

Göhler, Gerhard (Hg.), (1994): Die Eigenart der Institution. Zum Profil politischer Institutionentheoric. Baden-Baden.

Göhler, Gerhard (1994a): Politische Institutionen und ihr Kontext. Begriffliche und konzeptionelle Überlegungen zur Theorie politischer Institutionen. In: Ds. (Hg.), 
Die Eigenart der Institution. Zum Profil politischer Institutionentheorie. Baden-Baden. 19-46.

Göhler, Gerhard/Lenk, Kurt/Münkler, Herfried/Walther, Manfred (Hg.), (1990): Politische Institutionen im gesellschaftlichen Umbruch. Ideengeschichtliche Beiträge zur Theorie politischer Institutionen. Opladen.

Göhler, Gerhard/Lenk, Kurt/Schmalz-Bruns, Rainer (Hg.), (1990): Die Rationalität politischer Institutionen. Baden-Baden.

Goerner, E. A. (1993): Rawls's Apolitical Political Turn. In: The Review of Politics 55 (No. 4). 713-718.

Goodin, Robert E. (1989): The State as a Moral Agent. In: Alan Hamlin/ Philip Pettit (Hg.), The Good Polity. Oxford (Blackwell). 123-139.

Goodin, Robert E. (1992): Motivating Political Morality. Oxford (Blackwell).

Goodin, Robert E. (1993): Moral atrophy in the welfare state. In: Policy Sciences 26 (No. 2). 63-78.

Gretschmann, Klaus (1990): Neue ökonomische Institutionenanalyse. In: Jahrbuch zur Staats- und Verwaltungswissenschaft 4. 339-358.

Greven, Michael Th. (1990): Die politische Gesellschaft als Gegenstand der Politikwissenschaft. In: Ethik und Sozialwissenschaften 1 (H.2). 223-228.

Greven, Michael Th. (1992): Über demokratischen Dezisionismus. In: Dieter Emig/ Christoph Hüttig/Lutz Raphael (Hrsg.), Sprache und politische Kultur in der Demokratie. Hans Gerd Schumann zum Gedenken. Frankfurt a.M. u.a. 193-206.

Greven, Michael Th. (1993): Ist die Demokratie modern? Zur Rationalitätskrise der politischen Gesellschaft. In: PVS 34 (H.3). 399-413.

Greven, Michael Th. (1995): Macht in der Öffentlichkeit der Demokratie. Kritischer Kommentar zu R. Schmalz-Bruns. In: Gerhard Göhler (Hg.), Macht der Öffentlichkeit - Öffentlichkeit der Macht. Baden-Baden. 75-84 (im Erscheinen).

Grimm, Dieter (1987): Entstehungs- und Wirkungsbedingungen des modernen Konstitutionalismus. In: Simon, Dieter (Hg.): Akten des 26. Deutschen Rechtshistorikertages 1986 in Frankfurt. Frankfurt a.M. 45-76.

Grimm, Dieter (1990): Die Zukunft der Verfassung. In: Staatswissenschaften und Staatspraxis 1. 5-33.

Grimm, Dieter (1991): Die Zukunft der Verfassung. Frankfurt a.M.

Grimm, Dieter (1993): Der Staat in der kontinentaleuropäischen Tradition. In: Rüdiger Voigt (Hg.), Abschied vom Staat - Rückkehr zum Staat? Baden-Baden. 27-50.

Guggenberger, Bernd (1979): Die »vergessenen« Institutionen. In: Günther Rüther u.a., Die »vergessenen« Institutionen. Melle. 17-51.

Guggenberger, Bernd/Preuß, Ulrich K./UImann, Wolfgang (Hg.), (1991): Eine Verfassung für Deutschland. München.

Gukenbiehl, Hermann L. (1992): Institution und Organisation. In: Hermann Korte/ Bernhard Schäfers (Hg.), Einführung in die Hauptbegriffe der Soziologie. Opladen. 95-110.

Gutmann, Amy (1987): Democratic Education. Princeton/N.J. (Princeton University Press). 
Gutmann, Amy (1993): Democracy and Philosophy: Does Democracy need Foundations? In: Volker Gerhardt/Henning Ottmann/Martyn P. Thompson (Hg.), Politisches Denken. Jahrbuch 1993. Stuttgart, Weimar. 39-45.

Gutmann, Amy (1993a): The Disharmony of Democracy. In: John W. Chapman/Ian Shapiro (Hg.), Democratic Community (Nomos XXXV). New York/London (New York University Press). 126-160.

Gutmann, Amy (Hg.), (1988): Democracy and the Welfare State. Princeton (N.J.): Princeton University Press.

Gutmann, Amy/Thompson, Dennis (1990): Moral Conflict and Political Consensus. In: R. Bruce Douglass/Gerald M. Mara/Henty S. Richardson (Hg.), Liberalism and the Good. N.Y., London (Routledge). 125-147.

Habermas, Jürgen (1973): Legitimationsprobleme im Spätkapitalismus. Frankfurt a.M.

Habermas, Jürgen (1976): Können komplexe Gesellschaften eine vernünftige Identität ausbilden? In: Ds., Zur Rekonstruktion des Historischen Materialismus. Frankfurt a.M. 92-126.

Habermas, Jürgen (1981): Theorie des kommunikativen Handelns (2 Bde.). Frankfurt a.M.

Habermas, Jürgen (1986): Entgegnung. In: Axel Honneth/Hans Joas (Hg.): Kommunikatives Handeln. Beiträge zu Jürgen Habermas' »Theorie des kommunikativen Handelns«. Frankfurt a.M. 327-405.

Habermas, Jürgen (1987): Ist Legitimität durch Legalität möglich? In: Kritische Justiz 20. 1-16.

Habermas, Jürgen (1989): Ist der Herzschlag der Revolution zum Stillstand gekommen? Volkssouveränität als Verfahren. Ein normativer Begriff der Öffentlichkeit. In: Forum für Philosophie Bad Homburg (Hg.), Die Ideen von 1789 in der deutschen Rezeption. Frankfurt a.M. 7-36.

Habermas, Jürgen (1989a): Toward a Communication Concept of Rational Collective Will Formation. In: Ratio Juris 2. 144-154.

Habermas, Jürgen (1989b): Otfried Höffes politische Fundamentalphilosophie. Grenzen des vernunftrechtlichen Normativismus. In: Politische Vierteljahresschrift 30. 320-327.

Habermas, Jürgen (1990): Strukturwandel der Öffentlichkeit. Mit einem Vorwort zur Neuauflage. 1990. Frankfurt a.M.

Habermas, Jürgen (1990a): Die nachholende Revolution. Kleine politische Schriften VII. Frankfurt a.M.

Habermas, Jürgen (1991): Erläuterungen zur Diskursethik. In: Ds., Erläuterungen zur Diskursethik. Frankfurt a.M. 119-226.

Habermas, Jürgen (1991a): Vergangenheit als Zukunft. Zürich.

Habermas, Jürgen (1992): Faktizität und Geltung. Frankfurt a.M.

Habermas, Jürgen (1992a): Drei normative Modelle der Demokratie: Zum Begriff deliberativer Politik. In: Herfried Münkler (Hg.), Die Chancen der Freiheit. Iring Fetscher zum 70. Geburtstag. Frankfurt a.M. 11-24. 
Habermas, Jürgen (1994): Über den internen Zusammenhang von Rechtsstaat und Demokratie. In: Ulrich K. Preuß (Hg.), Zum Begriff der Verfassung. Die Ordnung des Politischen. Frankfurt a.M. 83-94.

Haltern, Utz (1993): Die Gesellschaft der Bürger. In: Geschichte und Gesellschaft 19. 100-134.

Hastedt, Heiner (1991): Aufklärung und Technik. Frankfurt a.M.

Heins, Volker (1992): Die Ambivalenzen der Zivilgesellschaft. In: PVS 33 (H.2). 235242.

Held, David (1989): The Contemporary Polarization of Democratic Theory: The Case for a Third Way. In: Ds., Political Theory and the Modern State. Cambridge (Polity Press). 174-188.

Hernes, Gudmund (1988): Wer regiert die Regierenden? Die norwegische »Machtuntersuchung «. In: Bernd Henningsen (Hg.), Norwegische Politikaspekte. Baden-Baden. 52-72.

Hesse, Joachim Jens (1990): Verhandlungslösungen und kooperativer Staat. In: Wolfgang Hoffmann-Riem/Eberhard Schmidt-Aßmann (Hg.), Konfliktbewältigung durch Verhandlungen. Bd. 1: Informelle und mittlerunterstützte Verhandlungen in Verwaltungsverfahren. Baden-Baden. 97-111.

Hesse, Joachim Jens (1990a): Staatliches Handeln in der Umorientierung: Thesen zur institutions- und verwaltungspolitischen Diskussion. In: Thomas Ellwein/Jachim Jens Hesse (Hg.), Staatswissenschaften: Vergessene Disziplin oder neue Herausforderung? Baden-Baden. 151-172.

Héritier, Adrienne (1993): Einleitung. Policy-Analyse. Elemente der Kritik und Perspektiven der Neuorientierung. In: Ds. (Hg.), Policy-Analyse. Kritik und Neuorientierung (PVS Sonderheft 24). Opladen. 9-36.

Hinsch, Wilfried (1992): Einleitung. In: John Rawls, Die Idee des politischen Liberalismus. Frankfurt a.M. 9-44.

Hirschman, Albert O. (1994): Social Conflicts as Pillars of Democratic Market Society. In: Political Theory 22 (No. 2). 203-218.

Hirst, Paul (1992): Comments on $\gg$ Secondary Associations and Democratic Government«. In: Politics and Society 20 (No.4 - Special Issue). 473-480.

Hirst, Paul (1994): Associative Democracy. New Forms of Economic and Social Government. Oxford (Polity Press).

Hoffmann-Riem, Wolfgang (1990): Verhandlungslösungen und Mittlereinsatz im Bereich der Verwaltung: Eine vergleichende Einführung. In: Ds./Eberhard SchmidtAßmann (Hg.), Konfliktbewältigung durch Verhandlungen. Bd. 1: Informelle und mittlerunterstützte Verhandlungen in Verwaltungsverfahren. Baden-Baden. 13-41.

Hoffmann-Riem, Wolfgang (1990a): Mittlerunterstützte Verhandlungslösungen im staatlichen Bereich. In: Thomas Ellwein/Joachim Jens Hesse (Hg.), Staatswissenschaften: Vergessene Disziplin oder neue Herausforderung? Baden-Baden. 85-95.

Hoffmann-Riem, Wolfgang (Hg.), (1993): Bericht der Enquete-Kommission »Parlamentsreform «. Baden-Baden. 
Hoffmann-Riem, Wolfgang/Schmidt-Aßmann, Eberhard (Hg.), (1990): Konfliktbewältigung durch Verhandlungen. Bd. 1: Informelle und mittlerunterstützte Verhandlungen in Verwaltungsverfahren. Baden-Baden.

Holtkamp, Lars/Schubert, Klaus (1993): Verhandlungslösungen in Mediationsverfahren: Erfolgsbedingungen und Restriktionen in der deutschen Abfallpolitik. In: Gegenwartskunde 42 (H. 4). 421-432.

Honneth, Axel (1991): Grenzen des Liberalismus. Zur politisch-ethischen Diskussion um den Kommunitarismus. In: Philosophische Rundschau 38. 1-20.

Honneth, Axel (1991a): Universalismus und kulturelle Differenz. Zu Michael Walzers Modell der Gesellschaftskritik. In: Merkur 45 (H.11). 1049-1055.

Honneth, Axel (1992): Kampf um Anerkennung. Zur moralischen Grammatik sozialer Konflikte. Frankfurt a.M.

Honneth, Axel (1992a): Ende des amerikanischen Traums? Gespräch über Michael Walzer. Die Versöhnung von Freiheit und Gleichheit. In: Die Neue Gesellschaft/ Frankfurter Hefte 39 (H.1). 16-26.

Honneth, Axel (1992b): Konzeptionen der »civil society«. In: Merkur 46 (H.1). 61-66. Honneth, Axel (1993): Posttraditionale Gemeinschaften. Ein konzeptueller Vorschlag. In: Micha Brumlik/Hauke Brunkhorst (Hg.), Gemeinschaft und Gerechtigkeit. Frankfurt a.M. 260-270.

Honneth, Axel (Hg.), (1993a): Kommunitarismus. Eine Debatte über die moralischen Grundlagen moderner Gesellschaften. Frankfurt a.M./New York.

Honneth, Axel (1993b): Einleitung. In: Ds. (Hg.), Kommunitarismus. Frankfurt a.M./ New York. 7-17.

Honneth, Axel (1994): Aspekte der Individualisierung. In: Ds., Desintegration. Bruchstücke einer soziologischen Zeitdiagnose. Frankfurt a.M. 20-28.

Höffe, Otfried (1987): Politische Gerechtigkeit. Frankfurt a.M.

Höffe, Otfried (1990): Kategorische Rechtsprinzipien. Ein Kontrapunkt der Moderne. Frankfurt a.M.

Höffe, Otfried (1993): Moral als Preis der Moderne. Ein Versuch über Wissenschaft, Technik und Umwelt. Frankfurt a.M.

Huntford, Roland (1973): Wohlfahrtsdiktatur. Das schwedische Modell. Frankfurt a.M./Berlin/Wien.

Jansen, Dorothea/Schubert, Klaus (Hg.), (1995): Netzwerke und Politikproduktion. Konzepte, Methoden, Perspektiven. Marburg.

Jasanoff, Sheila (1990): The Fifth Branch. Science Advisers as Policymakers. Cambridge/Mass., London (Harvard University Press).

Jänicke, Martin (1993): Ökologische und politische Modernisierung in entwickelten Industriegesellschaften. In: Volker von Prittwitz (Hg.), Umweltpolitik als Modernisierungsprozeß. Opladen. 15-29.

Jänicke, Martin (1993a): Vom Staatsversagen zur politischen Modernisierung? Ein System aus Verlegenheitslösungen sucht seine Form. In: Carl Böhret/Göttrik Wewer (Hg.), Regieren im 21. Jahrhundert. Zwischen Globalisierung und Regionalisierung (Festgabe für Hans-Hermann Hartwich zum 65. Geburtstag). Opladen. 63-77. 
Jänicke, Martin/Weidner, Helmut (1995): Successful Environmental Policy: An Introduction. In: Ds. (Hg.), Successful Environmental Policy. A Critical Evaluation of Twenty-Four Cases. Berlin. 10-26.

Joas, Hans (1985): Einleitung: Neuere Beiträge zum Werk George Herbert Meads. In: Ds. (Hg.), Das Problem der Intersubjektivität. Frankfurt a.M. 7-25.

Joas, Hans (1986): Die unglückliche Ehe von Hermeneutik und Funktionalismus. In: Axel Honneth/Hans Joas (Hg.): Kommunikatives Handeln. Beiträge zu Jürgen Habermas`»Theorie des kommunikativen Handelns«. Frankfurt a.M. 144-176.

Joas, Hans (1989): Institutionalisierung als kreativer Prozeß. Zur politischen Philosophie von Cornelius Castoriadis. In: PVS 30. 585-602.

Joas, Hans (1990a): Die Demokratisierung der Differenzierungsfrage. Die Krise des Fortschritts und die Kreativität des kollektiven Handelns. In: Soziale Welt 41 . 8-27.

Joas, Hans (1990b): Partizipation - >Yuppisierung - Gewalt. Über Kreativität heute. Ms.

Joas, Hans (1992): Die Kreativität des Handelns. Frankfurt a.M.

Joas, Hans (1992a): Pragmatismus und Gesellschaftstheorie. Frankfurt a.M.

Joas, Hans (1992b): Durkheim und der Pragmatismus. Bewußtseinspsychologie und die soziale Konstitution der Kategorien. In: Ds., Pragmatismus und Gesellschaftstheorie. Frankfurt a.M. 66-95.

Joas, Hans (1993): Gesellschaft und Demokratie in den USA. Die vergessene Vorgeschichte der Kommunitarismus-Diskussion. In: Micha Brumlik/Hauke Brunkhorst (Hg.), Gemeinschaft und Gerechtigkeit. Frankfurt a.M. 49-62.

Jürgens, Ulrich/Naschold, Frieder (1994): Arbeits- und industriepolitische Entwicklungsengpässe in der deutschen Industrie in den neunziger Jahren. In: Wolfgang Zapf/Meinolf Dierkes (Hg.), Institutionenvergleich und Institutionendynamik (WZB-Jahrbuch 1994). Berlin. 239-270.

Kalberg, Steven (1993): Cultural Foundations of Modern Citizenship. In: Brian S. Turner (Hg.), Citizenship and Social Theory. London u.a. (Sage). 91-114.

Kallscheuer, Otto (1991): Bewegungspolitik und Reform? - Reform der Bewegungspolitik? - Ideengeschichtliche und politische Anmerkungen. In: Forschungsjournal NSB 4 (H.1). 61-69.

Kateb, George (1990): Walt Whitman and the Culture of Democracy. In: Political Theory 18. 545-571.

Kathlene, Lyn/Martin, John A. (1991): Enhancing Citizen Participation: Panel Designs, Perspectives, and Policy Formation. In: Journal of Policy Analysis and Management 10 (No. 1). 46-63.

Kaufman-Osborn, Timothy V. (1985): Pragmatism, Policy-Science, and the State. In: American Journal of Political Science 29. 827-849.

Keck, Otto (1993): Information, Macht und gesellschaftliche Rationalität. Baden-Baden.

Kenis, Patrick/Schneider, Volker (1991): Policy Networks and Policy Analysis: Scrutinizing a New Analytical Toolbox. In: Bernd Marin/Renate Mayntz (Hg.), Policy Networks. Frankfurt a.M., Boulder/Col. 25-59. 
Kersting, Wofgang (1991): Die Liberalismus-Kommunitarismus-Kontroverse in der amerikanischen politischen Philosophie. In: Volker Gerhardt/Henning Ottmann/ Martyn P. Thompson (Hg.), Politisches Denken. Jahrbuch 1991. Stuttgart. 82-102.

Kersting, Wolfgang (1992): Liberalismus, Kommunitarismus, Republikanismus. In: Karl-Otto Apel/Matthias Kettner (Hg.), Zur Anwendung der Diskursethik in Politik, Recht und Wissenschaft. Frankfurt a.M. 127-148.

Kersting, Wolfgang (1993): Liberalismus und Kommunitarismus. Zu einer aktuellen Debatte. In: Information Philosophie (H.3). 4-19.

Kersting, Wolfgang (1994): Verfassung und kommunitäre Demokratie. In: Günter Frankenberg (Hg.), Auf der Suche nach der gerechten Gesellschaft. Frankfurt a.M. 84-12.

Kettner, Matthias (1995): The Disappearance of Discourse Ethics in Habermas' »Faktizität und Geltung « (Ms).

Kielmansegg, Peter Graf (1987): Some Remarks on the Learning Ability of Democratic Government. Comment on Richard Rose. In: Peter Koslowski (Hg.), Individual Liberty and Democratic Decision-Making. Tübingen. 173-180.

Kinder, Donald R./Herzog, Don (1993): Democratic Discussion. In: George E. Marcus/Russell L. Hanson (Hg.), Reconsidering the Democratic Public. University Park/Penn. (The Pennsylvania State University Press). 347-377.

King, Alexander/Schneider, Bertrand (1992): Die erste globale Revolution. Frankfurt a.M.

Kitschelt, Herbert (1993): Social Movements, Political Parties and Democratic Theory. In: The Annals of the American Academy of Political and Social Science 528. 13-29.

Kleger, Heinz (1992): Demokratiekonflikte in der Demokratie. Politische Sprache und politische Philosophie. In: M.Eisner/B.Fux (Hg.), Politische Sprache in der Schweiz zwischen Konsens und Konflikt. Zürich. 107-147.

Kleger, Heinz (1992a): Was ist Demokratie? Einige Überlegungen am Beispiel der Diskussion über zivile Widderstände. In: Karen Gloy (Hg.), Demokratietheorie. Ein Ost-West-Dialog. Tübingen. 30-63.

Kleger, Heinz (1992b): Die Rückkehr der Bürgergesellschaft. In: Widerspruch 12 (H.24). 49-61.

Kleger, Heinz (1993): Lernfähige Demokratie und reflexiver Staat. In: Rüdiger Voigt (Hg.): Abschied vom Staat - Rückkehr zum Staat? Baden-Baden. 443-457.

Kleger, Heinz (1993a): Der neue Ungehorsam. Widerstände und politische Verpflichtung in einer lernfähigen Demokratic. Frankfurt a.M.

Kleger, Heinz (1995): Verhandlungsdemokratic. Zur alten und neuen Theorie des kooperativen Staates (Ms). (Erscheint in: Rüdiger Voigt (Hg.), Der kooperative Staat. Baden-Baden).

Klein, Ansgar (1991): Das Projekt der Zivilgesellschaft - Anmerkungen zur Renaissance der demokratischen Frage. In: Forschungsjournal NSB 4 (H.1). 70-80.

Kloppenberg, James T. (1986): Uncertain Victory. Social Democracy and Progressivism in European and American Thought, 1870-1920. Oxford (Oxford University Press). 
Knight, Jack/Johnson, James (1994): Aggregation and Deliberation: On the Possibility of Democratic Legitimacy. In: Political Theory 22 (No. 2). 277-296.

Koenigs, Tom/Schaeffer, Roland (Hg.), (1993): Energiekonsens? Der Streit um die zukünftige Energiepolitik. München.

Kramnick, Isaac (1982): Republican Revisionism Revisited. In: American Historical Review 87. 629-664.

Kriesi, Hanspeter (1992): Bürgerkompetenz und direkte Demokratie. In: Widerspruch 12 (H.24). 92-100.

Kriesi, Hanspeter (1994): Akteure - Medien - Publikum. Die Herausforderung direkter Demokratie durch die Transformation der Öffentlichkeit. In: Friedhelm Neidhardt (Hg.), Öffentlichkeit, öffentliche Meinung, soziale Bewegungen (KZfSS Sonderheft 34). Opladen. 234-260.

Kumar, Krishan (1993): Civil society: an inquiry into the usefulness of an historical term. In: The British Journal of Sociology 44 (No. 3). 375-395.

Kymlicka, Will (1988): Liberalism and Communitarianism. In: Canadian Journal of Philosophy 47. 181-204.

Kymlicka, Will (1989): Liberalism, Community, and Culture. Oxford (Oxford University Press)

Kymlicka, Will/Norman, Wayne (1994): Return of the Citizen: A Survey of Recent Work on Citizenship. In: Ethics 104. 352-381.

Ladeur, Karl-Heinz (1990): Ethik der Komplexität und gesellschaftliche Institutionen. In: Ethik und Sozialwissenschaften 1. 74-77.

Ladeur, Karl-Heinz (1993): Von der Verwaltungshierarchie zum administrativen Netzwerk? Zur Erhaltung der Eigenständigkeit der Verwaltung unter Komplexitätsbedingungen. In: Die Verwaltung 26 (Nr. 2). 137-165.

Lane, Robert E. (1994): Quality of Life and Quality of Persons. A New Role for Government? In: Political Theory 22 (No. 2). 219-252.

Larmore, Charles (1993): Die Wurzeln radikaler Demokratie. In: Deutsche Zeitschrift für Philosophie 41 (H.2). 321-327.

Larmore, Charles, 1990: Political Liberalism. In: Political Theory 18. 339-360.

Lehmbruch, Gerhard (1991): Die deutsche Vereinigung. Strukturen und Strategien. In: PVS 32. 585-604.

Leif, Thomas (1993): Hoffnung auf Reformen? Reformstau und Partizipationsblockaden in den Parteien. In: Aus Politik und Zeitgeschichte B 43. 24-33.

Lenk, Kurt (1992): Freiheit und Kompromißbildung: Zum Demokratiekonzept Hans Kelsens. In: Herfried Münkler (Hg.), Die Chancen der Freiheit. Grundprobleme der Demokratie. Für Iring Fetscher zum 70. Geburtstag. München. 114-125.

Levi, Margaret (1990): A Logic of Institutional Change. In: Margaret Levi/K.S. Cook (Hg.), The Limits of Rationality. Chicago (University of Chicago Press). 402-418.

Lietzmann, Hans (1994): Staatswissenschaftliche Abendröte. Zur Renaissance der Staatsorientierung in Deutschland. In: Jürgen Gebhardt/Rainer Schmalz-Bruns (Hg.), Demokratie, Verfassung und Nation. Die politische Integration moderner Gesellschaften. Baden-Baden. 72-101. 
Lindner, Clausjohann (1990): Kritik der Theorie der partizipatorischen Demokratie. Opladen.

Lipietz, Alain (1991): Demokratie nach dem Fordismus. In: Das Argument 189. 677694.

Lipp, Wolfgang (1990): Institution und Veranstaltung. Zur neueren Entwicklung institutionellen Bewußtseins in den Sozialwissenschaften. In: Eckart Pankoke (Hg.), Institution und technische Zivilisation. Berlin. 31-50.

Lippmann, Walter (1965): The Public Opinion. New York (Free Press).

Luhmann, Niklas (1984): Soziale Systeme. Frankfurt a.M.

Luhmann, Niklas (1990): Gesellschaftliche Komplexität und öffentliche Meinung. In: Ds., Soziologische Aufklärung 5. Opladen. 170-182.

Luthardt, Wolfgang (1994): Direkte Demokratie. Ein Vergleich in Westeuropa. Baden-Baden.

Macedo, Stephen (1990): The Politics of Justification. In: Political Theory 18. 280304.

MacIntyre, Alasdair (1987): Der Verlust der Tugend. Frankfurt a.M./New York.

Madson, Richard (1991): Contentless Consensus. The Political Discourse of a Segmented Society. In: Alan Wolfe (Hg.), America at Century's End. Berkeley/Los Angeles (University of California Press). 440-460.

Magidan, Denise/Susskind, Lawrence/Weinstein, Alan (1990): Vorüberlegungen für eine verbesserte Konfliktbewältigung im Umweltbereich. In: Wolfgang HoffmannRiem/Eberhard Schmidt-Aßmann (Hg.), Konfliktbewältigung durch Verhandlungen. Baden-Baden. 151-176.

Majone, Giandomenico (1989): Evidence, Argument and Persuasion in the Policy Process. New Haven/Conn. (Yale University Press).

Majone, Giandomenico (1993): Wann ist Policy-Deliberation wichtig? In: Adrienne Héritier (Hg.), Policy-Analyse. Kritik und Neuorientierung (PVS Sonderheft 24). Opladen. 97-115.

Manin, Bernard (1987): On Legitimacy and Political Deliberation. In: Political Theory 15. 338-368.

Mansbridge, Jane (1988): Motivating Deliberation in Congress. In: Sarah Baumgartner Thurow (Hg.): E Pluribus Unum. Constitutional Principles and the Institutions of Government. Lanham/N.Y., London (University of America Press). 59-86.

Mansbridge, Jane (1990): Self-Interest in Political Life. In: Political Theory 18. 132153.

Mansbridge, Jane (1992): A Deliberative Perspective on Neocorporatism. In: Politics and Society 20 (No.4 - Special Issue). 493-505.

March, James G./Olsen, Johan P. (1989): Rediscovering Institutions. The Organizational Basis of Politics. New York (Free Press).

March, James G./Olsen, Johan P. (1994): Institutional Perspectives on Political Institutions (Ms).

Marcus, George E./Hanson, Russell L. (Hg.), (1993): Reconsidering the Democratic Public. University Park/Penn. (The Pennsylvania State University Press). 
Maus, Ingeborg (1990): Zur Theorie der Institutionalisierung bei Kant. In: Gerhard Göhler/Kurt Lenk/Herfried Münkler/Manfred Walther $(\mathrm{Hg}$.): Politische Institutionen im gesellschaftlichen Umbruch. Ideengeschichtliche Beiträge zur Theorie politischer Institutionen. Opladen. 358-385.

Maus, Ingeborg (1991): Sinn und Bedeutung von Volkssouveränität in der modernen Gesellschaft. In: Kritische Justiz 24. 137-150.

Maus, Ingeborg (1992): Zur Aufklärung der Demokratietheorie. Frankfurt a.M.

Maus, Ingeborg (1992a): Basisdemokratische Aktivitäten und rechtstaatliche Verfassung. Zum Verhältnis von institutionalisierter und nichtinstitutionalisierter Volkssouveränität. In: Thomas Kreuder (Hg.), Der orientierungslose Leviathan. Marburg. 99-116.

Mayer, Jörg M. (1994): »Wann sind Paketlösungen machbar? « Eine konstruktive Kritik an F. W. Scharpfs Konzept. In: PVS 35 (H. 3). 448-471.

Mayntz, Renate (1993): Policy-Netzwerke und die Logik von Verhandlungssystemen. In: Adrienne Héritier (Hg.), Policy-Analyse. Kritik und Neuorientierung (PVS Sonderheft 24). Opladen. 39-56.

McCarthy, Thomas (1986): Komplexität und Demokratie - die Versuchungen der Systemtheorie. In: Axel Honneth/Hans Joas (Hg.), Kommunikatives Handeln. Frankfurt a.M. 177-215.

McCarthy, Thomas (1991): Ideals and Illusions. On Reconstruction and Deconstruction in Comtemporary Critical Theory. Cambridge/Mass. (MIT Press).

Mead, George Herbert (1983): Naturrecht und die Theorie der politischen Institutionen. In: Hans Joas (Hg.), George Herbert Mead. Gesammelte Aufsätze (Bd.2). Frankfurt a.M. 403-423.

Melville, Gert (Hg.), (1992): Institution und Geschichte. Köln/Weimar/Wien.

Meyer, Thomas (1994): Die Transformation des Politischen. Frankfurt a.M.

Michelman, Frank I. (1994): Kollektiv, Gemeinschaft und das liberale Denken in Verfassungen. In: Günter Frankenberg ( $\mathrm{Hg}$.), Auf der Suche nach der gerechten Gesellschaft. Frankfurt a.M. 55-73.

Miller, David (1992): Deliberative Democracy and Social Choice. In: Political Studies 40 (Special Issue). 54-67.

Miller, Max (1992): Rationaler Dissens. Zur gesellschaftlichen Funktion sozialer Konflikte. In: Hans-Joachim Giegel (Hg.), Kommunikation und Konsens in modernen Gesellschaften. Frankfurt a.M. 31-58.

Moe, Terry M. (1990): Political Institutions: The Neglected Side of the Story. In: Journal of Law, Economics, and Organization 6. 213-253.

Mouffe, Chantal (1992): Democratic Citizenship and the Political Community. In: Ds. (Hg.), Dimensions of Radical Democracy. Pluralism, Citizenship, Community. London (Verso). 225-239.

Mouffe, Chantal (1992a): Preface: Democratic Politics Today. In: Ds. (Hg.), Dimensions of Radical Democracy. Pluralism, Citizenship, Community. London (Verso). $1-14$.

Mouffe, Chantal/Michael Walzer (1992): Gespräch über die »Communitarians «. In: Prokla 87. 286-297. 
Mucciaroni, Gary (1992): The Garbage Can Model \& the Study of Policy Making: A Critique. In: Polity 24 (H.3). 459-482.

Mulhall, Stephen/Swift, Adam (1992): Liberals \& Communitarians. Oxford (Blackwell).

Müller, Hans-Peter (1983): Wertkrise und Gesellschaftsreform. Emile Durkheims Schriften zur Politik. Stuttgart.

Müller, Hans-Peter (1991): Die Moralökonomie moderner Gesellschaften. Durkheims $»$ Physik der Sitten und des Rechts«. In: Ds. (Hg.), Emile Durkheim: Physik der Sitten und des Rechts. Frankfurt a.M. 307-341.

Müller, Jörg Paul (1993): Demokratische Gerechtigkeit. München.

Münch, Richard (1984): Die Struktur der Moderne. Grundmuster und differentielle Gestaltung des institutionellen Aufbaus der modernen Gesellschaften. Frankfurt a.M.

Münch, Richard (1993): Kreativität und Gesellschaft: Über die pragmatistische Erneuerung der Handlungstheorie in gesellschaftstheoretischer Absicht. In: Schweizerische Zeitschrift für Soziologie 19. 289-306.

Münch, Richard (1994): Politik und Nichtpolitik. Politische Steuerung als schöpferischer Prozeß. In: KZfSS 46 (H. 3). 381-405.

Münkler, Herfried (1991): Wieviel Tugend braucht die Demokratie? Voraussetzungen der Zivilgesellschaft. In: Neue Gesellschaft/Frankfurter Hefte 38. 612-617.

Münkler, Herfried (1992): Politische Tugend. Bedarf die Demokratie einer sozio-moralischen Grundlegung? In: Ds. (Hg.), Die Chancen der Freiheit. Für Iring Fetscher zum 70. Geburtstag. München. 25-46.

Münkler, Herfried (1994): Solidarität, Zivilgesellschaft und Bürgrtugend. In: Alois Riklin/Gerard Batliner (Hg.), Subsidiarität. Ein interdisziplinäres Symposium. Vaduz. 63-79.

Neal, Patrick/David Paris (1990): Liberalism and the Communitarian Crititque: A Guide for the Perplexed. In: Canadian Journal of Political Science 23 (No.3). 419439.

Neidhardt, Friedhelm (1994): Öffentlichkeit, öffentliche Meinung, soziale Bewegungen. In: Ds. (Hg.), Öffentlichkeit, öffentliche Meinung, soziale Bewegungen (KZfSS Sonderheft 34). Opladen. 7-41.

Neidhardt, Friedhelm (1994a): Die Rolle des Publikums. Anmerkungen zur Soziologie politischer Öffentlichkeit. In: Hans-Ulrich Derlien/Uta Gerhardt/Fritz W. Scharpf (Hg.), Systemrationalität und Partialinteresse. Festschrift für Renate Mayntz. Baden-Baden. 315-328.

North, Douglass C. (1990): Institutions, Institutional Change and Economic Performance. Cambridge (Cambrige U.P.).

Nullmeier, Frank (1990): Von Max Weber zu Konzepten der Wissens- und Intelligenzpolitologie. Hamburg (Diss.).

Nullmeier, Frank (1991): Zivilgesellschaftlicher Liberalismus - Schattenseiten eines Trends politischer Theorieentwicklung. In: Forschungsjournal NSB 4 (H.3). 13-26. 
Nullmeier, Frank (1993): Wissen und Policy-Forschung. Wissenspolitologie und rhetorisch-dialektisches Handlungsmodell. In: Adrienne Héritier (Hg.), Policy-Analyse. Opladen (PVS-Sonderheft 24). 175-196.

Nullmeier, Frank (1994): Interpretative Ansätze in der Politikwissenschaft. Hamburg (Ms).

Nullmeier, Frank/Rüb, Friedbert W. (1993): Die Transformation der Sozialpolitik. Vom Sozialstaat zum Sicherungsstaat. Frankfurt a.M./New York.

Nunner-Winkler, Gertrud (1994): Moral in der Politik. Eine Frage des Systems oder der Persönlichkeit? In: Hans-Ulrich Derlien/Uta Gerhardt/Fritz W. Scharpf (Hg.), Systemrationalität und Partialinteresse. Festschrift für Renate Mayntz. Baden-Baden. 123-149.

Nussbaum, Martha C. (1992): Human Functioning and Social Justice: In Defense of Aristotelian Essentialism. In: Political Theory 20 (H.2). 202-246.

O'Connor, James (1974): Die Finanzkrise des Staates. Frankfurt a.M.

O'Donnell, Guillermo (1994): Delegative Democracy. In: Journal of Democracy 5 (No. 1). 55-69.

Offe, Claus (1984): Politische Legitimation durch Mehrheitsentscheidung? In: Bernd Guggenberger/Claus Offe (Hg.), An den Grenzen der Mehrheitsdemokratie. Opladen. 150-183.

Offe, Claus (1986): Die Utopie der Null-Option. Modernität und Modernisierung als politische Gütekriterien. In: Peter Koslowski/Robert Spaemann/Reinhard Löw (Hg.): Moderne oder Postmoderne? Weinheim. 143-172.

Offe, Claus (1987): Die Staatstheorie auf der Suche nach ihrem Gegenstand. Beobachtungen zur aktuellen Diskussion. In: Thomas Ellwein/ Joachim Jens Hesse/Renate Mayntz/Fritz W. Scharpf (Hrsg.), Jahrbuch zur Staats- und Verwaltungswissenschaft Bd.1. Baden-Baden. 309-320

Offe, Claus (1987a): Über den institutionellen Rigorismus in der Demokratietheorie. Erwiderung auf Gesine Schwan. In: K.W. Hempfer/A.Schwan (Hg.): Grundlagen der politischen Kultur des Westens. Berlin. 79-92.

Offe, Claus (1987b): Challenging the boundaries of institutional politics: social movements since the 1960s. In: Charles S. Maier (Hg.): Changing Boundaries of the Political. Cambridge/Mass (Cambridge University Press). 63-105.

Offe, Claus (1989): Fessel und Bremse. Moralische und institutionelle Aspekte »intelligenter Selbstbeschränkung«. In: Axel Honneth/Thomas McCarthy/Claus Offe/ Albrecht Wellmer (Hg.), Zwischenbetrachtungen. Im Prozeß der Aufklärung. Jürgen Habermas zum 60. Geburtstag. Frankfurt a.M. 739-774.

Offe, Claus (1990): Reflections on the Institutional Self-Transformation of Movement Politics: A Tentative Stage Model. In: Russell J. Dalton/Manfred Kuechler (Hg.), Challenging the Political Order. New Social and Political Movements in Western Democracies. Oxford (Polity Press). 232-250.

Offe, Claus (1990a): Öffentliches Handeln und Strukturen der kollektiven Willensbildung - Aspekte einer sozialwissenschaftlichen Staatstheorie. In: Thomas Ellwein/ Joachim Jens Hesse (Hg.), Staatswissenschaften: Vergessene Disziplin oder neue Herausforderung? Baden-Baden. 173-190. 
Offe, Claus (1990b): Akzeptanz und Legitimität strategischer Optionen in der Sozialpolitik. In: Christoph Sachße/H.Tristram Engelhardt (Hg.): Sicherheit und Freiheit. Zur Ethik des Wohlfahrtsstaates. Frankfurt a.M. 179-202.

Offe, Claus (1992): Wider scheinradikale Gesten. In: Gunter Hofmann/Werner A. Perger (Hg.), Die Kontroverse. Weizsäckers Parteienkritik in der Diskussion. Frankfurt a.M. 126-142.

Offe, Claus (1994): Der Tunnel am Ende des Lichts. Erkundungen der politischen Transformation im Neuen Osten. Frankfurt a.M./ New York.

Offe, Claus/Preuß, Ulrich K. (1991): Democratic Institutions and Moral Resources. In: David Held (Hg.), Political Theory Today. Oxford (Polity Press). 143-171.

Olsen, Johan P. (1988): Administrative Reform and Theories of Organization. In: Colin S. Campbell/B. Guy Peters (Hg.): Organizing Governance, Governing Organizations. Pittsburgh (Pa): University of Pittsburgh Press. 233-254.

Olsen, Johan P. (1991): Political Science and Organization Theory. Parallel Agendas but Mutual Disregard. In: Roland M. Czada/Adrienne Windhoff-Héritier (Hg.): Political Choice. Institutions, Rules and the Limits of Rationality. Frankfurt a.M./New York. 87-119.

Ostrom, Elinor (1989): Institutionelle Arrangements und das Dilemma der Allmende. In: Manfred Glagow/Helmut Willke/Helmut Wiesenthal (Hg.): Gesellschaftliche Steuerungsrationalität und partikulare Handlungsstrategien. Pfaffenweiler. 199234.

Ostrom, Elinor (1989a): Microconstitutional Change in Multiconstitutional Political Systems. In: Rationality and Society 1 (H.1). 11-50.

Ostrom, Elinor (1990): Governing the Commons. The Evolution of Institutions for Collective Action. Cambridge (Cambridge University Press).

Ozawa, Connie P./Susskind, Lawrence (1990): Konfliktmittlung in Verfahrensstreitigkeiten mit wissenschaftlichem Bezug. In: Wolfgang Hoffmann-Riem/Eberhard Schmidt-ABmann (Hg.), Konfliktbewältigung durch Verhandlungen. Bd. 1: Informelle und mitlerunterstützte Verhandlungen in Verwaltungsverfahren. Baden-Baden. 177-190.

Pangle, Thomas (1992): The Ennobling of Democracy. The Challenge of the Postmodern Age. Baltimore/London (The Johns Hopkins University Press).

Pankoke, Eckart (Hg.), (1990): Institution und technische Zivilisation. Symposion zum 65. Geburtstag von Johannes Chr. Papalekas. Berlin.

Parsons, Talcott (1990): Prolegomena to a Theory of Social Institutions. In: American Sociological Review 55. 319-333.

Peschel-Gutzeit, Lore Maria (1994): Die Verfassungsberatung in der Gemeinsamen Kommission des Bundestages und des Bundesrates. In: Jürgen Gebhardt/Rainer Schmalz-Bruns (Hg.), Demokratie, Verfassung und Nation. Baden-Baden. 255270.

Petermann, Thomas (1991): Weg von TA - aber wohin? In: Ds. (Hg.), TechnikfolgenAbschätzung als Technikforschung und Politikberatung. Frankfurt a.M./New York. 271-298.

Peters, Bernhard (1991): Rationalität, Recht und Gesellschaft. Frankfurt a.M. 
Peters, Bernhard (1993): Die Integration moderner Gesellschaften. Frankfurt a.M.

Peters, Bernhard (1994): Der Sinn von Öffentlichkeit. In: Friedhelm Neidhardt (Hg.), Öffentlichkeit, öffentliche Meinung, soziale Bewegungen (KZfSS Sonderheft 34). Opladen. 42-76.

Phillips, Anne (1992): Must Feminists Give Up on Liberal Democracy? In: Political Studies 40 (Special Issue). 68-82.

Phillips, Derek L. (1993): Looking Backward. A Critical Appraisal of Communitarian Thought. Princeton/N.J. (Princeton University Press).

Poltier, Hugues (1989): De la Praxis ál'Institution et Retour. In: Révue européenne des sciences sociales 27 (No. 86). 419-439.

Prager, Jeffrey (1981): Moral Integration and Political Inclusion. A Comparison of Durkheim's and Weber's Theory of Democracy. In: Social Forces 59. 918-950.

Preuß, Ulrich K. (1985): Aktuelle Probleme einer linken Verfassungstheorie. In: Prokla 61. 65-79.

Preuß, Ulrich K. (1989): Perspektiven von Rechtsstaat und Demokratie. In: Kritische Justiz 22. 1-12.

Preuß, Ulrich K. (1989a): Was heißt radikale Demokratie heute? In: Forum für Philosophie Bad Homburg (Hg.): Die Ideen von 1789 in der deutschen Rezeption. Frankfurt a.M. 37-67.

Preuß, Ulrich K. (1989b): Rationality Potentials of Law: Allocative, Distributive and Communicative Rationality. In: Christian Joerges/David M. Trubek (Hg.), Critical Legal Thought: An American-German Debate. Baden-Baden. 525-555.

Preuß, Ulrich K. (1990): Revolution, Fortschritt und Verfassung. Zu einem neuen Verfassungsverständnis. Berlin.

Preuß, Ulrich K. (1990a): Verfassungstheoretische Überlegungen zur normativen Begründung des Wohlfahrtsstaates. In: Christoph Sachße/H.Tristram Engelhardt (Hg.), Sicherheit und Freiheit. Zur Ethik des Wohlfahrtsstaates. Ffm. 106-132.

PreuB, Ulrich K. (1994): Umrisse einer neuen konstitutionellen Form des Politischen. In: Ds., Revolution, Fortschritt und Verfassung. Frankfurt a.M. (erweiterte Neuausgabe). 123-170.

von Prittwitz, Volker (1990): Das Katastrophenparadox. Elemente einer Theorie der Umweltpolitik. Opladen.

von Prittwitz, Volker (1993): Reflexive Modernisierung und politisches Handeln. In: Ds. (Hg.), Umweltpolitik als Modernisierungsprozeß. Opladen. 31-49.

Rawls, John (1992): Die Idee des politischen Liberalismus. Schriften 1978-1990. Frankfurt a.M.

Rawls, John (1993): Political Liberalism. New York (Columbia University Press).

Rawls, John (1994): Das Ideal des öffentlichen Vernunftgebrauchs. In: Information Philosophie 22 (H. 1). 5-18.

Rehberg, Karl-Siegbert (1990): Eine Grundlagentheorie der Institutionen: Arnold Gehlen. Mit systematischen Schlußfolgerungen für eine kritische Institutionentheorie. In: Gerhard Göhler/Kurt Lenk/Rainer Schmalz-Bruns (Hg.), Die Rationalität politischer Institutionen. Baden-Baden. 115-144. 
Rehberg, Karl-Siegbert (1993): Leitfragen der kritischen Institutionenforschung. Entwurf einer Theorie und Analyse institutioneller Mechanismen. In: Gerhard Göhler (Hg.), Die Eigenart der Institution. Zum Profil der politischen Institutionentheorie. Baden-Baden (im Erscheinen).

Rehberg, Karl-Siegbert (1993a): Gemeinschaft und Gesellschaft - Tönnies und Wir. In: Micha Brumlik/Hauke Brunkhorst (Hg.), Gemeinschaft und Gerechtigkeit. Frankfurt a.M. 19-48.

Rehberg, Karl-Siegbert u.a. (1993): Unverfügbarkeit und Reflexivität - Eine Analyse hochkultureller Formveränderungen von Institutionen (Ms.).

Reich, Robert B. (1988): Policy Making in a Democracy. In: Ds. (Hg.), The Power of Public Ideas. Cambridge/Mass. (Ballinger). 123-156.

Reich, Robert B. (Hg.), (1988a): The Power of Public Ideas. Cambridge/Mass. (Ballinger).

Renn, Ortwin u.a. (1993): Public participation in decision making: A three-step procedure. In: John S. Dryzek/Douglas Torgerson (Hg.), Democracy and the Policy Sciences (=Policy Sciences 26, No. 3: Special Issue). 189-214.

Ritter, Claudia (1990): Zum politischen Potential der Alltagspraxis - Einige Anmerkungen zur Analyse soziokultureller Voraussetzungen neuer sozialer Bewegungen. In: Forschungsjournal Neue Soziale Bewegungen 3 (H.3). 12-21.

Rochon, Thomas R./Mazmanian, Daniel A. (1993): Social Movements and the Policy Process. In: The Annals of the American Academy of Political and Social Science 528. 75-87.

Rorty, Richard (1988): Solidarität oder Objektivität? Drei philosophische Essays. Stuttgart.

Rorty, Richard (1989): Kontingenz, Ironie und Solidarität. Frankfurt a.M.

Rödel, Ulrich (1989): Hannah Arendt und die Gefährdungen der Freiheit in einer säkularisierten politischen Ordnung. In: Forum für Philosophie Bad Homburg (Hg.): Die Ideen von 1789 in der deutschen Rezeption. Frankfurt a.M. 205-222.

Rödel, Ulrich (1992): Zivilgesellschaft als Handlungszusammenhang. In: Mitteilungen des Institut für Sozialforschung an der Johann Wolfgang Goethe-Universität Frankfurt am Main Nr.1.37-45.

Rödel, Ulrich (Hg.) (1990): Autonome Gesellschaft und libertäre Demokratie. Frankfurt a.M.

Rödel, Ulrich/Frankenberg, Günter/Dubiel, Helmut (1989): Die demokratische Frage. Frankfurt a.M.

Röhl, Klaus F. (1993): Verfahrensgerechtigkeit (Procedural Justice). Einführung in den Themenbereich und Überblick. In: ZfRSoz. 14 (H.1). 1-34.

Sabel, Charles F. (1993): Constitutional Ordering in Historical Context. In: Fritz W. Scharpf (Hg.), Games in Hierarchies and Networks. Analytical and Empirical Approaches to the Study of Governance Institutions. Frankfurt a.M., Boulder/Col. 65123.

Sales, Arnaud (1991): The Private, the Public and Civil Society: Social Realms and Power Structures. In: International Political Science Review 12. 295-312. 
Salomon, Lester M. (1990): The Nonprofit Sector and Government: The American Experience in Theory and Practice. In: Helmut K. Anheier/Wolfgang Seibel (Hg.), The Third Sector: Comparative Studies of Nonprofit Organizations. Berlin, New York. 219-240.

Sandel, Michael (1984): The Procedural Republic and the Unencumbered Self. In: Political Theory 12. 81-96.

Sandel, Michael J. (1982): Liberalism and the Limits of Justice. Cambridge u.a. (Cambridge University Press).

Sandel, Michael J. (1989): Moral Judgement and Liberal Toleration - Abortion and Homosexuality. In: California Law Review 77. 521-538.

Sander, Frank E. A. (1990): Alternative Methods of Dispute Resolution: A U.S. Perspective. In: Wolfgang Hoffmann-Riem/Eberhard Schmidt-Aßmann (Hg.), Konfliktbewältigung durch Verhandlungen. Baden-Baden. 141-149.

Sannwald, Rüdiger (1994): Die Beratungen zur Reform des Parlamentsrechts in der Gemeinsamen Verfassungskommission. In: ZParl 25 (H. 1). 15-32.

Sarcinelli, Ulrich (1990): Auf dem Weg in eine kommunikative Demokratie? Demokratische Streitkultur als Element politischer Kultur. In: Ds. (Hg.), Demokratische Streitkultur. Opladen. 29-51.

Sarcinelli, Ulrich (1993): »Verfassungspatriotismus « und »Bürgergesellschaft« oder: Was das demokratische Gemeinwesen zusammenhält. In: Aus Politik und Zeitgeschichte B 34. 25-37.

Saretzki, Thomas (1993): The genetic turn. Anmerkungen zur kritischen Risikotheorie am Beispiel der Freisetzung gentechnisch veränderter Organismen. Hamburg (Ms.).

Saretzki, Thomas (1994): Verhandelte Diskurse? Probleme der Vermittlung von Argumentation und Partizipation am Beispiel des TA-Verfahrens zum »Anbau gentechnisch erzeugter Herbizidresistenz« am Wissenschaftszentrum Berlin. Hamburg (Ms).

Saretzki, Thomas (1995): Macht der Öffentlichkeit: Selbstbindung der Politik durch öffentliche Diskurse. In: Gerhard Göhler (Hg.), Macht der Öffentlichkeit - Öffentlichkeit der Macht. Baden-Baden (im Erscheinen).

Sartori, Giovanni (1992): Demokratietheorie. Darmstadt.

Scharpf, Fritz W. (1987): Sozialdemokratische Krisenpolitik in Europa. Frankfurt a.M., New York.

Scharpf, Fritz W. (1989): Politische Steuerung und politische Institutionen. In: Politische Vierteljahresschrift 30. 10-21.

Scharpf, Fritz W. (1991): Political Institutions, Decision Styles, and Policy Choices. In: Roland M. Czada/Adrienne Windhoff-Héritier (Hg.), Political Choice. Institutions, Rules and the Limits of Rationality. Frankfurt a.M., New York. 53-86.

Scharpf, Fritz W. (1992): Die Handlungsfähigkeit des Staates am Ende des Zwanzigsten Jahrhunderts. In: Beate Kohler-Koch (Hg.), Staat und Demokratie in Europa. Opladen. 93-115.

Scharpf, Fritz W. (1992a): Einführung: Zur Theorie von Verhandlungssystemen. In: Arthur Benz/Fritz W. Scharpf/Reinhard Zintl, Horizontale Politikverflechtung. Zur Theorie von Verhandlungssystemen. Frankfurt a.M., New York. 11-27. 
Scharpf, Fritz W. (1993): Coordination in Hierarchies and Networks. In: Ds. (Hg.), Games in Hierarchies and Networks. Frankfurt a.M., Boulder/Col. 125-165.

Scharpf, Fritz W. (1993a): Legitimationsprobleme der Globalisierung. Regieren in Verhandlungssystemen. In: Carl Böhret/Göttrik Wewer (Hg.), Regieren im 21. Jahrhundert. Zwischen Globalisierung und Regionalisierung (Festgabe für HansHermann Hartwich zum 65. Geburtstag). Opladen. 165-185.

Scharpf, Fritz W. (1993b): Versuch über Demokratie im verhandelnden Staat. In: Roland Czada/Manfred G. Schmidt (Hg.), Verhandlungsdemokratie - Interessenvermittlung - Regierbarkeit. Festschrift für Gerhard Lehmbruch. Opladen. 25-50.

Scharpf, Fritz W. (1994): Politiknetzwerke als Steuerungssubjekte. In: Hans-Ulrich Derlien/Uta Gerhardt/Fritz W. Scharpf (Hg.), Systemrationalität und Partialinteresse. Festschrift für Renate Mayntz. Baden-Baden. 381-407.

Schatz, Heribert (1994): Diskussionsbeitrag. In: Ulrich Sarcinelli (Hg.), Öffentlichkeitsarbeit der Parlamente. Politikvermittlung zwischen Public Relations und Parlamentsdidaktik. Baden-Baden. 122-123.

Scheit, Herbert (1987): Wahrheit - Diskurs - Demokratie. Freiburg, München.

Schenk, Michael/Rössler, Patrick (1994): Das unterschätzte Publikum. Wie Themenbewußtsein und politische Meinungsbildung im Alltag von Massenmedien und interpersonaler Kommunikation beeinflußt werden. In: Friedhelm Neidhardt (Hg.), Öffentlichkeit, öffentliche Meinung, soziale Bewegungen (KZfSS Sonderheft 34). Opladen. 261-295.

Schmalz-Bruns, Rainer (1989): Ansätze und Perspektiven der Institutionentheorie. Eine bibliographische und konzeptuelle Einführung. Wiesbaden.

Schmalz-Bruns, Rainer (1990): Neo-Institutionalismus. In: Jahrbuch zur Staats- und Verwaltungswissenschaft 4. 315-337.

Schmalz-Bruns, Rainer (1991): Ein dritter Sektor zwischen Staat und bürgerlicher Gesellschaft? Demokratietheoretische Überlegungen zur Diffusion der Staatlichkeit. In: Michael Th. Greven (Hg.), Macht in der Demokratie. Baden-Baden. 175-211.

Schmalz-Bruns, Rainer (1992): Civil Society - ein postmodernes Kunstprodukt? Eine Antwort auf Volker Heins. In: PVS 33 (H.2). 243-255.

Schmalz-Bruns, Rainer (1992a): Die Konturen eines neuen Liberalismus. Zur Debatte um Liberalismus, Kommunitarismus und Civil Society. In: PVS 33 (H.4). 662-672.

Schmidt, Volker H. (1992): Lokale Gerechtigkeit. Perspektiven soziologischer Gerechtigkeitsanalyse. In: ZfS 21 (H.1). 3-15.

Schmidt, Volker H. (1993): Zum Verhältnis prozeduraler und distributiver Gerechtigkeit - Am Beispiel »lokaler « Verhandlungsprobleme. In: Zeitschrift für Rechtssoziologie 14 (H. 1). 80-96.

Schmitter, Philippe C. (1992): The Irony of Modern Democracy and Efforts to Improve Its Practice. In: Politics and Society 20 (No.4). 507-512.

Schmitter, Philippe C. (1994): Interests, Associations and Intermediation in a Reformed Post-Liberal Society. In: Wolfgang Streeck (Hg.), Staat und Verbände (PVS Sonderheft 25). Opladen. 160-171. 
Schnetz, Diemut (1989): Unterschätzte Akteure: Demokratie von unten in selbstorganisierten Bürgergruppen. In: Forschungsjournal Neue Soziale Bewegungen 2 (Sonderband). 124-130.

Schubert, Klaus (1995): Struktur-, Akteur- und Innovationslogik: Netzwerkkonzeptionen und die Analyse von Politikfeldern. In: Dorothea Jansen/Ds. (Hg.), Netzwerke und Politikproduktion. Konzepte, Methoden, Perspektiven. Marburg. 222-240.

Schulze-Fielitz, Helmuth (1990): Staatsaufgabenentwicklung und Verfassung. Zur normativen Kraft der Verfassung für das Wachstum und die Begrenzung der Staatsaufgaben. In: Dieter Grimm (Hg.), Wachsende Staatsaufgaben - sinkende Steuerungsfähigkeit des Rechts. Baden-Baden. 11-47.

Schulze-Fielitz, Helmuth (1993): Der Leviathan auf dem Wege zum nützlichen Haustier? In: Rüdiger Voigt (Hg.), Abschied vom Staat - Rückkehr zum Staat? BadenBaden. 95-120.

Sciulli, David (1986): Voluntaristic Action as a Distinct Concept: Theoretical Foundations of Societal Constitutionalism. In: American Sociological Review 51.743-766.

Scott, Richard W. (1993): Recent Developments in Organizational Sociology. In: Acta Sociologica 36. 63-68.

Seligman, Adam B. (1992): Trust and the Meaning of Civil Society. In: International Journal of Politics, Culture and Society 6 (No.1). 5-21.

Seligman, Adam B. (1993): The Fragile Ethical Vision of Civil Society. In: Brian S. Turner (Hg.), Citizenship and Social Theory. London u.a. (Sage). 139-161.

Selznick, Philip (1992): The Moral Commonwealth. Social Theory and the Promise of Community. Berkeley and Los Angeles/Cal. (University of California Press).

Selznick, Philipp (1989): Dworkin's Unfinished Task. In: California Law Review 77. 505-513.

Sened, Itai (1991): Contemporary Theory of Institutions in Perspective. In: Jourmal of Theoretical Politics 3 (H.4). 379-402.

Sinopoli, Richard C. (1993): Liberalism and Contested Conceptions of the Good: The Limits of Neutrality. In: Journal of Politics 55 (No.3). 644-663.

Soltan, Karol Edward (1993): What Is the New Constitutionalism? In: Stephen L. Elkin/Ds. (Hg.), A New Constitutionalism. Designing Political Institutions for a Good Society. Chicago/London (The University of Chicago Press). 3-19.

Sölter, Arpad (1993): Zivilgesellschaft als demokratietheoretisches Konzept. In: Jahrbuch für Politik 3 (H.1). 145-180.

Spescha, Marc (1992): Basisdemokratic ohne Volksmythos. Instrumente oppositioneller Politik in der direkten Demokratic. In: Widerspruch 12 (H.24). 101-112.

Spragens, Thomas A. Jr. (1990): Reason and Democracy. Durham/London (Duke University Press).

Staff, Ilse (1993): Überlegungen zur Neukonstitution einer Bürgergesellschaft. In: Blätter für deutsche und internationale Politik 38 (H.8). 917-925.

Stamm, Karl-Heinz (1988): Alternative Öffentlichkeit. Die Erfahrungsproduktion neuer sozialer Bewegungen. Frankfurt a.M., New York. 
Stamm, Karl-Heinz (1989): Die neuen sozialen Bewegungen und der Konstitutionsprozeß einer neuen Öffentlichkeit. In: Forschungsjournal Neue Soziale Bewegungen 2 (H.1). 5-11.

Stelzenmüller, Constanze (1994): Direkte Demokratie in den Vereinigten Staaten von Amerika. Baden-Baden.

Streeck, Wolfgang (1992): Inclusion and Secession: Questions on the Boundaries of Associative Democracy. In: Politics and Society 20 (No.4). 513-520.

Sullivan, William M. (1990): Bringing the Good Back In. In: R. Bruce Douglass/Gerald R. Mara/Henry S. Richardson (Hg.): Liberalism and the Good. London, New York (Routledge/Chapman \& Hall). 148-166.

Sunstein, Cass R. (1990): After the Rights Revolution. Reconceiving the Regulatory State. Cambridge/Mass., London (Harvard University Press).

Sunstein, Cass R. (1991): Preferences and Politics. In: Philosophy and Public Affairs 20. 3-34.

Sunstein, Cass R. (1993): The Partial Constitution. Cambridge, Mass./London (Harvard University Press).

Susskind, Lawrence/Cruikshank, Jeffrey (1987): Breaking the Impasse. Consensual Approaches to Resolving Public Disputes. New York (Basic Books).

Susskind, Lawrence/MacMahon, Gerard (1990): Theorie und Praxis ausgehandelter Normsetzung in den USA. In: Wolfgang Hoffmann-Riem/Eberhard Schmidt-AGmann (Hg.), Konfliktbewältigung durch Verhandlungen. Baden-Baden. 67-95.

Taylor, Charles (1988): Negative Freiheit. Zur Kritik des neuzeitlichen Individualismus. Frankfurt a.M.

Taylor, Charles (1989): Sources of the Self. Cambridge/Mass. (Cambridge University Press).

Taylor, Charles (1991): Die Beschwörung der Civil Society. In: Krzysztof Michalski (Hg.), Europa und die Civil Society. Stuttgart. 52-81.

Taylor, Charles (1992): The Ethics of Authenticity. Cambridge/Mass. (Harvard University Press).

Taylor, Charles (1993): Aneinander vorbei: Die Debatte zwischen Liberalismus und Kommunitarismus. In: Axel Honneth (Hg.), Kommunitarismus. Frankfurt, New York. 103-130.

Taylor, Charles (1993a): Der Begriff der >bürgerlichen Gesellschaft< im politischen Denken des Westens. In: Micha Brumlik/Hauke Brunkhorst (Hg.), Gemeinschaft und Gerechtigkeit. Frankfurt a.M. 117-148.

Taylor, Michael (1993): Cooperation, Norms, and Moral Motivation. In: Analyse \& Kritik 15. 70-86.

Tester, Keith (1992): Civil Society. London (Routledge).

Teubner, Gunther (1984): Das regulatorische Trilemma. Zur Diskussion um postinstrumentale Rechtsmodelle. In: Quaderni Fiorentini per la Storia del Pensiero Giuridico Moderno 13. 109-149.

Theisen, Heinz (1991): Zur Demokratieverträglichkeit der Bio- und Gentechnologie. In: Soziale Welt 42 (H.1). 109-130. 
Thigpen, Robert A. (1984): Michael Walzer's Political Theory of the Common Life. In: The Political Science Reviewer 14. 133-163.

Thigpen, Robert A./Lyle A. Downing (1989): Liberal and Communitarian Approaches to Justification. In: The Review of Politics 51. 533-550.

Thompson, Dennis F. (1988): Representatives in the Welfare State. In: Amy Gutmann (Hg.), Democracy and the Welfare State. Princeton/N.J. (Princeton University Press). 131-155.

Tole, Lise Ann (1993): Durkheim on Religion and Moral Community in Modernity. In: Sociological Inquiry 63 (No.1). 1-29.

Turner, Brian S. (1993): Contemporary Problems in the Theory of Citizenship. In: Ds. (Hg.), Citizenship and Sicial Theory. London u.a. (Sage). 1-18.

Turner, Bryan S. (1993): Talcott Parsons, universalism and the educational revolution: democracy versus professionalism. In: British Journal of Sociology 44 (No.1). 1-24.

Türk, Klaus (1989): Neuere Entwicklungen in der Organisationsforschung. Stuttgart.

Tyler, Tom R. (1993): Legitimizing unpopular public policies: Does procedure matter? In: ZfRSoz. 14 (H.1). 47-54.

Ueberhorst, Reinhard (1986): Technologiepolitik - was wäre das? In: Regine Kollek/ Beatrix Tappeser/Gunter Altrer (Hg.), Die ungeklärten Gefahrenpotentiale der Gentechnologie. München. 203-227.

Ueberhorst, Reinhard (1990): Normativer Diskurs und technologische Entwicklung. In: Günter Ropohl/Wilgart Schuchardt/Rainer Wolf (Hg.), Schlüsseltexte zur Technikbewertung. Dortmund (ILS). 149-162.

Ueberhorst, Reinhard (1992): Planungsstudie zur Bildung und Arbeitsplanung einer unabhängigen Kommission zur Förderung energiepolitischer Verständigungsprozesse in der Bundesrepublik Deutschland in den Jahren 1992-1995. Elmshorn.

Ueberhorst, Reinhard, u.a. (1983): Planungsstudie zur Gestaltung von Prüf- und Bürgerbeteiligungsprozessen im Zusammenhang mit nuklearen Großprojekten am Beispiel der Wiederaufarbeitungstechnologie (Studie erstellt im Auftrag der Hessischen Landesregierung). Wiesbaden.

Ueberhorst, Reinhard/de Man, Reinier (1990): Sicherheitsphilosophische Verständigungsaufgaben - Ein Beitrag zur Interpretation der internationalen Risikodiskussion. In: Matthias Schüz (Hg.), Risiko und Wagnis Bd.1. Pfullingen. 81-106.

Ueberhorst, Reinhard/de Man, Reinier (1992): Zweite Frankfurter Studie zur Förderung chemiepolitischer Verständigungsprozesse. Frankfurt a.M. (Umweltdezernat).

Unseld, Siegfried (Hg.), (1993): Politik ohne Projekt? Nachdenken über Deutschland. Frankfurt a.M.

Vanberg, Victor J./Congleton, Roger D. (1992): Rationality, Morality and Exit. In: APSR 86 (No.2). 418-431.

Vidmar, Neil (1993): Verfahrensgerechtigkeit und alternative Konfliktbewältigung. In: ZfRSoz. 14 (H.1). 35-46.

Voigt, Rüdiger (1993): Abschied vom Staat - Rückkehr zum Staat? In: Ds. (Hg.), Abschied vom Staat - Rückkehr zum Staat? Baden-Baden. 9-24.

Vollrath, Ernst (1989): Überlegungen zur neueren Diskussion über das Verhältnis von Praxis und Poiesis. In: AZP 14. 1-26. 
Vollrath, Ernst (1995): Zwei Begriffe des Politischen? Jürgen Habermas und die störrische Faktizität des Politischen. In: Volker Gerhardt/Henning Ottmann/Martyn P. Thompson (Hg.), Politisches Denken. Jahrbuch 1994. Stuttgart/Weimar. 175-192.

Walzer, Michael (1980): Radical Principles: Reflections of an Unreconstructed Democrat. New York (Basic Books).

Walzer, Michael (1981): Philosophy and Democracy. In: Political Theory 9. 379-399.

Walzer, Michael (1983): Spheres of Justice. A Defense of Pluralism and Equality. Oxford (Basil Blackwell).

Walzer, Michael (1984): Liberalism and the Art of Separation. In: Political Theory 12. 315-330.

Walzer, Michael (1988): Exodus und Revolution. Berlin.

Walzer, Michael (1988a): Socializing the Welfare-State. In: Amy Gutmann (Hg.), Democracy and the Welfare-State. Princeton/N.J. (Princeton University Press). 13-26.

Walzer, Michael (1990): The Communitarian Critique of Liberalism. In: Political Theory 18. 6-23.

Walzer, Michael (1990a): A Critique of the Philosophical Conversation. In: Michael Kelly (Hg.), Hermeneutics and Critical Theory in Ethics and Politics. Cambridge/ Mass., London (MIT Press). 182-196.

Walzer, Michael (1990b): Kritik und Gemeinsinn. Berlin.

Walzer, Michael (1990c): What Does it Mean to Be an American. In: Social Research 57 (No.3). 591-614.

Walzer, Michael (1991): Zweifel und Einmischung. Gesellschaftskritik im 20. Jahrhundert. Frankfurt a.M.

Walzer, Michael (1991a): Zwei Arten des Universalismus. In: Babylon. Beiträge zur jüdischen Gegenwart 6. 7-25.

Walzer, Michael (1991b): Constitutional Rights and the Shape of Civil Society. In: Robert E. Calvert (Hg.), »The Constitution of the People«. Reflections on Citizens and Civil Society. Lawrence/Kansas (University Press of Kansas). 113-126.

Walzer, Michael (1991c): The Idea of Civil Society. In: Dissent (Spring). 293-304.

Walzer, Michael (1992): Sphären der Gerechtigkeit. Ein Plädoyer für Pluralität und Gleichheit. Frankfurt a.M., New York.

Walzer, Michael (1992a): Was heißt zivile Gesellschaft? In: Ds., Zivile Gesellschaft und amerikanische Demokratie. Berlin. 64-97.

Walzer, Michael (1993): Die kommunitaristische Kritik am Liberalismus. In: Axel Honneth (Hg.), Kommunitarismus. Frankfurt a.M. 157-180.

Walzer, Michael (1994): Multiculturalism and Individualism. In: Dissent (Spring). 185-191.

Warnke, Georgia (1990a): Social Interpretation and Political Theory: Walzer and his Critics. In: Michael Kelly (Hg.), Hermeneutics and Critical Theory in Ethics and Politics. Cambridge/Mass., London (MIT Press). 204-226.

Warnke, Georgia (1990b): Rawls, Habermas, and Real Talk: A Reply to Walzer. In: Michael Kelly (Hg.), Hermeneutics and Critical Theory in Ethics and Politics. Cambridge/Mass., London (MIT Press). 197-203. 
Warren, Mark E. (1989): Liberal Constitutionalism as Ideology. In: Political Theory 17. 511-534.

Warren, Mark E. (1990): Nonfoundationalism and Democratic Judgment (Paper prepared for the 1990 Annual Meeting of the APSA at San Francisco).

Warren, Mark E. (1992): Democratic Theory and Self-Transformation. In: APSR 86 (No.1). 8-23.

Warren, Mark E. (1993): Can Participatory Democracy Produce Better Selves? Psychological Dimensions of Habermas's Discursive Model of Democracy. In: Political Psychology 14 (No.2). 209-234.

Weale, Albert (1994): Democracy versus Autonomy (Paper to be presented at the XVI World Congress of the International Political Science Association on Democratization. Berlin 21-25 August).

Wehner, Burkhard (1992): Die Katastrophen der Demokratie. Darmstadt.

Wehner, Burkhard (1993): Der Staat auf Bewährung. Über den Umgang mit einer erstarrten politischen Ordnung. Darmstadt.

Weiland, René (1992): Michael Walzer und der Universalismus. In: Die Neue Gesellschaft/Frankfurter Hefte 39 (H.6). 546-549.

Wellmer, Albrecht (1990): Models of Freedom in the Modern World. In: Michael Kelly (Hg.), Hermeneutics and Critical Theory in Ethics and Politics. Cambridge/ Mass., London (MIT Press). 227-252.

Wellmer, Albrecht (1993): Bedingungen einer demokratischen Kultur. Zur Debatte zwischen Liberalen und Kommunitaristen. In: Micha Brumlik/Hauke Brunkhorst (Hg.), Gemeinschaft und Gerechtigkeit. Frankfurt a.M. 173-196.

Westbrook, Robert B. (1991): John Dewey and American Democracy. Ithaca/New York, London (Cornell University Press).

White, Stephen K. (1988): Poststructuralism and Political Reflection. In: Political Theory 16. 186-208.

Wiesenthal, Helmut (1989): Sozialverträglichkeit und Systemrationalität. Zur Kritik eines modischen Steuerungskriteriums. In: Manfred Glagow/Helmut Willke/Helmut Wiesenthal $(\mathrm{Hg}$.): Gesellschaftliche Steuerungsrationalität und partikulare Handlungsstrategien. Pfaffenweiler. 127-163.

Wiesenthal, Helmut (1993): Konventionelles und unkonventionelles Organisationslernen. Ein Literaturbericht (MPG-Arbeitsgruppe $»$ Transformationsprozesse in den neuen Bundesländern « an der Humboldt-Universität zu Berlin). Berlin.

Willke, Helmut (1992): Ironie des Staates. Frankfurt a.M.

Willke, Helmut (1993): Abwicklung der Politik. In: Siegfried Unseld (Hg.), Politik ohne Projekt? Nachdenken über Deutschland. Frankfurt a.M. 54-84.

Wilson, James Q. (1993): The Moral Sense. New York u.a. (The Free Press).

Windhoff-Héritier, Adrienne (1987): Policy-Analyse. Eine Einführung. Frankfurt a.M., New York.

Wolfe, Alan (1991): America at Century's End. Berkeley/Los Angeles (University of California Press).

Young, Iris Marion (1989): Polity and Group Difference: A Critique of the Ideal of Universal Citizenship. In: Ethics 99. 250-274. 
Young, Iris Marion (1990): The Ideal of Community and the Politics of Difference. In: Linda Nicolson (Hg.), Feminism/Postmodernism. London (Routledge). 300-323. Zahlmann, Christel (Hg.), (1992): Kommunitarismus in der Diskussion. Berlin. Zapf, Wolfgang/Dierkes, Meinolf (Hg.), (1994): Institutionenvergleich und Institutionendynamik (WZB Jahrbuch 1994). Berlin.

Zilleßen, Horst (1993): Die Modernisierung der Demokratie im Zeichen der Umweltproblematik. In: Horst Zilleßen/Peter C. Dienel/Wendelin Strubelt (Hg.), Die Modernisierung der Demokratic. Opladen. 17-39.

Zilleßen, Horst/Barbian, Thomas (1992): Neue Formen der Kofliktregulierung in der Umweltpolitik. In: Aus Politik und Zeitgeschichte B 39-40. 14-23.

Zilleßen, Horst/Dienel, Peter C./Strubelt, Wendelin (Hg.), (1993): Die Modernisierung der Demokratie. Opladen.

Zolo, Danilo (1992): Democracy and Complexity. A Realist Approach. University Park/Penn. (The Pennsylvania State University Press).

Zucker, Lynne G. (Hg.), (1988): Institutional Patterns and Organizations. Culture and Environment. Cambridge/Mass. (Ballinger).

Zweck, Axel (1993): Die Entwicklung der Technikfolgenabschätzung zum gesellschaftlichen Vermittlungsinstrument. Opladen. 
Rüdiger Voigt (Hrsg.)

\section{Der kooperative Staat}

Krisenbewältigung durch Verhandlung?

Verhandlungslösungen scheinen als Steuerungsmuster besser zur Bewältigung von politischen Krisen geeignet zu sein als ein hoheitlich-hierarchisches Handeln des Staates. Denn Hierarchie stößt als Steuerungsmuster überall dort an Grenzen, wo wirtschaftlich und/ oder politisch mächtige Interessen einer direkten Umsetzung staatlicher Steuerungsintentionen entgegenstehen.

In vier Kapiteln (Der kooperative Staat: Ein neues Steuerparadigma?, Politikverflechtung im vielfach gegliederten Bundesstaat, Akteure im kooperativen Staat, Kooperative Steuerung in ausgewählten Politikfeldern) analysieren Politik- und Verwaltungswissenschaftler, Soziologen, Juristen und Philosophen ausgewählte Aspekte kooperativen Steuerungshandelns.

Stichworte zum Inhalt: Aushandlungsprozesse, Föderalismus, Hierarchie, Kooperation, Korporatismus, Netzwerkanalyse, Parteienstaat, Politikverflechtung, Problemverarbeitung, Rechtsstaat, Regionalisierung, Steuerung, Verhandlungen.

Das Buch richtet sich an alle, die an der Analyse des »arbeitenden Staates« interessiert sind: Soziologen, Politik-, Rechts- und Verwaltungswissenschaftler.

1995, 297 S., brosch., 89,-DM, 659,- öS, 89,-sFr,

ISBN 3-7890-3903-9 Postfach 610 • 76484 Baden-Baden

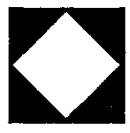


Nicolai Dose/Rüdiger Voigt (Hrsg.)

\section{Kooperatives Recht}

Kooperatives Verwaltungshandeln wird mittlerweile breit diskutiert. Im Gegensatz hierzu steht die relativ schwache empirische Fundierung. Weitgehend unberücksichtigt blieb auch, daß kooperatives Verwaltungshandeln sich häufig nicht quasi naturwüchsig eingestellt hat, sondern vom Gesetz- und Verordnungsgeber in vielen Bereichen durchaus absichtsvoll eingesetzt wird.

Der Sammelband setzt an diesen Lücken an: Den Schwerpunkt bilden empirische Untersuchungen in ausgewählten Politikfeldern. Sie werden ergänzt durch historisch orientierte sowie durch rechtsdogmatische Ausarbeitungen. Darüber hinaus werden Analysen zur Zulässigkeit und zu den strukturellen Bedingungen von Kooperation präsentiert.

Stichworte zum Inhalt: Immissionsschutzrecht, Bauplanungsrecht, Finanzverwaltung, Wirtschaftsstrafprozesse, städtebauliche Verträge, Rechtsstaat, Verfahrensökonomie, Rechtsverhältnislehre, Entscheidungstheorie, Spieltheorie und sozialpsychologische Analyse.

Der Band enthält Beiträge von einschlägig ausgewiesenen Wissenschaftlern und Praktikern. Er richtet sich an alle, die an der Erfassung und Analyse des tatsächlichen Verwaltungshandelns interessiert sind.

1995, 351 S., brosch., 69,-DM, 511,- öS, 69,-sFr,

ISBN 3-7890-3889-X

(Schriften zur Rechtspolitologie, Bd. 2) 